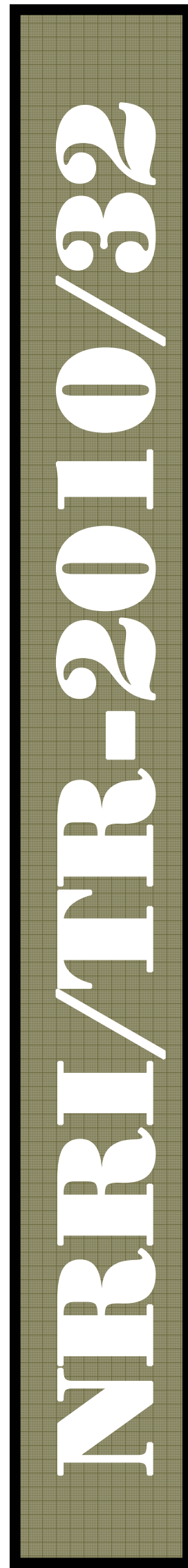

\title{
NEXT GENERATION METALLIC IRON NODULE TECHNOLOGY IN ELECTRIC ARC STEELMAKING - PHASE II DE-FG36-05G015185
} October 26, 2006 - Sept 30, 2010

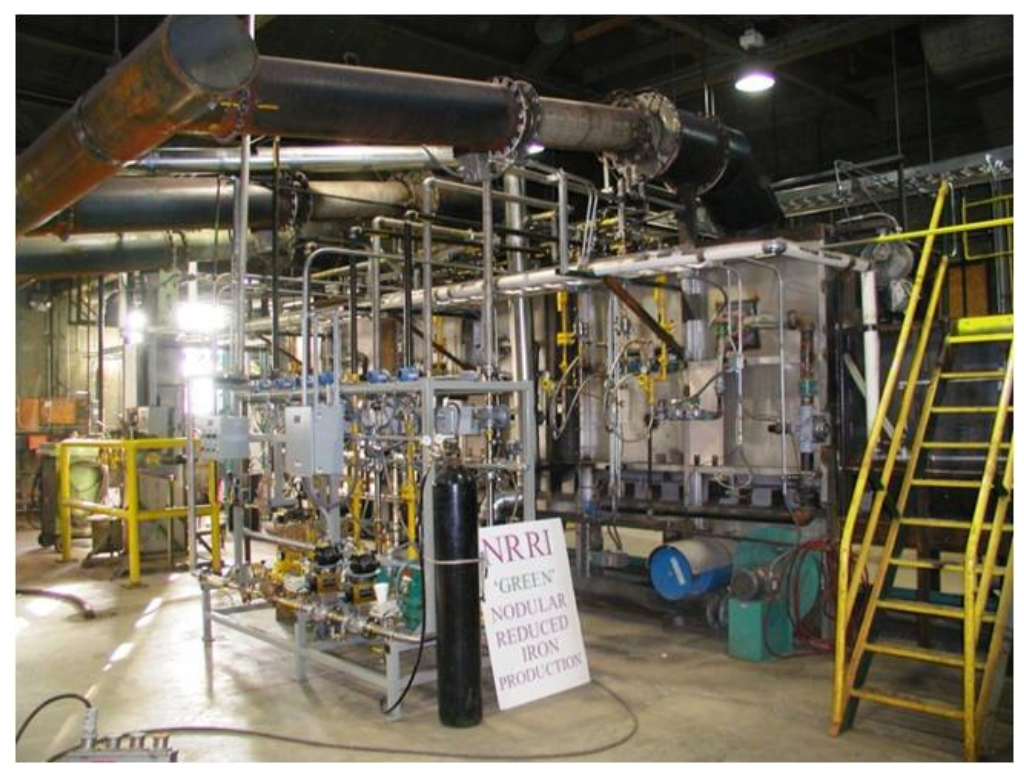

Respectfully Compiled and Submitted by: Donald R. Fosnacht, PI 218-720-4282

dfosnach@nrri.umn.edu Iwao Iwasaki, Co-PI 218-245-4201

iiwasaki@nrri.umn.edu Richard F. Kiesel, Co-PI 218-245-4207

rkiesel@nrri.umn.edu

David J. Englund 218-245-4216

denglund@d.umn.edu David W. Hendrickson 218-245-4204

dhendric@nrri.umn.edu Rodney L. Bleifuss 218-245-4201 rbleifus@d.umn.edu

Technical Report

NRRI/TR-2010/32

December 22, 2010

Natural Resources Research Institute University of Minnesota Duluth 5013 Miller Trunk Highway

Duluth, MN 55811 
This publication is accessible from the home page of the Economic Geology Group of the Center for Applied Research and Technology Development at the Natural Resources Research Institute, University of Minnesota, Duluth (http://www.nrri.umn.edu/egg) as a PDF file readable with Adobe Acrobat 6.0.

Date of release: December 22, 2010

DOCUMENT AVAILABILITY: Reports are available free via the U.S. Department of Energy (DOE) Information Bridge:

Web Site http://www.osti.gov/bridge

Reports are available to DOE employees, DOE contractors, Energy Technology Data Exchange (ETDE) representatives, and Informational Nuclear Information System (INIS) representatives from the following source:

Office of Scientific and Technical Information

P.O. Box 62

Oak Ridge, TN 37831

Tel: (865) 576-8401

Fax: (865) 576-5728

E-mail: reports@osti.gov

Web Site: http://www.osti.gov/contact.html

This report is based upon work supported by the U. S. Department of Energy under Award No. DE-FG3605 G015185.

Any findings, opinions, and conclusions or recommendations expressed in this report are those of the author(s) and do not necessarily reflect the views of the Department of Energy

Cover Photo Caption:

Pilot Furnace for producing Nodular Reduced Iron from iron bearing raw materials using various burner configurations.

\section{Recommended Citation:}

Fosnacht, D.R., Iwasaki, I., Kiesel, R.F., Englund, D.J., Hendrickson, D.W., and Bleifuss, R.L., 2010, Next Generation Metallic Iron Nodule Technology in Electric Arc Steelmaking - Phase II: Natural Resources Research Institute, University of Minnesota, Duluth, MN, Technical Report NRRI/TR-2010/32, 367 pp.

Natural Resources Research Institute

University of Minnesota, Duluth

5013 Miller Trunk Highway

Duluth, MN 55811-1442

Telephone: $218-720-4272$

Fax: 218-720-4329

e-mail: dfosnach@nrri.umn.edu

Web site: http://www.nrri.umn.edu/egg

C2010 by the Regents of the University of Minnesota

All rights reserved.

The University of Minnesota is committed to the policy that all persons shall have equal access to its programs, facilities, and employment without regard to race, color, creed, religion, national origin, sex, age marital status, disability, public assistance status, veteran status, or sexual orientation. 


\section{MASTER TABLE OF CONTENTS}

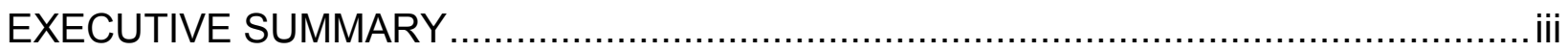

ACKNOWLEDGEMENTS …......................................................................... vii

PART 1: Fundamental Considerations in Converting Iron Oxide Components to Nodular Reduced Iron through Carbothermic Metallurgical Processing .......... 1

PART 2: Laboratory Development of Mix Chemistry and Process Conditions for NRI Development ............................................................................. 23

PART 3: A Computational Fluid Dynamics Process Furnace Model ...................... 229

PART 4: Demonstration of the Nodular Reduced Iron Process on the Pilot Linear Hearth Furnace at the Coleraine Minerals Research Laboratory ..... 313

PART 5: Commercialization Potential of the Technology .................................... 351

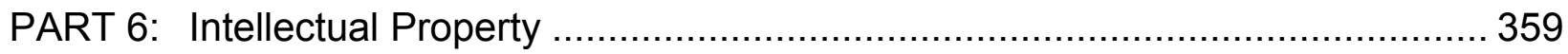

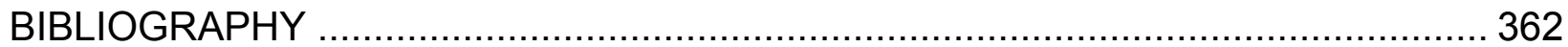


This page intentionally left blank. 


\section{EXECUTIVE SUMMARY}

\section{Objective}

The aim of the research program is to focus on demonstrating the best technology and processing conditions for converting iron oxide resources to high quality Nodular Reduced Iron (NRI). The resulting product is targeted to: 1) contain less gangue, 2) contain less sulfur, 3) be resistant to reoxidation, 4) cost less to produce and 5) use the existing transportation infrastructure and material handling systems compared to standard pig iron production. One distinct advantage of this processing technology is that it utilizes solid fuel (coal) rather than natural gas where cost and the effect of the combustion products on the furnace gas atmosphere are problematical. It also uses fine concentrates rather than fired pellets as required in the most prevalent gas-based, shaft DRI (direct reduced iron) systems in use today. The slag phase separated in the process may find application in slag wool preparation, cement raw materials, soil remediation, and water pollution control, thereby offsetting the overall cost and leaving no waste for disposal. High quality NRI will be universally acceptable feedstock across the steel industry, electric arc furnace (EAF), submerged arc furnace (SAF), basic oxygen furnace (BOF), iron foundries, or as supplementary iron units to the blast furnace (BF).

\section{Market and Technical Objectives}

An increase in iron and steel produced in electric arc furnaces (EAF) coupled with an increased demand for available high quality scrap and pig iron has generated a significant market for alternative iron units. Currently, most iron making processes require the agglomeration of iron bearing materials prior to processing into an alternative iron product, especially if the iron bearing material is a very fine material. The iron ore materials from the United States fall into this category of iron bearing material.

Several processes have been proposed as alternatives to the blast furnace and significant activity on a world-wide basis continues in developing these alternatives. The products from this process development are targeted to provide high quality, low impurity iron units to electric arc furnace (EAF) steel manufacturers, but can also be used to enhance blast furnace productivity, basic oxygen furnace coolant and scrap requirements, and can be used in various iron foundry applications. The material consists of approximately $96.5 \%$ to $97 \%$ metallic iron, 2.5 to $3 \%$ carbon and minimal tramp impurities. The material can be handled using conventional material handling techniques and is very dense and can easily penetrate steel slag. It is anticipated that the material will be used at rates up to $30 \%$ of the metallic charge into a high powered electric furnace and can be added to the furnace on either an intermittent basis or using continuous charging practices. The contained carbon provides valuable chemical energy to displace electrical power requirements during steel processing when oxygen blowing practices are employed in the EAF operation.

Depending on the cost of the incoming iron oxide materials, a preliminary economic analysis of the cost of iron nodule production by the development team indicates that 
iron nodule production costs can range from $\$ 190$ to $\$ 250$ per tonne using the data generated from the pilot scale testing. The biggest cost items are the cost of iron ore and coal required for the process. These items have escalated in price rapidly due to the world-wide expansion in steel production.

\section{Test Work at the Coleraine Minerals Research Laboratory}

A project was initiated at the Coleraine Minerals Research Laboratory, Natural Resources Research Institute, University of Minnesota Duluth, in March 2001 on producing nodular reduced iron from Minnesota's taconite concentrates with funding provided by the Economic Development Administration, Department of Commerce and from the University of Minnesota Permanent University Trust Fund for Mining Research. A significant result of this effort was the installation of a pilot scale Linear Hearth Furnace (LHF) which can be best described as a moving hearth iron reduction furnace simulator. The furnace is a forty-foot long $(12.2 \mathrm{~m})$ iron reduction furnace, consisting of three individual heating zones and a final cooling section. Continuation of this research program, both for Phases I and II of the current investigation was provided by the Department of Energy, Energy Efficiency and Renewable Energy, Industrial Technologies Program. A major emphasis of this project has been placed on lowering the production cost of NRI, producing larger-sized nodules, and improving the chemistry. From the greater than 4000 laboratory tube and box furnace tests, it was established that the correct combination of additives, fluxes, and reductant while controlling the furnace atmosphere (a) lowers the operating temperature, (b) decreases the use of reductant coal (c) improves the overall yield through generation of less micro nodules of iron, and (d) promotes desulphurization.

The research program in Phase I of this project focused on developing the best technology and processing conditions for converting iron oxide resources to high quality metallized iron nodules. The resulting product met the quality targets noted earlier: 1) contain less gangue, 2) contain less sulfur, 3) be resistant to reoxidation, 4) cost less to produce, and 5) use the existing transportation infrastructure and material handling systems. A key to successful operation of the pilot scale Linear Hearth Furnace (LHF) operation is control of the furnace atmosphere through either modification of the combustion system or through auxiliary atmosphere control devices that will enhance the $\mathrm{CO}$ levels near the reacting iron- and carbon-bearing materials. In Phase II of this project, various approaches were evaluated to modify this key condition within the existing pilot LHF. Through the course of this project the LHF has undergone several stages of development, transitioning from a walking beam, natural gas-air fired furnace to one with a continuous moving car system and three distinct combustion systems that can be used individually or in combination. It has routinely been used to test a variety of the variables shown to be important from the box furnace and tube furnace tests. The primary goal of the program was to develop sufficient understanding of the controlling variables associated with taconite iron ore reduction and smelting using coal based reductant materials. The were at the pilot scale clearly illustrates that it is possible to routinely produce high quality nodular reduced iron using fine iron ore concentrate, coal and fluxes. 
In addition to the laboratory and pilot scale test work to define the regimes for routine NRI production, a significant effort was under taken to model the process. Computational fluids dynamic (CFD) modeling and mass and energy modeling techniques were developed to allow a better phenomenological understanding of various chemical and physical interactions that take place in the reaction system. The process models that have been developed allow different reactor designs to be analyzed on a routine basis and have helped identify the critical control factors for future scale-up of the technology beyond the pilot level. They have also given significant insight into the potential for separation of the various chemical reaction conditions into separately controlled zones for efficient process optimization. The models also show that the use of oxy-fuel burners can lead to energy efficiency gains approaching $30 \%$ and improved projected furnace productivity of greater than $15 \%$ in comparison to airfuel combustion technology. The oxy-fuel combustion technology (both with natural gas and with coal as the fuel) has the potential for reducing the environmental foot print of pig iron production and should allow for more efficient collection and disposition of flue gas from the process for potential sequestration of the carbon dioxide for any future process.

\section{Summary}

High quality NRI can be routinely produced provided the right choice of temperature profile, atmosphere control and additives are employed. Part 2 of this report summarizes the variety of conditions tested and points out the best conditions for reaction mixtures and the use of auxiliary carbon materials that lead to high quality NRI production. The baseline operating conditions on both the oxy-gas and coal-oxygen based systems have been established through the work undertaken under pilot plant conditions. The furnace variables were manipulated to operate under positive pressure, and reducing atmosphere using the stoichiometry of the combustion to minimize oxygen content in the furnace atmosphere. These techniques were used to demonstrate both combustion systems in routine production of NRI under those conditions. The specific conditions identified should allow commercial production of nodules. This information is summarized in detail in Part 4 of the report. Complete process mass and energy balances for commercial scale development were derived from the CFD modeling using the practical furnace designs described in Part 3 of this report.

\section{Next Steps to Commercialization}

A key need for the process demonstration is to refine the economic analysis of the process using a facility design that is much closer to commercial size compared to the pilot furnace at the Coleraine Minerals Research Laboratory. The chief barriers to commercialization are:

(1) Confirmation of the technical feasibility of the pilot scale test results on a prototype level. This includes establishment of a cost-effective operating regime that will simultaneously achieves the desired yield of high metallurgically acceptable grades of iron nodules and the product size characteristics desired for electric arc furnace consumers. The work to date has identified optimal mix chemistries and appropriate operating regimes both on a laboratory and pilot 
scale that can be used as a basis for proceeding to the next scale of commercialization.

(2) The desired level of engineering detail must be developed as well so that commercialization issues can be minimized when full scale modules are constructed.

(3) The reliability of the various sub-processes including material preparation, exhaust gas handling, and product removal also need to be established so that working ratios for system availability are well understood. Both the process model developed and the pilot test facilities developed during this investigation can be used to facilitate the work in this area.

(4) The costs of the raw materials for the process are within control levels of the original assumptions so that the attractiveness of the new pig iron process remains favorable compared to alternative technology options for pig iron including conventional blast furnace iron production, charcoal mini-blast furnace iron production, or direct reduced iron or iron smelting processes.

\section{The Next Generation Linear Hearth Furnace}

The parametric study conducted in Part 3 of this report shows the next generation of the Linear Hearth Furnace (G5) has the potential to meet or exceed the current state of the art technology. Natural gas consumption can be minimized by selection of coal type and oxygen concentration in the oxidant streams. Gas consumption rates as low as $0.75 \mathrm{MMBTU} / \mathrm{mt} \mathrm{HM}(0.79 \mathrm{GJ} / \mathrm{mt} \mathrm{HM})$ were achieved when using medium and high volatile bituminous coals. Since coal costs are generally less than that for natural gas, reductant coal energy efficiency should be maximized. However, reductant coal addition is also constrained by agglomerate mix chemistry, stoichiometric addition rate, and volatile content. The study indicated total energy consumption based on natural gas and reductant coal could be as low as $13 \mathrm{MMBTU} / \mathrm{mt} \mathrm{HM}(13.7 \mathrm{GJ} / \mathrm{mt} \mathrm{HM})$. It is expected that hot hearth return would decrease both energy consumption and residence time. In a linear furnace system hot hearth return implies paired furnaces or an enclosed heated return. In addition the work has identified the conditions that are most efficient for iron ore reduction and for iron ore smelting. The work can be used to allow an optimized furnace or furnaces configuration to be developed that will lead to a very efficient process for NRI production. Carbon dioxide emission varied incrementally between 1100 and $1400 \mathrm{kgs} / \mathrm{mt}$ Hot Metal $(2,420$ and 3,080 $\mathrm{lb} / \mathrm{mt} \mathrm{HM})$. The rate was mainly affected by natural gas consumption, coal volatile content and marginally by briquette loading. Minimized emissions occurred at $82 \%$ oxygen, 35 minutes residence time, $0.79 \mathrm{GJ} / \mathrm{mt} \mathrm{HM}$ natural gas $(0.75 \mathrm{MMBTU} / \mathrm{mt} \mathrm{HM}), 24.4 \mathrm{~kg} / \mathrm{m}^{2}\left(5 \mathrm{lbs} / \mathrm{ft}^{2}\right)$ briquettes, and $4.9 \%$ coal volatiles

Oxygen consumption on a per ton basis is directly related to productivity and fuel input. Based on these simulations, the oxygen to product mass ratio ranged between 0.8 and 1.1. The models demonstrated an alternative for blending coals and/or hearth char to tailor a reductant volatile content for optimum energy input and furnace temperature.

Increased feed loading will help to minimize natural gas consumption, but increased loads are presumed to remain as a monolayer of agglomerated feed, multiple layers in effect increase residence time and decrease productivity. The parametric design 
incorporating both mass flow (hearth speed and feed loading) and natural gas firing rate, did not permit a true productivity assessment, because throughput and energy input were both independent. Bed temperature was a dependent variable, and simulations deviating from acceptable operating bed temperatures resulted in unrealistic productivity rates. The acceptable temperature range was defined as maximum temperature between 2600 and $2800^{\circ} \mathrm{F}\left(1427-1538^{\circ} \mathrm{C}\right)$. Total energy consumption for simulations with acceptable bed temperatures ranged as low as $13 \mathrm{MMBTU} / \mathrm{mt}$ Hot Metal $(13.7 \mathrm{GJ} / \mathrm{mt})$.

Productivity was solely a function of loading and hearth speed. It was based on iron flow through the furnace, irrespective of temperatures achieved. In cases where temperature did not reach melting point, production rate was of limited value. Coal type had a small impact on productivity through coal percentage in the mix, determined by coal type (\% Fix C), and ash content affecting flux addition and slag volume.

\section{Intellectual Property}

During the course of this investigation and prior to that, the work conducted under earlier funding, various intellectual properties have been generated. These properties have been assigned by the University to Nulron Technololgies, LLC. A listing of the various patents issued and published applications is given in Part 6 of this report. 


\section{ACKNOWLEDGEMENTS}

The project team gratefully acknowledges the financial contribution of the US Department of Energy for supporting grant DE-FG36-05G015185. The team also would like to note the contributions of Dr. Dibyajyoti Aichbhaumik, the DOE Project Manager for his advice and direction during the course of project implementation. Many participated in the execution of this grant. The team would like to acknowledge the work of Mr. Andy Lindgren for his diligence in the laboratory development of mix designs in collaboration with Dr. Iwasaki, with the assistance of Rick Peart, and Jim Sigfrinius. The team also recognizes the technical and practical contributions of Kyle Bartholomew. We also acknowledge the work and efforts of the Linear Hearth Team including Jerry Lien, Tim Kemp, Shaun Gram, Steve Zaitz, and Mike Swanson. We would also thank the University for providing financial support to the project from the Permanent University Trust Fund. Next, we would like to thank our corporate sponsor Nulron Technologies, LLC for their support and thoughtful discussions during the course of execution of this project. Finally, we would like to acknowledge the work of Mrs. Anda Bellamy in final preparation of this manuscript. 


\title{
PART 1: \\ Fundamental Considerations in Converting Iron Oxide Components to Nodular Reduced Iron Through Carbothermic Metallurgical Processing
}

\author{
by \\ Donald R. Fosnacht \\ Director \\ Center for Applied Research and Technology Development \\ 218-720-4282 \\ dfosnach@nrri.umn.edu
}

Natural Resources Research Institute

5013 Miller Trunk Hwy

Duluth, MN 55811 


\section{TABLE OF CONTENTS}

LIST OF FIGURES

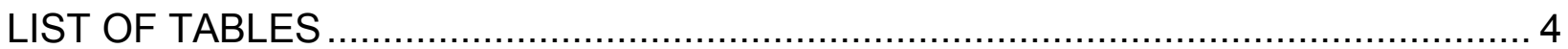

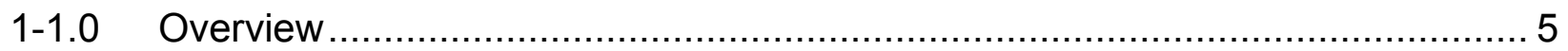

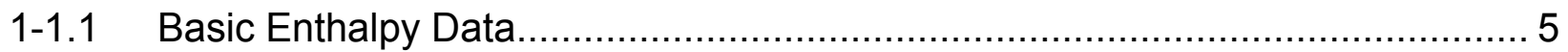

1-1.2 Major Chemical Reactions for Magnetite Reduction .................................. 6

1-1.3 Major Chemical Reactions for Hematite Reduction ..................................... 7

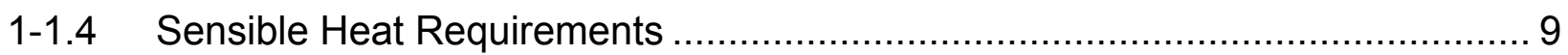

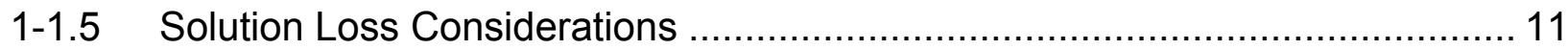

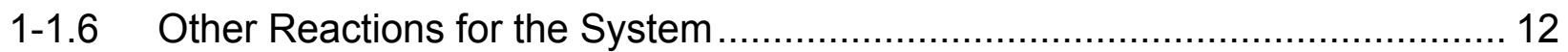

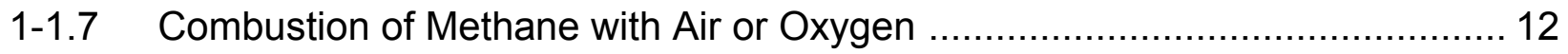

1-1.8 Estimating Coal Requirements for Process ............................................... 13

1-1.9 Net Energy from Methane in Natural Gas (Air to Oxygen Comparison)........... 17

1-1.10 Sequence of Events for the Metallurgical System...................................... 18

1-1.11 Development of Mass Balance Calculations ............................................... 19

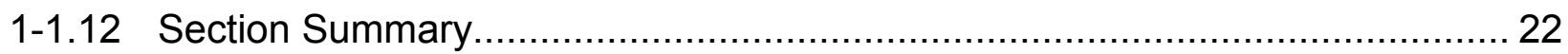




\section{LIST OF FIGURES}

Figure 1-1. Carbon Required for Reduction of Magnetite without Solution

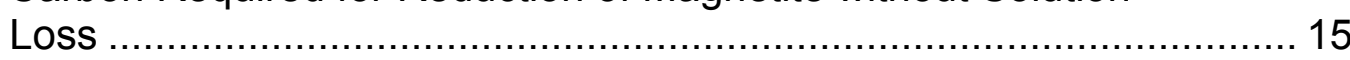

Figure 1-2. Carbon Required for Reduction as a Function of Degree of Solid

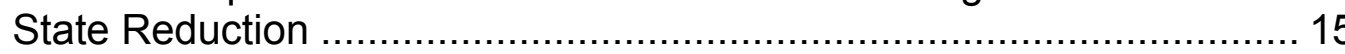

Figure 1-3. Variation in Species Partial Pressure in Atmospheres as a Function of Solution Loss 16

Figure 1-4. Coal Required at 85\% Fixed Carbon to Meet Solution Loss Requirements as a Function of Solution Loss Fraction. 16

Figure 1-5. Total Coal Required for Various \% SS Conditions Reflecting Both Reduction and Solution Loss at $85 \%$ FC in Coal 17

Figure 1-6. Net Energy Available per Mole of Methane (No Heat Recovery) 18 


\section{LIST OF TABLES}

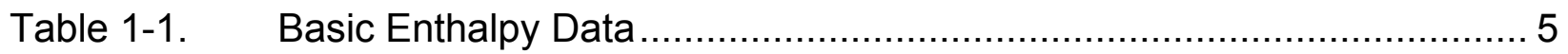

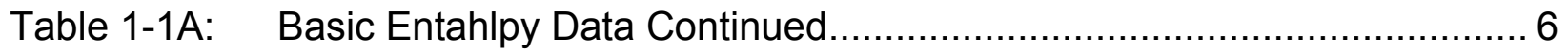

Table 1-2. Major Chemical Reactions for Magnetite Reduction ............................. 6

Table 1-3. Coal Required for Reduction as a Function of Fixed C and \% SS Reduction ................................................................................. 7

Table 1-4. Coal Required for Reduction as a Function of Fixed C and \% SS

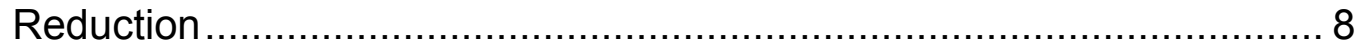

Table 1-5. Major Chemical Reactions for Hematite Reduction ................................. 9

Table 1-6. Sensible Heat Requirements for Magnetite and Carbon ........................ 10

Table 1-7. Total Enthalpy Required for Reduction and Sensible Heat

Requirements...................................................................... 10

Table 1-8. Reduction versus Sensible Heat Requirements ................................. 10

Table 1-9. Solution Loss Analysis - Analytical Treatment.................................... 11

Table 1-10. Carbon Required (kg) for Solution Loss Effect per $1000 \mathrm{~kg} \mathrm{Fe} \mathrm{.............} 12$

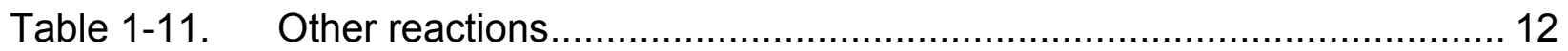

Table 1-12. Heat Contents $(\mathrm{kJ})$ at Various Furnace Temperatures for Products of Combustion ............................................................................ 13

Table 1-13. Carbon Requirement for fully "Solid State" Reduction for Magnetite

Table 1-14. Estimated Coal Required $(\mathrm{kg})$ at Various Fixed Carbon Contents and Varying Indirect Reduction Levels ............................................ 14

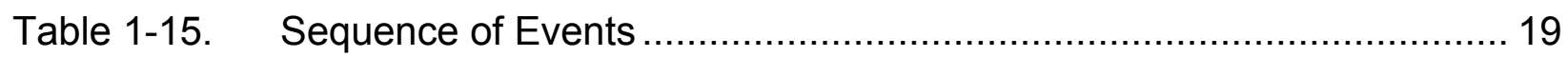

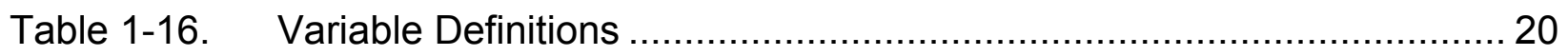

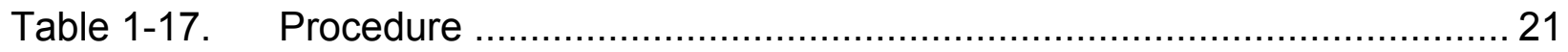




\section{1-1.0 Overview}

As discussed in other parts of this report, various processing conditions have been described in producing nodular reduced iron from iron ore, carbon, and flux containing mixtures under a variety of experimental conditions. This section describes some of the fundamental chemical and energy requirements for the metallurgical processing of the mixtures to nodular reduced iron and slag components. The carbon requirements in this evaluation have been estimated by assuming solid state reduction of the oxide forms by solid carbon. The actual process will involve both solid state reduction by carbon and indirect reduction by any hydrogen or carbon monoxide that may be formed during the process once the kinetic requirements of the system are satisfied by achieving the necessary reaction temperatures. The following describes the basic thermochemistry, reaction sequences and governing equations that govern the systems studied in this investigation.

\section{1-1.1 Basic Enthalpy Data}

Reference:

USGS Bulletin 1259

"Thermodynamic Properties of Minerals and Related Substances at 298.15 K, One Atmosphere Pressure, and at Higher Temperature," Richard A. Robie and David R. Waldbaum, US Government Printing Office, Washington, D.C., 1968

Table 1-1. Basic Enthalpy Data

\begin{tabular}{|c|c|c|c|c|c|c|c|c|}
\hline $\begin{array}{l}\text { Chemical } \\
\text { Form }\end{array}$ & MW & $\begin{array}{c}\Delta \boldsymbol{H}_{1400 \mathrm{~K} \text { in }} \\
\mathrm{kJl} / \mathrm{gfw}\end{array}$ & $\begin{array}{c}\Delta \boldsymbol{H}_{1700 \mathrm{~K} \text { in }} \\
\mathrm{kJl} / \mathrm{gfw}\end{array}$ & $\begin{array}{c}\mathrm{H}_{1400-} \mathrm{H}_{298 \mathrm{~K}} \\
\text { in } \mathrm{kJ} / \mathrm{gfw}\end{array}$ & $\begin{array}{c}\mathrm{H}_{1700-} \mathrm{H}_{2988 \mathrm{~K}} \\
\text { in kJ/gfw }\end{array}$ & MP K & $\begin{array}{c}\Delta \boldsymbol{H}_{\text {fusion }} \\
\mathrm{kJ} / \mathrm{gfw}\end{array}$ & $\begin{array}{c}\Delta \mathrm{H}_{298.15 \mathrm{~K}} \\
\text { in } \mathrm{kJ} / \mathrm{gfw}\end{array}$ \\
\hline $\mathrm{Fe}_{2} \mathrm{O}_{3}$ & 159.7 & -807.52 & -804.49 & 157.53 & 201.25 & & & \\
\hline $\mathrm{Fe}_{3} \mathrm{O}_{4}$ & 231.55 & -1090.64 & -1090.38 & 228.24 & 287.65 & & & \\
\hline $\mathrm{Fe}$ & 55.85 & 0.00 & 0.00 & 43.93 & 54.14 & 1804 & 14.77 & \\
\hline $\mathrm{CaO}$ & 74.08 & -641.69 & -639.70 & 56.19 & 72.97 & & & \\
\hline $\mathrm{SiO}_{2}$ & 60.085 & -901.74 & -949.81 & 73.81 & 92.30 & & & \\
\hline $\mathrm{O}_{2}$ & 32 & 0.00 & 0.00 & 36.97 & 47.97 & & & \\
\hline $\mathrm{CaF}_{2}$ & 78.08 & -1203.78 & -1153.13 & 94.89 & 165.98 & 1691 & 29.71 & \\
\hline $\mathrm{CH}_{4}$ & 16 & -92.42 & -92.60 & 69.61 & 93.76 & & & -74.81 \\
\hline $\mathrm{CO}_{2}$ & 48 & -395.44 & -396.00 & 55.91 & 73.49 & & & -393.509 \\
\hline $\mathrm{CO}$ & 28 & -114.54 & -117.00 & 35.34 & 45.94 & & & \\
\hline $\mathrm{C}$ & 12 & 0.00 & 0.00 & 20.87 & 28.02 & & & \\
\hline $\mathrm{H}_{2} \mathrm{O}$ & 18 & -245.62 & -250.93 & 43.43 & 57.68 & & & -285.83 \\
\hline $\mathrm{N}_{2}$ & 28 & 0.00 & 0.00 & 34.94 & 44.27 & & & \\
\hline
\end{tabular}


Table 1-1A: Basic Entahlpy Data Continued

\begin{tabular}{|c|c|c|c|c|}
\hline $\begin{array}{c}\text { Chemical } \\
\text { Form }\end{array}$ & $\mathrm{MW}$ & $\begin{array}{c}\Delta \mathbf{H}_{700 \mathrm{~K} \text { in }} \\
\mathbf{k J} / \mathrm{gfw}\end{array}$ & $\begin{array}{c}\Delta \mathbf{H}_{\text {vaporization }} \\
\mathbf{k J} / \mathrm{gfw}\end{array}$ & BP K \\
\hline $\mathrm{Ca}(\mathrm{OH})_{2}$ & 74.08 & -980.734 & & \\
\hline $\mathrm{H}_{2} \mathrm{O}$ & 18 & -249.914 & 40.656 & 373 \\
\hline $\mathrm{CaO}$ & 74.08 & -633.913 & & \\
\hline
\end{tabular}

\section{Conversion Factors}

$1 \mathrm{kcal}=3.97 \mathrm{BTU} \quad 1 \mathrm{kcal}=4.184 \mathrm{~kJ}$

\section{1-1.2 Major Chemical Reactions for Magnetite Reduction}

The taconite ores that have been the primary source for iron oxides for this evaluation are largely captured as magnetite concentrate with varying levels of largely siliceous gangue materials. Both solid state and indirect reduction can take place in the carbothermic metallurgical process. The mass and energy considerations for the major chemical reactions are summarized below Table 1-2 using data from the USGS Bulletin 1259.

\section{Table 1-2. Major Chemical Reactions for Magnetite Reduction}

\begin{tabular}{|c|c|c|c|c|c|c|}
\hline $\begin{array}{l}\text { "Solid State" } \\
\mathrm{Fe}_{3} \mathrm{O}_{4}+4 \mathrm{C}=3 \mathrm{Fe}+4 \mathrm{CO} \text { (1) } \\
\Delta \mathrm{Hf}_{1400}=\end{array}$ & 632.495 & $\mathrm{~kJ}$ & & & & \\
\hline per mole of $\mathrm{Fe}=$ & & & 210.83 & $\mathrm{~kJ}$ & 199.8 & BTU \\
\hline Per mass of $\mathrm{Fe}=$ & & & 3,775 & $\mathrm{~kJ} / \mathrm{kg} \mathrm{Fe}$ & 1626.3 & $\mathrm{BTU} / \mathrm{lb}$ \\
\hline$\Delta \mathrm{Hf}_{1700}=$ & 624.044 & $\mathrm{~kJ}$ & & & & \\
\hline per mole of $\mathrm{Fe}=$ & & & 208.01 & $\mathrm{~kJ}$ & 197.2 & BTU \\
\hline Per mass of $\mathrm{Fe}=$ & & & $3,724.5$ & $\mathrm{~kJ} / \mathrm{kg} \mathrm{Fe}$ & 1604.6 & $\mathrm{BTU} / \mathrm{lb}$ \\
\hline $\begin{array}{l}\text { Carbon Required per mole of } \mathrm{Fe}= \\
\text { Indirect Reduction Reaction }\end{array}$ & & & 1.33 & moles & & \\
\hline $\begin{array}{l}\mathrm{Fe}_{3} \mathrm{O}_{4}+4 \mathrm{CO}=3 \mathrm{Fe}+4 \mathrm{CO}_{2}(2) \\
\Delta \mathrm{Hf}_{1400}=\end{array}$ & -33.0 & $\mathrm{~kJ}$ & & -31.2 & BTU & \\
\hline per mole of $\mathrm{Fe}=$ & & & -10.99 & $\mathrm{~kJ}$ & 10.4 & BTU \\
\hline Per $\mathrm{kg}$ of $\mathrm{Fe}=$ & & & -196.73 & $\mathrm{~kJ} / \mathrm{kg} \mathrm{Fe}$ & 84.7 & $\mathrm{BTU} / \mathrm{lb}$ \\
\hline$\Delta \mathrm{Hf}_{1700}=$ & -27.3 & $\mathrm{~kJ}$ & & -25.9 & BTU & \\
\hline per mole of $\mathrm{Fe}=$ & & & -9.1 & $\mathrm{~kJ}$ & -8.6 & BTU \\
\hline Per mass of $\mathrm{Fe}=$ & & & -162.96 & $\mathrm{~kJ} / \mathrm{kg} \mathrm{Fe}$ & -70.2 & $\mathrm{BTU} / \mathrm{lb}$ \\
\hline $\begin{array}{l}\text { With } 50 \% \text { indirect Reduction by } \\
2\left(\mathrm{Fe}_{3} \mathrm{O}_{4}\right)+4 \mathrm{C}=6 \mathrm{Fe}+4 \mathrm{CO}_{2}(3) \\
\Delta \mathrm{Hf}_{1400}=\end{array}$ & 599.5 & $\mathrm{~kJ}$ & & 568.2 & BTU & \\
\hline per mole of $\mathrm{Fe}=$ & & & 99.92 & $\mathrm{~kJ}$ & 94.7 & BTU \\
\hline Per mass of $\mathrm{Fe}=$ & & & 1789.1 & $\mathrm{~kJ} / \mathrm{kg} \mathrm{Fe}$ & 770.8 & $\mathrm{BTU} / \mathrm{lb}$ \\
\hline$\Delta \mathrm{Hf}_{1700}=$ & 596.6 & $\mathrm{~kJ}$ & & 565.5 & BTU & \\
\hline per mole of Fe @1700 K = & & & 99.44 & $\mathrm{~kJ}$ & 94.3 & BTU \\
\hline Per mass of $\mathrm{Fe}=$ & & & 1780.5 & $\mathrm{~kJ} / \mathrm{kg} \mathrm{Fe}$ & 767.1 & $\mathrm{BTU} / \mathrm{lb}$ \\
\hline
\end{tabular}


The theoretical carbon required will depend on the degree of direct (solid state [SS\}) versus indirect reduction that takes place during processing. The amount of coal needed will be a function of the fixed carbon in the coals actually employed and these parameters are theoretically considered below (See Table 1-3):

Table 1-3. Coal Required for Reduction as a Function of Fixed C and \% SS Reduction

\begin{tabular}{|c|c|c|c|c|}
\hline \multicolumn{5}{|c|}{$\begin{array}{l}\text { Coal Required (kg) for Reduction As A Function of Fixed C and \% SS Reduction } \\
\text { For } 1000 \mathrm{~kg} \text { of Fe }\end{array}$} \\
\hline \multicolumn{5}{|l|}{ Magnetite Required $(\mathrm{kg})=$} \\
\hline$\%$ Solid State Reduction & $\frac{\text { "@100\% }}{\text { FC }}$ & "@90\%FC" & "@85\%FC" & "@80\%FC" \\
\hline $50 \%$ & 143 & 159 & 169 & 179 \\
\hline $66 \%$ & 191 & 212 & 225 & 239 \\
\hline $75 \%$ & 215 & 239 & 253 & 269 \\
\hline $100 \%$ & 286 & 318 & 336 & 357 \\
\hline \multicolumn{5}{|c|}{$\begin{array}{l}\text { Coal Required (Ib) for Reduction As A Function of Fixed C and \% SS Reduction } \\
\text { Per } 1 \text { ton of Fe }\end{array}$} \\
\hline$\%$ Solid State Reduction & $\frac{\text { "@100\% }}{\text { FC }}$ & "@90\%FC" & "@85\%FC" & "@80\%FC" \\
\hline $50 \%$ & 286 & 318 & 337 & 358 \\
\hline $66 \%$ & 382 & 424 & 449 & 477 \\
\hline $75 \%$ & 430 & 477 & 506 & 537 \\
\hline $100 \%$ & 572 & 635 & 672 & 714 \\
\hline
\end{tabular}

\section{1-1.3 Major Chemical Reactions for Hematite Reduction}

Other iron bearing species can also be used in the process to form nodular reduced iron. Most shipping ores used around the world consist of the more oxidized iron form (hematite) and similar considerations as noted are shown in the illustration below. In addition, since the iron is more oxidized, more carbon (and coal) will be necessary to reduce the iron to the elemental state (see Table 1-4). As a comparison, the coal required per gram mole of iron is 0.67 gram moles for magnetite and 0.75 gram moles for hematite. See Table 1-5 for the energy analysis for hematite. 
Table 1-4. Coal Required for Reduction as a Function of Fixed C and \% SS Reduction

Coal Required (kg) for Reduction As A Function of Fixed C and \% SS Reduction For $1000 \mathrm{~kg}$ of $\mathrm{Fe}$

Hematite required $(\mathrm{kg})=\quad \mathbf{1 4 3 0}$

\begin{tabular}{|c|c|c|c|c|}
\hline \% Solid State Reduction & $\frac{" \mathrm{a}, 100 \%}{\underline{\mathrm{FC}}}$ & "a,90\%FC" & "as5\%FC" & "a80\%FC" \\
\hline $50 \%$ & 161 & 179 & 190 & 201 \\
\hline $66 \%$ & 215 & 239 & 253 & 269 \\
\hline $75 \%$ & 242 & 269 & 284 & 302 \\
\hline $100 \%$ & 322 & 358 & 379 & 403 \\
\hline
\end{tabular}

Coal Required (Ib) for Reduction As A Function of Fixed C and \% SS Reduction Per 1 ton of $\mathrm{Fe}$

\begin{tabular}{|c|c|c|c|c|}
\hline \% Solid State Reduction & $\frac{" a 100 \%}{\mathrm{FC}}$ & "@90\%FC" & "@85\%FC" & "@80\%FC" \\
\hline $50 \%$ & $\overline{322}$ & 358 & 379 & 403 \\
\hline $66 \%$ & 430 & 477 & 506 & 537 \\
\hline $75 \%$ & 483 & 537 & 569 & 604 \\
\hline $100 \%$ & 645 & 716 & 758 & 806 \\
\hline
\end{tabular}


Table 1-5. Major Chemical Reactions for Hematite Reduction

\begin{tabular}{|c|c|c|c|c|c|}
\hline $\begin{array}{l}\text { "Solid State" } \\
\mathrm{Fe}_{2} \mathrm{O}_{3}+3 \mathrm{C}=2 \mathrm{Fe}+3 \mathrm{CO}(4) \\
\Delta \mathrm{Hf}_{1400}=\end{array}$ & 463.9 & $\mathrm{~kJ}$ & & & \\
\hline per mole of $\mathrm{Fe}=$ & & 232.0 & $\mathrm{~kJ}$ & 219.9 & BTU \\
\hline Per mass of $\mathrm{Fe}=$ & & 4,153 & $\begin{array}{l}\mathrm{kJ} / \mathrm{kg} \\
\mathrm{Fe} \\
\end{array}$ & 1789.3 & $\mathrm{BTU} / \mathrm{lb}$ \\
\hline$\Delta H f_{1700}=$ & 454.7 & $\mathrm{~kJ}$ & & & \\
\hline per mole of $\mathrm{Fe}=$ & & 227.4 & $\mathrm{~kJ}$ & 215.5 & BTU \\
\hline Per mass of $\mathrm{Fe}=$ & & 4071.1 & $\begin{array}{l}\mathrm{kJI} / \mathrm{kg} \\
\mathrm{Fe}\end{array}$ & 1753.9 & BTU/lb \\
\hline Carbon Required per mole of $\mathrm{Fe}=$ & & 1.5 & moles & & \\
\hline $\begin{array}{l}\text { Indirect Reduction Reaction } \\
\mathrm{Fe}_{2} \mathrm{O}_{3}+3 \mathrm{CO}=2 \mathrm{Fe}+3 \mathrm{CO}_{2}(5) \\
\Delta \mathrm{Hf}_{1400}=\end{array}$ & -35.18 & $\mathrm{~kJ}$ & & & \\
\hline per mole of $\mathrm{Fe}=$ & & -17.6 & $\mathrm{~kJ}$ & -16.7 & $\overline{B T U}$ \\
\hline Per mass of $\mathrm{Fe}=$ & & -315.0 & $\begin{array}{l}\mathrm{kJ} / \mathrm{kg} \\
\mathrm{Fe}\end{array}$ & -135.7 & BTU/lb \\
\hline$\Delta \mathrm{Hf}_{1700}=$ & -33.8 & $\mathrm{~kJ}$ & & & \\
\hline per mole of $\mathrm{Fe}=$ & & -16.9 & $\mathrm{~kJ}$ & -16.0 & BTU \\
\hline Per mass of $\mathrm{Fe}=$ & & -302.4 & $\begin{array}{l}\mathrm{kJ} / \mathrm{kg} \\
\mathrm{Fe}\end{array}$ & -130.3 & BTU/lb \\
\hline $\begin{array}{l}\text { With } 50 \% \text { indirect Reduction by CO } \\
2\left(\mathrm{Fe}_{2} \mathrm{O}_{3}\right)+3 \mathrm{C}=4 \mathrm{Fe}+3 \mathrm{CO}_{2}(6) \\
\Delta \mathrm{Hf}_{1400}= \\
\text { per mole of } \mathrm{Fe}=\end{array}$ & 428.73 & $\begin{array}{l}\text { kJ } \\
\quad 107.2\end{array}$ & $\mathrm{~kJ}$ & 101.6 & BTU \\
\hline Per mass of $\mathrm{Fe}=$ & & $1,919.1$ & $\begin{array}{l}\mathrm{kJ} / \mathrm{kg} \\
\mathrm{Fe}\end{array}$ & 826.8 & $\mathrm{BTU} / \mathrm{lb}$ \\
\hline$\Delta \mathrm{Hf}_{1700}=$ & 420.96 & $\mathrm{~kJ}$ & & & \\
\hline per mole of $\mathrm{Fe}=$ & & 105.2 & $\mathrm{~kJ}$ & 99.7 & BTU \\
\hline Per mass of $\mathrm{Fe}=$ & & 1884.3 & $\begin{array}{l}\mathrm{kJ} / \mathrm{kg} \\
\mathrm{Fe}\end{array}$ & 811.8 & $\mathrm{BTU} / \mathrm{lb}$ \\
\hline per mole of Fe @1400 K = & & 107.2 & $\mathrm{~kJ}$ & & \\
\hline per mole of Fe @1700 K = & & 105.2 & $\mathrm{~kJ}$ & & \\
\hline
\end{tabular}

\section{1-1.4 Sensible Heat Requirements}

In addition to the chemical enthalpy requirements, the raw materials have to be brought up to the reaction temperatures. For pure compounds, the following gives an estimate of the total amount of sensible energy that is required to bring the temperature to $1127^{\circ} \mathrm{C}\left(2060^{\circ} \mathrm{F}\right)$ and to $1427^{\circ} \mathrm{C}\left(2600^{\circ} \mathrm{F}\right)$. As can be seen, depending on the temperature the reduction reactions require between $61 \%$ and $67 \%$ for reduction of magnetite to iron and between $46.5 \%$ and $52.6 \%$ of the energy needed for the reduction of hematite to iron. The sensible heat requirements are a significant part of the overall metallurgical requirements in carbothermic reduction. See Tables 1-6,7,8 for detailed information on the energy requirements. 
Sensible Heat Requirements for Pure Compounds and Total Energy Estimates Reactions

$\mathrm{Fe}_{3} \mathrm{O}_{4}+4 \mathrm{C}=3 \mathrm{Fe}+4 \mathrm{CO}$

$\mathrm{Fe}_{3} \mathrm{O}_{4}+4 \mathrm{CO}=3 \mathrm{Fe}+4 \mathrm{CO}_{2}(2)$

$2\left(\mathrm{Fe}_{3} \mathrm{O}_{4}\right)+4 \mathrm{C}=6 \mathrm{Fe}+4 \mathrm{CO}_{2}(3)$

Table 1-6. Sensible Heat Requirements for Magnetite and Carbon

\begin{tabular}{|c|c|c|c|c|c|c|c|c|}
\hline \multirow[b]{2}{*}{ Species } & \multicolumn{2}{|c|}{ kJ per mole $\mathrm{Fe}_{3} \mathrm{O}_{4}$} & \multicolumn{2}{|c|}{ kJ per mole Fe } & \multicolumn{2}{|c|}{ kJ per kg of Fe } & \multicolumn{2}{|c|}{ BTUs per lb of Fe } \\
\hline & $\begin{array}{c}\Delta \mathbf{H}_{1400^{-}} \\
\mathbf{H}_{298.15} \\
\end{array}$ & $\begin{array}{c}\Delta \mathbf{H}_{1700^{-}} \\
\mathbf{H}_{298.15}\end{array}$ & $\begin{array}{l}\Delta \mathbf{H}_{1400^{-}} \\
\mathbf{H}_{298.15}\end{array}$ & $\begin{array}{c}\Delta \mathbf{H}_{1700^{-}} \\
\mathbf{H}_{298.15} \\
\end{array}$ & $\begin{array}{c}\Delta \mathbf{H}_{1400^{-}} \\
\mathbf{H}_{298.15}\end{array}$ & $\begin{array}{c}\Delta \mathbf{H}_{1700^{-}} \\
\mathbf{H}_{298.15}\end{array}$ & $\begin{array}{c}\Delta \mathbf{H}_{1400^{-}} \\
\mathbf{H}_{298.15}\end{array}$ & $\begin{array}{l}\Delta \mathbf{H}_{1700^{-}} \\
\mathbf{H}_{298.15}\end{array}$ \\
\hline $\mathrm{Fe}_{3} \mathrm{O}_{4}$ & 228.24 & 287.65 & & & & & & \\
\hline $\mathrm{C}$ & 20.87 & 28.02 & & & & & & \\
\hline Reaction 1 & 311.72 & 399.71 & 103.91 & 133.24 & $1,860.44$ & $2,385.64$ & 801.5 & $1,027.8$ \\
\hline Reaction 3 & 539.95 & 687.36 & 89.99 & 114.56 & 1,611.32 & $2,051.22$ & 694.2 & 883.7 \\
\hline
\end{tabular}

Table 1-7. Total Enthalpy Required for Reduction and Sensible Heat Requirements

\begin{tabular}{|c|c|c|c|c|c|c|}
\hline & $\begin{array}{l}\text { Reduction } \\
\text { at } 1400 \mathrm{~K} \\
\mathrm{~kJ} \text { per kg } \\
\mathrm{Fe}\end{array}$ & $\begin{array}{l}\text { Sensible } \\
\text { heat to } \\
1400 \mathrm{~K} \mathrm{~kJ} \\
\text { per kg Fe }\end{array}$ & $\begin{array}{l}\text { Reduction } \\
\text { at } 1700 \mathrm{~K} \\
\mathrm{~kJ} \text { per kg } \\
\mathrm{Fe}\end{array}$ & $\begin{array}{l}\text { Sensible } \\
\text { heat to } \\
1700 \mathrm{~K} \\
\mathrm{~kJ} \text { per kg } \\
\mathrm{Fe}\end{array}$ & $\begin{array}{l}\text { Total } \\
\text { Enthalpy } \\
\text { for } 1400 \\
\text { K kJ per } \\
\text { kg Fe }\end{array}$ & $\begin{array}{l}\text { Total } \\
\text { Enthalpy } \\
\text { for } \\
1700 \mathrm{~K} \text { kJ } \\
\text { per kg Fe }\end{array}$ \\
\hline Reaction 1 & 3,775 & 1,860 & 3,725 & 2,386 & 5,635 & 6,110 \\
\hline \multirow[t]{2}{*}{ Reaction 3} & 1,789 & 1,611 & 1,780 & 2,051 & 3,400 & 3,832 \\
\hline & $\begin{array}{l}\text { Reduction } \\
\text { at } 1400 \mathrm{~K} \\
\text { BTUs per } \\
\text { lb Fe }\end{array}$ & $\begin{array}{l}\text { Sensible } \\
\text { heat to } \\
1400 \mathrm{~K} \\
\text { BTUs per } \\
\text { lb Fe }\end{array}$ & $\begin{array}{l}\text { Reduction } \\
\text { at } 1700 \mathrm{~K} \\
\text { BTUs per } \\
\text { lb Fe }\end{array}$ & $\begin{array}{l}\text { Sensible } \\
\text { heat to } \\
1700 \mathrm{~K} \\
\text { BTUs } \\
\text { per lb Fe }\end{array}$ & $\begin{array}{l}\text { Total } \\
\text { Enthalpy } \\
\text { for } 1400 \\
\text { K BTUs } \\
\text { per lb Fe }\end{array}$ & $\begin{array}{l}\text { Total } \\
\text { Enthalpy } \\
\text { for } \\
\text { 1700K } \\
\text { BTUs per } \\
\text { lb Fe }\end{array}$ \\
\hline Reaction 1 & 1,626 & 802 & 1,605 & 1,028 & 2,428 & 2,632 \\
\hline Reaction 3 & 771 & 694 & 767 & 884 & 1,465 & 1,651 \\
\hline
\end{tabular}

Table 1-8. Reduction versus Sensible Heat Requirements

\begin{tabular}{|l|r|r|r|r|}
\hline & $\begin{array}{l}\text { Reduction } \\
\text { at 1400 K }\end{array}$ & $\begin{array}{l}\text { Sensible } \\
\text { Heat to } \\
\mathbf{1 4 0 0 ~ K}\end{array}$ & $\begin{array}{l}\text { Reduction } \\
\text { at 1700 K }\end{array}$ & $\begin{array}{l}\text { Sensible } \\
\text { Heat to } \\
\mathbf{1 7 0 0 ~ K}\end{array}$ \\
\hline Reaction 1 & $67.0 \%$ & $33.0 \%$ & $61.0 \%$ & $39.0 \%$ \\
\hline Reaction 3 & $52.6 \%$ & $47.4 \%$ & $46.5 \%$ & $53.5 \%$ \\
\hline
\end{tabular}




\section{1-1.5 Solution Loss Considerations}

In addition to the reduction and sensible heat requirements, the carbon dioxide that is formed during the reduction of iron oxides by carbon monoxide can further react with carbon to form more carbon monoxide. This reaction is called the carbon solution loss reaction or the "Boudoard reaction." This reaction requires energy and estimates of impact are shown in Tables 1-9 and 1-10. Water vapor can act in a similar manner to form hydrogen and carbon monoxide from the interaction with solid carbon.

Table 1-9. Solution Loss Analysis - Analytical Treatment

\begin{tabular}{|c|c|c|c|c|c|}
\hline \multicolumn{6}{|l|}{ 50_50 is Base Case } \\
\hline \multicolumn{6}{|c|}{ Reaction of Evolving $\mathrm{CO}_{2}$ with Carbon } \\
\hline \multicolumn{6}{|l|}{$\mathrm{C}+\mathrm{CO}_{2}=2 \mathrm{CO}(7)$} \\
\hline \multicolumn{6}{|l|}{$\Delta \mathbf{H f}_{1400}=166.4 \mathrm{~kJ}$} \\
\hline \multicolumn{6}{|l|}{$\Delta \mathbf{H} \mathbf{f}_{1700}=162.837 \mathrm{~kJ}$} \\
\hline \multicolumn{6}{|c|}{$\begin{array}{l}\text { Conversion of some evolving gas from the } \\
\text { reaction mix to CO will be energy absorbing }\end{array}$} \\
\hline \multicolumn{6}{|c|}{ Estimated Effect of Conversion at 1 atm total system pressure } \\
\hline & \multicolumn{3}{|c|}{ Base } & & \\
\hline Partial pressure of N2 & \multicolumn{3}{|c|}{0.79} & & \\
\hline Partial pressure of $\mathrm{CO}_{2}$ & \multirow{2}{*}{\multicolumn{3}{|c|}{0.18}} & & \\
\hline Partial Pressure of CO & & & & & \\
\hline Other Species & \multicolumn{3}{|c|}{$\begin{array}{c}0 \\
0.03\end{array}$} & & \\
\hline \multicolumn{6}{|c|}{ Estimated Gas Atmosphere Change per fractional reaction of $\mathrm{C}$ with $\mathrm{CO} 2$} \\
\hline Partial pressure of $\mathrm{N} 2$ & 0.79 & 0.79 & 0.79 & 0.79 & 0.79 \\
\hline Partial pressure of $\mathrm{CO}_{2}$ & 0.147 & 0.12 & 0.097 & 0.077 & 0.06 \\
\hline Partial Pressure of $\mathrm{CO}$ & 0.032 & 0.06 & 0.083 & 0.103 & 0.12 \\
\hline Fractional Reaction & 0.1 & 0.2 & 0.3 & 0.4 & 0.5 \\
\hline$\% \mathrm{CO}_{2}$ conversion & $10.00 \%$ & $20.00 \%$ & $30.00 \%$ & $40.00 \%$ & $50.00 \%$ \\
\hline
\end{tabular}

The above estimates were determined by calculation assuming that the moles of species will be proportional to vapor pressure via ideal gas law.

Carbon will be consumed on the degree of the solution loss reaction that takes place in the reaction system. If no water vapor were to be present, then carbon losses to this reaction can be estimated as shown in Table 1-10 below. 
Table 1-10. Carbon Required (kg) for Solution Loss Effect per $1000 \mathrm{~kg} \mathrm{Fe}$

\begin{tabular}{|c|c|c|c|c|}
\hline Solution Loss Fraction & $\frac{\mathbf{1 0 0} \%}{\mathbf{F C}}$ & $\frac{\mathbf{9 0} \%}{\mathbf{F C}}$ & $\frac{\mathbf{8 5} \%}{\mathbf{F C}}$ & $\frac{\mathbf{8 0} \%}{\mathbf{F C}}$ \\
\hline 0.1 & 14 & 16 & 17 & 18 \\
\hline 0.2 & 29 & 32 & 34 & 36 \\
\hline 0.3 & 43 & 48 & 51 & 54 \\
\hline 0.4 & 58 & 64 & 68 & 72 \\
\hline 0.5 & 72 & 80 & 85 & 90 \\
\hline
\end{tabular}

\section{1-1.6 Other Reactions for the System}

In the metallurgical system employed, other chemical reactions will occur depending on the various gangue constituents, the moisture level in the feed materials, and the fluxes used to form the desired final slags in the process. Some of these reactions are noted below (see Table 1-11).

Table 1-11. Other reactions

\begin{tabular}{|c|}
\hline $\begin{array}{l}\text { Dehydration of Lime at } 700 \mathrm{~K} \\
\left(\sim 427^{\circ} \mathbf{C}\right) \\
\mathrm{Ca}(\mathrm{OH})_{2}=\mathrm{CaO}+\mathrm{H}_{2} \mathrm{O}(8) \\
\Delta \mathrm{Hf}_{\mathbf{7 0 0}}=101.25 \mathrm{~kJ}\end{array}$ \\
\hline $\begin{array}{l}\text { Fusion of Fe } \\
\mathrm{Fe}(\mathrm{s})=\mathrm{Fe}(\mathrm{I})(9) \\
\Delta \mathrm{Hf}_{1804}=\mathbf{1 4 . 7 7} \mathbf{~ k J}\end{array}$ \\
\hline $\begin{array}{l}\text { Melting of } \mathrm{CaF}_{2} \\
\mathrm{CaF}_{2}(\mathrm{~s})=\mathrm{CaF}_{2}(\mathrm{I}) \\
\Delta \mathbf{H}_{1691}=\mathbf{2 9 . 7 1} \mathbf{k J}\end{array}$ \\
\hline $\begin{array}{l}\text { Steam Formation } \\
\mathrm{H} 20(\mathrm{l})=\mathrm{H} 2 \mathrm{O}(\mathrm{g})(11) \\
\Delta \mathbf{H}_{\mathbf{3 7 3}}=\mathbf{4 0 . 6 7} \mathbf{~ k J}\end{array}$ \\
\hline
\end{tabular}

\section{1-1.7 Combustion of Methane with Air or Oxygen}

In the investigation undertaken in this program both air and oxygen were used to combust with natural gas and flue gases to generate the required thermal energy for the system reactions. The methane in natural gas was reacted with the oxygen in air or with pure oxygen to form carbon dioxide and water vapor as shown in the equation below:

$$
\begin{aligned}
& \mathrm{CH}_{4}(\mathrm{~g})+2 \mathrm{O}_{2}(\mathrm{~g})=\mathrm{CO}_{2}(\mathrm{~g})+\mathrm{H}_{2} \mathrm{O}(\mathrm{g})(12) \\
& \Delta \mathbf{H f}_{\mathbf{2 9 8 . 1 5}}=\mathbf{- 8 9 0 . 4} \mathbf{~ k J}
\end{aligned}
$$

The air composition is assumed to have $79 \% \mathrm{~N} 2$ and $21 \% \mathrm{O} 2$ which implies the ratio of moles of $\mathrm{N} 2$ per mole of $\mathrm{O} 2$ is 3.762 . One can then assess the net energy available from the combustion reaction taking into account the sensible heat content of the 
product gases. This energy is then available to satisfy the energy requirements for the process reactions. This is summarized in Table 1-12.

Table 1-12. Heat Contents (kJ) at Various Furnace Temperatures for Products of Combustion

\begin{tabular}{|c|c|c|c|c|c|c|}
\hline Temperature in $\mathrm{K}$ & 1000 & 1200 & 1400 & 1600 & 1700 & 1800 \\
\hline \multicolumn{7}{|l|}{ Product } \\
\hline $\mathrm{CO}_{2}$ & 33.41 & 44.48 & 55.91 & 67.58 & 73.49 & 79.44 \\
\hline $\mathrm{H}_{2} \mathbf{O}$ & 69.99 & 78.49 & 87.46 & 96.86 & 101.70 & 106.62 \\
\hline $\mathbf{N}_{2}$ & 21.46 & 28.11 & 34.94 & 41.90 & 45.43 & 48.98 \\
\hline $\begin{array}{l}\text { Net Available Energy (kJ) at Temp } \\
\text { (K) }\end{array}$ & 1000 & 1200 & 1400 & 1600 & 1700 & 1800 \\
\hline Reaction with $\mathrm{O}_{2}$ & -716.97 & -688.90 & -659.54 & -629.07 & -613.47 & -597.68 \\
\hline Reaction with Air & -636.24 & -583.16 & -528.11 & -471.43 & -442.57 & -413.41 \\
\hline Difference & -80.73 & -105.74 & -131.43 & -157.63 & -170.90 & -184.27 \\
\hline $\begin{array}{l}\text { Energy Difference in \% of } \\
\text { Available }\end{array}$ & $11 \%$ & $15 \%$ & $20 \%$ & $25 \%$ & $28 \%$ & $31 \%$ \\
\hline
\end{tabular}

\section{1-1.8 Estimating Coal Requirements for Process}

This table illustrates that the lower the temperature that can be used for reduction, the more efficient the capture of effective combustion energy from the natural gas fuel. One of the aims of the current investigation is to determine conditions that would allow lower reaction temperatures to be used in the carbothermic reduction process. The carbon requirements for the process will depend on the amount of solid state (direct reduction) and the amount of indirect reduction that takes place in the actual process. For the purposes of the laboratory work, the carbon requirements have been calculated on the basis assuming $100 \%$ solid state reduction (see Table 1-13). The discussion on process conditions and mix design will describe this in more detail. In reality, some reduction with carbon monoxide and hydrogen will occur and this will reduce the overall carbon requirements for the process. The analysis that follows will illustrate the impact of increasing indirect reduction on the overall carbon requirements for the process. 
Table 1-13. Carbon Requirement for fully "Solid State" Reduction for Magnetite

\begin{tabular}{|lrl|}
\hline $\mathrm{Fe}_{3} \mathrm{O}_{4}+4 \mathrm{C}=3 \mathrm{Fe}+4 \mathrm{CO}(1)$ & & \\
$\Delta \mathbf{H f}_{\mathbf{1 4 0 0}}=$ & 633.75 & $\mathrm{~kJ}$ \\
$\Delta \mathbf{H f}_{\mathbf{1 7 0 0}}=$ & 624.04 & $\mathrm{~kJ}$ \\
per mole of Fe @ $1400 \mathrm{~K}=$ & 210.87 & $\mathrm{~kJ}$ \\
per mole of Fe @ 1700 K= & 207.94 & $\mathrm{~kJ}$ \\
& & \\
Carbon Required per mole of & & \\
$\mathrm{Fe}=$ & $1.33 \quad$ moles \\
No Solution Loss Predicted for Total Solid State Reduction \\
Total Carbon Required per 1000 kg of & $\mathbf{2 8 6 \quad \mathrm { kg }}$ \\
$\mathbf{F e}=$ &
\end{tabular}

For the reduction of magnetite to elemental iron and increasing degrees of indirect reduction (IR) by carbon monoxide, the overall carbon requirements will be reduced as illustrate below at $50 \%$ indirect reduction and $34 \%$ indirect reduction for carbon sources containing various amounts of fixed carbon This is summarized in Table 1-14.

Table 1-14. Estimated Coal Required (kg) at Various Fixed Carbon Contents and Varying Indirect Reduction Levels

\begin{tabular}{|c|c|c|c|c|}
\hline \multicolumn{5}{|c|}{$\begin{array}{c}\text { Total Coal Required for Reduction and Solution } \\
\text { Loss for } 50 \% \text { SS Reduction Case } 50 \% \text { IR }\end{array}$} \\
\hline $\begin{array}{c}\text { Solution } \\
\text { Loss } \\
\text { Fraction }\end{array}$ & $\begin{array}{l}100 \% \\
\text { FC }\end{array}$ & $\begin{array}{l}90 \% \\
\text { FC }\end{array}$ & $\begin{array}{l}85 \% \\
\text { FC }\end{array}$ & $80 \%$ FC \\
\hline 0.1 & 158 & 175 & 185 & 197 \\
\hline 0.2 & 172 & 191 & 202 & 215 \\
\hline 0.3 & 186 & 207 & 219 & 233 \\
\hline 0.4 & 201 & 223 & 236 & 251 \\
\hline 0.5 & 215 & 239 & 253 & 269 \\
\hline \multicolumn{5}{|c|}{$\begin{array}{l}\text { Total Coal Requirement for Reduction and } \\
\text { Solution Loss for } 66 \% \text { SS Reduction Case } 34 \% \text { IR }\end{array}$} \\
\hline $\begin{array}{l}\text { Solution } \\
\text { Loss } \\
\text { Fraction }\end{array}$ & $\begin{array}{l}100 \% \\
\text { FC }\end{array}$ & $\begin{array}{l}90 \% \\
\text { FC }\end{array}$ & $\begin{array}{l}85 \% \\
\text { FC }\end{array}$ & $80 \%$ FC \\
\hline 0.1 & 201 & 223 & 236 & 251 \\
\hline 0.2 & 210 & 233 & 247 & 263 \\
\hline 0.3 & 220 & 244 & 258 & 275 \\
\hline 0.4 & 229 & 255 & 270 & 286 \\
\hline 0.5 & 239 & 265 & 281 & 298 \\
\hline
\end{tabular}

These results illustrate that various factors will influence the total amount of coal that will actually have to be used to cause reduction and smelting of iron oxides to elemental iron. The degree of solution loss and the amounts of direct and indirect reduction both will have a significant impact on the final carbon required. In addition, the amount of gangue materials in both the iron ore and coal will have a significant impact on the final amount of coal required. These factors are considered in the mass balance and process 
modeling work that was conducted during this investigation. The results from this work are considered in a separate section of this report. Figures 1-1,2,3,4 illustrate the variation in carbon requirements as a function of the degree of solid state reduction versus indirect reduction and the amount of solution loss that may occur. They also show the expected changes in partial pressure as the amount of indirect reduction changes. Finally, Figure 1.5 illustrates how the degree of indirect reduction changes the overall amount of coal required for the reduction process at a fixed carbon level of $85 \%$ and for varying degrees of the solution loss reaction.

Figure 1-1. Carbon Required for Reduction of Magnetite without Solution Loss

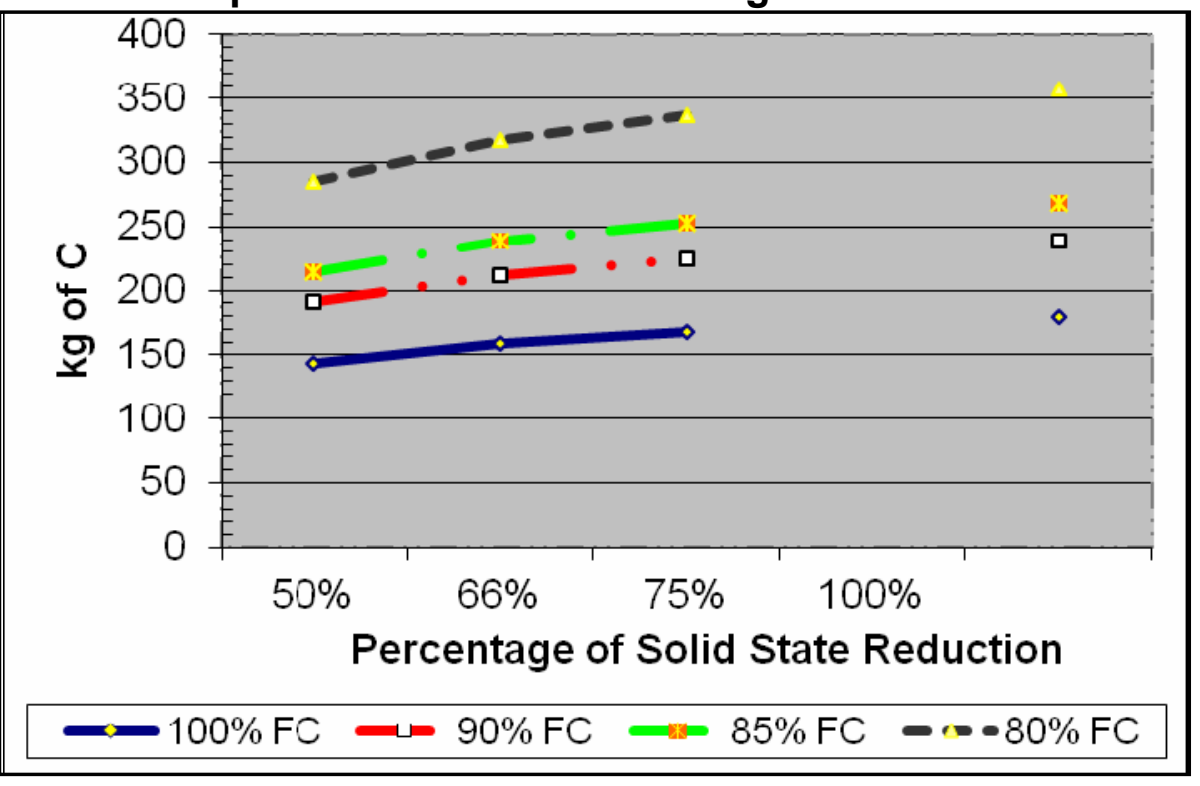

Figure 1-2. Carbon Required for Reduction as a Function of Degree of Solid State Reduction

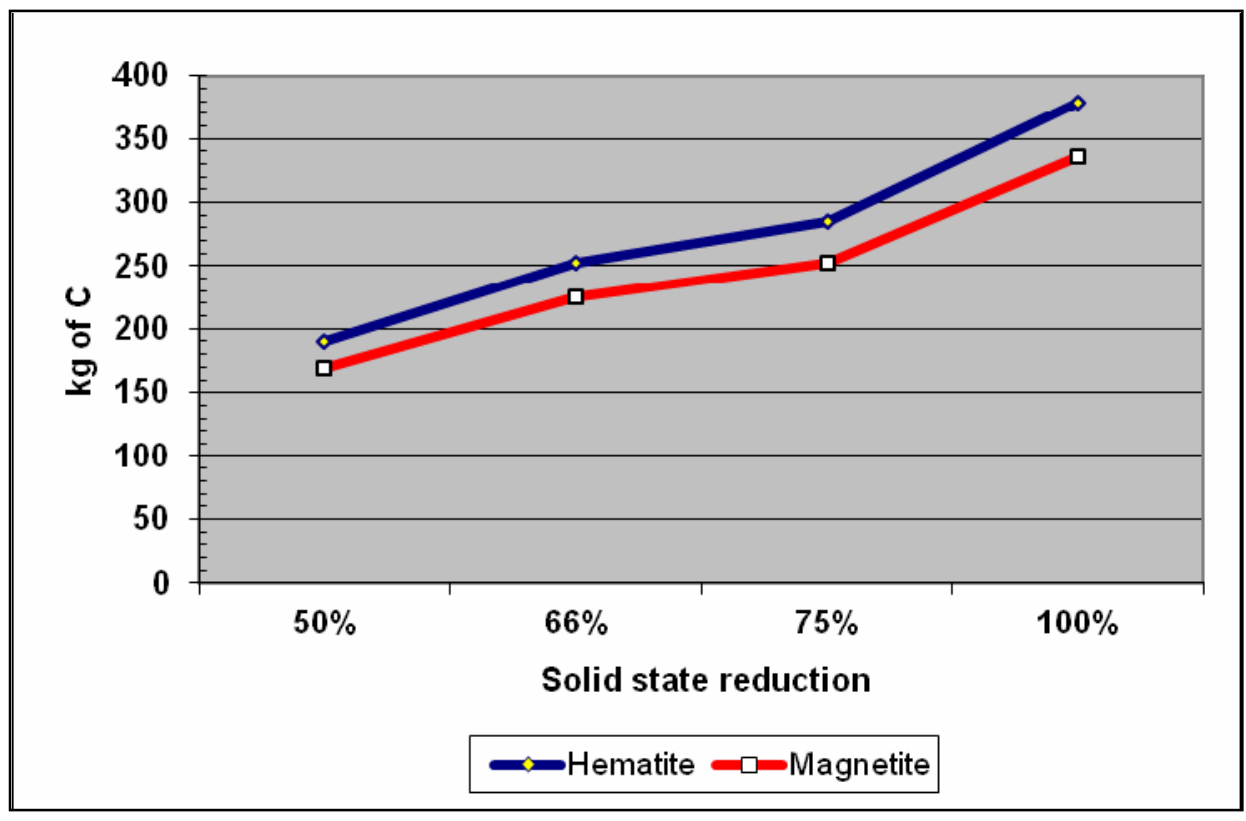


Figure 1-3. Variation in Species Partial Pressure in Atmospheres as a Function of Solution Loss

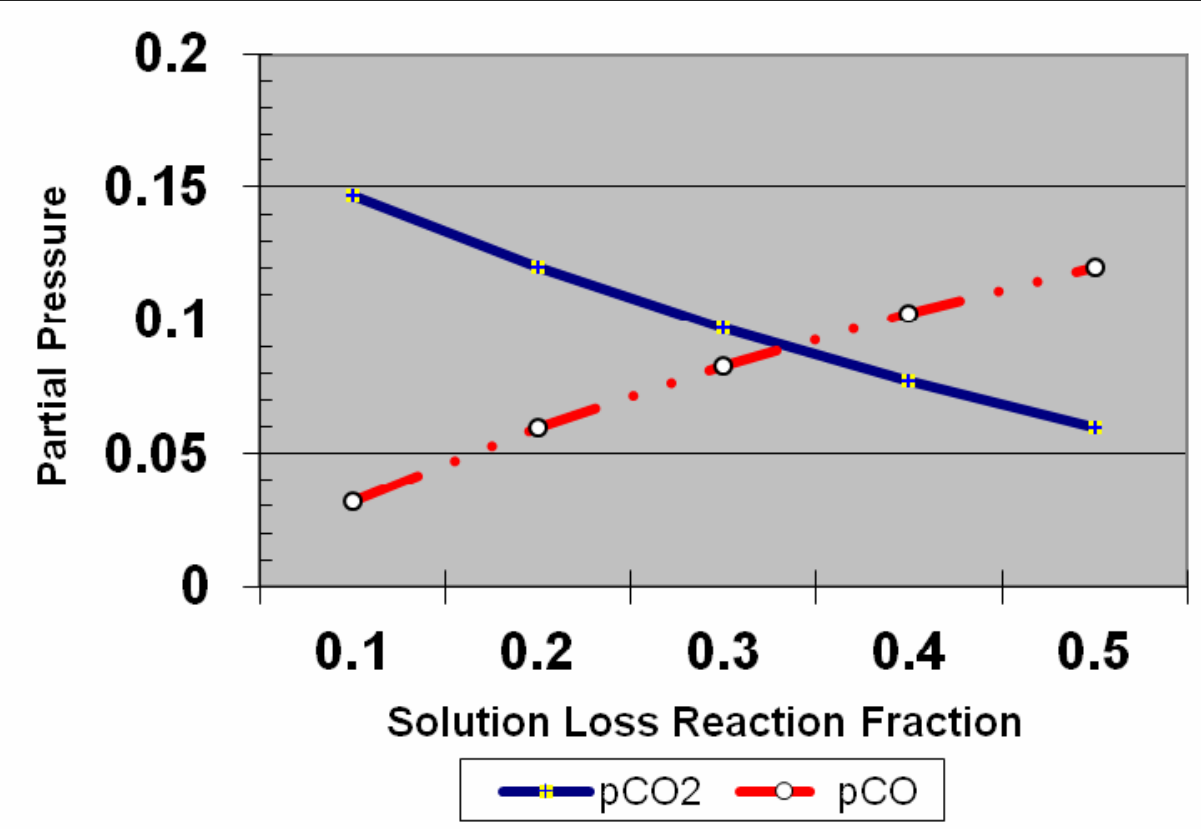

Figure 1-4. Coal Required at $85 \%$ Fixed Carbon to Meet Solution Loss Requirements as a Function of Solution Loss Fraction

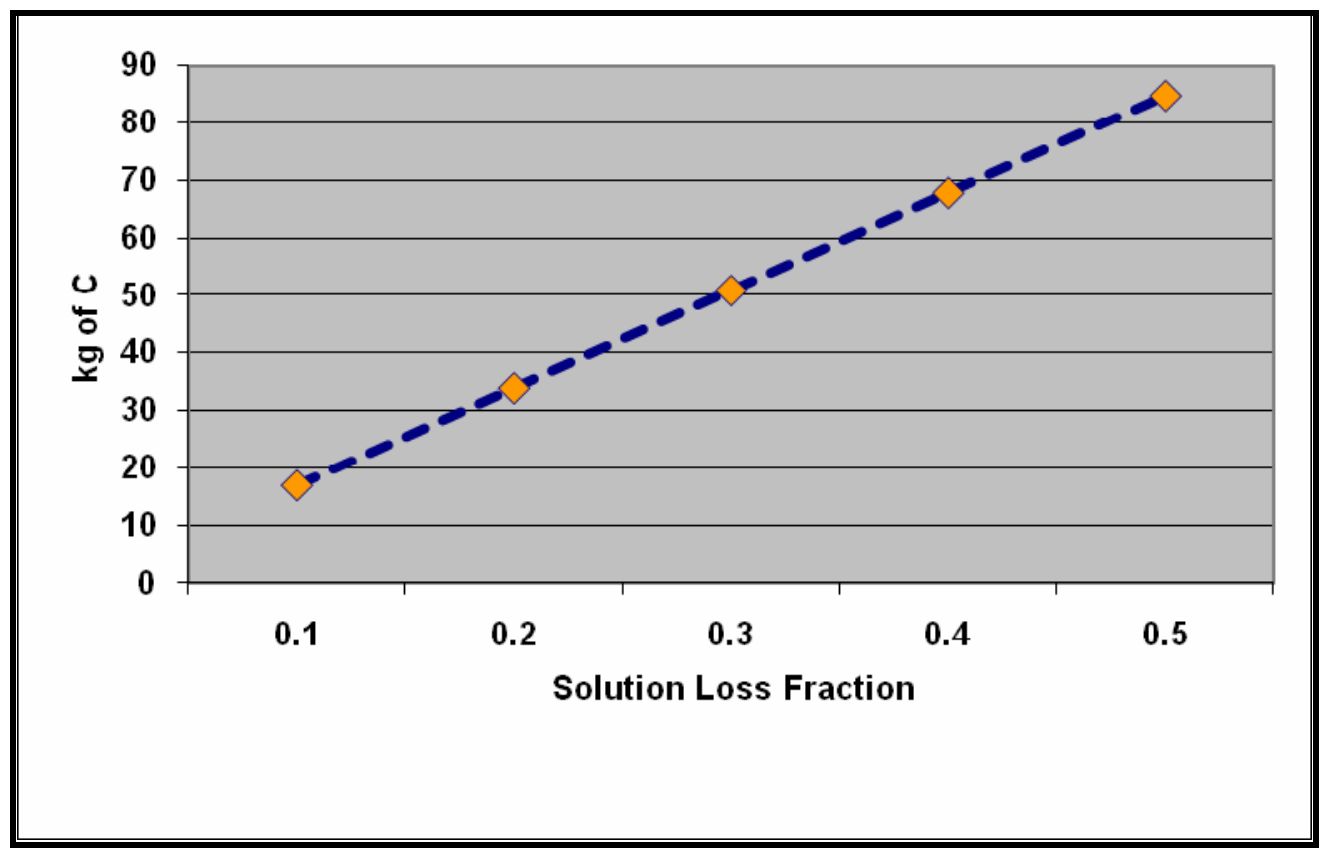


Figure 1-5. Total Coal Required for Various \% SS Conditions Reflecting Both Reduction and Solution Loss at $85 \%$ FC in Coal

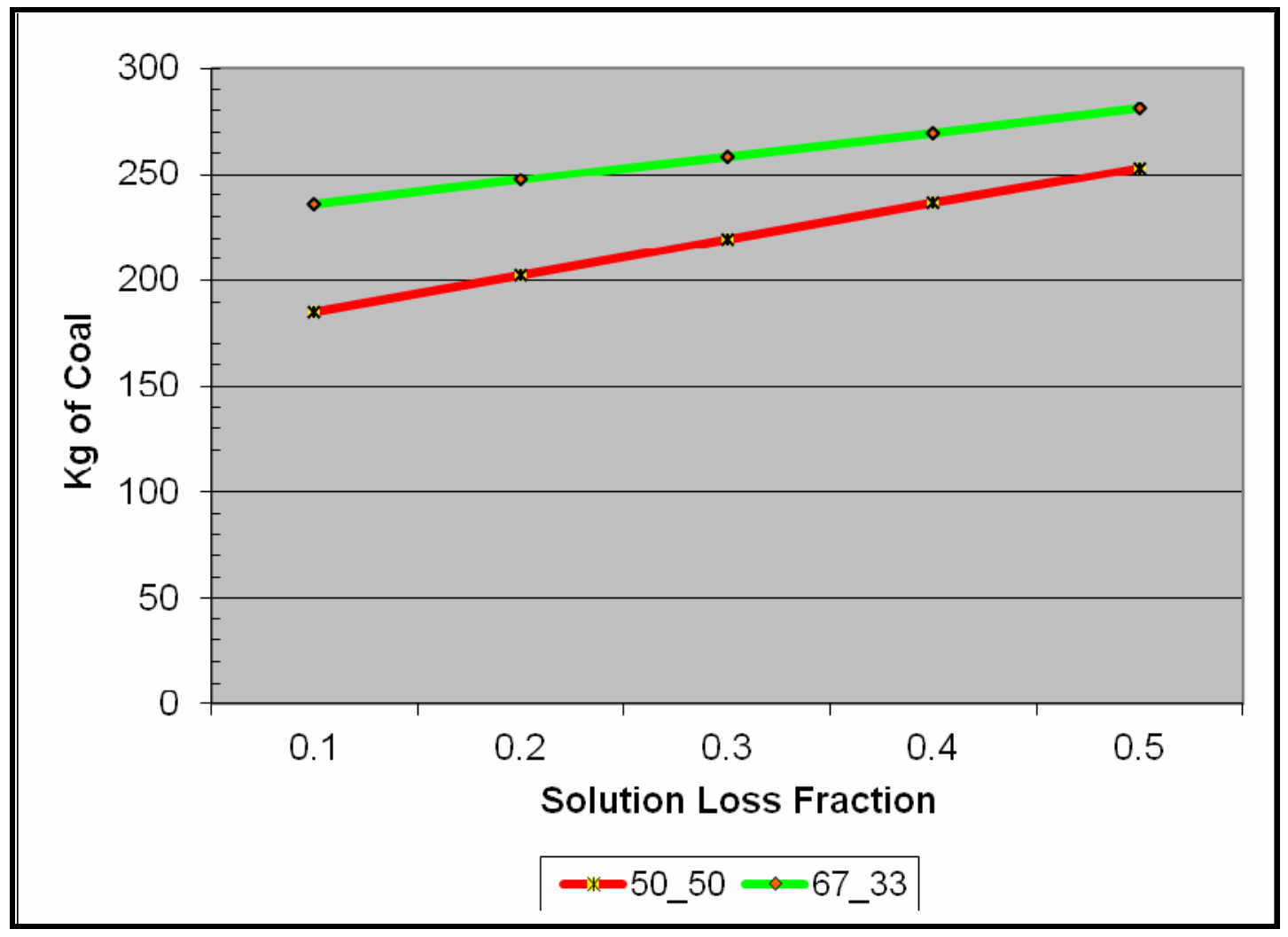

\section{1-1.9 Net Energy from Methane in Natural Gas (Air to Oxygen Comparison)}

This investigation examined the use of air and oxygen as an oxidant with natural gas and as noted in Table 1-12, the substitution of oxygen for air will lead to higher net levels of energy per unit of methane consumed from the natural gas. This is graphically illustrated in Figure 1-6. For this investigation, all the gas species in natural gas were examined in the Process Modeling section of the report, and in addition, the impact of preheating air to various temperatures prior to combustion is analyzed. One of the benefits in using pure oxygen is the potential of concentrating the carbon monoxide and carbon dioxide in the furnace off-gas by avoiding the dilution effect of the contained nitrogen in air. The use of computational fluid dynamics as illustrated in the Process modeling section of the report allows more complex interactions to be considered than that noted in this background theoretical treatment section. 
Figure 1-6. Net Energy Available per Mole of Methane (No Heat Recovery)

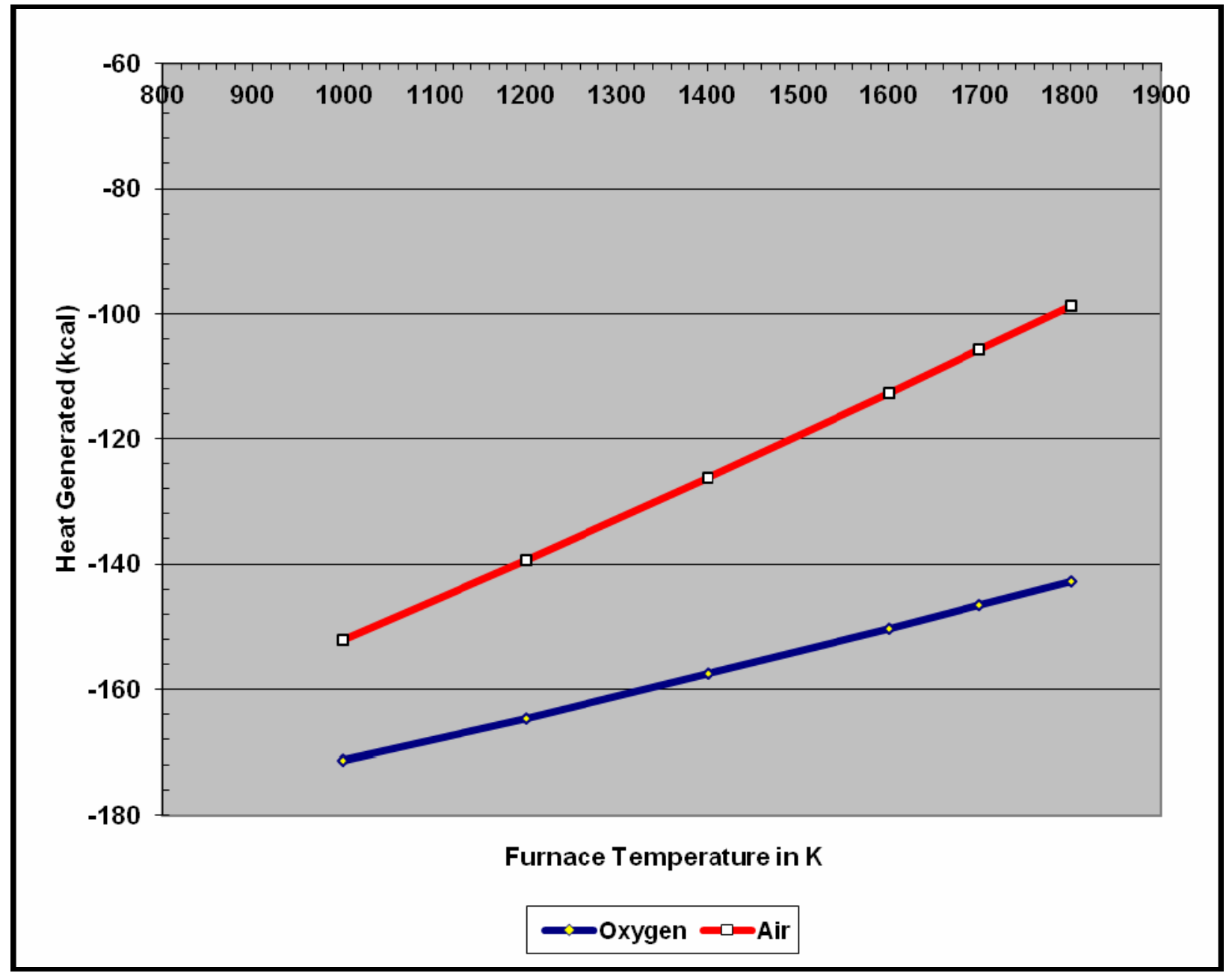

\section{1-1.10 Sequence of Events for the Metallurgical System}

Various phenomena occur in the processing of iron oxides with coal and fluxing agents to produce nodular reduced iron free of gangue components. The mixtures first lose any free water from the reaction mixture and various auxiliary coals that may be employed in the process. Then, coal begins to lose its light volatile matter and the hydrated water is then lost as the temperature in the system reaches the hydration temperature. If the fluxes employed contain carbonates, the carbonates begin to break down to carbon dioxide and mineral oxides at the calcinations temperature. As the temperature continues to rise, the reduction reactions begin to occur with the conversion of iron oxides to less oxidized forms and then eventually to elemental iron. This process generates increasing volumes of off-gas containing water vapor, carbon dioxide, carbon monoxide and other gas species. At even higher temperatures, carbon from coal begins to be absorbed by the reduced iron and as the carbon and temperature reach a certain level, the iron begins to melt and form a hot metal solution of iron and carbon. In a similar temperature range, the fluxes and gangue materials interact and form a molten slag. Various impurities in the reaction mixture then segregate between the molten metal and slag phases to depending on the production conditions employed. As the 
products leave the hot zones of the process, the liquid solutions of slag and metal solidify. This sequence is illustrated in Table 1-15.

Table 1-15. Sequence of Events

\begin{tabular}{|c|c|c|c|c|}
\hline \multirow[b]{2}{*}{ Event } & \multirow[b]{2}{*}{ Description } & \multicolumn{3}{|c|}{$\begin{array}{c}\text { Mixture Temperature } \\
\text { Range }\end{array}$} \\
\hline & & $\mathbf{K}$ & ${ }^{\circ} \mathrm{C}$ & ${ }^{\mathbf{0}} \mathbf{F}$ \\
\hline 1 & $\begin{array}{l}\text { Dehydration of free } \\
\text { water }\end{array}$ & 373.15 & 100 & 212 \\
\hline 2 & $\begin{array}{l}\text { Emission of volatile } \\
\text { matter from coal }\end{array}$ & 623 to 773 & 350 to 500 & 662 to 932 \\
\hline 3 & $\begin{array}{l}\text { Dehydration of bound } \\
\text { water from } \mathrm{Ca}(\mathrm{OH})_{2}\end{array}$ & 700 & 427 & 800 \\
\hline 4 & $\begin{array}{l}\text { Calcination of calcium } \\
\text { and magnesium } \\
\text { carbonates }\end{array}$ & $\sim 1000$ & $\sim 727$ & $\sim 1340$ \\
\hline 5 & $\begin{array}{l}\text { Reduction of magnetite } \\
\text { and hematite to iron }\end{array}$ & $>1100$ & $>827$ & $>1521$ \\
\hline 6 & $\begin{array}{l}\text { Melting of Fayalite } \\
\left(2 \mathrm{FeO} . \mathrm{SiO}_{2}\right)\end{array}$ & 1450 to 1477 & 1177 to 1204 & 2150 to 2200 \\
\hline 7 & $\begin{array}{l}\text { Melting of carbon } \\
\text { saturated iron }\end{array}$ & 1423 & 1150 & 2102 \\
\hline 8 & Melting of Slag & $>1584$ & $>1311$ & $>2392$ \\
\hline 9 & $\begin{array}{l}\text { Melting of wustite } \\
\text { (depending on dissolved } \\
\text { oxygen content) }\end{array}$ & 1646 through 1699 & 1373 through 1426 & 2503 through 2599 \\
\hline 10 & Melting of fluorspar & $\sim 1691$ & $\sim 1418$ & $\sim 2584$ \\
\hline 11 & Melting of pure iron & 1811 & 1538 & 2800 \\
\hline
\end{tabular}

\section{1-1.11 Development of Mass Balance Calculations}

For the process modeling and thermodynamic work undertaken as part of this program, various software programs were used as discussed in Section Three of this report. The mass balance for establishing the mix requirements needs to consider both the chemical and mineralogical make-up of the reaction system and the desired production level for the process considered. Simplified versions of mass balance are often used to bring the targeted mixture to close to the desired target composition. More complex models are used to improve the overall accuracy in achieving the desired mix and endpoint compositions. As an example of what is required to achieve a prediction of mix components, the following example shows the simplified procedure that can be employed. The actual mass balance determinations employed in Section Three include increased complexity beyond that described here. Table 1-16 summarizes the variable definitions for the simplified model that is illustrated. 
Table 1-16. Variable Definitions

\begin{tabular}{|c|c|}
\hline $\mathrm{M}_{\mathrm{mag}}$ & $=$ Mass of Magnetite Concentrate \\
\hline $\mathrm{M}_{\text {coal }}$ & $=$ Mass of Coal \\
\hline $\mathrm{M}_{\text {lime }}$ & $=$ Mass of Hydrated Lime \\
\hline $\mathrm{M}_{\mathrm{spar}}$ & $=$ Mass of Fluorspar \\
\hline $\mathrm{C}_{\mathrm{IM}}$ & $=\% \mathrm{Fe}$ in Concentrate \\
\hline $\mathrm{C}_{\mathrm{IC}}$ & $=\% \mathrm{Fe}$ in Coal \\
\hline $\mathrm{C}_{\mathrm{FC}}$ & $=\%$ Fixed Carbon in Coal \\
\hline $\mathrm{C}_{\text {Ash }}$ & $=\%$ Ash in Coal \\
\hline $\mathrm{C}_{\mathrm{ISiO} 2}$ & $=\%$ silica in Concentrate \\
\hline $\mathrm{C}_{\mathrm{IAl} 2 \mathrm{O} 3}$ & $=\%$ alumina in Concentrate \\
\hline $\mathrm{C}_{\mathrm{ICaO}}$ & $=\%$ Lime in Concentrate \\
\hline $\mathrm{C}_{\mathrm{IMgO}}$ & $=\% \mathrm{MgO}$ in Concentrate \\
\hline $\mathrm{C}_{\mathrm{CSiO} 2}$ & $=\%$ Silica in Coal Ash \\
\hline $\mathrm{C}_{\mathrm{CAl2O} 3}$ & $=\%$ Alumina in Coal Ash \\
\hline $\mathrm{C}_{\mathrm{CCaO}}$ & $=\%$ Lime in Coal Ash \\
\hline $\mathrm{C}_{\mathrm{CMgO}}$ & $=\%$ Magnesia in Coal Ash \\
\hline $\mathrm{C}_{\mathrm{LSiO} 2}$ & $=\%$ silica in Lime \\
\hline $\mathrm{C}_{\mathrm{LAl2O} 3}$ & $=\%$ alumina in Lime \\
\hline $\mathrm{C}_{\mathrm{LCaO}}$ & $=\% \mathrm{CaO}$ in Lime \\
\hline $\mathrm{C}_{\mathrm{LMgO}}$ & $=\% \mathrm{MgO}$ in Lime \\
\hline $\mathrm{C}_{\mathrm{SSiO} 2}$ & $=\%$ silica in Spar \\
\hline $\mathrm{C}_{\mathrm{SA} 12 \mathrm{O} 3}$ & $=\%$ alumina in Spar \\
\hline $\mathrm{C}_{\mathrm{SCaO}}$ & $=\% \mathrm{CaO}$ in Spar \\
\hline $\mathrm{C}_{\mathrm{SMgO}}$ & $=\% \mathrm{MgO}$ in Spar \\
\hline $\mathrm{C}_{\mathrm{SCaF} 2}$ & $=\%$ active $\mathrm{CaF} 2$ in Spar \\
\hline
\end{tabular}

\section{Basic governing equations for Magnetite Reduction for Defined Stoichiometry:}

(1) $\mathrm{Fe} 3 \mathrm{O} 4(\mathrm{~s})+4 \mathrm{C}(\mathrm{s})=3 \mathrm{Fe}(\mathrm{s})+4 \mathrm{CO}(\mathrm{g})$

One Mole of Fe Product will require 1.3333 Moles of Carbon Input in terms of Weight Units:

$55.85 \mathrm{~kg}$ of Fe Produced will require $12 * 1.3333 \mathrm{~kg}$ of C Input

Carbon Weight Input per Unit Fe Produced=0.2865

(2) Actual Input required: $=0.286 / \mathrm{CFC}$

(3) Weight of concentrate required: $=1 / \mathrm{C}_{\mathrm{IM}}$

(4) Silica Balance: $=\left(\mathrm{M}_{\mathrm{mag}} * \mathrm{Cl}_{\mathrm{SiO} 2}\right)+\left(\mathrm{M}_{\mathrm{coal}} * \mathrm{C}_{\mathrm{ash}} * \mathrm{CC}_{\mathrm{SiO} 2}\right)+\left(\mathrm{M}_{\mathrm{lime}} * \mathrm{CL}_{\mathrm{SiO} 2}\right)+\left(\mathrm{M}_{\mathrm{spar}} * \mathrm{CS}_{\mathrm{SiO} 2}\right)$

(5)"Lime" Balance: $=\left(\mathrm{M}_{\mathrm{mag}} * \mathrm{CI}_{\mathrm{CaO}}\right)+\left(\mathrm{M}_{\mathrm{coal}} * \mathrm{C}_{\mathrm{ash}} *\left(\mathrm{CC}_{\mathrm{CaO}}+\mathrm{CC}_{\mathrm{MgO}}\right)\right)+\left(\mathrm{M}_{\mathrm{lime}} *\left(\mathrm{CL}_{\mathrm{CaO}}+\mathrm{CL}_{\mathrm{MgO}}\right)\right)+\left(\mathrm{M}_{\mathrm{spar}} *\left(\mathrm{CS}_{\mathrm{CaO}}-\mathrm{CS}_{\mathrm{MgO}}\right)\right)$

(6) $\mathrm{CaO}$ needed: $=\mathrm{Ratio}\left(\mathrm{CaO} / \mathrm{SiO}_{2}\right)^{*}($ Silica Balance $)$

The basic procedure to solve for various mixture components is summarized in Table 1-17. 


\section{Table 1-17. Procedure}

1. Calculate coal required based on magnetite concentration per unit time processed

2. Calculate 1st estimate of silica input from coal and magnetite concentrate and spar to be used

3. Calculate hydrated lime used based on the lime to silica target set for the trial

4. Calculate actual Hydrated Lime Based on: $\quad=\left(\mathrm{M}_{\text {lime }}\right)^{\mathrm{o}} /\left(\mathrm{C}_{\mathrm{LCaO}}+\mathrm{C}_{\mathrm{LMgO}}\right)$

5. Iterate Silica Balance on basis of lime estimate

6. Iterate Hydrated Lime required based on silica balance and Lime to Silica target

\section{$\underline{\text { Example Calculation }}$}

\section{Base Case}

a. $2.5 \mathrm{Mg} / \mathrm{h}$ Fe Product

b. Mix Carbon Requirement at 100\% Stoichiometry (kg): 716

c. $\mathrm{C}_{\mathrm{FC}}=69.13 \%$

d. Mix Coal Requriement (kg): 1,036

e. $\mathrm{C}_{\mathrm{IM}}=68.10 \%$

f. Iron Ore Concentrate Needed (kg): 3,671

g. $\mathrm{C}_{\mathrm{ISiO} 2}=\quad 3.63 \%$

h. $\mathrm{C}_{\text {CAsh }}=\quad 9.32 \%$

I. $\mathrm{C}_{\mathrm{CSiO} 2}=\quad 47.81 \%$

j. $\mathrm{CL}_{\mathrm{SiO} 2}=\quad 0.48 \%$

k. $\mathrm{CS}_{\mathrm{SiO}^{2}}=\quad 0.76 \%$

Mspar

I. Fraction: $2 \%$

m. Initial Estimated Spar: 94

n. Initial Silica Balance: 180

Ratio Lime to Silica Target:

o. 1.24

p. Initial Estimate for Lime Requirement: 223

q. $\mathrm{C}_{\mathrm{ICaO}}=\quad 0.63 \%$

r. $\mathrm{C}_{\mathrm{IMgO}}=\quad 0.34 \%$

s. $\mathrm{C}_{\mathrm{CCaO}}=\quad 4.18 \%$

t. $\mathrm{C}_{\mathrm{CMgO}}=\quad 1.18 \%$

u. $\mathrm{C}_{\mathrm{SCaO}}=\quad 1.16 \%$

v. $\mathrm{C}_{\mathrm{SMgO}}=\quad 0.04 \%$

X. Lime from Coal, Iron Ore and Spar(kg): $\quad 42$

y. Lime from Hydrated Lime Required $(\mathrm{kg})$ : 181

z. $\mathrm{CLCaO}=\quad 75.25 \%$

aa. $\mathrm{CLMgO}=\quad 0.39 \%$

ab. Initial Estimate for Hydrated Lime (kg): 240

ac. New Spar Estimate(kg): $\quad 99$

ad. New Silica Balance (kg): 181

ae. Second Estimate for Lime $(\mathrm{kg})$ : $\quad 225$

af: $\quad$ 2nd estimate for Lime from Coal, Iron Ore and Spar (kg): $\quad 42$

ag. Lime from Hydrated Lime Required(kg): 183

ah. Final Estimate for Hydrated Lime (kg): 242 
As can be seen, various materials each have a chemical and mineralogical composition that needs to be considered in order to achieve the desired mixture chemistry. As the mixture is assembled, the impurity constituents need to be reflected in the mass balance in order to obtain the desired ratios of carbon to iron oxides and lime to silica. As can be seen, an iterative process that allows closure to achieve desired targets can be followed. The type of computations illustrated here can be rapidly done using available software once the governing equations for the system are specified.

\section{1-1.12 Section Summary}

This section of the report reviewed some of the fundamental parameters associated with the carbothermic reduction and smelting process to convert iron oxide bearing minerals to elemental iron and to iron carbon solutions. As can be seen various factors must be considered in achieving an efficient metallurgical system for routinely producing nodular reduced iron with low levels of impurities. The following three sections will summarize the experimental and process modeling work that has been carried out in the course of this investigation. The second section will summarize the laboratory and pilot scale work that has allowed identification of effective mix design, atmospheric controls and impurity separation techniques that will result in low sulfur, high metallization, carbon containing nodular iron to be routinely produced. The third section of the report will summarize all the work done on modeling the process using advanced computational techniques and will illustrate some of the important parameters in bringing the technology to a commercial level. The fourth section will illustrate the work achieved on our pilot size linear hearth furnace and the various furnace configurations employed and overall results from these configurations in producing nodular reduced iron. 


\title{
PART 2:
}

\section{Laboratory Development of Mix Chemistry and Process Conditions for NRI Development}

by

\author{
Iwao Iwasaki \\ Taconite Chair \\ Coleraine Minerals Research Laboratory \\ 218-245-4201 \\ iiwasaki@nrri.umn.edu \\ Richard F. Kiesel \\ Deputy Director \\ Coleraine Minerals Research Laboratory \\ 218-245-4207 \\ rkiesel@nrri.umn.edu \\ Natural Resources Research Institute \\ Coleraine Minerals Research Laboratory \\ P.O. Box 188 \\ Coleraine, Minnesota 55722
}




\section{Project Summary/Abstract}

The current trend in the steel industry is a gradual decline in conventional steelmaking from taconite pellets in blast furnaces, and an increasing number of alternative processes using metallic scrap iron, pig iron and metallized iron ore products. Currently, iron ores from Minnesota and Michigan are pelletized and shipped to the lower Great Lakes ports as blast furnace feed. The existing transportation system and infrastructure is geared to handling these bulk materials. In order to expand the opportunities for the existing iron ore mines beyond their blast furnace customer base, a new material is needed to satisfy the needs of the emerging steel industry while utilizing the existing infrastructure and materials handling.

A successful demonstration of Kobe Steel's ITmk3 process with a large-scale pilot plant at Northshore Mining, in Silver Bay, MN, led to the construction by Mesabi Nugget Corporation of a rotary hearth furnace of $60 \mathrm{~m}(200 \mathrm{ft})$ in diameter with a capacity of 500,000 tons/year commercial plant in Hoyt Lakes, MN, and started operation towards the end of 2009. A large-scale pilot plant campaign was also reported by JFE Steel, demonstrating their Hi-QIP process in Japan. The present project was to build upon and improve the process by further reducing cost, improving quality and creating added incentive for commercial development.

This project expanded previous research conducted at the University of Minnesota Duluth's Natural Resources Research Institute and that reported by Kobe Steel and JFE Steel. The project was continued to control Nodularized Reduced Iron (NRI) size, quality and cost by developing feed composition that minimized fusion time, micro NRI generation and NRI sulfur. The optimum feed composition for taconite concentrates of sub-stoichiometric medium-volatile bituminous coal, ground to -100 mesh, $2 \%$ fluorspar and hydrated lime to adjust the slag composition $\mathrm{B}_{2}\left((\mathrm{CaO}) /\left(\mathrm{SiO}_{2}\right)\right)$ to 1.5 was arrived at using electrically-heated box furnace with $\mathrm{N}_{2}-\mathrm{CO}$ atmosphere. A major difference between box furnace and gas-fired Linear Hearth Furnace (LHF) was high $\mathrm{CO}_{2}$, high $\mathrm{H}_{2} \mathrm{O}$ and highly turbulent furnace atmosphere of LHF.

Carbonaceous cover layer over feed mixtures was effective in producing quality NRI with minimal generation of micro NRI and NRI sulfur below $0.05 \% \mathrm{~S}$. Productivity could be maximized by minimizing the use of hearth and cover layer materials and largest possible cover layer materials to circumvent shielding of radiant heat transfer. The use of oxy-fuel burners shortened the fusion time by $10-30 \%$ compared to air-fuel burners.

With sub-bituminous coal, an excessive amount of molasses binder was required to produce strong enough briquettes to withstand handling and minimizing micro NRI generation in fusion because of high volatiles. Powder River Basin (PRB) char, carbonized at $1400^{\circ} \mathrm{C}$ required the least amount of molasses and was most effective in reduction and fusion reactions. As volatiles played an important role in the process by shrouding feed mixtures with reducing gas, PRB char may be used for the internal reductant and PRB coal as a makeup cover and hearth layer material. Quality NRI could be produced from hematite, which constitutes $90 \%$ of the world's iron ore resource, by modifying the addition levels of reductant and slag composition. 


\section{TABLE OF CONTENTS}

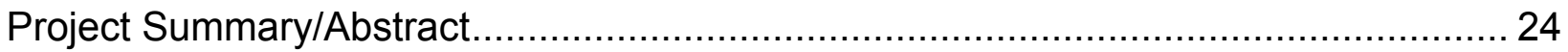

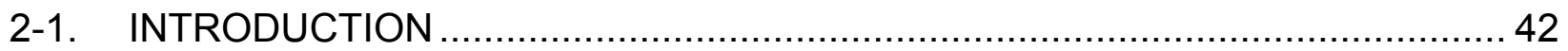

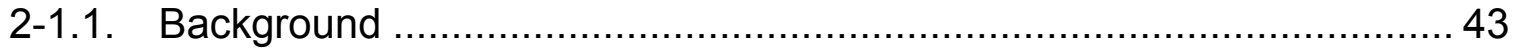

2-1.1.1. Work Done in Japan and Piloted in the US.......................... 43

2-1.1.2. Alternative to Kobe Steel Approach ........................................ 43

2-1.1.3. Test Work at the Coleraine Minerals Research

Laboratory...................................................................... 44

2-1.1.3.1. Laboratory Tube Furnace Tests ........................... 44

2-1.1.3.2. Laboratory Box Furnace Tests ............................. 45

2-1.1.3.3. Pilot-plant Linear Hearth Furnace Tests

(Rotary Hearth Simulator)..................................... 45

2-1.1.4. Proposed work ............................................................ 46

2-1.1.4.1. Oxygen-Fuel Burners.............................................. 46

2-1.1.4.2. Control of Local Atmosphere Above Feed

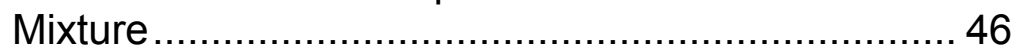

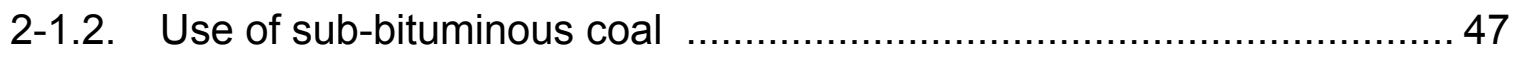

2-1.2.1. Previous work at the Coleraine Minerals Research

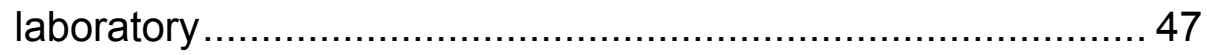

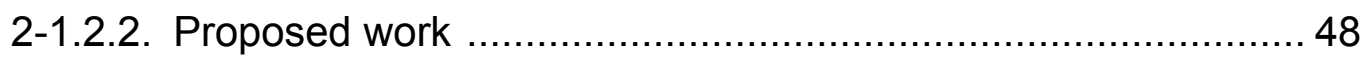

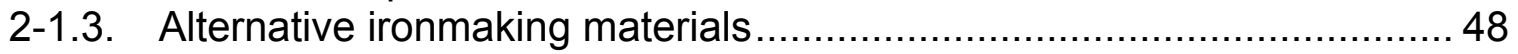

2-1.3.1. Previous work at the Coleraine Minerals Research

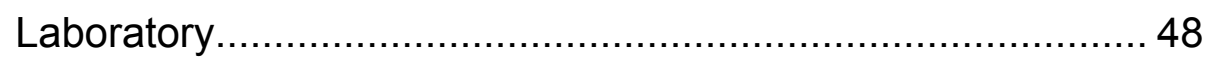

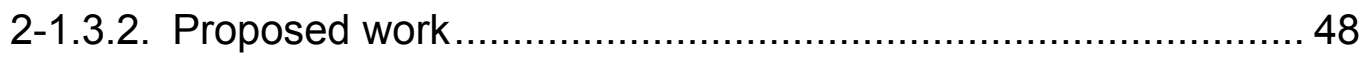

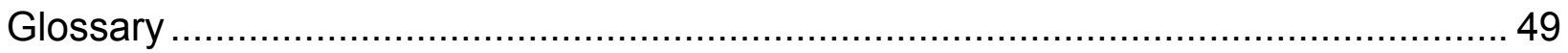

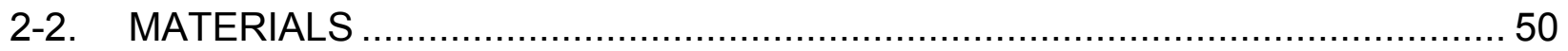

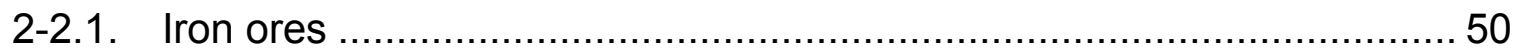

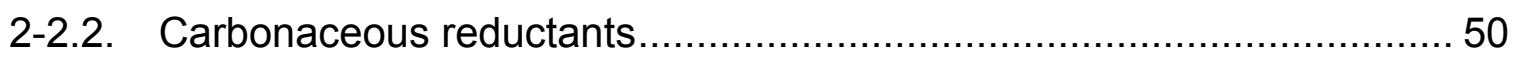

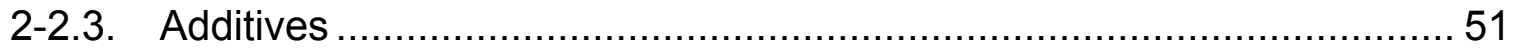

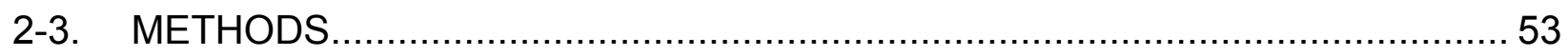

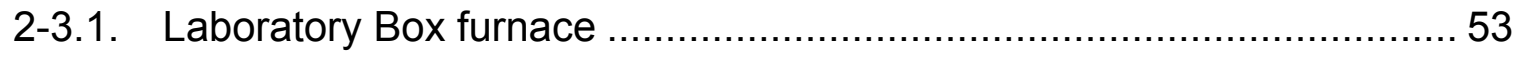

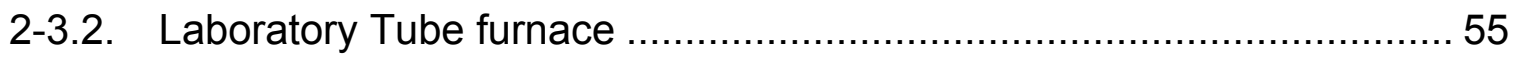

2-3.3. Linear Hearth Furnace (LHF) .................................................... 55

2-3.3.1. Walking beam tray conveying system................................ 55

2-3.3.2. Continuous moving pallet car system …….......................... 55

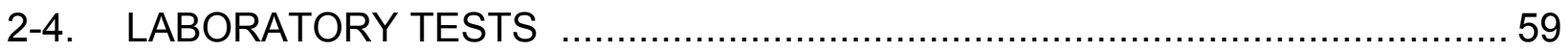

2-4.1. Baseline information using magnetic taconite concentrates and medium-volatile bituminous coal................................................. 59

2-4.1.1. Optimum sizes of reductant and hearth layer carbon ............. 59

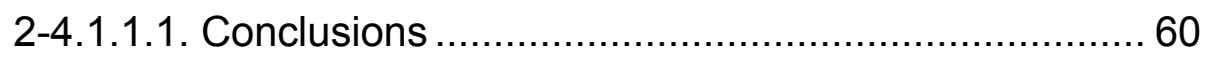

2-4.1.1.2. Reductant coal size ........................................ 60 
2-4.1.1.3. Size of carbonaceous materials used as hearth

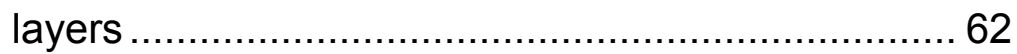

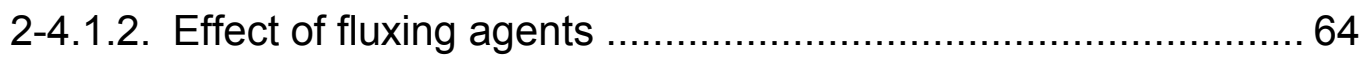

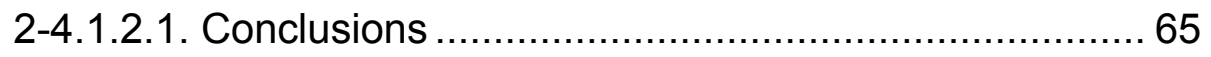

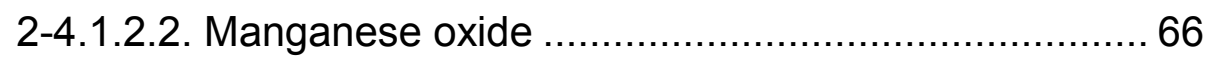

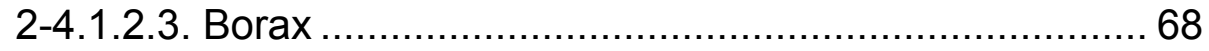

2-4.1.3. Effects of size, apparent density and height ......................... 68

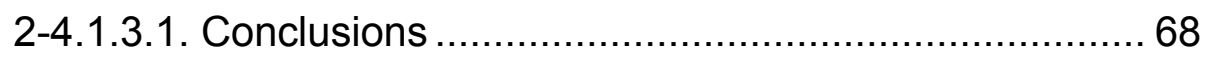

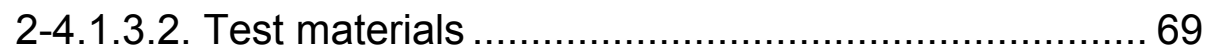

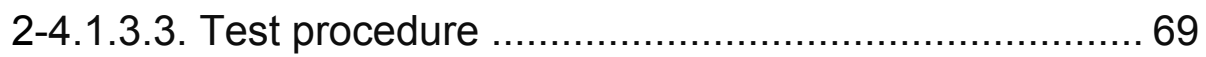

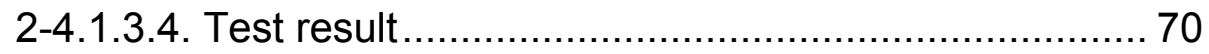

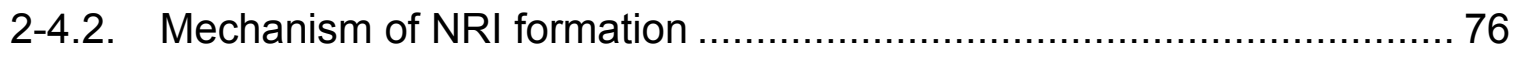

2-4.2.1. Metal-slag separation during NRI formation ......................... 76

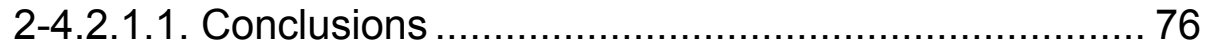

2-4.2.1.2. Experimental observation ...................................... 76

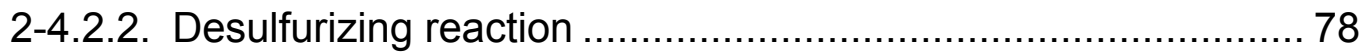

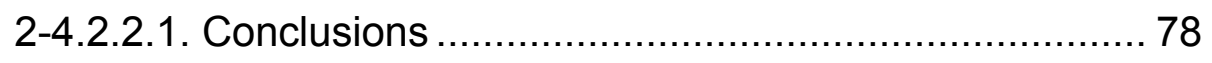

2-4.2.2.2. Feed producing no slag ...................................... 79

2-4.2.2.3. Typical feed mixture consisting of taconite concentrate $(\mathrm{K})$ and bituminous coal $(\mathrm{J})$................. 79

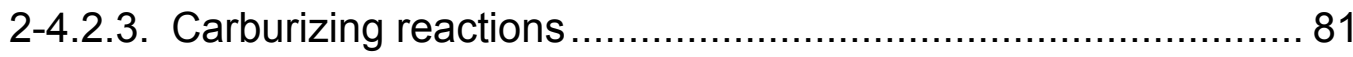

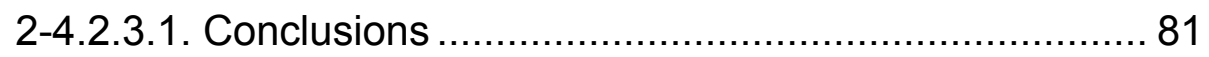

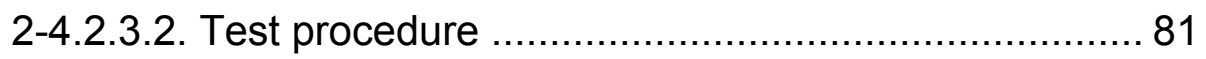

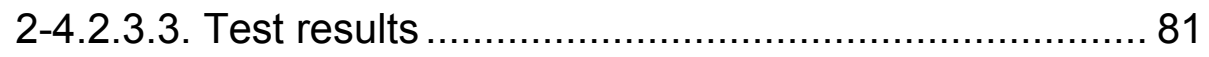

2-4.2.3.3.1. Alumina hearth layer............................ 81

2-4.2.3.3.2. Anthracite char hearth layer ................. 84

2-4.3. Generation and control of micro NRI ........................................... 85

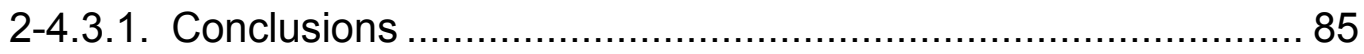

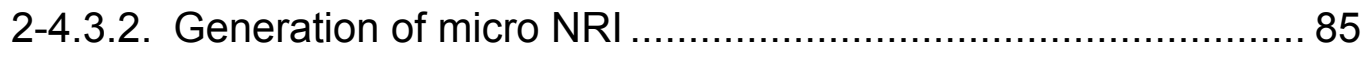

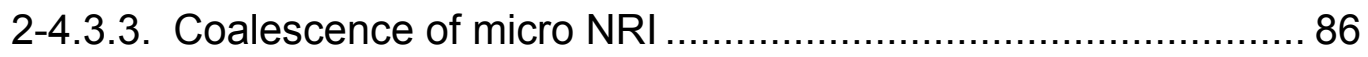

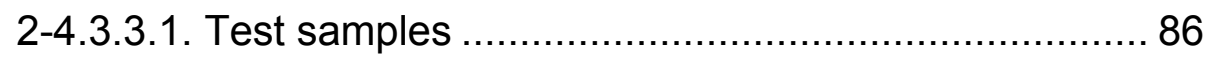

2-4.3.3.2. Test procedure .............................................. 86

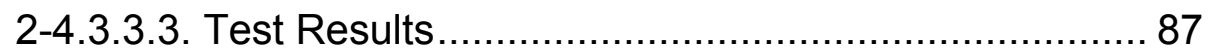

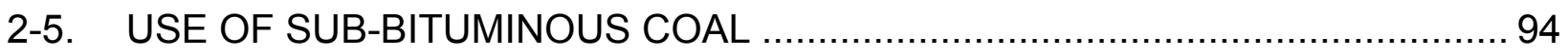

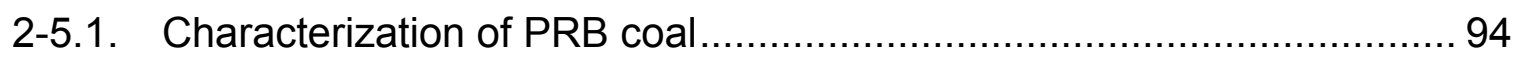

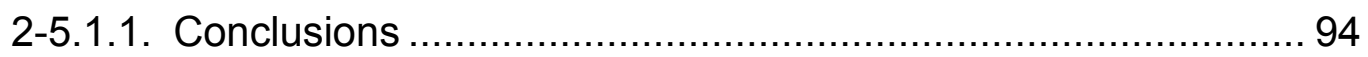

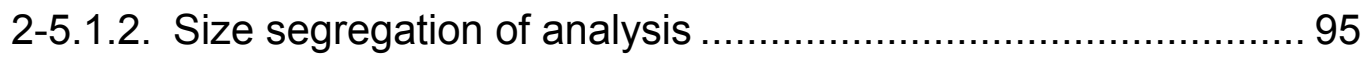

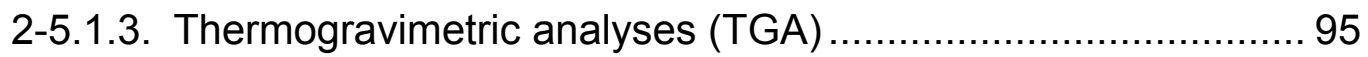

2-5.1.4. De-volatilization/carbonization characteristics ........................ 99

2-5.1.4.1. Roasting in LTD reduction setup .......................... 99

2-5.1.4.2. Carbonizing in box furnace .................................... 99 


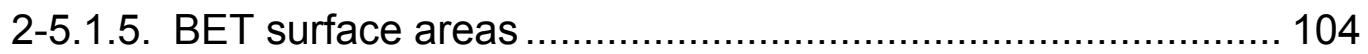

2-5.2. Preliminary box furnace tests with PRB coal and char ..................... 105

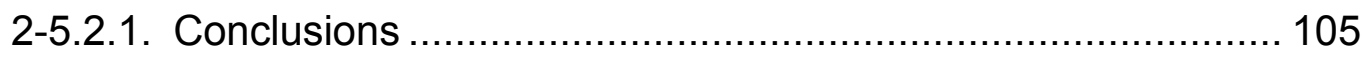

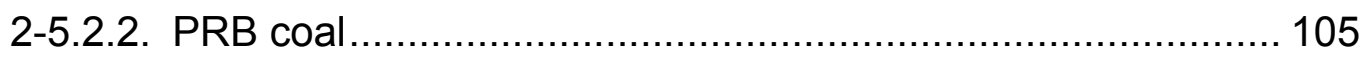

2-5.2.2.1. Test procedure .............................................. 106

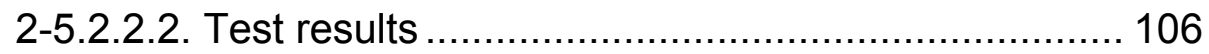

2-5.2.3. PRB char, carbonized at different temperatures ................... 109

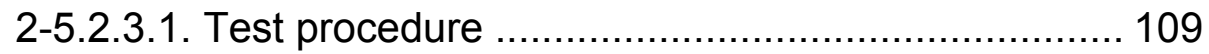

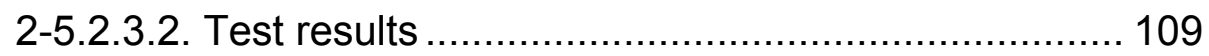

2-5.2.4. Overall correlation of test results ...................................... 114

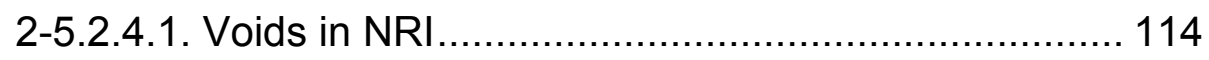

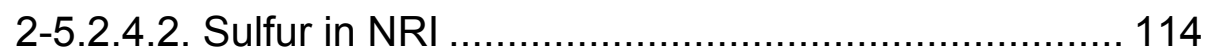

2-5.2.4.3. Minimum time to fusion...................................... 117

2-5.2.5. Bituminous coal $(F)-P R B$ coal/char mixtures as

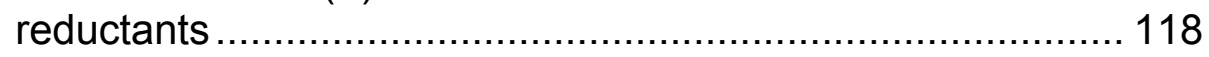

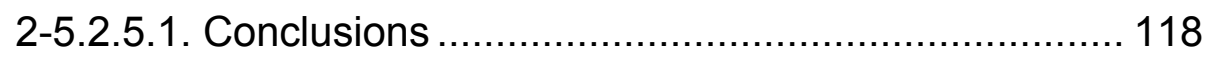

2-5.2.5.2. Test procedure .............................................. 119

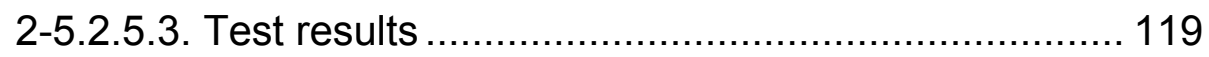

2-5.2.6. PRB coal/char as hearth layer ........................................ 126

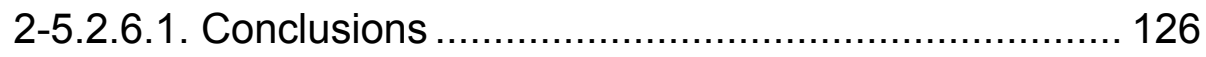

2-5.2.6.2. Test procedure .............................................. 126

2-5.2.6.3. Test results ...................................................... 126

2-5.2.7. Interaction of bituminous coal and PRB coal in feed with coke and PRB coal in hearth layer.................................... 130

2-5.2.7.1.Conclusions ......................................................... 130

2-5.2.7.2. Test procedure ............................................... 130

2-5.2.7.3. Test results ....................................................... 130

2-5.2.8. Interaction of $P R B$ coal and PRB char $\left(1400^{\circ} \mathrm{C}\right)$ used as reductant and hearth layer material .................................... 134

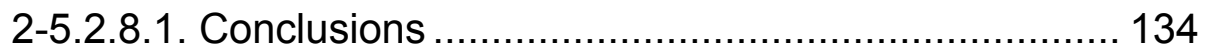

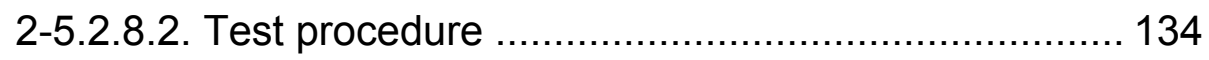

2-5.2.8.3. Test results ........................................................ 134

2-5.2.9. Equivalence of carbon in molasses and PRB coal/char........ 138

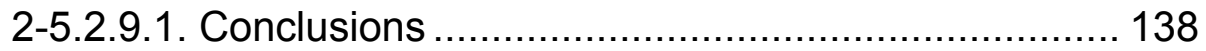

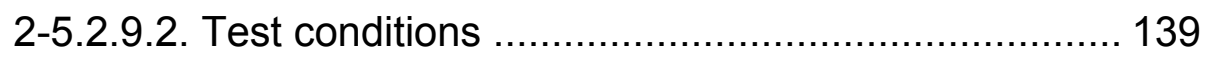

2-5.2.9.3. Test results ...................................................... 139

2-5.2.9.3.1. In the absence of molasses................ 139

2-5.2.9.3.2.In the presence of molasses ................ 141

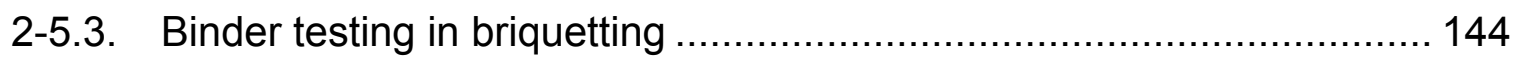

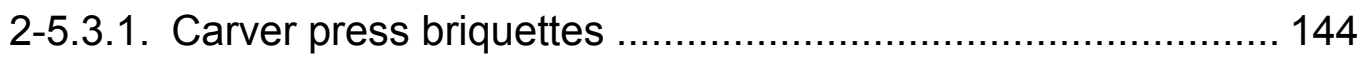

2-5.3.1.1. Conclusions ..................................................... 144 


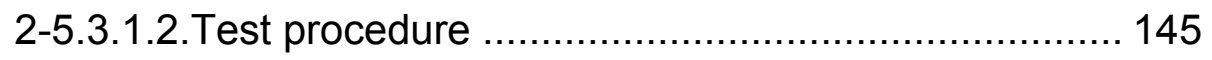

2-5.3.1.3. Test results ........................................................ 145

2-5.3.1.3.1. In the absence of binder ................... 145

2-5.3.1.3.2. Effect of binders ................................. 146

2-5.3.2. Laboratory Komarek briquetting machine ........................... 150

2-5.3.2.1. Test procedure .................................................... 150

2-5.3.2.2. Preliminary results with different binders .............. 151

2-5.3.2.2.1. Conclusions ..................................... 151

2-5.3.2.2.2. Test results....................................... 151

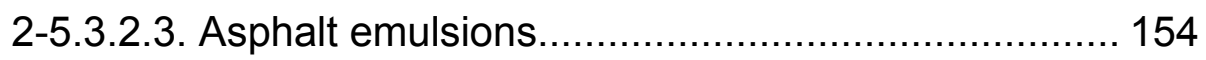

2-5.3.2.3.1. Conclusions........................................ 155

2-5.3.2.3.2. Chemical composition of asphalt emulsions........................................... 155

2-5.3.2.3.3. Effect of asphalt emulsions in briquetting .......................................... 155

2-5.3.2.3.4. Effect of asphalt emulsions on fusion behavior.................................. 156

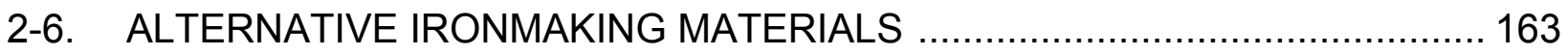

2-6.1. Preliminary tests on the effects of reductant coal and additives .......... 163

2-6.2. Screening tests of silicates and alumino-silicates ............................. 164

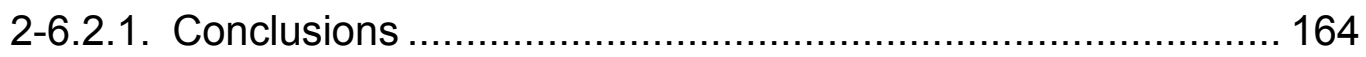

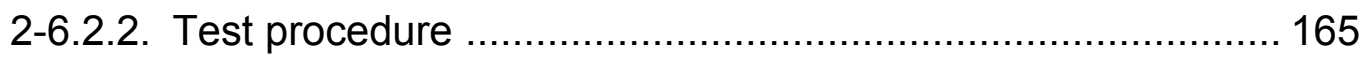

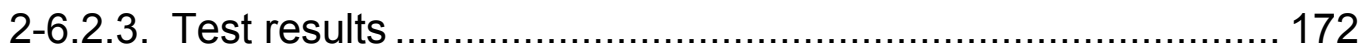

2-6.2.3.1. Wollastonite .................................................... 172

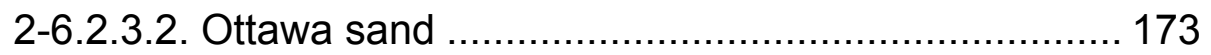

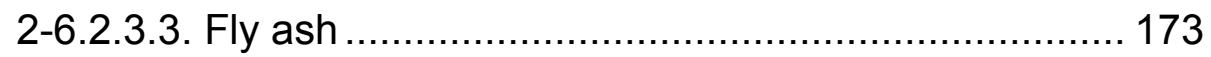

2-6.2.3.4. Nepheline svenite .............................................. 173

2-6.2.3.5. Anorthosite ................................................. 174

2-6.2.3.6. Taconite tailings.................................................. 174

2-6.2.3.7. Labradorite ................................................... 174

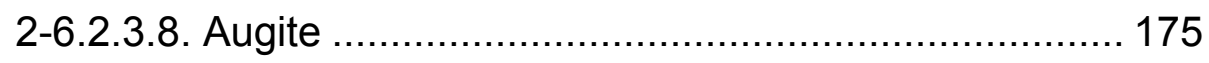

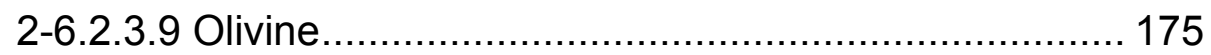

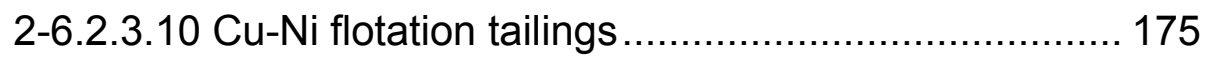

2-6.2.3.11. Summary ......................................................... 180

2-6.3. Effect of a combined use of fluorspar and $\mathrm{MnO}_{2}$ on Fusion time ....... 180

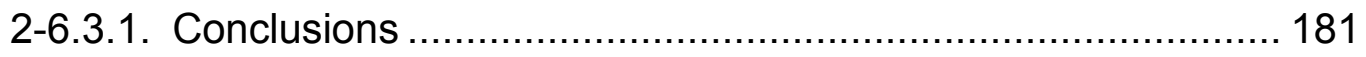

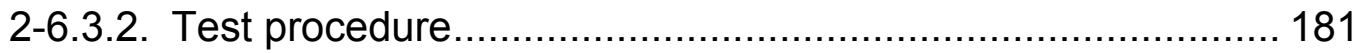

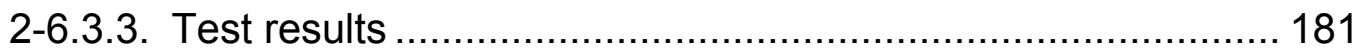

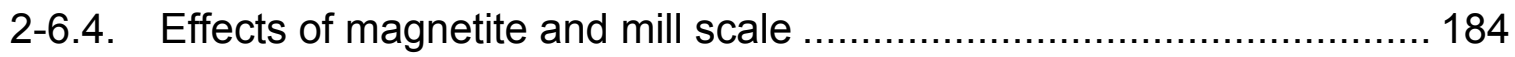

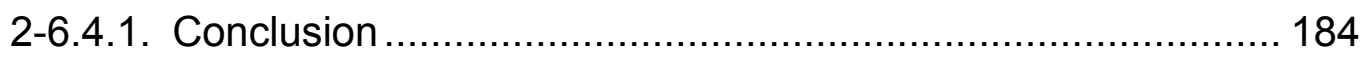

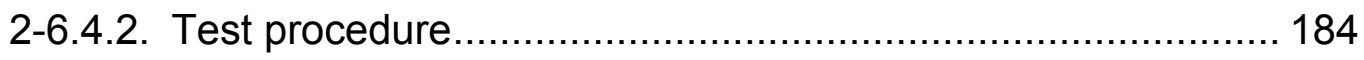




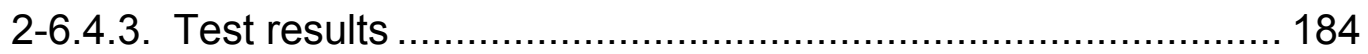

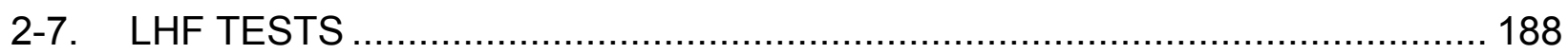

2-7.1. Preliminary tests with walking beam tray conveying system.............. 188

2-7.1.1. Conclusions .................................................................. 188

2-7.1.2. Standardized procedure for the preliminary series of tests .... 189

2-7.1.2.1. Feed mixtures..................................................... 189

2-7.1.2.2. Tray fabrication ................................................... 189

2-7.1.2.3. LHF operation.................................................. 189

2-7.1.2.4. Temperature measurements within coke layers .... 190

2-7.1.2.5. Sulfur distribution between NRI and slag.............. 190

2-7.1.3. Preliminary test results with hoods in Zone 2..................... 190

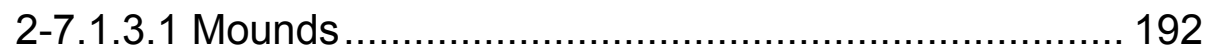

2-7.1.3.1.1. Effect of $\mathrm{CH}_{4}$ or $\mathrm{CO}$ injection .............. 192

2-7.1.3.1.2. Effect of cover layer coke .................... 193

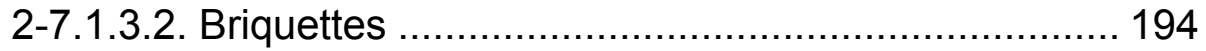

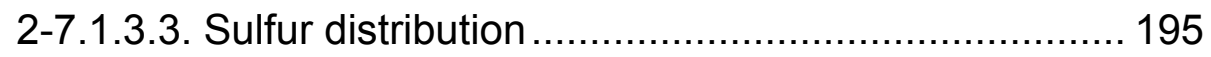

2-7.1.4. Preliminary tests without hood in Zone 2 …...................... 197

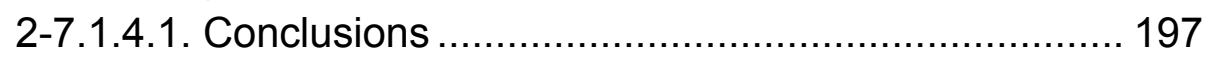

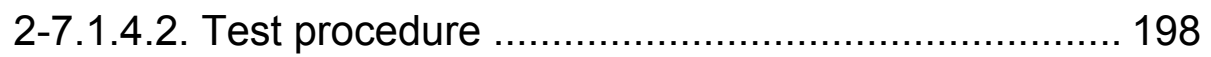

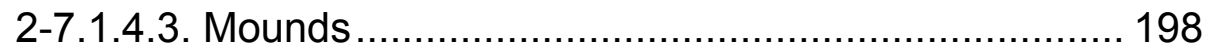

2-7.1.4.4. Briquettes ....................................................... 198

2-7.1.5. Effects of reductant coal, hearth layer and cover layer

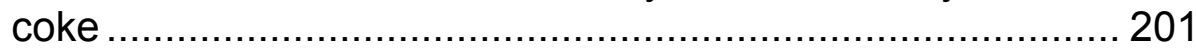

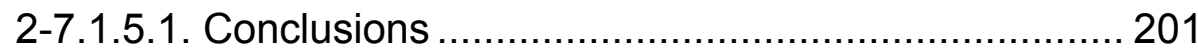

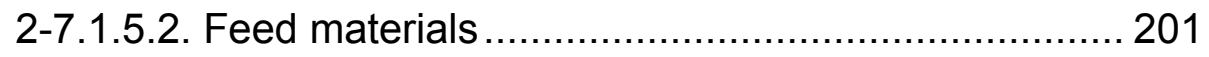

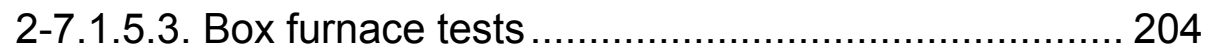

2-7.1.5.4. LHF tests ....................................................... 204

2-7.1.5.4.1. Single layer of briquettes .................... 204

2-7.1.5.4.2. Multi-layers of briquettes .................... 205

2-7.1.5.4.3. Effect of briquette loading .................. 206

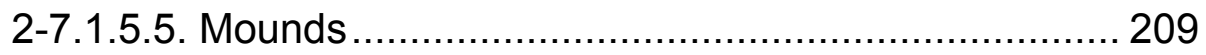

2-7.2. Continuous moving pallet car system ............................................... 211

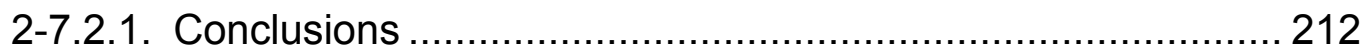

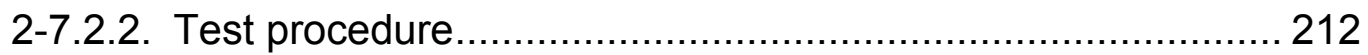

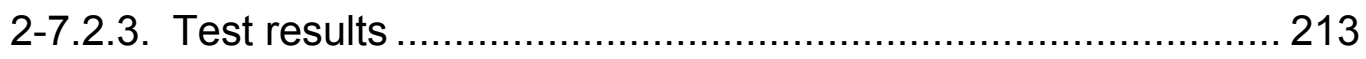

2-7.2.3.1. Comparison of oxy-fuel and air-fuel burners.......... 213

2-7.2.3.2. Effect of briquette size ......................................... 213

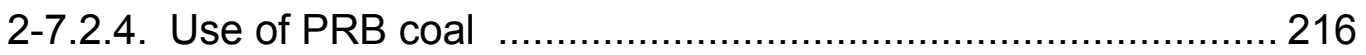

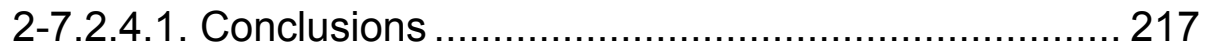

2-7.2.4.2. PRB coal properties......................................... 217

2-7.2.4.3 Test procedure ................................................ 218 


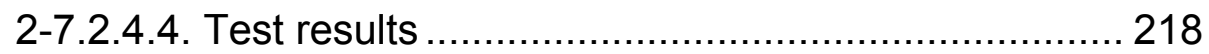

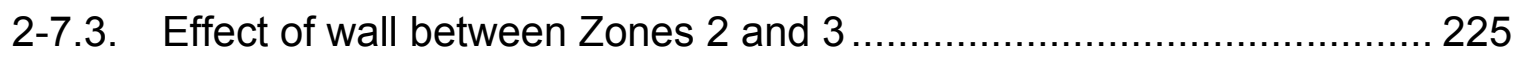

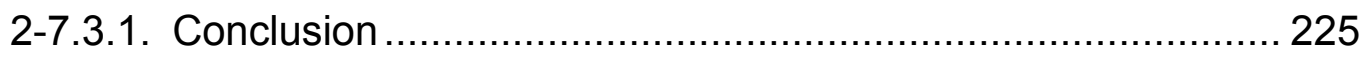

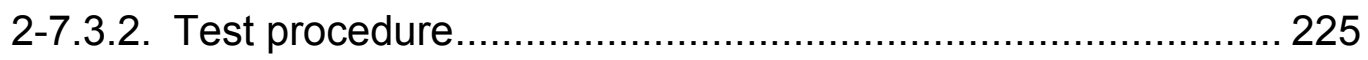

2-7.3.3. Test results ............................................................... 225

2-7.4. Effect of agglomerate shape on fusion time ................................... 226

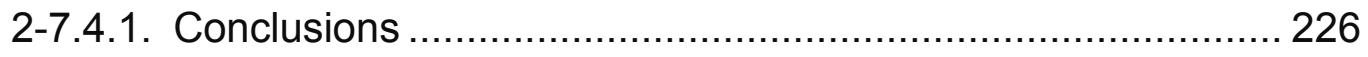

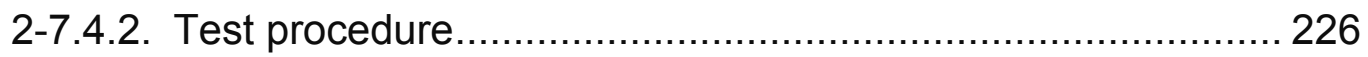

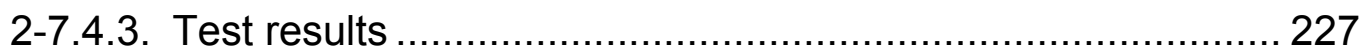

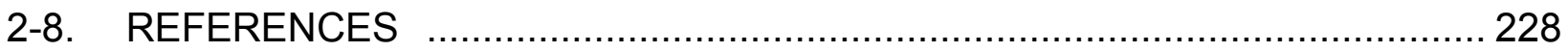




\section{LIST OF TABLES}

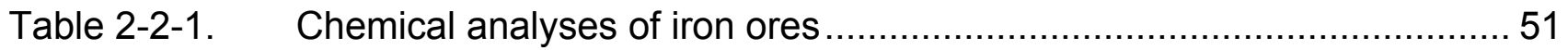

Table 2-2-2(a). Proximate analyses of carbonaceous materials .................................... 52

Table 2-2-2(b). Ash mineral analyses of carbonaceous reductants................................ 52

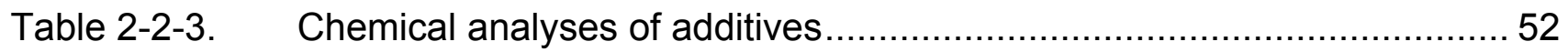

Table 2-4-1. Size distributions of medium-volatile bituminous coal of different mesh-of-grind, expressed as cumulative $\%$ weight passing.

Table 2-4-2. Summary on the effect of reductant coal size on fusion behavior and micro NRI generation when 6-segment mounds, consisting of taconite concentrate (Ma), different levels of coal at different mesh-of-grind and at slag composition $\left(\mathrm{L}_{1.5} \mathrm{FS}_{2}\right)$, were placed on $6 / 100$ mesh anthracite char, preheated at $1149^{\circ} \mathrm{C}\left(2100^{\circ} \mathrm{F}\right)$ for 5 minutes and heated at $1400^{\circ} \mathrm{C}\left(2552^{\circ} \mathrm{F}\right)$ for 15 minutes, while passing $80 \% \mathrm{~N}_{2}-20 \% \mathrm{CO}$ at $40 \mathrm{~L} / \mathrm{min}$

Table 2-4-3. Summary on the effects of hearth layer coke and anthracite char size on fusion behavior and micro NRI generation when 6segment mounds, consisting of taconite concentrate (Ma), 95\% stoichiometric coal, ground to -100 mesh and at slag composition $\mathrm{L}_{1.5} \mathrm{FS}_{2}$, were placed on $6 / 100$ mesh anthracite char, preheated at $1149^{\circ} \mathrm{C}\left(2100^{\circ} \mathrm{F}\right)$ for 5 minutes and heated at $1427^{\circ} \mathrm{C}$ $\left(2600^{\circ} \mathrm{F}\right)$ for 15 minutes, while passing $80 \% \mathrm{~N}_{2}-20 \% \mathrm{CO}$ at 40 $\mathrm{L} / \mathrm{min}$

Table 2-4-4. Summary of results of adding $\mathrm{MnO}_{2}$ to magnetic taconite concentrate, different amounts of bituminous coal and slag composition of $L_{1.5} F_{2}$. The feed mixtures in mounds were placed on 6/100 mesh coke hearth layer, heated at $1400^{\circ} \mathrm{C}$ for different periods of time in a $\mathrm{N}_{2}-\mathrm{CO}$ atmosphere

Table 2-4-5. Minimum time required to fusion by different sized domes and briquettes, showing the effects of the weight in a tray, apparent density and the height of feed.

Table 2-4-6. Analytical results of products and sulfur distribution 80

Table 2-4-7. Analytical results of NRI and slag, formed from briquettes, consisting of taconite concentrate $(\mathrm{Ma})$, bituminous coal $(\mathrm{K})$ and slag composition, $L_{1.5} \mathrm{FS}_{2}$, placed either on a hearth layer of $6 / 100$ mesh anthracite char or fine alumina powder in a fiber board tray, and heated at $1400^{\circ} \mathrm{C}$ for different periods of time 83

Table 2-5-1. Analytical results of PRB coal:

(a) Proximate and ultimate analyses of size fractions 96 
(b) Ash mineral analyses of size fractions.

Table 2-5-2. Preliminary tests showing the effect of carbonizing a PRB coal (6/100 mesh) in a LTD reduction test setup:

(a) Sizing of a head sample 101

(b) Proximate analyses before and after calcination 101

(c) Size distribution before and after test 102

Table 2-5-3. Effect of carbonization temperature (30 minutes at temperature) on the proximate analyses of PRB coal (6/100 mesh).... 103

Table 2-5-4. S Size reduction of PRB coal (-9.525 mm (-3/8") +3 mesh) by carbonizing at $1400^{\circ} \mathrm{C}\left(2552^{\circ} \mathrm{F}\right)$......

Table 2-5-5. BET surface areas of various coal, char and coke 104

Table 2-5-6. Composition of feed mixtures, consisting of taconite concentrate, PRB coal/char at $80 \%$ of the stoichiometric amount, unless otherwise stated, and slag composition $\mathrm{L}_{1.5} \mathrm{FS}_{2}$. 107

Table 2-5-7. Weight distribution of products formed by increasing the slag volume by adding PRB coal/char, placed on anthracite char hearth layer. 108

Table 2-5-8. Analytical results of NRI and slag showing the effects of PRB coal/char reductants, placed on anthracite hearth layer

Table 2-5-9. Forms of sulfur in PRB coal and char, carbonized at $1400^{\circ} \mathrm{C}$ $\left(2552^{\circ} \mathrm{F}\right)$

Table 2-5-10. Effect of hearth layer materials on the behavior of sulfur when 6segment mounds, consisting of taconite concentrate (Mc), $80 \%$ stoichiometric bituminous coal $(\mathrm{F})$ and slag composition $\mathrm{L}_{1.5} \mathrm{FS}_{2}$, were heated at $1400^{\circ} \mathrm{C}$ for different periods of time in a $\mathrm{N}_{2}-\mathrm{CO}$ atmosphere.

Table 2-5-11. Composition of feed mixtures, consisting of taconite concentrate, bituminous (F) and PRB coal mixtures at $80 \%$ of the stoichiometric amount, and slag composition $\mathrm{L}_{1.5} \mathrm{FS}_{2}$

Table 2-5-12. Composition of feed mixtures, consisting of taconite concentrate, medium-volatile bituminous $(F)$ and PRB char $\left(1400^{\circ} \mathrm{C}\right)$ mixtures at $80 \%$ of the stoichiometric amount, and slag composition $\mathrm{L}_{1.5} \mathrm{FS}_{2}$

Table 2-5-13. Summary of the effects of reductant and hearth layer coal/char on fusion time, micro NRI, NRI sulfur and slag iron of products, produced from 6-segment mounds of feed mixtures, consisting of taconite concentrate, bituminous coal $(\mathrm{J})$ and/or PRB coal at $80 \%$ of the stoichiometric amount and slag composition, $\mathrm{L}_{1.5} \mathrm{FS}_{2}$, placed on $6 / 100$ mesh coke and heated at $1400^{\circ} \mathrm{C}$ in a $\mathrm{N}_{2}-\mathrm{CO}$ atmosphere 
Table 2-5-14. Summary of the effects of reductant and hearth layer coal/char on fusion time, micro NRI, NRI sulfur and slag iron of products, produced from 6-segment mounds of feed mixtures, consisting of taconite concentrate, bituminous coal $(\mathrm{F})$ and/or PRB char at $80 \%$ of the stoichiometric amount and slag composition, $\mathrm{L}_{1.5} \mathrm{FS}_{2}$, placed on $6 / 100$ mesh coke and heated at $1400^{\circ} \mathrm{C}$ in a $\mathrm{N}_{2}-\mathrm{CO}$ atmosphere.

Table 2-5-15. Summary of the effects of reductant and hearth layer coal/char on fusion time, micro NRI, NRI sulfur and slag iron of products, produced from 6-segment mounds of feed mixtures, consisting of taconite concentrate, bituminous coal $(F)$ or PRB coal/char at $80 \%$ of the stoichiometric amount and slag composition, $\mathrm{L}_{1.5} \mathrm{FS}_{2}$, placed on different hearth layer materials and heated at $1400^{\circ} \mathrm{C}$ in a $\mathrm{N}_{2}-\mathrm{CO}$ atmosphere.

Table 2-5-16. Composition of feed mixtures, consisting of taconite concentrate, bituminous coal and PRB coal mixtures at $80 \%$ of the stoichiometric amount, and slag composition $\mathrm{L}_{1.5} \mathrm{FS}_{2}$

Table 2-5-17. Summary of replacing bituminous coal with PRB coal in feed, and replacing coke with PRB coal in hearth layer on fusion time, micro NRI generation and \%S in NRI.

Table 2-5-18. Composition of feed mixtures, consisting of taconite concentrate, PRB coal and PRB char mixtures at $80 \%$ of the stoichiometric amount, and slag composition $\mathrm{L}_{1.5} \mathrm{FS}_{2}$

Table 2-5-19. Summary of replacing PRB coal with PRB char in feed, and replacing PRB char with PRB coal in hearth layer on minimum time to fusion, micro NRI generation and \%S in NRI

Table 2-5-20. Effect of carbonization temperature (30 minutes at temperature) on the proximate analyses of PRB coal.

Table 2-5-21. Composition of feed mixtures, consisting of taconite concentrate (K), PRB coal (07-09-1) at different stoichiometric amounts, and slag composition $\mathrm{C} / \mathrm{S}=1.5$. No binder.

Table 2-5-22. Summary of test results on briquettes at different PRB coal addition, placed on PRB char. No binder

Table 2-5-23. Composition of feed mixtures, consisting of taconite concentrate $(\mathrm{K}), \mathrm{PRB}$ coal/char of different stoichiometric amounts, and slag composition $\mathrm{C} / \mathrm{S}=1.5$.

Table 2-5-24. Summary of test results on briquettes at different addition levels of PRB coal, briquetted with different amounts of molasses, placed on PRB char and heated at $1400^{\circ} \mathrm{C}$ in a $\mathrm{N}_{2}-\mathrm{CO}$ atmosphere 
Table 2-5-25. Summary of test results on briquettes at different addition levels of PRB char $\left(500^{\circ} \mathrm{C}\right)$, briquetted with different amounts of molasses, placed on PRB char and heated at $1400^{\circ} \mathrm{C}$ in a $\mathrm{N}_{2}-\mathrm{CO}$ atmosphere

Table 2-5-26. Summary of test results on briquettes at different addition levels of PRB char $\left(1000^{\circ} \mathrm{C}\right)$, briquetted with different amounts of molasses, placed on PRB char and heated at $1400^{\circ} \mathrm{C}$ in a $\mathrm{N}_{2}-\mathrm{CO}$ atmosphere

Table 2-5-27. Summary of test results on briquettes at different addition levels of PRB char $\left(1400^{\circ} \mathrm{C}\right)$, briquetted with different amounts of molasses, placed on PRB char and heated at $1400^{\circ} \mathrm{C}$ in a $\mathrm{N}_{2}-\mathrm{CO}$ atmosphere.

Table 2-5-28. Composition of feed mixtures, consisting of taconite concentrate, bituminous coal (F), PRB coal or PRB char, carbonized at $800^{\circ} \mathrm{C}$, at $80 \%$ of the stoichiometric amount, and slag composition $\mathrm{L}_{1.5} \mathrm{FS}_{2}$

Table 2-5-29. Effect of compacting load on wet and dry compression strengths of Carver press briquettes, consisting of taconite concentrate, different coal/char at $80 \%$ of the stoichiometric amount and slag composition $\mathrm{L}_{1.5} \mathrm{FS}_{2}$, formed with no binder (Compression test load applied to cylindrical surfaces). Compression Strength in $\mathrm{Ib}_{\mathrm{f}}$ 148

Table 2-5-30. Summary of the effect of binders on wet and dry strengths of Carver press briquettes formed at $15,000 \mathrm{lb}$ load. Compression Strength in $\mathrm{lb}_{\mathrm{f}}$

Table 2-5-31. Summary of the effect of binders on drop numbers of Carver press briquettes formed at $66,720 \mathrm{~N}(15,000 \mathrm{lb})$ load. Drop height $304.8 \mathrm{~mm}(12 ")$ onto steel plate

Table 2-5-32. Drop numbers of briquettes, consisting of taconite concentrate $(\mathrm{K})$ and $85 \%$ stoichiometric PRB coal as a function of time .

Table 2-5-33. Chemical composition of asphalt emulsions 155

Table 2-5-34. Effect of the performance grade of asphalt in asphalt emulsions on drop numbers of briquettes, consisting of Taconite concentrate $(\mathrm{K})$ and $85 \%$ stoichiometric PRB coal as a function of time. Drops from $457.2 \mathrm{~mm}$ (18").

Table 2-5-35. Composition of feed mixtures, consisting of taconite concentrate (K), PRB coal at different stoichiometric amounts, and slag composition $\mathrm{C} / \mathrm{S}=1.5$, and briquetted with $10 \% \mathrm{SS}-1$

Table 5-36. Effect of 10\% SS-1 on drop numbers of briquettes, consisting of taconite concentrate $(\mathrm{K})$, different amounts of PRB coal as a function of time. Drops from $457.2 \mathrm{~mm}(18 ")$ 159 
Table 2-5-37. Analyses of carbon after preheating inside the door for 3 minutes and heating in Zone $1\left(1149^{\circ} \mathrm{C}\right)\left[2100^{\circ} \mathrm{F}\right]$ for 5 minutes. 160

Table 2-5-38. Composition of feed mixtures, consisting of taconite concentrate $(\mathrm{K}), \mathrm{PRB}$ coal at different stoichiometric amounts, and slag composition $\mathrm{C} / \mathrm{S}=1.5$, and briquetted with $10 \% \mathrm{SS}-1$, used in the second series of tests 161

Table 2-5-39. Effect of 10\% SS-1 on drop numbers of briquettes, consisting of taconite concentrate $(K)$, different amounts of PRB coal as a function of time. Drops from $457.2 \mathrm{~mm}$ (18")

Table 2-5-40. Summary of second series of test results showing the effect of PRB coal on briquettes, consisting of taconite concentrate $(K)$, different amounts of PRB coal, $2 \%$ fluorspar and slag basicity $\mathrm{C} / \mathrm{S}$ of 1.5 , briquetted with $10 \%$ SS-1 (PG 58-28), placed on PRB char and heated at $1400^{\circ} \mathrm{C}\left(2552^{\circ} \mathrm{F}\right)$ in a $\mathrm{N}_{2}-\mathrm{CO}$ atmosphere 162

Table 2-6-1. Summary of preliminary test results with briquettes, consisting of high-grade hematite, 70 or $80 \%$ stoichiometric bituminous coal (J), $4 \%$ wollastonite with different additives and slag composition $\mathrm{C} / \mathrm{S}=1.5$, placed over a $6 / 100$ mesh coke hearth layer and heated at $1400^{\circ} \mathrm{C}\left(2552^{\circ} \mathrm{F}\right)$ for 20 minutes in a $\mathrm{N}_{2}-\mathrm{CO}$ atmosphere (Those in bold numbers are with $70 \%$ stoichiometric coal.) 164

Table 2-6-2. Chemical composition of silicate minerals 166

Table 2-6-3. Chemical composition of base raw materials:

(a) Iron oxides and additives 167

(b) Proximate analysis of bituminous coal $(\mathrm{J})$ 167

Table 2-6-4. Composition of feed mixtures, consisting of high-grade hematite, bituminous coal $(\mathrm{J})$ at $70 \%$ stoichiometric amount together with different additives, and slag composition as indicated by $\mathrm{C} / \mathrm{S}^{*}$ 168

Table 2-6-5. Summary of the effects of slag basicity and $\mathrm{MnO}_{2}$ on briquettes, consisting of high-grade hematite, $70 \%$ stoichiometric bituminous coal $(\mathrm{J}), 4 \%$ different silicates and $2 \%$ fluorspar, unless otherwise stated, placed over a 6/100 mesh coke hearth layer and heated at $1400^{\circ} \mathrm{C}$ for 20 minutes in a $\mathrm{N}_{2}$-CO atmosphere

Table 2-6-6. Summary of the effect of $\mathrm{MnO}_{2}$ on briquettes, consisting of highgrade hematite, $70 \%$ stoichiometric bituminous coal $(\mathrm{J})$, different silicate additives, $2 \%$ fluorspar and slag composition $\mathrm{C} / \mathrm{S}=1.5$, placed on a $6 / 100$ mesh coke hearth layer and heated at $1400^{\circ} \mathrm{C}$ for different periods of time in a $\mathrm{N}_{2}-\mathrm{CO}$ atmosphere 183 
Table 2-6-7. Summary of the effect of $\mathrm{MnO}_{2}$ on briquettes, consisting of highgrade hematite, $70 \%$ stoichiometric bituminous coal $(\mathrm{J})$, different silicate additives, $2 \%$ fluorspar and slag composition $\mathrm{C} / \mathrm{S}=1.7$, placed on a $6 / 100$ mesh coke hearth layer and heated at $1400^{\circ} \mathrm{C}$ for different periods of time in a $\mathrm{N}_{2}-\mathrm{CO}$ atmosphere

Table 2-6-8. Chemical composition of raw materials:

(a) Iron oxides and additives. 185

(b) Proximate analysis of bituminous coal (J) 185

Table 2-6-9. Composition of feed mixtures, consisting of high-grade hematite, taconite concentrate $(\mathrm{K})$ or mill scale, bituminous coal $(\mathrm{J})$ at $70 \%$ or $80 \%$ stoichiometric amount, and Slag composition of $\mathrm{C} / \mathrm{S}^{*}=1.5$ 186

Table 2-6-10. Summary of test results showing the effects of replacing highgrade hematite with taconite concentrate $(\mathrm{K})$, or with mill scale, using 6 mounds of feed mixtures, containing 70 or $80 \%$ stoichiometric bituminous coal $(\mathrm{J}), 2 \%$ fluorspar and slag composition $\mathrm{C} / \mathrm{S}=1.5$, placed over a $6 / 100$ mesh coke hearth layer and heated at 140 186

Table 2-7-1. The distribution of sulfur in feed into NRI and slag, as affected by the amount of coal addition and coarse coke cover 196

Table 2-7-2. Analytical results of NRI and slag produced from Lab Komarek briquettes, showing the effect of furnace atmosphere. Cover layer coke $-12.7 \mathrm{~mm}(-1 / 2 ")+3$ mesh and $3.66 \mathrm{~kg} / \mathrm{m}^{2}\left(0.75 \mathrm{lb} / \mathrm{ft}^{2}\right)$ 199

Table 2-7-3. Chemical analyses of LHF test raw materials:

(a) Proximate analyses of bituminous coal $(\mathrm{J})$ 202

(b) Iron ore, additives and coal ash 202

Table 2-7-4. Composition of feed mixtures consisting of taconite concentrate $(\mathrm{K})$, bituminous coal $(\mathrm{J})(8.34 \%$ ash, $90 \%-100$ mesh) at different addition levels in terms of the stoichiometric amount and slag composition $\mathrm{L}_{1.5} \mathrm{FS}_{2}$

Table 2-7-5. Box furnace test results of Lab Komarek briquettes, consisting of taconite concentrate $(\mathrm{K})$, bituminous coal $(\mathrm{J})(8,34 \%$ ash, $90 \%$ -100 mesh) at different addition levels in terms of the stoichiometric amount and slag composition $\mathrm{L}_{1.5} \mathrm{FS}_{2}$. placed on $6 / 100$ mesh coke, and heated at $1400^{\circ} \mathrm{C}\left(2552^{\circ} \mathrm{F}\right)$.... 203

Table 2-7-6. Effects of the addition levels of a low ash coal (8.34\% ash) and of thickness of the hearth layer coke on fusion time of briquettes, $35.6 \mathrm{~mm} \times 22.9 \mathrm{~mm} \times 11.4 \mathrm{~mm}$ (1.4"x0.9"x0.45") in size. 205

Table 2-7-7. Coke samples used:

(a) Size distribution 207

(b) Proximate analysis 207 
Table 2-7-8. Comparison of fusion time when coke $(H)(-3 / 8$ ") or 6/100 mesh coke $(\mathrm{M})$ was used as the hearth layer

Table 2-7-9. Productivity, expressed as the ratio of the number of briquettes in a tray and fusion time in minutes

Table 2-7-10. Comparison of fusion time with loosely-packed and closelypacked briquettes on fusion time

Table 2-7-11. LHF test summary on taconite concentrate (K), $85 \%$ stoichiometric bituminous coal $(\mathrm{J}), 2 \%$ fluorspar at slag composition $\mathrm{C} / \mathrm{A}=1.5$. (Note: $4.9 \mathrm{~kg} / \mathrm{m}^{2}=1.0 \mathrm{lb} / \mathrm{ft}^{2}$ )

Table 2-7-12. Fusion behaviors of lab and pilot plant briquettes 216

Table 2-7-13. LHF test summary on taconite concentrate (K), 85\% stoichiometric bituminous (J) or PRB coal, $2 \%$ fluorspar at slag composition $\mathrm{C} / \mathrm{A}=1.5$.

Table 2-7-14. Effect of wall between Zones 2 and 3 on fusion time and NRI sulfur 225

Table 2-7-15. Comparison of fusion time of briquettes and balls 227 


\section{LIST OF FIGURES}

Figure 2-3-1. Test setup and schematic diagram of laboratory box furnace ........... 54

Figure 2-3-2. Test setup and schematic diagram of laboratory tube furnace ..........55

Figure 2-3-3. General view of the three hot zones and the cooling zone of LHF with oxy-fuel burners

Figure 2-4-1. Size distributions of coke and anthracite char used as hearth layer material

Figure 2-4-2. $\quad \mathrm{CaO}-\mathrm{Al}_{2} \mathrm{O}_{3}-\mathrm{SiO}_{2}$ phase diagram showing slag compositions of Composition ( $\mathrm{L})$ and with increasing additions of slaked lime by an increment of $1 \%\left(L_{1}\right.$ and $\left.L_{2}\right)$.....

Figure 2-4-3. Minimum time required for fusion plotted against the heights of agglomerates

Figure 2-4-4. Minimum time required for fusion plotted against total weight in a graphite tray.

Figure 2-4-5. Minimum time required for fusion plotted against apparent density 75

Figure 2-4-6. Effect of time at $1400^{\circ} \mathrm{C}\left(2552^{\circ} \mathrm{F}\right)$ on NRI formation from briquettes of $53 \mathrm{~mm} \times 50 \mathrm{~mm}$ x $32 \mathrm{~mm}$ (2.1"x1.9"x1.25"), consisting of taconite concentrate $(\mathrm{Mb})$, bituminous coal $(\mathrm{F})$ at $80 \%$ of the stoichiometric amount and slag composition $\left(\mathrm{L} 1.5 \mathrm{FS}_{2}\right)$, placed on 6/100 mesh anthracite char

Figure 2-4-7 (a) Effect of time at $1400^{\circ} \mathrm{C}\left(2552^{\circ} \mathrm{F}\right)$ on NRI formation from

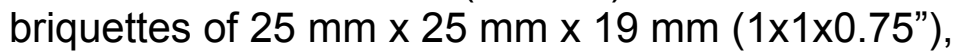
consisting of taconite concentrate $(\mathrm{Mb})$, bituminous coal $(\mathrm{F})$ at $80 \%$ of the stoichiometric amount and slag composition $\left(\mathrm{L} 1.5 \mathrm{FS}_{2}\right)$, placed on 6/100 mesh anthracite char

Figure 2-4-7 (b) Views of briquettes in Figure 4-7(a) from top and bottom, showing slag accumulating at bottom initially and then moving to sides as the briquettes fused

Figure 4-8. 2.5g piles of 14/20 mesh micro NRI and crushed NRI, placed over $20 / 100$ mesh coke hearth layer, and heated at $1350^{\circ} \mathrm{C}$ $\left(2462^{\circ} \mathrm{F}\right)$ for different periods of time in a $\mathrm{N}_{2}-\mathrm{CO}$ atmosphere 88

Figure 2-4-9. SEM photographs of the surface of a 14/20 mesh micro NRI particle at (a) 50X and (b) 500X magnification 89

Figure 2-4-10. SEM photographs of the surface of a 14/20 mesh crushed NRI particle at (a) 50X and (b) 500X magnification 90 
Figure 2-4-11. 2.5g piles of mixtures of 14/20 mesh micro NRI and crushed $\mathrm{NRI}$ in the ratios of $(75: 25)$ on the left, $(50: 50)$ in the middle and $(25: 75)$ on the right, placed over 20/100 mesh coke hearth layer, and heated at $1350^{\circ} \mathrm{C}\left(2462^{\circ} \mathrm{F}\right)$ for different periods of time in a $\mathrm{N}_{2}-\mathrm{CO}$ atmosphere.

Figure 2-4-12. Mixtures of taconite concentrate (K) with 85\% stoichiometric coal and slag composition $\mathrm{L}_{1.5} \mathrm{FS}_{2}$ and micro NRI in the ratios of (100:0), (95:5), (89:11) and (75:25) over 20/100 mesh coke hearth layer, and heated at $1350^{\circ} \mathrm{C}\left(2462^{\circ} \mathrm{F}\right)$ for different periods.

Figure 2-4-13. Mixtures of micro NRI and crushed NRI in the ratios of (100:0), (75:25), (50:50) and (25:75) over 20/100 mesh coke hearth layer, and heated at $1400^{\circ} \mathrm{C}\left(2552^{\circ} \mathrm{F}\right)$ for different periods of time in a $\mathrm{N}_{2}-\mathrm{CO}$ atmosphere.

Figure 2-5-1. Thermogravimetric analysis (TGA) curve of PRB coal, determined by R.J. Lee Group

Figure 2-5-2. Thermogravimetric analysis (TGA) curve of a mediumvolatile bituminous coal, determined by R.J. Lee group 98

Figure 2-5-3 (a) Temperature profile of the carbonization tests 100

Figure 2-5-3 (b) Percent weight loss plotted against temperature in carbonizing 6/100 mesh PRB coal 100

Figure 2-5-4 (a) \% $\mathrm{CO}$ and $\% \mathrm{CO}_{2}$ in the effluent gas as a function of time when PRB coal and char, carbonized at different temperatures were used as reductants (Open symbols $\% \mathrm{CO}$, filled symbols $\% \mathrm{CO}_{2}$ ) ....

Figure 2-5-4 (b) \% $\mathrm{CO} /\left(\mathrm{CO}+\mathrm{CO}_{2}\right)$ in the effluent gas as a function of time when PRB coal and char at different temperatures were used as reductants

Figure 2-5-5(a) 6-segment domes, prepared from a dry mixture of taconite concentrate, bituminous coal $(\mathrm{F})$ at $80 \%$ stoichiometric amount and slag composition $\mathrm{L}_{1.5} \mathrm{FS}_{2}$, placed over $6 / 100$ mesh anthracite char hearth layer and heated at $1400^{\circ} \mathrm{C}$ $\left(2552^{\circ} \mathrm{F}\right)$ for different periods of time in a $\mathrm{N}_{2}-\mathrm{CO}$ atmosphere 115

Figure 2-5-5 (b) Polished sections of Photo 405(a) and two additional tests. 115

Figure 2-5-6 (a) Six segment mounds, prepared from a dry mixture of taconite concentrate, $80 \%$ stoichiometric $6 / 100$ mesh PRB char, carbonized at $1400^{\circ} \mathrm{C}\left(2552^{\circ} \mathrm{F}\right)$ and ground to -100 mesh, and slag composition L1.5FS2, placed on 6/100 mesh PRB char hearth layer and heated at $1400^{\circ} \mathrm{C}\left(2552^{\circ} \mathrm{F}\right)$ for different periods 


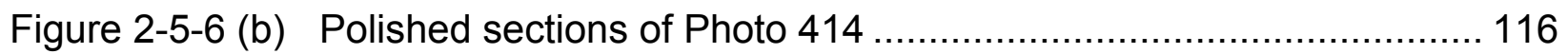

Figure 2-5-7. Effect of the amount of taconite concentrates on the minimum time to fusion

Figure 2-5-8. Summary of test results and products, formed from 6segment mounds, consisting of taconite concentrate, bituminous coal $(F)$ replaced with different amounts of PRB coal/char at $80 \%$ of the stoichiometric amount and slag composition $\mathrm{L}_{1.5} \mathrm{FS}_{2}$, placed on $6 / 100$ mesh coke hearth layer, and heated at $1400^{\circ} \mathrm{C}$ in a $\mathrm{N}_{2}-\mathrm{CO}$ atmosphere

Figure 2-5-9 (a) Effluent gas composition of $\left(\mathrm{CO}+\mathrm{CO}_{2}\right)$ from feed mixtures, containing different proportions of bituminous coal (F)-PRB coal, placed on coke hearth layer and heated in the standardized schedule in a $\mathrm{N}_{2}-\mathrm{CO}$ atmosphere

Figure 2-5-9 (b) Effluent gas composition, expressed as $\mathrm{CO} /\left(\mathrm{CO}+\mathrm{CO}_{2}\right)$, of gas analysis data, shown in Figure 5-9(a).

Figure 2-5-10 (a) Effluent gas composition of $\left(\mathrm{CO}+\mathrm{CO}_{2}\right)$ from feed mixtures, containing different proportions of bituminous coal (F)-PRB char, placed on coke hearth layer and heated in the standardized schedule in a $\mathrm{N}_{2}-\mathrm{CO}$ atmosphere 125

Figure 2-5-10 (b) Effluent gas composition, expressed as $\mathrm{CO} /\left(\mathrm{CO}+\mathrm{CO}_{2}\right)$, of gas analysis data, shown in Figure 5-10(a)

Figure 2-5-11 (a) Effluent gas composition of $\left(\mathrm{CO}+\mathrm{CO}_{2}\right)$ from feed mixtures, containing $100 \%$ PRB char, placed on either coke or PRB char $\left(1400^{\circ} \mathrm{C}\right)$ hearth layer and heated in the standard schedule in a $\mathrm{N}_{2}-\mathrm{CO}$ atmosphere.

Figure 2-5-11 (b) Effluent gas composition, expressed as $\mathrm{CO} /(\mathrm{CO}+\mathrm{CO} 2)$, of gas analysis data, shown Figure 5-11(a).

Figure 2-5-12. Response surfaces showing the effects of \%PRB coal in total carbonaceous materials (PRB coal and bituminous coal) added to feed and \%PRB coal in hearth layer (PRB coal and coke) on: (a) Fusion time, (b) Micro NRI generation and (c) \%S in NRI.

Figure 2-5-13. Response surfaces showing the effects of \%PRB coal in total carbonaceous materials (PRB coal and PRB char) added to feed and \%PRB coal in hearth layer (PRB coal and PRB char) on: (a) Fusion time, (b) Micro NRI generation and (c) \%S in NRI 
Figure 2-5-14. Drop numbers of briquettes, consisting of taconite concentrate $(\mathrm{K})$ and $85 \%$ stoichiometric PRB coal (P-557), showing the effects of the amount of addition of SS-1h used as a binder on aging of briquettes

Figure 2-5-15. Drop numbers of briquettes, consisting of taconite concentrate $(\mathrm{K})$ and $85 \%$ stoichiometric PRB coal, showing the effects of mixing ratios of SS- $1 \mathrm{~h}$ and Bunker $\mathrm{c}$ in emulsions, used as a binder on aging of briquettes 154

Figure 2-7-1. Ratio of \%S in slag and \%S in NRI plotted against \%S in slag. Filled squares are for LHF tests on feed mixtures consisting of taconite concentrate (Ma) and $80 \%$ stoichiometric bituminous coal (F), and open squares for box furnace tests on feed mixtures consisting of taconite concentrate $(\mathrm{K})$ and $80 \%$ stoichiometric bituminous coal $(\mathrm{J})$, both at slag composition $\mathrm{L}_{1.5} \mathrm{FS}_{2}$.

Figure 2-7-2. Fusion time as affected by the loading of loose-packed and close-packed briquettes in single, double and triple layers. Note $1.0 \mathrm{lb} / \mathrm{ft}^{2}=4.88 \mathrm{~kg} / \mathrm{m}^{2}$.

Figure 2-7-3. Comparison of LHF operations using oxy-fuel and air-fuel burners showing the effect of the coverage of cover layer coke on productivity, expressed as (a) car speed at fusion and (b) time to fusion in the high temperature zone. (Note: $\left.4.88 \mathrm{~kg} / \mathrm{m}^{2}=1.0 \mathrm{lb} / \mathrm{ft}^{2}\right)$.

Figure 2-7-4. Size distributions of $-5 / 8$ " +3 mesh PRB coal before and after roasting in the box furnace at $1400^{\circ} \mathrm{C}\left(2552^{\circ} \mathrm{F}\right)$ for 20 minutes in a $\mathrm{N}_{2}-\mathrm{CO}$ atmosphere. Size distribution of $12.7 \mathrm{~mm}(-1 / 2 ")+6$ mesh coke is included for comparison 219

Figure 2-7-5. Products of lab briquettes in single layer (10\% SS-1h), placed on a 3/100 mesh PRB coal hearth layer of $12.7 \mathrm{~mm}$ $(1 / 2 ")$ deep, covered with different amounts of $-15.9 \mathrm{~mm} \mathrm{(-}$ $5 / 8$ ") +3 mesh PRB coal, heated in the LHF and before PRB char cover removed:

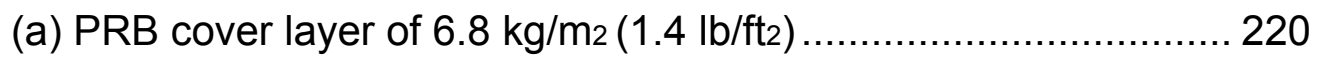

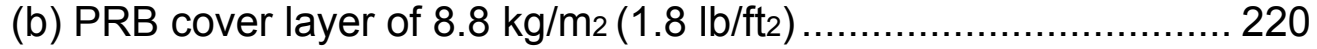

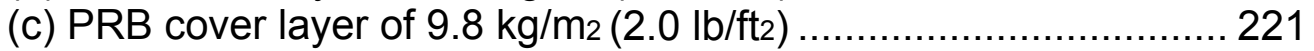

Figure 2-7-6 (a) Flame shooting out from the entrance end of LHF when a sample tray was in Zone 1.

Figure 2-7-6 (b) Flame shooting out from the discharge end of LHF when a sample tray was in Zone 3. 


\section{2-1. INTRODUCTION}

An increase in steel produced in electric arc furnaces (EAF) coupled with a decrease in the number of operating modern blast furnaces has generated a significant market for alternative iron units. This trend is driven by fundamental changes in the steel industry including the capital and environmental problems associated with coke production, the advent of thin slab casting, and the establishment of independent cold mill processors who buy hot band from any available source. The growth of electric arc steelmaking has subsequently reduced the need for iron oxide pellets for blast furnace use. To ensure the existence of the operating iron ore mines and the viability of our iron ore reserves, development of value-added iron products from taconite is necessary to supplement the reduced demand for taconite pellets. Currently, most processes require the agglomeration of iron bearing materials prior to processing into an alternative iron product, especially if the iron bearing material is a very fine material. The iron ore materials from the United States fall into this category. The North American operations must comminute the iron ore to very fine sizes in order to liberate the siliceous minerals from the iron taconite minerals.

Several processes have been proposed as alternatives to the blast furnace and significant activity on a world-wide basis continues in developing these alternatives. Mesabi Nugget Corporation, after demonstrating Kobe Steel's ITmk3 process by producing iron nuggets in a 25,000 t/y pilot plant in Silver Bay, MN, has constructed a $500,000 \mathrm{t} / \mathrm{y}$ commercial plant in Hoyt Lakes, MN and started operation towards the end of 2009. A similar pilot plant campaign is also being demonstrated outside of Tokyo, Japan producing "High Quality Iron Pebbles" using JFE Steel's Hi-QIP process. As with any new process or technology, much opportunity exists for further reducing cost, improving quality and creating added incentive for commercial development.

The research program focused on complementing the current processes and developing the best technology and processing conditions for converting iron oxide resources to high quality nodulized reduced iron (NRI). The resulting product will; 1) contain less gangue, 2) contain less sulfur, 3) be resistant to reoxidation, 4) cost less to produce and 5) use the existing transportation infrastructure and material handling systems. One distinct advantage of this processing technology is that it utilizes solid fuel (coal) rather than natural gas where cost and the effect of the combustion products on the furnace gas atmosphere are problematical. It also uses fine concentrates rather than fired pellets as required in the most prevalent gas-based, shaft DRI (direct reduced iron) systems in use today. The slag phase separated in the process may find application in slag wool preparation, cement raw materials, soil remediation, and water pollution control, thereby offsetting the overall cost and leaving no waste for disposal. The nodulized reduced iron (NRI) will be universally acceptable feedstock across the steel industry, electric arc furnace (EAF), submerged arc furnace (SAF), basic oxygen furnace (BOF), iron foundries, or as supplementary iron units to the blast furnace (BF). 


\section{2-1.1 Background}

\section{2-1.1.1 Work Done in Japan and Piloted in the US}

In 2000, Kobe Steel, Ltd. reported a metallic iron nugget process (ITmk3), in which a pilot plant rotary hearth furnace of 0.4 tons/hour, or nominally 3,000 tons/year, was used to demonstrate the feasibility of the process ${ }^{(1),(2)}$. The furnace is $4 \mathrm{~m}(13 \mathrm{ft})$ in outside diameter and $0.8 \mathrm{~m}(2.6 \mathrm{ft})$ hearth width. In this process, coal-added dried balls are fed to the rotary hearth furnace, the iron ore concentrate is reduced and fuses when the temperature reaches $1450^{\circ}$ to $1500^{\circ} \mathrm{C}\left(2642^{\circ}\right.$ to $\left.2732^{\circ} \mathrm{F}\right)$. In the final section, the products are cooled and discharged. The cooled products, consisting of pellet-sized metallic iron nuggets and slag, are broken apart and separated. The metallic iron nuggets produced by Kobe Steel's process are typically about 6.35 to $9.53 \mathrm{~mm}(1 / 4$ to $3 / 8 ")$ in size. The iron nuggets reportedly analyze 96 97\% metallic $\mathrm{Fe}$ and $2.5 \sim 3.5 \% \mathrm{C}$. The technology led to the construction of a 25,000 tons/year demonstration plant, processing taconite-coal mixtures which were agglomerated into balls at the Northshore site $^{(3),(4),(5)}$. After successful demonstration of the pilot plant trials, Mesabi Nugget Corporation has constructed a rotary hearth furnace of $60 \mathrm{~m}(200 \mathrm{ft})$ in diameter with a capacity of 500,000 tons/year commercial plant in Hoyt Lakes, MN, and has started operation towards the end of $2009^{(6),(7),(8)}$.

\section{2-1.1.2 Alternative to Kobe Steel Approach}

Kawasaki Steel also reported an iron pebble process (Hi-QIP), based on laboratory batch tests ${ }^{(9)}$. In this process, a pulverized anthracite layer of $30 \mathrm{~mm}(1.2$ inch) thick is spread over the hearth and a regular pattern of dimples, $50 \mathrm{~mm}$ diameter and $15 \mathrm{~mm}$ deep (2"x0.6"), are made. Then, a layer of iron ore and coal mixture of $15 \mathrm{~mm}(0.6$ ") thick is placed and heated to $1500^{\circ} \mathrm{C}\left(2732^{\circ} \mathrm{F}\right)$. The iron ore is reduced to metallic iron, fused and collected in the dimples as iron pebbles and slag. Then, the iron pebbles and slag are broken apart and separated. This Kawasaki Steel's process circumvents the balling and drying steps, and the product size is about $25.4 \mathrm{~mm}(1 ")$.

Kawasaki Steel, now called JFE Steel after the merger with NKK in 2003, built a 10,000 $\mathrm{t} / \mathrm{y}$ rotary hearth furnace demonstration plant in near Tokyo, Japan ${ }^{(10)}$. The furnace is $7 \mathrm{~m}$ (23ft.) in outside diameter and $1 \mathrm{~m}$ (3.3ft.) hearth width. The operating temperature is reported to be $1500-1550^{\circ} \mathrm{C}\left(2732-2822^{\circ} \mathrm{F}\right)$. The pebbles analyzed $2.1-3.0 \% \mathrm{C}$ and $0.21-$ $0.25 \% \mathrm{~S}$ with the slag basicity in the range of $0.8-1.6$. The FeO contents of slag were 3$10 \%$, corresponding to iron recoveries exceeding 97\%. Productivity was 0.9-1.2 ton $/ \mathrm{m}^{2} /$ day $\left(7.7-10.2 \mathrm{lb} / \mathrm{ft}^{2} /\right.$ hour $)$ depending on the gangue content of the iron ore. With balls, briquettes and compacts, productivity was $1.23 \mathrm{ton} / \mathrm{m}^{2} /$ day $\left(10.5 \mathrm{lb} / \mathrm{ft}^{2} / \mathrm{h}\right)^{(11)}$.

The metallic iron nugget or pebble processes, therefore, involve mixing of iron ores, pulverized coal and some additives either with or without balling, and an iron ore-coal mixture is fed to a rotary hearth furnace, heated to a temperature reportedly as high as $1450^{\circ} \sim 1550^{\circ} \mathrm{C}\left(2642^{\circ} \sim 2822^{\circ} \mathrm{F}\right)$ to form fused metallic iron products. Metallic iron nuggets or pebbles and slag can be separated with mild mechanical action and magnetically separated. 


\section{2-1.1.3 Test Work at the Coleraine Minerals Research Laboratory}

A project was initiated at the Coleraine Minerals Research Laboratory, Natural Resources Research Institute, University of Minnesota Duluth, in March 2001 on producing nodulized reduced iron (NRI) from Minnesota's taconite concentrates with funding provided by the Economic Development Administration, Department of Commerce and from the University of Minnesota Permanent University Trust Fund for Mining Research.

A major emphasis of the project was placed on lowering the production cost of NRI, producing larger-sized NRI, and improving the chemistry of NRI. The delivered cost of $\mathrm{NRI}$ is the major concern of all the mini-mill operators. Therefore, primary emphasis was placed on lowering the process temperature from the range reportedly used $\left(1450^{\circ}\right.$ to $1550^{\circ} \mathrm{C}$ ) $\left[2642^{\circ}\right.$ to $\left.2822^{\circ} \mathrm{F}\right]$ in order to alleviate refractory wear, maintenance costs and overall energy requirements.

A market assessment of NRI properties was undertaken to gauge the preferred NRI size for use in electric furnace melting technology. Furnace operations that employ conventional bucket charging practices appear to prefer large-size NRI. Other operations that employ direct injection systems for iron materials indicate that a combination of sizes may be important for their operations.

Dried iron ore balls with a maximum size of approximately $19 \mathrm{~mm}(3 / 4$ ") diameter shrink to NRI of about $9.5 \mathrm{~mm}(3 / 8$ ") in size through the losses of oxygen from iron ore during the reduction process and by the losses of coal by gasification, of weight due to slagging of gangue and ash, and of porosity.

Major findings in this phase of the investigation are briefly summarized below ${ }^{(12)}$.

2-1.1.3.1 Laboratory Tube Furnace Tests: The test program was initiated using a tube furnace with a $50.8 \mathrm{~mm}(2$ ") dia. x $1168 \mathrm{~mm}$ (48") long mullite tube, which takes $25.4 \mathrm{~mm}$ (1") wide x $101.6 \mathrm{~mm}$ (4") long and $25.4 \mathrm{~mm}$ (1") high graphite boat, to screen the test conditions for use in laboratory box and pilot plant linear hearth furnaces. Major parameters investigated included such raw materials as:

(1) taconite concentrates with different levels of silica content,

(2) different carbonaceous reductants including Eastern anthracite, low-, medium- and high-volatile bituminous and Western sub-bituminous coals as well as their carbonized char and coke, and

(3) different types of additives, such as balling binders and some specific additives for slag fusion temperature reduction and NRI sulfur control.

Furnace operating conditions, such as temperature and time at temperature, furnace atmosphere, hearth layer materials, NRI and slag chemistries as well as NRI size, were varied. Taconite concentrates with different levels of silica indicated that magnetic concentrates with $6 \% \mathrm{SiO}_{2}$ produced $\mathrm{NRI}$ more readily than a more expensively produced flotation concentrate of $4 \% \mathrm{SiO}_{2}$, or super-concentrate of $2 \% \mathrm{SiO}_{2}$. 
The choice and amount of addition of carbonaceous reductants was an important factor in NRI formation. While anthracite, low- and medium-volatile bituminous coal as well as coke worked well both in dry balled feed and feed without prior agglomeration, subbituminous coal was totally unsatisfactory in agglomerated mixtures, and its char generated inordinately large amounts of micro NRI under similar conditions. The optimum level of carbonaceous reductants was $75-85 \%$ of the stoichiometric requirement for $\mathrm{NRI}$ formation, based on fixed carbon analyses with minimum generation of micro NRI, when the furnace atmosphere consisted of $\mathrm{N}_{2}-\mathrm{CO}$ mixtures.

Certain additives were found to be effective for lowering the fusion temperature of NRI, while some other additives lowered sulfur in NRI to as low as less than $0.01 \%$.

Furnace atmosphere profoundly influenced the temperature needed to form fully fused $\mathrm{NRI}$. Increasing concentrations of $\mathrm{CO}_{2}$ required higher temperatures, but the fusion behaviors of NRI became less sensitive to the presence of $\mathrm{CO}_{2}$ over $1400^{\circ} \mathrm{C}$.

2-1.1.3.2 Laboratory Box Furnace Tests: A laboratory, electrically-heated box furnace, having two $304.8 \mathrm{~mm}$ (12") x $304.8 \mathrm{~mm}$ (12") x $304.8 \mathrm{~mm}$ (12") heating chambers with the two chambers capable of controlling temperatures up to $1450^{\circ} \mathrm{C}$ $\left(2642^{\circ} \mathrm{F}\right)$ independently, and which accepted a $127 \mathrm{~mm}\left(5^{\prime \prime}\right)$ wide x $152.4 \mathrm{~mm}$ (6") long $\mathrm{x}$ $38.1 \mathrm{~mm}(1-1 / 2$ ") high graphite or ceramic fiber board tray was used. A major emphasis was placed in developing methods to produce larger-sized NRI by feeding dry raw material mixtures in an attempt to circumvent costly balling and drying steps. A series of different sized NRI was produced, ranging from $8.38 \mathrm{~mm}(0.33$ ") to $63.5 \mathrm{~mm}(2.5$ ").

Box furnace tests provided an opportunity to further develop methods which showed promise in controlling the generation of micro NRI. Modification of hearth materials as well as proper selection of additives to feed mixtures were studied and found that certain approaches were extremely promising.

2-1.1.3.3 Pilot-plant Linear Hearth Furnace Tests (Rotary Hearth Simulator): The natural gas-fired pilot-scale linear hearth furnace (LHF) was a forty-foot long iron reduction furnace, consisting of three individual heating zones and a final cooling section. Sample trays were conveyed through the furnace by a hydraulically driven walking beam system. Zones were controlled individually according to temperature, pressure and feed rate, making this furnace capable of simulating several reduced iron processes and operating conditions. The LHF was used to test a variety of test variables shown to be important from the box furnace and tube furnace tests.

From laboratory tube and box furnace tests, it was established that high CO atmospheres in the NRI process (a) lower the operating temperature, (b) decrease the amount of reductant coal with an additional advantage of minimizing the formation of micro NRI, and (c) promote the desulfurization of NRI.

In the natural gas-fired rotary hearth furnace (RHF) or linear hearth furnace (LHF), furnace gases typically analyze $10 \% \mathrm{CO}_{2}$ with low $\mathrm{CO}(2-4 \%$ in the LHF), and there appears to be some difficulty in lowering sulfur in NRI to below $0.1 \%$ because of increased $\mathrm{FeO}$ in slag. The $\mathrm{FeO}$ content in the slag controls the oxidation state from a 
thermodynamic perspective and makes sulfur removal to the slag less favorable. In laboratory tests, fully fused NRI could be formed at as low as $1325^{\circ} \mathrm{C}\left(2417^{\circ} \mathrm{F}\right)$ under a $\mathrm{N}_{2}$-CO atmosphere, and sulfur in NRI could be lowered to as low as $0.01 \%$ or less. Thus, from both a product quality standpoint and from an operating standpoint, furnace atmosphere control is a key control variable and must be considered in design of the overall furnace operating conditions.

A major difference in the test conditions of the LHF from laboratory electric furnaces was the high $\mathrm{CO}_{2}$, low $\mathrm{CO}$ concentrations and high turbulence from the burner combustion products. In an attempt to quantify the difference, Computational Fluid Dynamics (CFD) modeling of the LHF was performed using the ANSYS Tascflow software. The results indicated that the furnace gas circulated vigorously within each zone, and while the temperature at the sample trays in Zone 3 was relatively uniform $\left(2600^{\circ} \mathrm{F}\left(1427^{\circ} \mathrm{C}\right)\right)$, furnace gas velocities approached $1-3 \mathrm{~m} / \mathrm{s}(3-10 \mathrm{ft} / \mathrm{s})$ in localized regions at tray level. In the box furnace, however, the furnace gas velocities were estimated at as low as two to three orders of magnitude less, $0.03-0.003 \mathrm{~m} / \mathrm{s}(0.1-0.01$ $\mathrm{ft} / \mathrm{s})$.

\section{2-1.1.4 Proposed work}

A key to successful operation of the pilot scale LHF operation is control of the furnace atmosphere in Zones 2 and 3 of the furnace through either modification of the heating system employed or through auxiliary atmosphere control devices that will enhance the CO levels near the reacting iron- and carbon-bearing materials. Various approaches were evaluated to modify this key condition within the existing pilot LHF.

2-1.1.4.1 Oxygen-Fuel Burners: The use of oxygen-fuel burners will reduce the volume of flue gas, thereby alleviating the turbulence within the furnace and conserving the energy associated with heating chemically inert nitrogen ${ }^{(12)}$. Turbulence may be further reduced through evaluation of flame shape characteristics. In a steel reheating furnace, replacing air-fuel burners with oxygen-fuel burners is reported to save the fuel by 50 to $60 \%{ }^{(13)}$. Reduction in NOX emission is another advantage. Burners of different designs are reported to affect the NOX emission. Burner selection, based on the manner in which the flame heats the samples along with NOX emission, requires careful evaluation. Pressure swing adsorption (PSA) and vacuum swing adsorption (VSA) methods using molecular sieve beads separate oxygen from air to 90 to $95 \% \mathrm{O}_{2}$. Cursory CFD modeling indicated that the use of $90 \% \mathrm{O}_{2}-10 \% \mathrm{~N}_{2}$ for combustion of natural gas in burners lowered the furnace gas velocities by $75 \%(0$ to $1 \mathrm{~m} / \mathrm{s}$ ( 0 to 3 $\mathrm{ft} / \mathrm{s})$ ).

2-1.1.4.2 Control of Local Atmosphere Above Feed Mixture: The furnace atmosphere encountered contains more $\mathrm{CO}_{2}$ than is desirable based on our laboratory experimentation. The $\mathrm{CO}_{2}$ acts as an oxidizing source and reacts with the carbon in the reaction mixture or the hearth layer, and leads to conditions that are not optimal for lowering the reduction and fusion temperatures. In order to counteract the impact of $\mathrm{CO}_{2}$, specialized concepts to modify the atmosphere immediately above the reacting iron- and carbon-bearing mixture were investigated. 
(1) A method proposed to explore was to install a hood, or plate, just above the charging trays so that they are not directly exposed to the ambient furnace atmosphere. A reducing gas was injected through a series of metal or ceramic tubes under the hood or plate directly over the sample trays. This injection system would be positioned in the furnace within the intermediate temperature zone (2000 to $2250 \mathrm{~F}$ ). This was to make it possible to control the degree of reduction, that was essentially complete reduction to metallic iron at a relatively low temperature, and also retain some free carbon in the charge that would help facilitate fusion as the charge was moved into the high temperature zone of the furnace. The temperature of the charge materials would be maintained by preheating upstream of the hood, or auxiliary heat supplied by radiant tube burners incorporated into the hood, or by adjusting the thickness of the insulation on the hood to allow indirect heating by the furnace gases passing over the hood. The actual system to be used (injection tubes, hood or plate composition, ceramic or clad metal etc.,) would depend on engineering and material limitations.

(2) To insulate feed mixtures from the turbulence of the burner gas, yet allow for sufficient radiant heat to pass through and heat the moving trays evenly, a permeable layer of heat- and atmosphere-resistant materials may be installed above the samples. This can be accomplished with a layer of carbonaceous cover layer materials. As the cover layer would interfere with the radiant heat transfer to the feed materials, the type and the size of the cover layer materials needed to be explored.

\section{2-1.2 Use of sub-bituminous coal}

\section{2-1.2.1 Previous work at the Coleraine Minerals Research laboratory}

In a previous project, medium-volatile bituminous coal was selected as the most desirable reductant from preliminary laboratory tests from a suite of Eastern and Western coals as well as coke and char, and has routinely been used in the investigation. On the Iron Range, the use of Western sub-bituminous coal offers an economically attractive alternative, as these coals are more readily accessible with the transportation system already in place, are abundant and readily available, low in cost and low in sulfur. Direct use of sub-bituminous coal in balling and briquetting resulted in an extremely weak dry strength due perhaps to high moisture as well as volatile matter, and definitely precludes its use in agglomerated feed mixtures (balls and briquettes). Development of suitable binders will be necessary. Alternatively, a few preliminary tests indicated that feed mixtures without balling showed considerable promise in producing NRI.

An alternative to the direct use of sub-bituminous coal would be to carbonize the coal prior to its use. Carbonization eliminates moisture and volatile matter, and produces char. Carbonization also removes about half of sulfur in sub-bituminous coal. The char can be mixed with iron ores for the process, and also can be used as a hearth layer material. The use of char decreases the amount needed for the metallization reaction, leading to increased productivity. Volatile matter can be utilized to supplement natural gas for heating the furnace. Preliminary tests indicated that fully carbonized subbituminous coal led to equally satisfactory dried strengths as medium-volatile bituminous coal. 


\section{2-1.2.2 Proposed work}

The manner, in which volatiles are released upon heating and the volatiles released affect the reduction of iron oxides, needs to be characterized for their effective use. The effect of volatiles on the reduction reaction could be investigated by roasting PRB coal to different temperatures and the amount of volatiles in the char varied. The use of the char would characterize the behavior of NRI formation and the quality of the products.

Replacing medium-volatile bituminous coal with Powder River Basin (PRB) coal and char as reductants, as well as replacing coke with PRB coal in hearth layers would provide additional information on the role played by volatiles. Using PRB coal and char as both reductant and hearth layer materials will be investigated to explore how PRB $\mathrm{coal} / \mathrm{char}$ may be utilized effectively in the process.

As the preliminary balling and briquetting tests resulted in weak wet strengths and extremely weak dry strengths, efforts were directed towards developing suitable binders for balling and briquetting.

Basic information gathered in the box furnace was used to select the test conditions in the LHF, both as a reductant as well as hearth and cover layer materials.

\section{2-1.3 Alternative ironmaking materials}

\section{2-1.3.1 Previous work at the Coleraine Minerals Research Laboratory}

In a previous project, the behavior of NRI formation from pellet screened fines, consisting mainly of $\mathrm{Fe}_{2} \mathrm{O}_{3}$, was briefly tested. As compared to magnetic concentrates, notably larger amounts of micro NRI were generated. The amount of micro NRI generation could be decreased by decreasing the addition of the reductant coal, but NRI sulfur increased to well over $0.1 \% \mathrm{~S}$.

Large amounts of pellet plant wastes and lean ores, both are mainly hematite, are available on the Iron Range. Steel plant wastes, such as dusts and fumes, are mainly $\mathrm{Fe}_{2} \mathrm{O}_{3}$. Also the majority of iron ore deposits in the world are hematite. In order to utilize these iron resources, therefore, it became of interest to characterize the behavior of NRI formation from hematite resources with respect to micro NRI generation and sulfur in NRI.

\section{2-1.3.2 Proposed work}

Accelerating NRI formation, minimizing micro NRI generation and keeping NRI sulfur below $0.05 \% S$ are necessary for utilizing hematite resources. In order to accelerate the formation of NRI, the manner in which the nature of slag-forming gangue minerals affect the slag fusion temperature needs to be explored, and to minimize the generation of micro NRI, the manner in which micro NRI form needs to be clarified. A high-grade hematite ore will be a convenient prototype material for investigating how the composition of slag-forming gangue minerals may affect the effect of different elements in the minerals on the fusion behavior of slag as well as its desulfurizing ability. 
In this manner, the optimum conditions for utilizing hematite resources available locally as well as world-wide may be identified by providing suitable chemistry for producing quality NRI at maximum production rate.

\section{Glossary}

Abbreviated notation of lime and fluorspar in slag

In order to simplify the notation of the fluxing additive of lime and fluorspar, the following notation was used in this report. Composition (L) is located in the low fusion temperature trough near $(\mathrm{CaO}) /\left(\mathrm{SiO}_{2}\right)$ of 1.2 in the $\mathrm{CaO}-\mathrm{SiO}_{2}-\mathrm{Al}_{2} \mathrm{O}_{3}$ phase diagram. The slag compositions were abbreviated by indicating the amounts of additional lime used in percent as a suffix, for example, $L_{0.5}$ and $L_{1}$ indicated lime additions of $0.5 \%$ and $1 \%$, respectively, over that of Composition (L). The amount of fluorspar (abbreviated to FS) added in percent was also indicated as a suffix, for example, $\mathrm{L}_{0.5} \mathrm{FS}_{0.25}$, which represented that $0.25 \%$ by weight of fluorspar was added to a feed mixture with Slag Composition of $L_{0.5}$.

\section{Micro NRI}

Both in box furnace and LHF tests, NRI with a range of sizes formed depending on the test conditions used. The magnetic products after each test were collected with a hand magnet and screened into +1/4", $-1 / 4 "+20$ mesh and -20 mesh. Plus $1 / 4$ " fractions were fully metallic when the products were judged to be fused. Minus $1 / 4$ " +20 mesh fractions were essentially all metallic and referred to as "micro NRI". Minus 20 mesh fractions had large amounts of fine carbon particles to which small metallic iron particles were attached.

\section{Stoichiometric amount}

In an attempt to quantify the amount of coal, coke or char needed as a reductant in feed mixture, the amount of carbon required to reduce iron oxides to metallic iron with the formation of $\mathrm{CO}$ was calculated and termed "stoichiometric amount" according to

$$
\begin{aligned}
& \mathrm{FeO}+\mathrm{C}=\mathrm{Fe}+\mathrm{CO} \\
& \mathrm{Fe} 3 \mathrm{O} 4+4 \mathrm{C}=3 \mathrm{Fe}+4 \mathrm{CO} \\
& \mathrm{Fe} 2 \mathrm{O} 3+3 \mathrm{C}=2 \mathrm{Fe}+3 \mathrm{CO}
\end{aligned}
$$

Fixed carbon from proximate analysis was used in the calculation. 


\section{2-2 MATERIALS}

\section{2-2.1 Iron ores}

Four magnetic concentrates, a high-grade hematite ore and a mill scale sample were used in the investigation. The chemical compositions are given in Table 2-2-1. Most of the tests were carried out with magnetic taconite concentrates for the continuation of the project in progress because of the local interest on the Iron Range. The magnetic concentrates were received from operating plants. Magnetic taconite concentrates are typically $90 \%-325$ mesh $(-44 \mu \mathrm{m})$.

The high-grade hematite, rather than lean ores and pellet plant wastes available on the Iron Range, was selected for the study because hematite generated notably larger amounts of micro NRI than magnetic concentrates, and the composition of slag on the process may be investigated by the addition of different gangue minerals. In this manner, how different elements in gangue minerals affected the fusion behavior of slag as well as their desulfurizing ability, may be investigated.

A mill scale, consisting mainly of $\mathrm{FeO}$, was included to study briefly the effect of the oxidation states of ironmaking raw materials.

\section{2-2.2 Carbonaceous reductants}

For reductant coal, two medium-volatile bituminous coals and several different subbituminous coals were used in the investigation. Coke and anthracite were tested for hearth and cover layers. The analytical results of the samples are given in Table 2-2-2.

Medium-volatile bituminous coal was used for continuing the investigation on exploring various parameters in laboratory box furnace as well as in linear hearth furnace (LHF) tests. From a previous investigation, medium-volatile bituminous coal was found to be the most suited as reductant coal from a suite of Eastern and Western coals as well as from coke and char. The two medium-volatile bituminous coals had similar proximate analyses, and behaved similarly in the process.

For sub-bituminous coal, several different samples of Powder River Basin (PRB) coal were used. Throughout the investigation, laboratory tests with PRB coal-added feed mixtures were plagued by widely erratic fusion behaviors. The problem was identified to result from widely variable fixed carbon analysis even when PRB coal was carefully split into smaller portions for laboratory grinding. Typically, twelve samples, ground to -100 mesh and kept in 5-gallon pails, were pipe-sampled and analyzed. Proximate analyses of the 12 pails averaged $39.8 \pm 6.3 \%$ fixed carbon, ranging from a low of $30.8 \%$ to a high of $49.2 \%$. Variation of fixed carbon was not limited to among the pails, but also within a pail. As the coal from a pail was used up, fusion behavior suddenly changed in more than one occasion. Inconsistency in the test results was thought to be attributable to the variation even within a pail. Thorough mixing of the coal and proximate analysis in each pail was necessary. Typical analytical results are included in Table 2-2-2.

Later, a sample, ground to -200 mesh in a plant scale, in four 55 -gallon drums was received. Their fixed carbon analyzed within $0.25 \%$ among the four drums, and 
consistent fusion behaviors were obtained with this sample. The analytical results are included in Table 2-2-2.

Coke and anthracite samples were received in 55-gallon drums and used by splitting into 5-gallon pails for use.

\section{2-2.3 Additives}

Two major additives used in preparing feed mixtures were hydrated lime for controlling slag basicity, and fluorspar as a flux. The compositions are given in Table 2-2-3. For investigating the effects of some minor additives in feed mixtures, for example, electrolytic manganese dioxide and borax were in pure chemical forms in order to simplify the interpretation of each element on the fusion behavior. A number of silicate and alumino-silicate minerals for investigating the fusion behaviors of hematite are presented in Chapter 6.

Table 2-2-1. Chemical analyses of iron ores

\begin{tabular}{|c|c|c|c|c|c|c|}
\hline & $\begin{array}{c}\text { Taconite } \\
\text { conc } \\
\text { (Ma) }\end{array}$ & $\begin{array}{c}\text { Taconite } \\
\text { conc } \\
\text { (Mb) }\end{array}$ & $\begin{array}{c}\text { Taconite } \\
\text { conc } \\
\text { (Mc) }\end{array}$ & $\begin{array}{c}\text { Taconite } \\
\text { conc } \\
\text { (K) }\end{array}$ & $\begin{array}{c}\text { High } \\
\text { grade } \\
\text { hematite }\end{array}$ & $\begin{array}{c}\text { Mill } \\
\text { scale }\end{array}$ \\
\hline & & & & & & \\
$\mathrm{T.Fe}$ & 67.81 & 67.2 & 67.6 & 69.94 & 66.61 & 70.57 \\
$\mathbf{m e t} \mathbf{F e}$ & & & & & & 1.84 \\
$\mathrm{FeO}$ & 4.79 & 5.74 & 5.28 & 3.51 & 1.07 & 61.35 \\
$\mathrm{SiO}_{2}$ & 0.04 & 0.18 & 0.10 & 0.02 & 0.90 & 0.37 \\
$\mathrm{Al}_{2} \mathbf{O}_{3}$ & 0.42 & 0.31 & 0.41 & 0.67 & 0.03 & 1.28 \\
$\mathbf{C a O}$ & 0.47 & 0.45 & 0.28 & 0.02 & 0.02 & 0.55 \\
$\mathbf{M g O}$ & 0.27 & & & & & \\
\hline
\end{tabular}


Table 2-2-2(a). Proximate analyses of carbonaceous materials

\begin{tabular}{|l|c|c|c|c|c|c|}
\hline & Volatile & $\begin{array}{c}\text { Fixed } \\
\text { carbon }\end{array}$ & Ash & Sulfur & $\begin{array}{c}\% \\
\text { moist. }\end{array}$ & BTU/lb \\
\hline $\begin{array}{c}\text { Bituminous } \\
\text { coal (F) }\end{array}$ & 22.54 & 67.10 & 9.39 & 0.47 & 0.97 & 13836 \\
$\begin{array}{l}\text { Bituminous } \\
\text { coal (J) }\end{array}$ & 21.08 & 69.59 & 8.81 & 0.62 & 0.52 & 14143 \\
PRB coal (1) & 36.52 & 44.24 & 4.77 & 0.39 & 14.47 & 10291 \\
PRB coal (2) & 36.43 & 42.22 & 6.18 & 0.32 & 15.17 & 9981 \\
Anthracite & 6.77 & 77.01 & 14.39 & 0.74 & 1.83 & 12333 \\
Anthracite char & 0.09 & 83.88 & 15.97 & 0.58 & 0.06 & 11412 \\
Coke & 0.59 & 88.71 & 10.51 & 0.67 & 0.19 & 12552 \\
\hline
\end{tabular}

Table 2-2-2(b). Ash mineral analyses of carbonaceous reductants

\begin{tabular}{|l|r|r|r|r|r|}
\hline & \multicolumn{1}{|c|}{$\mathrm{SiO}_{2}$} & \multicolumn{1}{|c|}{$\mathrm{Al}_{2} \mathrm{O}_{3}$} & \multicolumn{1}{c|}{$\mathrm{CaO}$} & \multicolumn{1}{c|}{$\mathrm{MgO}$} & $\mathrm{Fe}_{2} \mathrm{O}_{3}$ \\
\hline $\begin{array}{c}\text { Bituminous } \\
\text { coal (F) }\end{array}$ & 59.04 & 28.79 & 1.68 & 0.54 & 5.47 \\
$\begin{array}{c}\text { Bituminous } \\
\text { coal (J) } \\
\text { PRB coal (1) }\end{array}$ & 51.56 & 29.63 & 3.32 & 1.14 & 8.19 \\
PRB coal (2) & 31.15 & 16.47 & 15.55 & 4.70 & 10.25 \\
Anthracite & 54.02 & 16.62 & 22.06 & 4.44 & 5.72 \\
\hline
\end{tabular}

Table 2-2-3. Chemical analyses of additives

\begin{tabular}{|l|c|c|c|c|}
\hline & $\mathrm{SiO}_{2}$ & $\mathbf{A l}_{2} \mathbf{O}_{3}$ & $\mathbf{C a O}$ & $\mathbf{M g O}$ \\
\hline Hydrated lime & 0.43 & 0.00 & 68.8 & 0.32 \\
Fluorspar & 1.87 & 0.12 & 1.28 & 0.00 \\
\hline
\end{tabular}




\section{2-3 METHODS}

For laboratory investigations, an electrically-heated box furnace was used. Exploratory tests on slag fusion temperatures were carried out in a tube furnace. Pilot plant tests were carried out with a natural gas-fired linear hearth furnace (LHF). Initially, a major emphasis was placed on relating box furnace tests to LHF tests. A brief description of box and tube furnaces and LHF is given below.

\section{2-3.1 Laboratory Box furnace}

An electrically-heated box furnace, $990.6 \mathrm{~mm}$ (39") high x $838.2 \mathrm{~mm}$ (33") wide X $1320.8 \mathrm{~mm}$ (52") long, consisting of two $304.8 \mathrm{~mm}$ (12") x $304.8 \mathrm{~mm}$ (12") x $304.8 \mathrm{~mm}$ (12") heating chambers with two chambers capable of controlling temperatures up to $1450^{\circ} \mathrm{C}\left(2642^{\circ} \mathrm{F}\right)$ independently, using two Chromalox 2104 controllers. Four helical silicon carbide heating elements were installed on both sides in each chamber. A total of 16 heating elements in the two chambers were rated at $18 \mathrm{~kW}$. The furnace setup and its schematic diagram are shown in Figure 2-3-1. A Type $S$ thermocouple was suspended from the top into the middle of each chamber 4.5" above the bottom floor. The temperature variation over a $152.4 \mathrm{~mm}(6 ")$ long tray was within a few degrees. The furnace was preceded by a cooling chamber, $406.4 \mathrm{~mm}$ (16") high x $330.2 \mathrm{~mm}$ (13") wide $\times 609.6 \mathrm{~mm}(24$ ") long, with a side door through which a sample tray, $127 \mathrm{~mm}$ (5") wide $\times 152.4 \mathrm{~mm}$ (6") long $\times 38.1 \mathrm{~mm}$ (1.5") high with a thickness of $3.175 \mathrm{~mm}(1 / 8 ")$ was introduced, and a view window at the top. A gas inlet port, another small view window and a port for a push rod to move a sample tray into the furnace were located on the outside wall of the chamber. On the side attached to the furnace, a flip-up door was installed to shield the radiant heat from coming through. A $12.7 \mathrm{~mm}(1 / 2$ ") hole in the flip-up door allowed the gas to pass through and the push rod to move the tray inside the furnace. At the opposite end of the furnace, a furnace gas exhaust port, a gas sampling port and a port for a push rod to move a tray out of the furnace were located. The furnace was designed and constructed by the Applied Thermal Technology of Minnesota, Plymouth, Minnesota.

To control the furnace atmosphere, $\mathrm{N}_{2}, \mathrm{CO}$ and $\mathrm{CO}_{2}$ were supplied to the furnace in different combinations via respective rotameters. Total gas flow could be adjusted in the range of 10 to $50 \mathrm{~L} / \mathrm{min}$. In most tests, graphite trays were used, but in some tests, trays made of fiber boards with a thickness of $12.7 \mathrm{~mm}(1 / 2$ ") were used. After introducing a tray into the cooling chamber, the furnace was purged with a gas, typically a mixture of $\mathrm{N}_{2}$ and $\mathrm{CO}$ at 18 and $2 \mathrm{~L} / \mathrm{min}$, respectively, for 15 minutes to expel the air when a tray was introduced into the cooling chamber.

Initially, the tray was pushed just inside of the flip-up door, held there for 3 minutes for preheating, then into the first chamber, held at $1149^{\circ} \mathrm{C}\left(2100^{\circ} \mathrm{F}\right)$, for 5 minutes, and then into the second chamber, held at $1400^{\circ} \mathrm{C}\left(2552^{\circ} \mathrm{F}\right)$ for certain periods of time. After the test, the tray was pushed to the back of the flip-up door and held there for 3 minutes, and then into the cooling chamber. After cooling for 10 minutes, the tray was removed from the cooling chamber for inspection if NRI was formed. 

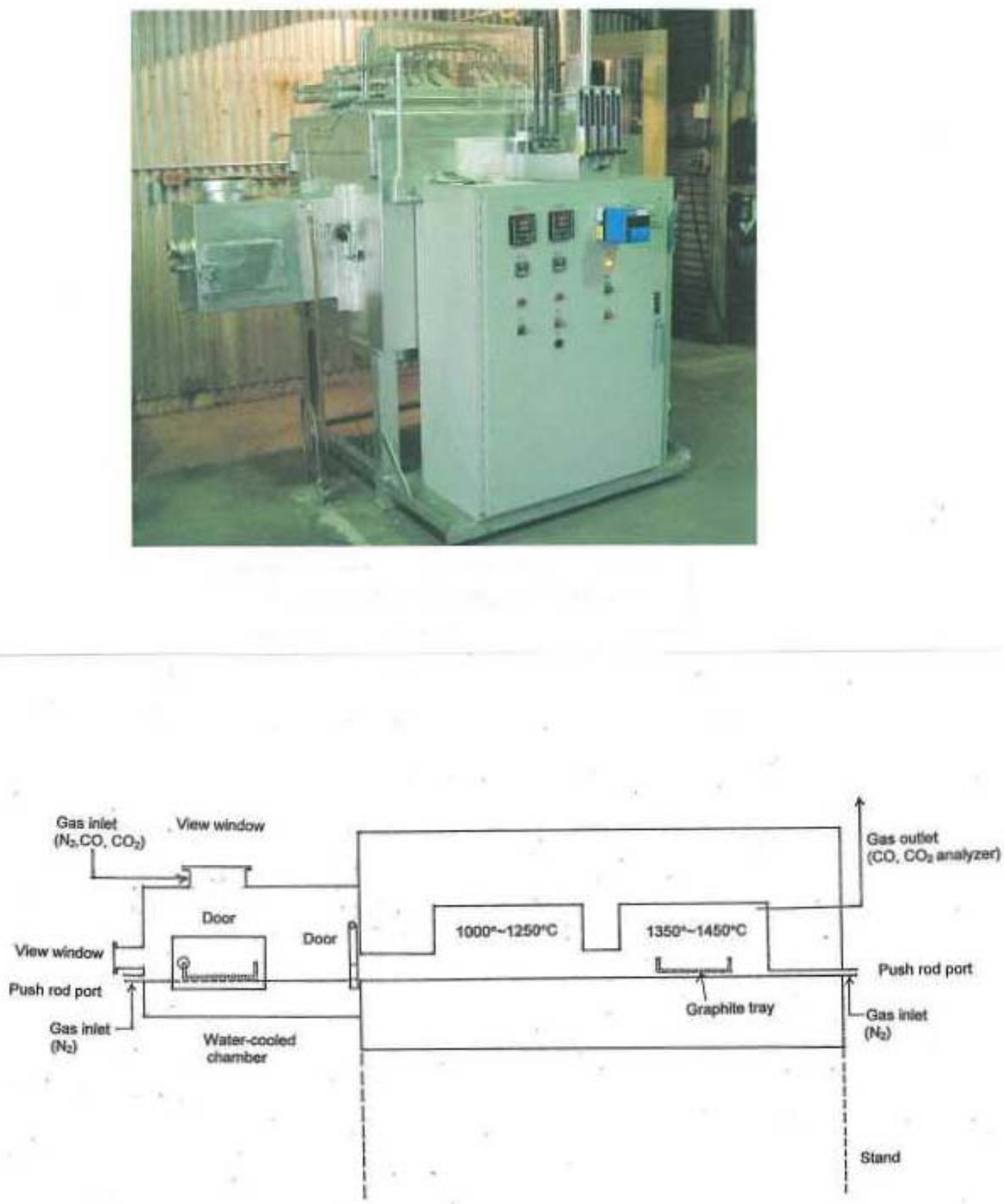

Figure 2-3-1. Test setup and schematic diagram of laboratory box furnace. 


\section{2-3.2 Laboratory Tube furnace}

A $50.8 \mathrm{~mm}$ (2") diameter horizontal tube furnace, $406.4 \mathrm{~mm}$ (16") high x $508 \mathrm{~mm}$ (20") wide $\times 1041.4 \mathrm{~mm}$ (41") long, with 4 silicon carbide heating elements, rated at $8 \mathrm{~kW}$, and West 2070 temperature controller, supplied by Burrell Corporation, Pittsburgh, PA, was fitted with a $50.8 \mathrm{~mm}$ (2") diameter x $1219.2 \mathrm{~mm}$ (48") long mullite tube. The test setup and its schematic diagram are shown in Figure 2-3-2. At one end of the combustion tube, a Type $\mathrm{R}$ thermocouple and a gas inlet tube was placed, and at the other end, a water-cooled chamber was attached, to which a gas exit port and a sampling port were connected.

To control the furnace atmosphere, $\mathrm{N}_{2}$ and $\mathrm{CO}$ were supplied to the combustion tube via respective rotameters. Tests were carried out with a mixture, consisting of an $\mathrm{N}_{2}$ and CO mixture at 2 and $1 \mathrm{~L} / \mathrm{min}$, respectively. Graphite boats, $25.4 \mathrm{~mm}$ (1") wide x 101.6 $\mathrm{mm}(4 ")$ long $\times 25.4 \mathrm{~mm}$ (1") high with a thickness of $3.175 \mathrm{~mm}(1 / 8$ "), was used for the tests.

\section{2-3.3 Linear Hearth Furnace (LHF) \\ 2-3.3.1 Walking beam tray conveying system}

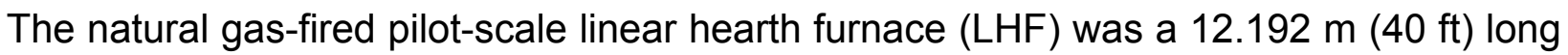
iron reduction furnace, consisting of three individual heating zones and a final cooling section. Sample trays were conveyed through the furnace by a hydraulically driven walking beam system (later replaced by a cart system). Zones were controlled individually according to temperature, pressure and feed rate, making this furnace capable of simulating several reduced iron processes and operating conditions.

The PLC control system regulated individual zone burners to manage zone temperatures. A pair of $474,775 \mathrm{~kJ} / \mathrm{h}(450,000 \mathrm{BTU} / \mathrm{h})$ natural gas fired burners heats Zones 1 and 2. Zone 1 was operated at $982^{\circ} \mathrm{C}\left(1800^{\circ} \mathrm{F}\right)$, while Zone 2 was operated in the range of $1149-1204^{\circ} \mathrm{C}\left(2100-2200^{\circ} \mathrm{F}\right)$. Zone 3 was fired by a pair of 1.055 Million $\mathrm{kJ} / \mathrm{h}$ (1 Million $\mathrm{BTU} / \mathrm{h}$ ) burners that were required to achieve the operating temperatures of as high as $1427^{\circ} \mathrm{C}\left(2600^{\circ} \mathrm{F}\right)$ in reasonable time to complete testing within a day. Reducing the burner air, to operate the burners sub-stoichiometric and operating zone pressures positive was required to reduce oxygen levels to $0.0 \%$ and provide acceptable furnace atmospheres for iron ore reduction.

The LHF was used to test a variety of test variables shown to be important from the box furnace tests. The furnace was demonstrated to be useful for testing a multiplicity of test parameters in a very short period of time.

\section{2-3.3.2 Continuous moving pallet car system}

Later, the LHF was modified to replace the air-fuel burners by oxy-fuel burners, and its effect on the operating behaviors of the furnace was investigated. A total of eight oxyfuel burners at $263,764 \mathrm{~kJ} / \mathrm{h}(250,000 \mathrm{Btu} / \mathrm{h})$ per burner were installed while air-fuel burners were preserved, allowing dual combustion capability. In addition, a continuous moving pallet car system with 609.6 mm (24") x 609.4 mm (24") x 203.2 mm (8") fiber 
pallet cars and mechanical indexing system replaced the previous walking beam system.

Finally, in the final stages of the program, a solid fuel/oxygen burner system was added to the furnace at the discharge end of zone 3. This burner used dilute phase transport for the coal or solid fuel injected into the burner and was rated at 527,528 $\mathrm{kJ} / \mathrm{h}(500,000$ BTU/h).

A general view of the LHF with oxy-fuel burners and continuous moving pallet car system is shown in Figure 2-3-3. The feed and discharge ends of the LHF may be seen in Figures 2-7-6(a) and (b) in Chapter 2-7. 

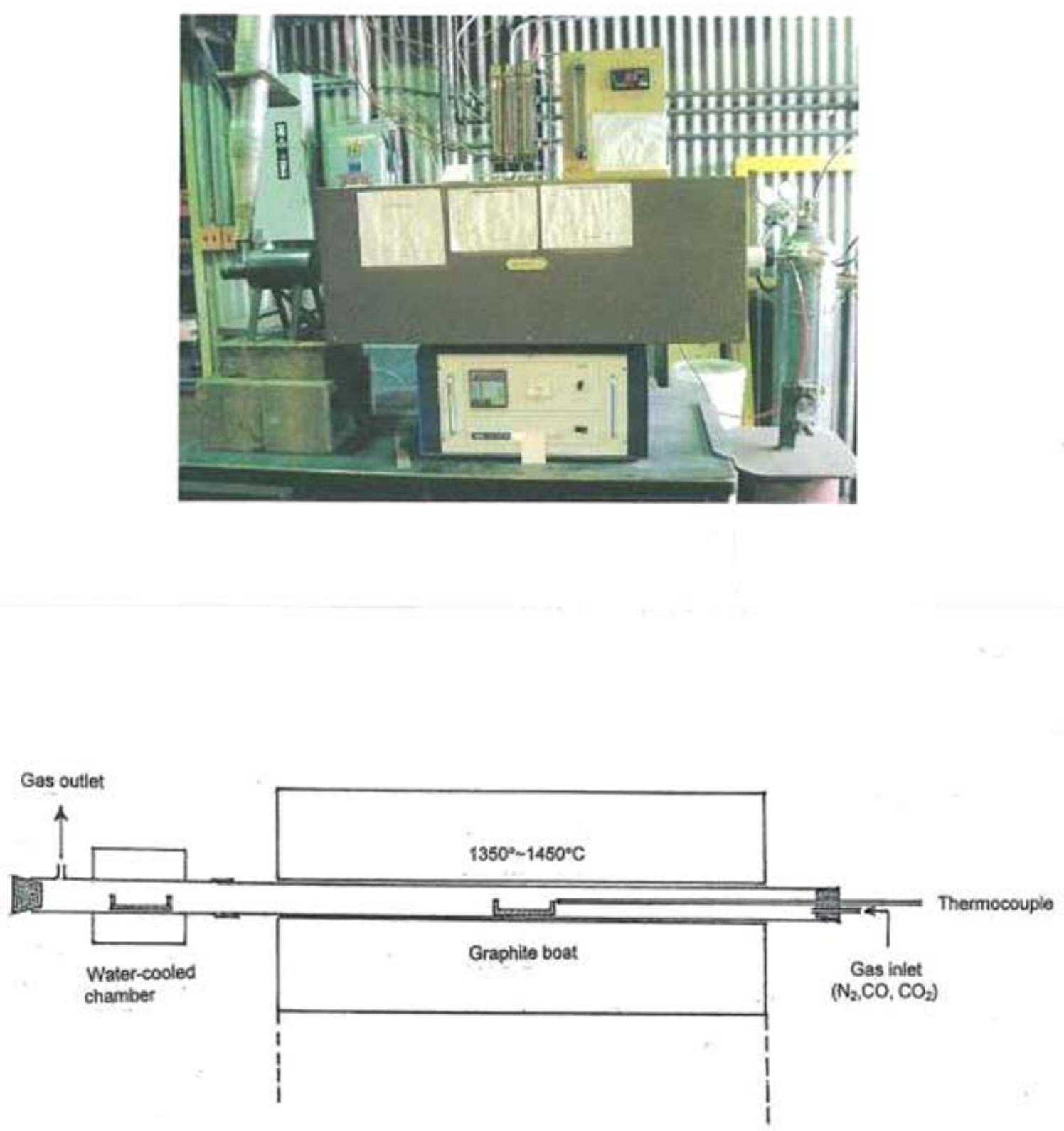

Figure 2-3-2. Test setup and schematic diagram of laboratory tube furnace. 


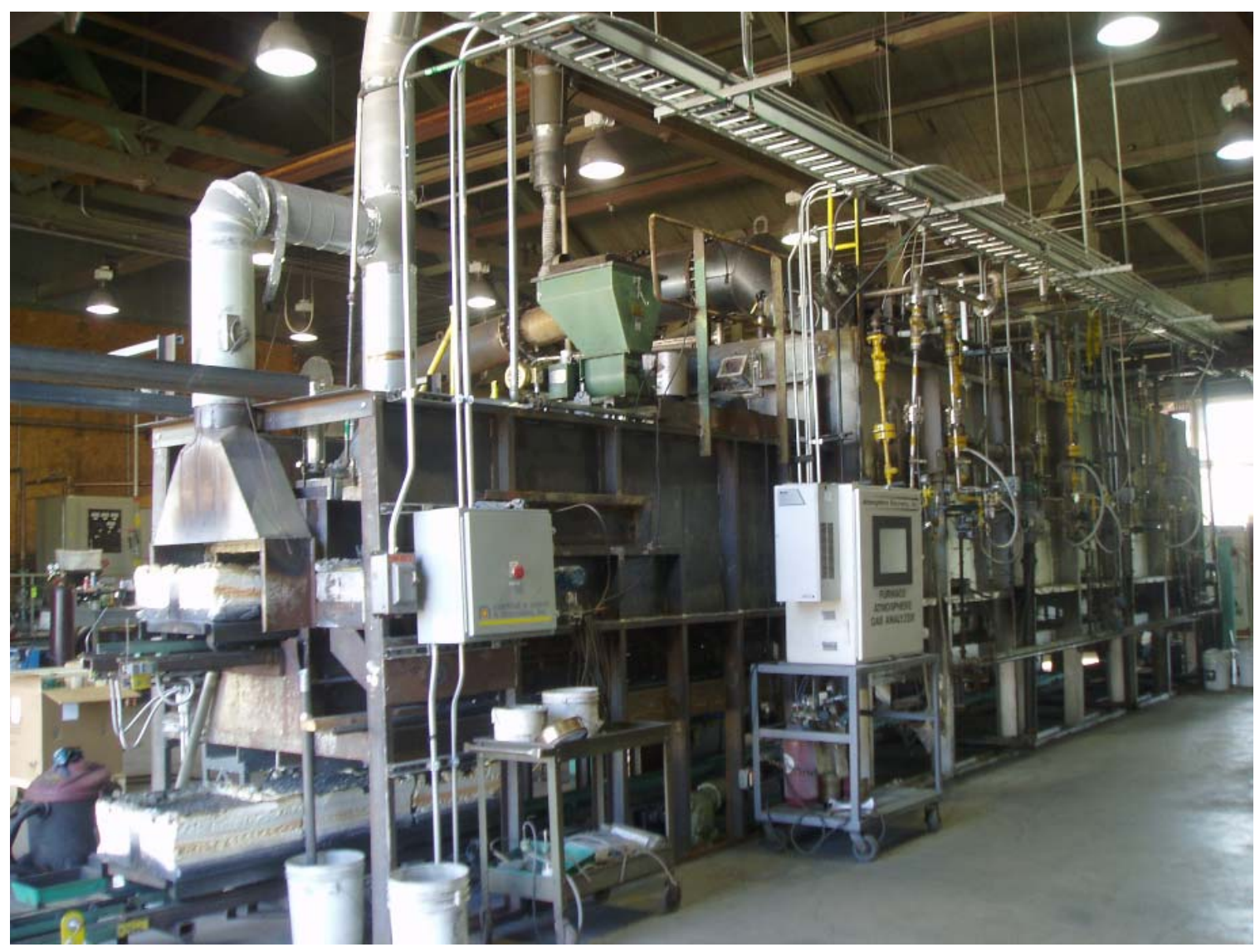

Figure 2-3-3. General view of the three hot zones and the cooling zone of LHF with oxy-fuel burners. 


\section{2-4 LABORATORY TESTS}

In the previous project, a test program was initiated using graphite boats in the tube furnace and later continued using graphite trays in the box furnace under different furnace atmospheres. NRI with low sulfur could be produced with minimum generation of micro NRI by adding reductant coal in the range of $80-85 \%$ of the stoichiometric amount in a $\mathrm{N}_{2}-\mathrm{CO}$ atmosphere. The presence of $\mathrm{CO}_{2}$ not only increased the fusion time and sulfur in NRI, but also severely corroded graphite boats and trays. In the LHF, fused NRI could be produced only if the reductant coal was increased to $115-125 \%$ of the stoichiometric amount, but the reproducibility of the results was not particularly consistent, and sulfur in NRI was high, in the range of $0.15-0.25 \% \mathrm{~S}$.

In the electrically-heated box furnace, the furnace atmosphere could be controlled at will, but in the gas-fired LHF, the furnace atmosphere was dictated by the composition of the combustion products of the burners. A major problem of producing fully fused NRI in the LHF was thought to be due to highly turbulent and high $\mathrm{CO}_{2}$, high $\mathrm{H}_{2} \mathrm{O}$ furnace atmosphere. Therefore, disrupting the turbulence and providing high $\mathrm{CO}$ atmosphere near feed materials was essential in producing quality NRI consistently in the LHF.

Cover layer coke was found to be one of the ways to produce NRI consistently in the LHF though it would interfere with the radiant heat transfer. Most significantly, the use of cover layer coke produced $\mathrm{NRI}$ analyzing below $0.05 \% \mathrm{~S}$. In the present project, therefore, it was decided to use graphite trays in a $\mathrm{N}_{2}-\mathrm{CO}$ atmosphere in the box furnace tests. For investigating the effect of $\mathrm{CO}_{2}$, refractory trays, made of ceramic fiber boards, were used, but the fiber board trays became brittle after use and came apart after a few tests.

In this part, the topics covered were: (1) optimum sizes of reductant and hearth layer carbon; (2) effect of fluxing agents; (3) effects of size, apparent density and shape of feed mixtures; (4) mechanism of NRI formation; (5) use of sub-bituminous coal; and (6) alternative iron-making materials.

In each section, conclusions are presented first, followed by test procedures and results in support of the conclusions.

\section{2-4.1 Baseline information using magnetic taconite concentrates and medium-volatile bituminous coal}

\section{2-4.1.1 Optimum sizes of reductant and hearth layer carbon}

In the preliminary series of tests, reductant coals were ground to -100 mesh from published information, and hearth layer coal was arbitrarily chosen to be 20/100 mesh to prevent slag from reaching the tray bottom. The optimum sizes of reductant coal, and of coke as well as anthracite char used as hearth layer materials were investigated from fusion behavior and the generation of micro NRI. 


\section{2-4.1.1.1 Conclusions:}

1) The optimum size of coal added as a reductant was -65 to -100 mesh. Finer mesh-of-grind of coal formed NRI just as effectively, but the amount of micro NRI increased somewhat. The use of coarser coal required increased amounts of coal for forming fully fused NRI, suggesting that a certain amount of fine coal was necessary for the formation of fully fused NRI.

2) The size of coke used as a hearth layer material appeared to affect the formation of micro NRI: -10 mesh coke formed minimal amounts of micro NRI when the feed mixtures were in the form of mounds. It was reported earlier that coke ground to -100 mesh as hearth layer notably increased the amount of micro NRI.

3) The optimum size of anthracite char used as a hearth layer material was also -10 mesh. The amounts of micro NRI generated were notably less than coke of corresponding top sizes. The difference may be attributable to their size distributions; coke contained larger amounts of fine fractions even though the top limiting sizes were the same.

2-4.1.1.2 Reductant coal size: To explore the optimum size range of reductant coal, three series of tests were carried out using medium-volatile bituminous coal, ground to $200,100,-48,-28,-14$ and -8 mesh. The size distributions of coal, ground to different sizes, are given in Table 2-4-1.

After a few preliminary tests, test condition was set using 6-segment mounds, consisting of feed mixtures with taconite concentrate (Ma), bituminous coal (F) and slag composition $\mathrm{L}_{1.5} \mathrm{FS}_{2}$, placed on $6 / 100$ mesh anthracite char, preheated at $1149^{\circ} \mathrm{C}$ $\left(2100^{\circ} \mathrm{F}\right)$ for 5 minutes and heated at $1400^{\circ} \mathrm{C}\left(2552^{\circ} \mathrm{F}\right)$ for 15 minutes, while passing $80 \% \mathrm{~N}_{2}-20 \% \mathrm{CO}$ at $40 \mathrm{~L} / \mathrm{min}$. Three series of tests were carried out at coal addition levels of $80 \%, 90 \%$ and $100 \%$ of the stoichiometric amount using coal ground to -200 to -8 mesh. Their weight distributions are given in Table 2-4-2.

With $80 \%$ stoichiometric coal addition, one NRI did not fuse when -28 mesh coal was used. The number of NRI not fused increased with coal of coarser mesh-of-grind. The amounts of micro NRI remained at about $1 \%$ throughout the range, but the amount appeared to be minimal when -100 mesh coal was used. Micro NRI increased somewhat when -200 mesh coal was used.

With $90 \%$ stoichiometric coal addition, one of the iron nuggets was not fused when -14 and -8 mesh coal were used, widening the range where fully fused NRI formed. The amount of micro NRI remained at about $2 \%$ throughout the range, but again the amount appeared to be minimal when -100 mesh coal was used. In fact, the amount of micro NRI was the highest when -200 mesh coal was used. 
Table 2-4-1. Size distributions of medium-volatile bituminous coal of different mesh-of-grind, expressed as cumulative $\%$ weight passing.

$\begin{array}{cccccc}\begin{array}{c}\text { Size } \\ \text { mesh }\end{array} & \underline{-8 \text { mesh }} & \underline{-14 \text { mesh }} & \underline{-28 \text { mesh }} & \underline{-48 \text { mesh }} & \underline{-100 \text { mesh }} \\ 10 & 90.3 & & & & \\ 14 & 80.1 & & & & \\ 20 & 70.4 & 87.9 & & & \\ 28 & 59.9 & 74.8 & & & \\ 35 & 53.3 & 66.5 & 88.9 & \\ 48 & 44.2 & 55.1 & 73.7 & \\ 65 & 36.7 & 45.8 & 61.2 & 83.0 \\ 100 & 29.0 & 36.1 & 48.3 & 65.5\end{array}$

Table 2-4-2. Summary on the effect of reductant coal size on fusion behavior and micro NRI generation when 6-segment mounds, consisting of taconite concentrate (Ma), different levels of coal at different mesh-of-grind and at slag composition $\left(\mathrm{L}_{1.5} \mathrm{FS}_{2}\right)$, were placed on $6 / 100$ mesh anthracite char, preheated at $1149^{\circ} \mathrm{C}\left(2100^{\circ} \mathrm{F}\right)$ for 5 minutes and heated at $1400^{\circ} \mathrm{C}\left(2552^{\circ} \mathrm{F}\right)$ for 15 minutes, while passing $80 \% \mathrm{~N}_{2}-20 \% \mathrm{CO}$ at $40 \mathrm{~L} / \mathrm{min}$.

\begin{tabular}{|c|c|c|c|c|c|c|}
\hline \multirow{2}{*}{$\begin{array}{l}\text { Reductant } \\
\text { coal size } \\
\text { mesh }\end{array}$} & \multicolumn{2}{|c|}{$80 \%$ stoich. } & \multicolumn{2}{|c|}{$90 \%$ stoich. } & \multicolumn{2}{|c|}{$100 \%$ stoich. } \\
\hline & $\begin{array}{l}\text { Not fused } \\
\text { (out of 6) }\end{array}$ & $\begin{array}{c}\text { Micro NRI } \\
\%\end{array}$ & $\begin{array}{l}\text { Not fused } \\
\text { (out of 6) }\end{array}$ & $\begin{array}{c}\text { Micro NRI } \\
\%\end{array}$ & $\begin{array}{l}\text { Not fused } \\
\text { (out of } 6 \text { ) }\end{array}$ & \begin{tabular}{|c} 
Micro NRI \\
$\%$
\end{tabular} \\
\hline-200 & 0 & 0.5 & 0 & 1.6 & 0 & 3.2 \\
\hline $86 \%-100$ & 0 & 0.2 & 0 & 0.7 & 0 & 3.4 \\
\hline-48 & 0 & 0.6 & 0 & 1.4 & 0 & 4.6 \\
\hline-28 & 1 & 0.6 & 0 & 0.7 & 0 & 3.6 \\
\hline-14 & 4 & 1.0 & 1 & 1.5 & 0 & 4.1 \\
\hline-8 & 2 & 0.7 & 1 & 1.2 & 0 & 3.9 \\
\hline
\end{tabular}


With $100 \%$ stoichiometric coal addition, fully fused NRI formed even when coal as coarse as -8 mesh was used. In this series of tests, the use of coal coarser than -28 mesh coal led to the break-up of primary NRI into increasing amount of mini NRI. The amount of micro NRI remained at about $5 \%$ throughout the range. Here again, the amount appeared to be minimal when -100 mesh coal was used.

From the foregoing observations, it was concluded that the optimum size of coal added as a reductant was -65 to -100 mesh.

2-4.1.1.3 Size of carbonaceous materials used as hearth layers: In the previous project, it was shown that the amounts of micro NRI formed were less when a feed mixture was placed on 20/65 mesh and 20/28 mesh coke than when the feed mixture was placed on -20 and -100 mesh coke. These observations indicated that the presence of fine coke aggravated the generation of micro NRI.

To explore the optimum size of coke used as hearth layers, a series of tests were carried out on mounds of the same feed composition as before, placed on hearth layers of coke of different sizes, preheated at $1149^{\circ} \mathrm{C}\left(2100^{\circ} \mathrm{F}\right)$ for 5 minutes and heated at $1400^{\circ} \mathrm{C}\left(2552^{\circ} \mathrm{F}\right)$ for 15 minutes while passing $80 \% \mathrm{~N}_{2}-20 \% \mathrm{CO}$ at $40 \mathrm{~L} / \mathrm{min}$. Products formed from the mounds, placed on 20/100, 14/48 and 6/14 mesh coke are summarized in Table 2-4-3. In these tests, -100 mesh fraction was screened out in order to avoid contamination of a dust filter by fine coke particles prior to the introduction of effluent gas into a gas analyzer.

It was noted that the narrow size ranges, particularly of 6/14 mesh, appeared to form increased amounts of micro NRI due presumably to more of the feed mixtures near the interface trapped between coarse particles.

Another series of tests was carried out on the same feed mixtures in 6-segment mounds, placed on hearth layers of $10 / 100$ and 6/100 mesh coke to investigate if wider size ranges might generate less micro NRI. The results are included in Table 2-4-3. The amounts of micro NRI were less, and were minimal when 10/100 mesh coke was used.

To investigate if the use of anthracite char as hearth layer made any difference, the same feed mixtures in 6-segment mounds were placed on hearth layers of 20/100, 10/100 and 6/100 mesh anthracite char. The results are given in Table 2-4-3. Again, the amounts of micro NRI were minimal when 10/100 mesh coke was used, and the anthracite char gave less micro NRI than coke. This difference may be attributable to the presence of reduced amounts of fine fractions in the anthracite char than in coke (Figure 2-4-1). 


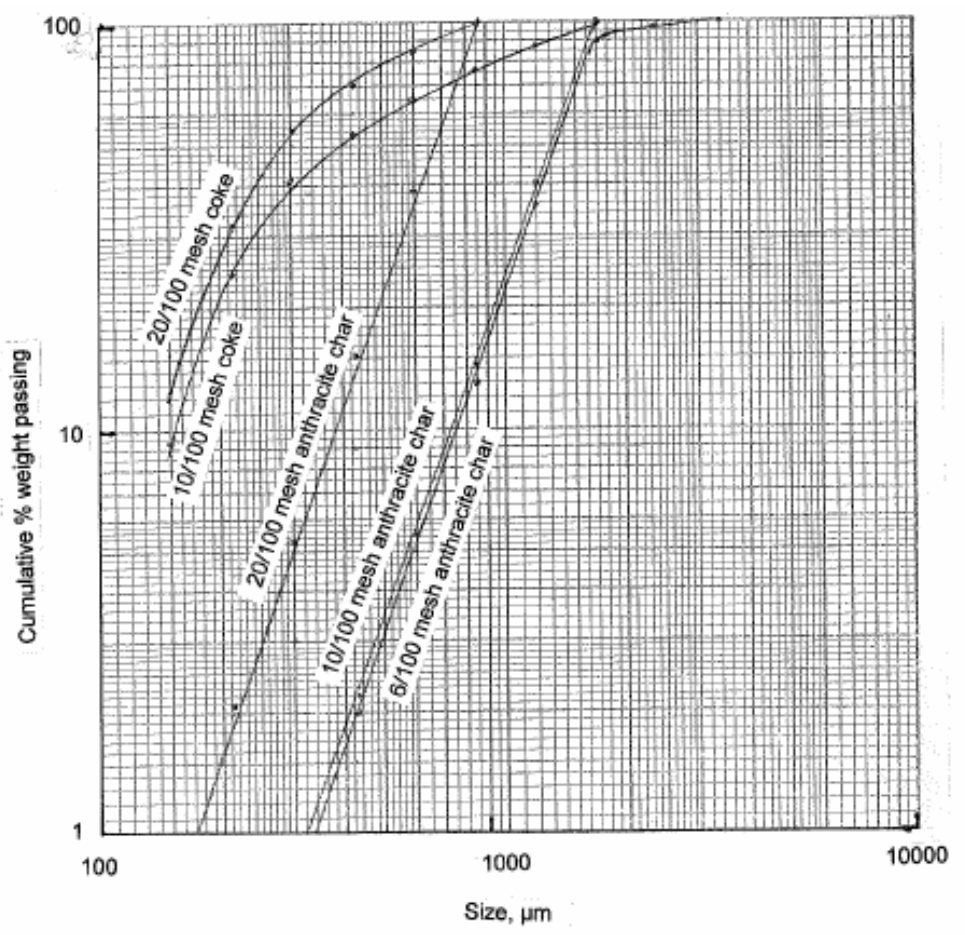

Figure 2-4-1. Size distributions of coke and anthracite char used as hearth layer material.

Table 2-4-3. Summary on the effects of hearth layer coke and anthracite char size on fusion behavior and micro NRI generation when 6-segment mounds, consisting of taconite concentrate (Ma), $95 \%$ stoichiometric coal, ground to -100 mesh and at slag composition $\mathrm{L}_{1.5} \mathrm{FS}_{2}$, were placed on $6 / 100$ mesh anthracite char, preheated at $1149^{\circ} \mathrm{C}\left(2100^{\circ} \mathrm{F}\right)$ for 5 minutes and heated at $1427^{\circ} \mathrm{C}\left(2600^{\circ} \mathrm{F}\right)$ for 15 minutes, while passing $80 \% \mathrm{~N}_{2}-20 \% \mathrm{CO}$ at $40 \mathrm{~L} / \mathrm{min}$.

\begin{tabular}{|c|c|c|}
\hline \multirow{2}{*}{$\begin{array}{c}\text { Hearth layer } \\
\text { mesh }\end{array}$} & \multicolumn{2}{|c|}{ Micro NRI. \% } \\
\cline { 2 - 3 } 20/100 & Coke & Anthracite char \\
$\mathbf{1 0 / 1 0 0}$ & 3.6 & 4.1 \\
$\mathbf{6 / 1 0 0}$ & 5.4 & 2.1 \\
$\mathbf{1 4 / 4 8}$ & 4.6 & 2.6 \\
$6 / 14$ & 5.5 & --- \\
\hline
\end{tabular}




\section{2-4.1.2 Effect of fluxing agents}

From the previous project, it was concluded that three major parameters of interest in the box furnace tests were: (1) accelerating fusion; (2) minimizing micro NRI generation; and (3) lowering NRI sulfur. These parameters were found to be counteracting, namely, fusion could be accelerated and NRI sulfur could be lowered by increasing the coal addition, but the generation of micro NRI increased. The box furnace was used to continue the investigation to explore the effects of fluxing agents for minimizing fusion time and NRI sulfur without increasing micro NRI generation. Magnetic taconite concentrates and medium-volatile bituminous coals were used as the baseline condition for the investigation.

For lowering fusion temperatures, the $\mathrm{CaO}-\mathrm{Al}_{2} \mathrm{O}_{3}-\mathrm{SiO}_{2}$ phase diagram, shown in Figure 2-4-2, was used to select the slag composition. The low fusion temperature valley region, ranging from $1463^{\circ} \mathrm{C}\left(2665^{\circ} \mathrm{F}\right)$ to $1310^{\circ} \mathrm{C}\left(2390^{\circ} \mathrm{F}\right)$ starting at about $55 \% \mathrm{CaO}$ along the $\mathrm{SiO}_{2}-\mathrm{CaO}$ line, was a useful guide in choosing anticipated slag compositions for lowering the process temperature. When satisfactory NRI were formed, slag analyzed low iron, less than $0.1 \% \mathrm{Fe}$. Thus the effect of $\mathrm{Fe}$ on the fusion temperature of slag was considered to be minimal.

To remove sulfur from NRI, lime contents in slag need to be raised. By labeling the composition of a feed mixture in the low temperature valley region $(L)$, a feed mixture with additional $1 \%$ hydrated lime was labeled $\left(L_{1}\right)$, and with $2 \%$ hydrated lime $\left(L_{2}\right)$. The three compositions are plotted in the $\mathrm{CaO}-\mathrm{Al}_{2} \mathrm{O}_{3}-\mathrm{SiO}_{2}$ phase diagram in Figure 2-4-2.

Replacement of hydrated lime with limestone led essentially to identical results. Hydrated lime was chosen because of its binder property.

For lowering sulfur in NRI, lime contents in slag need to be increased as indicated by the reaction

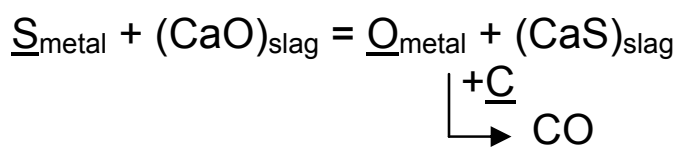

The increased lime leads to higher fusion temperatures and longer time to form fully fused NRI.

Fluorspar has been used widely as a flux to dissolve high-lime slag in steelmaking processes for accelerating the kinetics of refining. Fluorspar was tested in the NRI process, and found to be effective in lowering the fusion time as well as NRI sulfur.

In an attempt to reduce cost and to circumvent the potential fluoride emission in steelmaking, there have been a number of studies searching for substitutes for fluorspar. However, no suitable substitute has been found as good as fluorspar in improving the fluidities of high-lime slag. 


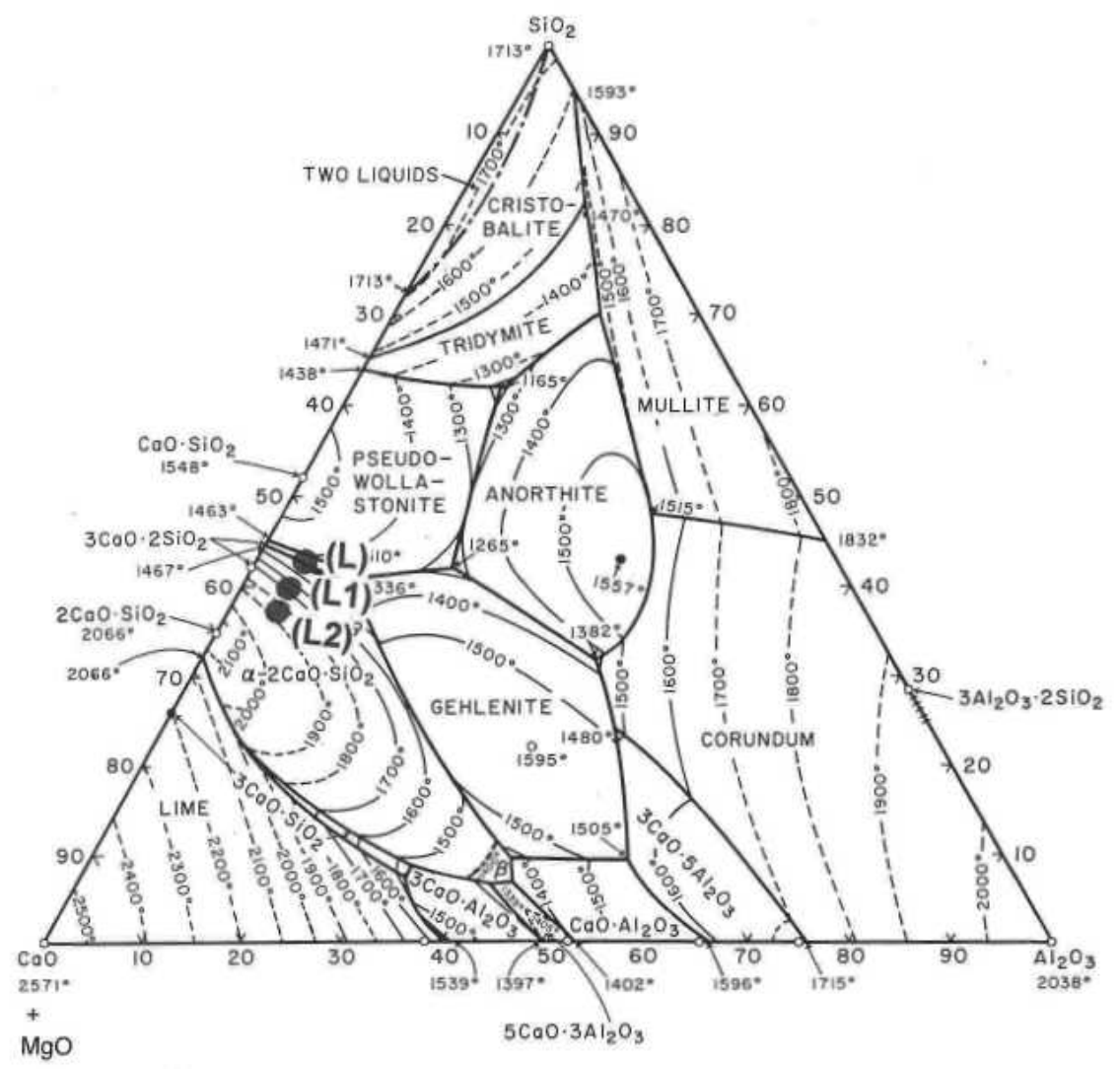

Figure 2-4-2. $\mathrm{CaO}-\mathrm{Al}_{2} \mathrm{O}_{3}-\mathrm{SiO}_{2}$ phase diagram showing slag compositions of Composition (L) and with increasing additions of slaked lime by an increment of $1 \%\left(L_{1}\right.$ and $\left.L_{2}\right)$.

Two compounds were tested as potential alternatives to fluorspar in the NRI process, namely, manganese oxide and borax. Manganese oxides have often been added to the feeds to blast furnaces for control of sulfur. Borax has been used as a flux in glassmaking and blowpipe analyses.

In this investigation, battery-grade $\mathrm{MnO}_{2}$ was used as it was available on hand, and $\mathrm{MnO}_{2}$ is known to change readily into $\mathrm{MnO}$ upon heating in mildly reducing atmospheres. Therefore, any manganese oxides or manganese-containing iron ores may be used in practice in place of $\mathrm{MnO}_{2}$. Locally, Cuyuna manganiferous iron ores become of interest for this application.

\section{2-4.1.2.1 Conclusions:}

1) A combined use of manganese oxide and fluorspar was effective in decreasing the fusion time, whereas $\mathrm{MnO}_{2}$ without fluorspar increased the fusion time, and NRI sulfur became higher $(0.056-0.075 \%$ S) than when fluorspar by itself was used $(0.044-0.048 \% S)$. 
2) Locally, Cuyuna manganiferrous iron ores may be used as a manganese source.

3) Replacement of fluorspar with an equivalent in molar amount of borax took longer time to form fully fused NRI, accompanied by the generation of large amounts of mini and micro NRI. Also sulfur in NRI was higher than when fluorspar was used.

2-4.1.2.2 Manganese oxide: A series of tests were performed by adding $1 \% \mathrm{MnO}_{2}$ to a feed mixture, consisting of taconite concentrate $(\mathrm{Ma})$ and bituminous coal $(\mathrm{F})$ at $95 \%$ of the stoichiometric amount and heating at $1400^{\circ} \mathrm{C}$ for different periods of time in a $\mathrm{N}_{2}-\mathrm{CO}$ atmosphere. Fusion time was determined to be 10 minutes. By increasing the amount of $\mathrm{MnO}_{2}$ to $4 \%$, fusion time decreased to 7 minutes. By decreasing the amount of the coal to $80 \%$ of the stoichiometric amount, the fusion time increased to 11 and 9 minutes, respectively, with $1 \%$ and $4 \% \mathrm{MnO}_{2}$.

With the coal at $95 \%$ of the stoichiometric amount, the amounts of micro NRI became notably higher than with $80 \%$, in agreement with the previous observations on the level of the reductant coal addition. As summarized in Table 2-4-4, fusion time notably decreased from 14 minutes in the absence of $\mathrm{MnO}_{2}$ to 11 minutes at $1 \% \mathrm{MnO}_{2}$ and to 9 minutes at $4 \% \mathrm{MnO}_{2}$, both at $80 \%$ stoichiometric coal. With $95 \%$ stoichiometric coal, the minimum time to fusion was even shorter, but the amount of micro NRI increased.

NRI sulfur at fusion time was low, $0.025 \%$ and $0.030 \% \mathrm{~S}$ at $1 \%$ and $4 \% \mathrm{MnO}_{2}$, respectively, when $95 \%$ stoichiometric coal was used, but increased to $0.061 \%$ and $0.032 \% \mathrm{~S}$ as fusion time increased, respectively. With $80 \%$ stoichiometric coal, NRI sulfur decreased from $0.044-0.027 \%$ and $0.040 \%$ S, respectively, for $1 \%$ and $4 \% \mathrm{MnO}_{2}$ addition at fusion time. When the NRI were held for 20 minutes at $1400^{\circ} \mathrm{C}$, sulfur increased at $1 \% \mathrm{MnO}_{2}$, while decreased at $4 \% \mathrm{MnO}_{2}$. 
Table 2-4-4. Summary of results of adding $\mathrm{MnO}_{2}$ to magnetic taconite concentrate, different amounts of bituminous coal and slag composition of $L_{1.5} F_{S_{2}}$. The feed mixtures in mounds were placed on 6/100 mesh coke hearth layer, heated at $1400^{\circ} \mathrm{C}$ for different periods of time in a $\mathrm{N}_{2}-\mathrm{CO}$ atmosphere.

$\begin{array}{llccc}\underline{\mathbf{M n O}_{2}} & \begin{array}{c}\text { Coal } \\ \text { \% stoich. }\end{array} & \begin{array}{c}\text { Fusion time } \\ \text { at } 1400^{\circ} \mathbf{C}\end{array} & \begin{array}{c}\% \text { micro } \\ \text { NRI }\end{array} & \begin{array}{c}\% \text { in in } \\ \text { NRI }\end{array} \\ \underline{\mathbf{2 \%} \text { fluorspar }} & 80 & 14 \mathrm{~min} & 0.1 & 0.044 \\ 0 \% & 95 & 10 \mathrm{~min} & 13.7 & 0.025 \\ 1 \% & 95 & 7 \mathrm{~min} & 3.0 & 0.030 \\ 4 \% & 80 & 11 \mathrm{~min} & 0.7 & 0.027 \\ 1 \% & 80 & 9 \mathrm{~min} & 0.6 & 0.040 \\ 4 \% & & & & \end{array}$

\section{No fluorspar}

$\begin{array}{lllll}5 \% & 80 & 17 \min & 7.5 & 0.056\end{array}$

$\mathrm{MnO}_{2}$-added slag was green-colored and was more fragile than the slag in the absence of $\mathrm{MnO}_{2}$, and crumbled on handling. Often, green-colored slag crumbled in place.

The recoveries of manganese to NRI were limited as in blast furnaces. The recovery decreased with increasing $\mathrm{MnO}_{2}$ addition: about $50 \%$ in the case of $1 \% \mathrm{MnO}_{2}$ to about $30 \%$ in the case of $4 \% \mathrm{MnO}_{2}$. At $95 \%$ stoichiometric coal, the recoveries were higher by about $10 \%$, due apparently to direct reduction of $\mathrm{MnO}$ for the formation of metallic manganese (Note that iron is reduced essentially to $100 \%$ metal).

To investigate if $\mathrm{MnO}_{2}$ by itself acted as a flux, a test was performed with $2 \% \mathrm{MnO}_{2}$, but without fluorspar. Fusion time of 17 minutes was markedly longer than when a combination of $\mathrm{MnO}_{2}$ and fluorspar was used of 10 minutes.

$\mathrm{NRI}$ sulfur at fusion time (17 minutes) analyzed $0.056 \% \mathrm{~S}$, and increased to $0.075 \% \mathrm{~S}$ after holding at the temperature to 20 minutes. Therefore, the use of $\mathrm{MnO}_{2}$ by itself as a flux was not effective in lowering sulfur in NRI. In the absence of fluorspar, manganese reduction was also adversely affected, and the amounts of occluded metallic iron fines in slag were notably higher than in the presence of fluorspar. 
It was concluded that a combined use of $\mathrm{MnO}_{2}$ and fluorspar was effective in decreasing fusion time, minimizing the generation of micro NRI, and lowering sulfur in NRI effectively to $0.02 \% \mathrm{~S} . \mathrm{MnO}_{2}$ without fluorspar appeared to increase the time at temperature, and NRI sulfur was lowered only to $0.06-0.08 \% \mathrm{~S}$.

2-4.1.2.3 Borax: A series of tests were performed on a feed mixture by substituting $2 \%$ fluorspar with $3.8 \%$ borax, equivalent in molar amounts, heated at $1400^{\circ} \mathrm{C}\left(2552^{\circ} \mathrm{F}\right)$ in a $\mathrm{N}_{2}$-CO atmosphere to arrive at the fusion time. The feed mixture formed fully fused NRI in 18 minutes, which was 8 minutes longer than the feed mixture with $2 \%$ fluorspar.

NRI were accompanied by a large amount of micro NRI. Prolonged heating at the temperature to 30 minutes did not decrease the amount of micro NRI too much. This is in contrast to the tests with $2 \%$ fluorspar. There was virtually no micro NRI. Also, with borax, NRI sulfur was high $(0.040-0.052 \% \mathrm{~S})$ as compared to $0.017-0.038 \% \mathrm{~S}$ with fluorspar.

Therefore, borax was not an effective flux causing only some lowering of NRI sulfur, and micro NRI increased. As will be shown in the processing of hematite (see 7.3.1), soda ash was demonstrated to be effective in desulfurizing of $\mathrm{NRI}$, but increased the generation of micro NRI. Apparently, $\mathrm{Na}_{2} \mathrm{O}$ in borax had a similar effect on the magnetic taconite concentrate. In addition, alkali oxides $\left(\mathrm{Na}_{2} \mathrm{O}\right.$ and $\left.\mathrm{K}_{2} \mathrm{O}\right)$ are known to adversely affect the life of refractories in blast furnaces, and their presence becomes of concern in the NRI process. In fact, a combination of boric acid $\left(\mathrm{H}_{3} \mathrm{BO}_{3}\right)$ and lime, simulating colemanite (calcium borate), was investigated in a tube furnace in the previous project period. An addition of boric acid in different combinations with hydrated lime did not help decrease the amount of micro NRI, and NRI sulfur exceeded $0.05 \% \mathrm{~S}$ to slag composition $\left(\mathrm{L}_{1}\right)$ with $1 \%$ boric acid.

\section{2-4.1.3 Effects of size, apparent density and height}

It was noted in earlier tests that Komarek briquettes of $50.8 \mathrm{~mm}(2$ ") $\times 50.8 \mathrm{~mm}(2$ ") $\mathrm{x}$ $31.75 \mathrm{~mm}(1.25 ")$ in size required nearly twice as long time to fuse as 6-segment mounds, and cutting the briquettes into half the height reduced the time to full fusion to the level of 6-segment domes. The height of feed mixtures appeared to be an important variable in the rate of forming fully fused NRI. The effects of size, apparent densities and the height of feed mixtures on fusion time were investigated

\section{2-4.1.3.1 Conclusions:}

1) The most important variable that governed fusion time was the height of feed mixtures, indicating that the time needed for radiant heat cast upon the surfaces of agglomerates to penetrate through the agglomerate governed the fusion time required to form fully fused NRI.

2) In the case of briquettes, fusion time was governed by the briquette height so long as the total weight in a tray was the same. However, fusion time increased with increasing total weight in a tray when the briquette heights were kept the same. Therefore, fusion time was governed by both briquette height and total mass (weight) in a tray. 
3) In the case of 6- and 12-segment mounds, the fusion time increased with an increase in total weight in the graphite tray and with an increase in apparent density (because their volumes and heights were fixed). Also 12-segment mounds required shorter time to fuse than 6 -segment mounds indicating that the surface areas of feed mixtures exposed to radiant heat played a role.

2-4.1.3.2 Test materials: Tests were carried out using 6- and 12-segment mounds and briquettes of different sizes, prepared from a feed mixture by mixing taconite concentrate $(\mathrm{Mb})$, bituminous coal $(\mathrm{F})$ at $80 \%$ of the stoichiometric amount, hydrated lime and fluorspar with slag composition $\mathrm{L}_{1.5} \mathrm{FS}_{2}$, as follows:

6-segment mounds: The sample trays were prepared with a feed mixture using a 6segment mold, made of plastic ice cube tray, $50.8 \mathrm{~mm}$ (2") wide x $44.45 \mathrm{~mm}$ (1.75") long $\times 17.78 \mathrm{~mm}(0.7$ ") deep in each pocket. The apparent density was determined to be 1.4-1.6, depending on the degree of packing. To increase the apparent density, the dry feed mixture was wetted in a kitchen mixer and the moistened feed was used to prepare 6-segment mounds in a similar manner. The optimum moisture was 14.2$14.3 \%$. The apparent density increased to 1.8 .

12-segment mounds: The sample trays were prepared using a 12-segment, elongated dome-shaped mold of $25.4 \mathrm{~mm}$ (1") wide x $48.26 \mathrm{~mm}$ (1.9") long x $17.78 \mathrm{~mm}$ (0.7") deep in each pocket, made of a plastic ice cube tray. The apparent density was determined to be 1.2. To increase the apparent density, the dry feed mixture was wetted in a kitchen mixer and the moistened feed was use to prepare 12-segment mounds in a similar manner. The apparent density was determined to be 1.5-1.8, depending on the amount of water used to moisten the feed.

In all cases, the grooves were filled to half way with the hearth layer material to prevent molten NRI from coalescing.

Pilot plant Komarek briquettes: Briquettes were prepared using a 50-ton Komarek briquetting machine with rollers having pocket size initially that produced briquettes of $50.8 \mathrm{~mm}(2 ") \times 50.8 \mathrm{~mm}(2 ") \times 31.75 \mathrm{~mm}(1.25$ "). The pocket size was later changed to $25.4 \mathrm{~mm}(1$ ") $\times 25.4 \mathrm{~mm}$ (1") x $19.05 \mathrm{~mm}(0.75$ "). The optimum moisture content was determined to be about $9 \%$. The briquettes weighed about $100 \mathrm{~g}$ each for the large briquettes, and about $18 \mathrm{~g}$ each for the small briquettes. Both briquettes measured apparent densities of 2.1-2.2.

Laboratory Komarek briquettes: Laboratory Komarek briquetting machine with rollers having pocket size of $22.86 \mathrm{~mm}(0.9 ")$ x $35.56 \mathrm{~mm}(1.4 ") \times 12.7 \mathrm{~mm}(0.5$ ") was used. The optimum moisture content was $9 \%$. The apparent density was measured to be 2.4 .

Carver press briquettes: For testing small amounts of raw materials, a Carver press was used to form briquettes of $25.4 \mathrm{~mm}$ (1") in diameter and $15.24 \mathrm{~mm}(0.6$ ") high from the feed mixture. The apparent density was determined to be 2.4 .

2-4.1.3.3 Test procedure: A pre-determined amount of feed, either in mounds or briquettes, was placed on a hearth layer of 6/100 mesh anthracite char in a $127 \mathrm{~mm}$ (5") 
x $152.4 \mathrm{~mm}(6 ") \times 38.1 \mathrm{~mm}(1.5 ")$ graphite tray. The sample tray was placed in the cooling chamber of the box furnace and purged with $90 \% \mathrm{~N}_{2}-10 \% \mathrm{CO}$ at $20 \mathrm{~L} / \mathrm{min}$ for 30 minutes to drive out the oxygen in the furnace. The tray was pushed inside the flip-up door for 3 minutes, then into Zone 1 at $1149^{\circ} \mathrm{C}\left(2100^{\circ} \mathrm{F}\right)$ for 5 minutes, followed by into Zone 2 at $1400^{\circ} \mathrm{C}\left(2552^{\circ} \mathrm{F}\right)$ and holding there for different periods of time to arrive at the minimum time required to form fully fused NRI. After a pre-determined time in Zone 2, the tray was pushed out to the back of the flip-up door for 10 minutes for preliminary cooling. This was followed by 10 minute cooling in the cooling chamber before the tray was taken out for observation. Fusion time reported was estimated to the nearest one minute.

2-4.1.3.4 Test results: The amount of the feed mixture in a tray was varied so that the effects of total weight, apparent density and height on fusion time could be isolated. For example, the total weight in a mound was varied by changing the force in packing the feed mixture into the mold. In the case of briquettes, four $50.8 \mathrm{~mm}(2$ ") x $50.8 \mathrm{~mm}$ (2") x $31.75 \mathrm{~mm}$ (1.25") pilot-plant Komarek briquettes were initially tested. This was followed by comparing one $50.8 \mathrm{~mm}(2 ")$ x $50.8 \mathrm{~mm}(2 ")$ x $31.75 \mathrm{~mm}(1.25$ ") pilot-plant Komarek briquette, six $25.4 \mathrm{~mm}$ (1")x $25.4 \mathrm{~mm}$ (1") x $19.05 \mathrm{~mm}(0.75$ ") pilot plant Komarek briquettes, six Carver press briquettes and nine Laboratory Komarek briquettes, weighing approximately the same, 100,109, 109 and 106g, respectively. Yet another test was carried out by grinding two $50.8 \mathrm{~mm}(2 ")$ x $50.8 \mathrm{~mm}\left(2^{\prime \prime}\right)$ x $31.75 \mathrm{~mm}(1.25$ ") pilot-plant Komarek briquettes to a height of $24 \mathrm{~mm}(0.94$ ") to test the effects of total weight and height.

All the results, carried out on 6- and 12-segment mounds as well as different sizes and types of briquettes, are summarized in Table 2-4-5, and the fusion time was plotted as a function of the height of agglomerates in Figure 2-4-3, of the total weight in graphite trays in Figure 2-4-4, and of apparent densities in Figure 2-4-5.

Figure 2-4-3 shows that the height of feed mixtures correlated well with the minimum time required for fusion, indicating that the time needed for radiant heat cast upon the surfaces of agglomerates to penetrate through governed the time required to form fully fused NRI.

In Figure 2-4-4, the fusion time was plotted against the total weight in the graphite tray. In the case of 6- and 12-segment mounds, the fusion time increased with an increase in total weight in the graphite tray. In addition, it was noted that 12-segment mounds required somewhat shorter time to fuse than 6-segment mounds, indicating that the surface areas of feed mixtures exposed for receiving radiant heat played a role. In the case of briquettes, the data points near $100 \mathrm{~g}$ were essentially independent of the weight, and only the large Komarek briquettes had notably longer time for fusion, regardless of their weight.

Figure 2-4-5 shows that the fusion time for 6 - and 12-segment mounds increased with increasing apparent densities, but for briquettes, apparent densities varied little in the range of 2.1-2.4, and the fusion time was dependent on briquette height and total weight. 
With two $50.8 \mathrm{~mm}(2 ") \times 50.8 \mathrm{~mm}(2 ") \times 31.75 \mathrm{~mm}(1.25$ ") Komarek briquettes, ground to a height of $24 \mathrm{~mm}(0.94$ "), the fusion time fell close to the regression line in Figure 24-3, supporting a view that the height of the feed governed the fusion time. Therefore, it may be visualized that the minimum time required to form fully fused NRI was governed by the penetration of radiant heat through the agglomerates. 
Table 2-4-5. Minimum time required to fusion by different sized domes and briquettes, showing the effects of the weight in a tray, apparent density and the height of feed.

\begin{tabular}{|c|c|c|c|c|}
\hline & $\begin{array}{c}\text { Total } \\
\text { weight } \\
\text { g }\end{array}$ & $\begin{array}{c}\text { Apparent } \\
\text { density } \\
\mathrm{cm} / \mathrm{g}\end{array}$ & $\begin{array}{c}\text { Height } \\
\text { of feed } \\
\text { mm }\end{array}$ & $\begin{array}{c}\text { Fusion } \\
\text { time } \\
\text { min }\end{array}$ \\
\hline$\underline{6 \text {-segment mounds }}$ & & & & \\
\hline Dry & 212 & 1.4 & 13 & 10 \\
\hline Dry & 287 & 1.6 & 17 & 12 \\
\hline $14.1 \%$ moist. $^{1)}$ & 269 & 1.5 & 17 & 12 \\
\hline $\begin{array}{l}\quad 14.3 \% \text { moist. }^{2)} \\
\text { 12-segment } \\
\underline{\text { mounds }}\end{array}$ & 313 & 1.8 & 17 & 14 \\
\hline Dry & 205 & 1.2 & 17 & 8 \\
\hline $14.0 \%$ moist. $^{1)}$ & 257 & 1.5 & 17 & 10 \\
\hline $\begin{array}{l}\quad 14.2 \% \text { moist. }{ }^{2)} \\
\text { Komarek } \\
\text { briquettes }\end{array}$ & 313 & 1.8 & 17 & 10 \\
\hline $2 \times 2 \times 1.25^{\prime \prime}(4)^{3)}$ & 391 & 2.1 & 32 & 20 \\
\hline $2 \times 2 \times 1.25 "(1)$ & 98 & 2.1 & 32 & 19 \\
\hline $2 \times 2 \times 0.95^{\prime \prime}(2)^{4)}$ & 160 & 2.1 & 24 & 15 \\
\hline $1 \times 1 \times 0.75 "(6)$ & 109 & 2.3 & 18 & 9 \\
\hline $\begin{array}{l}0.9 \times 1.4 \times 0.5 ”(9) \\
\text { Carver press briq. }\end{array}$ & 106 & 2.4 & 13 & 5 \\
\hline 1"diax 0.6" (6) & 109 & 2.4 & 15 & 9 \\
\hline
\end{tabular}

1) $164 \mathrm{~mL} / 1000 \mathrm{~g}$ used in wetting the feed mixture.

2) $170 \mathrm{~mL} / 1000 \mathrm{~g}$ used in wetting the feed mixture.

3) Number in parentheses indicate the number of briquettes used.

4) $2 \times 2 \times 1-1 / 4$ " briquettes ground to $24 \mathrm{~mm}$ in thickness. 


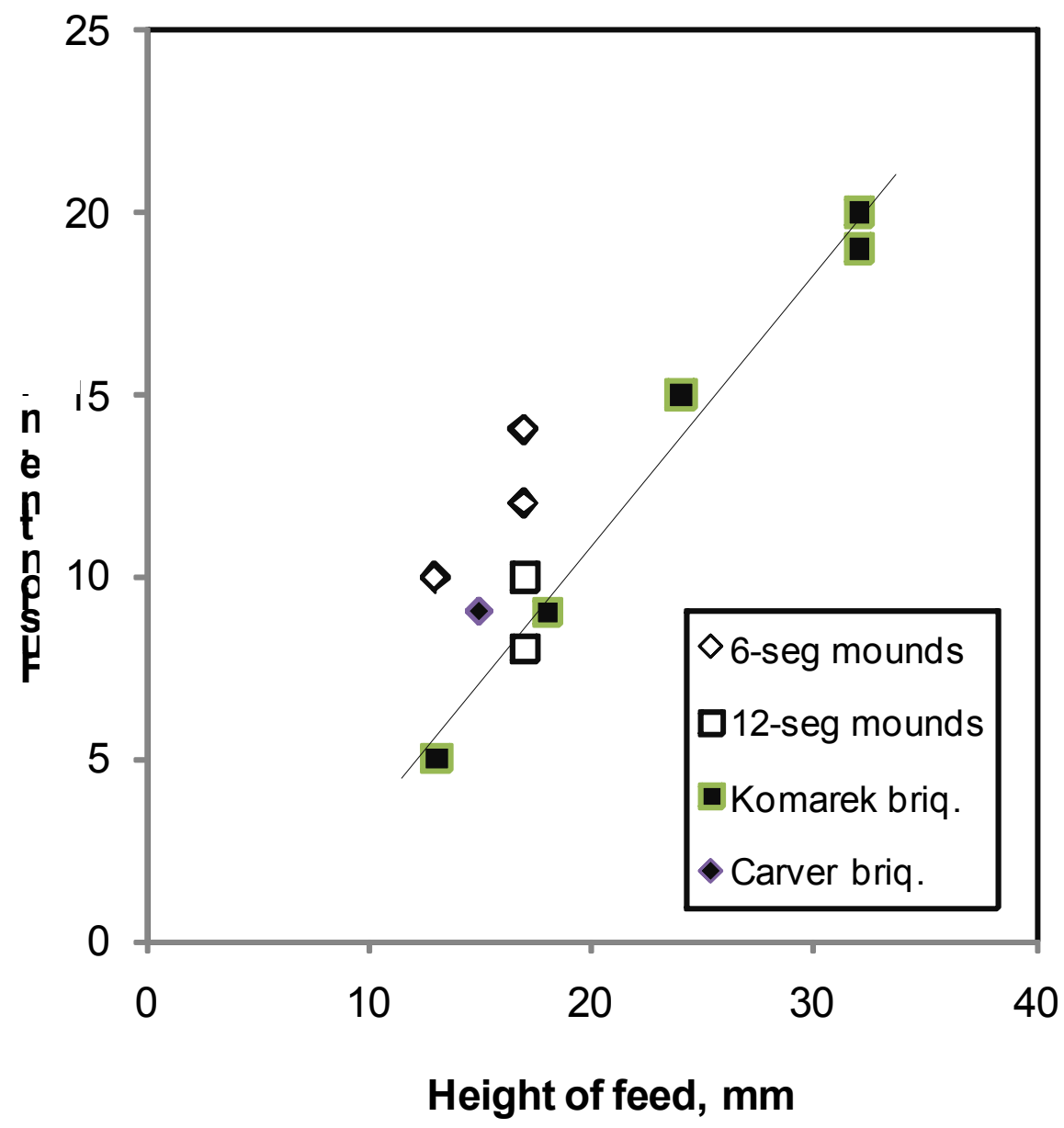

Figure 2-4-3. Minimum time required for fusion plotted against the heights of agglomerates. 


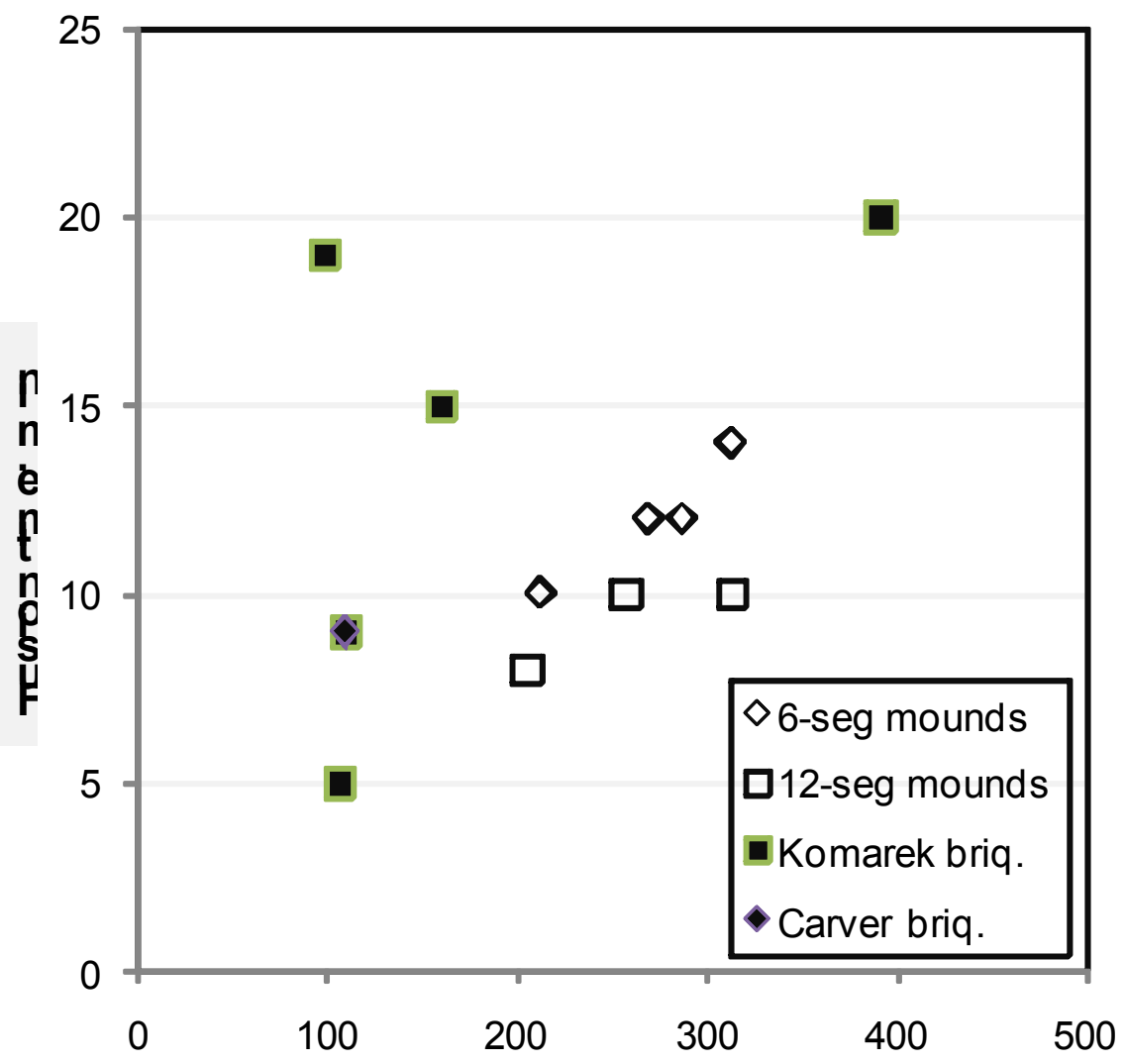

Total weight, $\mathbf{g}$

Figure 2-4-4. Minimum time required for fusion plotted against total weight in a graphite tray. 


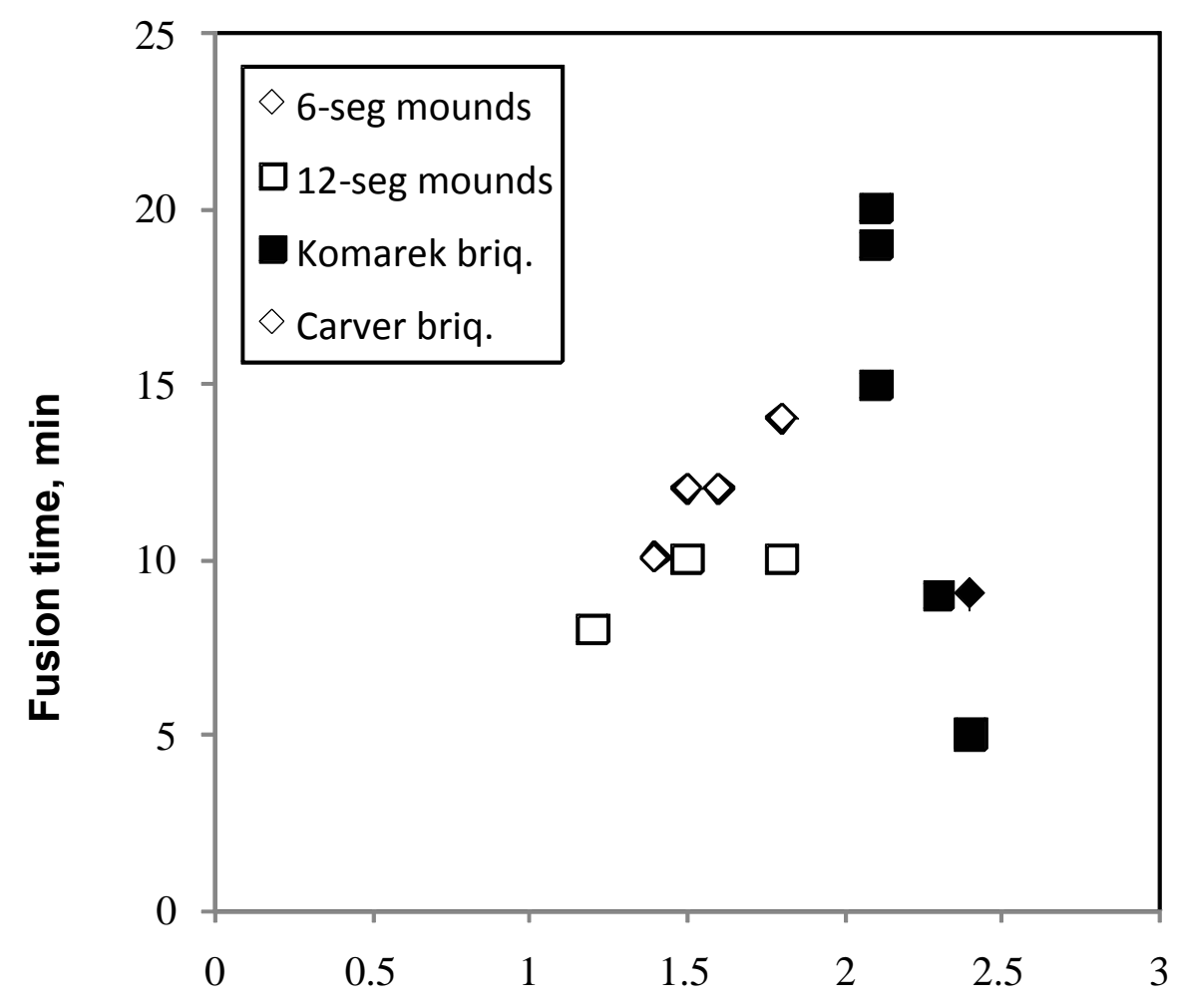

Apparent density, g/cm 3

Figure 2-4-5. Minimum time required for fusion plotted against apparent density. 


\section{2-4.2 Mechanism of NRI formation}

\section{2-4.2.1 Metal-slag separation during NRI formation}

Formation of fully-fused NRI depends not only on the effectiveness of the radiant and conductive heat transfer, but also on the rate of carburizing of the sponge iron with carbon coming from the hearth layer and also perhaps from the cover layer. During the investigation on the effect of briquette size, briquette samples heated for different periods of time led to an observation, which appeared to shed some light on how metal and slag separate during NRI formation. In this section, the manner in which metal-slag separation could affect carburizing sponge iron for fusion was investigated.

\section{2-4.2.1.1 Conclusions:}

1) Briquettes heated at $1400^{\circ} \mathrm{C}$ for different periods of time showed that slag was observed to form initially at the bottom of the briquettes. Apparently, slag fused before sponge iron, and accumulated at the bottom of the briquettes.

2) The presence of slag at bottom would interfere with carburizing of the sponge iron by preventing direct contact with hearth layer carbon. Nevertheless, the molten metal was observed to propagate from the bottom to the top of the briquettes.

3) It may be speculated that higher fluidity of the slag would accelerate the carburizing reaction by facilitating the contacts between sponge iron and hearth layer coke.

2-4.2.1.2 Experimental observation: Briquette samples heated at $1400^{\circ} \mathrm{C}\left(2552^{\circ} \mathrm{F}\right)$ for different periods of time, shown in Figure 2-4-6, provided experimental evidence that carburizing could be a critical parameter controlling the rate of fused NRI formation.

In the figure, a briquette heated for 15 minutes was essentially sponge iron, not yet fused, as seen from top as well as from bottom. With briquettes heated for 20 minutes, the views from bottom, (c) and (d), show a large bleb of molten slag in the center, surrounded by partially fused slag particles, on which sponge iron rested. The view of the same briquettes from top remained sponge iron, not yet fused.

Apparently, slag fused first and collected at the bottom. The layer of slag at bottom would certainly interfere with carburizing. After 25 minutes, the briquette turned into fully-fused NRI with slag coagulated and came up, surrounding the NRI (e). Therefore, between 20 and 25 minutes, carburizing took place, presumably only from the sides, thereby lowering the melting point of sponge iron, and eventually melted to form NRI.

Melting of NRI proceeded from bottom and the melting front moved upward as sponge iron carburized. Thus, the thickness of the feed controlled the time needed for fusion by the rate of carburizing of sponge iron formed as an initial step of NRI formation. 


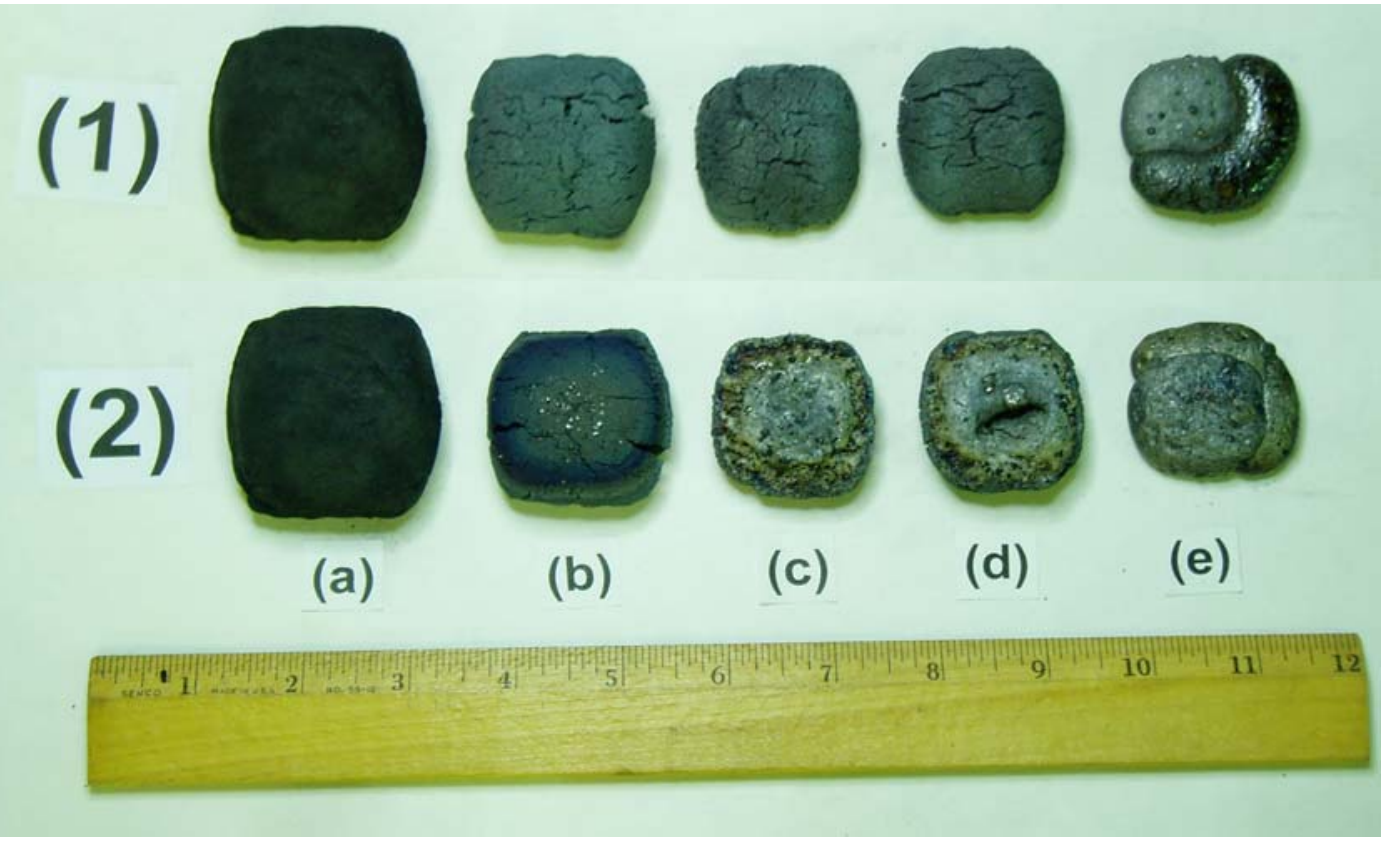

Figure 2-4-6. Effect of time at $1400^{\circ} \mathrm{C}\left(2552^{\circ} \mathrm{F}\right)$ on NRI formation from briquettes of $53 \mathrm{~mm} \times 50 \mathrm{~mm} \times 32 \mathrm{~mm}(2.1$ "' $\times 1.9$ "' $\times 1.25$ "), consisting of taconite concentrate $(\mathrm{Mb})$, bituminous coal $(\mathrm{F})$ at $80 \%$ of the stoichiometric amount and slag composition ( $\left(\mathrm{L}_{.5} \mathrm{FS}_{2}\right.$ ), placed on $6 / 100$ mesh anthracite char.

(1) View from top; (2) view from bottom

(a) Feed briquette; (b) $15 \mathrm{~min}$; (c) and (d) $20 \mathrm{~min}$; (e) $25 \mathrm{~min}$.

A similar series of tests were performed by making briquettes from the same feed mixture, consisting of taconite concentrate $(\mathrm{Mb})$, medium-volatile bituminous coal at 80 $\%$ of the stoichiometric amount and at Slag Composition $\mathrm{L}_{1.5} \mathrm{FS}_{2}$, into briquettes of 25.4 $\mathrm{mm} \times 25.4 \mathrm{~mm} \times 19 \mathrm{~mm}(1 \times 1 \times 0.75 ")$ in size, and a similar series of tests was performed as a function of time at $1400^{\circ} \mathrm{C}\left(2552^{\circ} \mathrm{F}\right)$.

Nine briquettes were arranged on a layer of 6/100 mesh anthracite char in graphite trays, as shown in Figure $2-4-7(\mathrm{a})$. The samples were heated at $1400^{\circ} \mathrm{C}\left(2552^{\circ} \mathrm{F}\right)$ for 4 , 6,8 , and 10 minutes. Heating for 10 minutes was required to form fully-fused NRI. Briquettes were not completely fused by heating for 8 minutes, as suggested by less smooth surfaces of the NRI.

From these results, briquettes with a thickness of $19 \mathrm{~mm}(0.75$ ") formed fully fused NRI in 10 minutes, while briquettes with a thickness of $32 \mathrm{~mm}(1.25$ ") required 25 minutes. Views from top and bottom of the briquettes are shown in Figure 2-4-7(b). Here again, when the reaction was stopped after 4 minutes, sponge iron was the initial product. After 5 minutes, the briquette shrunk further, but the top side remained sponge iron, while the bottom side became covered with slag. After 8 minutes, the sponge iron started to melt and coalesced into NRI. The bottom side showed a number of micro NRI in the slag matrix. The product was completely separated into NRI and slag after 10 minutes. 
Thus, the molten slag accumulated at the bottom of sponge iron first, presumably interfering with the carburizing reaction, but eventually the sponge iron fused by absorbing carbon from the hearth layer, and slag, being lighter than molten NRI, coalesced and moved around NRI to grow into large slag droplets.

\section{2-4.2.2 Desulfurizing reaction}

To determine the role played by slag in desulfurizing, a test was carried out on a feed mixture, consisting of Fisher Chemical ferric oxide, ground graphite at $80 \%$ of the stoichiometric amount and ferrous sulfate $\left(\mathrm{FeSO}_{4} \cdot 7 \mathrm{H}_{2} \mathrm{O}\right)$. The amount of ferrous sulfate was added so that sulfur was in the same range of sulfur in bituminous coal (J). The results were compared with a typical feed mixture, consisting of taconite concentrate $(\mathrm{K})$, bituminous coal $(\mathrm{J})$ at $80 \%$ of the stoichiometric coal, hydrated lime and fluorspar.

\section{2-4.2.2.1 Conclusions:}

1) Sulfur came mainly from coal added as a reductant and some from the carbonaceous hearth layer.

2) In the absence of slag, about $2 / 3$ of sulfur went to the furnace gas and about $1 / 3$ absorbed by NRI.

3) In the presence of high lime slag, essentially all sulfur stayed with NRI and slag.

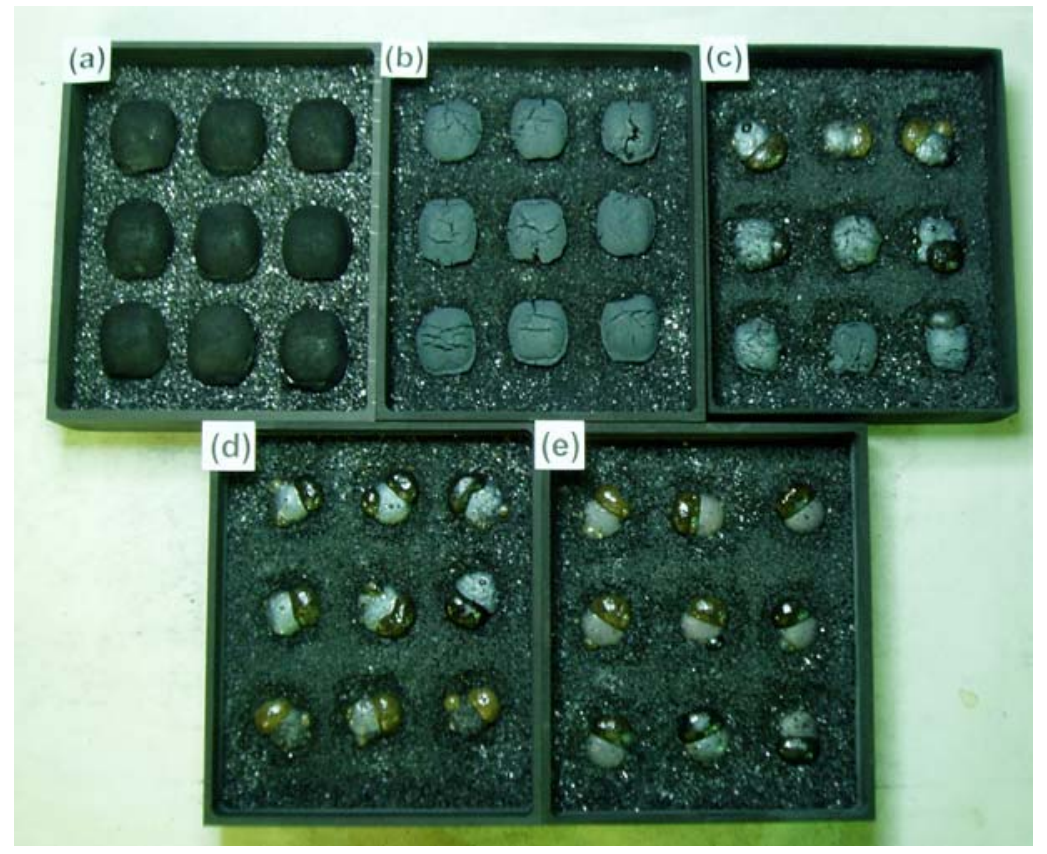

Figure 2-4-7(a). Effect of time at $1400^{\circ} \mathrm{C}\left(2552^{\circ} \mathrm{F}\right)$ on NRI formation from briquettes

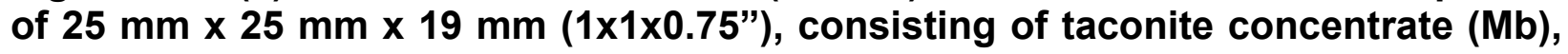
bituminous coal (F) at $80 \%$ of the stoichiometric amount and slag composition $\left(\mathrm{L1}_{.5} \mathrm{FS}_{2}\right)$, placed on 6/100 mesh anthracite char.

(a) Feed briquette; (b) $4 \mathrm{~min}$; (c) $6 \mathrm{~min}$; (d) $8 \mathrm{~min}$; (e) $10 \mathrm{~min}$ 
(1)

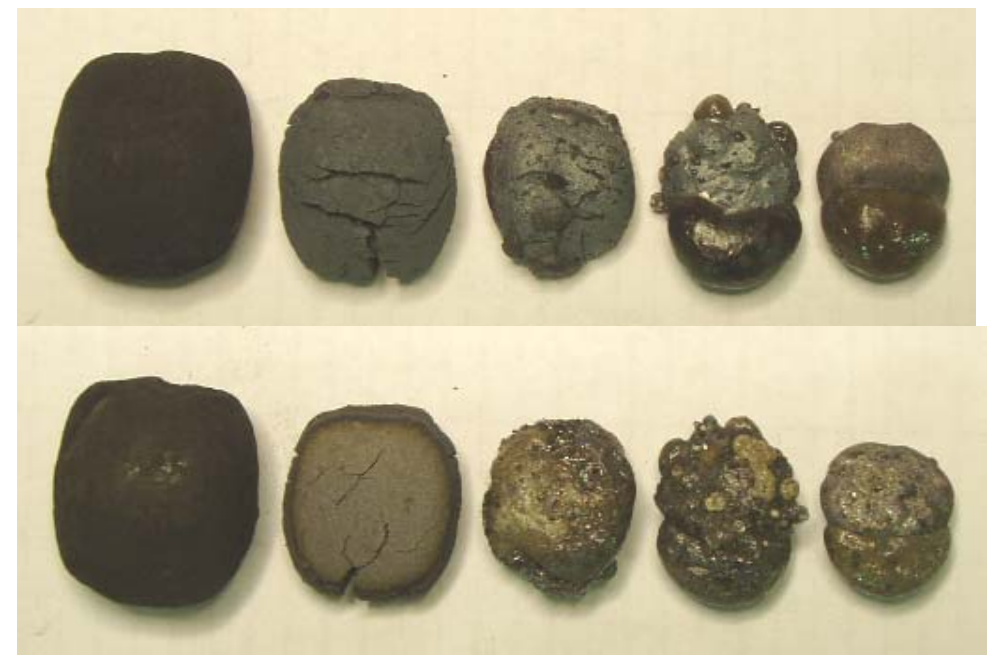

$\begin{array}{lllll}\text { (a) } & \text { (b) } & \text { (c) } & \text { (d) } & \text { (e) }\end{array}$

Figure 2-4-7(b). Views of briquettes in Figure 2-4-7(a) from top and bottom, showing slag accumulating at bottom initially and then moving to sides as the briquettes fused.

(1) View from top; (2) view from bottom

(a) Feed briquette; (b) $4 \mathrm{~min}$; (c) $5 \mathrm{~min}$; (d) $8 \mathrm{~min}$; (e) $10 \mathrm{~min}$.

2-4.2.2.2 Feed producing no slag: A feed mixture prepared from the following composition was formed into Carver press briquettes.

$\begin{array}{lr}\mathrm{Fe}_{2} \mathrm{O}_{3} \text { (Fisher Chemical) } & 83.9 \% \\ \mathrm{Graphite} & 15.1 \% \\ \mathrm{FeSO}_{4} \cdot 7 \mathrm{H}_{2} \mathrm{O} & 1.0 \%\end{array}$

Six briquettes were placed on 6/100 mesh graphite in a graphite tray, and heated at $1400^{\circ} \mathrm{C}\left(2552^{\circ} \mathrm{F}\right)$ for 20 minutes in a $\mathrm{N}_{2}-\mathrm{CO}$ atmosphere, as in the standardized box furnace test procedure. Graphite analyzed no sulfur and, therefore, was chosen as the reductant as well as the hearth layer material.

The product consisted only of NRI and no slag, nor any micro NRI. The weight recovery of NRI was $61.1 \%$. The NRI analyzed $4.79 \% \mathrm{C}$ and $0.054 \% \mathrm{~S}$. The weight of the NRI agreed with the calculated weight of metallic iron plus dissolved carbon within $1 \%$ of the product weight.

From the sulfur contents of the feed mixture and the NRI, the amount of sulfur lost to the furnace atmosphere was calculated to be $71 \%$ and the NRI absorbed $29 \%$.

2-4.2.2.3 Typical feed mixture consisting of taconite concentrate $(K)$ and bituminous coal $(\mathrm{J})$ : For comparison, a typical feed mixture, consisting of taconite concentrate $(\mathrm{K})$, bituminous coal $(\mathrm{J})$, hydrated lime and fluorspar, was formed into 6 Carver press briquettes and placed on 6/100 mesh anthracite char hearth layer in a 
graphite tray, and heated at $1400^{\circ} \mathrm{C}\left(2552^{\circ} \mathrm{F}\right)$ for 20 minutes in a $\mathrm{N}_{2}-\mathrm{CO}$ atmosphere. The feed composition was as follows:

$\begin{array}{lr}\text { Taconite concentrate (2) } & 74.9 \% \\ \text { Bituminous coal (2) } & 16.9 \% \\ \text { Lime hydrate } & 6.2 \% \\ \text { Fluorspar } & 2.0 \%\end{array}$

The weight recovery of the product was $64.6 \%$ of the weight of the briquettes. The analytical results of $\mathrm{NRI}$ and slag are given in Table 2-4-6 below.

The amount of sulfur distributing among NRI, slag and furnace atmosphere was estimated by subtracting the amount of sulfur in products (NRI and slag) from the amount of sulfur in feed briquettes, and expressed as \%S in NRI, slag and furnace atmosphere by dividing the difference by the amount of sulfur in feed briquettes. The results are included in Table 2-4-6.

The amount of sulfur lost to the furnace atmosphere was $-2.9 \%$. The negative number was thought to be due to the accumulation of errors in sample weights and analytical results, which suggested that all the sulfur in the feed briquettes was absorbed by the products and essentially no sulfur was lost to the furnace atmosphere. The sulfur in the products was distributed $85 \%$ to slag and $15 \%$ to $\mathrm{NRI}$ at this test condition. This indicated the role played by slag in preventing sulfur from leaving the products during reduction to furnace atmosphere.

Table 2-4-6. Analytical results of products and sulfur distribution

\begin{tabular}{|l|c|ccc|c|}
\hline & \multirow{3}{*}{ \%wt } & \multicolumn{3}{|c|}{ Analyses } & S \\
& \%Fe & \%C & $\%$ distribution \\
NRI & 82.3 & --- & 3.45 & 0.033 & 15.3 \\
Slag & 17.7 & 0.07 & --- & 0.85 & 84.7 \\
Furnace atm. & & --- & --- & -- & -2.9 \\
\hline
\end{tabular}




\section{2-4.2.3 Carburizing reactions}

To form fully fused NRI, the sponge iron needs to be carburized. This would mean that the amount of reductant carbon required needs to be in excess of the stoichiometric amount, consisting of the amount needed for the reduction of taconite concentrate and for carburizing. However, in order to suppress the formation of micro NRI, the amount of reductant carbon for taconite concentrate needed to be about $80 \%$ of the stoichiometric amount. In an attempt to identify the contribution of carbonaceous hearth layer to carburizing, the effects of the amount of reductant coal addition, weight loss of carbonaceous hearth layer and furnace atmosphere on fusion behaviors and NRI sulfur were investigated.

\section{2-4.2.3.1 Conclusions:}

1) Briquettes with $100 \%$ stoichiometric coal placed on a hearth layer of alumina in a $\mathrm{N}_{2}-\mathrm{CO}$ atmosphere fused, indicating that about $10 \%$ of the magnetic concentrate was reduced by $\mathrm{CO}$ in the furnace gas. When the addition of coal was increased to $110 \%$ of the stoichiometric amount, the reduction by $\mathrm{CO}$ in the furnace gas lowered to $1 \%$.

2) Sulfur in NRI formed over alumina hearth layer was higher (0.044-0.056\%S) than those of anthracite char hearth layer due to the morphology and chemistry of the slag.

3) In a $\mathrm{N}_{2}-\mathrm{CO}$ atmosphere, time required for forming fully fused NRI was shorter than in a $\mathrm{N}_{2}-\mathrm{CO}_{2}$ atmosphere. In a $\mathrm{N}_{2}-\mathrm{CO}$ atmosphere, NRI sulfur was lower $(0.030-0.032 \% \% \mathrm{~S})$ than that in a $\mathrm{N}_{2}-\mathrm{CO}_{2}$ atmosphere $(0.038-0.046 \% \mathrm{~S})$.

4) Iron in slag formed in $\mathrm{N}_{2}-\mathrm{CO}$ atmosphere was lower than iron in slag formed in $\mathrm{N}_{2}-\mathrm{CO}_{2}$ atmosphere, though they were all well below $1 \% \mathrm{Fe}$.

5) Increasing the time at $1400^{\circ} \mathrm{C}\left(2552^{\circ} \mathrm{F}\right)$ to 20 minutes in a $\mathrm{N}_{2}-\mathrm{CO}$ atmosphere lowered the NRI sulfur to $0.019 \% \mathrm{~S}$. In a $\mathrm{N}_{2}-\mathrm{CO}_{2}$ atmosphere, the sulfur even increased to $0.063-0.070 \%$ S.

2-4.2.3.2 Test procedure: Six briquettes, $25.4 \mathrm{~mm}(1$ ") $\times 25.4 \mathrm{~mm}$ (1")x $19.05 \mathrm{~mm}$ $(0.75$ ") in size, made in a pilot plant Komarek briquetting machine from raw materials, consisting of taconite concentrate $(\mathrm{Ma})$, bituminous coal $(\mathrm{K})$ and slag composition, $\mathrm{L}_{1.5} \mathrm{FS}_{2}$, were placed either on a hearth layer of $6 / 100$ mesh anthracite char or of fine alumina powder in a fiber board tray, and heated in the standardized heating schedule in $\mathrm{N}_{2}, \mathrm{~N}_{2}-\mathrm{CO}$ and $\mathrm{N}_{2}-\mathrm{CO}_{2}$ atmospheres.

\section{2-4.2.3.3 Test results:}

2-4.2.3.3.1 Alumina hearth layer

Komarek briquettes with $80 \%$ stoichiometric coal placed on a hearth layer of fine alumina did not fuse regardless of the furnace atmosphere. This was to be expected as the briquettes had insufficient amount of the reductant coal for completing the reduction. An additional test was performed in a $\mathrm{N}_{2}-\mathrm{CO}$ atmosphere with the Komarek briquettes with $80 \%$ stoichiometric coal, but extending the time at $1400^{\circ} \mathrm{C}\left(2552^{\circ} \mathrm{F}\right)$ to 20 minutes to see if even a part of sponge iron might fuse. The briquettes did not fuse and remained as sponge iron as before. 
To study if briquettes at $100 \%$ and $110 \%$ stoichiometric coal might fuse under the same condition, six briquettes were made with a Carver press, placed over a fine alumina hearth layer and heated at $1400^{\circ} \mathrm{C}\left(2552^{\circ} \mathrm{F}\right)$ for 20 minutes. The test produced fully fused NRI. The slag at both $100 \%$ and $110 \%$ stoichiometric coal are seen to have spread through the hearth layer by reacting with the fine alumina, and no slag beads are seen to be attached to the NRI. The slag reacted with fine alumina, penetrated through the hearth layer and reacted with the fiber board tray.

The NRI at $100 \%$ and $110 \%$ stoichiometric coal were analyzed for $\mathrm{C}$ and $\mathrm{S}$. The results are given in Table 2-4-7. The carbon contents of the NRI were $3.04 \%$ and $3.19 \% \mathrm{C}$, respectively. Apparently, $\mathrm{CO}$ in the furnace gas took part in the reduction of the concentrate, thereby preserving enough reductant coal to carburize the sponge iron for fusion. From the balance of the carbon in the feed mixture and the carbon dissolved in the NRI, it was estimated that in the case of $100 \%$ stoichiometric coal, CO in the furnace gas participated in the reduction of about $10 \%$ of the magnetite. In the case of $110 \%$ stoichiometric coal, only about $1 \%$ of the total carbon in forming fully fused NRI was estimated to come from $\mathrm{CO}$ in the furnace gas, which amounted to about $1 \%$ of the dissolved carbon in the NRI. 
Table 2-4-7. Analytical results of NRI and slag, formed from briquettes, consisting of taconite concentrate (Ma), bituminous coal $(K)$ and slag composition, $L_{1.5} F_{2}$, placed either on a hearth layer of $6 / 100$ mesh anthracite char or fine alumina powder in a fiber board tray, and heated at $1400^{\circ} \mathrm{C}$ for different periods of time.

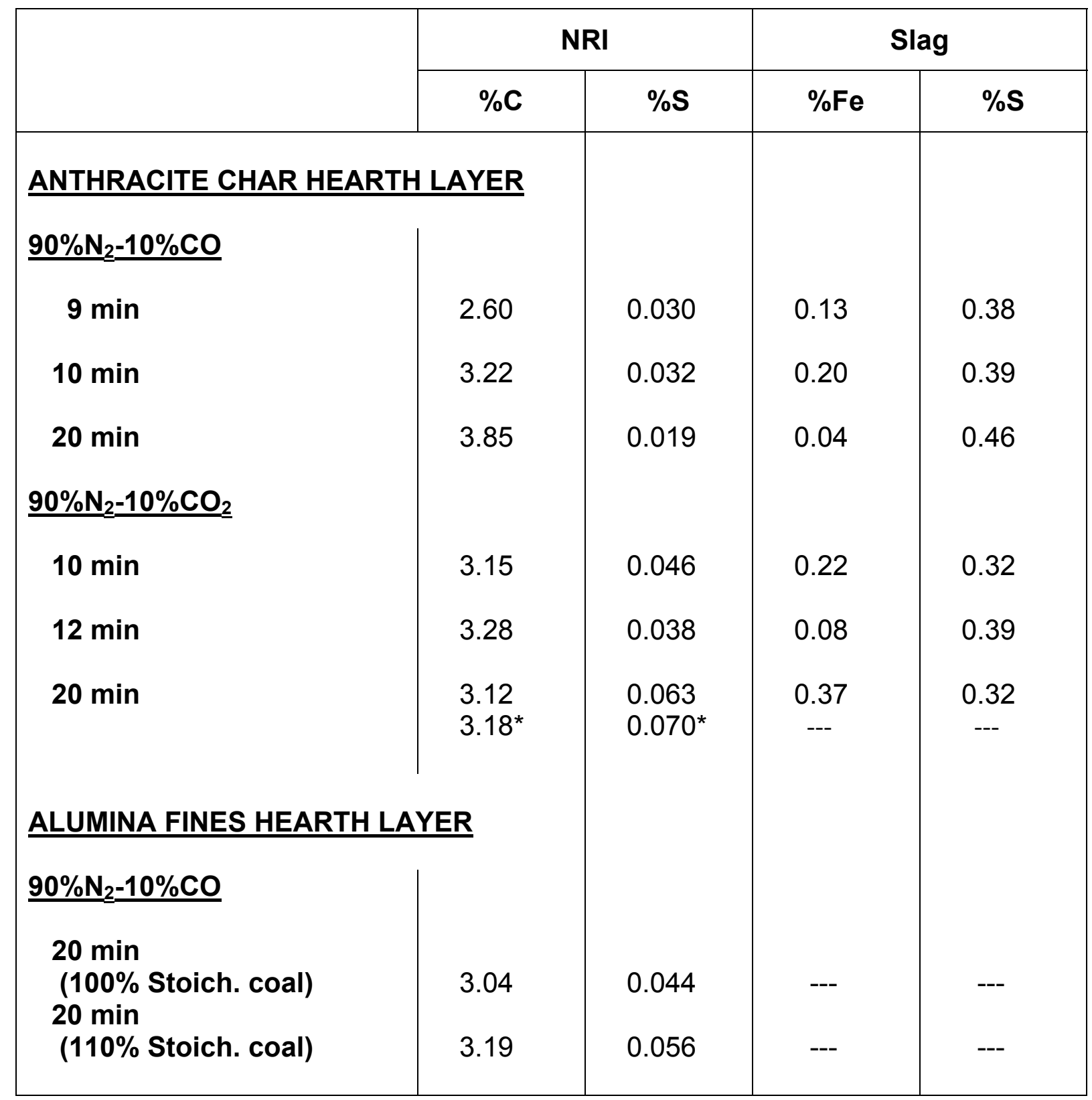

* Duplicate test 
The sulfur contents of NRI made with $100 \%$ and $110 \%$ stoichiometric coal of 0.044 and $0.059 \% \mathrm{~S}$, respectively were higher than when carbonaceous hearth layer was used $(0.02$ to $0.03 \% S)$. The slag reacted with alumina, and no slag beads were attached to $\mathrm{NRI}$. Thus, the contact area was greatly reduced for effective absorption of sulfur by slag from NRI. Also, the reaction with alumina lowered the basicity of slag, thereby adversely affecting the desulfurizing capacity. Nevertheless, the sulfur contents were much lower than expected in view of little metal-slag contacts. Perhaps large amounts of sulfur might have been lost to the furnace atmosphere, similar to a test using chemical $\mathrm{Fe}_{2} \mathrm{O}_{3}$ and graphite, reported in 4.2.2.2.

\section{2-4.2.3.3.2 Anthracite char hearth layer}

Initially, six Komarek briquettes with $80 \%$ stoichiometric coal, placed on 6/100 mesh anthracite char in a fiber board tray, were heated at $1400^{\circ} \mathrm{C}\left(2552^{\circ} \mathrm{F}\right)$ in a $\mathrm{N}_{2}$ atmosphere for 12 minutes. Unlike with the alumina hearth layer, all the briquettes fully fused even in a $\mathrm{N}_{2}$ atmosphere. In a $90 \% \mathrm{~N}_{2}-10 \% \mathrm{CO}$ atmosphere, fusion time decreased to 9 minutes. Slag beads attached to the fused NRI were white in color, suggesting that Fe contents were low. The slag analyzed $0.13 \% \mathrm{Fe}$.

In these tests, $160 \mathrm{~g}$ of $6 / 100$ mesh anthracite char was used as the hearth layer. Weights after the tests in a $\mathrm{N}_{2}$-CO atmosphere were decreased by about $2 \%$. With a feed at $80 \%$ stoichiometric coal, the remaining $20 \%$ had to come from CO in the furnace gas as well as from the hearth layer. The amount of carbon from coal in the feed, dissolved carbon in NRI and the loss of weight in the hearth layer were calculated. From the calculation, it was estimated that about $15 \%$ of the deficient carbon came from the hearth layer and about $85 \%$ from $\mathrm{CO}$ in the furnace gas. Such an observation suggested that cover layers of carbonaceous materials would increase the CO concentration near the feed mixture and promote the carburizing reaction for fusion.

In a $90 \% \mathrm{~N}_{2}-10 \% \mathrm{CO}_{2}$ atmosphere, it took a little longer time of 10 minutes to form fully fused NRI. In the presence of $\mathrm{CO}_{2}$, the slag beads appeared black on the surface, suggesting iron in the slag phase was oxidized. However, this oxidation must have been only on the surface as the slag analyzed $0.22 \% \mathrm{Fe}$, slightly higher than the slag formed in a $\mathrm{N}_{2}-\mathrm{CO}$ atmosphere.

In an attempt to investigate what effect a prolonged time at temperature might have on the carbon and sulfur analyses of NRI along with the iron and sulfur analyses of slag, two additional tests were carried out by extending the time at $1400^{\circ} \mathrm{C}\left(2552^{\circ} \mathrm{F}\right)$ to 20 minutes in the furnace atmospheres of $\mathrm{N}_{2}-\mathrm{CO}$ and $\mathrm{N}_{2}-\mathrm{CO}_{2}$, and the $\mathrm{NRI}$ and slag were analyzed. The weight distribution and analytical results are included in Table 2-4-7.

In a $\mathrm{N}_{2}$ - $\mathrm{CO}$ atmosphere, holding the products at $1400^{\circ} \mathrm{C}\left(2552^{\circ} \mathrm{F}\right)$ for 20 minutes raised the carbon content from $2.60 \%$ to $3.85 \% \mathrm{C}$, whereas decreased the sulfur content from $0.030 \%$ to $0.019 \% \mathrm{~S}$. Iron in slag decreased from $0.13 \%$ to $0.04 \% \mathrm{Fe}$. In a $\mathrm{N}_{2}-\mathrm{CO}_{2}$ atmosphere, however, carbon in NRI remained essentially constant at $3.15-3.18 \% \mathrm{C}$, whereas sulfur in NRI increased from $0.048 \%$ to $0.063-0.070 \%$ S. Iron in slag also increased from $0.22 \%$ to $0.37 \% \mathrm{Fe}$. 


\section{2-4.3 Generation and control of micro NRI}

The amount of coal added to feed mixtures governs fusion time, micro NRI generation and sulfur in NRI. In this section, the manner in which micro NRI are generated and the reason why micro $\mathrm{NRI}$ are resistant to coalescence were investigated.

\section{2-4.3.1 Conclusions}

1) A circumstantial evidence suggested that micro NRI formed by venting out of $\mathrm{CO}$ gas generated within feed mixtures, thereby spewing fine iron particles off to the vicinity of parent NRI.

2) Micro NRI thus set free were resistant to coalescence by fine carbonaceous particles attached to their surfaces.

3) Although micro NRI could be minimized by decreasing the coal addition to substoichiometric amounts, sulfur in parent NRI increased beyond the specification of $0.05 \% \mathrm{~S}$. This was particularly pronounced when hematite was the feed material $(>0.1 \% \mathrm{~S})$. Development of slag composition for controlling the sulfur becomes essential.

\section{2-4.3.2 Generation of micro NRI}

Increasing the coal addition to feed mixtures decreased fusion time, increased micro $\mathrm{NRI}$, and decreased sulfur in parent NRI. Decreasing coal addition has exactly the opposite effect. The amounts of coal needed for minimizing micro NRI generation to less than a few percent for the three types of iron oxides are:

$\begin{array}{ll}\text { Mill scale (mainly } \mathrm{FeO} \text { equivalent) } & 90-95 \% \text { stoichiometric } \\ \text { Taconite concentrate }\left(\mathrm{Fe}_{3} \mathrm{O}_{4}\right) & 80-85 \% \\ \text { Hematite }\left(\mathrm{Fe}_{2} \mathrm{O}_{3}\right) & 65-70 \%\end{array}$

The amount of carbon required to reduce the iron oxides to metallic iron increases and the volume of $\mathrm{CO}$ generated increases with their oxidation states.

$$
\begin{gathered}
\mathrm{FeO}+\mathrm{C}=\mathrm{Fe}+\mathrm{CO} \\
1 / 3 \mathrm{Fe}_{3} \mathrm{O}_{4}+4 / 3 \mathrm{C}=\mathrm{Fe}+4 / 3 \mathrm{CO} \\
1 / 2 \mathrm{Fe}_{2} \mathrm{O}_{3}+3 / 2 \mathrm{C}=\mathrm{Fe}+3 / 2 \mathrm{CO}
\end{gathered}
$$

CO generated inside a feed mixture vents out and spews out fine iron particles through the interstices of feed mixtures. When the volume of $\mathrm{CO}$ increases, the venting pressure inside the feed mixture increases, and the gas would loosen more of the mixture and spews more fine iron off to generate micro NRI. Occasionally, briquettes were observed to move around over the hearth layer coke during the NRI formation. Such a behavior suggested that venting gas from the bottom lifted the feed mixture, indicating that the pressure of the gas was high.

In order to control the generation of micro NRI to less than a few percent, the volume of $\mathrm{CO}$ from feed mixtures needs to be held below a certain level. This condition was met when the amount of coal in feed mixtures was decreased to $80-85 \%$ and $65-70 \%$ 
stoichiometric coal for $\mathrm{Fe}_{3} \mathrm{O}_{4}$ and $\mathrm{Fe}_{2} \mathrm{O}_{3}$, respectively. These numbers are roughly in agreement with the amounts estimated from the reduction reactions given above. Preliminary tests with mill scale, with chemical composition equivalent to $\mathrm{FeO}$, indicated that markedly less micro NRI were generated than with magnetic taconite concentrates, even when the amount of coal in feed mixtures was increased to as high as $100-110 \%$ of the stoichiometric amount. Such an observation supported the interpretation that the volume of $\mathrm{CO}$ emitted out of feed mixtures was responsible for the generation of micro NRI.

\section{2-4.3.3 Coalescence of micro NRI}

Micro NRI were observed to spread in the vicinity of parent nodules, but they appeared to resist coalescence among themselves or with parent NRI. In an attempt to confirm if micro NRI resisted coalescence, the fusion behaviors of micro NRI and parent NRI, crushed and screened into a same size range (termed "crushed NRI" in this report), were compared.

2-4.3.3.1 Test samples: A micro NRI sample was prepared from a mixture of micro $\mathrm{NRI}$ collected from a number of box furnace and LHF tests by screening out the size fraction of 14/20 mesh. Crushed NRI were prepared by crushing several parent NRI, and screening out the same size fraction. The analytical results of the two test samples are given below:

\begin{tabular}{|c|c|c|}
\hline & $\% \mathrm{C}$ & $\% \mathrm{~S}$ \\
\hline Micro NRI & 3.94 & 0.07 \\
\hline Crushed NRI & 2.33 & 0.05 \\
\hline
\end{tabular}

2-4.3.3.2 Test procedure: A $50.8 \mathrm{~mm}$ (2") diameter horizontal tube furnace, fitted with a $50.8 \mathrm{~mm}$ (2") diameter x $203.2 \mathrm{~mm}$ (48") long mullite tube, was used for the tests. Initially, the temperature was set at $1350^{\circ} \mathrm{C}\left(2462^{\circ} \mathrm{F}\right) . \mathrm{N}_{2}$ and $\mathrm{CO}$ were passed through the combustion tube at the rates of 2 and $1 \mathrm{~L} / \mathrm{min}$, respectively.

Initially, $2.5 \mathrm{~g}$ each of the micro and crushed NRI were piled in two locations on hearth layer of 20/100 mesh coke in a graphite boat of $25.4 \mathrm{~mm}$ (1") wide x $25.4 \mathrm{~mm}$ (1") high $\mathrm{x}$ $101.6 \mathrm{~mm}$ (4") long with a wall thickness of $3.175 \mathrm{~mm}(1 / 8$ "), as shown in Figure 2-48(a). A series of tests were performed to determine the fusion time of the two samples.

Then, mixtures of micro and crushed NRI in the ratios of (75:25), (50:50) and (25:75) were prepared, placed in graphite boats and tested in the same manner to explore their fusion behaviors.

In another series, a feed mixture, consisting of taconite concentrate $(\mathrm{K})$, bituminous coal $(J)$ at $85 \%$ of the stoichiometric amount and slag composition $L_{1.5} F_{2}$, was prepared, mixed with the micro NRI in the ratios of (95:5), (89:11) and (75:25), and tested. These ratios correspond to those of NRI formed fresh from the feed mixture and the micro NRI of (90:10), (80:20) and (60:40) for direct comparison with the previous tests. 
The effect of temperature on fusion time on the mixtures of the micro and crushed NRI was investigated by raising the temperature to $1400^{\circ} \mathrm{C}\left(2552^{\circ} \mathrm{F}\right)$. In this series of tests, the ratios of micro NRI and crushed NRI were varied from (100:0) to $(75: 25),(50: 50)$ and $(25: 75)$. The time at $1400^{\circ} \mathrm{C}\left(2552^{\circ} \mathrm{F}\right)$ was varied from 2 to 5 and 10 minutes for comparison of the results at $1350^{\circ} \mathrm{C}\left(2462^{\circ} \mathrm{F}\right)$.

2-4.3.3.3 Test Results: Figure 2-4-8 shows the feed and the products obtained by heating at $1350^{\circ} \mathrm{C}\left(2462^{\circ} \mathrm{F}\right)$ for $1,5,10$ and 20 minutes. It is evident that the crushed $\mathrm{NRI}$ coalesced in less than 1 minute, while the micro NRI did not coalesce even after 20 minutes. From the carbon analysis of the micro NRI $(3.94 \% \mathrm{C})$, they certainly were melted at the temperature, yet they did not coalesce, indicating that there was some coating on the surface which prevented the coalescence of the micro NRI.

Figures 4-9 and 4-10 show the SEM photographs of the surfaces of the micro and crushed NRI. A large number of fine carbonaceous particles are seen to be attached to the surface of the micro NRI, whereas the surface of the crushed NRI was essentially free of carbonaceous particles. Therefore, these carbonaceous particles on the micro $\mathrm{NRI}$ were thought to prevent their coalescence.

Mixtures of micro and crushed NRI: As the crushed NRI analyzed less carbon than the micro NRI, the crushed NRI with less carbon $(2.33 \% \mathrm{C})$ would absorb the carbon on the surfaces of the micro NRI upon contact when the two samples are mixed, and both together would lead to fusion.

Figure 2-4-11 shows the products obtained by heating the mixtures of $(75: 25)$ on the left, $(50: 50)$ in the middle and $(25: 75)$ on the right at $1350^{\circ} \mathrm{C}\left(2462^{\circ} \mathrm{F}\right)$ for 3,10 and 20 minutes. Here again, the (75:25) mixture was seen to resist coalescence. When the time at temperature was increased to 20 minutes, some larger NRI were beginning to form. With (50:50) and (25:75) mixtures, more micro NRI coalesced into single NRI, but still a number of micro NRI are seen to be attached to the surface. With the $(25: 75)$ mixture, the number of micro NRI attached to the surface became notably less, but some micro NRI remained separate. Apparently, the rate of carbon uptake by crushed $\mathrm{NRI}$ was not rapid enough to coalesce micro NRI into parent NRI. 


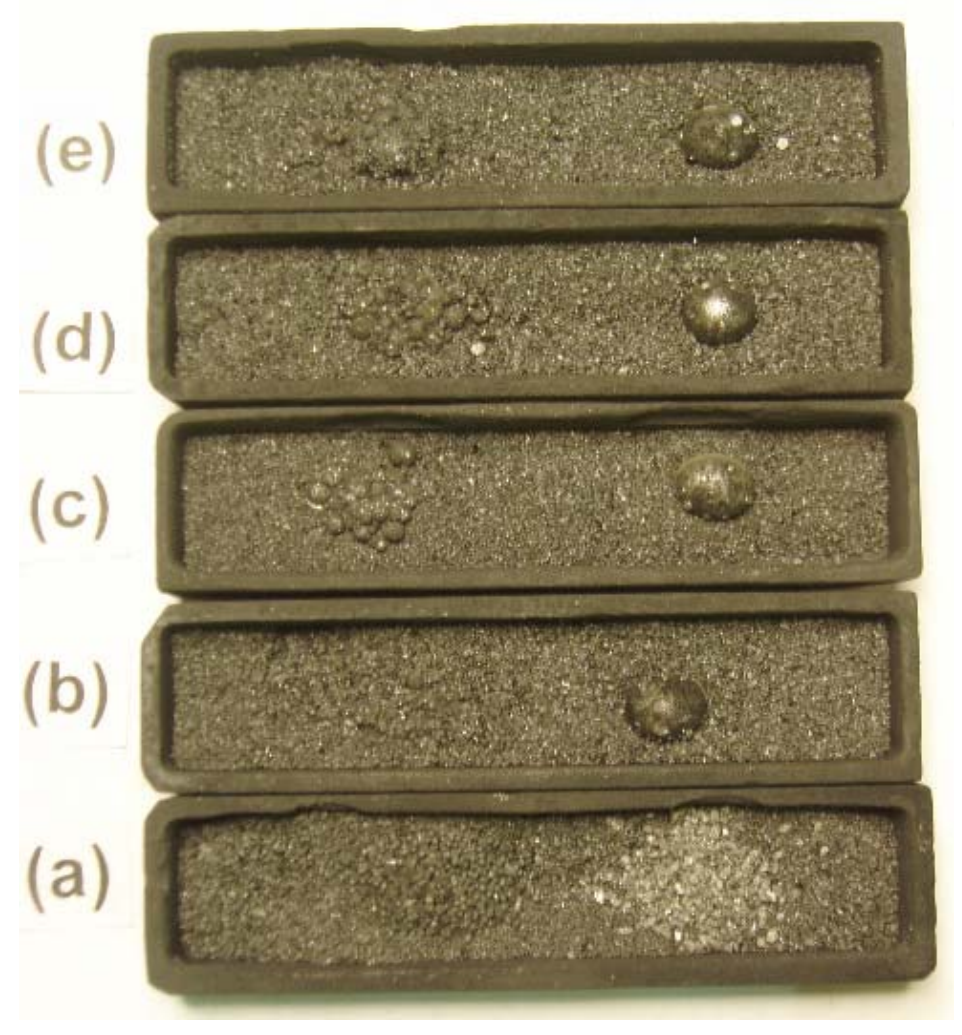

Figure 2-4-8. 2.5g piles of 14/20 mesh micro NRI and crushed NRI, placed over $20 / 100$ mesh coke hearth layer, and heated at $1350^{\circ} \mathrm{C}\left(2462^{\circ} \mathrm{F}\right)$ for different periods of time in a $\mathrm{N}_{2}-\mathrm{CO}$ atmosphere.
(a) Feed
(b) 1 minute
(c) 5 minute
(d) 10 minute
(e) 20 minute 

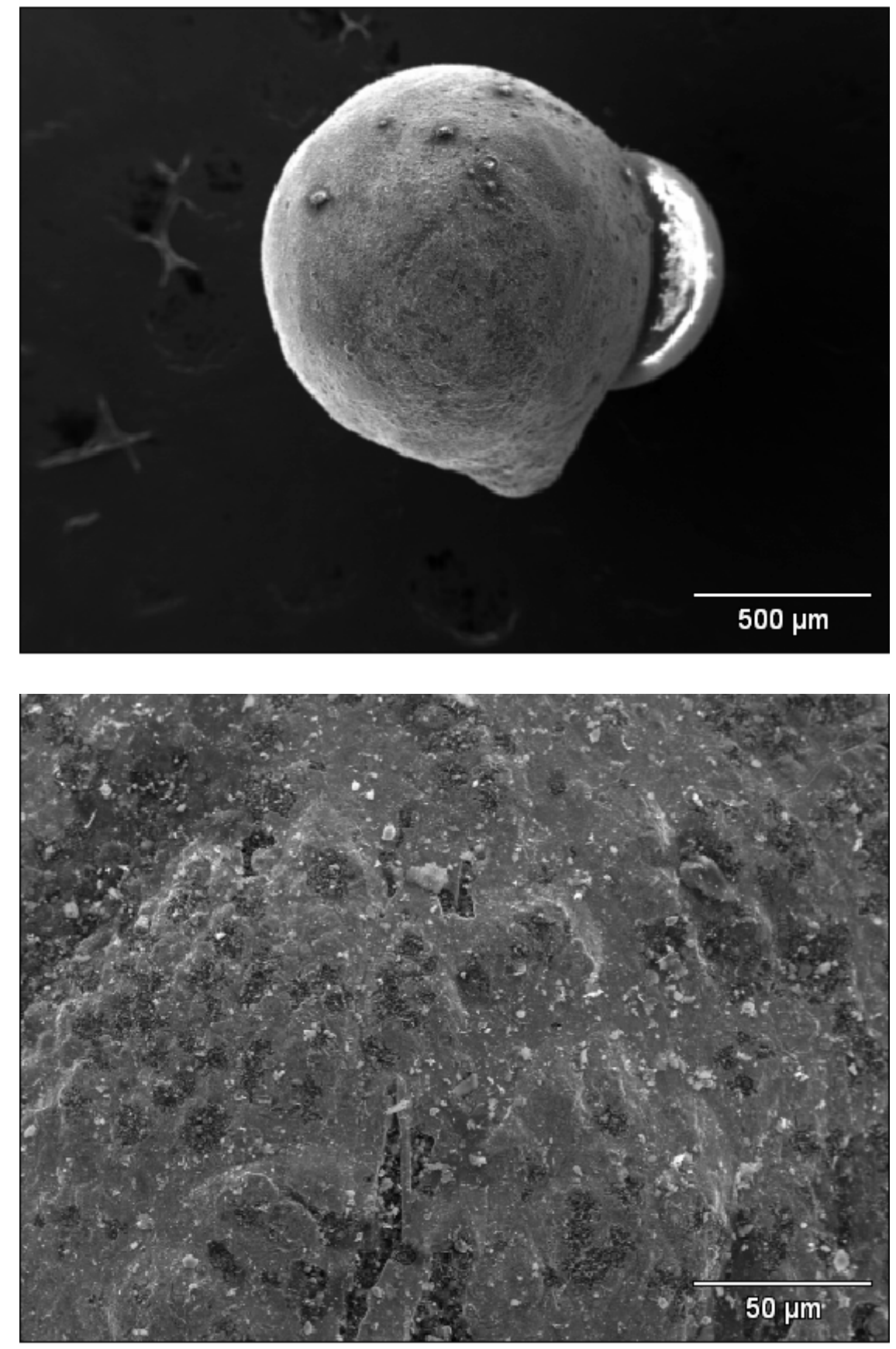

Figure 2-4-9. SEM photographs of the surface of a 14/20 mesh micro NRI particle at (a) $50 \mathrm{X}$ and (b) $500 \mathrm{X}$ magnification. 

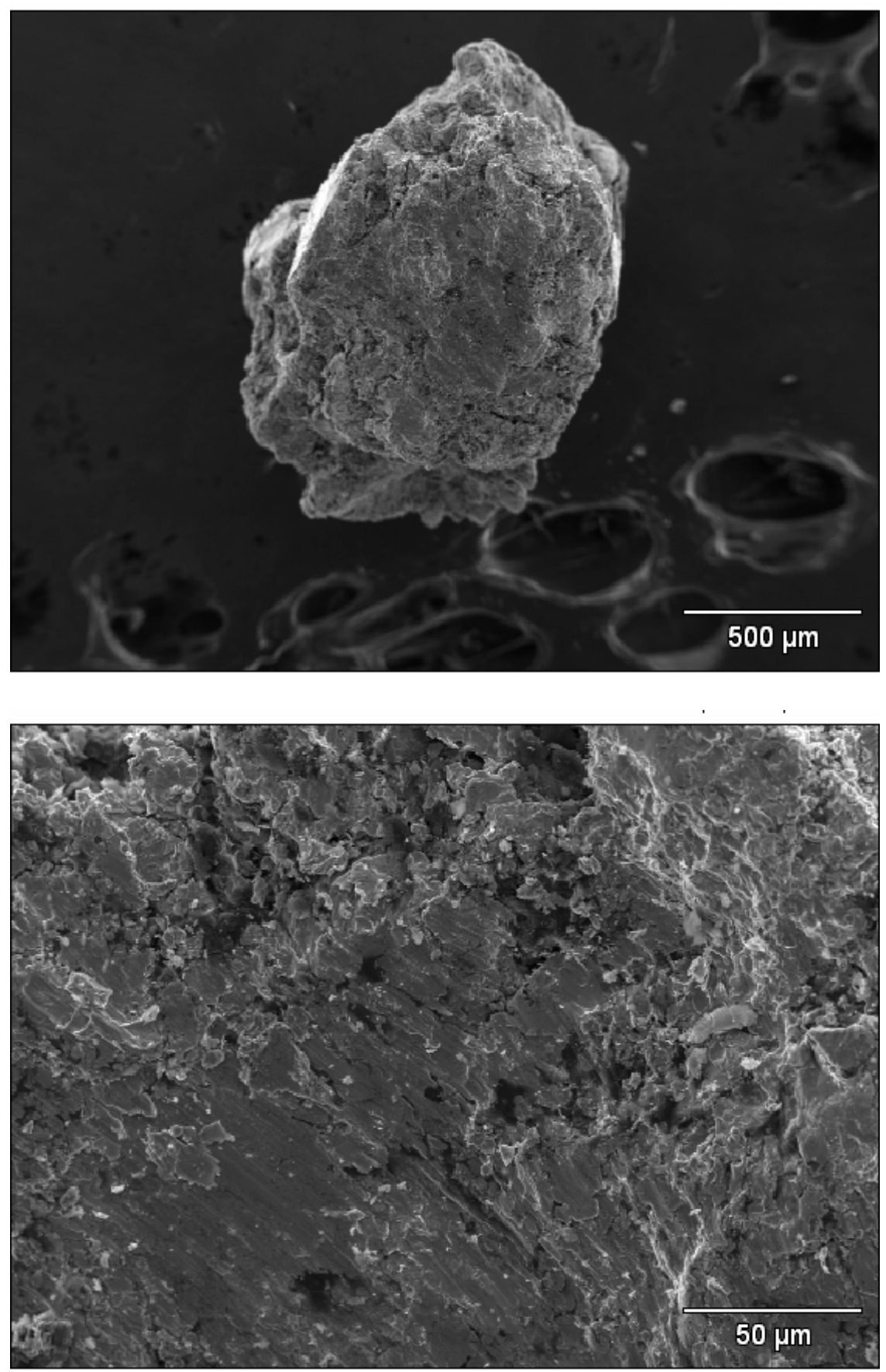

Figure 2-4-10. SEM photographs of the surface of a 14/20 mesh crushed NRI particle at (a) 50X and (b) 500X magnification. 
Mixtures of feed and micro NRl: The presence of magnetite in feed mixtures is expected to accelerate the removal of carbonaceous particles on the micro NRI. This particular point was investigated by heating the mixtures of taconite concentrate $(K)$ with $85 \%$ stoichiometric coal and slag composition $\mathrm{L}_{1.5} \mathrm{FS}_{2}$ and the micro NRI in the ratios of (100:0), (95:5), (89:11) and (75:25).

Figure $2-4-12$ shows the products obtained by heating at $1350^{\circ} \mathrm{C}\left(2462^{\circ} \mathrm{F}\right)$ for 1,2 and 5 minutes. The feed mixture required a little longer than 2 minutes to fuse, whereas its mixtures with the micro NRI fused in 2 minutes, regardless of the amount of the micro $\mathrm{NRI}$ used. In fact, the higher the amount of micro NRI, the fusion time appeared to be shorter for the 1-minute test, although the results of ((89:11) was out of line. Exact fusion behaviors were difficult to reproduce due perhaps to a slight variation of the temperature decrease when a boat was introduced into the tube furnace, and the short time at temperature.

Such an observation suggested that micro NRI can be mixed into feed mixtures and may even help accelerate the formation of NRI.

Fusion time at $1400^{\circ} \mathrm{C}\left(2552^{\circ} \mathrm{F}\right)$ : Figure $2-4-13$ shows the products obtained by heating at $1400^{\circ} \mathrm{C}\left(2552^{\circ} \mathrm{F}\right)$ for 2,5 and 10 minutes. The micro NRI by themselves resisted coalescence even at $1400^{\circ} \mathrm{C}\left(2552^{\circ} \mathrm{F}\right)$ although they increased their size somewhat at this temperature and also with time at the temperature. The size of the products was noted to increase with the amount of the crushed NRI in the mixture. In fact, the products of (50:50) and (25:75) mixtures formed near normal sized NRI, but some micro $\mathrm{NRI}$ still remained. Apparently, the increase in temperature in the presence of over $50 \%$ crushed NRI promoted the coalescence of micro NRI. 


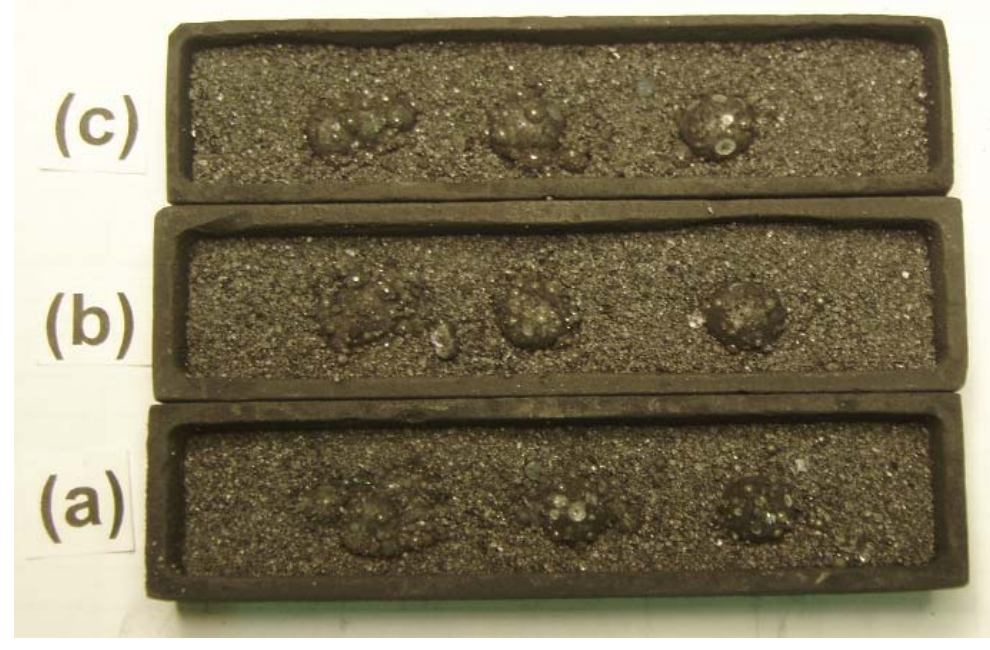

Figure 2-4-11. 2.5g piles of mixtures of $14 / 20$ mesh micro NRI and crushed NRI in the ratios of $(75: 25)$ on the left, $(50: 50)$ in the middle and $(25: 75)$ on the right, placed over $20 / 100$ mesh coke hearth layer, and heated at $1350^{\circ} \mathrm{C}\left(2462^{\circ} \mathrm{F}\right)$ for different periods of time in a $\mathrm{N}_{2}$ - $\mathrm{CO}$ atmosphere.

(a) 3 minute

(b) 10 minute

(c) 20 minute

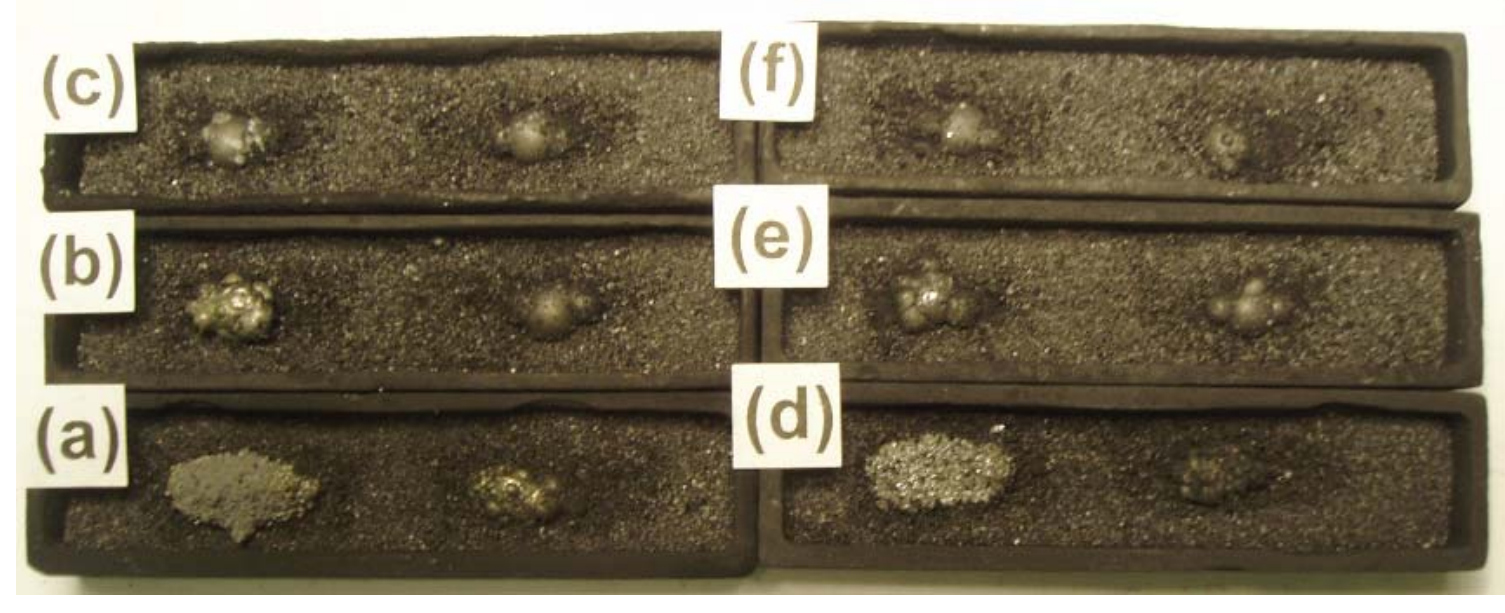

Figure 2-4-12. Mixtures of taconite concentrate (K) with $85 \%$ stoichiometric coal and slag composition $L_{1.5} F_{2}$ and micro NRI in the ratios of (100:0), (95:5), (89:11) and $(75: 25)$ over $20 / 100$ mesh coke hearth layer, and heated at $1350^{\circ} \mathrm{C}\left(2462^{\circ} \mathrm{F}\right)$ for different periods of time in a $\mathrm{N}_{2}$-CO atmosphere.
(a) 1 minute, left (100:0), right (95:5);
(d) 1 minute; left (89:11), right (75:25)
(b) 2 minute, left (100:0), right (95:5);
(e) 2 minute; left (89:11), right (75:25)
(c) 5 minute, left (100:0), right (95:5);
(f) 5 minute; left (89:11), right (75:25) 


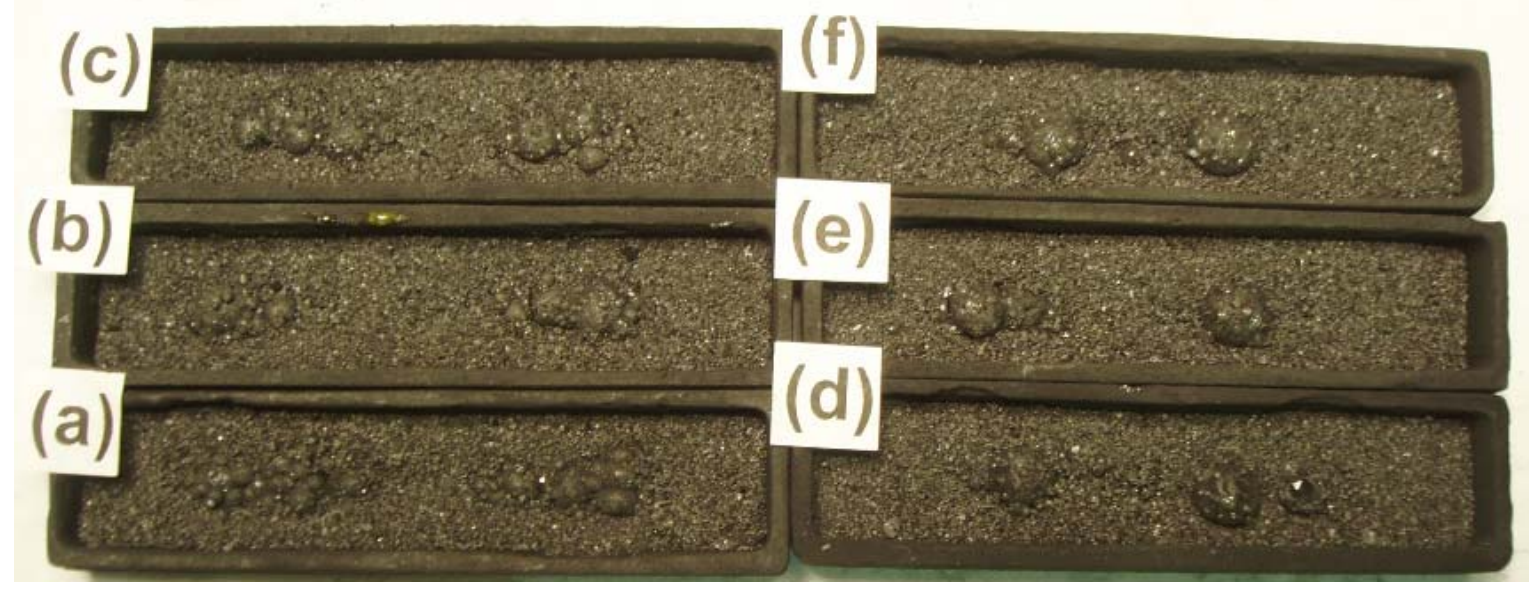

Figure 2-4-13. Mixtures of micro NRI and crushed NRI in the ratios of (100:0), (75:25), (50:50) and (25:75) over 20/100 mesh coke hearth layer, and heated at $1400^{\circ} \mathrm{C}\left(2552^{\circ} \mathrm{F}\right)$ for different periods of time in a $\mathrm{N}_{2}-\mathrm{CO}$ atmosphere.

(a) 2 minute, left (100:0), right (75:25); (d) 2 minute; left (50:50), right (25:75)

(b) 5 minute, left (100:0), right (75:25); (e) 5 minute; left (50:50), right (25:75)

(c) 10 minute, left (100:0), right (75:25); (f) 10 minute; left (50:50), right (25:75) 


\section{2-5 USE OF SUB-BITUMINOUS COAL}

In a previous project, medium-volatile bituminous coal was selected as the most desirable reductant from a suite of Eastern and Western coals as well as coke and char, and has routinely been used in the investigation. On the Iron Range, however, the use of Western sub-bituminous coals offer an economically attractive alternative, as they are more readily accessible with the transportation system already in place, are abundant and readily available, low in cost and low in sulfur.

A few preliminary tests indicated that the direct use of sub-bituminous coal in agglomeration (balls and briquettes) resulted in weak wet strengths and in extremely weak dry strengths due perhaps to high moisture as well as volatile matter, and precluded its use as agglomerated feed in the absence of binders.

An alternative to the direct use of sub-bituminous coal would be to carbonize the coal prior to its use. Carbonization eliminates moisture and volatile matter, and produces char. Carbonization also removes about half of the contained sulfur in sub-bituminous coal. The char can be mixed with iron ores for the NRI process, and also can be used as hearth as well as cover layer materials. The use of char, being high in fixed carbon, decreases the amount needed for the process, leading to increased productivity. Volatile matter can be utilized to supplement natural gas for heating the furnace. A few preliminary tests in a previous project indicated that carbonized sub-bituminous coal led to balls with equally satisfactory wet and dry strengths as medium-volatile bituminous coal.

In the present investigation, a Powder River Basin (PRB) coal, received from Minnesota Power \& Light (MP\&L) Boswell Plant, Cohasset, MN, was used as a Western subbituminous coal. The topics are divided into (1) characterization of a PRB coal/char; (2) effect of PRB coal and char on the fusion behavior of NRI; (3) effect of replacing bituminous coal (F) with PRB coal as reductant; (4) PRB coal and char as hearth layer; (5) interaction of PRB coal and char as reductant and hearth layer; (6) interaction of bituminous coal with PRB coal in feed and coke with PRB coal in hearth layer; and (7) equivalence of carbon in molasses and PRB coal/char.

\section{2-5.1 Characterization of PRB coal}

Size segregation of analytical results in different sizes, thermogravimetric analysis, devolatilization characteristics and BET surface areas were investigated.

\section{2-5.1.1 Conclusions}

Plus 6 mesh and 6/100 mesh fractions had similar proximate and ash mineral analyses, while -100 mesh fraction was more than twice as high in ash $(5 \%$ and $12 \%$, respectively), and about a half as high in fixed carbon ( 45 and $25 \%$, respectively).

A TGA curve of a PRB coal at a heating rate of $10^{\circ} \mathrm{C} / \mathrm{min}\left(18^{\circ} \mathrm{F} / \mathrm{min}\right)$ indicated that after the removal of moisture, rapid de-volatilization takes place from $350^{\circ} \mathrm{C}\left(662^{\circ} \mathrm{F}\right)$ to $600^{\circ} \mathrm{C}$ $\left(1112^{\circ} \mathrm{F}\right)$, followed by slow de-volatilization, leading to an overall weight loss of $48.3 \%$. 
After carbonizing at $1400^{\circ} \mathrm{C}\left(2552^{\circ} \mathrm{F}\right)$ for 30 minutes, the PRB char lost $54 \%$ of its weight and analyzed $2.2 \%$ volatiles. The size of char particles shrunk to about twothirds of the starting coal.

There were major differences in the BET surface areas of bituminous coal $(\mathrm{J})$, PRB coal and char: $0.05,2.35$ and $4.53 \mathrm{~m}^{2} / \mathrm{g}$, respectively.

\section{2-5.1.2 Size segregation of analysis}

The PRB coal in a 5-gallon pail was screened at 6 mesh and 100 mesh. The size distribution and the proximate and ultimate analyses of the size fractions as well as their composite analyses are given in Table 2-5-1(a) and ash mineral analyses in Table 2-5$1(b)$.

The analytical results of the +6 mesh and $6 / 100$ mesh fractions were essentially similar. Though the weight percent was only $5.9 \%$, the -100 mesh fraction had ash content of more than 2.5 times than the coarser fractions, and the ash mineral analyses were higher in $\mathrm{SiO}_{2}$ and lower in $\mathrm{CaO}$ and $\mathrm{MgO}$. Therefore, the -100 mesh fraction might be used as a reductant after upgrading.

\section{2-5.1.3 Thermogravimetric analyses (TGA)}

A sample each of the PRB coal and a medium-volatile bituminous coal were sent to R.J. Lee Group, Monroeville, PA, for TGA analyses. The instrument used was reported to be a simultaneous TGA/DSC (Q600 SDT), manufactured by TA Instruments. The specific experimental conditions used were as follows:

Sample size: 16.0610 and $19.7690 \mathrm{mg}$ (loaded in open ceramic crucibles)

Heating rate: $10^{\circ} \mathrm{C} / \mathrm{min}\left(18^{\circ} \mathrm{F} / \mathrm{min}\right)$

Data sampling interval: $0.5 \mathrm{sec} /$ point

Temperature range: $35-1400^{\circ} \mathrm{C}$

Nitrogen flow: $100 \mathrm{~mL} / \mathrm{min}$

The Universal Analysis 2000 Software (Version 4.1D, TA instruments) was used for the processing of the data. The TGA analysis results are shown in Figures 2-5-1 and 2-5-2. 
Table 2-5-1. Analytical results of PRB coal

(a) Proximate and ultimate analyses of size fractions

\begin{tabular}{|c|r|r|r|r|}
\hline & $+\mathbf{6}$ mesh & $\begin{array}{r}\mathbf{6 / 1 0 0} \\
\text { mesh }\end{array}$ & $\mathbf{- 1 0 0}$ mesh & Composite \\
\hline \% weight & 41.3 & 52.8 & 5.9 & 100.0 \\
Moisture & 13.00 & 14.47 & 12.04 & 13.72 \\
Volatile & 37.47 & 36.52 & 51.42 & 37.79 \\
Fixed carbon & 45.00 & 44.24 & 24.74 & 43.40 \\
Ash & 4.53 & 4.77 & 11.80 & 5.09 \\
S & 0.34 & 0.39 & 0.52 & 0.38 \\
Carbon & 64.09 & 63.62 & 58.10 & 63.49 \\
Hydrogen & 3.90 & 3.67 & 3.38 & 3.61 \\
Nitrogen & 0.58 & 0.62 & 0.51 & 0.60 \\
Oxygen & 13.56 & 12.46 & 13.65 & 12.98 \\
BTU/lb & 10,454 & 10,291 & 9,531 & 10,313 \\
& & & & \\
\hline
\end{tabular}


(b) Ash mineral analyses of size fractions

\begin{tabular}{|c|c|c|c|c|}
\hline & +6 mesh & $\begin{array}{l}6 / 100 \\
\text { mesh }\end{array}$ & $\begin{array}{c}-100 \\
\text { mesh }\end{array}$ & Composite \\
\hline$\% \mathbf{w t}$ & 41.3 & 52.8 & 5.9 & 100.0 \\
\hline T. Fe & 7.18 & 6.50 & 9.75 & 6.97 \\
\hline $\mathrm{SiO}_{2}$ & 31.15 & 30.89 & 45.38 & 31.85 \\
\hline $\mathrm{Al}_{2} \mathrm{O}_{3}$ & 16.47 & 16.17 & 15.23 & 16.24 \\
\hline $\mathrm{CaO}$ & 15.55 & 15.14 & 9.10 & 14.95 \\
\hline $\mathrm{MgO}$ & 4.70 & 4.36 & 2.56 & 4.39 \\
\hline S & 5.61 & 6.42 & 3.36 & 5.91 \\
\hline $\mathbf{P}$ & 0.10 & 0.28 & 0.15 & 0.20 \\
\hline $\mathrm{Na}_{2} \mathrm{O}$ & 3.29 & 3.20 & 2.23 & 3.18 \\
\hline $\mathrm{K}_{2} \mathrm{O}$ & 0.76 & 0.83 & 1.38 & 0.97 \\
\hline
\end{tabular}

The initial $4.7 \%$ weight loss in Figure 2-5-1 would represent the loss of moisture. The difference from the moisture content of the bulk sample of $9.84 \%$ must be due to drying during purging with a stream of nitrogen prior to the start of the test. The rapid decrease in weight at $0.15 \% / \mathrm{min}$ between $350^{\circ}$ to $600^{\circ} \mathrm{C}\left(662^{\circ}\right.$ to $\left.1112^{\circ} \mathrm{F}\right)$, leading to a weight decrease of $27 \%$, is attributable to the loss of light molecular weight volatiles. The slow loss in weight beyond $600^{\circ} \mathrm{C}$ at $0.02 \% / \mathrm{min}$ suggested the loss of heavier molecular weight fractions of the volatiles. The overall weight loss of $48.26 \%$ agreed well with the weight loss of $53.9 \%$ after heating in the box furnace at $1400^{\circ} \mathrm{C}\left(2552^{\circ} \mathrm{F}\right)$ for 30 minutes (see Table $2-5-3$ ). Its proximate analysis showed $2.23 \%$ volatiles indicating still some volatiles remained even after heating at this high temperature.

Figure 2-5-2 shows the TGA curve of a medium-volatile bituminous coal for comparison. The initial weight loss due to moisture was low $(0.6 \%)$, much of the weight loss due to volatile matter occurred in a similar manner, but somewhat slower rates of devolatilization in two stages, and the overall weight loss of $23.39 \%$ was in line with the difference in the ranks of the two coal samples. 


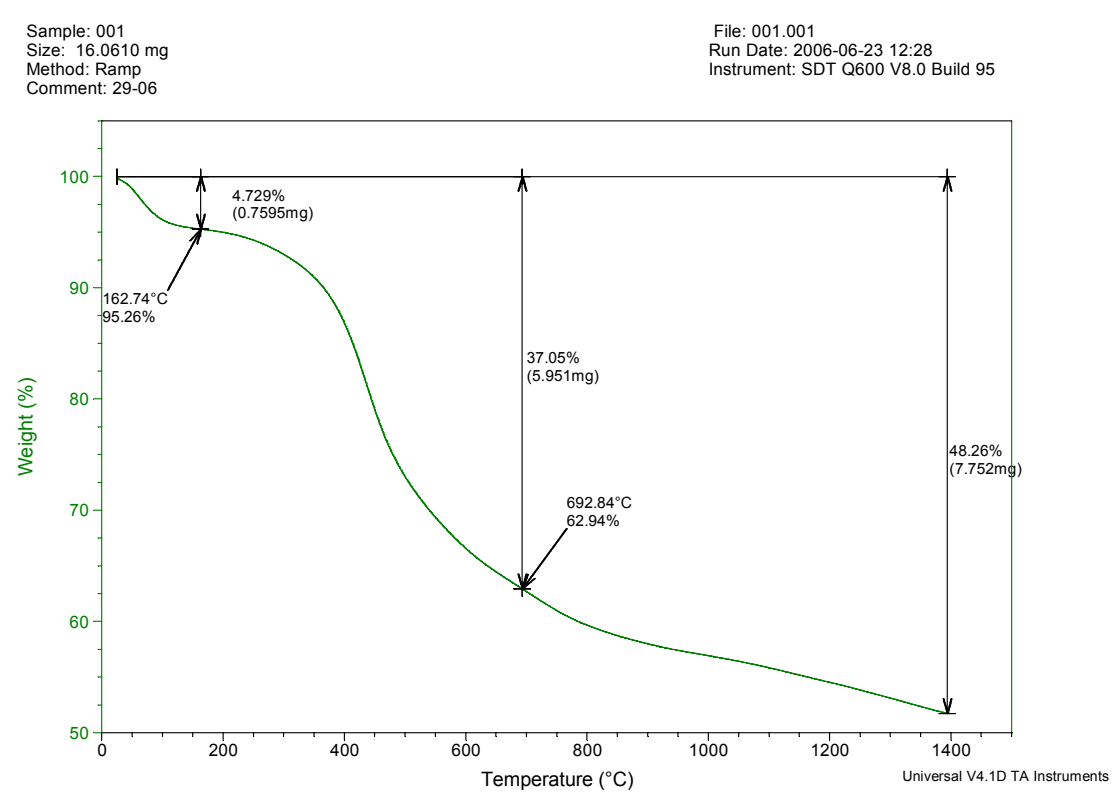

Figure 2-5-1. Thermogravimetric analysis (TGA) curve of PRB coal, determined by R.J. Lee Group.

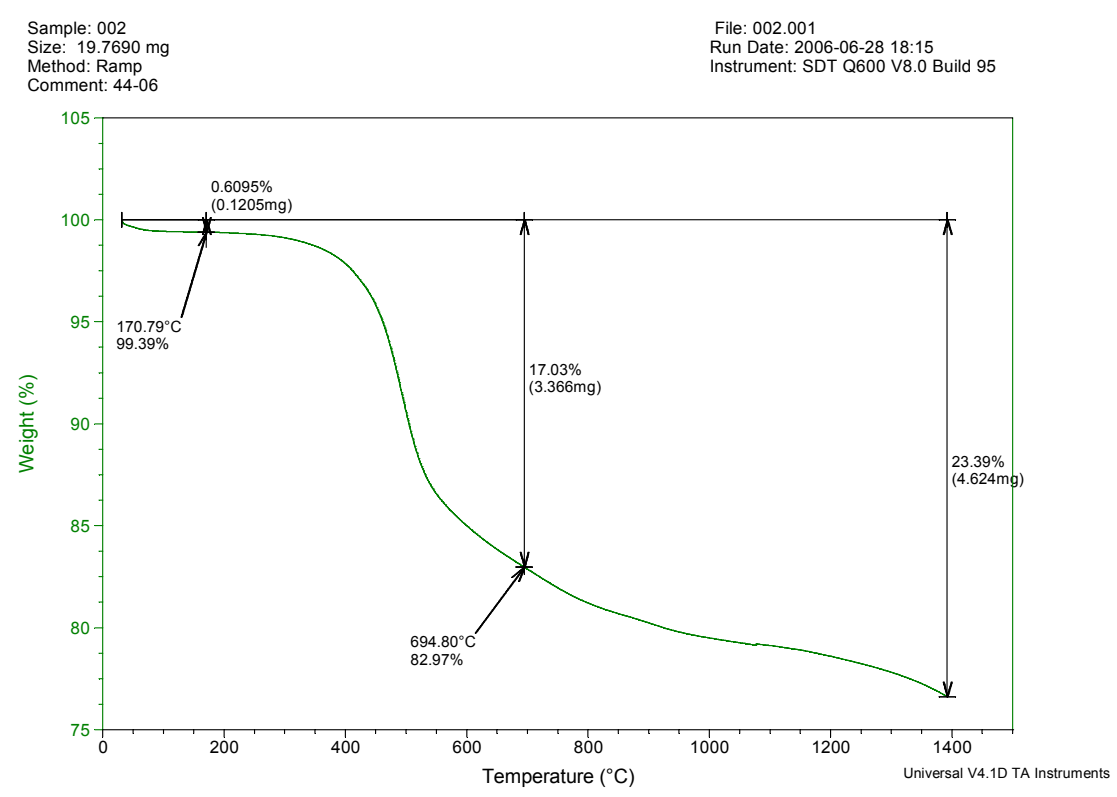

Figure 2-5-2. Thermogravimetric analysis (TGA) curve of a medium-volatile bituminous coal, determined by R.J. Lee group. 


\section{2-5.1.4 De-volatilization/carbonization characteristics}

2-5.1.4.1 Roasting in LTD reduction setup: A low temperature degradation (LTD) test setup takes up to about two lbs of the coal, is capable of monitoring the weight loss in heating, and can be heated to $1000^{\circ} \mathrm{C}\left(1832^{\circ} \mathrm{F}\right)$. An attempt was made to devolatilize and carbonize the PRB coal by charging about two lbs of the $6 / 100$ mesh fraction at a time. Nitrogen was passed through the sample at a rate of $50 \mathrm{~L} / \mathrm{min}$.

Heating rate of the reactor temperature could not be controlled, but from a plot of temperature against time, shown in Figure 2-5-3(a), the heating rate was estimated to be in the range of $25-30^{\circ} \mathrm{C} / \mathrm{min}\left(45-54^{\circ} \mathrm{F} / \mathrm{min}\right)$. A typical weight loss against temperature curve is shown in Figure $2-5-3(b)$. The weight is seen to decrease steadily at approximately the same rate from $100^{\circ}$ to $800^{\circ} \mathrm{C}\left(212^{\circ}\right.$ to $\left.1472^{\circ} \mathrm{F}\right)$ and remained nearly constant thereafter. The weight loss by roasting was $42 \%$. The volume decreased to $41 \%$. The bulk density of the 'as received' and the roasted samples remained essentially the same at $867 \mathrm{~kg} / \mathrm{m}^{3}\left(54 \mathrm{lb} / \mathrm{ft}^{3}\right)$.

In the reactor, the samples became notably smaller in size after roasting. Size distributions before and after roasting were determined and the results are given in Table 2-5-2(c). It is apparent that +8 mesh fraction decreased, while 10/48 mesh fractions increased, suggesting that there was a decrease in size either by shrinkage or by breakdown upon roasting.

The sample emitted a large volume of black smoke at the beginning of the tests, but the test setup did not have an after burner, and the smoke was expelled through a long duct to an exhaust fan. After about 10 tests, soot deposited and some organics volatilized and condensed in the duct, resulting in a minor explosion. Hence, the test with the present setup was discontinued.

2-5.1.4.2 Carbonizing in box furnace: Four hundred grams of the 6/100 mesh fraction was charged into a $101.6 \mathrm{~mm}\left(4^{\prime \prime}\right) \times 127 \mathrm{~mm}\left(5^{\prime \prime}\right)$ x $38.1 \mathrm{~mm}$ (1.5") graphite tray, and heated at $500^{\circ}, 1000^{\circ}$ and $1400^{\circ} \mathrm{C}\left(932^{\circ}, 1832^{\circ}\right.$ and $\left.2552^{\circ} \mathrm{F}\right)$ for 30 minutes in an atmosphere of $90 \% \mathrm{~N}_{2}$ and $10 \% \mathrm{CO}$, passed at $20 \mathrm{~L} / \mathrm{min}$. The weights after carbonizing, expressed as percent of the feed weight, and their proximate analyses are given in Table 2-5-3. 


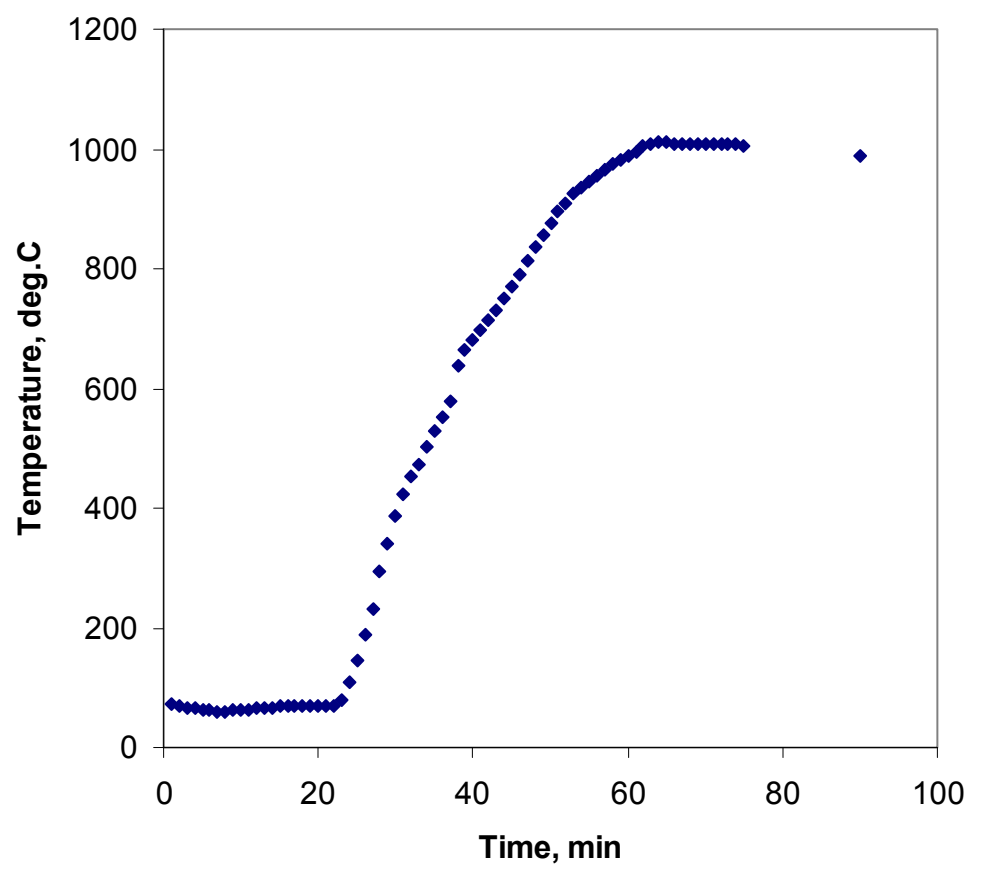

Figure 2-5-3(a). Temperature profile of the carbonization tests

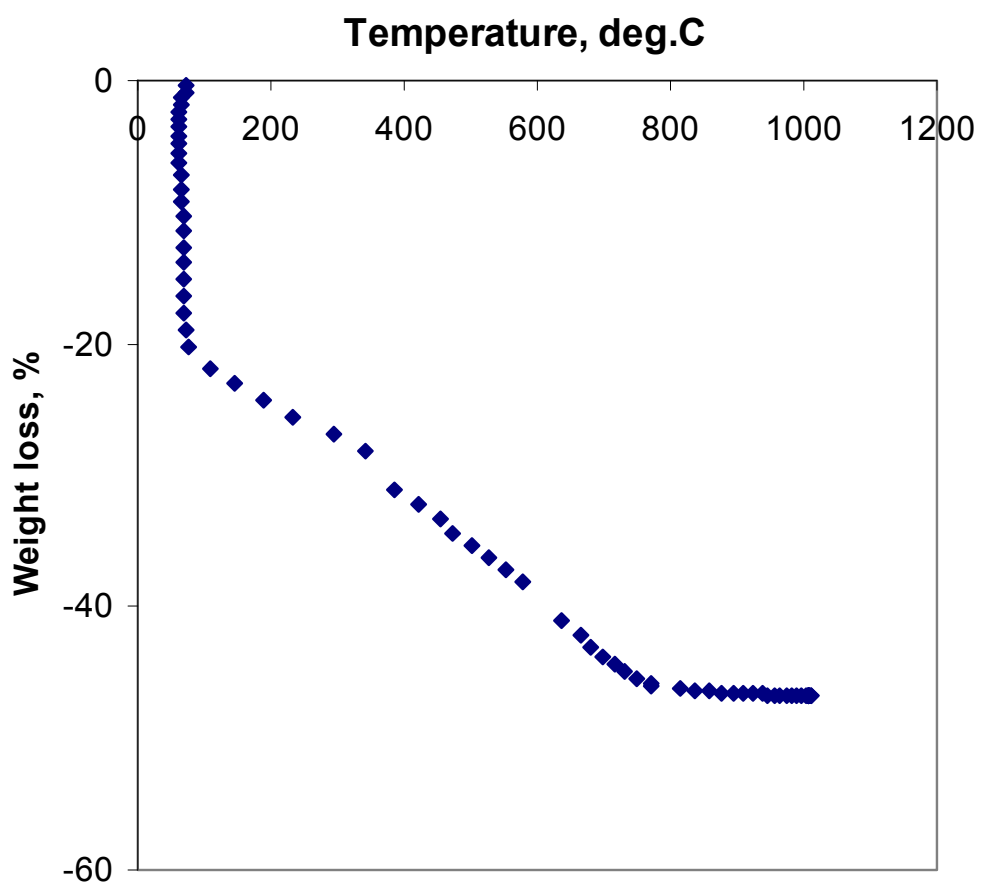

Figure 2-5-3(b). Percent weight loss plotted against temperature in carbonizing 6/100 mesh PRB coal 
Table 2-5-2. Preliminary tests showing the effect of carbonizing a PRB coal (6/100 mesh) in a LTD reduction test setup

(a) Sizing of a head sample

\begin{tabular}{|c|c|}
\hline $\begin{array}{c}\text { Size } \\
\text { mesh }\end{array}$ & \% weight \\
\hline $\mathbf{+ 6}$ & 23.7 \\
$\mathbf{6 / 1 0 0}$ & 68.0 \\
$\mathbf{- 1 0 0}$ & 8.3 \\
\hline
\end{tabular}

(b) Proximate analyses before and after calcination

\begin{tabular}{|l|c|c|}
\hline Weight & $\begin{array}{c}\text { Before } \\
\text { test }\end{array}$ & $\begin{array}{c}\text { After } \\
\text { test }\end{array}$ \\
\hline Moisture & 100.0 & 42.1 \\
Volatile & 9.84 & 0.98 \\
Fixed carbon & 37.94 & 3.64 \\
Ash & 47.34 & 87.28 \\
Sulfur & 4.88 & 8.10 \\
Btu/lb & 0.43 & 0.47 \\
\hline
\end{tabular}

*Bulk densities:

Before test: $866 \mathrm{~kg} / \mathrm{m}^{3}\left(54.1 \mathrm{lb} / \mathrm{ft}^{3}\right)$

After test: $\quad 875 \mathrm{~kg} / \mathrm{m}^{3}\left(54.6 \mathrm{lb} / \mathrm{ft}^{3}\right)$ 
(c) Size distribution before and after test

\begin{tabular}{|c|c|c|}
\hline $\begin{array}{c}\text { Size } \\
\text { mesh }\end{array}$ & $\begin{array}{c}\text { Before } \\
\text { test }\end{array}$ & $\begin{array}{c}\text { After } \\
\text { test }\end{array}$ \\
\hline $\mathbf{8}$ & 11.4 & 2.3 \\
$\mathbf{1 0}$ & 17.0 & 18.2 \\
$\mathbf{1 4}$ & 14.0 & 17.0 \\
$\mathbf{2 0}$ & 12.7 & 16.2 \\
$\mathbf{2 8}$ & 11.7 & 15.1 \\
$\mathbf{3 5}$ & 10.2 & 13.4 \\
$\mathbf{4 8}$ & 8.3 & 10.7 \\
$\mathbf{6 5}$ & 6.6 & 5.1 \\
$\mathbf{1 0 0}$ & 5.2 & 0.9 \\
$\mathbf{- 1 0 0}$ & 2.9 & 1.1 \\
\hline
\end{tabular}


Table 2-5-3. Effect of carbonization temperature (30 minutes at temperature) on the proximate analyses of PRB coal (6/100 mesh)

\begin{tabular}{|l|c|c|c|c|}
\hline & As rec'd & $\begin{array}{c}\text { Carbonized } \\
\text { at } \mathbf{5 0 0}^{\circ} \mathbf{C} \\
\left.\mathbf{( 9 3 2}^{\circ} \mathbf{F}\right)\end{array}$ & $\begin{array}{c}\text { Carbonized } \\
\text { at } \mathbf{1 0 0 0}^{\circ} \mathbf{C} \\
(\mathbf{1 8 3 2} \mathbf{F})\end{array}$ & $\begin{array}{c}\text { Carbonized } \\
\text { at } \mathbf{1 4 0 0}^{\circ} \mathbf{C} \\
\left.\mathbf{( 2 5 2}^{\circ} \mathbf{F}\right)\end{array}$ \\
\hline \% weight & 100.0 & 73.2 & 50.0 & 46.1 \\
Moisture & 14.47 & 3.92 & 3.32 & 0.38 \\
Volatile & 36.52 & 28.42 & 2.16 & 2.23 \\
Fixed carbon & 44.24 & 61.49 & 85.87 & 88.83 \\
Ash & 4.77 & 6.17 & 8.65 & 8.56 \\
Sulfur & 0.39 & 0.393 & 0.45 & 0.47 \\
Btu/lb & & 12,191 & 12,823 & 13,295 \\
kJ/kg & 10,291 & 28,297 & 29,764 & 30,859 \\
\hline
\end{tabular}

Table 2-5-4. Size reduction of PRB coal (-9.525 $\mathrm{mm}\left(-3 / 8^{\prime \prime}\right)+3$ mesh) by carbonizing at $1400^{\circ} \mathrm{C}\left(2552^{\circ} \mathrm{F}\right)$

\begin{tabular}{|c|c|c|}
\hline $\begin{array}{c}\text { Size } \\
\text { mesh }\end{array}$ & $\begin{array}{c}\text { PRB } \\
\text { coal }\end{array}$ & $\begin{array}{c}\text { Carbonized at } \\
\mathbf{1 4 0 0}^{\circ} \mathrm{C}\left(\mathbf{2 5 5 2}^{\circ} \mathrm{F}\right)\end{array}$ \\
\hline $\mathbf{3}$ & 100 & 26.9 \\
$\mathbf{4}$ & -- & 67.1 \\
$\mathbf{6}$ & --- & 3.5 \\
$-\mathbf{6}$ & --- & 2.5 \\
\hline
\end{tabular}

It is noted that the weight decreased to about one half, some component that absorbed $3-4 \%$ moisture remained even after heating at $1000^{\circ} \mathrm{C}\left(1832^{\circ} \mathrm{F}\right)$, and about $2 \%$ volatiles remained even after heating at $1400^{\circ} \mathrm{C}\left(2552^{\circ} \mathrm{F}\right)$. Though the product, carbonized at $1400^{\circ} \mathrm{C}\left(2552^{\circ} \mathrm{F}\right)$, analyzed $0.47 \% \mathrm{~S}$ which was higher than the sulfur content of $0.39 \%$ in the feed, the weight of the product was reduced to $55.4 \%$ of the feed. This translated to the reduction of sulfur in the coal by about one-third by carbonizing. 
As seen in Table 2-5-2(c), carbonizing made the char notably smaller than the coal. To investigate if the size reduction was due to shrinkage or breakage, about $200 \mathrm{~g}$ of $-9.525 \mathrm{~mm}\left(-3 / 8^{\prime \prime}\right)+3$ mesh fraction of the PRB coal was carbonized at $1400^{\circ} \mathrm{C}\left(2552^{\circ} \mathrm{F}\right)$ for 30 minutes as before. The size distribution of the char along with the weight decrease by carbonizing is given in Table 2-5-4. The weight decrease was about a half of the original weight, and the particle size became smaller to about $2 / 3$ of the coal, mainly by shrinkage. Apparently, the amount of fines generated by breakage during carbonizing was relatively minor.

\section{2-5.1.5 BET surface areas}

For the determination of BET surface areas, PRB coal and char, bituminous coal $(\mathrm{J})$, anthracite char and coke breeze, all ground to -100 mesh, were sent to the Characterization Facility of the University of Minnesota Minneapolis. A Micromeritics Model ASAP 2000A was used with nitrogen for measurements. The results are presented in Table 2-5-5.

As compared to bituminous coal $(\mathrm{J})$ and anthracite char, the surface area of PRB coal was an order of magnitude larger, and doubled by carbonizing to char. The surface area of coke breeze approached that of PRB coal.

Table 2-5-5. BET surface areas of various coal, char and coke

\begin{tabular}{|l|c|}
\hline & $\begin{array}{c}\text { BET surface } \\
\text { area, } \mathbf{~}^{2} / \mathbf{g}\end{array}$ \\
\hline Bituminous coal (J) & 0.05 \\
PRB coal (1) & 2.35 \\
PRB char (1400 $\left.{ }^{\circ} \mathrm{C}\right)$ & 4.53 \\
Anthracite char & 0.86 \\
Coke breeze & 1.84 \\
\hline
\end{tabular}




\section{2-5.2 Preliminary box furnace tests with PRB coal and char}

Preliminary tests on the fusion behaviors of a taconite concentrate using PRB coal and char, carbonized at different temperatures as reductants and hearth layer, are reported in this section.

\section{2-5.2.1 Conclusions}

1) With -100 mesh fraction of $P R B$ coal at $80 \%$ of the stoichiometric amount led to the formation of only micro NRI in a short time, apparently due to a large volume of volatiles effusing out and breaking the feed to small pieces. Lowering the -100 mesh fraction to $40 \%$ stoichiometric coal produced satisfactory NRI with additional reductants coming from $\mathrm{CO}$ in the gas atmosphere and from the hearth layer char.

2) Fusion time with $6 / 100$ mesh coal and char increased steadily from 9 minutes with the PRB coal to 16 minutes with the char, carbonized at $1400^{\circ} \mathrm{C}$. With high fixed carbon, the amount of char needed to $80 \%$ of the stoichiometric amount decreased and the amount of concentrate increased. Although the fusion time increased in direct proportion to the amount of the concentrate in the feed mixtures, productivity would not be affected as much regardless of the form of the PRB coal/char used.

3) With $6 / 100$ mesh fraction of PRB coal and char, carbonized at $500^{\circ}, 1000^{\circ}$ and $1400^{\circ} \mathrm{C}\left(932^{\circ}, 1832^{\circ}\right.$ and $\left.2552^{\circ} \mathrm{F}\right)$, NRI sulfur increased from $0.07 \%$ to $0.15 \%$ even though the total sulfur in feed mixtures decreased from $0.13 \%$ to $0.11 \%$. The analysis of the form of sulfur in PRB coal and char suggested that perhaps increased NRI sulfur might be related to higher organic sulfur in the char.

4) Iron in the slag was one to two orders of magnitude higher as the carbonizing temperature increased $(2-20 \% \mathrm{Fe})$ than when a bituminous coal was used as a reductant (less than $1 \% \mathrm{Fe}$ ).

5) CO concentrations in the effluent gas rapidly reached maximum when samples were introduced into Zone 2 by the reduction reaction, and decreased asymptotically with time. When the concentrations of $\mathrm{CO}$ and $\mathrm{CO}_{2}$ were expressed in terms of $\mathrm{CO} /\left(\mathrm{CO}+\mathrm{CO}_{2}\right)$, the highest ratio was observed with PRB coal and decreased with char, carbonized at higher temperatures. After 5 minutes in Zone 2, the order reversed. Such an observation suggested that volatiles played a key role in lowering sulfur in NRI and iron in slag.

6) Clarification of the reason why sulfur in NRI as well as iron in slag were high is essential to developing means to control them for making use of PRB coal/char in the process.

\section{2-5.2.2 PRB coal}

As 6/100 mesh and -100 mesh fractions of a PRB coal (29-06-IV) showed a wide difference in their volatile and ash contents as well as in their ash mineral analyses (Tables 2-5-1(a) and (b)), two series of tests were performed to compare the effects of the two size fractions used as reductants. 
2-5.2.2.1 Test procedure: Six segment mounds were prepared in a $101.6 \mathrm{~mm}(4$ ") $\mathrm{x}$ $127 \mathrm{~mm}(5 ") \times 38.1 \mathrm{~mm}$ (1.5") graphite tray from a dry feed mixture of taconite concentrate (Mb), PRB coal at $80 \%$ of the stoichiometric amount and slag composition $\mathrm{L}_{1.5} \mathrm{FS}_{2}$, placed over 6/100 mesh anthracite char hearth layer. The composition of the feed mixtures is given in Table 2-5-6. For comparison, the composition of the 'standard' feed mixture with bituminous $(F)$ coal is included in the table. The trays were heated in the standardized manner in a $\mathrm{N}_{2}-\mathrm{CO}$ atmosphere.

\section{2-5.2.2.2 Test results:}

-100 mesh fraction: With -100 mesh PRB coal, the products appeared to be fully fused in 6 minutes at temperature, but the products crumbled completely into small pieces. The product after heating for 4 minutes was metallized, but not fused. The magnetic products were removed from the trays and screened into different size fractions. Plus 14 mesh fraction of the 4-minute test was irregularly-shaped and unfused sponge iron particles, while the same size fraction of the 6-minute test consisted of spherical micro NRI.

Such a behavior was thought to result from break-up of the mounds by a large volume of volatiles effusing out, and the small broken pieces were metallized separately and fused in a short time due to their size. It was thought, therefore, that by lowering the amount of addition of the coal, the amount of volatiles would be less and might survive the de-volatilization stage. The amount of coal addition was lowered to $60 \%$ and $40 \%$ of the stoichiometric amount, and tests were performed by assuming that the reduction would proceed by reacting with $\mathrm{CO}$ in the gas atmosphere and with carbon in the hearth layer char. This was indeed the case and normal-sized NRI formed in both cases, but at $60 \%$ stoichiometric coal, large amounts of mini and micro NRI formed, due perhaps to still excessive volatiles.

It is interesting to note that the amount of volatiles in the feed mixture of $40 \%$ stoichiometric coal was about the same as the feed mixture with the 6/100 mesh PRB coal at $80 \%$ of the stoichiometric amount. The amounts of volatiles in these tests were calculated to be in the range of $10-15 \%$ of the unit weight of the concentrate. In both cases, satisfactory NRI formed. The amounts of volatiles at 60 and $80 \%$ of the stoichiometric amount were $20-25 \%$ and $30-35 \%$, respectively, of the unit weight of the concentrate. Therefore, the -100 mesh fraction may be consumed by mixing small amounts at a time into another reductant coal, or after removing the volatiles by carbonizing.

6/100 mesh fraction: With 6/100 mesh, ground to -100 mesh for use, the composition of the feed mixtures is included in Table 2-5-6. Key points of the test results are summarized in Table 2-5-7. Slag basicities in terms of C/S, calculated from the gangue components of the feed mixtures, were 1.5. Sulfur analyses of NRI were higher $(0.07 \% \mathrm{~S})$ than when bituminous coal $(\mathrm{F})$ was used $(0.02-0.03 \% \mathrm{~S})$, even though $\mathrm{C} / \mathrm{S}$ was the same in both cases. 
Table 2-5-6. Composition of feed mixtures, consisting of taconite concentrate, PRB coal/char at $80 \%$ of the stoichiometric amount, unless otherwise stated, and slag composition $L_{1.5} \mathrm{FS}_{2}$.

\begin{tabular}{|c|c|c|c|c|}
\hline $\begin{array}{c}\text { PRB } \\
\text { coal/char }\end{array}$ & $\begin{array}{l}\text { Minntac } \\
\text { conc. }\end{array}$ & $\begin{array}{c}\text { PRB } \\
\text { coal/char }\end{array}$ & $\begin{array}{c}\text { Lime } \\
\text { hydrate }\end{array}$ & $\begin{array}{c}\text { Fluorspar } \\
\text { Acid- } \\
\text { grade }\end{array}$ \\
\hline \multicolumn{5}{|l|}{ PRB coal } \\
\hline \multicolumn{5}{|l|}{-100 mesh } \\
\hline $80 \%$ stoich. & 55.2 & 34.5 & 8.3 & 2.0 \\
\hline $60 \%$ stoich. & 61.1 & 28.7 & 8.2 & 2.0 \\
\hline $40 \%$ stoich. & 68.4 & 21.4 & 8.2 & 2.0 \\
\hline $6 / 100$ mesh* & 67.4 & 23.6 & 7.0 & 2.0 \\
\hline \multicolumn{5}{|l|}{$\underline{6 / 100 \text { mesh char* }}$} \\
\hline $500^{\circ} \mathrm{C}$ & 72.4 & 18.2 & 7.4 & 2.0 \\
\hline $1000^{\circ} \mathrm{C}$ & 76.5 & 13.8 & 7.7 & 2.0 \\
\hline $1400^{\circ} \mathrm{C}$ & 76.9 & 13.4 & 7.7 & 2.0 \\
\hline $1400^{\circ} \mathrm{C}(90 \%)^{\star *}$ & 75.6 & 14.8 & 7.6 & 2.0 \\
\hline \multicolumn{5}{|l|}{ Bituminous coal (F) } \\
\hline As rec'd & 72.6 & 16.6 & 8.8 & 2.0 \\
\hline
\end{tabular}


Table 2-5-7. Weight distribution of products formed by increasing the slag volume by adding PRB coal/char, placed on anthracite char hearth layer.

\begin{tabular}{|c|c|c|c|}
\hline $\begin{array}{c}\text { PRB } \\
\text { coal/char }\end{array}$ & $\begin{array}{l}\text { Time at } \\
1400^{\circ} \mathrm{C}\end{array}$ & $\begin{array}{c}\text { Micro } \\
\text { NRI }\end{array}$ & $\begin{array}{l}\text { NRI } \\
\% \mathrm{~S}\end{array}$ \\
\hline \multicolumn{4}{|l|}{ PRB coal } \\
\hline-100 mesh & & & \\
\hline $80 \%$ stoich. & $6 \mathrm{~min}^{3)}$ & 100 & --- \\
\hline $60 \%$ stoich. & $20 \mathrm{~min}$ & 9.7 & -- \\
\hline $40 \%$ stoich. & $20 \mathrm{~min}$ & 1.2 & --- \\
\hline $6 / 100$ mesh $^{1)}$ & $\begin{array}{l}9 \min ^{4)} \\
20 \min \end{array}$ & $\begin{array}{l}0.6 \\
0.8\end{array}$ & $\begin{array}{l}0.074 \\
0.065\end{array}$ \\
\hline \multicolumn{4}{|l|}{ 6/100 mesh char $^{1)}$} \\
\hline $\begin{array}{l}500^{\circ} \mathrm{C} \\
1000^{\circ} \mathrm{C} \\
1400^{\circ} \mathrm{C} \\
1400^{\circ} \mathrm{C}(90 \%)^{2)}\end{array}$ & $\begin{array}{l}12 \min ^{4)} \\
20 \min ^{4} \\
15 \min ^{4)} \\
20 \min ^{4} \\
15 \min ^{4)} \\
20 \min ^{4} \\
16 \min ^{4)} \\
20 \min ^{-}\end{array}$ & $\begin{array}{c}0.7 \\
0.5 \\
0.4 \\
0.3 \\
0.1 \\
0.7 \\
11.3 \\
22.3\end{array}$ & $\begin{array}{l}0.128 \\
0.119 \\
0.140 \\
0.173 \\
0.137 \\
0.153 \\
0.038 \\
0.009\end{array}$ \\
\hline \multicolumn{4}{|l|}{ Bituminous coal $(F)$} \\
\hline-100 mesh & $\begin{array}{l}10 \min ^{4)} \\
20 \mathrm{~min}\end{array}$ & $\begin{array}{l}0.5 \\
0.6\end{array}$ & $\begin{array}{l}0.038 \\
0.017\end{array}$ \\
\hline
\end{tabular}

1) Ground to -100 mesh

2) $90 \%$ stoichiometric $P R B$ char

3) Products were all micro NRI

4) Fusion time 


\section{2-5.2.3 PRB char, carbonized at different temperatures}

The manner in which PRB char may be used as a reductant was investigated by carbonizing at $500^{\circ}, 1000^{\circ}$ and $1400^{\circ} \mathrm{C}\left(932^{\circ}, 1832^{\circ}\right.$ and $\left.2552^{\circ} \mathrm{F}\right)$, respectively.

2-5.2.3.1 Test procedure: The effect of carbonizing the 6/100 mesh PRB coal by heating at $500^{\circ}, 1000^{\circ}$ and $1400^{\circ} \mathrm{C}\left(932^{\circ}, 1832^{\circ}\right.$ and $2552^{\circ} \mathrm{F}$, respectively) for 30 minutes on proximate analyses is reported in Table 2-5-3. The resulting chars were ground to -100 mesh for use in preparing the feed mixtures. Based on the fixed carbon and ash analyses, the compositions of the feed mixtures were estimated, as shown in Table 2-5-6. A series of box furnace tests was performed in the standardized manner to investigate the fusion behaviors using PRB coal and char.

2-5.2.3.2 Test results: Key points of the results after 20 minutes at $1400^{\circ} \mathrm{C}\left(2552^{\circ} \mathrm{F}\right)$ are given in Table 2-5-7. The fusion time increased from 9 minutes with the coal, to 12 minutes with the char carbonized at $500^{\circ} \mathrm{C}\left(932^{\circ} \mathrm{F}\right)$, then to 15 minutes with the char carbonized at $1000^{\circ} \mathrm{C}\left(1832^{\circ} \mathrm{F}\right)$, and finally to 16 minutes with the char carbonized at $1400^{\circ} \mathrm{C}$.

The analytical results of $\mathrm{NRI}$ and slag are given in Table 2-5-8. Even though slag basicities were kept in the same range as with the PRB coal, sulfur in NRI became higher with the char carbonized at higher temperatures. NRI produced at fusion time and 20 minutes at the temperature using PRB coal analyzed 0.074 and $0.065 \%$, respectively. With $\mathrm{PRB}$ char, carbonized at $500^{\circ} \mathrm{C}\left(932^{\circ} \mathrm{F}\right)$, NRI analyzed 0.128 and $0.119 \% \mathrm{~S}$, respectively. With PRB char, carbonized at $1400^{\circ} \mathrm{C}\left(2552^{\circ} \mathrm{F}\right)$, NRI sulfur was still higher in the range of 0.137 and $0.153 \% \mathrm{~S}$, respectively. Sulfur in slag decreased as PRB coal was replaced with PRB char, particularly with those carbonized at higher temperatures.

To investigate the reason why NRI sulfur became higher than when bituminous coal was used as a reductant, sulfur in feed mixtures and products were calculated to see how sulfur was distributed among NRI, slag and furnace atmosphere. The results are given in Table 2-5-8.

The amounts of sulfur reported to the products (NRI and slag) from feed mixtures are listed in the column, "\%S to products." The values averaged about $80 \%$, indicating that about $20 \%$ of sulfur in feed mixtures was released into the furnace atmosphere. The amounts of sulfur in feed mixtures reported to NRI were calculated and given in the column, "\%S to NRI." With PRB char, from the amount of sulfur absorbed by the products, $75 \%$ of the sulfur was associated with $\mathrm{NRI}$ and $25 \%$ with slag. It was estimated that about $60 \%$ of the sulfur in the feed mixtures went to NRI. The numbers did not include the sulfur which might have been absorbed from the hearth layer. 
Table 2-5-8. Analytical results of NRI and slag showing the effects of PRB coal/char reductants, placed on anthracite hearth layer

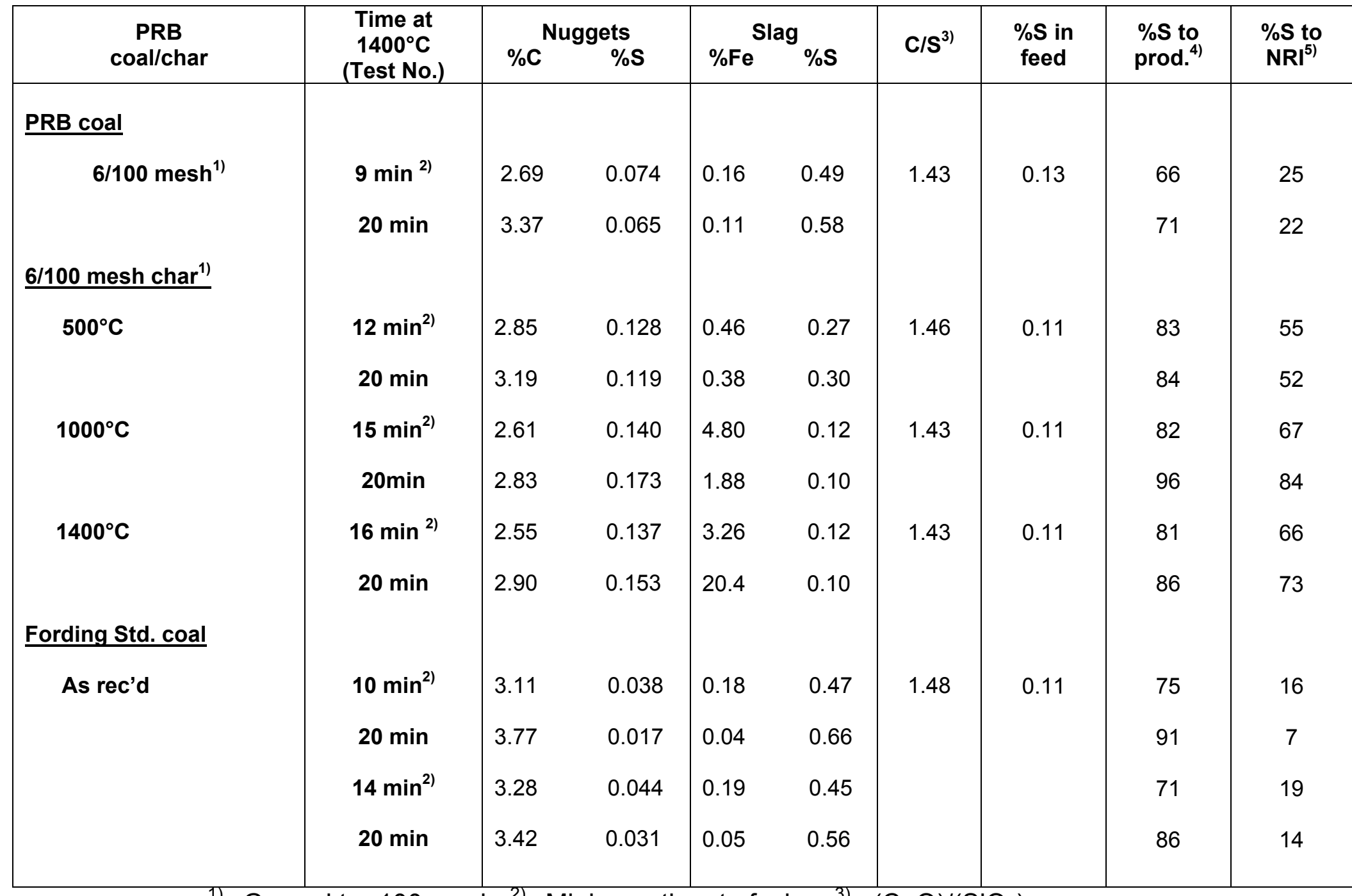

1) Ground to -100 mesh: ${ }^{2)}$ Minimum time to fusion; ${ }^{3)}(\mathrm{CaO}) /\left(\mathrm{SiO}_{2}\right)$;

4) Sulfur in feed recovered in products (NRI and slag); ${ }^{5)}$ Sulfur in feed recovered in NRI 
For comparison, two sets of results, when bituminous coal $(F)$ was used, are included in Table 2-5-8. In these tests, the amount of the feed mixture was varied by changing the packing of the material. Fusion time in the two sets of results was different, 10 minutes and 14 minutes, respectively. The reason for the difference is the weights of the feed mixtures used in these tests. Nevertheless, the amounts of sulfur reported to the products (NRI and slag) were about the same, 70-90\%. However, the amount of sulfur associated with NRI ranged only $7-19 \%$, which indicated that much of sulfur was absorbed by slag.

Therefore, in all the tests including both PRB coal/char and bituminous coal, \%S in feed mixtures remained essentially the same at about $0.11 \% \mathrm{~S}$, yet sulfur reporting to NRI from the feed mixtures with PRB coal (22-25\%) and, in particular, with PRB char (52$84 \%$ ) was significantly higher than the feed mixtures with the bituminous coal $(7-19 \%)$. Increased sulfur in NRI might be related to the reactivities of PRB coal/char and bituminous coal. In fact, BET surface areas of PRB coal and char were two orders of magnitude larger than bituminous coal $\left(2.35,4.53\right.$ and $0.05 \mathrm{~m}^{2} / \mathrm{g}$, respectively), but their effects were not immediately obvious. Also the forms of sulfur in PRB coal and char, carbonized at $1400^{\circ} \mathrm{C}$, were analyzed and given in Table 2-5-9. Pyritic and sulfate sulfur were identical, but some difference was noted in the organic sulfur $(0.30$ an $0.43 \%$, respectively, for PRB coal and char). Somehow organic sulfur might be more readily absorbed by NRI.

Iron in slag analyzed 0.11-0.16 \%Fe when PRB coal was used. With the char, carbonized at $500^{\circ} \mathrm{C}$, the slag analyzed $0.38-0.46 \% \mathrm{Fe}$. With the char, carbonized at $1000^{\circ} \mathrm{C}$, the slag analyzed $1.88-4.80 \% \mathrm{Fe}$. With the char, carbonized at $1400^{\circ} \mathrm{C}$, the iron contents increased further to 3.26-20.4\%Fe. The increased iron contents when the char, carbonized at higher temperatures, was used may be related to the effluent gas analyses of increased $\mathrm{CO}_{2}$ concentration in the effluent gas.

The effluent gas was analyzed for $\mathrm{CO}$ and $\mathrm{CO}_{2}$ using an AGA 5000 gas analyzer, and the results of $\mathrm{CO}$ and $\mathrm{CO}_{2}$ concentrations as a function of time are plotted in Figure 2-5$4(\mathrm{a})$, and also plotted in terms of $\mathrm{CO} /\left(\mathrm{CO}+\mathrm{CO}_{2}\right)$ in Figure 2-5-4(b). Marked increase in $\mathrm{CO}$ concentration when a sample tray was introduced into Zone 2 indicated that the reduction reaction took place in this period. In Zone 1 and in the early stage in Zone 2, the gas composition in terms of $\mathrm{CO} /\left(\mathrm{CO}+\mathrm{CO}_{2}\right)$ with PRB coal was the highest and decreased with char carbonized at higher temperatures. After about 5 minutes in Zone 2 , the order of the ratio, $\mathrm{CO} /\left(\mathrm{CO}+\mathrm{CO}_{2}\right)$, reversed.

Therefore, increase in iron in slag with char, carbonized at higher temperatures, could not be related to the furnace atmosphere in the late stage in Zone 2. Apparently, volatiles released in the early stages in Zone 2 played a key role in keeping both sulfur in NRI and iron in slag low. Clarification of the reason why sulfur in NRI as well as iron in slag were high is essential to developing means of controlling them for making use of $\mathrm{PRB}$ coal/char in the process. 
Table 2-5-9. Forms of sulfur in PRB coal and char, carbonized at $1400^{\circ} \mathrm{C}\left(2552^{\circ} \mathrm{F}\right)$

\begin{tabular}{|c|c|c|}
\hline $\begin{array}{c}\text { Forms of } \\
\text { sulfur }\end{array}$ & $\begin{array}{c}\text { PRB coal } \\
(\mathbf{2 9 - 0 6 )}\end{array}$ & $\begin{array}{c}\text { PRB char } \\
(\mathbf{1 4 0 0} \mathbf{C})\end{array}$ \\
\hline Total & 0.39 & 0.51 \\
Pyritic & 0.05 & 0.04 \\
Sulfate & 0.04 & 0.04 \\
Organic & 0.30 & 0.43 \\
\hline
\end{tabular}




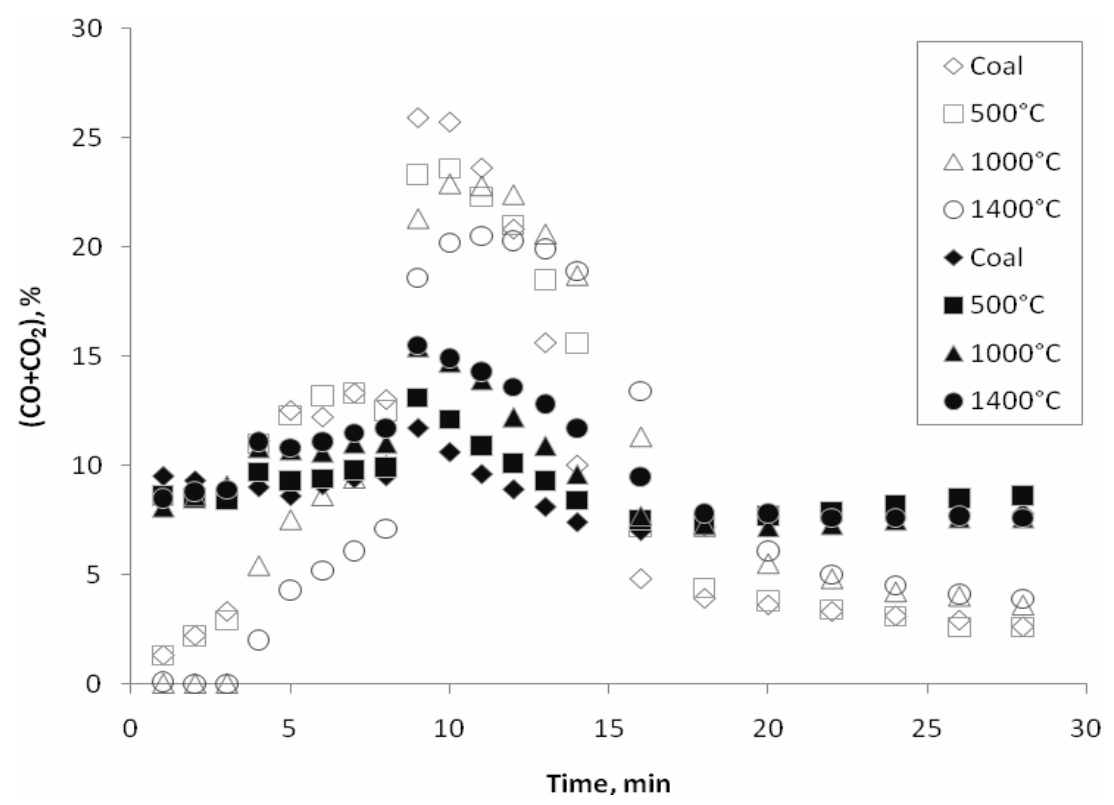

Figure 2-5-4(a). \% $\mathrm{CO}$ and $\% \mathrm{CO}_{2}$ in the effluent gas as a function of time when PRB coal and char, carbonized at different temperatures were used as reductants (Open symbols \%CO, filled symbols $\% \mathrm{CO}_{2}$ ).

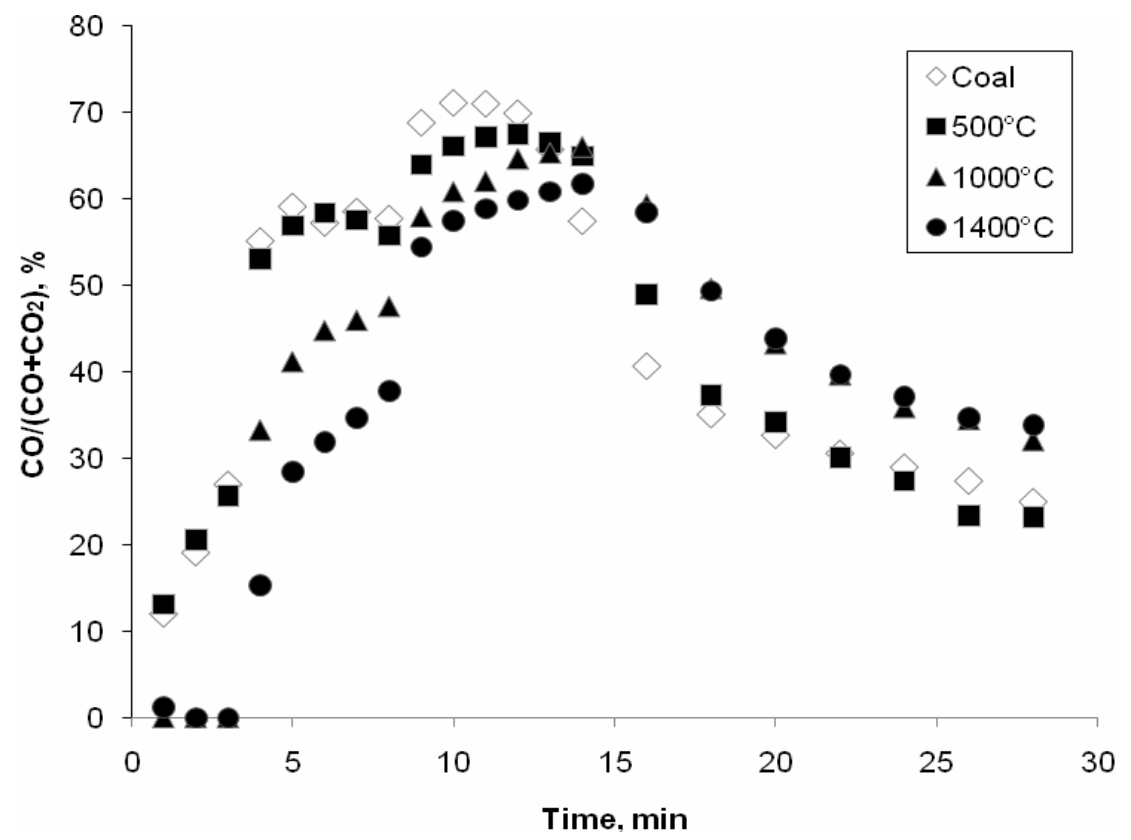

Figure 2-5-4(b). \% $\mathrm{CO} /\left(\mathrm{CO}+\mathrm{CO}_{2}\right)$ in the effluent gas as a function of time when PRB coal and char at different temperatures were used as reductants. 


\section{2-5.2.4 Overall correlation of test results}

2-5.2.4.1 Voids in NRI: Minimum time to full fusion had been judged to have reached by visually observing the smooth and round surfaces of the NRI. When bituminous coal $(F)$ was used as a reductant, a number of voids were observed at incipient fusion, but the voids quickly disappeared soon afterwards (Figure 2-5-5). However, the NRI formed with PRB char as reductants and particularly when NRI were on the PRB char hearth layer, angular voids remained even after keeping at $1400^{\circ} \mathrm{F}\left(2552^{\circ} \mathrm{F}\right)$ for 20 minutes (Figure 2-5-6).

The presence of angular voids suggested that sponge iron did not become fluid enough due to insufficient carburizing. It may be speculated that the manner in which the char particles, being solid and porous, made contacts with concentrate surfaces might have interfered with carburizing. Also ash minerals being finely disseminated in the char might have affected the contacts. \%C in NRI was consistently low, indicating that the rate of carburizing was slow. The slow carburizing was responsible for the 'not quite fully fused' appearance, suggesting that high melting points of NRI might have trapped the voids from the pores in feed mixtures.

Though NRI appeared not fully fused before reaching the fully fused state, \%S of NRI was within the desired specification of $0.05 \%$ and the metallic iron products with voids could be used in EAF.

2-5.2.4.2 Sulfur in NRI: One of the most puzzling behaviors in the use of PRB $\mathrm{coal} /$ char was sulfur in NRI, particularly when different types of hearth layers were used. Sulfur was notably lower when PRB char was used as the hearth layer than when coke was used. This behavior may be attributable to the absorption of sulfur from hearth layer materials, as sulfur in PRB char $(0.47 \% \mathrm{~S})$ was lower than sulfur in coke $(0.69 \% \mathrm{~S})$.

Perhaps, shroud of high $\mathrm{CO}$ atmosphere generated by highly reactive PRB char might be promoting desulfurization, as indicated by higher $\left(\mathrm{CO}+\mathrm{CO}_{2}\right)$ and $\mathrm{CO} /\left(\mathrm{CO}+\mathrm{CO}_{2}\right)$ with PRB char than coke hearth layer in the hearth layer (see 5.2.6).

Table 2-5-10 summarizes the effect of hearth layer materials on sulfur distribution among NRI and slag when 6-segment mounds, consisting of taconite concentrate (Mc), $80 \%$ stoichiometric bituminous coal $(F)$ and slag composition $L_{1.5} F_{2}$, were processed in the usual manner. The table shows the distribution of sulfur among NRI, slag and the amounts gone into the furnace atmosphere by making the material balance of sulfur in feed mounds and products. The amounts not accounted for in the products were assumed to have gone into the furnace atmosphere. The distribution between NRI and slag varied depending on the test conditions, but the amounts of sulfur reporting to the furnace atmosphere were essentially constant and stayed in the range of 30 to $40 \%$. 


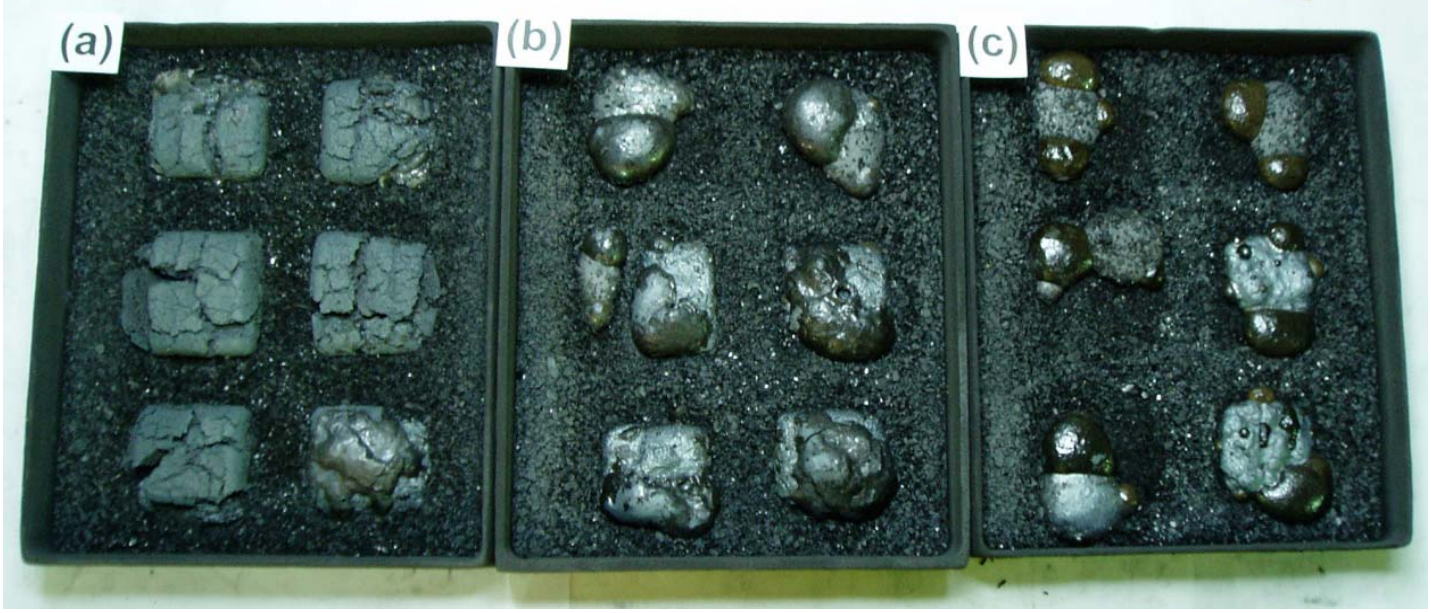

Figure 2-5-5(a). 6-segment domes, prepared from a dry mixture of taconite concentrate, bituminous coal (F) at $80 \%$ stoichiometric amount and slag composition $L_{1.5} F_{2}$, placed over $6 / 100$ mesh anthracite char hearth layer and heated at $1400^{\circ} \mathrm{C}\left(2552^{\circ} \mathrm{F}\right)$ for different periods of time in a $\mathrm{N}_{2}-\mathrm{CO}$ atmosphere.

(a) 8 minutes (B-561)

(b) 10 minutes (B-564)

(c) 11 minutes (B-565) --- time to incipient fusion

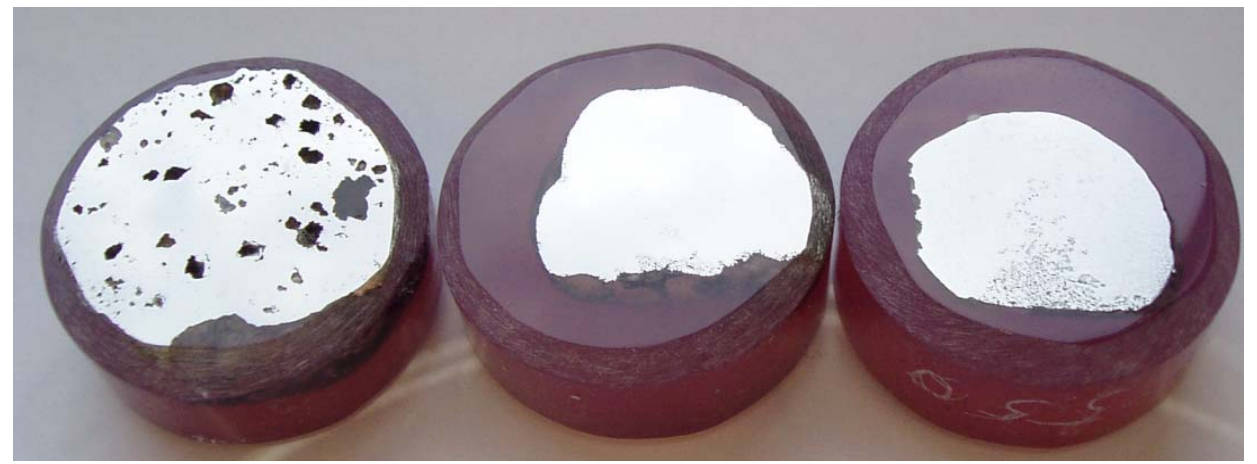

Figure 2-5-5(b). Polished sections of Photo 405(a) and two additional tests

(a) 11 minutes (B-565) --- time to incipient fusion

(b) 12 minutes (B-553) --- minimum time to full fusion

(c) 20 minutes (B-550) 

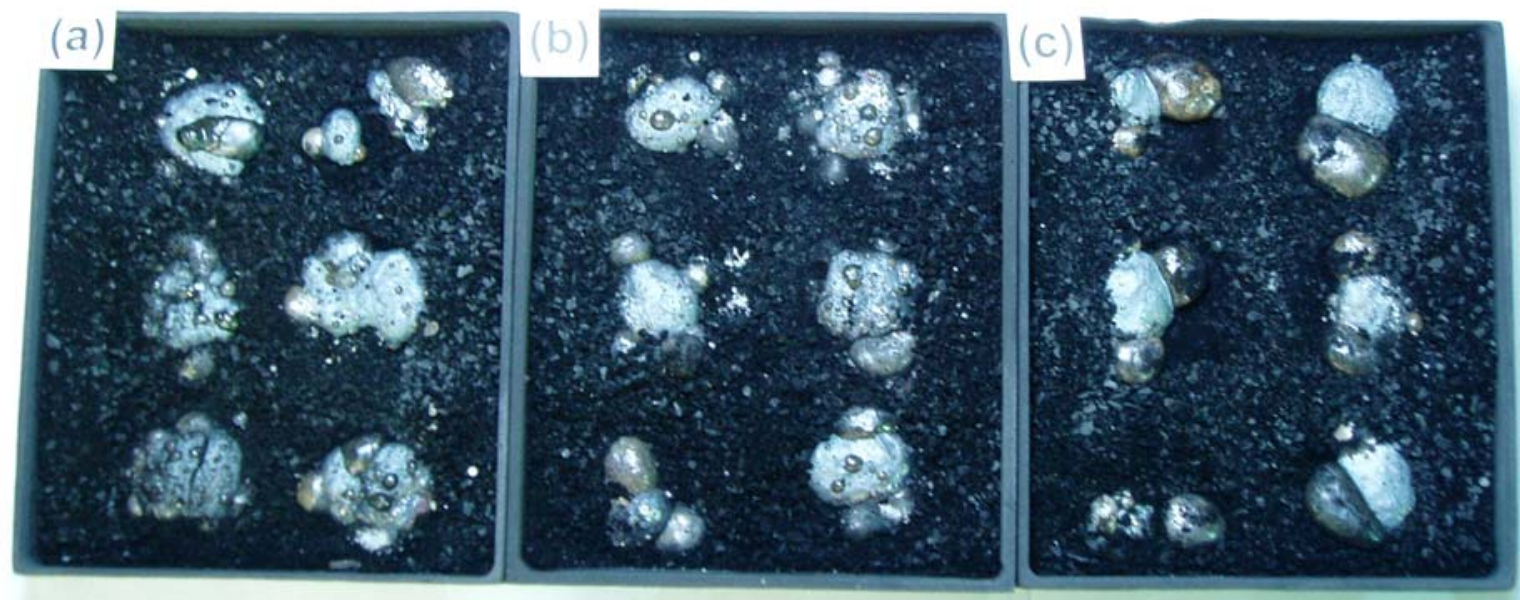

Figure 2-5-6(a). Six segment mounds, prepared from a dry mixture of taconite concentrate, $80 \%$ stoichiometric $6 / 100$ mesh PRB char, carbonized at $1400^{\circ} \mathrm{C}$ $\left(2552^{\circ} \mathrm{F}\right)$ and ground to -100 mesh, and slag composition L1.5FS2, placed on $6 / 100$ mesh PRB char hearth layer and heated at $1400^{\circ} \mathrm{C}\left(2552^{\circ} \mathrm{F}\right)$ for different periods of time in a N2-CO atmosphere.
(a) 13 minutes
(b) 14 minutes --- Time to incipient fusion
(c) 16 minutes

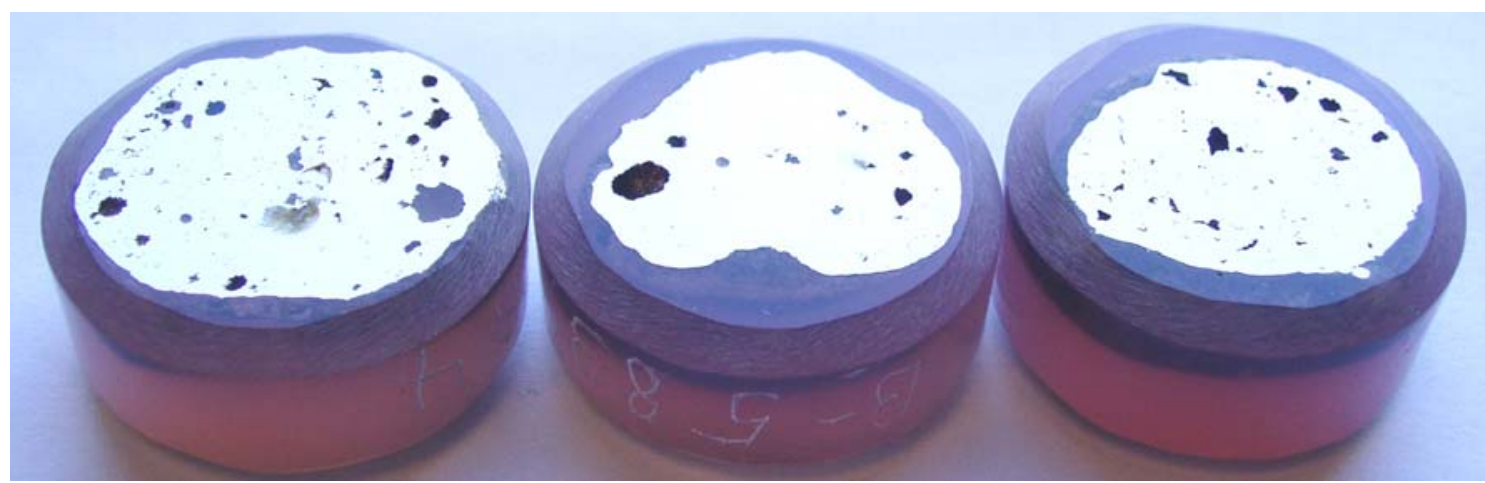

(b)

(c)

(d)

Figure 2-5-6(b). Polished sections of Photo 414
(a) and two additional tests
(b) 14 minutes --- Time to incipient fusion
(c) 18 minutes
(d) 20 minutes 
Table 2-5-10. Effect of hearth layer materials on the behavior of sulfur when 6segment mounds, consisting of taconite concentrate (Mc), $80 \%$ stoichiometric bituminous coal $(F)$ and slag composition $L_{1.5} \mathrm{FS}_{2}$, were heated at $1400^{\circ} \mathrm{C}$ for different periods of time in a $\mathrm{N}_{2}$ - $\mathrm{CO}$ atmosphere.

\begin{tabular}{|c|c|c|c|c|c|c|c|c|c|}
\hline \multirow{2}{*}{$\begin{array}{l}\text { Hearth } \\
\text { layer } \\
\text { material }\end{array}$} & \multirow{2}{*}{$\begin{array}{c}\text { Time at } 1400^{\circ} \mathrm{C} \\
\text { (Test No.) }\end{array}$} & \multirow{2}{*}{$\begin{array}{c}\text { Feed } \\
\% S\end{array}$} & \multicolumn{2}{|c|}{$N R I^{1)}$} & \multicolumn{2}{|c|}{ Slag } & \multicolumn{3}{|c|}{ S distribution, \% } \\
\hline & & & $\% w t$ & $\% S$ & $\% w t$ & \%S & NRI & Slag & Atm. \\
\hline \multirow{4}{*}{$\begin{array}{l}\text { Anthracite } \\
\text { char }\end{array}$} & $11 \min (B-565)$ & 0.13 & 49.3 & 0.056 & 13.5 & 0.32 & 22.4 & 34.4 & 43.2 \\
\hline & $12 \min (B-589)$ & 0.13 & 49.8 & 0.062 & 14.0 & 0.28 & 24.6 & 31.3 & 44.1 \\
\hline & $20 \min (B-550)$ & 0.13 & 49.5 & 0.058 & 14.2 & 0.33 & 22.9 & 37.4 & 39.7 \\
\hline & $12 \min (B-567)$ & 0.13 & 47.6 & 0.042 & 13.3 & 0.38 & 20.0 & 40.3 & 39.7 \\
\hline \multirow{3}{*}{ PRB char } & $14 \min (B-554)$ & 0.13 & 48.7 & 0.026 & 12.2 & 0.46 & 10.1 & 56.6 & 33.3 \\
\hline & $20 \min (B-551)$ & 0.13 & 49.5 & 0.021 & 14.0 & 0.51 & 8.3 & 56.9 & 34.8 \\
\hline & $11 \min (B-566)$ & 0.13 & 48.3 & 0.056 & 14.8 & 0.37 & 21.6 & 43.6 & 34.8 \\
\hline \multirow{2}{*}{ Coke } & $12 \min (B-555)$ & 0.13 & 49.5 & 0.049 & 14.4 & 0.30 & 19.3 & 34.4 & 46.3 \\
\hline & $20 \min (B-552)$ & 0.13 & 49.9 & 0.027 & 14.7 & 0.43 & 10.7 & 50.3 & 39.0 \\
\hline
\end{tabular}

${ }^{1)}$ Includes both NRI and micro NRI (\%S in micro NRI assumed to be the same as NRI)

2-5.2.4.3 Minimum time to fusion: Fusion time increased markedly from 9 minutes with the PRB coal to 16 minutes with the char, carbonized at $1400^{\circ} \mathrm{C}\left(2552^{\circ} \mathrm{F}\right)$. Figure 2-5-7 shows that the fusion time, plotted as a function of the amount of the taconite concentrate in the feed mixtures, which is seen to be directly proportional. As the amounts of PRB coal/char were kept constant at $80 \%$ of the stoichiometric amount in terms of fixed carbon, such an observation suggested that the amount of NRI produced per unit time, or productivity, might not change much regardless of the form of the reductant used. 


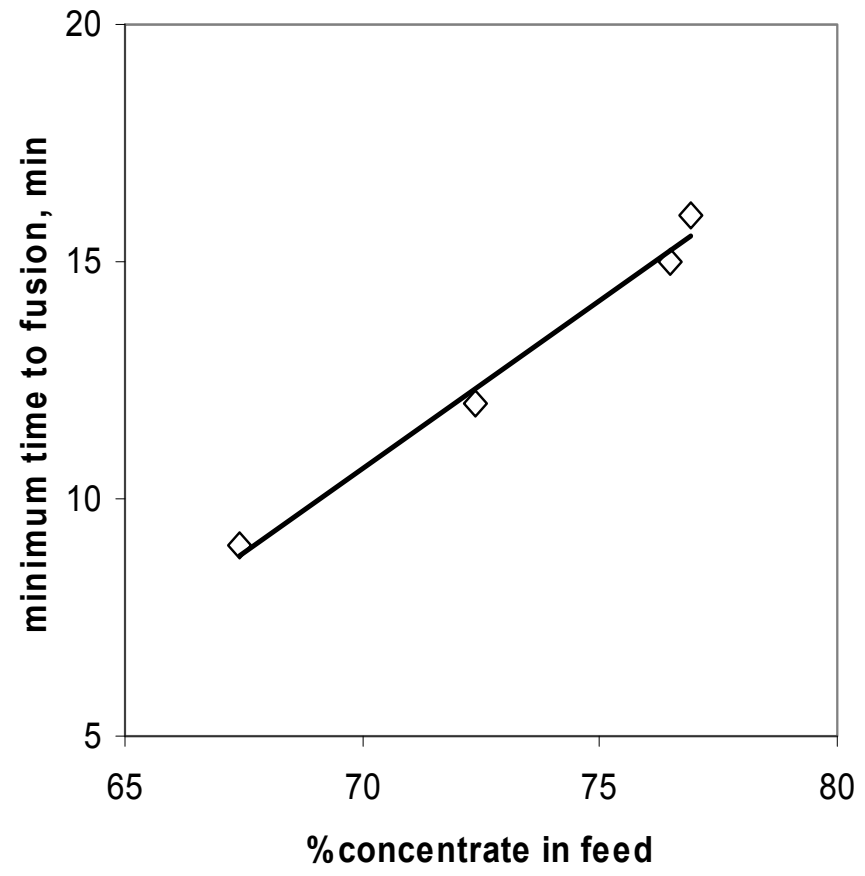

Figure 2-5-7. Effect of the amount of taconite concentrates on the minimum time to fusion.

\section{2-5.2.5 Bituminous coal (F) -PRB coal/char mixtures as reductants}

From the comparison of PRB coal and PRB char, volatiles were found to be helpful in the formation of fused products, but bituminous coals with less volatiles were more effective in forming fused NRI with low sulfur, and have been routinely used in the development of the process. Perhaps the manner in which bituminous coal makes contact with concentrates might be affecting the process as well as the quality of NRI. To explore how these two types of coals behaved, two series of tests were carried out by replacing bituminous coal with PRB coal and its char, carbonized at $1400^{\circ} \mathrm{C}$ $\left(2552^{\circ} \mathrm{F}\right)$, as reductants. The ratios were varied from $100 \%$ bituminous coal to $100 \%$ PRB coal/char in $25 \%$ increments, but keeping the addition levels of the mixtures at $80 \%$ of the stoichiometric amount.

\section{2-5.2.5.1 Conclusions:}

1) With bituminous coal (F)-PRB coal mixtures, fusion time and NRI sulfur were affected little, due presumably to accelerated reduction of the concentrate by volatiles.

2) With bituminous coal $(F)-P R B$ char mixtures, there were little increases in fusion time, NRI sulfur and iron in slag when PRB char replaced bituminous coal (1) up to about $50 \%$. When the char was increased to above $75 \%$, fusion time, NRI sulfur and particularly iron in slag increased.

3) Volatiles played a key role in the formation of quality NRI. 
4) Carburizing of sponge iron/NRI appeared to be controlled by the manner in which coal/char contacted concentrate surfaces during reaction.

2-5.2.5.2 Test procedure: The feed compositions are given in Tables 5-11 and 5-12. Six-segment mounds, consisting of taconite concentrate, bituminous coal (F) and/or PRB coal, $2 \%$ fluorspar and slag composition, $\mathrm{L}_{1.5} \mathrm{FS}_{2}$, were placed on coke hearth layer, and heated according to the standardized heating schedule in a $\mathrm{N}_{2}$-CO atmosphere. In another series of tests, PRB char was used in place of PRB coal as a reductant.

2-5.2.5.3 Test results: Test results are summarized in Tables 2-5-13 and 2-5-14, and the two sets of results are plotted against the ratios of bituminous coal $(F)$ and PRB coal or char in Figure 2-5-8.

With a combination of bituminous coal $(F)$ and PRB coal, fusion time was essentially unaffected by increasing PRB coal in the mixture. Micro NRI remained minimal regardless of the amount of PRB coal in the mixture. NRI sulfur remained essentially constant and remained below $0.05 \% \mathrm{~S}$.

Effluent gas analyses are plotted in terms of $\left(\mathrm{CO}+\mathrm{CO}_{2}\right)$ and $\mathrm{CO} /\left(\mathrm{CO}+\mathrm{CO}_{2}\right)$ in Figure 25-9. In Zone 1 and in the early stage in Zone 2, both $\left(\mathrm{CO}+\mathrm{CO}_{2}\right)$ and $\mathrm{CO} /\left(\mathrm{CO}+\mathrm{CO}_{2}\right)$ increased rapidly and reached maximum soon after trays were in Zone 2, indicating that much of the reduction reaction occurred. Both $\left(\mathrm{CO}+\mathrm{CO}_{2}\right)$ and $\mathrm{CO} /\left(\mathrm{CO}+\mathrm{CO}_{2}\right)$ increased somewhat with increasing PRB coal due to the higher volatile content of PRB coal, but the difference was small, which might account for the little difference in both fusion time and NRI sulfur. 
Table 2-5-11. Composition of feed mixtures, consisting of taconite concentrate, bituminous (F) and PRB coal mixtures at $80 \%$ of the stoichiometric amount, and slag composition $\mathrm{L}_{1.5} \mathrm{FS}_{2}$.

\begin{tabular}{|c|c|c|c|c|c|c|}
\hline $\begin{array}{c}\text { Coal } r \\
\text { Bitu. } \\
\text { coal }\end{array}$ & $\begin{array}{l}\text { ixture } \\
\text { PRB } \\
\text { coal }\end{array}$ & $\begin{array}{c}\text { Taconite } \\
\text { conc. }\end{array}$ & $\begin{array}{c}\text { Reduct } \\
\text { Bitu. } \\
\text { coal }\end{array}$ & $\begin{array}{l}\text { it coal } \\
\text { PRB } \\
\text { coal }\end{array}$ & $\begin{array}{c}\text { Lime } \\
\text { hydrate }\end{array}$ & Fluorspar \\
\hline $100 \%$ & $0 \%$ & 72.7 & 16.7 & 0.0 & 8.6 & 2.0 \\
\hline $75 \%$ & $25 \%$ & 71.3 & 12.3 & 6.2 & 8.2 & 2.0 \\
\hline $50 \%$ & $50 \%$ & 71.1 & 8.0 & 12.2 & 7.8 & 2.0 \\
\hline $25 \%$ & $75 \%$ & 68.6 & 3.9 & 18.0 & 7.4 & 2.0 \\
\hline $0 \%$ & $100 \%$ & 67.4 & 0.0 & 23.6 & 7.0 & 2.0 \\
\hline
\end{tabular}

Table 2-5-12. Composition of feed mixtures, consisting of taconite concentrate, medium-volatile bituminous $(F)$ and PRB char $\left(1400^{\circ} \mathrm{C}\right)$ mixtures at $80 \%$ of the stoichiometric amount, and slag composition $\mathrm{L}_{1.5} \mathrm{FS}_{2}$.

\begin{tabular}{|c|c|c|c|c|c|c|}
\hline $\begin{array}{c}\text { Coal } r \\
\text { Bitu. } \\
\text { coal }\end{array}$ & $\begin{array}{l}\text { ixture } \\
\text { PRB } \\
\text { char }\end{array}$ & $\begin{array}{c}\text { Taconite } \\
\text { conc. }\end{array}$ & $\begin{array}{l}\text { Reducta } \\
\text { Bitu. } \\
\text { coal }\end{array}$ & $\begin{array}{l}\text { it coal } \\
\text { PRB } \\
\text { char }\end{array}$ & $\begin{array}{c}\text { Lime } \\
\text { hydrate }\end{array}$ & Fluorspar \\
\hline $100 \%$ & $0 \%$ & 72.7 & 16.7 & 0.0 & 8.6 & 2.0 \\
\hline $75 \%$ & $25 \%$ & 73.7 & 12.7 & 3.2 & 8.4 & 2.0 \\
\hline $50 \%$ & $50 \%$ & 74.7 & 8.6 & 6.5 & 8.2 & 2.0 \\
\hline $25 \%$ & $75 \%$ & 75.8 & 4.35 & 9.9 & 7.95 & 2.0 \\
\hline $0 \%$ & $100 \%$ & 76.9 & 0.0 & 13.4 & 7.7 & 2.0 \\
\hline
\end{tabular}


Table 2-5-13. Summary of the effects of reductant and hearth layer coal/char on fusion time, micro NRI, NRI sulfur and slag iron of products, produced from 6segment mounds of feed mixtures, consisting of taconite concentrate, bituminous coal $(\mathrm{J})$ and/or PRB coal at $80 \%$ of the stoichiometric amount and slag composition, $L_{1.5} \mathrm{FS}_{2}$, placed on $6 / 100$ mesh coke and heated at $1400^{\circ} \mathrm{C}$ in a $\mathrm{N}_{2}-\mathrm{CO}$ atmosphere.

\begin{tabular}{|c|c|c|c|c|c|}
\hline \multicolumn{2}{|c|}{ Reductant } & \multirow{2}{*}{$\begin{array}{c}\text { Fusion } \\
\text { time, } \\
\text { min }\end{array}$} & \multirow{2}{*}{$\begin{array}{l}\text { Micro } \\
\text { NRI, \% }\end{array}$} & \multirow{2}{*}{$\begin{array}{l}\text { NRI } \\
\% S\end{array}$} & \multirow{2}{*}{$\begin{array}{l}\text { Slag } \\
\% \mathrm{Fe}\end{array}$} \\
\hline $\begin{array}{l}\text { Bitu. } \\
\text { coal }\end{array}$ & $\begin{array}{l}\text { PRB } \\
\text { coal }\end{array}$ & & & & \\
\hline 100 & 0 & 12 & 3.3 & 0.037 & 0.18 \\
\hline 75 & 25 & 11 & 1.9 & 0.039 & 0.17 \\
\hline 50 & 50 & 10 & 1.3 & 0.054 & 0.17 \\
\hline 25 & 75 & 11 & 0.4 & 0.023 & 0.10 \\
\hline $\mathbf{0}$ & 100 & 12 & 1.6 & 0.031 & 0.11 \\
\hline
\end{tabular}

Table 2-5-14. Summary of the effects of reductant and hearth layer coal/char on fusion time, micro NRI, NRI sulfur and slag iron of products, produced from 6segment mounds of feed mixtures, consisting of taconite concentrate, bituminous coal (F) and/or PRB char at $80 \%$ of the stoichiometric amount and slag composition, $L_{1.5} \mathrm{FS}_{2}$, placed on $6 / 100$ mesh coke and heated at $1400^{\circ} \mathrm{C}$ in a $\mathrm{N}_{2}$-CO atmosphere.

\begin{tabular}{|c|c|c|c|c|c|}
\hline \multicolumn{2}{|c|}{ Reductant } & \multirow{2}{*}{$\begin{array}{c}\text { Fusion } \\
\text { time, } \\
\text { min }\end{array}$} & \multirow{2}{*}{$\begin{array}{c}\text { Micro } \\
\text { NRI, \% }\end{array}$} & \multirow{2}{*}{$\begin{array}{l}\text { NRI } \\
\% S\end{array}$} & \multirow{2}{*}{$\begin{array}{l}\text { Slag } \\
\% \mathrm{Fe}\end{array}$} \\
\hline $\begin{array}{l}\text { Bitu. } \\
\text { coal }\end{array}$ & $\begin{array}{l}\text { PRB } \\
\text { char }\end{array}$ & & & & \\
\hline 100 & 0 & 12 & 3.3 & 0.037 & 0.18 \\
\hline 75 & 25 & 12 & 2.1 & 0.042 & 0.28 \\
\hline 50 & 50 & 14 & 1.3 & 0.056 & 0.30 \\
\hline 25 & 75 & 15 & 2.0 & 0.063 & 0.59 \\
\hline 0 & 100 & 17 & 1.3 & 0.111 & 1.79 \\
\hline
\end{tabular}



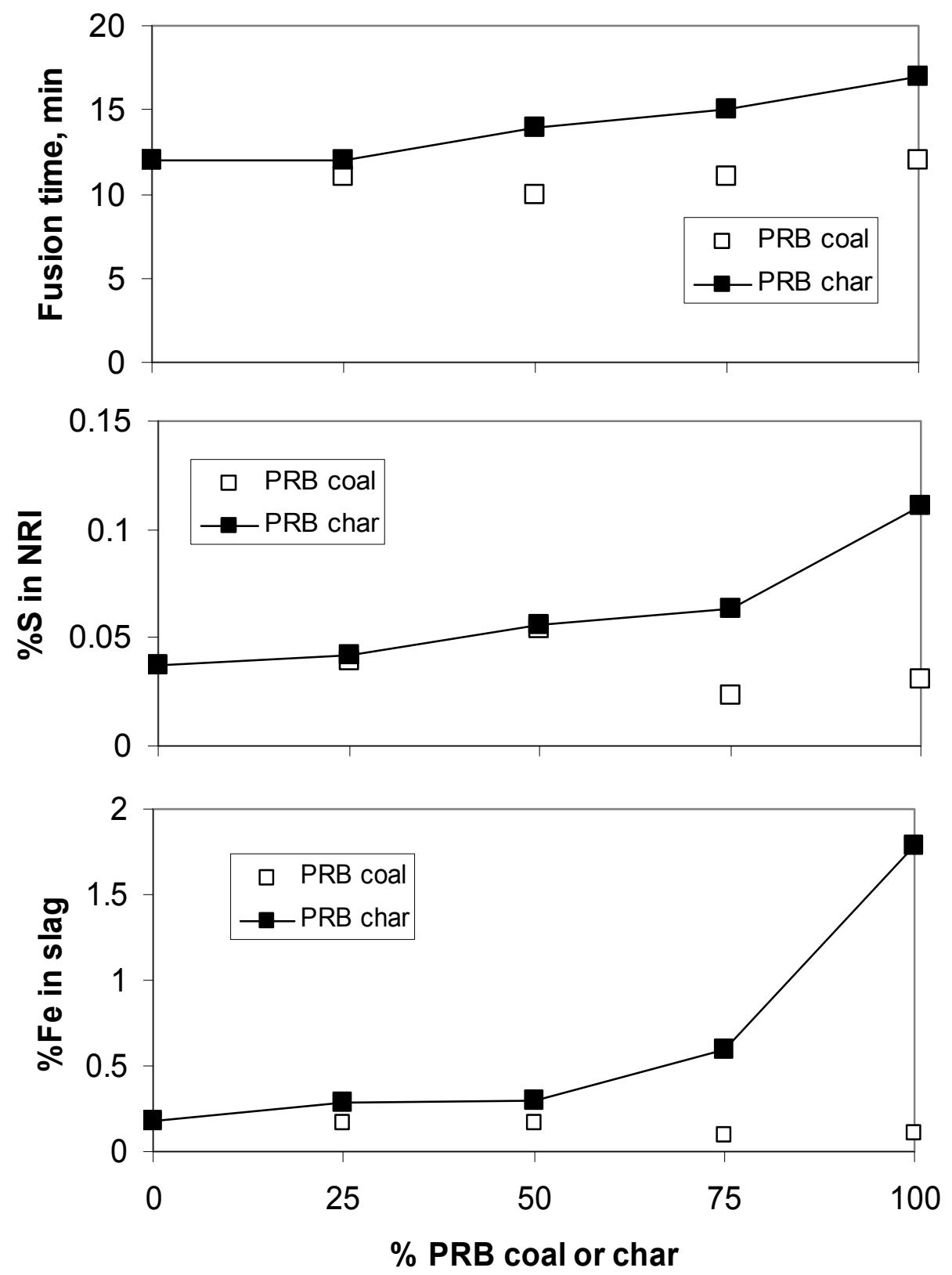

Figure 2-5-8. Summary of test results and products, formed from 6-segment mounds, consisting of taconite concentrate, bituminous coal (F) replaced with different amounts of PRB coal/char at $\mathbf{8 0} \%$ of the stoichiometric amount and slag composition $L_{1.5} \mathrm{FS}_{2}$, placed on $6 / 100$ mesh coke hearth layer, and heated at $1400^{\circ} \mathrm{C}$ in a $\mathrm{N}_{2}-\mathrm{CO}$ atmosphere. 


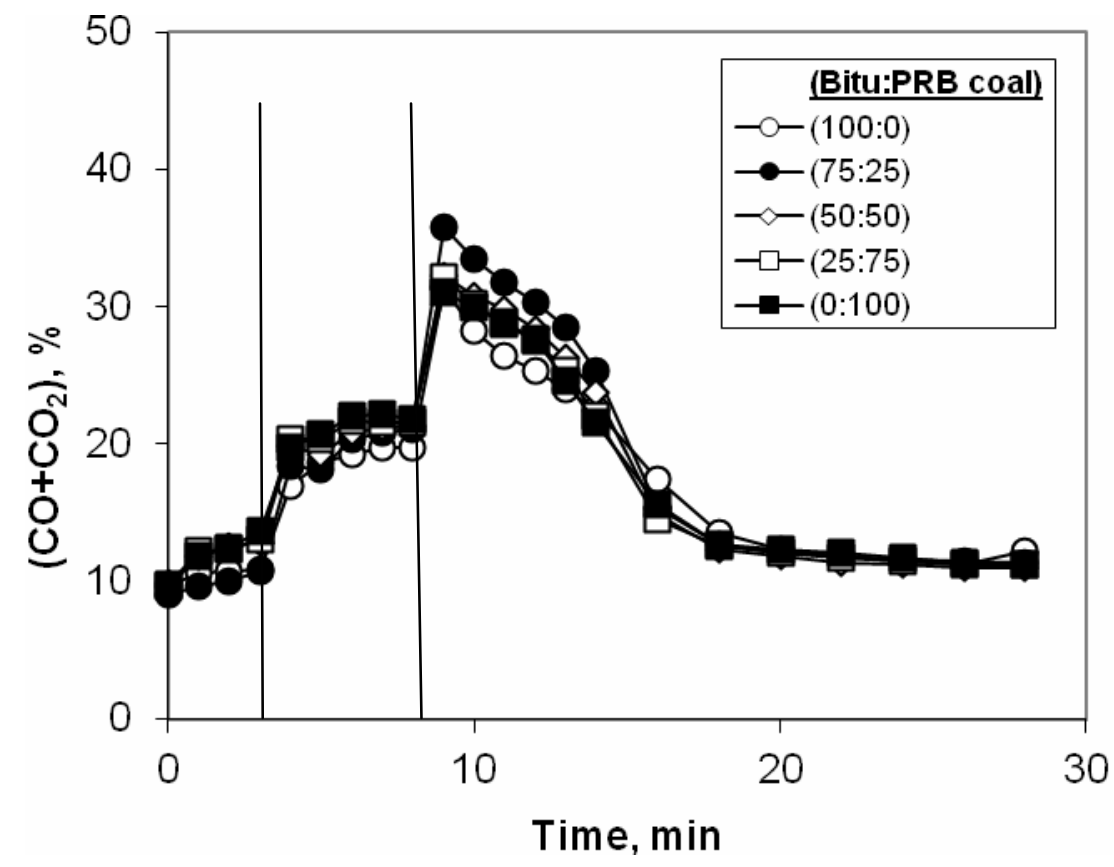

Figure 2-5-9(a). Effluent gas composition of $\left(\mathrm{CO}+\mathrm{CO}_{2}\right)$ from feed mixtures, containing different proportions of bituminous coal $(F)-P R B$ coal, placed on coke hearth layer and heated in the standardized schedule in a $\mathrm{N}_{2}-\mathrm{CO}$ atmosphere.

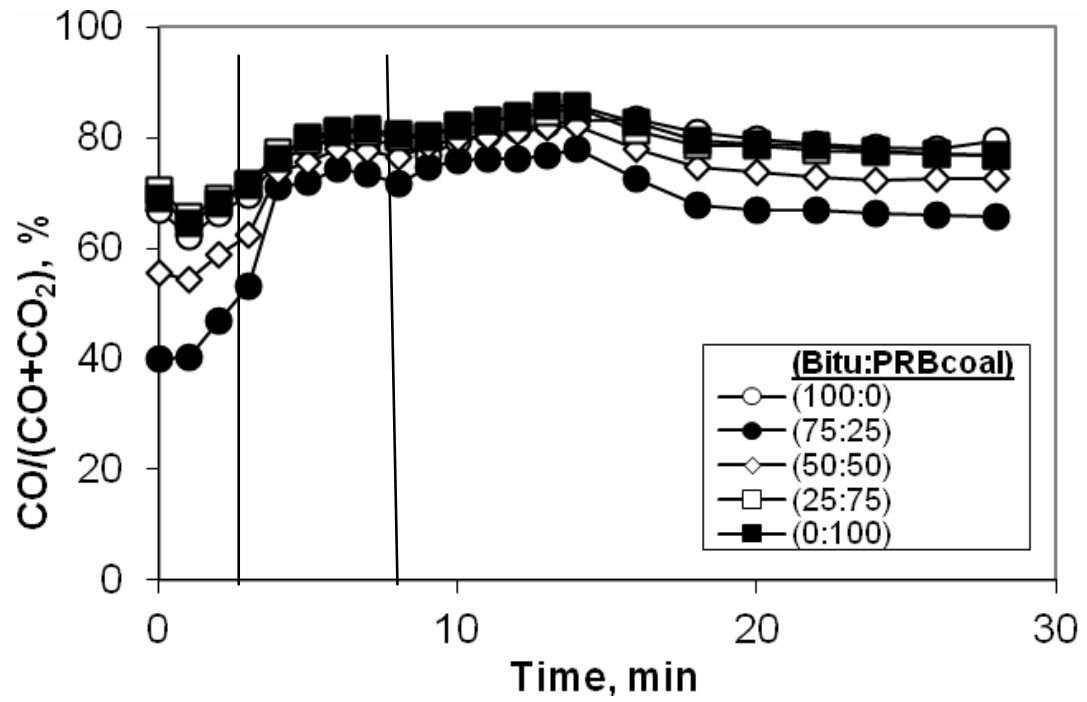

Figure 2-5-9(b). Effluent gas composition, expressed as $\mathrm{CO} /\left(\mathrm{CO}+\mathrm{CO}_{2}\right)$, of gas analysis data, shown in Figure 2-5-9(a). 
When PRB char $\left(1400^{\circ} \mathrm{C}\right)$ was used in the mixture, fusion time increased from 12 minutes to 17 minutes on increasing PRB char. Generation of micro NRI remained minimal. However, NRI sulfur increased from $0.037 \%$ S with $100 \%$ bituminous coal $(F)$ to $0.111 \% \mathrm{~S}$ with $100 \%$ PRB char. Increasing the time at $1400^{\circ} \mathrm{C}$ to 20 minutes decreased NRI sulfur by only 0.01 to $0.02 \%$ S.

In an attempt to investigate the reason why NRI sulfur increased with increasing PRB char, while NRI sulfur remained essentially below $0.05 \% S$ with increasing PRB coal, the forms of sulfur in the PRB coal and char were analyzed. The results are given in Table 2-5-9. The results, however, were essentially identical except for a minor difference in organic sulfur ( 0.30 and $0.43 \%$, respectively).

Effluent gas analyses are plotted in terms of $\left(\mathrm{CO}+\mathrm{CO}_{2}\right)$ and $\mathrm{CO} /\left(\mathrm{CO}+\mathrm{CO}_{2}\right)$ in Figure 25-10. Both $\left(\mathrm{CO}+\mathrm{CO}_{2}\right)$ and $\mathrm{CO} /\left(\mathrm{CO}+\mathrm{CO}_{2}\right)$ showed similar behavior as with bituminous coal (F)-PRB coal mixtures.

A closer examination of Figures 5-9 and 5-10 shows that when PRB coal was replacing bituminous coal $(\mathrm{F}), \mathrm{CO} /\left(\mathrm{CO}+\mathrm{CO}_{2}\right)$ increased as $\mathrm{PRB}$ coal increased in the feed, whereas the ratio decreased when PRB char was replacing bituminous coal $(F)$.

Increase in $\mathrm{CO} /\left(\mathrm{CO}+\mathrm{CO}_{2}\right)$ when PRB coal increased in the feed suggested that the reduction reactions were accelerated by volatiles released from both bituminous coal $(F)$ and PRB coal. Decrease in the ratio when PRB char increased in the feed suggested that the reduction reaction slowed as PRB char released little volatiles. Marked increase of iron in slag with $100 \%$ PRB char might be caused by the formation of more difficultly reducing fayalite-type slag by the slow reaction during reduction.

Iron in slag being relatively constant up to $50 \%$ PRB char might be related to the manner in which bituminous coal $(F)$ interacted with the concentrate surfaces without getting affected by the presence of less amounts of PRB char in the hearth layer. In the presence of $75-100 \%$ PRB char, the contacts between PRB coal and sponge iron/NRI would be predominant, thereby slowing carburization. Increased iron in slag in the form of $\mathrm{FeO}$ caused decreased contacts between char and sponge iron/NRI, and interfered with the desulfurizing of NRI. 


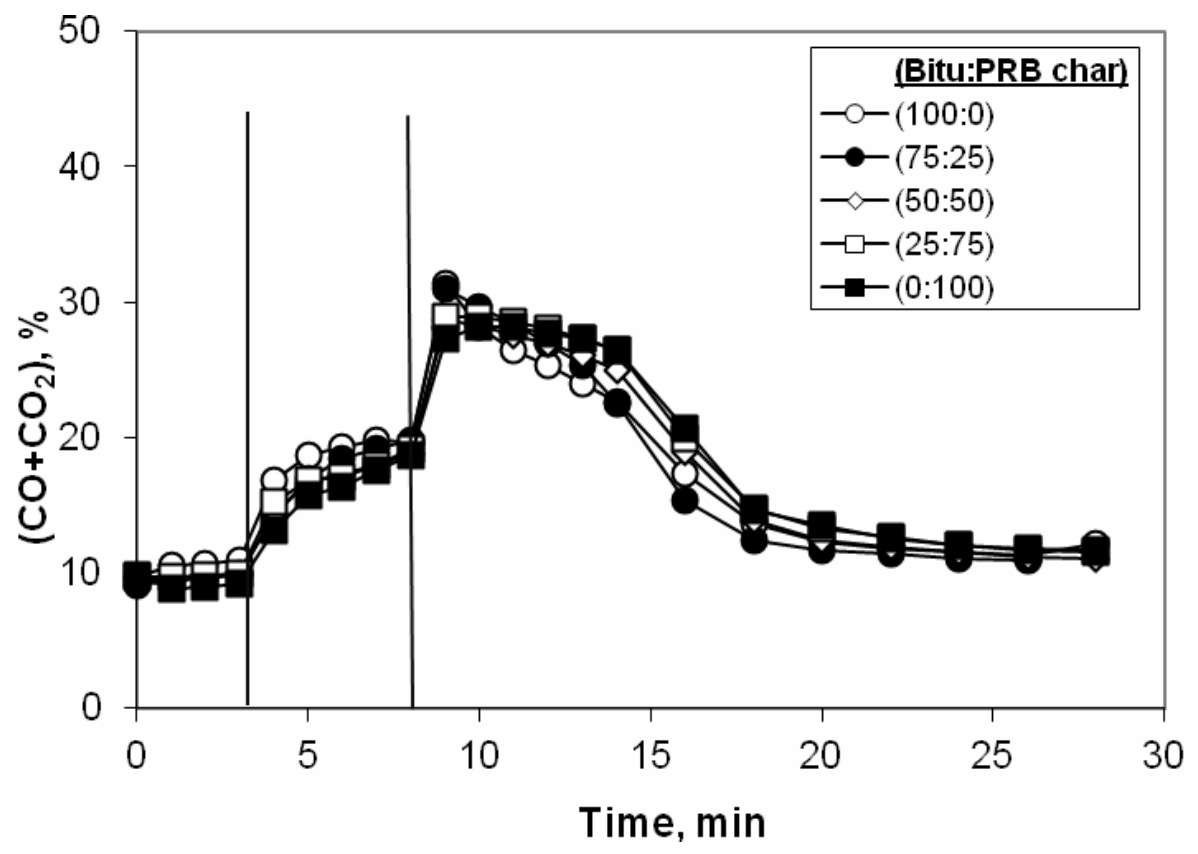

Figure 2-5-10(a). Effluent gas composition of $\left(\mathrm{CO}+\mathrm{CO}_{2}\right)$ from feed mixtures, containing different proportions of bituminous coal (F)-PRB char, placed on coke hearth layer and heated in the standardized schedule in a $\mathrm{N}_{2}-\mathrm{CO}$ atmosphere.

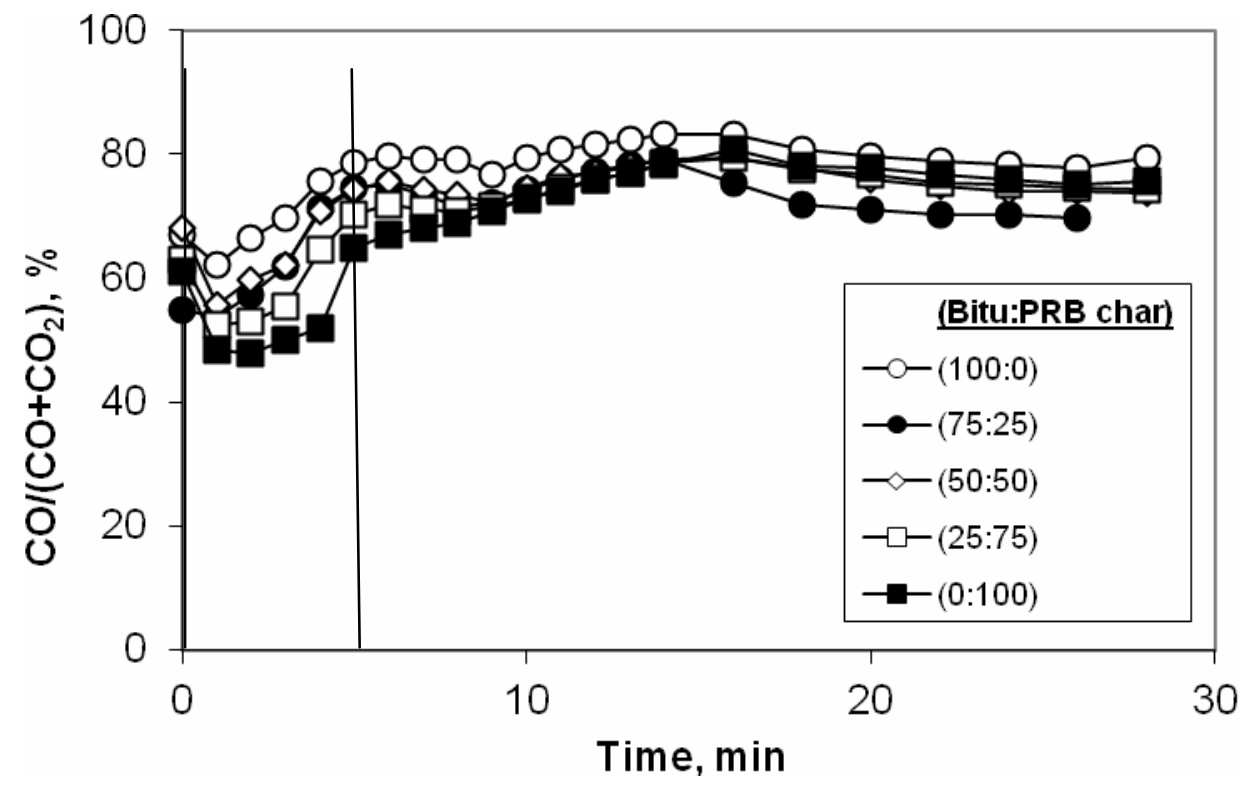

Figure 2-5-10(b). Effluent gas composition, expressed as $\mathrm{CO} /\left(\mathrm{CO}+\mathrm{CO}_{2}\right)$, of gas analysis data, shown in Figure 2-5-10(a). 


\section{2-5.2.6 PRB coal/char as hearth layer}

Carburizing of sponge iron from hearth layer materials plays a key role in forming NRI by lowering the melting point of sponge iron. Box furnace tests were carried out using either coke or anthracite char as hearth layer material in most of the tests thus far. In this section, the effect of using PRB char as hearth layer material was investigated and explored how PRB char compared with coke as hearth layer.

\section{2-5.2.6.1 Conclusions:}

1) It took longer time to form fused NRI when feed mixtures were placed on PRB char than on coke hearth layer, regardless of whether bituminous coal $(F), P R B$ coal or char, carbonized at $500^{\circ}, 1000^{\circ}$ and $1400^{\circ} \mathrm{C}$, was used as a reductant.

2) $\mathrm{NRI}$ sulfur remained below $0.05 \% \mathrm{~S}$ when $\mathrm{PRB}$ char was used as hearth layer, regardless of whether bituminous coal (F), PRB coal or char, carbonized at $500^{\circ}$, $1000^{\circ}$ and $1400^{\circ} \mathrm{C}$, was used as a reductant.

3) $\mathrm{NRI}$ sulfur as well as iron in slag increased when PRB char, carbonized at $1000^{\circ}$ and $1400^{\circ} \mathrm{C}$, was used as a reductant at $80 \%$ of the stoichiometric amount and placed on coke hearth layer.

4) NRI sulfur could be lowered to below $0.05 \% \mathrm{~S}$ with coke hearth layer, although micro NRI increased.

2-5.2.6.2 Test procedure: Six-segment mounds, consisting of taconite concentrate, $80 \%$ stoichiometric bituminous coal $(\mathrm{F})$, PRB coal or char, carbonized at $500^{\circ} \mathrm{C}, 1000^{\circ} \mathrm{C}$ and $1400^{\circ} \mathrm{C}$, and slag composition $\mathrm{L}_{1.5} \mathrm{FS}_{2}$, were placed on a hearth layer of either $6 / 100$ mesh coke or PRB char, carbonized at $1400^{\circ} \mathrm{C}$.

2-5.2.6.3 Test results: The results are summarized in Table 2-5-15. From the table, hearth layers of PRB char and coke are seen to have affected the fusion time, NRI analyses of both carbon and sulfur, and iron in slag.

It took longer time to fuse when the feed mixtures with bituminous coal $(F)$, PRB coal or char as a reductant were placed on PRB char than on coke hearth layer. As it was pointed out earlier (see 5.2.2.1), the manner in which PRB coal and char made contacts with concentrate surfaces was found to vary from the coke hearth layer. These differences appear to reduce the rate of carburization of sponge iron/NRI. In fact, as shown in Table 2-5-15, \%C in NRI, formed on PRB char hearth layer, was consistently lower than NRI, formed on coke, supporting a view that the rates of carburizing were slow.

With PRB char hearth layer, NRI produced using PRB coal or PRB char, carbonized at different temperatures, remained well below $0.05 \% \mathrm{~S}$. However, when the feed mixtures were placed on coke hearth layer, NRI sulfur increased to $0.1 \%$ S when PRB char carbonized at $1000^{\circ}$ and $1400^{\circ} \mathrm{C}$ was used as a reductant. There was no correlation between \%C and \%S in NRI. 
Table 2-5-15. Summary of the effects of reductant and hearth layer coal/char on fusion time, micro NRI, NRI sulfur and slag iron of products, produced from 6segment mounds of feed mixtures, consisting of taconite concentrate, bituminous coal (F) or PRB coal/char at $\mathbf{8 0 \%}$ of the stoichiometric amount and slag composition, $\mathrm{L}_{1.5} \mathrm{FS}_{2}$, placed on different hearth layer materials and heated at $1400^{\circ} \mathrm{C}$ in a $\mathrm{N}_{2}$ - $\mathrm{CO}$ atmosphere.

\begin{tabular}{|c|c|c|c|c|c|}
\hline \multirow[b]{2}{*}{ Hearth layer } & \multirow{2}{*}{$\begin{array}{c}\text { Fusion } \\
\text { time, min }\end{array}$} & \multirow{2}{*}{$\begin{array}{c}\text { Micro } \\
\text { NRI, \% } \\
\end{array}$} & \multicolumn{2}{|c|}{ NRI } & \multirow{2}{*}{$\begin{array}{l}\text { Slag } \\
\% \mathrm{Fe}\end{array}$} \\
\hline & & & $\% \mathrm{C}$ & $\% \mathrm{~S}$ & \\
\hline \multicolumn{6}{|c|}{ Bituminous coal $(1)^{*}$} \\
\hline Anth. char & 11 & 0.9 & 3.05 & 0.057 & 0.29 \\
\hline PRB char & 12 & 3.6 & 2.25 & 0.042 & 0.21 \\
\hline Coke & 11 & 1.7 & 3.04 & 0.056 & 0.21 \\
\hline \multicolumn{6}{|l|}{ PRB coal* $^{*}$} \\
\hline PRB char & 12 & 1.5 & 2.39 & 0.029 & 0.15 \\
\hline Coke & 9 & 1.4 & 2.73 & 0.049 & 0.16 \\
\hline \multicolumn{6}{|c|}{ PRB char $\left(500^{\circ} \mathrm{C}\right)^{*}$} \\
\hline PRB char & 13 & 2.1 & 2.10 & 0.030 & 0.11 \\
\hline Coke & 10 & 1.9 & 2.22 & 0.054 & 0.20 \\
\hline \multicolumn{6}{|c|}{ PRB char $\left(1000^{\circ} \mathrm{C}\right)^{*}$} \\
\hline PRB char & 16 & 0.3 & 2.08 & 0.042 & 0.11 \\
\hline Coke & 13 & 0.7 & 2.46 & 0.101 & 1.42 \\
\hline \multicolumn{6}{|c|}{ PRB char $\left(80 \% \text { stoich., } 1400^{\circ} \mathrm{C}\right)^{*}$} \\
\hline PRB char & 14 & 6.6 & 2.21 & 0.024 & 0.50 \\
\hline Coke & 13 & 1.8 & 2.15 & 0.100 & 3.22 \\
\hline \multicolumn{6}{|c|}{ PRB char $\left(90 \% \text { stoich., } 1400^{\circ} \mathrm{C}\right)^{*}$} \\
\hline PRB char & 16 & 11.9 & 1.96 & 0.038 & 0.20 \\
\hline Coke & 12 & 12.0 & 2.48 & 0.037 & 0.35 \\
\hline
\end{tabular}

- Added as a reductant in feed mixtures. 
Iron in slag did not change much when a feed with PRB coal or char was placed on PRB char hearth layer. When a feed with PRB char, carbonized at $1000^{\circ}$ and $1400^{\circ} \mathrm{C}$, was placed on coke hearth layer, iron in slag increased. Increased iron in slag resulted in increased sulfur in NRI.

Effluent gases were analyzed for $\mathrm{CO}$ and $\mathrm{CO}_{2}$ concentrations, and the results were plotted as $\left(\mathrm{CO}+\mathrm{CO}_{2}\right)$ and $\mathrm{CO} /\left(\mathrm{CO}+\mathrm{CO}_{2}\right)$ as a function of time in Figures 5-11(a) and (b), respectively. $\left(\mathrm{CO}+\mathrm{CO}_{2}\right)$ was higher when $\mathrm{PRB}$ char was used as the hearth layer compared to using coke in the hearth layer, indicating that char hearth layer helped to react with the concentrate more effectively. Also $\mathrm{CO} /\left(\mathrm{CO}+\mathrm{CO}_{2}\right)$ was higher when char was the hearth layer. From the effluent gas analyses, PRB char would have accelerated the reduction reaction, but longer fusion time resulted, which did not collaborate with the gas analysis results.

An attempt was made to explore if an increased addition of PRB char, carbonized at $1400^{\circ} \mathrm{C}$, might decrease NRI sulfur. When its addition was increased to $90 \%$ of the stoichiometric amount, NRI sulfur decreased to below $0.05 \% \mathrm{~S}$ although the amount of micro NRI markedly increased. The results are included in Table 2-5-15. The reason why a combination of $\mathrm{PRB}$ char, carbonized at $1000^{\circ}$ and $1400^{\circ} \mathrm{C}$, as a reductant and coke hearth layer led to increased sulfur in NRI and increased iron in slag was not resolved. Perhaps, the combination of PRB char reductant and coke hearth layer led to premature loss of the reductant char. 


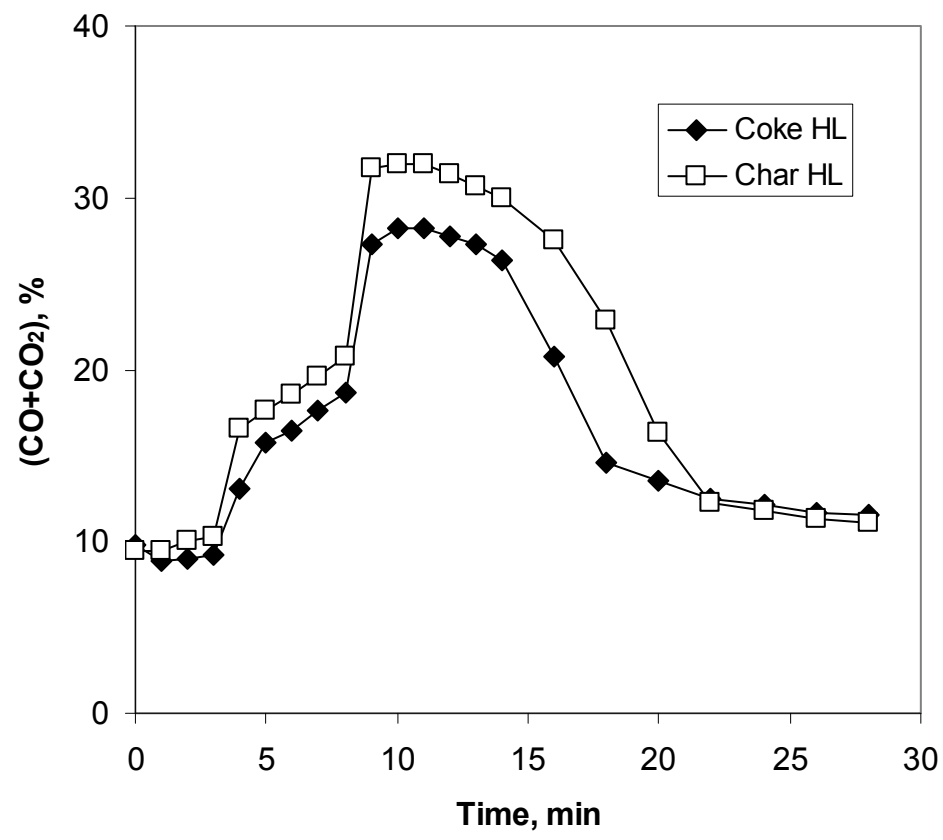

Figure 2-5-11(a). Effluent gas composition of $\left(\mathrm{CO}+\mathrm{CO}_{2}\right)$ from feed mixtures, containing $100 \%$ PRB char, placed on either coke or PRB char $\left(1400^{\circ} \mathrm{C}\right)$ hearth layer and heated in the standard schedule in a $\mathrm{N}_{2}-\mathrm{CO}$ atmosphere.

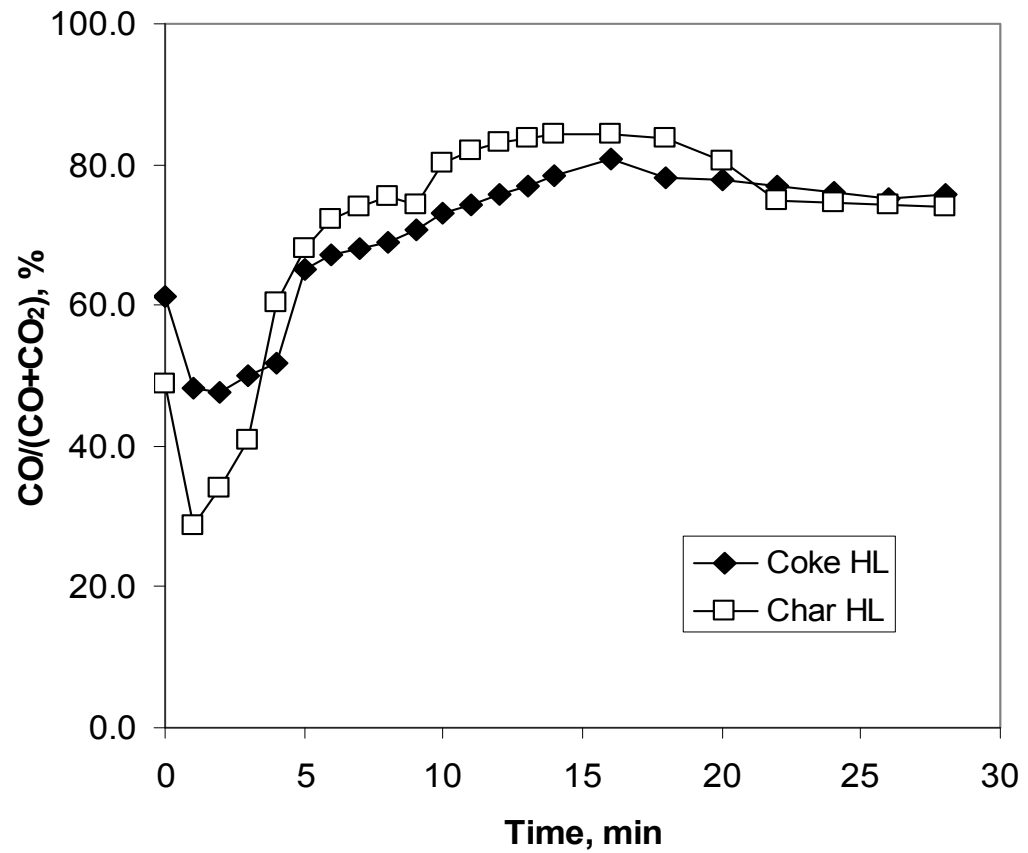

Figure 2-5-11(b). Effluent gas composition, expressed as $\mathrm{CO} /(\mathrm{CO}+\mathrm{CO} 2)$, of gas analysis data, shown Figure 2-5-11(a). 


\section{2-5.2.7 Interaction of bituminous coal and PRB coal in feed with coke and PRB coal in hearth layer}

Preliminary tests indicated that volatiles from PRB coal in feed played a key role in forming fused NRI. In these tests either coke, anthracite char or PRB char was used as hearth layer. To examine the effect of volatiles generated from hearth layer, a series of tests were carried out by replacing coke with PRB coal in hearth layer. Also, how the volatiles from reductant coal and from hearth layer interacted in the process was investigated by replacing bituminous coal $(F)$ with PRB coal in feed.

\section{2-5.2.7.1 Conclusions:}

1) The effects of replacing bituminous coal $(F)$ with $P R B$ coal in feed (in levels up to $50 \%$ ) on fusion time and on NRI sulfur were relatively minor at a given make-up of hearth layer. An increase in PRB coal in hearth layers decreased fusion time.

2) NRI sulfur changed little by increasing PRB coal in feed and in hearth layer, and remained less than $0.05 \% \mathrm{~S}$ in all the tests.

3) The amount of micro NRI was affected the most by increasing PRB coal in feed as well as in hearth layer. Micro NRI decreased with increasing PRB coal in feed, while micro NRI increased with increasing PRB coal in hearth layer.

4) Volatiles from PRB coal in hearth layer accelerated the reduction of iron concentrate by a shroud of reducing atmosphere.

2-5.2.7.2 Test procedure: Feed mixtures were prepared by varying the ratios of bituminous coal and PRB coal from (100:0) to (75:25) and to (50:50), but keeping the total amount of the reductant coal constant at $80 \%$ of the stoichiometric amount. The composition of the mixtures is given in Table 2-5-16. The composition of hearth layer was varied from $100 \%$ coke to $100 \%$ PRB coal (coke:PRB coal) ratios of (100:0), (87.5:12.5), (75:25) and (50:50), and (0:100).

The box furnace tests were carried out following the 'standardized' procedure using 6segment mounds in graphite trays.

2-5.2.7.3 Test results: Key points of the results of fusion time, micro NRI generation and NRI sulfur are summarized in Table 2-5-17. In the table, fusion time was essentially unaffected by increasing PRB coal in feed for a given hearth layer composition. As the amount of iron concentrate in feed was about the same, little change in fusion time with increasing PRB coal is in agreement with the previous results (Figure 2-5-7). However, there was a steady decrease when coke was replaced by PRB coal in hearth layer. As the amount of PRB coal in the hearth layer was much larger than in feed, volatiles from hearth layer accelerated the reaction. 
Table 2-5-16. Composition of feed mixtures, consisting of taconite concentrate, bituminous coal and PRB coal mixtures at $\mathbf{8 0} \%$ of the stoichiometric amount, and slag composition $\mathrm{L}_{1.5} \mathrm{FS}_{2}$.

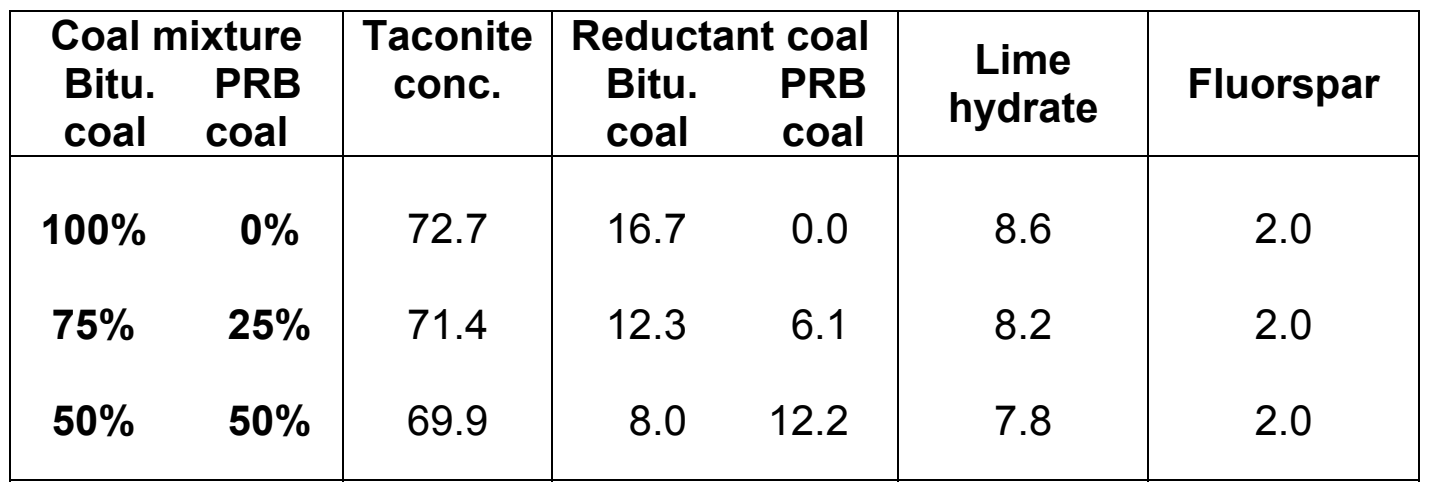

Table 2-5-17. Summary of replacing bituminous coal with PRB coal in feed, and replacing coke with PRB coal in hearth layer on fusion time, micro NRI generation and $\% S$ in NRI.

\begin{tabular}{|c|c|c|c|}
\hline Feed & \multicolumn{3}{|c|}{$\%$ PRB coal } \\
\hline H.L. & $0 \%$ & $25 \%$ & $50 \%$ \\
\hline $\begin{array}{l}100 \% \text { coke- } 0 \% \text { PRB coal } \\
\text { Fusion time } \\
\% \text { micro NRI } \\
\% \text { S }\end{array}$ & $\begin{array}{l}12 \\
3.3 \\
0.037\end{array}$ & $\begin{array}{l}12 \\
2.1 \\
0.042\end{array}$ & $\begin{array}{c}14 \\
1.3 \\
0.056\end{array}$ \\
\hline $\begin{array}{l}87.5 \% \text { coke-12.5\% PRB coal } \\
\text { Fusion time } \\
\% \text { micro NRI } \\
\% \text { S }\end{array}$ & $\begin{array}{l}11 \\
5.1 \\
0.036\end{array}$ & $\begin{array}{l}11 \\
4.5 \\
0.045\end{array}$ & $\begin{array}{l}11 \\
1.9 \\
0.040\end{array}$ \\
\hline $\begin{array}{l}75 \% \text { coke-25\% PRB coal } \\
\text { Fusion time } \\
\% \text { micro NRI } \\
\% \text { S }\end{array}$ & $\begin{array}{l}10 \\
5.1 \\
0.038\end{array}$ & $\begin{array}{c}11 \\
4.9 \\
0.038\end{array}$ & $\begin{array}{c}11 \\
5.3 \\
0.038\end{array}$ \\
\hline $\begin{array}{l}50 \% \text { coke- } 50 \% \text { PRB coal } \\
\text { Fusion time } \\
\% \text { micro NRI } \\
\% \text { S }\end{array}$ & $\begin{array}{c}10 \\
6.2 \\
0.037\end{array}$ & $\begin{array}{l}10 \\
5.4 \\
0.045\end{array}$ & $\begin{array}{c}10 \\
6.6 \\
0.033\end{array}$ \\
\hline $\begin{array}{l}0 \% \text { coke- } 100 \% \text { PRB coal } \\
\text { Fusion time } \\
\% \text { micro NRI } \\
\% \text { S }\end{array}$ & $\begin{array}{l}10 \\
13.1 \\
0.028\end{array}$ & $\begin{array}{l}--- \\
--- \\
---\end{array}$ & $\begin{array}{l}11 \\
4.0 \\
0.029\end{array}$ \\
\hline
\end{tabular}


The amount of micro NRI decreased as bituminous coal $(F)$ was replaced by PRB coal in feed, whereas the amount of micro NRI increased as coke was replaced by PRB coal in hearth layer increased. While volatiles from PRB coal in hearth layer increased the amount of micro NRI, volatiles from PRB coal in hearth layer not only helped the reduction of iron concentrate, but also a large volume of effusing volatiles from hearth layer caused the formation of micro NRI. The reason why increasing PRB coal in feed and in hearth layer had diametrically opposite effects was puzzling. Perhaps feed mixtures in mounds were not tightly held together and a large amount of effusing volatiles from hearth layer spewed out iron concentrate particles, resulting in the formation of micro NRI.

$\mathrm{NRI}$ sulfur was about the same and remained in the range of $0.02-0.03 \% \mathrm{~S}$. Sulfur in both bituminous coal and PRB coal were about the same, $0.40 \%$ and $0.39 \%$, respectively.

In an attempt to visualize the effects of the levels of PRB coal addition on fusion time, micro NRI formation and \%S in NRI, regression equations were generated from the data summarized in Table 2-5-17. The terms involving $E$ were small and neglected.

(Fusion time $)=11.8874-0.0811 X_{1}+0.0123 X_{2}+0.0007 X_{1}^{2}-0.0002 X_{2}^{2}-9.35 E^{-5} X_{1} X_{2}$; $\mathrm{r}=0.89$

$(\Phi=13)$

$($ Micro NRI $)=2.0759+0.1476 \mathrm{X}_{1}-0.0047 \mathrm{X}_{2}-0.0005 \mathrm{X}_{1}^{2}+5.62 \mathrm{E}^{-6} \mathrm{X}_{2}^{2}-0.0015 \mathrm{X}_{1} \mathrm{X}_{2}$; $\mathrm{r}=0.91$

$(\Phi=13)$

$(\% S)=0.0389-0.0001 X_{1}-0.0004 X_{2}-3.04 E^{-7} X_{1}^{2}+4.84 E^{-6} X_{2}^{2}-2.33 E^{-6} X_{1} X_{2}$; $\mathrm{r}=0.81$

$(\Phi=13)$

where $\mathrm{X}_{1}=\% \mathrm{PRB}$ coal in hearth layer

$\mathrm{X}_{2}=\% \mathrm{PRB}$ coal in total carbon added to feed

$r=$ multiple correlation coefficient

$\Phi=$ degrees of freedom

Response surfaces were obtained by using EXCEL Chart Wizard, and plotted in Figure 2-5-12. In Figure 2-5-12(a), the effect of PRB coal on fusion time was essentially unaffected. In Figure 2-5-12(b), the generation of micro NRI is shown to be dependent on the amount of PRB coal both in feed and hearth layer. Figure 2-5-12(c) shows the results of \%S in NRI. The results are essentially unaffected by the amounts of PRB coal in feed and in hearth layer. 


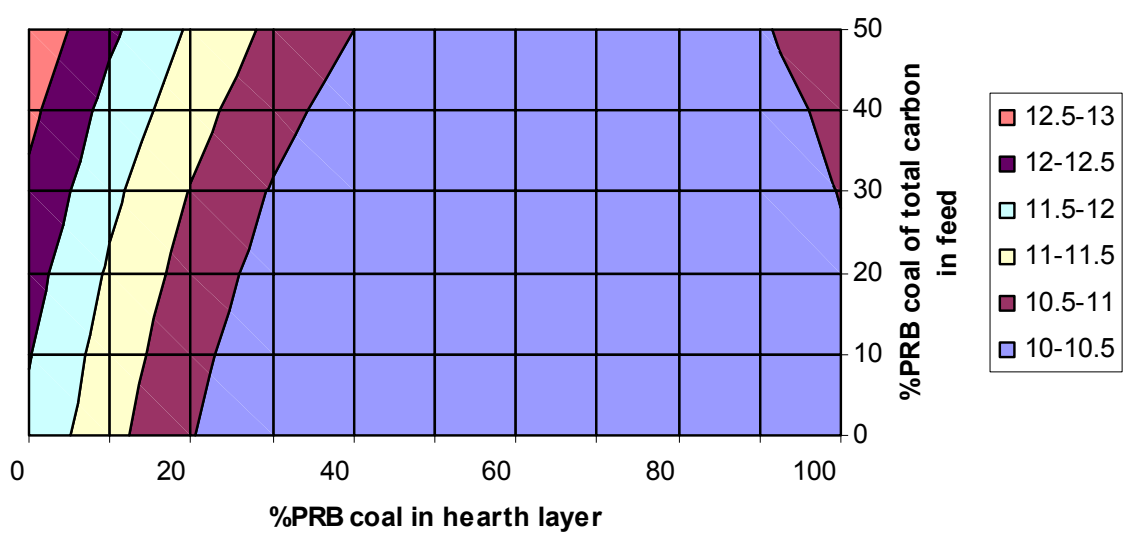

(a) Fusion time

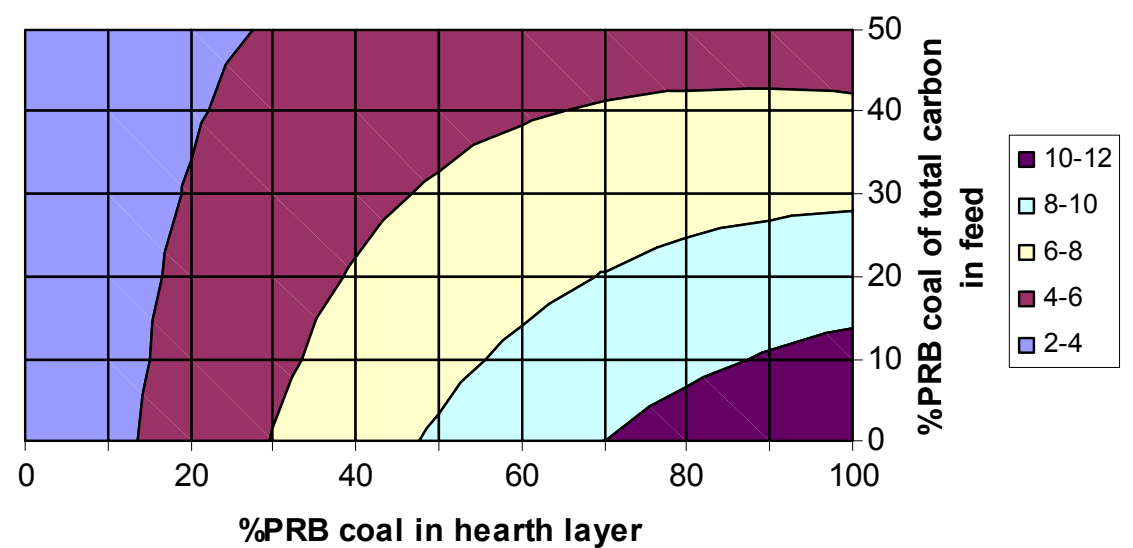

(b) Micro NRI generation

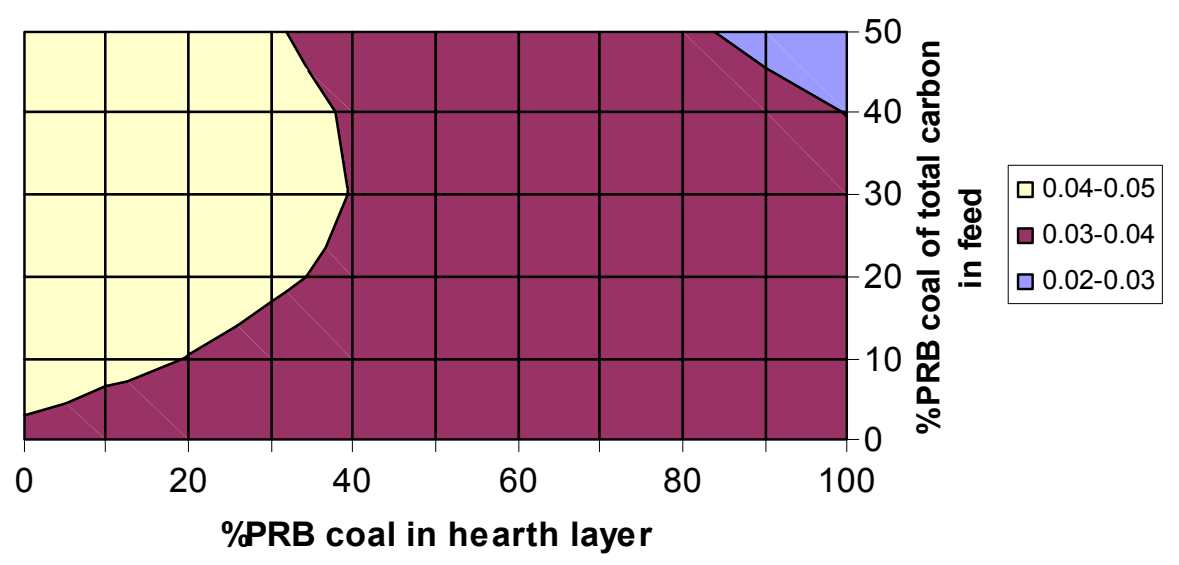

(c) $\% \mathrm{~S}$ in NRI

Figure 2-5-12. Response surfaces showing the effects of \%PRB coal in total carbonaceous materials (PRB coal and bituminous coal) added to feed and \%PRB coal in hearth layer (PRB coal and coke) on: (a) Fusion time, (b) Micro NRI generation and (c) \%S in NRI. 


\section{2-5.2.8 Interaction of PRB coal and PRB char $\left(1400^{\circ} \mathrm{C}\right)$ used as reductant and hearth layer material}

Thus far, medium-volatile bituminous coal was selected as the most desirable reductant from a suite of Eastern and Western coals as well as coke and char, and has routinely been used in the investigation. An attempt was made to search for less expensive alternative to the process. In this section, the effects of using PRB coal and char both as reductants and hearth layer materials were studied to ascertain how the high volatile content of PRB coal would affect the formation of fused NRI.

\section{2-5.2.8.1 Conclusions:}

1) Replacing $P R B$ char with $P R B$ coal in feed shortened the fusion time and markedly decreased the generation of micro NRI, while sulfur in NRI was unaffected and remained in the range of $0.02-0.03 \% \mathrm{~S}$.

2) By carbonizing PRB coal to char, approximately $50 \%$ of its weight was lost. When the PRB char was used in feed mixes, more concentrate and less char were used because of its high fixed carbon in the PRB char. However, it took longer time to form fused NRI. Therefore, the effect on productivity should be evaluated by taking into account of the amount of iron concentrate and fusion time.

2-5.2.8.2 Test procedure: Taconite concentrate and PRB coal were used for the tests. PRB char was prepared by carbonizing the PRB coal at $1400^{\circ} \mathrm{C}\left(2552^{\circ} \mathrm{F}\right)$ for 20 minutes.

To explore the effect of increasing PRB coal in the mixtures of PRB coal and PRB char, the ratios were varied from $100 \%$ PRB char to $100 \%$ PRB coal in $25 \%$ increments, but fixing the addition levels of the mixtures at $80 \%$ of the stoichiometric amount. The compositions of the mixtures are given in Table 2-5-18. The composition of hearth layer was varied from $100 \%$ PRB char to $50 \%$ PRB char, $50 \%$ PRB coal (PRB char:PRB coal) ratios of (100:0), (75:25) and (50:50) mixtures of PRB char and coal.

Box furnace tests were carried out following the 'standardized' procedure using 6segment mounds in a graphite tray.

2-5.2.8.3 Test results: Key points of the results, fusion time, micro NRI formation and $\% \mathrm{~S}$ in NRI are summarized in Table 2-5-19. In the table, it is seen that the fusion time decreased with increasing PRB coal both as a reductant in feed and in hearth layer. Micro NRI generation became notably higher, particularly when PRB char addition in feed became high in the range of $75 \%$ to $100 \%$. Sulfur in NRI did not show any particular trend and remained in the range of $0.02-0.03 \% \mathrm{~S}$. 
Table 2-5-18. Composition of feed mixtures, consisting of taconite concentrate, PRB coal and PRB char mixtures at $\mathbf{8 0 \%}$ of the stoichiometric amount, and slag composition $\mathrm{L}_{1.5} \mathrm{FS}_{2}$.

\begin{tabular}{|c|c|c|c|c|c|c|}
\hline $\begin{array}{c}\text { Coal n } \\
\text { PRB } \\
\text { coal }\end{array}$ & $\begin{array}{c}\text { ixture } \\
\text { PRB } \\
\text { char }\end{array}$ & $\begin{array}{l}\text { Taconite } \\
\text { conc. }\end{array}$ & $\begin{array}{c}\text { Reduct } \\
\text { PRB } \\
\text { coal }\end{array}$ & $\begin{array}{l}\text { nt coal } \\
\text { PRB } \\
\text { char }\end{array}$ & $\begin{array}{c}\text { Lime } \\
\text { hydrate }\end{array}$ & Fluorspar \\
\hline $100 \%$ & $0 \%$ & 67.5 & 23.25 & 0.0 & 7.25 & 2.0 \\
\hline $75 \%$ & $25 \%$ & 69.6 & 18.0 & 3.05 & 7.35 & 2.0 \\
\hline $50 \%$ & $50 \%$ & 71.85 & 12.35 & 6.3 & 7.5 & 2.0 \\
\hline $25 \%$ & $75 \%$ & 74.25 & 6.4 & 9.75 & 7.6 & 2.0 \\
\hline $0 \%$ & $100 \%$ & 76.8 & 0.0 & 13.45 & 7.75 & 2.0 \\
\hline
\end{tabular}

Table 2-5-19. Summary of replacing PRB coal with PRB char in feed, and replacing PRB char with PRB coal in hearth layer on minimum time to fusion, micro NRI generation and \%S in NRI.

\begin{tabular}{|l|ccccc|}
\hline \multicolumn{1}{|c|}{ Feed } & \multicolumn{5}{|c|}{ \% PRB coal } \\
H.L. & $\mathbf{0} \%$ & $\mathbf{2 5 \%}$ & $\mathbf{5 0 \%}$ & $\mathbf{7 5 \%}$ & $\mathbf{1 0 0 \%}$ \\
\hline $\begin{array}{l}\mathbf{1 0 0 \%} \text { char-0\% coal } \\
\begin{array}{l}\text { Fusion time } \\
\text { \%micro NRI } \\
\text { \%S }\end{array}\end{array}$ & 16 & 16 & 16 & 14 & 14 \\
\hline $\begin{array}{l}\mathbf{7 5 \%} \text { char-25\% coal } \\
\text { Fusion time } \\
\text { \%micro NRI }\end{array}$ & 0.8 & 5.9 & 1.3 & 1.2 & 2.6 \\
& 14 & 14 & 13 & 12 & 13 \\
\hline $\begin{array}{l}\mathbf{5 0 \%} \text { char-50\% coal } \\
\text { Fusion time } \\
\text { \%micro NRI } \\
\text { \%S }\end{array}$ & 11.3 & 8.7 & 1.8 & 1.9 & 2.3 \\
& 0.022 & 0.022 & 0.022 & 0.025 & 0.027 \\
\hline
\end{tabular}


In an attempt to visualize the effects of the levels of PRB coal on fusion time and micro $\mathrm{NRI}$ formation, regression equations were generated from the data summarized in Table 2-5-19.

(Fusion time $)=15.8619-0.092 X_{1}+0.0010 X_{2}+0.0013 X_{1}^{2}-0.0002 X_{2}^{2}-0.0004 X_{1} X_{2}$; $r=0.92$

$(\Phi=14)$

$\left(\right.$ Micro NRI) $=9.8414+0.0980 \mathrm{X}_{1}-0.2179 \mathrm{X}_{2}-0.0010 \mathrm{X}_{1}^{2}+0.0014 \mathrm{X}_{2}^{2}-0.0006 \mathrm{X}_{1} \mathrm{X}_{2}$; $\mathrm{r}=0.96$ $(\Phi=14)$

where $\mathrm{X}_{1}=\% \mathrm{PRB}$ coal in hearth layer

$\mathrm{X}_{2}=\% \mathrm{PRB}$ coal in total carbon added to feed

$r=$ multiple correlation coefficient

$\Phi=$ degrees of freedom

Response surfaces were obtained by using EXCEL Chart Wizard, and plotted in Figure 2-5-13. PRB coal both in feed and in hearth layer are important in decreasing the fusion time, suggesting that volatiles helped accelerate the reduction of iron concentrate. A large amount of micro NRI was generated as PRB char in feed increased above $75 \%$. Micro NRI decreased to minimum when PRB coal in feed was $50-100 \%$. The reason why more micro NRI was generated when PRB char was the main reductant has not been resolved. 


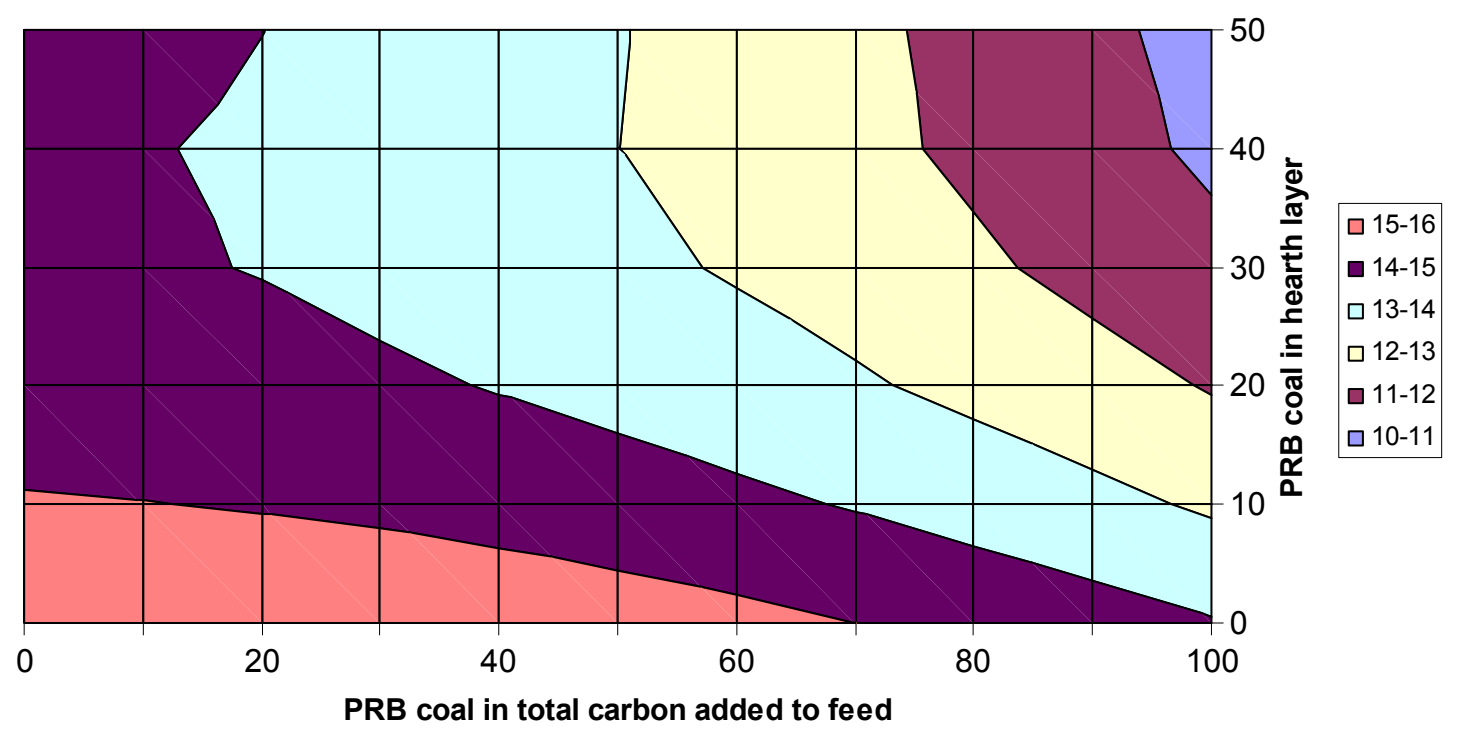

(a) Fusion time

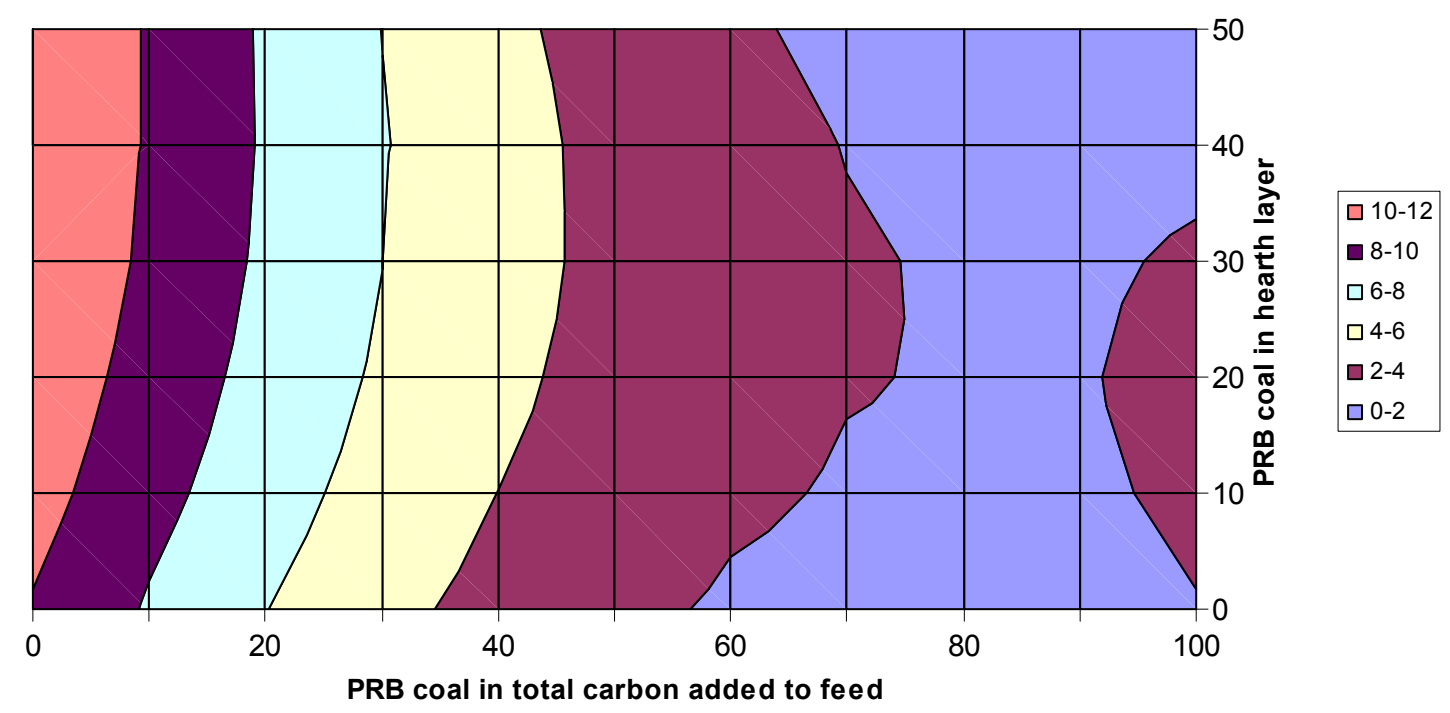

(b) Micro NRI generation

Figure 2-5-13. Response surfaces showing the effects of \%PRB coal in total carbonaceous materials (PRB coal and PRB char) added to feed and \%PRB coal in hearth layer (PRB coal and PRB char) on: (a) Fusion time, (b) Micro NRI generation and (c) \%S in NRI. 


\section{2-5.2.9 Equivalence of carbon in molasses and PRB coal/char}

Binder testing in briquetting indicated that molasses worked satisfactorily as a binder (see the next chapter), and appeared to contribute to reductant carbon.

Brief screening tests were made to estimate the equivalence of carbon in molasses and PRB coal by optimizing the use of molasses as a binder, and adjusting the level of PRB coal for minimum fusion time without increasing the generation of micro NRI. After seeing some success with PRB coal, the investigation was extended to briquettes with PRB char, carbonized at $500^{\circ}, 1000^{\circ}$ and $1400^{\circ} \mathrm{C}$

\section{2-5.2.9.1 Conclusions:}

1) The amounts of PRB coal/char and molasses binder needed to be adjusted to optimum combinations by taking both briquette strength and fusion behavior into account simultaneously.

2) The optimum combinations of PRB coal/char and molasses for both briquette strength and fusion behavior were estimated to be as follows:

\section{\% stoichiometric $\quad$ Molasses}

PRB coal

PRB char $\left(500^{\circ} \mathrm{C}\right)$

$\left(1000^{\circ} \mathrm{C}\right)$

$\left(1400^{\circ} \mathrm{C}\right)$
$75-80$

$75-80$

90

$85-90$
$12 \%$

$10-12 \%$

$4-5 \%$

$4-5 \%$

3) With PRB char, carbonized at $1000^{\circ} \mathrm{C}$ and $1400^{\circ} \mathrm{C}$, strong enough briquettes were produced with much less molasses as a binder than when PRB coal and PRB char, carbonized at $500^{\circ} \mathrm{C}$, were used.

4) Carbon resulting from molasses needed to be taken into account as a reductant carbon along with PRB coal/char.

5) For molasses to act as a reductant, its effectiveness depended on the amount of volatiles in PRB coal/char. The volatiles appeared to interfere with molasses to act as a reductant.

6) In order for $\mathrm{NRI}$ to form in minimum fusion time with minimum generation of micro NRI, it was necessary to adjust the sum of reductant carbon from PRB coal/char and from molasses to about $95 \%$ of the stoichiometric amount, allowing for the volatiles of PRB coal and char to affect the role played by molasses in reduction and carburizing reactions.

7) Near the optimum conditions, the amount of micro NRI could be decreased to about $1 \%$ or less by extending the time at $1400^{\circ} \mathrm{C}$ for an additional minute beyond fusion time.

In practice, therefore, a part of hearth layer char could be used as an internal carbon for reduction, and fresh PRB coal added to PRB char for recycling to hearth layer. In this manner, the volatiles in PRB coal could be utilized in heating as well as in accelerating the reduction reaction. 
2-5.2.9.2 Test conditions: PRB char samples were prepared by placing 6/100 mesh $\mathrm{PRB}$ coal in a graphite tray and heating in the box furnace at $500^{\circ} \mathrm{C}, 1000^{\circ} \mathrm{C}$ and $1400^{\circ} \mathrm{C}$ for 30 minutes in a $\mathrm{N}_{2}-\mathrm{CO}$ atmosphere. The PRB char samples were stageground dry to -100 mesh in a ring grinder. Proximate analyses of PRB coal as well as PRB char, carbonized at these temperatures, are given in Table 2-5-20.

Briquettes were prepared by mixing taconite concentrate (K), PRB coal or char, hydrated lime and fluorspar with molasses as a binder in a Lab Komarek briquetting machine. The molasses analyzed $35 \%$ moisture and $18.9 \% \mathrm{C}$. The carbon content of the molasses was expressed in terms of PRB coal or char by using their fixed carbon analyses.

Equivalent amounts of carbon contributed by $1 \%$ molasses to feed mixtures were calculated to be as follows:

\section{\% stoichiometric coal or char}

$\begin{array}{rr}\text { PRB coal } & 2.45 \% \\ \text { PRB char } & \\ 500^{\circ} \mathrm{C} & 1.87 \% \\ 1000^{\circ} \mathrm{C} & 1.48 \% \\ 1400^{\circ} \mathrm{C} & 1.50 \%\end{array}$

\section{2-5.2.9.3 Test results}

2-5.2.9.3.1 In the absence of molasses

In an attempt to establish how much PRB coal might be replaced by the addition of molasses, a series of tests was carried out using taconite concentrate (K)-PRB coal mixtures in the absence of binders. PRB coal was varied from 85 to $105 \%$ of the stoichiometric amount with $2 \%$ fluorspar and slag composition of $\mathrm{C} / \mathrm{S}=1.5$. The feed compositions are given in Table 2-5-21. These mixtures were briquetted with water only. The briquettes had hardly any strength, particularly with higher coal additions, and the recoveries in the briquette preparation were extremely poor. This clearly illustrated the need for developing an appropriate binder for commercial processing.

Nevertheless, box furnace tests were carried out in the usual manner. The results are summarized in Table 2-5-22. As the addition of PRB coal increased to above $95 \%$ of the stoichiometric amount, fusion time became half as long without increasing micro NRI, increasing NRI carbon, and decreasing NRI sulfur to below $0.05 \% \mathrm{~S}$. In view of the increase in micro NRI at $105 \%$ stoichiometric coal, the optimum amount of PRB coal was estimated to be in the range of $95-100 \%$ of the stoichiometric amount. Apparently, highly reactive PRB coal with large internal surfaces was consumed faster than bituminous coals in the process. 
Table 2-5-20. Effect of carbonization temperature (30 minutes at temperature) on the proximate analyses of PRB coal.

\begin{tabular}{|l|c|c|c|c|}
\hline & As rec'd & $\begin{array}{c}\text { Carbonized } \\
\text { at } \mathbf{5 0 0}^{\circ} \mathbf{C} \\
\left.\mathbf{( 9 3 2}^{\circ} \mathbf{F}\right)\end{array}$ & $\begin{array}{c}\text { Carbonized } \\
\text { at } \mathbf{1 0 0 0}^{\circ} \mathbf{C} \\
\left.\mathbf{( 1 8 3 2}^{\circ} \mathbf{F}\right)\end{array}$ & $\begin{array}{c}\text { Carbonized } \\
\text { at } \mathbf{1 4 0 0}^{\circ} \mathbf{C} \\
\left.\mathbf{( 2 5 5 2}^{\circ} \mathbf{F}\right)\end{array}$ \\
\hline Moisture & 15.17 & 5.16 & 1.36 & 0.18 \\
Volatile & 36.43 & 32.20 & 2.49 & 0.65 \\
Fixed carbon & 42.22 & 57.08 & 83.26 & 86.12 \\
Ash & 6.18 & 5.56 & 12.89 & 13.05 \\
Sulfur & 0.32 & 0.41 & 0.41 & 0.43 \\
Btu/lb & 9,981 & 11,507 & 12,460 & 12,773 \\
$\mathbf{k J / k g}$ & 23,167 & 26,709 & 28,921 & 29,648 \\
\hline
\end{tabular}

Table 2-5-21. Composition of feed mixtures, consisting of taconite concentrate (K), PRB coal (07-09-1) at different stoichiometric amounts, and slag composition $\mathrm{C} / \mathrm{S}=1.5$. No binder.

\begin{tabular}{|c|c|c|c|c|c|}
\hline $\begin{array}{c}\text { PRB coal } \\
\text { \% stoich. }\end{array}$ & $\begin{array}{c}\text { Mix } \\
\text { No. }\end{array}$ & $\begin{array}{c}\text { Taconite } \\
\text { conc. }\end{array}$ & $\begin{array}{c}\text { PRB } \\
\text { coal }\end{array}$ & $\begin{array}{c}\text { Lime } \\
\text { hydrate }\end{array}$ & Fluorspar \\
\hline & & & & & \\
$\mathbf{8 5}$ & P-714 & 66.40 & 26.78 & 4.82 & 2.0 \\
$\mathbf{9 0}$ & P-710 & 65.32 & 27.90 & 4.78 & 2.0 \\
$\mathbf{9 5}$ & P-711 & 64.29 & 28.99 & 4.72 & 2.0 \\
$\mathbf{1 0 0}$ & P-712 & 63.27 & 30.03 & 4.70 & 2.0 \\
$\mathbf{1 0 5}$ & P-713 & 62.28 & 31.04 & 4.68 & 2.0 \\
\hline
\end{tabular}

Table 2-5-22. Summary of test results on briquettes at different PRB coal addition, placed on PRB char. No binder.

\begin{tabular}{|c|c|c|cc|}
\hline $\begin{array}{c}\text { PRB coal } \\
\text { \% stoich. }\end{array}$ & Fusion & Micro NRI & \multicolumn{2}{|c|}{ NRI } \\
time, $\mathbf{~ m i n}$ & $\%$ & \%C & \%S \\
\hline & & & & \\
$\mathbf{8 5}$ & $\mathbf{1 0}$ min & 0.8 & 1.47 & 0.075 \\
$\mathbf{9 0}$ & $\mathbf{9} \mathbf{~ m i n}$ & 0.6 & 1.72 & 0.071 \\
$\mathbf{9 5}$ & $\mathbf{5} \mathbf{~ m i n}$ & 0.1 & 1.94 & 0.047 \\
$\mathbf{1 0 0}$ & $\mathbf{5} \mathbf{~ m i n}$ & 0.1 & 2.24 & 0.036 \\
$\mathbf{1 0 5}$ & $\mathbf{5} \mathbf{~}$ in & 4.8 & 2.92 & 0.028 \\
\hline
\end{tabular}




\section{2-5.2.9.3.2 In the presence of molasses}

The optimum amount of PRB coal in the absence of any binder was $95-100 \%$ of the stoichiometric amount, but briquettes with PRB coal had hardly any strength. Molasses acted as a satisfactory binder for wet drop numbers, but the drop numbers decreased markedly upon drying. In order to give sufficient dry drop numbers, it was necessary to add $12-15 \%$ by weight of molasses for oven-dried briquettes to survive even about 4 drops from a height of 18 ". The amount of molasses could be markedly decreased by using PRB char, carbonized at temperatures higher than about $1000^{\circ} \mathrm{C}$ and removing the volatiles to below a few percent.

Briquettes, made with various combinations of PRB coal/char and molasses, were used to search for both sufficiently high dry drop numbers and for minimum fusion time, micro $\mathrm{NRI}$ and NRI sulfur. Feed compositions are given in Table 2-5-23, and the results of drop numbers of briquettes and box furnace tests are summarized in Tables 5-24 to 527.

A combination of $75-80 \%$ stoichiometric PRB coal and $12 \%$ molasses binder was found to give dry drop number of about 4 as well as fusion behavior including minimum fusion time, micro NRI and NRI sulfur, as indicated in bold numbers in Table 2-5-24. 12\% molasses was calculated to be equivalent to $29 \%$ stoichiometric PRB coal, and $60 \%$ of this $29 \%$ is $17 \%$. The total carbon at the optimum would then be $92-97 \%$ of the stoichiometric amount.

With PRB char, the amounts of PRB char and molasses were varied so that dry drop numbers were sufficiently high, and at the same time, both fusion time and micro NRI were at their minima. The optimum combinations were indicated in bold numbers in Tables 2-5-25 to 2-5-27, and summarized as follows:

\section{\% stoichiometric $\quad$ Molasses}

PRB coal

$75-80$

$12 \%$

PRB char $\left(500^{\circ} \mathrm{C}\right)$

$75-80$

$\left(1000^{\circ} \mathrm{C}\right)$

90

$\left(1400^{\circ} \mathrm{C}\right)$

90

$10-12 \%$

$4-5 \%$

$4-5 \%$

Under these conditions, the sum of carbon from PRB coal or from char and molasses came to be about $95 \%$ of the stoichiometric amount if carbon from molasses was assumed to be about $60 \%$ effective when used with PRB coal; about $80 \%$ effective with PRB char $\left(500^{\circ} \mathrm{C}\right)$; and $90-100 \%$ effective with PRB char $\left(1000^{\circ}\right.$ and $\left.1400^{\circ} \mathrm{C}\right)$. In Tables 2-5-24 to 2-5-27, it was noted that drop numbers with PRB coal and char, carbonized at $500^{\circ} \mathrm{C}$, decreased, whereas with PRB char, carbonized at $1000^{\circ}$ and $1400^{\circ} \mathrm{C}$, markedly increased upon drying. Therefore, for molasses to act as an effective binder as well as a reductant, the amount of volatiles of PRB coal/char appeared to be playing a significant role. Perhaps, the volatiles were interfering with molasses to act as a binder as well as a reductant. 
Box furnace test results indicated that NRI sulfur remained below $0.05 \% \mathrm{~S}$ in all cases. These observations suggested that PRB char, carbonized at $1400^{\circ} \mathrm{C}$, required the least amount of molasses for producing strong enough briquettes and was most effective in reduction and carburizing reactions.

In practice, therefore, a part of hearth layer char, already passed through the furnace at $1400^{\circ} \mathrm{C}$, could be used as an internal carbon for reduction. In order to make up for the losses in the furnace as well as for the amount diverted for use as a reductant, fresh PRB coal may be added to PRB char for recycling. In this manner, the volatiles in PRB coal could be utilized in heating the furnace as well as in accelerating the reduction reaction.

Table 2-5-23. Composition of feed mixtures, consisting of taconite concentrate (K), PRB coal/char of different stoichiometric amounts, and slag composition $\mathrm{C} / \mathrm{S}=1.5$

\begin{tabular}{|c|c|c|c|c|c|}
\hline $\begin{array}{l}\text { Coal/char } \\
\% \text { stoich. }\end{array}$ & $\begin{array}{l}\text { Mix } \\
\text { No. }\end{array}$ & $\begin{array}{l}\text { Taconite } \\
\text { conc. }\end{array}$ & $\begin{array}{l}\text { PRB } \\
\text { coal }\end{array}$ & $\begin{array}{c}\text { Lime } \\
\text { hydrate }\end{array}$ & Fluorspar \\
\hline \multicolumn{6}{|l|}{ PRB coal } \\
\hline $\begin{array}{l}85 \\
80 \\
75 \\
65\end{array}$ & \begin{tabular}{|l} 
P-557 \\
P-830 \\
P-740 \\
P-734
\end{tabular} & $\begin{array}{l}66.40 \\
68.26 \\
69.38 \\
71.11\end{array}$ & $\begin{array}{l}26.78 \\
24.79 \\
23.62 \\
21.94\end{array}$ & $\begin{array}{l}4.82 \\
4.95 \\
5.00 \\
4.95\end{array}$ & $\begin{array}{l}2.0 \\
2.0 \\
2.0 \\
2.0\end{array}$ \\
\hline \multicolumn{6}{|c|}{ PRB char $\left(500^{\circ} \mathrm{C}\right)$} \\
\hline $\begin{array}{l}75 \\
80 \\
85\end{array}$ & \begin{tabular}{|l|} 
P-840 \\
P-829 \\
P-808
\end{tabular} & $\begin{array}{l}72.47 \\
71.45 \\
70.46\end{array}$ & $\begin{array}{l}20.33 \\
21.37 \\
22.93\end{array}$ & $\begin{array}{l}5.20 \\
5.18 \\
5.15\end{array}$ & $\begin{array}{l}2.0 \\
2.0 \\
2.0\end{array}$ \\
\hline \multicolumn{6}{|c|}{ PRB char $\left(1000^{\circ} \mathrm{C}\right)$} \\
\hline 90 & P-741 & 75.97 & 16.45 & 5.58 & 2.0 \\
\hline \multicolumn{6}{|c|}{ PRB char $\left(1400^{\circ} \mathrm{C}\right)$} \\
\hline $\begin{array}{l}85 \\
90 \\
95\end{array}$ & \begin{tabular}{|l|} 
P-732 \\
P-827 \\
p-737
\end{tabular} & $\begin{array}{l}77.14 \\
76.40 \\
75.67\end{array}$ & $\begin{array}{l}15.26 \\
16.00 \\
16.73\end{array}$ & $\begin{array}{l}5.60 \\
5.60 \\
5.60\end{array}$ & $\begin{array}{l}2.0 \\
2.0 \\
2.0\end{array}$ \\
\hline
\end{tabular}


Table 2-5-24. Summary of test results on briquettes at different addition levels of PRB coal, briquetted with different amounts of molasses, placed on PRB char and heated at $1400^{\circ} \mathrm{C}$ in a $\mathrm{N}_{2}-\mathrm{CO}$ atmosphere.

\begin{tabular}{|c|c|cc|c|c|c|}
\hline $\begin{array}{c}\text { PRB coal } \\
\text { \% stoich. }\end{array}$ & $\begin{array}{c}\text { Molasses } \\
\text { \% }\end{array}$ & \multicolumn{2}{|c|}{$\begin{array}{c}\text { Drop No. } \\
\text { Wet }\end{array}$} & $\begin{array}{c}\text { Fusion } \\
\text { time, } \text { min }\end{array}$ & $\begin{array}{c}\text { Micro NRI } \\
\text { \% }\end{array}$ & $\begin{array}{c}\text { NRI } \\
\text { \%S }\end{array}$ \\
\hline & & & & & & \\
$\mathbf{8 5}$ & $\mathbf{1 2}$ & 5.1 & 3.0 & 4 & 5.2 & 0.028 \\
$\mathbf{8 5}$ & $\mathbf{1 3 . 5}$ & 7.8 & 4.6 & 5 & 9.2 & 0.030 \\
$\mathbf{8 5}$ & $\mathbf{1 5}$ & 16.0 & 8.1 & 4 & 22.6 & 0.024 \\
$\mathbf{8 0}$ & $\mathbf{1 2}$ & $>\mathbf{4 0}$ & $\mathbf{3 . 6}$ & $\mathbf{4}$ & $\mathbf{0 . 3}$ & $\mathbf{0 . 0 2 7}$ \\
$\mathbf{7 5}$ & $\mathbf{1 2}$ & $>\mathbf{3 7 . 4}$ & $\mathbf{4 . 2}$ & $\mathbf{5}$ & $\mathbf{0 . 2}$ & $\mathbf{0 . 0 3 6}$ \\
$\mathbf{6 5}$ & $\mathbf{1 2}$ & $>27.2$ & 5.8 & 11 & 0.0 & 0.044 \\
\hline
\end{tabular}

Table 2-5-25. Summary of test results on briquettes at different addition levels of PRB char $\left(500^{\circ} \mathrm{C}\right)$, briquetted with different amounts of molasses, placed on PRB char and heated at $1400^{\circ} \mathrm{C}$ in a $\mathrm{N}_{2}-\mathrm{CO}$ atmosphere.

\begin{tabular}{|c|c|c|c|c|c|c|}
\hline $\begin{array}{l}500^{\circ} \mathrm{C} \text { char } \\
\% \text { stoich. }\end{array}$ & $\begin{array}{c}\text { Molasses } \\
\%\end{array}$ & $\begin{array}{l}\text { Dror } \\
\text { Wet }\end{array}$ & $\begin{array}{l}\text { No. } \\
\text { Dry }\end{array}$ & $\begin{array}{c}\text { Fusion } \\
\text { time, min }\end{array}$ & $\begin{array}{l}\text { Micro } \\
\text { NRI \% } \\
\end{array}$ & $\begin{array}{l}\text { NRI } \\
\% S\end{array}$ \\
\hline 85 & 10 & $>40$ & 4.2 & 4 & 6.5 & 0.032 \\
\hline 80 & 10 & $>40$ & 7.2 & $4^{1)}$ & 3.5 & 0.031 \\
\hline 80 & 10 & $>40$ & 7.2 & 5 & 0.5 & 0.035 \\
\hline 80 & 10 & $>40$ & 7.2 & 6 & 0.5 & 0.034 \\
\hline 75 & 12 & $>40$ & 10.0 & $5^{1)}$ & 0.4 & 0.037 \\
\hline 75 & 12 & $>40$ & 10.0 & 6 & 0.5 & 0.037 \\
\hline
\end{tabular}

1) Minimum time to fusion

Table 2-5-26. Summary of test results on briquettes at different addition levels of PRB char $\left(1000^{\circ} \mathrm{C}\right)$, briquetted with different amounts of molasses, placed on PRB char and heated at $1400^{\circ} \mathrm{C}$ in a $\mathrm{N}_{2}-\mathrm{CO}$ atmosphere.

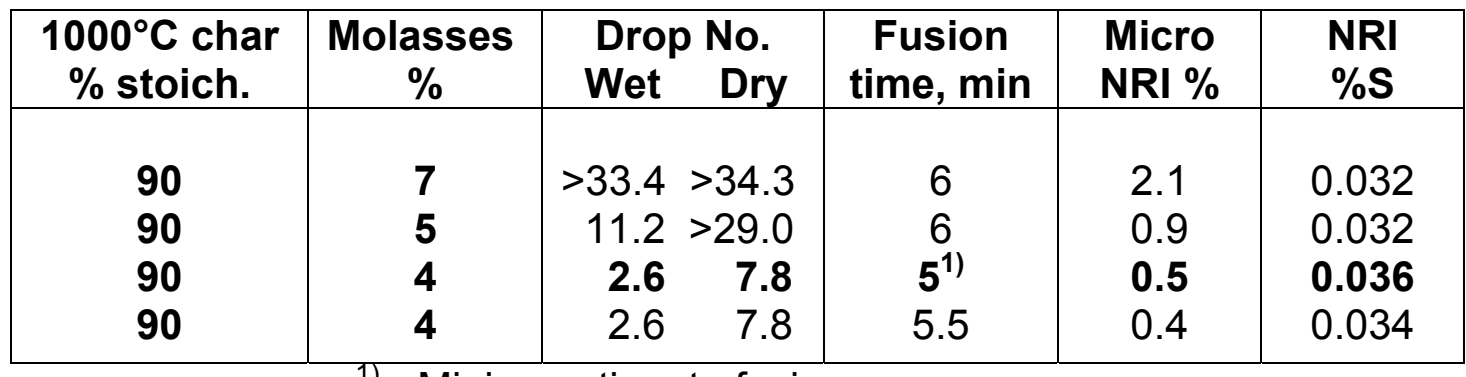

1) Minimum time to fusion 
Table 2-5-27. Summary of test results on briquettes at different addition levels of PRB char $\left(1400^{\circ} \mathrm{C}\right)$, briquetted with different amounts of molasses, placed on PRB char and heated at $1400^{\circ} \mathrm{C}$ in a $\mathrm{N}_{2}-\mathrm{CO}$ atmosphere.

\begin{tabular}{|c|c|c|c|c|c|}
\hline $\begin{array}{l}1400^{\circ} \mathrm{C} \text { char } \\
\% \text { stoich. }\end{array}$ & $\begin{array}{c}\text { Molasses } \\
\% \\
\end{array}$ & $\begin{array}{l}\text { Drop No. } \\
\text { Wet Dry }\end{array}$ & $\begin{array}{c}\text { Fusion } \\
\text { time, min }\end{array}$ & $\begin{array}{l}\text { Micro } \\
\text { NRI \% } \\
\end{array}$ & $\begin{array}{l}\text { NRI } \\
\% S\end{array}$ \\
\hline 85 & 5 & $8.2>33.4$ & $6^{1)}$ & 3.4 & 0.033 \\
\hline 85 & 5 & $8.2>33.4$ & 7 & 1.4 & 0.030 \\
\hline 95 & 5 & $10.8>20.7$ & 5 & 14.1 & 0.031 \\
\hline 90 & 3 & 2.8 & 5 & 15.4 & 0.030 \\
\hline 90 & 4 & $4.6 \quad 23.4$ & $5^{1)}$ & 9.5 & 0.034 \\
\hline 90 & 4 & $4.6 \quad 23.4$ & 5.5 & 3.5 & 0.030 \\
\hline 90 & 4 & $4.6 \quad 23.4$ & 6 & 3.8 & 0.034 \\
\hline 90 & 4 & $4.6 \quad 23.4$ & 7 & 2.0 & 0.032 \\
\hline
\end{tabular}

\section{2-5.3 Binder testing in briquetting}

Direct use of sub-bituminous coal in balling and briquetting resulted in weak wet strengths and in extremely weak dry strengths, which precluded their use in agglomerated mixtures in the absence of binders. In preparation for LHF tests with briquettes, made of taconite concentrate-PRB coal mixtures, development of a binder that makes briquettes strong enough to withstand handling was undertaken.

Initially, a Carver press was used for preparing briquettes to explore the effects of binders, and later a Laboratory Komarek briquetting machine was acquired, and tests were resumed to examine a few promising binders.

\section{2-5.3.1 Carver press briquettes}

In this section, preliminary results on different binders using Carver press briquettes are presented. An attempt was made to relate the briquettes to a pilot-plant 50-ton Komarek briquetting machine.

\section{2-5.3.1.1 Conclusions}

1) Compression strength of briquettes, formed in a Carver press at $66,720 \mathrm{~N}$ $(15,000 \mathrm{lb})$ load, were not a good indicator for testing such binders as molasses, Peridur $315.15 \mathrm{C}$, Staranic 105 starch, bentonite and sodium silicate, up to $2 \%$ by weight. These binders showed little effects on wet and dry strengths. Only Peridur showed an increase in dry strength.

2) Drop numbers were more promising in showing the effectiveness of binders than compression strength measurements. Drop numbers, measured in the direction of flat surface, were markedly higher than those measured in the direction of side. 
3) Of the binders, only bentonite showed steady improvement in drop numbers with an increasing amount of its addition when briquettes were dropped in the direction of flat surface. However, drop numbers in the direction of side showed little effect of bentonite.

4) Wet drop numbers with bentonite decreased with time due presumably to the reaction of sodium bentonite with hydrated lime, thereby converting into calcium bentonite. Such an observation suggested bentonite-added wet briquettes need to be fluxed with limestone rather than with hydrated lime for adjusting slag basicity.

5) Peridur markedly increased the wet numbers when briquettes were dropped in the direction of side, but there was no improvement when the briquettes were dropped in the direction of flat surface. Dry drop numbers with Peridur were markedly higher than those with bentonite.

2-5.3.1.2 Test procedure: Three types of coals were tested with a taconite concentrate, all at $80 \%$ of the stoichiometric amount. PRB char was prepared by carbonizing at $900^{\circ} \mathrm{C}$ for 20 minutes. The compositions of feed mixtures are given in Table 2-5-28.

Cylindrical briquettes of $25.4 \mathrm{~mm}(1 ")$ in diameter and $15.2 \mathrm{~mm}(0.6$ ") high were made with the feed mixture. The load applied in the Carver press was $22,240,44,480,66,720$ and $89,600 \mathrm{~N}(5,000,10,000,15,000$ and 20,000 lbs). Wet and dry strengths were measured using IMADA digital force gauge Model DPS-220R by applying the load to cylindrical surfaces. The wet strengths were measured immediately, 1 hour and 2 hours after preparation to see if there was any change in their strengths with time. The dry strengths were measured after drying at $105^{\circ} \mathrm{C}\left(221^{\circ} \mathrm{F}\right)$.

To compare the wet and dry strengths of briquettes made by Carver press with those made by a 50-ton Komarek briquetting machine with rollers having a pocket size that produced briquettes of $25 \times 25 \times 19 \mathrm{~mm}(1 \times 1 \times 0.75$ ") in size and operating at a pressing force of $5,338 \mathrm{~N}(1,200 \mathrm{lbs})$, were measured, but the strengths made by Carver press and Komarek briquetting machine were so different that no correlation could be established. It was arbitrarily decided, therefore, that briquettes made by Carver press with applied load of $66,723 \mathrm{~N}(15,000 \mathrm{lbs})$ were used for testing of binders.

Drop tests were tried on Carver press briquettes by dropping from a height of $304.8 \mathrm{~mm}$ (12") initially onto a sheet of a conveyor belt rubber. A wet briquette dropped in the direction of flat surface survived over 300 drops. Even in the direction of side, a briquette did not break until 68 drops. Hence, dropping onto a steel plate was selected for testing. The measurements were made both in the direction of flat surface and of side. Five briquettes were tested at each condition and the results averaged.

\section{2-5.3.1.3 Test results}

\section{2-5.3.1.3.1 In the absence of binder}

Test results with three coals are summarized in Table 2-5-29. With PRB coal, wet strengths, regardless of the loads applied, were 17.8 to $22.2 \mathrm{~N}$ (4 to $5 \mathrm{lbs}$ ) immediately after preparation, and decreased steadily to about $8.9 \mathrm{~N}(2 \mathrm{lbs})$ after 2 hours. Dry strengths were less than $8.9 \mathrm{~N}$ (2 lbs). With PRB char, briquettes formed by applying 
$66,700 \mathrm{~N}(15,000 \mathrm{lb})$ load were tested. The wet strength immediately after preparation was $44.5 \mathrm{~N}(10 \mathrm{lb})$ and increased to $53.4 \mathrm{~N}(12 \mathrm{lb})$ after 2 hours. The dry strengths were $93.4 \mathrm{~N}(21 \mathrm{lb})$ when the briquettes were dried immediately after preparation, and increased to $137.9 \mathrm{~N}(31 \mathrm{lb})$ when dried after 2 hours. For comparison, similar tests were performed on a feed mixture with bituminous coal $(F)$. Wet strengths were as high as about $62.3 \mathrm{~N}(14 \mathrm{lbs})$ in the range of $44,480 \mathrm{~N}$ to $66,720 \mathrm{~N}(10,000$ to $15,000 \mathrm{lb})$ applied load, and the dry strengths in the range of 133.4 to $204.6 \mathrm{~N} \mathrm{(30} \mathrm{to} 46 \mathrm{lbs}$ ). It is apparent that PRB coal gave uniquely weak wet and dry strengths.

Table 2-5-28. Composition of feed mixtures, consisting of taconite concentrate, bituminous coal (F), PRB coal or PRB char, carbonized at $800^{\circ} \mathrm{C}$, at $80 \%$ of the stoichiometric amount, and slag composition $\mathrm{L}_{1.5} \mathrm{FS}_{2}$.

\begin{tabular}{|c|c|c|c|}
\hline $\begin{array}{c}\text { Taconite } \\
\text { conc }\end{array}$ & Coal/char & $\begin{array}{l}\text { Hyd. } \\
\text { lime }\end{array}$ & Fluorspar \\
\hline \multicolumn{4}{|c|}{ Bituminous coal $(F)$} \\
\hline 72.6 & 16.6 & 8.8 & 2.0 \\
\hline \multicolumn{4}{|l|}{ PRB coal } \\
\hline 66.3 & 24.6 & 7.1 & 2.0 \\
\hline \multicolumn{4}{|l|}{ PRB char } \\
\hline 74.8 & 14.7 & 8.5 & 2.0 \\
\hline
\end{tabular}

\section{2-5.3.1.3.2 Effect of binders}

Compression strengths: Five binders, namely, molasses, Peridur 315.15C, Staranic 105 starch, bentonite and sodium silicate, were tested on a feed mixture with bituminous coal $(F)$ by forming Carver press briquettes at addition levels of $1 \%$ by weight and $10 \%$ moisture. Wet strengths immediately, 1 hour and 2 hours after preparation were determined and found that they were well within the experimental error. Hence, all the data at each condition were combined and overall average values were calculated. The overall average values of the wet strengths and dry strengths are summarized in Table 2-5-30.

Wet strengths with the three organic binders were not significantly different from the results in the absence of binders. The two inorganic binders appeared to improve the wet strengths somewhat. The dry strengths with the starch and bentonite remained about the same as in the absence of binders. Molasses even adversely affected the dry strengths. Peridur, a CMC product, adversely affected the wet strengths but showed markedly improved dry strengths.

Similar series of tests were carried out by increasing the addition levels of the five binders to $2 \%$ by weight. In these tests, both wet and dry strengths were determined 
immediately and after 2 hours after preparation, and the results averaged as before. The results are included in Table 2-5-30. Both wet and dry strengths showed essentially the same trend and were in about the same range as at an addition level of $1 \%$.

Drop numbers: As compression strengths did not show any meaningful effect of binders, drop tests were tried to see if the effect may be brought out. Initially, five binders were tested at addition levels of $2 \%$. The results are given in Table 2-5-31. Drop numbers in the direction of the flat surface were within the experimental error, except for bentonite.

To explore if any trend could be observed, the amount of bentonite was varied from $1 \%$ to $3 \%$. The results indicated steady improvement from 76.5 to 97 to 112 to $138 \mathrm{~N}(17.2$ to 21.8 to 25.2 to $31.0 \mathrm{lb}$ ) for $0 \%, 1 \%, 2 \%$ and $3 \%$ bentonite, respectively, suggesting that the drop numbers in the direction of flat surface could be a potential indicator of the binder effect. However, drop numbers in the direction of side were within the experimental error.

Another point of note was that wet drop numbers of bentonite-added briquettes kept in a plastic bag for 2 hours decreased with time. This may be due presumably to the reaction of sodium bentonite with hydrated lime, thereby converting into calcium bentonite. Such an observation suggested that bentonite-added wet briquettes need to be dried soon after preparation, or perhaps the lime fluxing agent added in the form of limestone. Peridur markedly increased the wet drop numbers when briquettes were dropped in the direction of side, but there was no improvement when the briquettes were dropped in the direction of flat surface. Dry drop numbers with Peridur were markedly higher than those with bentonite. 
Table 2-5-29. Effect of compacting load on wet and dry compression strengths of Carver press briquettes, consisting of taconite concentrate, different coal/char at $80 \%$ of the stoichiometric amount and slag composition $\mathrm{L}_{1.5} \mathrm{FS}_{2}$, formed with no binder (Compression test load applied to cylindrical surfaces). Compression Strength in $\mathrm{Ib}_{\mathrm{f}}$

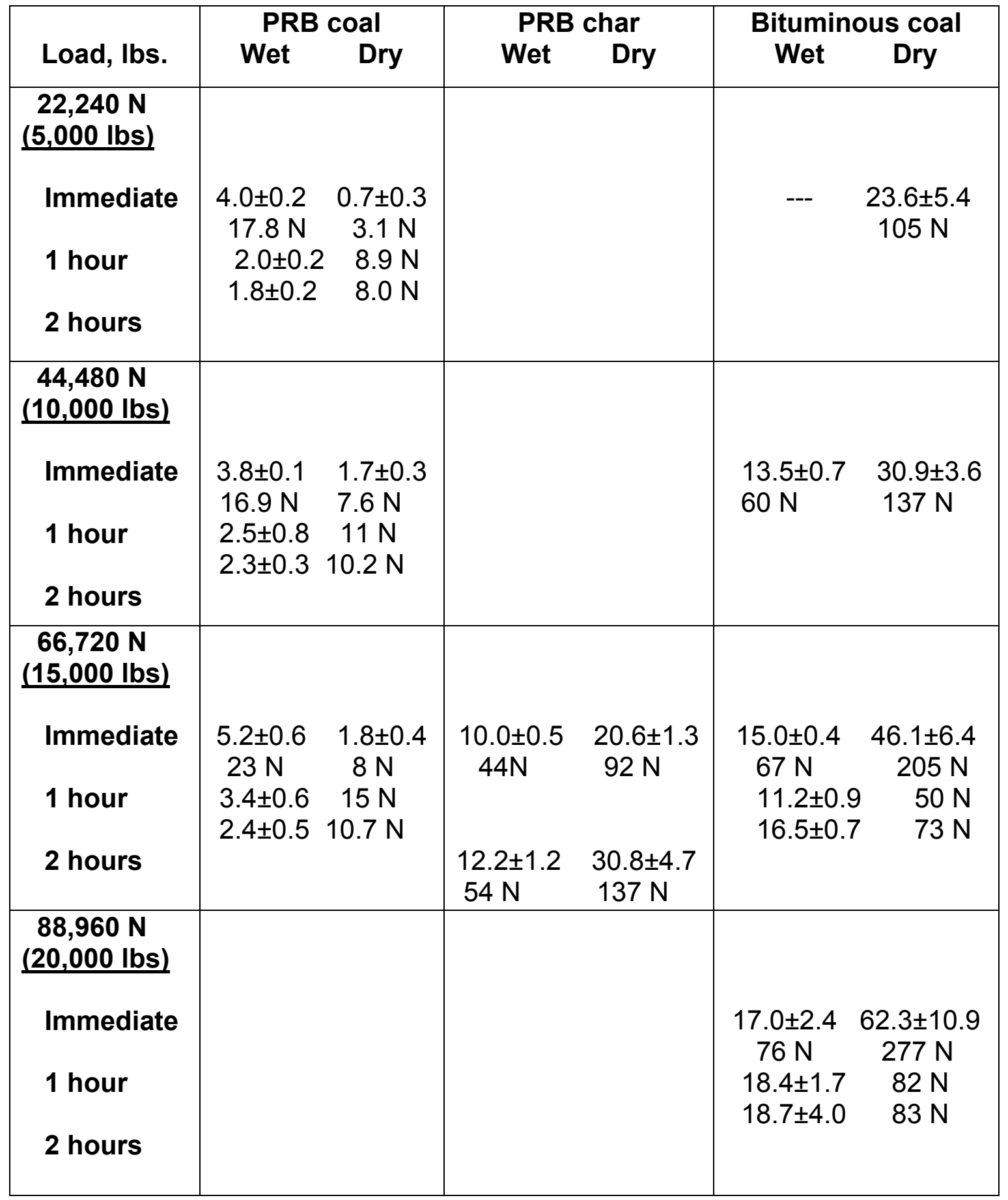


Table 2-5-30. Summary of the effect of binders on wet and dry strengths of Carver press briquettes formed at $15,000 \mathrm{lb}$ load. Compression Strength in $\mathrm{Ib}_{\mathrm{f}}$

\begin{tabular}{|c|c|c|c|}
\hline \multicolumn{2}{|r|}{ Binder } & \multirow{2}{*}{$\begin{array}{l}\text { Wet Strength in N } \\
\text { Overall Average } \\
\left(\mathrm{Ib}_{\mathrm{f}} \text { and variation }\right)\end{array}$} & \multirow{2}{*}{$\begin{array}{l}\text { Dry Strength in } \mathbf{N} \\
\text { Average } \\
\left(\mathrm{lb}_{\mathrm{f}} \text { and variation }\right)\end{array}$} \\
\hline Amount & Additive & & \\
\hline & None & $64 \mathbf{N}(14.3+2.5)$ & $205 \mathrm{~N}(46.1+6.4)$ \\
\hline \multirow[t]{5}{*}{$1 \%$} & Molasses & $65 \mathbf{N}(14.7+1.6)$ & $126 \mathrm{~N}(28.4+3.2)$ \\
\hline & Peridur 315.15C & $58 \mathbf{N}(13.1+1.0)$ & $279 \mathrm{~N}(62.7 \pm 4.1)$ \\
\hline & $\begin{array}{l}\text { Staranic } 105 \\
\text { Starch }\end{array}$ & $64 \mathbf{N}(14.3 \pm 0.6)$ & $219 \mathbf{N}(49.2 \pm 3.1)$ \\
\hline & Bentonite & $75 \mathrm{~N}(16.9 \pm 1.0)$ & $219 \mathbf{N}(49.2 \pm 7.3)$ \\
\hline & Sodium Silicate & $74 \mathbf{N}(16.7 \pm 0.9)$ & 247 N $(55.5+3.6)$ \\
\hline \multirow[t]{5}{*}{$2 \%$} & Molasses & $69 \mathbf{N}(15.5 \pm 1.6)$ & $210 \mathrm{~N}(47.2 \pm 3.8)$ \\
\hline & Peridur 315.15C & $53 \mathbf{~ N ~}(12.0 \pm 0.4)$ & $387 \mathrm{~N}(87.0 \pm 8.5)$ \\
\hline & $\begin{array}{l}\text { Staranic } 105 \\
\text { Starch }\end{array}$ & $63 \mathbf{N}(14.2 \pm 7.4)$ & $190 \mathbf{N}(42.8 \pm 6.5)$ \\
\hline & Bentonite & $69 \mathbf{N}(15.6 \pm 1.9)$ & $184 \mathbf{N}(41.3 \pm 4.6)^{*}$ \\
\hline & Sodium Silicate & $65 \mathbf{N}(14.6 \pm 1.2)$ & $227 \mathrm{~N}(51.0 \pm 8.1)^{\star}$ \\
\hline
\end{tabular}

${ }^{*}$ Average of dry strengths placed in a drying oven immediately and 2 hour after preparation.

Table 2-5-31. Summary of the effect of binders on drop numbers of Carver press briquettes formed at $66,720 \mathrm{~N}(15,000 \mathrm{lb})$ load. Drop height $304.8 \mathrm{~mm}$ (12") onto steel plate.

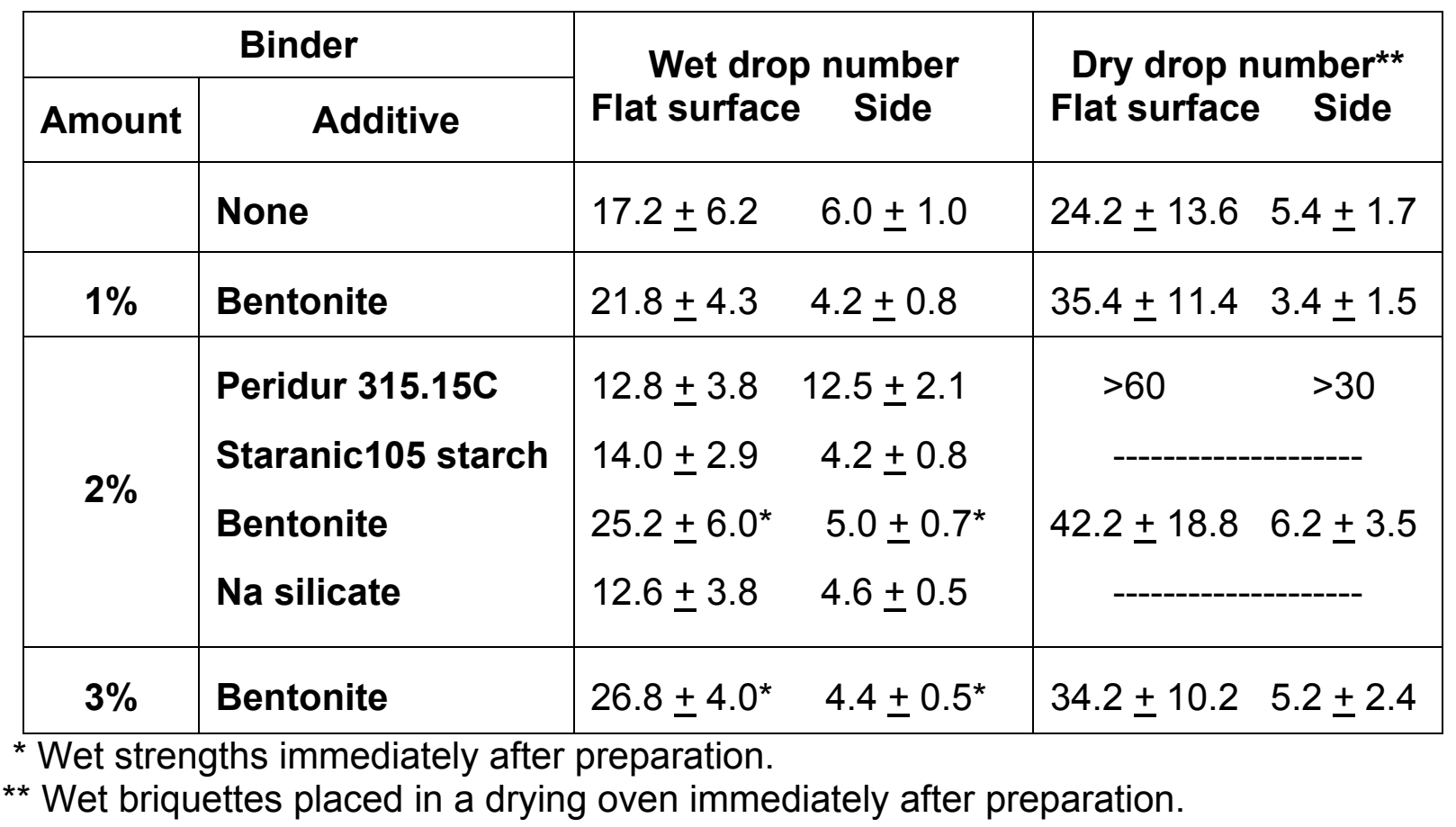




\section{2-5.3.2 Laboratory Komarek briquetting machine}

Since the preliminary tests using a Carver press were made, a laboratory Komarek briquetting machine became available. The Laboratory Komarek briquetting machine had rollers with a pocket size that produced briquettes of $35 \times 22 \times 13 \mathrm{~mm}(1.4 \times 0.9 \times 0.5 ")$ in size and operating at a pressing force of $5782 \mathrm{~N}$ (1300 lbs). A few preliminary tests were made using molasses, Bunker $C$ heavy oil, asphalt emulsions and sodium silicate as binders.

Later, asphalt emulsions of different softness, prepared by Flint Hills Resources were tested.

2-5.3.2.1 Test procedure: The composition of a feed mixture, consisting of taconite concentrate $(\mathrm{K})$ and $85 \%$ stoichiometric PRB coal was as follows:

\begin{tabular}{|c|c|c|c|}
\hline $\begin{array}{c}\text { Taconite } \\
\text { conc }\end{array}$ & $\begin{array}{c}\text { PRB } \\
\text { coal }\end{array}$ & $\begin{array}{c}\text { Hyd. } \\
\text { lime }\end{array}$ & $\begin{array}{c}\text { Fluor- } \\
\text { spar }\end{array}$ \\
\hline 66.4 & 26.8 & 4.8 & 2.0 \\
\hline
\end{tabular}

Molasses was received from United States Sugar Corporation, Clewiston, FL. Sodium silicate was N-sodium silicate received from PQ Corporation, Valley Forge, PA. Asphalt emulsions, SS-1h and CSS-1h, were received from Flint Hills Resources, St. Paul, MN. Bunker $\mathrm{C}$ heavy oil was received from Murphy Oil, Superior, WI.

Type CSS-1h was prepared by emulsifying asphalt using a cationic surfactant, whereas Type SS-1h was prepared by using an anionic surfactant. As the emulsions stood for a while, some emulsion particles settled out to the bottom of a 5-gallon pail. To fully redisperse, the emulsions were stirred by heating to $50-55^{\circ} \mathrm{C}$, as recommended by Flint Hills Resources. For preparing the mixtures of SS-1h and Bunker C, Bunker $\mathrm{C}$ as well as makeup water were also heated to the same temperature, and mixed vigorously together to pre-determined ratios for adjusting the moisture of feed mixtures for briquetting. When Bunker $\mathrm{C}$ was tested by itself, an anionic detergent, Dawn ( $2 \%$ by weight), was used to emulsify the Bunker C-water mixture in a Waring blender. Asphalt emulsions with three different softness, SS-1h (PG 64-22), SS-1 (PG 58-28) and SS-1s (PG 52-34), received from Flint Hills Resources, were included in the tests.

A $2000 \mathrm{~g}$ feed mixture was charged into a V-mixer together with a binder solution containing sufficient water for briquetting, and mixed for 5 minutes. The moist mixture was fed to the Laboratory Komarek briquetting machine at a constant feed rate. Drop tests were carried out by dropping the briquettes from a height of $457.2 \mathrm{~mm}$ (18") onto a steel plate 


\section{2-5.3.2.2 Preliminary results with different binders:}

\section{2-5.3.2.2.1 Conclusions}

1) SS-1h in the range of $8-10 \%$ gave wet drop numbers of about 10 , and even though their dry drop numbers decreased, they remained much higher than molasses.

2) Bunker $C$ emulsion gave high wet drop numbers, but lost its strength upon drying.

3) Oven-dried briquettes, made with mixtures of Bunker $\mathrm{C}$ and $\mathrm{SS}-1 \mathrm{~h}$ in the ratios of (50:50) and, in particular, (25:75) were notably higher in drop numbers than SS$1 \mathrm{~h}$ by itself, suggesting that petroleum residues, from which not as much volatiles are removed, might be better suited for binders.

4) Wet drop numbers notably increased with time to about 4 hours, and decreased gradually overnight, but remained much higher than oven-dried briquettes.

5) CSS-1 $\mathrm{h}$ did not give as high drop numbers as SS-1h.

6) SS-1h in the range of $8-10 \%$ was at optimum for giving briquettes sufficient drop strength.

7) Asphalt binders become of interest as they replace a part of reductant coal by their high carbon contents and a part of fuel by their high calorific values.

\section{2-5.3.2.2.2 Test results}

Initially, the effect of the addition level of SS-1h was tested. Based on the exploratory test results, the addition level was narrowed to 8,9 and $10 \%$. The drop tests were carried out on 10 briquettes immediately after preparation, 1 hour, 2 hours, 4 hours and overnight. The tests were also carried out on briquettes dried in an oven at $105^{\circ} \mathrm{C}\left(221^{\circ}\right.$ F). The results with all the binders tested are given in Table 2-5-32.

With molasses, about $10 \%$ by weight was necessary to give sufficiently strong wet drop numbers, but oven-dried briquettes did not survive more than two drops. It was necessary to increase molasses to nearly $15 \%$ before strong enough dry drop numbers were obtained. $\mathrm{N}$-sodium silicate was totally ineffective.

Sufficiently strong drop numbers were obtained with $10 \%$ by weight of SS-1h. Drop numbers with CSS-1h, also with $10 \%$ by weight, were notably lower than SS-1h, suggesting that the electrical charge on the emulsified asphalt was not as favorable. Bunker $\mathrm{C}$ was also tested, but had no binder capability. A few exploratory tests indicated that a mixture of SS-1h and Bunker $\mathrm{C}$ showed promise, suggesting that softer asphalt might act as better binders. During the tests, the drop numbers of wet briquettes were noted to increase with time.

Further tests were carried out with SS-1h by determining the drop numbers of wet briquettes immediately, 1 hour, 2 hours, 4 hours and next day for comparison with ovendried briquettes. The results are given in Figure 2-5-14. With $100 \% \mathrm{SS}-1 \mathrm{~h}$, drop numbers improved somewhat with time. The amount of addition of $8 \%$ was insufficient, whereas the addition of $9 \%$ and $10 \%$ gave equally high drop numbers. Oven-drying made the briquettes notably weaker. 
Table 2-5-32. Drop numbers of briquettes, consisting of taconite concentrate (K) and $85 \%$ stoichiometric PRB coal as a function of time

\begin{tabular}{|c|c|c|}
\hline & Immediate & $\begin{array}{l}\text { Oven } \\
\text { dried }\end{array}$ \\
\hline \multicolumn{3}{|l|}{ Molasses } \\
\hline $8 \%$ & $4.4 \pm 1.5$ & $2.2 \pm 1.1$ \\
\hline $10 \%$ & $10.7 \pm 4.1$ & $2.2 \pm 1.3$ \\
\hline $12 \%$ & $5.1 \pm 3.0$ & $3.0 \pm 1.8$ \\
\hline 13.5 & $7.8 \pm 4.1$ & $4.6 \pm 2.2$ \\
\hline $15 \%$ & $16.0 \pm 8.0$ & $8.1 \pm 3.0$ \\
\hline \multicolumn{3}{|l|}{ Bunker C } \\
\hline $8 \%$ & $3.2 \pm 1.0$ & $2.5 \pm 1.9$ \\
\hline $10 \%$ & $3.1 \pm 1.5$ & $1.1 \pm 0.3$ \\
\hline $\begin{array}{c}(50: 50) \text { Bunker C: } \\
\text { SS-1h } \\
10 \% \text { total }\end{array}$ & $14.4 \pm 7.5$ & $7.0 \pm 2.3$ \\
\hline $\begin{array}{c}\text { (25:75) Bunker C: } \\
\text { SS-1h } \\
10 \% \text { total }\end{array}$ & $13.1 \pm 8.0$ & $15.2 \pm 7.9$ \\
\hline \multicolumn{3}{|l|}{ SS-1h } \\
\hline $8 \%$ & $7.2 \pm 5.1$ & $3.7 \pm 1.3$ \\
\hline $10 \%$ & $12.6 \pm 4.8$ & $6.5 \pm 3.1$ \\
\hline \multicolumn{3}{|l|}{ CSS-1h } \\
\hline $10 \%$ & $7.9 \pm 3.8$ & $6.2 \pm 2.2$ \\
\hline $\begin{array}{l}\mathrm{N} \text { - sodium silicate } \\
10 \%\end{array}$ & $1.2 \pm 0.4$ & $1.2 \pm 0.4$ \\
\hline
\end{tabular}


The effect of mixtures, consisting of SS-1h and Bunker C, were tested by keeping the total amount of addition constant at 10\%, and varying their ratios from (100:0), (87.5:12.5), (75:25), (62.5:37.5) and (50:50). In this series of tests, the effect of aging was extended by exposing the briquettes to the air for 7 days for comparison with ovendried briquettes. The results of drop tests are given in Figure 2-5-15.

By adding Bunker C to SS-1h, drop numbers notably increased with time. With (75:25) mixture, the drop numbers appeared to reach maximum, then gradually decreased to (50:50) mixture. The drop numbers are by nature highly variable as indicated by the large standard deviation associated with each determination. Nevertheless, the general trend of the beneficial effect of the mixture was evident.

After 7 days of drying in the air, the briquettes were dry and their drop numbers became somewhat lower, but were much stronger than oven-dried briquettes. Obviously, some drying method needs to be developed in order to retain the drop strength rather than the quick drying in a drying oven held at $105^{\circ} \mathrm{C}\left(221^{\circ} \mathrm{F}\right)$.

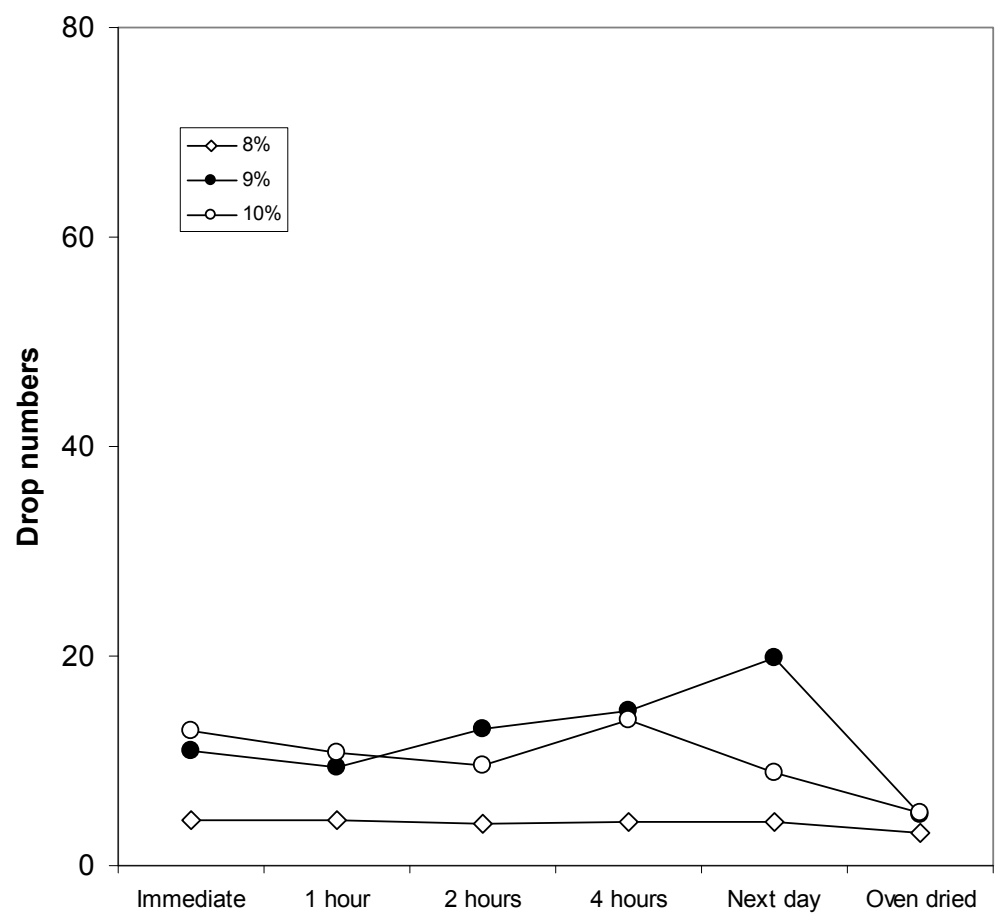

Figure 2-5-14. Drop numbers of briquettes, consisting of taconite concentrate (K) and $85 \%$ stoichiometric PRB coal (P-557), showing the effects of the amount of addition of SS-1h used as a binder on aging of briquettes. 


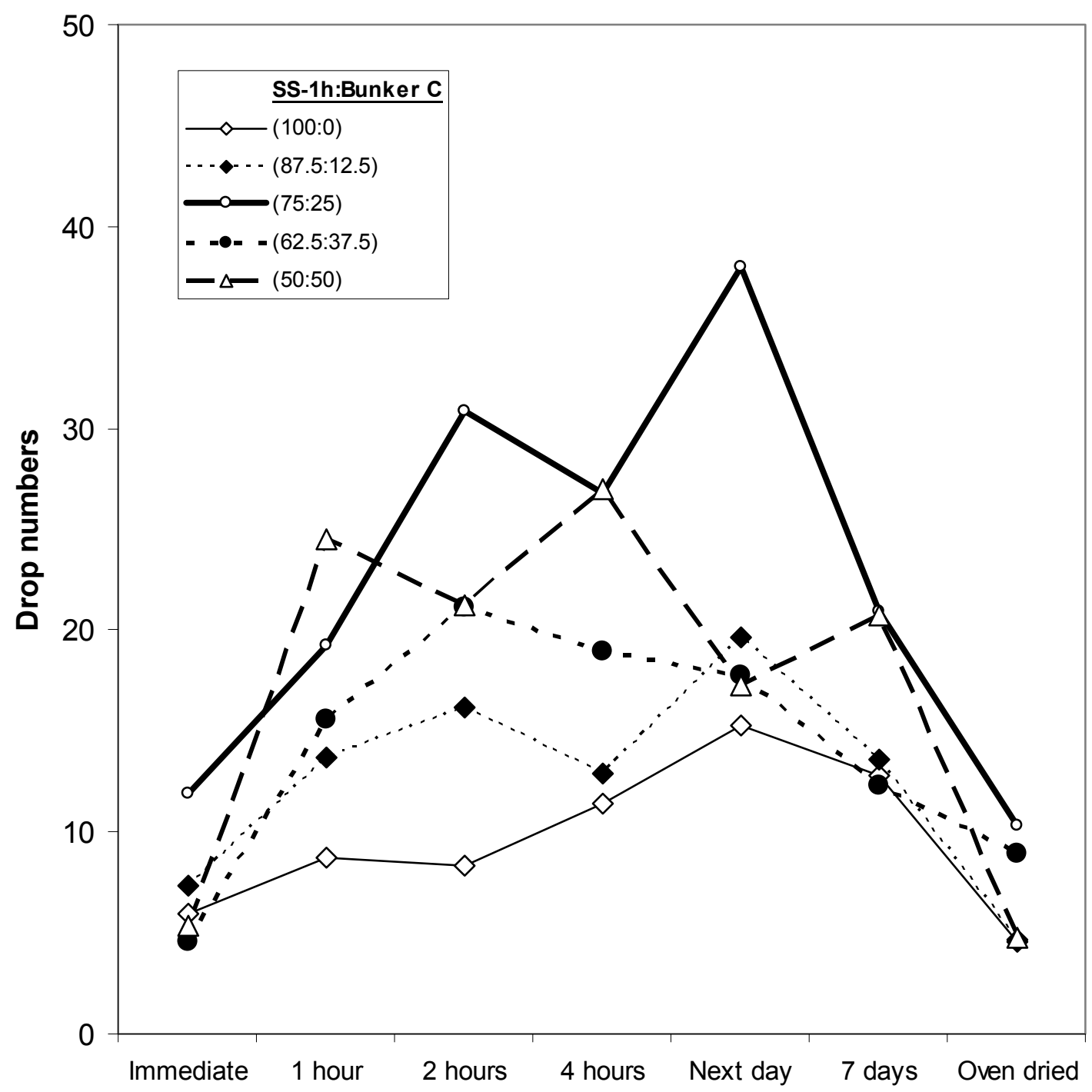

Figure 2-5-15. Drop numbers of briquettes, consisting of taconite concentrate (K) and $85 \%$ stoichiometric PRB coal, showing the effects of mixing ratios of SS-1h and Bunker $\mathrm{c}$ in emulsions, used as a binder on aging of briquettes.

2-5.3.2.3 Asphalt emulsions: Binder tests with an asphalt emulsion, SS-1h (PG 6422), showed promise in preparing briquettes with sufficient wet and dry drop strengths, particularly when mixed with Bunker $C$. In consultation with Flint Hills Resources, two additional emulsions with softer asphalts, (SS-1 (PG 58-28) and SS-1s (PG 52-34)), were received for testing. According to Flint Hills Resources, the softer asphalts are similar to SS-1h mixed with Bunker C.

In this section, briquette strengths with the two softer asphalt emulsions were compared with SS-1h (PG 62-22), and their effects on the fusion behaviors of briquettes were investigated. 


\section{2-5.3.2.3.1 Conclusions}

1) Although asphalt emulsions worked well as briquetting binders and added a large amount of carbon to briquettes, they somehow made reductant PRB coal less active.

2) Feed mixtures with 60 to $85 \%$ stoichiometric PRB coal, briquetted with asphalt binders, did not fuse even after heating at $1400^{\circ} \mathrm{C}$ for $10-20$ minutes. Residual carbon after heating in Zone $1\left(1149^{\circ} \mathrm{C}\right)$ for 5 minutes was essentially in the same range as those without binders.

3) Asphalt emulsions appeared to gasify without leaving much of their carbon to briquettes. In addition, asphalt emulsions appeared to have taken along a part of fixed carbon from PRB coal in gasification.

\section{2-5.3.2.3.2 Chemical composition of asphalt emulsions}

The three asphalt emulsions were dried at $100^{\circ} \mathrm{C}\left(212^{\circ} \mathrm{F}\right)$ overnight to estimate their moisture contents. The asphalt emulsions were analyzed for carbon and sulfur. An attempt was made to ash SS-1h for analyzing other minor elements, but the treatment did not produce any ash. The carbon and sulfur analyses are given in Table 2-5-33.

\section{Table 2-5-33. Chemical composition of asphalt emulsions}

\begin{tabular}{|c|c|c|c|c|c|}
\hline & \multirow{2}{*}{ Moist. } & \multicolumn{2}{|c|}{ Moisture free } & \multicolumn{2}{|c|}{ As emulsions } \\
\hline & & $\% \mathrm{C}$ & $\% S$ & $\% \mathrm{C}$ & $\% S$ \\
\hline $\begin{array}{l}\text { SS-1h } \\
\text { (PG 64-22) }\end{array}$ & 38.5 & 77.5 & 5.9 & 47.7 & 3.6 \\
\hline $\begin{array}{l}\text { SS-1 } \\
\text { (PG58-28) }\end{array}$ & 35.1 & 82.0 & 5.9 & 53.2 & 3.8 \\
\hline $\begin{array}{l}\text { SS-1s } \\
\text { (PG 52-34) }\end{array}$ & 35.3 & 80.5 & 6.0 & 52.1 & 3.9 \\
\hline
\end{tabular}

\section{2-5.3.2.3.3 Effect of asphalt emulsions in briquetting}

Initially, the effect of the addition level of the two asphalt emulsions, SS-1 and SS-1s, was tested on briquettes, consisting of taconite concentrate $(\mathrm{K}), 85 \%$ stoichiometric PRB coal, $2 \%$ fluorspar and slag basicity C/S of 1.5 . Based on the previous results, the addition level was narrowed to 7, 8 and $10 \%$. The drop tests were carried out on 10 briquettes immediately after preparation, 1 hour, 2 hours, overnight and 7 days later. The tests were also carried out on briquettes dried in an oven at $105^{\circ} \mathrm{C}\left(221^{\circ} \mathrm{F}\right)$. The results are given in Table 2-5-34 together with the results of SS-1h, reported earlier, for comparison. 
Among the three emulsions, SS-1 (PG 58-28) had the highest drop strengths. According to Flint Hills Resources, this emulsion corresponds to a mixture of $(75: 25) \mathrm{SS}-1 \mathrm{~h}$ and Bunker $\mathrm{C}$. The briquettes are seen to improve the drop strength somewhat with time. The amount of addition of $10 \%$ gave sufficiently high drop numbers. After 7 days, the briquettes were essentially dry and the drop strengths even increased further. Ovendrying made the briquettes notably weaker.

\section{2-5.3.2.3.4 Effect of asphalt emulsions on fusion behavior}

In an attempt to establish how much asphalt emulsions could contribute as a reductant to PRB coal, the amount of carbon added to feed mixtures were estimated. From the analytical results in Table 2-5-33, $1 \%$ emulsion would correspond to $0.5 \% \mathrm{C}$. For taconite concentrate (K)-PRB coal mixtures, an addition of 1\% stoichiometric PRB coal corresponds to $0.2 \%$ by weight of the coal, or approximately $0.08 \% \mathrm{C}$, as its fixed carbon analyzed $42 \%$. Therefore, an addition of $1 \%$ asphalt emulsion corresponds approximately to $6 \%$ stoichiometric PRB coal.

The effect of asphalt emulsion on the formation of NRI was investigated by briquetting feed mixtures at 60,70 and $80 \%$ stoichiometric PRB coal using 10\% SS-1 as a binder. Ten percent of asphalt emulsion would contribute $60 \%$ stoichiometric PRB coal in terms of total carbon including volatiles. By comparing the fusion time, micro NRI generation and NRI sulfur with the results in the absence of the asphalt emulsion, it was thought that the contribution of carbon from the asphalt emulsion to the reductant carbon could be estimated. The feed compositions are given in Table 2-5-35.

Drop tests were carried out on 10 briquettes for $60-80 \%$ stoichiometric PRB coal. The results are given in Table 2-5-36. It is apparent that the drop numbers decreased with increasing PRB coal.

Box furnace tests on these briquettes, however, did not show any sign of fusion even when the samples were held at $1400^{\circ} \mathrm{C}$ for 20 minutes. Such a behavior was totally unexpected. During the pre-heating stage, notably copious amount of smoke was observed to generate from the furnace. It appeared, therefore, that volatiles from asphalt emulsions as well as from PRB coal were lost. 
Table 2-5-34. Effect of the performance grade of asphalt in asphalt emulsions on drop numbers of briquettes, consisting of Taconite concentrate $(K)$ and $85 \%$ stoichiometric PRB coal as a function of time. Drops from 457.2 mm (18")

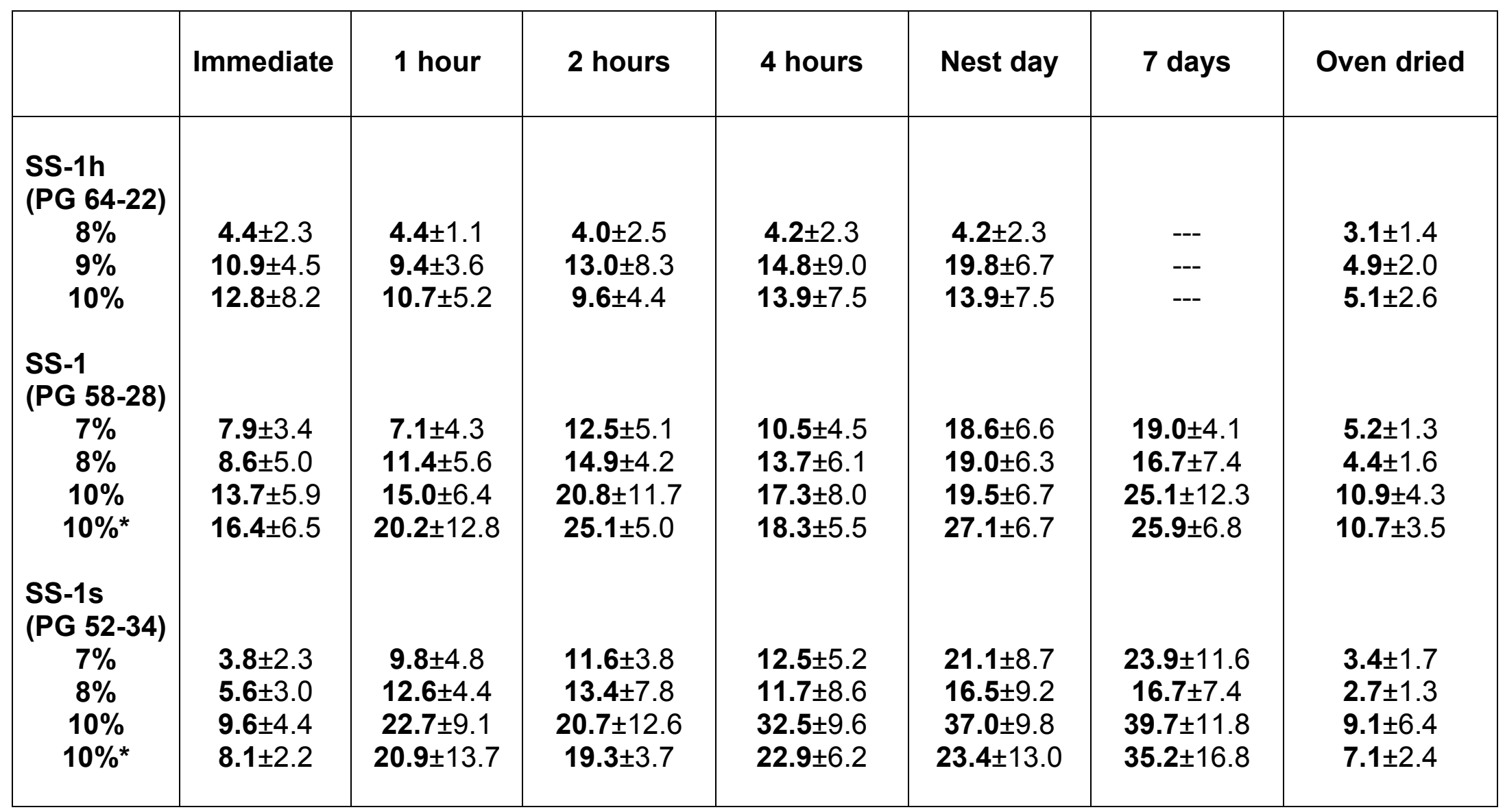

- Duplicate tests 
To explore how much carbon might be left before fusion reactions started, three briquettes each with Jim Walter coal as well as with PRB coal at different levels of its addition in the absence and in the presence of asphalt emulsions, were placed on PRB char hearth layer in a graphite tray, and pre-heated for 3 minutes inside the door, followed by 5 minutes in Zone 1 at $1149^{\circ}\left(2100^{\circ} \mathrm{F}\right)$ in an $\mathrm{N}_{2}-\mathrm{CO}$ atmosphere, as with the usual heating schedule. The tray was cooled in the cooling chamber for 30 minutes, and then placed under a hood of $\mathrm{N}_{2}$ atmosphere until room temperature was reached to prevent re-igniting by oxidation. Briquettes with molasses as a binder were also included in the investigation to explore if volatiles from PRB coal as well as from the carbohydrate binder affected the coal added as reductant. The briquettes, thus treated, were analyzed for Fe and $\mathrm{C}$ for comparison.

The results of $\mathrm{Fe}$ and $\mathrm{C}$ analyses are given in Table 2-5-37 together with fixed carbon analysis of feed briquettes. The residual $C$ in all cases were essentially in the same range, which suggested that neither asphalt emulsions nor molasses remained much after heating in Zone $1\left(1149^{\circ} \mathrm{C}\right)$ for 5 minutes. The iron analyses were again essentially in the same range, which indicated that the vaporization of volatiles had very little effect on the reduction of magnetite.

In an attempt to confirm the unexpected behavior of the asphalt emulsion on fusion behavior, briquettes with $85 \%$ stoichiometric PRB coal using $10 \%$ asphalt emulsions of the three asphalt viscosities as binders were tested by heating at $1400^{\circ} \mathrm{C}\left(2552^{\circ} \mathrm{F}\right)$ for 10 minutes. None of the briquettes fused.

Further confirmation of the asphalt emulsions on fusion behavior was made on briquettes with $100 \%$ stoichiometric PRB coal using 10\% SS-1 (PG 58-28). The feed composition is given in Table 2-5-38. Drop numbers of the briquettes are given in Table 2-5-39. Drop numbers decreased to 4.8, immediately after preparation and 5.0 after oven drying, indicating the adverse effect of adding an excessive amount of PRB coal. The briquettes resulted in all micro NRI after 10 minutes at $1400^{\circ} \mathrm{C}$. Such a fusion behavior indicated that the reductant carbon was much in excess. This is in contrast to the results with 60 to $80 \%$ stoichiometric PRB coal, briquetted with 10\% SS-1 (PG 58$28)$, which did not fuse even after 20 minutes at $1400^{\circ} \mathrm{C}\left(2552^{\circ} \mathrm{F}\right)$.

In an attempt to explore if the results were reproducible, briquettes were prepared with 90 and $80 \%$ stoichiometric PRB coal using 10\% SS-1 (PG58-28) as a binder. The feed composition is included in Table 2-5-38, and the drop numbers in Table 2-5-39. The briquettes were heated at $1400^{\circ} \mathrm{C}\left(2552^{\circ} \mathrm{F}\right)$ for 10 minutes in a similar manner as before. The results are summarized in Table 2-5-40. At $90 \%$ stoichiometric coal, two out of three briquettes fully fused and one nearly fused, suggesting that the minimum time to full fusion would be a few minutes longer.

This is in contrast to the briquettes in the absence of a binder, which fused in 5 minutes. At $80 \%$ stoichiometric coal, the briquettes did not fuse, in agreement with the previous results (Table 2-5-35). 
Table 2-5-35. Composition of feed mixtures, consisting of taconite concentrate $(\mathrm{K})$, PRB coal at different stoichiometric amounts, and slag composition $\mathrm{C} / \mathrm{S}=1.5$, and briquetted with $10 \%$ SS-1

\begin{tabular}{|c|c|c|c|c|c|}
\hline $\begin{array}{c}\text { PRB coal } \\
\text { \% stoich. }\end{array}$ & $\begin{array}{c}\text { Mix } \\
\text { No. }\end{array}$ & $\begin{array}{c}\text { Keetac } \\
\text { conc. }\end{array}$ & $\begin{array}{c}\text { PRB } \\
\text { coal }\end{array}$ & $\begin{array}{c}\text { Lime } \\
\text { hydrate }\end{array}$ & Fluorspar \\
\hline $\mathbf{6 0}$ & P-724 & 72.39 & 20.61 & 5.0 & 2.0 \\
$\mathbf{7 0}$ & P-725 & 69.88 & 23.22 & 4.9 & 2.0 \\
$\mathbf{8 0}$ & P-726 & 67.52 & 25.63 & 4.85 & 2.0 \\
\hline
\end{tabular}

Table 2-5-36. Effect of $10 \%$ SS-1 on drop numbers of briquettes, consisting of taconite concentrate $(K)$, different amounts of PRB coal as a function of time. Drops from $457.2 \mathrm{~mm}\left(18^{\prime \prime}\right)$.

\begin{tabular}{|c|c|c|c|c|c|}
\hline $\begin{array}{c}\text { PRB coal } \\
\% \text { stoich. }\end{array}$ & Immediate & 1 hour & 2 hours & Nest day & $\begin{array}{c}\text { Oven } \\
\text { dried }\end{array}$ \\
\hline 60 & $16.9 \pm 7.9$ & $16.5 \pm 8.4$ & $20.3 \pm 7.7$ & $22.3 \pm 12.5$ & $15.1 \pm 6.7$ \\
70 & $12.7 \pm 6.1$ & $12.6 \pm 6.4$ & $17.3 \pm 11.9$ & $19.0 \pm 7.3$ & $7.8 \pm 4.5$ \\
80 & $10.9 \pm 7.9$ & $17.5 \pm 7.1$ & $13.8 \pm 8.3$ & $23.9 \pm 11.7$ & $6.0 \pm 3.1$ \\
\hline
\end{tabular}


Table 2-5-37. Analyses of carbon after preheating inside the door for 3 minutes and heating in Zone $1\left(1149^{\circ} \mathrm{C}\right)\left[2100^{\circ} \mathrm{F}\right]$ for 5 minutes.

\begin{tabular}{|c|c|c|c|c|c|c|}
\hline Mix or & Coal & Binde & & Fixed $C^{2)}$ & 11 & $9^{\circ} \mathrm{C}^{3)}$ \\
\hline Briq. No. & $\%$ stoich. & Name & $\%$ & (calc'd) & $\% \mathrm{C}$ & $\% \mathrm{Fe}$ \\
\hline P-269 & $85^{1)}$ & --- & & 12.5 & 7.62 & 60.31 \\
\hline P-714R & 85 & --- & & 11.3 & 6.42 & 60.81 \\
\hline P-710 & 90 & --- & & 11.8 & 5.12 & 61.36 \\
\hline P-711 & 95 & --- & & 12.2 & 8.45 & 61.36 \\
\hline P-712 & 100 & --- & & 12.7 & 6.61 & 60.45 \\
\hline P-713 & 105 & --- & & 13.1 & 9.60 & 60.59 \\
\hline $\mathrm{Br}-135$ & 85 & SS-1h & 10 & $11.3^{4)}$ & 8.66 & 60.48 \\
\hline $\mathrm{Br}-153$ & 85 & SS-1 & 10 & $11.3^{4)}$ & 6.25 & 60.33 \\
\hline $\mathrm{Br}-152$ & 85 & SS-1s & 10 & $11.3^{4)}$ & 5.84 & 60.52 \\
\hline $\mathrm{Br}-124$ & 85 & Molasses & 13.5 & $11.3^{4)}$ & 7.98 & 60.27 \\
\hline $\mathrm{Br}-120$ & 85 & Molasses & 15 & $11.3^{4)}$ & 4.86 & 61.52 \\
\hline
\end{tabular}

1) Bituminous coal $(\mathrm{J})$; all others PRB coal

2) Fixed carbon: Bituminous coal (J) $69.67 \%$; PRB coal $42.22 \%$

3) 3 minutes behind door +5 minutes at $1149^{\circ} \mathrm{C}\left(2100^{\circ} \mathrm{F}\right)$

4) Carbon from binders not included 
Table 2-5-38. Composition of feed mixtures, consisting of taconite concentrate (K), PRB coal at different stoichiometric amounts, and slag composition $C / S=1.5$, and briquetted with $10 \%$ SS-1, used in the second series of tests.

\begin{tabular}{|c|c|c|c|c|c|}
\hline $\begin{array}{c}\text { PRB coal } \\
\text { \% stoich. }\end{array}$ & $\begin{array}{c}\text { Mix } \\
\text { No. }\end{array}$ & $\begin{array}{c}\text { Keetac } \\
\text { conc. }\end{array}$ & $\begin{array}{c}\text { PRB } \\
\text { coal }\end{array}$ & $\begin{array}{c}\text { Lime } \\
\text { hydrate }\end{array}$ & Fluorspar \\
\hline $\mathbf{1 0 0}$ & P-712 & 63.27 & 30.03 & 4.70 & 2.0 \\
$\mathbf{9 0}$ & P-739 & 66.09 & 27.01 & 4.90 & 2.0 \\
$\mathbf{8 0}$ & P-738 & 68.26 & 24.79 & 4.95 & 2.0 \\
\hline
\end{tabular}

Table 2-5-39. Effect of 10\% SS-1 on drop numbers of briquettes, consisting of taconite concentrate $(K)$, different amounts of PRB coal as a function of time. Drops from $457.2 \mathrm{~mm}$ (18”).

\begin{tabular}{|c|c|c|}
\hline $\begin{array}{c}\text { PRB coal } \\
\text { \% stoich. }\end{array}$ & Immediate & $\begin{array}{c}\text { Oven } \\
\text { dried }\end{array}$ \\
\hline 100 & $4.8 \pm 1.1$ & $5.0 \pm 2.0$ \\
90 & $15.8 \pm 7.0$ & $10.2 \pm 3.7$ \\
80 & $4.0 \pm 1.6$ & $8.8 \pm 3.2$ \\
\hline
\end{tabular}


Table 2-5-40. Summary of second series of test results showing the effect of PRB coal on briquettes, consisting of taconite concentrate $(K)$, different amounts of PRB coal, $2 \%$ fluorspar and slag basicity C/S of 1.5, briquetted with $10 \%$ SS-1 (PG $58-28)$, placed on PRB char and heated at $1400^{\circ} \mathrm{C}\left(2552^{\circ} \mathrm{F}\right)$ in a $\mathrm{N}_{2}-\mathrm{CO}$ atmosphere.

\begin{tabular}{|c|c|c|c|c|}
\hline PRB coal & Fusion & Micro NRI & \multicolumn{2}{|c|}{ NRI } \\
\hline$\%$ stoich. & time, $\min$ & & $\% \mathrm{C}$ & $\% S$ \\
\hline 100 & $(5)^{1)} \min$ & \multicolumn{2}{|c|}{ All micro NRI } & \\
\hline 90 & $\sim 10^{2)} \min$ & --- & --- & --- \\
\hline 80 & $>10^{3)} \mathrm{min}$ & Not fusec & & \\
\hline
\end{tabular}

1) At 5 minutes, products were all micro $\mathrm{NRI}$ and no further tests made.

2) Two out of 3 briquettes fully fused, one nearly fused

Hence, it was concluded that asphalt emulsions gasified upon heating, and in addition, even helped to gasify a part of fixed carbon from PRB coal prematurely and adversely affected the fusion behavior. Yet, at $100 \%$ stoichiometric PRB coal, the asphalt emulsion made only micro NRI and metallic fines. Evidently, the asphalt emulsion somehow made the optimum level of PRB coal extremely narrow. Therefore, further tests with asphalt emulsions were discontinued. 


\section{2-6 ALTERNATIVE IRONMAKING MATERIALS}

In a previous project, the behavior of NRI formation from pellet screened fines, consisting mainly of $\mathrm{Fe}_{2} \mathrm{O}_{3}$, was briefly tested. As compared to magnetic concentrates, notably larger amounts of micro NRI were generated. The amount of micro NRI generation could be decreased by decreasing the addition of the reductant coal to $70 \%$ of the stoichiometric amount, but NRI sulfur increased to over $0.1 \% \mathrm{~S}$.

Large amounts of pellet plant wastes and lean ores, both are mainly hematite, are available on the Iron Range. Steel plant wastes, such as dusts and fumes, are mainly $\mathrm{Fe}_{2} \mathrm{O}_{3}$. Also, the majority of iron ore deposits in the world are hematite. In order to utilize these iron resources, therefore, it became of interest to characterize the behavior of NRI formation of hematite resources with respect to micro NRI generation and NRI sulfur.

A high-grade hematite ore, analyzing $1 \%$ each of $\mathrm{SiO}_{2}$ and $\mathrm{Al}_{2} \mathrm{O}_{3}$, was used as a prototype feed for exploring the effect of gangue minerals. The composition of slag may be varied by the addition of different gangue minerals, and the effect of different elements in gangue minerals may be investigated on the fusion behavior of slag as well as its desulfurizing ability. A series of tests were carried out using silicates and alumino-silicates so that the roles that $\mathrm{MgO}, \mathrm{Al}_{2} \mathrm{O}_{3}, \mathrm{Na}_{2} \mathrm{O}$ and $\mathrm{K}_{2} \mathrm{O}$ play in slag, consisting of $\mathrm{SiO}_{2}$ and $\mathrm{CaO}$ as major components, might be examined. Silicate gangue of local interest, namely, power plant fly ash, magnetic taconite tailings, Minnesota's Cu$\mathrm{Ni}$ flotation tailings and its major constituent minerals, were included as they are or will be available in finely ground states in large quantities.

\section{2-6.1 Preliminary tests on the effects of reductant coal and additives}

Initially, a few attempts were made to confirm the observation made in the previous project on pellet screened fines, and to search for additives that lower NRI sulfur without increasing micro NRI.

A few preliminary tests were performed on the high-grade hematite ore by adding bituminous coal $(\mathrm{J})$ at $80 \%$ and $70 \%$ of the stoichiometric amount together with wollastonite and fluorspar. Wollastonite $\left(\mathrm{CaSiO}_{3}\right)$ was used rather than a combination of $\mathrm{SiO}_{2}$ and $\mathrm{CaO}$ in an attempt to facilitate the fusion and circumvent the formation of fayalite $\left(\mathrm{Fe}_{2} \mathrm{SiO}_{4}\right)$-type slag in the process. Brief investigations were made to ascertain the effects of adding soda ash $\left(\mathrm{Na}_{2} \mathrm{CO}_{3}\right), \mathrm{MnO}_{2}$ and some additional fluorspar, all at $\mathrm{C} / \mathrm{S}$ of 1.5. The results are summarized in Table 2-6-1. The tests confirmed the previous results on pellet screened fines that decreasing the coal addition from $80 \%$ to $70 \%$ of the stoichiometric amount decreased the amount of micro NRI, but the addition of $2 \%$ fluorspar along with $4 \%$ wollastonite was not effective in lowering NRI sulfur (0.106$0.141 \% \mathrm{~S}$ ). Further increase of fluorspar to $4 \%$ had virtually no effect on micro NRI generation and NRI sulfur. An addition of soda ash was effective in lowering NRI sulfur $(0.054-0.081 \% \mathrm{~S})$, but micro NRI generation could not be lowered effectively. A combination of wollastonite, fluorspar and $\mathrm{MnO}_{2}$ was the most effective in lowering micro NRI generation and showed some promise in lowering NRI sulfur. 
Table 2-6-1. Summary of preliminary test results with briquettes, consisting of high-grade hematite, $\mathbf{7 0}$ or $\mathbf{8 0 \%}$ stoichiometric bituminous coal (J), $4 \%$ wollastonite with different additives and slag composition $C / S=1.5$, placed over a 6/100 mesh coke hearth layer and heated at $1400^{\circ} \mathrm{C}\left(2552^{\circ} \mathrm{F}\right)$ for 20 minutes in a $\mathrm{N}_{2}$-CO atmosphere (Those in bold numbers are with $70 \%$ stoichiometric coal.)

\begin{tabular}{|c|c|c|c|c|c|c|c|c|c|}
\hline & \multicolumn{5}{|c|}{ Slag basicity } & \multicolumn{2}{|c|}{$\%$ micro NRI } & \multicolumn{2}{|c|}{$\% S$ in NRI } \\
\hline & $\mathrm{C} / \mathrm{S}$ & $B / S$ & $\mathrm{~B} / \mathrm{A}$ & $\mathrm{B}^{*} / \mathrm{A}$ & $\mathrm{B}^{*} / \mathrm{S}$ & $70 \%$ & $80 \%$ & $70 \%$ & $80 \%$ \\
\hline $\begin{array}{l}4 \% \text { wollastonite } \\
+2 \% \text { fluorspar }\end{array}$ & 1.5 & 1.5 & 1.1 & 1.1 & 1.5 & 4.2 & $\begin{array}{r}28.9 \\
-29.7\end{array}$ & $\begin{array}{r}0.106 \\
-0.141\end{array}$ & $\begin{array}{r}0.090 \\
-0.088\end{array}$ \\
\hline $\begin{array}{l}4 \% \text { wollastonite } \\
+4 \% \text { fluorspar }\end{array}$ & 1.5 & 1.5 & 1.1 & 1.1 & 1.5 & $\begin{array}{r}5.2 \\
-8.3\end{array}$ & $\begin{array}{r}22.8 \\
-19.0\end{array}$ & $\begin{array}{r}0.118 \\
-0.114\end{array}$ & $\begin{array}{r}0.090 \\
-0.076\end{array}$ \\
\hline $\begin{array}{c}4 \% \text { wollastonite } \\
+2 \% \text { fluorspar } \\
+2 \% \mathrm{Na}_{2} \mathrm{CO}_{3}\end{array}$ & 1.5 & 1.5 & 1.1 & 1.1 & 1.5 & $\begin{array}{r}8.3 \\
-4.1\end{array}$ & $\begin{array}{r}25.8 \\
-19.8\end{array}$ & $\begin{array}{r}0.054 \\
-0.081\end{array}$ & $\begin{array}{r}0.037 \\
-0.039\end{array}$ \\
\hline $\begin{array}{l}4 \% \text { wollastonite } \\
+2 \% \text { fluorspar } \\
+2 \% \mathrm{MnO}_{2}\end{array}$ & 1.5 & 1.5 & 1.1 & 1.1 & 1.5 & $\begin{array}{r}1.5 \\
-1.2\end{array}$ & $\begin{array}{r}27.1 \\
-18.5\end{array}$ & $\begin{array}{r}0.084 \\
-0.096\end{array}$ & $\begin{array}{r}0.055 \\
-0.078\end{array}$ \\
\hline & $\begin{array}{l}\mathrm{C}=(\mathrm{C} \\
\mathrm{S}=(\mathrm{S} \\
\mathrm{B}=(\mathrm{C} \\
\mathrm{A}=(\mathrm{C} \\
\mathrm{B}^{*}=(C\end{array}$ & כ) & 0) & $\mathrm{a}_{2} \mathrm{C}$ & & & & & \\
\hline
\end{tabular}

\section{2-6.2 Screening tests of silicates and alumino-silicates}

Based on the foregoing observations, ten different silicate minerals were selected, and three series of tests were carried out to screen out more desirable silicates for further optimization of the processing conditions.

\section{2-6.2.1 Conclusions}

1) A combined use of fluorspar and $\mathrm{MnO}_{2}$ was the key to desulfurization. Fluorspar in combination with $\mathrm{MnO}_{2}$ was effective in lowering the generation of micro NRI and NRI sulfur, regardless of the type of silicates and alumino-silicates used, particularly when $\mathrm{C} / \mathrm{S}$ was raised to 1.6 and 1.7 .

2) For promoting fusion and desulfurization, either the addition of fluorspar or $\mathrm{MnO}_{2}$ separately was not as effective as their use in combination.

3) Cursory measurements of slag fusion temperatures indicated that fluorspar in combination with $\mathrm{MnO}_{2}$ lowered the temperature by approximately $100^{\circ} \mathrm{C}$ $\left(180^{\circ} \mathrm{F}\right)$. Fluorspar in the absence of $\mathrm{MnO}_{2}$, or $\mathrm{MnO}_{2}$ in the absence of fluorspar was not as effective. 
4) It may be speculated that slag must be not only in the range of $(\mathrm{CaO}) /\left(\mathrm{SiO}_{2}\right)$ or $[(\mathrm{CaO})+(\mathrm{MgO})] /\left(\mathrm{SiO}_{2}\right)$ of 1.5 to 1.7 , but also fused and fluid for forming fully fused and low sulfur NRI. If slag did not fuse, either the products did not fuse, or NRI were jagged and not fully fused. Then slag had high fusion temperature and was presumably viscous, and NRI sulfur remained high. It becomes of interest to determine slag fusion temperature and fluidity more precisely for better correlation.

\section{2-6.2.2 Test procedure}

The chemical compositions of silicate and alumino-silicate minerals are given in Table 2-6-2. Ottawa sand was assumed to be essentially $\mathrm{SiO}_{2}$. All the mineral samples were ground to -100 mesh for use. The chemical compositions of base raw materials are given in Table 2-6-3.

Initially, most of the tests were carried out with a fixed condition of $4 \%$ silicate or alumino-silicate mineral, $2 \%$ fluorspar and $4 \% \mathrm{MnO}_{2}$, all at the slag basicity $\mathrm{C} / \mathrm{S}$ of 1.5 to 1.7 , in order to expedite which of the minerals were effective in lowering NRI sulfur. Some tests were carried out in the presence of fluorspar, but in the absence of $\mathrm{MnO}_{2}$, while some other tests were carried out in the absence of fluorspar, but in the presence of $\mathrm{MnO}_{2}$ in an attempt to bring out the effect of a combined use of fluorspar and $\mathrm{MnO}_{2}$. In these tests, electrolytic $\mathrm{MnO}_{2}$ was used as it was on hand and immediately available. $\mathrm{MnO}_{2}$ is known to be readily reduced to $\mathrm{MnO}$, so any manganese ores may be used instead. Locally, Cuyuna manganiferrous iron ores are available for this application. The composition of feed mixtures is given in Table 2-6-4. 
Table 2-6-2. Chemical composition of silicate minerals

$\begin{array}{lccccccccccc} & \underline{\mathrm{Fe}} & \underline{\mathrm{SiO}_{2}} & \underline{\mathrm{Al}_{2}} \underline{\underline{O}}_{3} & \underline{\mathrm{CaO}} & \underline{\mathrm{MgO}} & \underline{\mathrm{MnO}} & \underline{\mathrm{Na}_{2}} \underline{\underline{O}} & \underline{\mathrm{K}_{2}} \underline{\mathrm{O}} & \underline{\mathrm{TiO}_{2}} & \underline{\mathrm{S}} & \underline{\mathrm{P}} \\ \text { Wollastonite } & & 44.26 & 1.6 & 49.75 & 1.1 & & & & & & \\ \text { PRB coal fly ash } & 5.58 & 44.36 & 19.34 & 19.44 & 4.77 & 0.13 & 1.54 & 0.52 & & 0.48 & 0.088 \\ \text { Nepheline syenite } & 0.02 & 23.7 & 0.22 & 0.04 & & & 14.5 & 4.66 & & <0.006 & 0.017 \\ \text { Anorthosite } & 0.58 & 50.18 & 31.65 & 15.17 & 0.24 & & 3.49 & 0.08 & & 0.089 & 0.015 \\ \text { Taconite tailings } & 15.63 & 69.24 & 0.27 & 1.59 & 3.29 & & & & & 0.016 & 0.015 \\ \text { Labradorite } & 3.29 & 54.12 & 21.94 & 10.91 & 1.66 & & 4.94 & 0.23 & & 0.023 & 0.037 \\ \text { Augite } & 7.17 & 52.98 & 1.46 & 23.66 & 12.62 & & 0.71 & 0.085 & & 0.013 & 0.008 \\ \text { Olivine } & 6.55 & 42.21 & 0.14 & 0.44 & 54.5 & & 0.014 & 0.011 & & 0.008 & 0.001 \\ \text { Cu-Ni tailings } & 15.15 & 50.02 & 13.35 & 6.7 & 5.55 & & 1.86 & 0.57 & 1.68 & 0.16 & 0.07 \\ & & & & & & & & & \mathrm{Cu} & \mathrm{Ni} & \mathrm{Co} \\ & & & & & & & & & 0.065 & 0.04 & 0.007\end{array}$


Table 2-6-3. Chemical composition of base raw materials

(a) Iron oxides and additives

\begin{tabular}{|c|c|c|c|c|}
\hline & $\begin{array}{c}\text { High- } \\
\text { grade } \\
\text { hematite }\end{array}$ & $\begin{array}{c}\text { Bituminous } \\
\text { coal (J) } \\
\text { ash }\end{array}$ & $\begin{array}{c}\text { Hydrated } \\
\text { lime }\end{array}$ & $\begin{array}{c}\text { Fluor- } \\
\text { spar }\end{array}$ \\
\hline $\begin{array}{c}\text { T.Fe } \\
\mathbf{m e t ~ F e ~}^{+++}\end{array}$ & 66.61 & & 0.05 & 0.05 \\
$\mathbf{F e}^{++}$ & & & & \\
$\mathbf{S i O}_{2}$ & 1.07 & 51.56 & 0.43 & 1.87 \\
$\mathbf{A l}_{2} \mathbf{O}_{3}$ & 0.90 & 29.63 & 0.00 & 0.12 \\
$\mathbf{C a O}$ & 0.03 & 3.32 & 68.8 & 1.28 \\
$\mathbf{M g O}_{\mathbf{M n O}}$ & 0.02 & 1.14 & 0.32 & 0.00 \\
$\mathbf{N a}_{\mathbf{2}} \mathbf{O}$ & & & & \\
$\mathbf{K}_{\mathbf{2}} \mathbf{O}$ & & & & \\
$\mathbf{S}$ & 0.010 & & 0.45 & 0.44 \\
$\mathbf{P}$ & 0.031 & & 0.005 & 0.025 \\
& & & & \\
\hline
\end{tabular}

(b) Proximate analysis of bituminous coal ( $\mathrm{J})$

\begin{tabular}{|l|c|}
\hline & $\begin{array}{c}\text { Bituminous } \\
\text { coal }\end{array}$ \\
\hline Moisture & 0.66 \\
Volatile & 20.73 \\
Fixed carbon & 69.67 \\
Ash & 8.94 \\
Sulfur & 0.61 \\
Btu/lb & 14,118 \\
kJ/kg & 32,770 \\
\hline
\end{tabular}


Table 2-6-4. Composition of feed mixtures, consisting of high-grade hematite, bituminous coal $(\mathrm{J})$ at $70 \%$ stoichiometric amount together with different additives, and slag composition as indicated by $\mathrm{C} / \mathrm{S}^{*}$.

\begin{tabular}{|c|c|c|c|c|c|c|c|c|c|}
\hline & $\mathrm{C} / \mathrm{S}^{*}$ & $\begin{array}{l}\text { Hema- } \\
\text { tite }\end{array}$ & $\begin{array}{l}\text { Bitu. } \\
\text { coal }\end{array}$ & $\begin{array}{l}\text { Hyd. } \\
\text { lime }\end{array}$ & $\begin{array}{l}\text { Fluor- } \\
\text { spar }\end{array}$ & $\begin{array}{c}\text { Wollas- } \\
\text { Tonite } \\
\text { or } \mathrm{SiO}_{2}\end{array}$ & $\begin{array}{l}\text { Neph. } \\
\text { syenite }\end{array}$ & Fly ash & $\mathrm{MnO}_{2}$ \\
\hline $\begin{array}{l}4 \% \mathrm{~N} \text {. syenite } \\
+2 \% \mathrm{MnO}_{2}(\mathrm{P}-391)\end{array}$ & 1.5 & 68.65 & 14.8 & 8.55 & 2.0 & & 4.0 & & 2.0 \\
\hline $\begin{array}{l}4 \% \mathrm{~N} \text {. syenite } \\
+2 \% \mathrm{MnO}_{2}(\mathrm{P}-392)\end{array}$ & 1.6 & 68.15 & 14.7 & 9.15 & 2.0 & & 4.0 & & 2.0 \\
\hline $\begin{array}{l}4 \% \mathrm{~N} \text {. syenite } \\
+2 \% \mathrm{MnO}_{2}(\mathrm{P}-393)\end{array}$ & 1.7 & 67.7 & 14.6 & 9.7 & 2.0 & & 4.0 & & 2.0 \\
\hline $\begin{array}{l}4 \% \mathrm{~N} \text {. syenite } \\
+4 \% \mathrm{MnO}_{2}(\mathrm{P}-394)\end{array}$ & 1.5 & 67.05 & 14.45 & 8.5 & 2.0 & & 4.0 & & 4.0 \\
\hline $\begin{array}{l}4 \% \mathrm{~N} \text {. syenite } \\
+4 \% \mathrm{MnO}_{2}(\mathrm{P}-395)\end{array}$ & 1.6 & 66.6 & 14.35 & 9.05 & 2.0 & & 4.0 & & 4.0 \\
\hline $\begin{array}{l}6 \% \text { N. syenite } \\
+4 \% \mathrm{MnO}_{2}(\mathrm{P}-396)\end{array}$ & 1.7 & 66.15 & 14.25 & 9.6 & 2.0 & $\begin{array}{l}\text { Wollas- } \\
\text { tonite }\end{array}$ & 4.0 & & 4.0 \\
\hline $\begin{array}{l}6 \% \text { Wollastonite } \\
+4 \% \mathrm{MnO}_{2}(\mathrm{P}-397)\end{array}$ & 1.7 & 69.9 & 15.05 & 5.05 & 2.0 & 4.0 & & & 4.0 \\
\hline $\begin{array}{l}\text { 4\% Fly ash } \\
+4 \% \mathrm{MnO}_{2}(\mathrm{P}-581)\end{array}$ & 1.5 & 69.2 & 14.95 & 5.85 & 2.0 & & & $\begin{array}{c}\text { Fly ash } \\
4.0\end{array}$ & 4.0 \\
\hline $\begin{array}{l}\text { 4\% Fly ash } \\
+4 \% \mathrm{MnO}_{2}(\mathrm{P}-398)\end{array}$ & 1.6 & 68.85 & 14.85 & 6.3 & 2.0 & & & 4.0 & 4.0 \\
\hline $\begin{array}{l}4 \% \text { Fly ash } \\
+4 \% \mathrm{MnO}_{2}(\mathrm{P}-399)\end{array}$ & 1.7 & 68.5 & 14.75 & 6.75 & 2.0 & Ottawa & & 4.0 & 4.0 \\
\hline $\begin{array}{l}2 \% \text { Ottawa sand } \\
+4 \% \mathrm{MnO}_{2}(\mathrm{P}-426)\end{array}$ & 1.5 & 69.55 & 15.0 & 7.45 & 2.0 & 2.0 & & & 4.0 \\
\hline $\begin{array}{l}2 \% \text { Ottawa sand } \\
+4 \% \mathrm{MnO}_{2}(\mathrm{P}-427)\end{array}$ & 1.6 & 69.15 & 14.9 & 7.95 & 2.0 & 2.0 & & & 4.0 \\
\hline $\begin{array}{l}2 \% \text { Ottawa sand } \\
+4 \% \mathrm{MnO}_{2}(\mathrm{P}-428)\end{array}$ & 1.7 & 68.75 & 14.8 & 8.45 & 2.0 & 2.0 & & & 4.0 \\
\hline
\end{tabular}


Table 2-6-4. Continued.

\begin{tabular}{|c|c|c|c|c|c|c|c|c|c|}
\hline & $\mathrm{C} / \mathrm{S}^{*}$ & $\begin{array}{c}\text { Hema- } \\
\text { tite }\end{array}$ & $\begin{array}{l}\text { Bitu. } \\
\text { coal }\end{array}$ & $\begin{array}{l}\text { Hyd. } \\
\text { lime }\end{array}$ & $\begin{array}{l}\text { Fluor- } \\
\text { spar }\end{array}$ & $\begin{array}{l}\text { Anor- } \\
\text { thosite }\end{array}$ & $\begin{array}{c}\text { Taco- } \\
\text { nite } \\
\text { tails }\end{array}$ & $\begin{array}{l}\text { Labra- } \\
\text { dorite }\end{array}$ & $\mathrm{MnO}_{2}$ \\
\hline $\begin{array}{l}4 \% \text { Anorthosite } \\
+0 \% \mathrm{MnO}_{2}(\mathrm{P}-431)\end{array}$ & 1.5 & 71.75 & 15.5 & 6.75 & 2.0 & 4.0 & & & 0.0 \\
\hline $\begin{array}{l}4 \% \text { Anorthosite } \\
+4 \% \mathrm{MnO}_{2}(\mathrm{P}-432)\end{array}$ & 1.5 & 68.6 & 14.8 & 6.6 & 2.0 & 4.0 & & & 4.0 \\
\hline $\begin{array}{l}4 \% \text { Anorthosite } \\
+0 \% \mathrm{MnO}_{2}(\mathrm{P}-433)\end{array}$ & 1.6 & 71.35 & 15.4 & 7.25 & 2.0 & 4.0 & & & 0.0 \\
\hline $\begin{array}{l}\text { 4\% Anorthosite } \\
+4 \% \mathrm{MnO}_{2}(\mathrm{P}-434)\end{array}$ & 1.6 & 68.2 & 14.7 & 7.1 & 2.0 & 4.0 & & & 4.0 \\
\hline $\begin{array}{l}\text { 4\% Anorthosite } \\
+0 \% \mathrm{MnO}_{2}(\mathrm{P}-435)\end{array}$ & 1.7 & 70.95 & 15.3 & 7.75 & 2.0 & 4.0 & & & 0.0 \\
\hline $\begin{array}{l}\text { 4\% Anorthosite } \\
+4 \% \mathrm{MnO}_{2}(\mathrm{P}-436)\end{array}$ & 1.7 & 67.85 & 14.6 & 7.55 & 2.0 & 4.0 & & & 4.0 \\
\hline $\begin{array}{l}4 \% \text { Taconite tails } \\
+0 \% \mathrm{MnO}_{2}(\mathrm{P}-343)\end{array}$ & 1.5 & 70.25 & 15.15 & 8.6 & 2.0 & & 4.0 & & 0.0 \\
\hline $\begin{array}{l}4 \% \text { Taconite tails } \\
+4 \% \mathrm{MnO}_{2}(\mathrm{P}-549)\end{array}$ & 1.5 & 67.05 & 14.45 & 8.5 & 2.0 & & 4.0 & & 4.0 \\
\hline $\begin{array}{l}4 \% \text { Taconite tails } \\
+0 \% \mathrm{MnO}_{2}(\mathrm{P}-344)\end{array}$ & 1.6 & 69.75 & 15.05 & 9.2 & 2.0 & & 4.0 & & 0.0 \\
\hline $\begin{array}{l}\text { 4\% Taconite tails } \\
+4 \% \mathrm{MnO}_{2}(\mathrm{P}-550)\end{array}$ & 1.6 & 66.6 & 14.35 & 9.05 & 2.0 & & 4.0 & & 4.0 \\
\hline $\begin{array}{l}4 \% \text { Taconite tails } \\
+0 \% \mathrm{MnO}_{2}(\mathrm{P}-548)\end{array}$ & 1.7 & 69.25 & 14.95 & 9.8 & 2.0 & & 4.0 & & 0.0 \\
\hline $\begin{array}{l}4 \% \text { Taconite tails } \\
+4 \% \mathrm{MnO}_{2}(\mathrm{P}-551)\end{array}$ & 1.7 & 66.15 & 14.25 & 9.6 & 2.0 & & 4.0 & & 4.0 \\
\hline $\begin{array}{l}4 \% \text { Labradorite } \\
+0 \% \mathrm{MnO}_{2}(\mathrm{P}-447)\end{array}$ & 1.5 & 71.3 & 15.4 & 7.3 & 2.0 & & & 4.0 & 0.0 \\
\hline $\begin{array}{l}4 \% \text { Labradorite } \\
+4 \% \mathrm{MnO}_{2}(\mathrm{P}-448)\end{array}$ & 1.5 & 68.15 & 14.7 & 7.15 & 2.0 & & & 4.0 & 4.0 \\
\hline $\begin{array}{l}4 \% \text { Labradorite } \\
+0 \% \mathrm{MnO}_{2}(\mathrm{P}-449)\end{array}$ & 1.6 & 70.85 & 15.3 & 7.85 & 2.0 & & & 4.0 & 0.0 \\
\hline
\end{tabular}

${ }^{*} \mathrm{C} / \mathrm{S}=(\mathrm{CaO}) /\left(\mathrm{SiO}_{2}\right)$ 
Table 2-6-4. Continued.

\begin{tabular}{|c|c|c|c|c|c|c|c|c|c|}
\hline & $\mathbf{C} / \mathbf{S}^{*}$ & $\begin{array}{c}\text { Hema } \\
\text {-tite }\end{array}$ & $\begin{array}{l}\text { Bitu. } \\
\text { coal }\end{array}$ & $\begin{array}{l}\text { Hyd. } \\
\text { lime }\end{array}$ & $\begin{array}{l}\text { Fluor- } \\
\text { spar }\end{array}$ & $\begin{array}{l}\text { Labra- } \\
\text { dorite }\end{array}$ & Augite & Olivine & $\mathrm{MnO}_{2}$ \\
\hline $\begin{array}{l}4 \% \text { Labradorite } \\
+4 \% \mathrm{MnO}_{2}(\mathrm{P}-450)\end{array}$ & 1.6 & 67.7 & 14.6 & 7.7 & 2.0 & 4.0 & & & 4.0 \\
\hline $\begin{array}{l}4 \% \text { Labradorite } \\
+0 \% \mathrm{MnO}_{2}(\mathrm{P}-451)\end{array}$ & 1.7 & 70.45 & 15.2 & 8.35 & 2.0 & 4.0 & & & 0.0 \\
\hline $\begin{array}{l}4 \% \text { Labradorite } \\
+4 \% \mathrm{MnO}_{2}(\mathrm{P}-452)\end{array}$ & 1.7 & 67.3 & 14.5 & 8.2 & 2.0 & 4.0 & & & 4.0 \\
\hline $\begin{array}{l}4 \% \text { Augite } \\
+0 \% \mathrm{MnO}_{2}(\mathrm{P}-453)\end{array}$ & 1.5 & 72.0 & 15.5 & 6.5 & 2.0 & & 4.0 & & 0.0 \\
\hline $\begin{array}{l}4 \% \text { Augite } \\
+4 \% \mathrm{MnO}_{2}(\mathrm{P}-454)\end{array}$ & 1.5 & 68.8 & 14.85 & 6.35 & 2.0 & & 4.0 & & 4.0 \\
\hline $\begin{array}{l}4 \% \text { Augite } \\
+0 \% \mathrm{MnO}_{2}(\mathrm{P}-455)\end{array}$ & 1.6 & 71.6 & 15.4 & 7.0 & 2.0 & & 4.0 & & 0.0 \\
\hline $\begin{array}{l}4 \% \text { Augite } \\
+4 \% \mathrm{MnO}_{2}(\mathrm{P}-456)\end{array}$ & 1.6 & 68.4 & 14.75 & 6.85 & 2.0 & & 4.0 & & 4.0 \\
\hline $\begin{array}{l}4 \% \text { Augite } \\
+0 \% \mathrm{MnO}_{2}(\mathrm{P}-457)\end{array}$ & 1.7 & 71.1 & 15.35 & 7.55 & 2.0 & & 4.0 & & 0.0 \\
\hline $\begin{array}{l}4 \% \text { Augite } \\
+4 \% \mathrm{MnO}_{2}(\mathrm{P}-458)\end{array}$ & 1.7 & 67.95 & 14.65 & 7.4 & 2.0 & & 4.0 & & 4.0 \\
\hline $\begin{array}{l}4 \% \text { Olivine } \\
+0 \% \mathrm{MnO}_{2}(\mathrm{P}-459)\end{array}$ & 1.5 & 71.7 & 15.45 & 6.85 & 2.0 & & & 4.0 & 0.0 \\
\hline $\begin{array}{l}4 \% \text { Olivine } \\
+4 \% \mathrm{MnO}_{2}(\mathrm{P}-460)\end{array}$ & 1.5 & 68.8 & 14.8 & 6.7 & 2.0 & & & 4.0 & 4.0 \\
\hline $\begin{array}{l}4 \% \text { Olivine } \\
+0 \% \mathrm{MnO}_{2}(\mathrm{P}-461)\end{array}$ & 1.6 & 71.3 & 15.4 & 9.3 & 2.0 & & & 4.0 & 0.0 \\
\hline $\begin{array}{l}4 \% \text { Olivine } \\
+4 \% \mathrm{MnO}_{2}(\mathrm{P}-462)\end{array}$ & 1.6 & 68.15 & 14.7 & 7.15 & 2.0 & & & 4.0 & 4.0 \\
\hline $\begin{array}{l}4 \% \text { Olivine } \\
+0 \% \mathrm{MnO}_{2}(\mathrm{P}-463)\end{array}$ & 1.6 & 70.95 & 15.3 & 7.75 & 2.0 & & & 4.0 & 0.0 \\
\hline $\begin{array}{l}4 \% \text { Olivine } \\
+4 \% \mathrm{MnO}_{2}(\mathrm{P}-464)\end{array}$ & 1.7 & 67.7 & 14.6 & 7.6 & 2.0 & & & 4.0 & 4.0 \\
\hline
\end{tabular}

${ }^{*} \mathrm{C} / \mathrm{S}=(\mathrm{CaO}) /\left(\mathrm{SiO}_{2}\right)$ 
Table 2-6-4. Continued.

\begin{tabular}{|c|c|c|c|c|c|c|c|c|}
\hline & $\begin{array}{c}C / \mathbf{S}^{*} \\
\text { or } \mathrm{B} / \mathbf{S}^{* *}\end{array}$ & $\begin{array}{l}\text { Hema- } \\
\text { tite }\end{array}$ & $\begin{array}{l}\text { Bitu. } \\
\text { coal }\end{array}$ & $\begin{array}{l}\text { Hyd. } \\
\text { lime }\end{array}$ & $\begin{array}{l}\text { Fluor- } \\
\text { spar }\end{array}$ & Olivine & $\begin{array}{l}\text { Cu-Ni } \\
\text { Tails }\end{array}$ & $\mathrm{MnO}_{2}$ \\
\hline $\begin{array}{l}\text { 4\% Olivine } \\
+0 \% \mathrm{MnO}_{2}(\mathrm{P}-519)\end{array}$ & $1.5^{\star *}$ & 74.3 & 16.0 & 3.7 & 2.0 & 4.0 & & 0.0 \\
\hline $\begin{array}{l}4 \% \text { Olivine } \\
+4 \% \mathrm{MnO}_{2}(\mathrm{P}-520)\end{array}$ & $1.5^{\star \star}$ & 71.1 & 15.35 & 3.35 & 2.0 & 4.0 & & 4.0 \\
\hline $\begin{array}{l}4 \% \text { Olivine } \\
+0 \% \mathrm{MnO}_{2}(\mathrm{P}-521)\end{array}$ & $1.6^{* *}$ & 73.9 & 15.95 & 4.15 & 2.0 & 4.0 & & 0.0 \\
\hline $\begin{array}{l}\text { 4\% Olivine } \\
+0 \% \mathrm{MnO}_{2}(\mathrm{P}-522)\end{array}$ & $1.6^{* *}$ & 70.75 & 15.25 & 4.0 & 2.0 & 4.0 & & 4.0 \\
\hline $\begin{array}{l}\text { 4\% Olivine } \\
+4 \% \mathrm{MnO}_{2}(\mathrm{P}-523)\end{array}$ & $1.7^{* *}$ & 73.5 & 15.85 & 4.65 & 2.0 & 4.0 & & 0.0 \\
\hline $\begin{array}{l}\text { 4\% Olivine } \\
+0 \% \mathrm{MnO}_{2}(\mathrm{P}-524)\end{array}$ & $1.7^{* *}$ & 7.04 & 15.15 & 4.45 & 2.0 & 4.0 & & 4.0 \\
\hline $\begin{array}{l}4 \% \mathrm{Cu}-\mathrm{Ni} \text { tailings } \\
+4 \% \mathrm{MnO}_{2}(\mathrm{P}-462)\end{array}$ & 1.5 & 71.4 & 15.4 & 7.2 & 2.0 & & 4.0 & 0.0 \\
\hline $\begin{array}{l}4 \% \mathrm{Cu}-\mathrm{Ni} \text { tailings } \\
+0 \% \mathrm{MnO}_{2}(\mathrm{P}-463)\end{array}$ & 1.5 & 68.25 & 14.7 & 7.05 & 2.0 & & 4.0 & 4.0 \\
\hline $\begin{array}{l}4 \% \mathrm{Cu}-\mathrm{Ni} \text { tailings } \\
+4 \% \mathrm{MnO}_{2}(\mathrm{P}-464)\end{array}$ & 1.6 & 71.0 & 15.3 & 7.7 & 2.0 & & 4.0 & 0.0 \\
\hline $\begin{array}{l}4 \% \text { Cu-Ni tailings } \\
+0 \% \mathrm{MnO}_{2}(\mathrm{P}-519)\end{array}$ & 1.6 & 67.8 & 14.65 & 7.55 & 2.0 & & 4.0 & 4.0 \\
\hline $\begin{array}{l}\text { 4\% Cu-Ni tailings } \\
+4 \% \mathrm{MnO}_{2}(\mathrm{P}-520)\end{array}$ & 1.7 & 70.6 & 15.2 & 8.2 & 2.0 & & 4.0 & 0.0 \\
\hline $\begin{array}{l}4 \% \mathrm{Cu}-\mathrm{Ni} \text { tailings } \\
+0 \% \mathrm{MnO}_{2}(\mathrm{P}-521)\end{array}$ & 1.7 & 67.4 & 14.55 & 8.05 & 2.0 & & 4.0 & 4.0 \\
\hline
\end{tabular}

${ }^{*} \mathrm{C} / \mathrm{S}=(\mathrm{CaO}) /\left(\mathrm{SiO}_{2}\right) ;{ }^{* *} \mathrm{~B} / \mathrm{S}=(\mathrm{CaO}+\mathrm{MgO}) /\left(\mathrm{SiO}_{2}\right)$ 
Box furnace tests were carried out following the 'standardized' procedure using 6segment mounds in graphite trays. To expedite the investigation on the effect of additives, the sample trays were held in Zone 2 at $1400^{\circ} \mathrm{C}\left(2552^{\circ} \mathrm{F}\right)$ for 20 minutes. From these investigations, several additives were selected for optimization of the amount of additives and fusion time.

Cursory measurements of slag fusion temperatures were made on slag samples obtained in the box furnace tests. Slag samples from box furnace tests were broken into a few pieces, placed on 6/100 mesh coke in a graphite boat and heated in a tube furnace at different temperatures for 3 minutes with furnace gas passing at $1 \mathrm{~L} / \mathrm{min} \mathrm{CO}$ and $2 \mathrm{~L} / \mathrm{min} \mathrm{N}_{2}$. The tests were started from $1260^{\circ} \mathrm{C}\left(2300^{\circ} \mathrm{F}\right)$ and the temperature was raised or lowered by $20^{\circ} \mathrm{C}\left(36^{\circ} \mathrm{F}\right)$ until the broken slag fused into a smooth and rounded piece.

\section{2-6.2.3 Test results}

The weight distributions of products and analytical results of iron nodules for all the tests were obtained, and the essential points of the results, namely slag fusion temperatures, micro NRI and NRI sulfur, are summarized for all the minerals in Table 2-6-5. Their slag basicities are included as defined below.

$$
\begin{aligned}
& \mathrm{C} / \mathrm{S}=(\mathrm{CaO}) /\left(\mathrm{SiO}_{2}\right) \\
& \mathrm{B} / \mathrm{S}=[(\mathrm{CaO})+(\mathrm{MgO})] /\left(\mathrm{SiO}_{2}\right) \\
& \mathrm{B} / \mathrm{A}=[(\mathrm{CaO})+(\mathrm{MgO})] /\left[\left(\mathrm{SiO}_{2}\right)+\left(\mathrm{Al}_{2} \mathrm{O}_{3}\right)\right] \\
& \mathrm{B}^{*} / \mathrm{S}=\left[(\mathrm{CaO})+(\mathrm{MgO})+\left(\mathrm{Na}_{2} \mathrm{O}\right)+\left(\mathrm{K}_{2} \mathrm{O}\right)\right] /\left(\mathrm{SiO}_{2}\right) \\
& \mathrm{B}^{*} / \mathrm{A}=\left[(\mathrm{CaO})+(\mathrm{MgO})+\left(\mathrm{Na}_{2} \mathrm{O}\right)+\left(\mathrm{K}_{2} \mathrm{O}\right)\right] /\left(\left(\mathrm{SiO}_{2}\right)+\left(\mathrm{Al}_{2} \mathrm{O}_{3}\right)\right]
\end{aligned}
$$

Most of the slag basicities could be represented by $\mathrm{C} / \mathrm{S}$, except when $\mathrm{MgO}, \mathrm{Na}_{2} \mathrm{O}$ and $\mathrm{K}_{2} \mathrm{O}$ were high. Even when $\mathrm{Na}_{2} \mathrm{O}$ and $\mathrm{K}_{2} \mathrm{O}$ were high as in the case of nepheline syenite $\left(14.5 \% \mathrm{Na}_{2} \mathrm{O}, 4.66 \% \mathrm{~K}_{2} \mathrm{O}\right), \mathrm{B}^{*} / \mathrm{S}$ and $\mathrm{B}^{*} / \mathrm{A}$ became higher by 0.2 , and labradorite $\left(4.94 \% \mathrm{Na}_{2} \mathrm{O}, 0.23 \% \mathrm{~K}_{2} \mathrm{O}\right)$ by 0.1 than $\mathrm{C} / \mathrm{S}$, their fusion behaviors were not visibly affected. Only when $\mathrm{MgO}$ was exceptionally high in the case of olivine $(54.5 \% \mathrm{MgO})$, the slags did not fuse in the range of $\mathrm{C} / \mathrm{S}$ of 1.5 to 1.7 , and the basicities needed to include $\mathrm{MgO}$ and adjusted to $\mathrm{B} / \mathrm{S}$ of 1.5 to 1.7 .

Test results on individual minerals are elaborated in the following sections.

2-6.2.3.1 Wollastonite: Wollastonite became of interest because of its composition $\left(\mathrm{CaSiO}_{3}\right)$ as compared to Ottawa sand $\left(\mathrm{SiO}_{2}\right)$ together with the equivalent amount of lime. Wollastonite may circumvent the formation of iron silicate-type slag, which is known to be difficultly reducible. Based on the preliminary test results, an investigation was initiated with $4 \%$ wollastonite to explore the effects of (a) increased use of fluorspar, (b) addition of $\mathrm{MnO}_{2}$, and (c) slag basicity, $\mathrm{C} / \mathrm{S}$, of 1.5, 1.6 and 1.7. The coal addition was fixed at $70 \%$ of the stoichiometric amount. The results are summarized in Table 2-6-5. The following observations were made.

1) The addition of fluorspar by itself was not particularly effective in lowering sulfur in $\mathrm{NRI}$ even when $\mathrm{C} / \mathrm{S}$ was raised to as high as 1.7. 
2) A combination of $2 \%$ fluorspar and $2-4 \% \mathrm{MnO}_{2}$ at $\mathrm{C} / \mathrm{S}$ of 1.6 and 1.7 showed the most promise in minimizing micro NRI generation and lowering NRI sulfur to as low as $0.025 \% \mathrm{~S}$.

3) In the absence of fluorspar, the addition of $\mathrm{MnO}_{2}$ formed fused $\mathrm{NRI}$ in narrow basicity ranges. With $4 \% \mathrm{MnO}_{2}$, fused $\mathrm{NRI}$ analyzing $0.04-0.05 \% \mathrm{~S}$ were obtained in the range of $\mathrm{C} / \mathrm{S}=1.5$ to 1.6 , but the products were not fused at $\mathrm{C} / \mathrm{S}=1.7$. Slag fusion temperatures were high.

2-6.2.3.2 Ottawa sand: The tests were carried out in the presence of $2 \%$ fluorspar in the absence and presence of $4 \% \mathrm{MnO}_{2}$. The results are summarized in Table 2-6-5. Four percent Ottawa sand with $2 \%$ fluorspar fused when $\mathrm{C} / \mathrm{S}$ was 1.5 , but had hardly any effect on NRI sulfur. When $\mathrm{C} / \mathrm{S}$ was raised to 1.6, both sponge iron and slag fused only partially. The addition of $\mathrm{MnO}_{2}$ formed fused NRI with NRI sulfur decreasing from $0.048 \%$ to $0.030 \% \mathrm{~S}$ as $\mathrm{C} / \mathrm{S}$ increased from 1.5 to 1.7 . Slag fusion temperature was lowered from $1300^{\circ} \mathrm{C}$ in the absence of $\mathrm{MnO}_{2}$ to $1200^{\circ} \mathrm{C}$ in the presence of $\mathrm{MnO}_{2}$.

2-6.2.3.3 Fly ash: Fly ash became of interest as it is widely available and already fine for direct use in feed mixtures. Also the high $\mathrm{Al}_{2} \mathrm{O}_{3}$ content of fly ash became of interest in combination with $\mathrm{SiO}_{2}$ for fusion behavior. Tests were carried out in the presence of $2 \%$ fluorspar and in the absence and presence of $4 \% \mathrm{MnO}_{2}$. The results are summarized in Table 2-6-5. With $4 \%$ fly ash and $2 \%$ fluorspar, the generation of micro $\mathrm{NRI}$ decreased to minimum, but NRI sulfur was over $0.1 \% \mathrm{~S}$. The addition of $4 \% \mathrm{MnO}_{2}$ along with $2 \%$ fluorspar lowered sulfur in NRI to $0.03 \% \mathrm{~S}$

Slag fusion temperature showed marked decrease with the addition of $\mathrm{MnO}_{2}$ from $1300^{\circ}$ to $1200^{\circ} \mathrm{C}$.

2-6.2.3.4 Nepheline svemite: Nepheline syemite became of interest because of its high alkali metal oxides $\left(14.5 \% \mathrm{Na}_{2} \mathrm{O}\right.$ and $\left.4.66 \% \mathrm{~K}_{2} \mathrm{O}\right)$. Preliminary tests showed some promise in lowering sulfur to $0.056 \% \mathrm{~S}$ when the $\mathrm{C} / \mathrm{S}$ ratio was raised to 1.6 . However, when its addition was increased to $6 \%$, the products did not fuse in spite of its high $\mathrm{Na}_{2} \mathrm{O}$ and $\mathrm{K}_{2} \mathrm{O}$ contents.

Tests were carried out somewhat more in detail because of its high alkali metal oxides, namely, in the presence of $2 \%$ fluorspar in the absence and presence of $2 \%$ and $4 \%$ $\mathrm{MnO}_{2}$, and in the absence of fluorspar but in the presence of $2 \%$ and $4 \% \mathrm{MnO}_{2}$. The results are summarized in Table 2-6-5.

With $2 \%$ fluorspar in the absence of $\mathrm{MnO}_{2}$, NRI sulfur was in excess of $0.05 \% \mathrm{~S}$. A combination of $2 \%$ fluorspar and $2-4 \% \mathrm{MnO}_{2}$ in the range of $\mathrm{C} / \mathrm{S}$ between 1.5 and 1.7 minimized the generation of $\mathrm{NRI}$ and lowered $\mathrm{NRI}$ sulfur to below $0.05 \% \mathrm{~S}$. Increasing the amount of $\mathrm{MnO}_{2}$ to $4 \%$ decreased NRI sulfur to as low as $0.018 \% \mathrm{~S}$. In the absence of fluorspar, however, the products did not fuse by the addition of $\mathrm{MnO}_{2}$.

With $2 \%$ fluorspar in the absence of $\mathrm{MnO}_{2}$, slag fusion temperature remained high $\left(1280-1300^{\circ} \mathrm{C}\right)$, while the addition of $\mathrm{MnO}_{2}$ markedly lowered the temperature to about $1200^{\circ} \mathrm{C}$. 
2-6.2.3.5 Anorthosite: Anorthosite became of interest because of its alumina content $\left(31.65 \% \mathrm{Al}_{2} \mathrm{O}_{3}\right)$ as compared to wollastonite $\left(1.5 \% \mathrm{Al}_{2} \mathrm{O}_{3}\right)$. The tests were carried out in the presence of $2 \%$ fluorspar, but in the absence of $\mathrm{MnO}_{2}$ first, and then together with $4 \% \mathrm{MnO}_{2}$. The results are summarized in Table 2-6-5. In the absence of $\mathrm{MnO}_{2}$, jagged $\mathrm{NRI}$ formed when $\mathrm{C} / \mathrm{S}$ was 1.5 , and separation of the NRI from slag was difficult. Weight distribution of the products, therefore, should be regarded as approximate. NRI analyzed $0.060 \% \mathrm{~S}$. When C/S was increased to 1.6 and 1.7 , the products did not fuse fully. Apparently, the presence of $\mathrm{Al}_{2} \mathrm{O}_{3}$ raised the fusion temperature, compared to wollastonite.

Slag fusion temperature in the absence of $\mathrm{MnO}_{2}$ was indeed higher than with wollastonite. By the addition of $\mathrm{MnO}_{2}$, fusion temperature decreased by $120^{\circ} \mathrm{C}$ to $1200^{\circ} \mathrm{C}$.

2-6.2.3.6 Taconite tailings: Taconite tailings i currently available in fine size ranges in large quantities in northern Minnesota. As the main component of taconite tailings is quartz, those tailings were thought to behave similarly to Ottawa sand, but the presence of minor amounts of ferro-magnesium silicates might have influenced their fusion behavior.

Fused products were obtained in the absence of $\mathrm{MnO}_{2}$ even when $\mathrm{C} / \mathrm{S}$ was as high as 1.7 , unlike with Ottawa sand, due presumably to the presence of $\mathrm{MgO}(3.29 \% \mathrm{MgO})$. However, NRI sulfur ranged from $0.101 \%$ to $0.067 \%$ S, decreasing as C/S increased. In the presence of $4 \% \mathrm{MnO}_{2}$, sulfur in NRI decreased to the range of $0.035 \%$ to $0.025 \% \mathrm{~S}$, again decreasing as $\mathrm{C} / \mathrm{S}$ increased. The results are summarized in Table 2-6-5.

Slag fusion temperature in the absence of $\mathrm{MnO}_{2}$ was $1280^{\circ}$ to $1300^{\circ} \mathrm{C}$, while the temperature decreased to $1200^{\circ} \mathrm{C}$ by the addition of $\mathrm{MnO}_{2}$.

2-6.2.3.7 Labradorite: The main objective of testing labradorite was to provide information on the use of $\mathrm{Cu}-\mathrm{Ni}$ flotation tailings, as it is one of the main gangue minerals in Duluth Complex. Although the chemical composition of labradorite is similar to anorthosite, the addition of labradorite formed fully fused products when C/S was in the range of 1.5 to 1.7 in the absence of $\mathrm{MnO}_{2}$, whereas anorthosite did not unless $\mathrm{MnO}_{2}$ was added. Such a behavior might be attributable to the difference in their $\mathrm{Al}_{2} \mathrm{O}_{3}$ and $\mathrm{Na}_{2} \mathrm{O}$ contents $\left(31.35 \% \mathrm{Al}_{2} \mathrm{O}_{3}\right.$ and $3.49 \% \mathrm{Na}_{2} \mathrm{O}$ in anorthosite, $21.94 \% \mathrm{Al}_{2} \mathrm{O}_{3}$ and $4.94 \% \mathrm{Na}_{2} \mathrm{O}$ in labradorite).

The tests were carried out in the presence of $2 \%$ fluorspar, but in the absence of $\mathrm{MnO}_{2}$ and then in the presence of $4 \% \mathrm{MnO}_{2}$. The results are summarized in Table 2-6-5. In the presence of only $2 \%$ fluorspar, $\mathrm{NRI}$ sulfur was about $0.1 \% \mathrm{~S}$. By the addition of $\mathrm{MnO}_{2}$, $\mathrm{NRI}$ sulfur was lowered to $0.040 \%$ to $0.034 \% \mathrm{~S}$, decreasing as C/S was raised from 1.5 to 1.7 .

Slag fusion temperature in the absence of $\mathrm{MnO}_{2}$ was $1300^{\circ}$ to $1320^{\circ} \mathrm{C}$, while the temperature decreased to $1200^{\circ} \mathrm{C}$ by the addition of $\mathrm{MnO}_{2}$. 
2-6.2.3.8 Augite: Augite is another one of the main gangue minerals in Duluth Complex. Its fusion behavior became of interest as the MgO content (12.62\%) was much less than that of olivine $(54.5 \%)$.

The tests were carried out in the presence of $2 \%$ fluorspar, but in the absence of $\mathrm{MnO}_{2}$ and then in the presence of $4 \% \mathrm{MnO}_{2}$. The results are summarized in Table 2-6-5. In the presence of only $2 \%$ fluorspar, NRI sulfur was in the range of 0.05 to $0.09 \% \mathrm{~S}$. By the addition of $\mathrm{MnO}_{2}$, NRI sulfur was lowered to $0.031 \%$ to $0.026 \% \mathrm{~S}$ decreasing as $\mathrm{C} / \mathrm{S}$ was raised from 1.5 to 1.7 .

Slag fusion temperature in the absence of $\mathrm{MnO}_{2}$ was $1200^{\circ}$ to $1240^{\circ} \mathrm{C}$. This low fusion temperature may be attributable to the presence of $\mathrm{MgO}$. The fusion temperature decreased to $1200^{\circ}$ to $1180^{\circ} \mathrm{C}$ by the addition of $\mathrm{MnO}_{2}$.

2-6.2.3.9 Olivine: Olivine is the third of the main gangue minerals in Duluth complex. It is essentially magnesium silicate as compared with wollastonite, which is essentially calcium silicate.

The tests were carried out in the presence of $2 \%$ fluorspar, but in the absence of $\mathrm{MnO}_{2}$ and then in the presence of $4 \% \mathrm{MnO}_{2}$. The results are summarized in Table 2-6-5. When the slag basicity, expressed as C/S, was adjusted in the range of 1.5 to 1.7, both $\mathrm{NRI}$ and slag were not fully fused whether $\mathrm{MnO}_{2}$ was added or not. This was suspected to be due to high $\mathrm{MgO}$ of olivine (54.5\%). Their basicity was re-adjusted in terms of $\mathrm{B} / \mathrm{S}$ $\left\{[(\mathrm{CaO})+(\mathrm{MgO})] /\left(\mathrm{SiO}_{2}\right)\right\}$, and the tests were repeated. The products fully fused in 20 minutes. NRI sulfur remained over $0.05 \% \mathrm{~S}$ even in the presence of $\mathrm{MnO}_{2}$. Further optimization of conditions is necessary to lower NRI sulfur to below $0.05 \% \mathrm{~S}$.

Slag fusion temperature in the absence of $\mathrm{MnO}_{2}$ was $1220^{\circ} \mathrm{C}$. This low fusion temperature may be attributable to high $\mathrm{MgO}$. The fusion temperature remained essentially the same at $1220^{\circ}$ in the presence of $\mathrm{MnO}_{2}$.

2-6.2.3.10 Cu-Ni flotation tailings: As $\mathrm{Cu}-\mathrm{Ni}$ flotation tailings will become available in large quantities near the taconite mines once the $\mathrm{Cu}-\mathrm{Ni}$ mining starts in northern Minnesota, and also as augite and olivine showed unique fusion behavior due to its high $\mathrm{MgO}$ content, the flotation tailings as an additive becomes of interest in practice.

The tests were carried out in the presence of $2 \%$ fluorspar, but in the absence of $\mathrm{MnO}_{2}$ and then in the presence of $4 \% \mathrm{MnO}_{2}$. The results are summarized in Table 2-6-5. In the presence of only $2 \%$ fluorspar, sulfur in NRI was in the range of 0.07 to $0.11 \% \mathrm{~S}$. By the addition of $\mathrm{MnO}_{2}, \% \mathrm{~S}$ in NRI was lowered to $0.034 \%$ to $0.032 \% \mathrm{~S}$ decreasing somewhat as C/S was raised from 1.5 to 1.7 .

Slag fusion temperature in the absence of $\mathrm{MnO}_{2}$ was $1280^{\circ} \mathrm{C}$. The fusion temperature decreased to the range of $1180^{\circ}$ to $1200^{\circ} \mathrm{C}$ by the addition of $\mathrm{MnO}_{2}$. 
Table 2-6-5. Summary of the effects of slag basicity and $\mathrm{MnO}_{2}$ on briquettes, consisting of high-grade hematite, $70 \%$ stoichiometric bituminous coal $(\mathrm{J}), 4 \%$ different silicates and $2 \%$ fluorspar, unless otherwise stated, placed over a $6 / 100$ mesh coke hearth layer and heated at $1400^{\circ} \mathrm{C}$ for 20 minutes in a $\mathrm{N}_{2}-\mathrm{CO}$ atmosphere.

\begin{tabular}{|c|c|c|c|c|c|c|c|c|c|}
\hline $\mathrm{C} / \mathrm{S}$ & \multicolumn{3}{|c|}{$\begin{array}{c}\text { Slag fusion temp, }{ }^{\circ} \mathrm{C} \\
\text { No } \mathrm{MnO}_{2} \quad 2 \% \mathrm{MnO}_{2} \quad 4 \% \mathrm{MnO}_{2}\end{array}$} & \multicolumn{3}{|c|}{ Micro NRI, \% } & No $\mathrm{MnO}_{2}$ & $\begin{array}{l}\% \mathrm{~S} \text { in NRI } \\
2 \% \mathrm{MnO}_{2}\end{array}$ & $4 \% \mathrm{MnO}_{2}$ \\
\hline \multicolumn{10}{|c|}{ Wollastonite } \\
\hline \multicolumn{10}{|c|}{ No fluorspar } \\
\hline 1.5 & --- & 1300 & 1300 & --- & 3.3 & 3.6 & --- & 0.064 & 0.045 \\
\hline 1.6 & --- & Not fused & 1300 & --- & Not fused & 2.3 & --- & Not fused & 0.042 \\
\hline 1.7 & --- & Not fused & Not fused & --- & Not fused & Not fused & --- & Not fused & Not fused \\
\hline \multicolumn{10}{|c|}{$\underline{2 \% \text { fluorspar }}$} \\
\hline 1.5 & 1300 & 1240 & 1220 & 4.2 & 1.2 & 1.5 & 0.106 & 0.096 & 0.025 \\
\hline 1.6 & 1320 & 1200 & 1220 & 3.1 & 2.0 & 1.0 & 0.115 & 0.061 & 0.024 \\
\hline 1.7 & --- & 1200 & 1200 & --- & 1.1 & 2.9 & --- & 0.051 & 0.024 \\
\hline \multicolumn{10}{|c|}{$4 \%$ fluorspar } \\
\hline 1.5 & 1260 & --- & --- & $\begin{array}{l}5.2 \\
-8.3\end{array}$ & --- & --- & 0.114 & --- & --- \\
\hline 1.6 & 1280 & --- & --- & 2.2 & --- & --- & 0.104 & --- & --- \\
\hline 1.7 & 1270 & --- & --- & 1.9 & --- & --- & 0.147 & --- & --- \\
\hline
\end{tabular}


Table 2-6-5. Continued.

\begin{tabular}{|c|c|c|c|c|c|c|c|c|c|}
\hline $\mathrm{C} / \mathrm{S}$ & \multicolumn{3}{|c|}{$\begin{array}{l}\text { Slag fusion temp, }{ }^{\circ} \mathrm{C} \\
\mathrm{No}_{\mathrm{MnO}_{2}} \quad 2 \% \mathrm{MnO}_{2} \quad 4 \% \mathrm{MnO}_{2}\end{array}$} & \multicolumn{3}{|c|}{\begin{tabular}{cc}
\multicolumn{3}{c}{ Micro NRI, \% } \\
${\mathrm{No} \mathrm{MnO}_{2}}_{2} \quad 2 \% \mathrm{MnO}_{2} \quad 4 \% \mathrm{MnO}_{2}$
\end{tabular}} & \multicolumn{3}{|c|}{$\begin{array}{ll} & \% \mathrm{~S} \text { in NRI } \\
\mathrm{No} \mathrm{MnO}_{2} & 2 \% \mathrm{MnO}_{2} \quad 4 \% \mathrm{MnO}_{2}\end{array}$} \\
\hline \multicolumn{10}{|c|}{$4 \%$ Nepheline syenite } \\
\hline 1.5 & --- & Not fused & Not fused & --- & Not fused & Not fused & --- & Not fused & Not fused \\
\hline 1.6 & --- & Not fused & Not fused & --- & Not fused & Not fused & --- & Not fused & Not fused \\
\hline 1.7 & --- & Not fused & Not fused & --- & Not fused & Not fused & --- & Not fused & Not fused \\
\hline \multicolumn{4}{|c|}{$\underline{2 \% \text { fluorspar }}$} & & & & & & \\
\hline 1.5 & 1280 & 1180 & 1240 & 0.8 & 1.8 & 0.7 & 0.102 & 0.043 & 0.026 \\
\hline 1.6 & 1300 & 1180 & 1200 & 1.3 & 1.4 & 1.1 & 0.060 & 0.034 & 0.018 \\
\hline 1.7 & --- & 1180 & 1200 & --- & 0.8 & 0.6 & --- & 0.041 & 0.030 \\
\hline \multicolumn{7}{|c|}{ 6\% Nepheline syenite } & & & \\
\hline 1.5 & Not fused & --- & --- & Not fused & -- & --- & Not fused & --- & --- \\
\hline 1.6 & Not fused & --- & --- & Not fused & --- & --- & Not fused & --- & --- \\
\hline
\end{tabular}


Table 2-6-5. Continued.

\begin{tabular}{|c|c|c|c|c|c|c|}
\hline $\mathrm{C} / \mathrm{S}$ & \multicolumn{2}{|c|}{$\begin{array}{l}\text { Slag fusion temp, }{ }^{\circ} \mathrm{C} \\
\text { No } \mathrm{MnO}_{2} \quad 4 \% \mathrm{MnO}_{2}\end{array}$} & \multicolumn{2}{|c|}{$\begin{array}{c}\text { Micro NRI, \% } \\
\text { No } \mathrm{MnO}_{2} \quad 4 \% \mathrm{MnO}_{2}\end{array}$} & \multicolumn{2}{|c|}{$\begin{array}{c}\% \mathrm{~S} \text { in NRI } \\
\text { No } \mathrm{MnO}_{2} \quad 4 \% \mathrm{MnO}_{2}\end{array}$} \\
\hline \multicolumn{7}{|c|}{ Ottawa sand } \\
\hline 1.5 & 1300 & 1220 & 1.8 & 2.6 & 0.132 & 0.048 \\
\hline 1.6 & Not fused & 1200 & Not fused & 1.3 & Not fused & 0.036 \\
\hline 1.7 & --- & 1200 & --- & 1.7 & --- & 0.030 \\
\hline \multicolumn{7}{|c|}{ Fly ash } \\
\hline 1.5 & 1280 & 1200 & 1.8 & 3.8 & 0.147 & 0.062 \\
\hline 1.6 & 1320 & 1200 & 1.2 & 1.5 & 0.108 & 0.032 \\
\hline 1.7 & --- & 1200 & --- & 2.4 & --- & 0.035 \\
\hline \multicolumn{7}{|c|}{$\underline{\text { Taconite tails }}$} \\
\hline 1.5 & 1280 & 1200 & 1.2 & 0.9 & 0.101 & 0.035 \\
\hline 1.6 & 1280 & 1200 & 0.4 & 0.8 & 0.097 & 0.034 \\
\hline 1.7 & 1300 & 1200 & 0.6 & 1.8 & 0.067 & 0.025 \\
\hline \multicolumn{7}{|c|}{ Anorthosite } \\
\hline 1.5 & 1320 & 1200 & 1.6 & 2.2 & 0.060 & 0.037 \\
\hline 1.6 & Not fused & 1200 & Not fused & 0.8 & Not fused & 0.040 \\
\hline 1.7 & Not fused & 1200 & Not fused & 1.3 & Not fused & 0.038 \\
\hline
\end{tabular}


Table 2-6-5. Continued.

\begin{tabular}{|c|c|c|c|c|c|c|}
\hline $\mathrm{C} / \mathrm{S}$ & \multicolumn{2}{|c|}{ 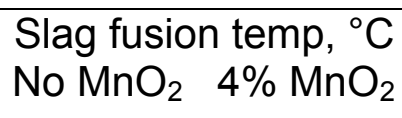 } & \multicolumn{2}{|c|}{$\begin{array}{c}\text { Micro NRI, \% } \\
\text { No } \mathrm{MnO}_{2} \quad 4 \% \mathrm{MnO}_{2}\end{array}$} & \multicolumn{2}{|c|}{$\begin{array}{c}\% \mathrm{~S} \text { in NRI } \\
\text { No } \mathrm{MnO}_{2} \quad 4 \% \mathrm{MnO}_{2}\end{array}$} \\
\hline \multicolumn{7}{|c|}{ Labradorite } \\
\hline 1.5 & 1300 & 1200 & 2.9 & 1.9 & 0.091 & 0.040 \\
\hline 1.6 & 1320 & 1200 & 1.6 & 1.4 & 0.102 & 0.036 \\
\hline 1.7 & 1320 & 1200 & 1.5 & 1.0 & 0.088 & 0.034 \\
\hline \multicolumn{7}{|c|}{ Augite } \\
\hline 1.5 & 1220 & 1200 & 1.1 & 0.9 & 0.086 & 0.031 \\
\hline 1.6 & 1220 & 1200 & 1.1 & 0.8 & 0.093 & 0.032 \\
\hline 1.7 & 1220 & 1180 & 1.2 & 0.5 & 0.052 & 0.026 \\
\hline \multicolumn{7}{|c|}{ Olivine } \\
\hline $1.5^{*}$ & 1220 & 1220 & 8.1 & 1.3 & 0.086 & 0.051 \\
\hline $1.6^{*}$ & 1240 & 1220 & 5.0 & 1.4 & 0.086 & 0.050 \\
\hline $1.7^{*}$ & 1240 & 1200 & 1.8 & 1.2 & 0.101 & 0.060 \\
\hline \multicolumn{7}{|c|}{$\underline{\text { Cu-Ni tails }}$} \\
\hline 1.5 & 1280 & 1180 & 1.3 & 1.2 & 0.107 & 0.034 \\
\hline 1.6 & 1280 & 1200 & 1.6 & 1.1 & 0.071 & 0.036 \\
\hline 1.7 & 1280 & 1200 & 1.4 & 0.8 & 0.084 & 0.032 \\
\hline
\end{tabular}

- Basicity of olivine is expressed as $(\mathrm{CaO}+\mathrm{MgO}) /\left(\mathrm{SiO}_{2}\right)$ 


\section{2-6.2.3.11 Summary:}

1) Combined use of fluorspar and $\mathrm{MnO}_{2}$

Regardless of which silicates were used, fully fused NRI analyzing less than $0.05 \% S$ were obtained under a fixed condition of feed composition of $4 \%$ mineral, $2 \%$ fluorspar and $4 \% \mathrm{MnO}_{2}$, and heated at $1400^{\circ} \mathrm{C}\left(2552^{\circ} \mathrm{F}\right)$ for 20 minutes in a $\mathrm{N}_{2}-\mathrm{CO}$ atmosphere. Most of the slags fused at about $1200^{\circ} \mathrm{C}\left(2192^{\circ} \mathrm{F}\right)$. Decreasing the amount of $\mathrm{MnO}_{2}$ to $2 \%$ to nepheline syenite increased NRI sulfur somewhat, but remained below $0.05 \% \mathrm{~S}$.

2) Fluorspar without $\mathrm{MnO}_{2}$

When fluorspar was used without $\mathrm{MnO}_{2}$, most of the feed mixtures formed fused NRI, but NRI sulfur remained high and stayed in the range of 0.05 to $0.1 \% \mathrm{~S}$.

3) $\mathrm{MnO}_{2}$ without fluorspar

In the presence of $\mathrm{MnO}_{2}$ without fluorspar for wollastonite or nepheline syenite in the feed, products did not fuse, particularly when C/S was 1.6 or higher. With wollastonite, even when fused NRI were formed, slag fusion temperatures were high, $1300^{\circ} \mathrm{C}$ $\left(2372^{\circ} \mathrm{F}\right)$. Yet, NRI sulfur became lower, particularly when $\mathrm{MnO}_{2}$ addition was $4 \%$. Apparently, the presence of increased $\mathrm{MnO}_{2}$ lowered NRI sulfur.

4) Minerals that had difficulty fusing in the absence of $\mathrm{MnO}_{2}$

The addition of Ottawa sand over C/S of 1.6, nepheline syenite when its addition was increased to $6 \%$, or anorthosite did not form fully fused NRI. Olivine when basicity was expressed as $\mathrm{C} / \mathrm{S}$ in the range of 1.5 to 1.7 did not fuse. Because of its high $\mathrm{MgO}$ $(54.5 \% \mathrm{MgO})$, basicity needed to be expressed as $(\mathrm{C}+\mathrm{M}) / \mathrm{S}$ in the range of 1.5 to 1.7 to form fused NRI.

5) Effect of $\mathrm{MgO}$

$\mathrm{MgO}$, particularly in the form of augite, appeared to lower the fusion temperature. It becomes of interest to test the effect of adding $\mathrm{MgO}$ and $\mathrm{SiO}_{2}$ separately rather than in the form of magnesium silicate at the same slag composition.

\section{2-6.3 Effect of a combined use of fluorspar and $\mathrm{MnO}_{2}$ on Fusion time}

In the previous section, tests were carried out by fixing the heating time to 20 minutes at $1400^{\circ} \mathrm{C}\left(2552^{\circ} \mathrm{F}\right)$ in order to screen the promising silicates and alumino-silicates for slag composition. A combined use of fluorspar and $\mathrm{MnO}_{2}$, regardless of the type of silicates and alumino-silicates used, was found to lower the slag fusion temperatures by approximately $100^{\circ} \mathrm{C}\left(180^{\circ} \mathrm{F}\right)$, kept the generation of micro nodules to below a few percent and NRI sulfur to below $0.05 \% \mathrm{~S}$. In this section, the manner in which a combined use of fluorspar and $\mathrm{MnO}_{2}$ and slag basicity affected fusion time, was investigated. 


\section{2-6.3.1 Conclusions}

1) Beneficial effect of adding $\mathrm{MnO}_{2}$ along with fluorspar on dramatically decreasing fusion time by $1 / 3$ to $1 / 2$ was established without adversely affecting NRI sulfur or micro NRI generation at slag basicity $\mathrm{C} / \mathrm{S}$ of 1.5 .

2) Increasing the slag basicity $C / S$ to 1.7 increased the fusion time even though $\mathrm{NRI}$ sulfur became somewhat lower than at C/S of 1.5. Nevertheless, the effect on lowering $\mathrm{NRI}$ sulfur was minor and $\mathrm{C} / \mathrm{S}$ of 1.5 was deemed optimum.

3) Electrolytic $\mathrm{MnO}_{2}$ is known to be readily reduced to $\mathrm{MnO}$, so any manganese ores may be used instead. Locally, Cuyuna manganiferrous iron ores are available for this application.

4) Although nepheline syenite showed promise in lowering NRI sulfur to below $0.05 \% \mathrm{~S}$ in the absence of $\mathrm{MnO}_{2}$, vaporization of alkali metals becomes of concern for their adverse effect on refractories.

\section{2-6.3.2 Test procedure}

In order to limit the number of tests, five minerals, namely, Ottawa sand, nepheline syenite, fly ash, taconite tailings and $\mathrm{Cu}-\mathrm{Ni}$ flotation failings, were selected for the study. Ottawa sand $\left(\mathrm{SiO}_{2}\right)$ was taken as a reference material as being one of the most refractory towards slag formation and also is a common gangue in oxidized iron ores. Nepheline syenite was one of the readily fusible because of its high alkali content. The other three, fly ash, taconite tailings and $\mathrm{Cu}-\mathrm{Ni}$ flotation tailings, are available as already in fine sizes or expected to be available in the near future.

Initially, the tests were carried out with a fixed condition of $4 \%$ siliceous gangue additive, $2 \%$ fluorspar, either none or $4 \% \mathrm{MnO}_{2}$ and slag composition of $\mathrm{C} / \mathrm{S}$ of 1.5 , and the minimum time to fusion, micro NRI generation and NRI sulfur were determined. Then, the effect of slag basicity was investigated by changing $\mathrm{C} / \mathrm{S}$ to 1.7 , but keeping all the other components the same, to see if an increase in slag basicity helped to further decrease the fusion time, or to lower NRI sulfur.

\section{2-6.3.3 Test results}

The test results of fusion time, micro NRI generation and NRI sulfur at slag basicity of 1.5 are summarized in Table 2-6-6, and at slag basicity of 1.7 in Table 2-6-7.

In Table 2-6-6, a combined use of fluorspar and $\mathrm{MnO}_{2}$ at $\mathrm{C} / \mathrm{S}$ of 1.5 is seen to decrease the fusion time markedly to one half when Ottawa sand and fly ash were used. In the case of nepheline syenite, taconite tailings and $\mathrm{Cu}-\mathrm{Ni}$ flotation tailings, fusion time became shorter than Ottawa sand and fly ash in the absence of $\mathrm{MnO}_{2}$. Nevertheless, the addition of $4 \% \mathrm{MnO}_{2}$ decreased the fusion time by $1 / 3$. As reported earlier, slag fusion temperatures with different mineral species were lowered by about the same amount $\left(100^{\circ} \mathrm{C}\right)$ by the addition of $4 \% \mathrm{MnO}_{2}$, thereby facilitating the formation of slag. Micro NRI generation became even somewhat less with the addition of $\mathrm{MnO}_{2}$.

Sulfur analysis of NRI was over $0.1 \% \mathrm{~S}$ in the absence of $\mathrm{MnO}_{2}$, except nepheline syenite, but sulfur decreased to well below $0.05 \% \mathrm{~S}$ in the presence of $4 \% \mathrm{MnO}_{2}$. In the 
case of nepheline syenite, $\mathrm{NRI}$ sulfur was already low in the absence of $\mathrm{MnO}_{2}$ $(0.048 \% \mathrm{~S})$, and decreased further by the addition of $4 \% \mathrm{MnO}_{2}$.

The results at C/S of 1.7 are summarized in Table 2-6-7. By increasing the slag basicity, fusion time increased. The effect was more pronounced in the case of Ottawa sand $\left(\mathrm{SiO}_{2}\right)$ and taconite tailings $\left(69.24 \% \mathrm{SiO}_{2}, 0.27 \% \mathrm{Al}_{2} \mathrm{O}_{3}\right)$. Apparently, highly siliceous slags were less tolerant of high lime for fusion. Micro NRI generation was not affected.

NRI sulfur became somewhat lower than $\mathrm{C} / \mathrm{S}$ of 1.5 , but not enough to warrant further investigation. Here again, NRI sulfur in the presence of $4 \% \mathrm{MnO}_{2}$ was well below $0.05 \% \mathrm{~S}$ in all cases, attesting to the beneficial effect of adding $\mathrm{MnO}_{2}$ in controlling NRI sulfur. In the case of nepheline syenite, NRI sulfur was $0.063 \% \mathrm{~S}$ in the absence of $\mathrm{MnO}_{2}$, but decreased to $0.045 \% \mathrm{~S}$ in the presence of $2 \% \mathrm{MnO}_{2}$ and further decreased to $0.035 \% \mathrm{~S}$ in the presence of $4 \% \mathrm{MnO}_{2}$.

The foregoing tests demonstrated that the beneficial effects of adding $\mathrm{MnO}_{2}$ along with fluorspar on decreasing fusion time as well as NRI sulfur. 
Table 2-6-6. Summary of the effect of $\mathrm{MnO}_{2}$ on briquettes, consisting of highgrade hematite, $70 \%$ stoichiometric bituminous coal (J), different silicate additives, $2 \%$ fluorspar and slag composition $\mathrm{C} / \mathrm{S}=1.5$, placed on a $6 / 100$ mesh coke hearth layer and heated at $1400^{\circ} \mathrm{C}$ for different periods of time in a $\mathrm{N}_{2}-\mathrm{CO}$ atmosphere.

\begin{tabular}{|c|c|c|c|c|c|c|}
\hline \multirow{2}{*}{$\begin{array}{l}\text { Silicate } \\
\text { additive }\end{array}$} & \multicolumn{2}{|c|}{$\begin{array}{c} \\
\text { Fusion time, } \min .\end{array}$} & \multicolumn{2}{|c|}{ Micro nodules, \% } & \multicolumn{2}{|c|}{$\%$ S, iron nodules } \\
\hline & no $\mathrm{MnO}_{2}$ & $4 \% \mathrm{MnO}_{2}$ & no $\mathrm{MnO}_{2}$ & $4 \% \mathrm{MnO}_{2}$ & no $\mathrm{MnO}_{2}$ & $4 \% \mathrm{MnO}_{2}$ \\
\hline Ottawa sand & 20 & 10 & 2.2 & 1.0 & 0.106 & 0.035 \\
\hline Fly ash & 16 & 8 & 4.8 & 0.8 & 0.127 & 0.049 \\
\hline N. syenite & 13 & 9 & 1.3 & 1.7 & 0.048 & 0.038 \\
\hline Taconite tails & 12 & 9 & 1.0 & 0.4 & 0.102 & 0.031 \\
\hline Cu-Ni tails & 12 & 9 & 1.3 & 0.7 & 0.102 & 0.036 \\
\hline
\end{tabular}

Table 2-6-7. Summary of the effect of $\mathrm{MnO}_{2}$ on briquettes, consisting of highgrade hematite, $70 \%$ stoichiometric bituminous coal $(\mathrm{J})$, different silicate additives, $2 \%$ fluorspar and slag composition $\mathrm{C} / \mathrm{S}=1.7$, placed on a $6 / 100$ mesh coke hearth layer and heated at $1400^{\circ} \mathrm{C}$ for different periods of time in a $\mathrm{N}_{2}-\mathrm{CO}$ atmosphere.

\begin{tabular}{|c|c|c|c|c|c|c|}
\hline \multirow{2}{*}{$\begin{array}{l}\text { Silicate } \\
\text { additive }\end{array}$} & \multicolumn{2}{|c|}{ Fusion time, min. } & \multicolumn{2}{|c|}{ Micro nodules, \% } & \multicolumn{2}{|c|}{$\%$ S, iron nodules } \\
\hline & no $\mathrm{MnO}_{2}$ & $4 \% \mathrm{MnO}_{2}$ & no $\mathrm{MnO}_{2}$ & $4 \% \mathrm{MnO}_{2}$ & no $\mathrm{MnO}_{2}$ & $4 \% \mathrm{MnO}_{2}$ \\
\hline Ottawa sand & $>20$ & $>20$ & --- & --- & --- & --- \\
\hline Fly ash & 16 & 9 & 2.0 & 1.9 & 0.100 & 0.039 \\
\hline N. syenite & 13 & 8 & 1.5 & 2.3 & 0.063 & 0.035 \\
\hline Taconite tails & $16-20$ & $13-17$ & 1.4 & 1.3 & 0.067 & 0.027 \\
\hline Cu-Ni tails & 13 & 10 & 1.5 & 1.8 & 0.091 & 0.032 \\
\hline
\end{tabular}




\section{2-6.4 Effects of magnetite and mill scale}

To explore if the generation of micro NRI with hematite could be controlled by mixing either with magnetite or $\mathrm{FeO}$, two series of tests were carried out. In one series, a highgrade hematite was mixed with taconite concentrate $(\mathrm{K})$, and in another series, with mill scale, as the mill scale consisted mainly of $\mathrm{FeO}$. A combination of $\mathrm{FeO}$ and $\mathrm{Fe}_{2} \mathrm{O}_{3}$ forms $\mathrm{Fe}_{3} \mathrm{O}_{4}$ upon heating.

\section{2-6.4.1 Conclusion}

The addition of either magnetite, or $\mathrm{FeO}$ in the form of mill scale could not remedy the problems of increased micro NRI generation, nor increased NRI sulfur.

\section{2-6.4.2 Test procedure}

Chemical composition of high-grade hematite, taconite concentrate $(\mathrm{K})$, mill scale and bituminous coal $(\mathrm{J})$ are given in Table 2-6-8. Tests were carried out by replacing the high-grade hematite with either taconite concentrate $(K)$ or mill scale by $1 / 3$ and $2 / 3$, together with bituminous coal $(\mathrm{J})$ at $80 \%$ and $70 \%$ of the stoichiometric amount. Hydrated lime was added to adjust the slag composition to the C/S ratio of 1.5 . The compositions of the mixtures are given in Table 2-6-9.

The box furnace tests were carried out following the 'standardized' procedure using 6segment mounds in graphite trays. The sample trays were held in Zone 2 at $1400^{\circ} \mathrm{C}$ $\left(2552^{\circ} \mathrm{F}\right)$ for 20 minutes in $\mathrm{N}_{2}$-CO atmosphere.

\section{2-6.4.3 $\underline{\text { Test results }}$}

Essential points of the test results, namely \%micro NRI and \%S in NRI are summarized in Table 2-6-10. In the table, the results on high-grade hematite, taconite concentrate $(\mathrm{K})$, mill scale by themselves are included for comparison.

Taconite concentrate $(\mathrm{K})$ by itself at $80 \%$ stoichiometric coal generated essentially no micro NRI and \%S in NRI was $0.046 \%$ S. Even when high-grade hematite was diluted with twice as much of taconite concentrate $(K)$, micro NRI were generated more than the proportion of the hematite present. NRI sulfur was well below $0.05 \% \mathrm{~S}$, regardless of the mixing ratios of the hematite and the magnetic concentrate. When the coal addition was decreased to $70 \%$ stoichiometric coal, the generation of micro NRI decreased to a few percent, but their amounts were higher than taconite concentrate $(K)$ by itself. NRI sulfur decreased somewhat, but remained near $0.1 \% \mathrm{~S}$.

When mill scale was mixed with the high-grade hematite at $80 \%$ stoichiometric coal, the amount of micro NRI decreased, more or less, in proportion to the amount of mill scale in the feed mixtures, and NRI sulfur remained less than $0.05 \% \mathrm{~S}$. When the amount of coal was lowered to $70 \%$ of the stoichiometric amount, the generation of micro NRI decreased to a few percent, but NRI sulfur remained near $0.1 \% \mathrm{~S}$. 
As the approach was found to be ineffective for controlling the generation of micro NRI and NRI sulfur, no further tests were made.

Table 2-6-8. Chemical composition of raw materials.

(a) Iron oxides and additives

\begin{tabular}{|c|c|c|c|c|c|c|}
\hline & $\begin{array}{c}\text { High- } \\
\text { grade } \\
\text { hematite }\end{array}$ & $\begin{array}{c}\text { Taconite } \\
\text { conc }\end{array}$ & $\begin{array}{c}\text { Mill } \\
\text { scale }\end{array}$ & $\begin{array}{c}\text { Bitu. coal } \\
\text { ash }\end{array}$ & $\begin{array}{c}\text { Hydrated } \\
\text { lime }\end{array}$ & $\begin{array}{c}\text { Fluor- } \\
\text { spar }\end{array}$ \\
\hline & & & & & & \\
$\mathbf{T . F e}$ & 66.61 & 69.94 & 71.95 & & 0.05 & 0.05 \\
$\mathbf{m e t} \mathbf{F e}$ & & 20.40 & 4.83 & & & \\
$\mathrm{Fe}^{++}$ & & 3.51 & 1.28 & 51.56 & 0.43 & 1.87 \\
$\mathrm{SiO}_{2}$ & 1.07 & 0.51 & & \\
$\mathbf{A l}_{\mathbf{2}} \mathbf{O}_{3}$ & 0.90 & 0.02 & 0.25 & 29.63 & 0.00 & 0.12 \\
$\mathbf{C a O}$ & 0.03 & 0.67 & 1.14 & 3.32 & 68.8 & 1.28 \\
$\mathbf{M g O}$ & 0.02 & 0.39 & 0.13 & 1.14 & 0.32 & 0.00 \\
$\mathbf{S}$ & 0.010 & 0.008 & $<0.010$ & & 0.45 & 0.44 \\
$\mathbf{P}$ & 0.031 & 0.011 & 0.005 & 0.15 & 0.005 & 0.025 \\
\hline
\end{tabular}

(b) Proximate analysis of bituminous coal $(\mathrm{J})$

\begin{tabular}{|l|c|}
\hline & Bitu. coal \\
\hline Moisture & 0.66 \\
Volatile & 20.73 \\
Fixed carbon & 69.67 \\
Ash & 8.94 \\
Sulfur & 0.61 \\
Btu/lb & 14118 \\
& \\
\hline
\end{tabular}


Table 2-6-9. Composition of feed mixtures, consisting of high-grade hematite, taconite concentrate $(\mathrm{K})$ or mill scale, bituminous coal $(\mathrm{J})$ at $70 \%$ or $80 \%$ stoichiometric amount, and Slag composition of $C / S^{*}=1.5$.

\begin{tabular}{|c|c|c|c|c|c|c|c|}
\hline & $\begin{array}{l}\text { Coal } \\
\% \text { stoich. }\end{array}$ & $\begin{array}{c}\text { High- } \\
\text { grade } \\
\text { hematit }\end{array}$ & $\begin{array}{l}\text { Taconite } \\
\text { conc }\end{array}$ & $\begin{array}{c}\text { Mill } \\
\text { scale }\end{array}$ & $\begin{array}{l}\text { Bitu. } \\
\text { coal }\end{array}$ & $\begin{array}{l}\text { Hyd. } \\
\text { lime }\end{array}$ & $\begin{array}{l}\text { Fluor- } \\
\text { spar }\end{array}$ \\
\hline \multicolumn{8}{|l|}{$\begin{array}{l}\text { Hematite: } \\
\text { Keetac conc } \\
\end{array}$} \\
\hline 2/3:1/3 (P-351) & 80 & 50.15 & 25.05 & & 18.15 & 4.65 & 2.0 \\
\hline 1/3:2/3 (P-352) & 80 & 24.9 & 49.8 & & 17.6 & 5.7 & 2.0 \\
\hline 2/3:1/3 (P-353) & 70 & 51.5 & 25.7 & & 16.3 & 4.5 & 2.0 \\
\hline $1 / 3: 2 / 3(P-354)$ & 70 & 25.5 & 51.1 & & 15.8 & 5.6 & 2.0 \\
\hline \multicolumn{8}{|l|}{$\begin{array}{l}\text { Hematite: } \\
\text { Mill scale } \\
\end{array}$} \\
\hline 2/3:1/3 (P-380) & 80 & 51.55 & & 25.75 & 17.5 & 3.2 & 2.0 \\
\hline 1/3:2/3 (P-381) & 80 & 26.25 & & 52.6 & 16.3 & 2.85 & 2.0 \\
\hline 2/3:1/3 (P-382) & 70 & 52.8 & & 26.4 & 15.7 & 3.1 & 2.0 \\
\hline 1/3:2/3 (P-383) & 70 & 26.8 & & 53.8 & 14.6 & 2.7 & 2.0 \\
\hline
\end{tabular}


Table 2-6-10. Summary of test results showing the effects of replacing high-grade hematite with taconite concentrate $(K)$, or with mill scale, using 6 mounds of feed mixtures, containing 70 or $\mathbf{8 0 \%}$ stoichiometric bituminous coal $(\mathrm{J}), 2 \%$ fluorspar and slag composition $\mathrm{C} / \mathrm{S}=1.5$, placed over a $6 / 100$ mesh coke hearth layer and heated at $1400^{\circ} \mathrm{C}$ for 20 minutes in a $\mathrm{N}_{2}-\mathrm{CO}$ atmosphere.

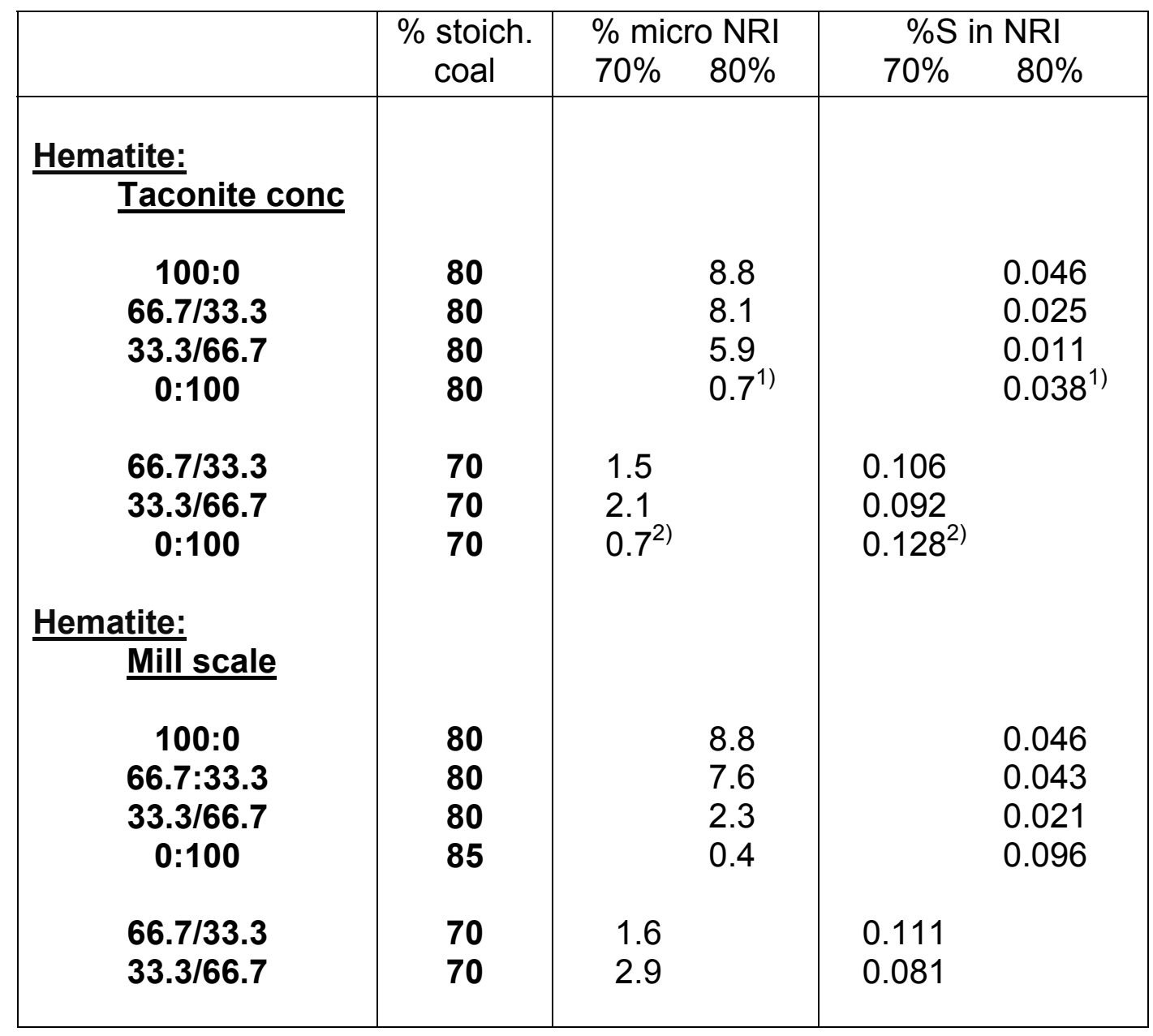

1) At fusion time of 11 minutes

2) At fusion time of 13 minutes 


\section{2-7 LHF TESTS}

A major difference between the test conditions of the LHF and the box furnace is the high $\mathrm{CO}_{2}$, low $\mathrm{CO}$ concentrations and high turbulence of the burner combustion products.

The furnace atmosphere in the linear hearth furnace (LHF), fired with natural gas-air burners, analyzed $10 \% \mathrm{CO}_{2}$ and $2-4 \% \mathrm{CO}$, in agreement with the stoichiometry of combustion,

$$
\begin{gathered}
\mathrm{CH}_{4}+2 \mathrm{O}_{2}+2(3.76) \mathrm{N}_{2}=\mathrm{CO}_{2}+2 \mathrm{H}_{2} \mathrm{O}+2(3.76) \mathrm{N}_{2} \\
\mathrm{CO}_{2}=9.5 \% ; \mathrm{H}_{2} \mathrm{O}=19 \%
\end{gathered}
$$

From computational fluid dynamics (CFD) modeling of the LHF, the furnace gas was noted to be circulating vigorously within each zone, and while the temperature at the surfaces of trays in Zone 3 was relatively uniform $1427^{\circ} \mathrm{C}\left(2600^{\circ} \mathrm{F}\right)$, furnace gas velocities approached $1-3 \mathrm{~m} / \mathrm{s}(3-10 \mathrm{ft} / \mathrm{s})$ in localized regions at the tray level. In the box furnace, on the other hand, the furnace gas velocities were estimated at as much as two to three orders of magnitude less, $0.03-0.003 \mathrm{~m} / \mathrm{s}(0.1-0.01 \mathrm{ft} / \mathrm{s})$. Therefore, the operating conditions of the LHF cannot be simulated by increasing the gas flow in the box furnace.

In laboratory tests, fully fused NRI could be formed at as low as $1325^{\circ} \mathrm{C}\left(2417^{\circ} \mathrm{F}\right)$ under a $\mathrm{N}_{2}-\mathrm{CO}$ atmosphere, and NRI sulfur could be lowered to as low as $0.01 \%$ or less. Thus, from both a product quality standpoint and from an operating standpoint, furnace atmosphere control becomes a key control variable and must be taken into consideration in the design of overall furnace operating conditions.

To counteract the oxidizing effect of $\mathrm{CO}_{2}$ and the high turbulence of combustion gas in the gas-fired LHF, two localized atmosphere control methods were tested, namely,

1. Cover the feed mixture with coarse coke/char/coal to disrupt the highly turbulent gas as well as to maintain CO-rich gas near the feed surfaces.

2. Install a hood, or plate above the feed materials to isolate them from the combustion products by injecting reducing gas under the hood.

\section{2-7.1 Preliminary tests with walking beam tray conveying system}

\section{2-7.1.1 Conclusions}

Conclusions gleaned from the preliminary tests are summarized first, followed by detailed information on the test procedures and the results:

1) Coarse coke cover over the mounds of feed mixtures at 2.4 and $4.9 \mathrm{~kg} / \mathrm{m}^{2}(0.5$ and $1.0 \mathrm{lb} / \mathrm{ft}^{2}$ ) (visually 50 and $100 \%$ coverage) was effective in forming fully fused NRI with feed mixtures containing as low as $80 \%$ stoichiometric coal.

2) Sulfur contents of NRI made in this manner were in the range of 0.02 to $0.04 \% \mathrm{~S}$. The higher the coverage by coarse coke, the lower the sulfur in NRI. 
3) Under these conditions, iron contents of slag were about $1 \% \mathrm{FeO}$. The slag appeared white and readily separated from NRI.

4) Micro NRI generated ranged from 1 to $4 \%$ with their amounts increasing with an increase in the reductant coal.

5) By injecting $\mathrm{CH}_{4}$ under the hood in Zone 2, the feed mixture with $80 \%$ stoichiometric coal did not fuse, while the feed mixture with $110 \%$ stoichiometric coal fused. However, the sulfur content of NRI analyzed $0.14 \% \mathrm{~S}$, and the iron content of the slag analyzed about $3 \% \mathrm{FeO}$. The slag was strongly attached to $\mathrm{NRI}$, and they had to be broken to separate them.

6) Direct feeding of wet briquettes of $25 \times 25 \times 18 \mathrm{~mm}(1 \times 1 \times 0.75 ")$ in size led to decrepitation by the internal pressure of evaporating moisture upon introduction into Zone 1 at $982^{\circ} \mathrm{C}\left(1800^{\circ} \mathrm{F}\right)$.

\section{2-7.1.2 Standardized procedure for the preliminary series of tests}

2-7.1.2.1 Feed mixtures: Feed mixtures consisted of taconite concentrate (Mb), medium-volatile bituminous coal and slag composition $\mathrm{L}_{1.5} \mathrm{FS}_{2}$. Feed mixtures were

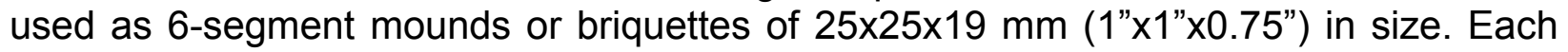
mound weighed $34 \mathrm{~g}$ and the briquette weighed $13 \mathrm{~g}$. The mounds or briquettes were placed on a layer of 6/100 mesh anthracite char. When the feed samples were covered with coke in different size fractions or in different amounts, a sheet of paper was placed over the feed mixtures to distribute the coke evenly over the feed mixtures.

2-7.1.2.2 Tray fabrication: Tests were initiated with fiber board trays, with or without steel frames. Both of them worked well in the first test, but the material became brittle after use in LHF tests, and could not be used any more than a few times at best. Graphite trays took the thermal shock well, but corroded severely by the high $\mathrm{CO}_{2}$ and highly turbulent furnace atmosphere. Lining the inside with 1" fiber boards protected graphite from corroding and could be used a number of times. Corrosion of graphite curbs was protected by painting with Vesuvius 3000 as needed.

2-7.1.2.3 LHF operation: The heating schedule of feed samples in the LHF was standardized as follows unless stated otherwise. A sample tray traveled through Zone 1 at $982^{\circ} \mathrm{C}\left(1800^{\circ} \mathrm{F}\right)$ without stopping in 3 minutes, then through Zone 2 at $1316^{\circ} \mathrm{C}$ $\left(2400^{\circ} \mathrm{F}\right)$ by moving one stroke of $139.7 \mathrm{~mm}\left(5.5^{\prime \prime}\right)$ every 16 seconds requiring a total time of 5 minutes. Then, the tray was moved to the center of Zone 3 at 55 seconds per stroke requiring a total time of 10 minutes. The tray was held there at $1427^{\circ} \mathrm{C}\left(2600^{\circ} \mathrm{F}\right)$ for long enough time to visually ascertain the fusion of mounds or briquettes, and moved into the cooling zone without stopping. The tray was held in the cooling zone for 20 minutes and discharged.

$\mathrm{NRI}$ analyses were made on products at or near the fusion time. NRI in a tray were split several times to about a dozen NRI, crushed, again split to about $10 \mathrm{~g}$ and ground to -100 mesh for analyses. 
2-7.1.2.4 Temperature measurements within coke layers: TempCHEK by Orton Ceramics was used to estimate the temperatures at the tray bottom as well as at the briquette levels. At the briquette level, care was taken to keep TempCHEKs away from slag formed during the process.

The temperatures thus measured at the briquette level were essentially the same at about $1371^{\circ} \mathrm{C}\left(2500^{\circ} \mathrm{F}\right)$ regardless of whether fully fused NRI were formed or not. The temperatures at the tray bottom correlated well with the fusion behavior of the products. The temperatures near the side walls were somewhat higher than in the middle of the trays, indicating that there was some conduction of heat through the side walls. Fully fused NRI were formed when the temperature at the tray bottom approached $1371^{\circ} \mathrm{C}$ $\left(2500^{\circ} \mathrm{F}\right)$. The results suggested that the formation of fused NRI was governed by the length of time sponge iron was exposed to temperatures near $1371^{\circ} \mathrm{C}\left(2500^{\circ} \mathrm{F}\right)$.

2-7.1.2.5 Sulfur distribution between NRI and slag: When the ratios of $\% S$ in slag and \%S in NRI, (\%S)/[\%S], were plotted against \%S in NRI, [\%S], a good correlation was obtained between these two variables. Figure 2-7-1 shows such a correlation from the results obtained from LHF tests on a taconite concentrate and bituminous coal (F) (filled squares) and from box furnace tests on a Keetac concentrate and bituminous coal (J) (open squares). From the regression curve, it appeared that $(\% \mathrm{~S}) /[\% \mathrm{~S}]$ should be larger than about 15 in order to keep the sulfur in NRI below $0.05 \% \mathrm{~S}$.

\section{2-7.1.3 Preliminary test results with hoods in Zone 2}

In the LHF, 20 silicon carbide pipes of rectangular shape, $76.2 \mathrm{~mm} \times 38.1 \mathrm{~mm} \times 762$ $\mathrm{mm}$ (3"x1.5"x30"), were placed side by side about $114 \mathrm{~mm}(4.5$ ") above the tray surface,

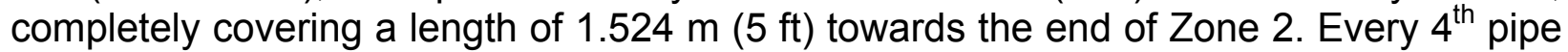
had five $6.35 \mathrm{~mm}(0.25$ ") holes, $152.4 \mathrm{~mm}$ (6") apart underneath for introducing reducing gases $\left(\mathrm{CH}_{4}\right.$ or $\left.\mathrm{CO}\right)$. The reducing gases were introduced for 10 minutes when the tray was travelling underneath the hood. The gas sampling probe in Zone 2 was located 76.2-101.6 mm (3-4") above the sample surface, but below the hood. The probe in Zone 3 was located $203.2 \mathrm{~mm}$ (8") above the sample surface. 


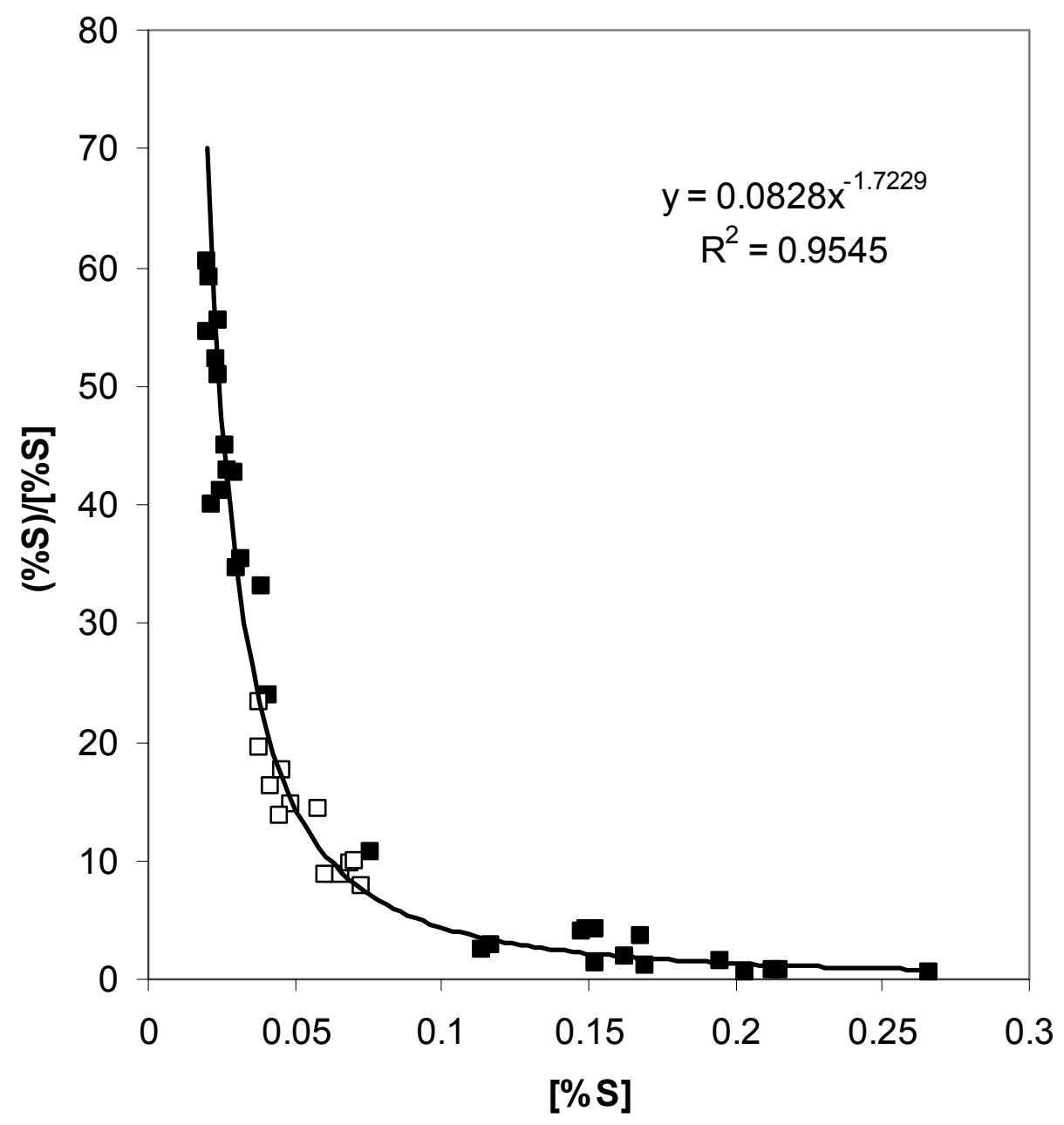

Figure 2-7-1. Ratio of \%S in slag and \%S in NRI plotted against \%S in slag. Filled squares are for LHF tests on feed mixtures consisting of taconite concentrate (Ma) and $80 \%$ stoichiometric bituminous coal $(F)$, and open squares for box furnace tests on feed mixtures consisting of taconite concentrate $(K)$ and $\mathbf{8 0} \%$ stoichiometric bituminous coal $(\mathrm{J})$, both at slag composition $\mathrm{L}_{1.5} \mathrm{FS}_{2}$. 


\section{2-7.1.3.1 Mounds:}

\section{2-7.1.3.1.1 Effect of $\mathrm{CH}_{4}$ or $\mathrm{CO}$ injection}

A tray with two columns of mounds with 80 and $110 \%$ stoichiometric coal was tested. During the test, $\mathrm{CH}_{4}$ was introduced at $0.57 \mathrm{~m}^{3} / \mathrm{h}\left(20 \mathrm{ft}^{3} / \mathrm{h}\right)$ for 10 minutes, and held at $1427^{\circ} \mathrm{C}\left(2600^{\circ} \mathrm{F}\right)$ in Zone 3 for 20 minutes.

The mounds with $80 \%$ stoichiometric coal did not fuse, while those with $110 \%$ stoichiometric coal fused. The weight of micro NRI amounted to $4.7 \%$. This amount was considerably less than $12 \%$, reported in a previous project period without $\mathrm{CH}_{4}$ injection. The decrease might be the result of the reducing gas injection or the effect of the hood at the critical period of reduction in Zone 2.

The NRI analyzed $0.139 \% \mathrm{~S}$ and $3.09 \% \mathrm{C}$. These results may be compared with the NRI produced in the absence of $\mathrm{CH}_{4}$ injection under a similar condition (with $115 \%$ stoichiometric coal, however), reported in the previous project, which analyzed $0.152 \% \mathrm{~S}$ and $3.15 \% \mathrm{C}$. Therefore, the injection of $\mathrm{CH}_{4}$ had a minor effect in lowering the uptake of sulfur by NRI, yet the sulfur remained in excess of $0.1 \%$. This might be due to the oxidizing effects of high $\mathrm{CO}_{2}$ and the turbulence of the furnace gas at high temperatures in Zone 3.

The slag analyses of $1.57 \% \mathrm{Fe}, 2.88 \% \mathrm{FeO}$ and $0.47 \% \mathrm{~S}$ also indicated that $\mathrm{CH}_{4}$ injection had a minor effect in lowering the $\mathrm{FeO}$ content of the slag as compared to the analytical results of slag in the absence of $\mathrm{CH}_{4}$ injection, which were reported in the previous project; $6.0 \% \mathrm{Fe}, 6.3 \% \mathrm{FeO}$ and $0.213 \% \mathrm{~S}$. The effect of $\mathrm{FeO}$ in slag on desulfurizing of $\mathrm{NRI}$ is apparent; the lower the FeO, the lower the sulfur in NRI and the higher the sulfur in slag.

$\mathrm{CO}$ concentrations in the furnace gas increased to about $7 \%$ in Zone 2, but the analyzer could not measure another component of the combustion product, $\mathrm{H}_{2}$ and $\mathrm{H}_{2} \mathrm{O}$. When the gas sampling probe was moved to Zone 3, the $\mathrm{CO}$ concentrations remained essentially the same at about $1.3 \% \mathrm{CO}$ whether $\mathrm{CH}_{4}$ was injected or not, indicating that the furnace gas was highly turbulent and well mixed.

Another test was performed with two columns of mounds, identical to those in the previous test. Two types of duplex balls were also included in a tray. The heating schedule in Zones 1 and 2 remained the same, but the temperature in Zone 3 was initially set at $1349^{\circ} \mathrm{C}\left(2460^{\circ} \mathrm{F}\right)$ and later raised to $1427^{\circ} \mathrm{C}\left(2600^{\circ} \mathrm{C}\right)$. During the test, $\mathrm{CO}$ was introduced at $0.254 \mathrm{~m}^{3} / \mathrm{h}\left(9 \mathrm{ft}^{3} / \mathrm{h}\right)$ for 8 minutes. The tray was held in Zone 3 for 22 minutes. As in the previous test, the mounds at $110 \%$ of the stoichiometric coal fused, while those at $80 \%$ of the stoichiometric coal did not. Both types of duplex balls did not fuse.

The furnace gas composition followed essentially the identical trend as in previous tests, but CO concentration increased to over $10 \%$ at 11 minutes into the test. 


\section{2-7.1.3.1.2 Effect of cover layer coke}

Effect of reductant coal: In one series of tests, the effect of the amount of the reductant coal was investigated by placing three rows of mounds with 85,90 and $95 \%$ stoichiometric coal in a tray. The mounds were covered with $4.88,2.44$, and $1.22 \mathrm{~kg} / \mathrm{m}^{2}$ $\left(1.0,0.5\right.$ and $\left.0.25 \mathrm{lb} / \mathrm{ft}^{2}\right)(100,50$ and $25 \%$ coverage) of $12.7 \mathrm{~mm} \mathrm{(-1/2")})+4$ mesh coke. No reducing gas was introduced when the tray was underneath the hood. The tray was held at $1400^{\circ} \mathrm{C}\left(2552^{\circ} \mathrm{F}\right)$ for 24 minutes.

Most of the outermost rows and columns were not fused because coarse coke particles rolled off around the periphery, and the mounds were exposed to the furnace gas and oxidized. Except for a few unfused pieces around the periphery, all three sections formed satisfactory NRI. The amount of micro NRI at $85 \%$ stoichiometric coal was $1.4 \%$ and increased to $3.3 \%$ as the amount of added coal increased to $95 \%$ of the stoichiometric amount. The outermost pieces were excluded from the samples from each section for weight measurements and chemical analyses.

The NRI analyzed about $0.02 \% \mathrm{~S}$. Fe, and $\mathrm{FeO}$ in slag analyzed notably lower than 0.2 and $0.3 \%$, respectively, and the sulfur analyzed about $1 \%$. With $85 \%$ of the stoichiometric coal, the coarse coke cover layer of $2.44 \mathrm{~kg} / \mathrm{m}^{2}\left(0.5 \mathrm{lb} / \mathrm{ft}^{2}\right)(50 \%$ coverage) produced NRI just as effectively at $90 \%$ of the stoichiometric coal. The amounts of micro NRI increased from $0.8 \%$ with $85 \%$ stoichiometric coal to $2.9 \%$ with $95 \%$ stoichiometric coal. Hence, minimizing the added coal minimized the amount of micro NRI generation.

The coarse coke cover layer lowered the amount of micro NRI to 1 to $2 \%$, as compared to 10 to $15 \%$ without coarse coke cover, as reported in the previous project. It may also be noted that the coal addition of $85 \%$ of the stoichiometric amount generated minimal amount of micro NRI.

The NRI analyzed about $0.04 \% \mathrm{~S}$. It is apparent that coarse coke cover of $50 \%(2.44$ $\mathrm{kg} / \mathrm{m}^{2}\left[0.5 \mathrm{lb} / \mathrm{ft}^{2}\right]$ ) resulted in doubling the sulfur content, yet it remained below $0.05 \% \mathrm{~S}$. An increase in reductant coal from 85 to $95 \%$ of the stoichiometric amount appeared to increase NRI sulfur, suggesting that much of the sulfur must have come from added coal. Fe and $\mathrm{FeO}$ contents were in the same range as in the case of full coverage (4.88 $\left.\mathrm{kg} / \mathrm{m}^{2}\left[1.0 \mathrm{lb} / \mathrm{ft}^{2}\right]\right)$, but sulfur contents were somewhat lower than $1 \%$.

The products from the feed mixtures with 85,90 and $95 \%$ stoichiometric coal, covered with coarse coke at $1.22 \mathrm{~kg} / \mathrm{m}^{2}\left(0.25 \mathrm{lb} / \mathrm{ft}^{2}\right)(25 \%$ coverage), resulted in large amounts of unfused pieces, indicating that the coarse coke cover layer of $1.22 \mathrm{~kg} / \mathrm{m}^{2}\left(0.25 \mathrm{lb} / \mathrm{ft}^{2}\right)$ ( $25 \%$ coverage) was not sufficient to prevent the high $\mathrm{CO}_{2}$, turbulent furnace gas from affecting the NRI formation.

The maximum $\mathrm{CO}$ concentration in the furnace gas of $4.4 \%$ was reached at about 10 minutes into the test, which was only 2 to $3 \%$ lower than when $\mathrm{CH}_{4}$ was injected. The above results indicated that the coarse coke cover layer of 2.44 to $4.88 \mathrm{~kg} / \mathrm{m}^{2}(0.5$ to 1.0 $\left.\mathrm{lb} / \mathrm{ft}^{2}\right)$ (50 to $100 \%$ coverage) was necessary to form fully-fused products, and to lower the NRI sulfur to below $0.05 \% \mathrm{~S}$. 
Effect of cover layer coke: In the second series of tests, the effect of increased coverage by coarse coke was investigated on two trays of feed mixtures of mounds with $80 \%$ stoichiometric coal. In both trays, the mounds were divided into three equal rows and the rows were covered with coarse coke at $6.1,4.88$, and $3.66 \mathrm{~kg} / \mathrm{m}^{2}(1.25,1.0$ and $\left.0.75 \mathrm{lb} / \mathrm{ft}^{2}\right)$. The trays were sent through the LHF according to the standardized heating schedule and heated at $1427^{\circ} \mathrm{C}\left(2600^{\circ} \mathrm{F}\right)$ for 20 minutes. In these tests, the hood was present, but no reducing gas was introduced.

Sulfur analyses of $\mathrm{NRI}$ increased from 0.020 to $0.030 \%$ with decreasing coke coverage. Iron analyses of slag were low, 0.03 to $0.3 \% \mathrm{Fe}$ and 0.27 to $0.55 \% \mathrm{FeO}$. Ratio, (S)/[S], ranged 55 to 35 , again decreasing with decreasing coke coverage.

The NRI and associated black-colored slag from the periphery were analyzed. Iron analysis of the slag was notably higher than that from the interior, $0.82 \% \mathrm{Fe}$ and $1.20 \% \mathrm{FeO}$. Sulfur analysis of the NRI was $0.076 \% \mathrm{~S}$ with the ratio, (S)/[S], of 10.8 . The results clearly show that an exposure of the products to the furnace atmosphere was detrimental to the removal of sulfur from NRI into slag.

Effect of temperature and time at temperature: In the third series of tests, a tray of feed mixtures as in the second series of tests was sent through the LHF according to the standardized heating schedule, but the temperature of Zone 3 was lowered to $1399^{\circ} \mathrm{C}$ $\left(2550^{\circ} \mathrm{F}\right)$. The tray was kept at the temperature for 20 minutes.

More than a half of the iron products were not fused. Only at the coke coverage of 0.75 $\mathrm{Ib} / \mathrm{ft}^{2}$, the amount of fully fused NRI approached a half of the product. Nevertheless, NRI and associated slag were selected from the area with $3.66 \mathrm{~kg} / \mathrm{m}^{2}\left(0.75 \mathrm{lb} / \mathrm{ft}^{2}\right)$ coke coverage and analyzed. The sulfur analysis of NRI was $0.034 \% \mathrm{~S}$ and the iron analyses of the slag were $0.26 \% \mathrm{Fe}$ and $0.54 \% \mathrm{FeO}$. The ratio, $(\mathrm{S}) /[\mathrm{S}]$, was 33 .

By increasing the time at $1399^{\circ} \mathrm{C}\left(2550^{\circ} \mathrm{F}\right)$ to 30 minutes, fused $\mathrm{NRI}$ formed under all the conditions. The amounts of micro NRI were about $1 \%$. The sulfur analyses were in the range of 0.02 to $0.03 \% \mathrm{~S}$, but there was an increasing trend of sulfur with decreasing coke coverage.

2-7.1.3.2 Briquettes: As the briquettes of $53 \times 50 \times 32 \mathrm{~mm}(2.1 \times 1.9 \times 1.25$ ") in size required nearly twice as long to fuse as compared to the 6-segment mounds, the pocket size of the rollers was changed and briquettes of $25 \times 25 \times 19 \mathrm{~mm}(1 \times 1 \times 0.75 ")$ in size were prepared from a feed mixture of the same composition at $80 \%$ of the stoichiometric coal. Two half-sized trays were made. In one tray, wet briquettes with $8.5 \%$ moisture were placed in the tray. For comparison, completely dried briquettes were placed in another tray. In both trays, briquettes were placed over 6/100 mesh anthracite char layers. The trays were heated in the LHF according to the standardized test procedure with $\mathrm{CH}_{4}$ injection at $0.57 \mathrm{~m}^{3} / \mathrm{h}\left(20 \mathrm{ft}^{3} / \mathrm{h}\right)$ for 10 minutes under the hood. The trays were held in Zone 3 at $1427^{\circ} \mathrm{C}\left(2600^{\circ} \mathrm{F}\right)$ for 16 minutes.

In Tray (1), a number of small pieces scattered among some fused NRI as well as not yet fused pieces. These small pieces were generated by decrepitation due to convective heat transfer in Zone 1, leading to vaporization of moisture and build-up of excessive 
pressure within the briquettes. Differential thermal expansion may also contribute to the break up. Therefore, wet briquettes may not be fed to the LHF in the standardized operating condition. The dry briquettes survived the heating cycle of the standardized test procedure. There was no decrepitation, but most of the briquettes were not fused.

The test was repeated by extending the time at $1427^{\circ} \mathrm{C}\left(2600^{\circ} \mathrm{F}\right)$ to 20 minutes, but with only dry briquettes, and no reducing gas was injected. The products were fully fused. Micro NRI at $80 \%$ stoichiometric coal were low, 1.0 and $0.5 \%$, for coke covers of 4.88 and $3.66 \mathrm{~kg} / \mathrm{m}^{2}\left(1.0\right.$ and $\left.0.75 \mathrm{lb} / \mathrm{ft}^{2}\right)$, respectively, while those at $110 \%$ stoichiometric coal were notably higher, 5.0 and $3.5 \%$, for coke covers of 4.88 and $3.66 \mathrm{~kg} / \mathrm{m}^{2}(1.0$ and $\left.0.75 \mathrm{lb} / \mathrm{ft}^{2}\right)$, respectively. Therefore, the generation of micro NRI was less at $80 \%$ stoichiometric coal. Another point to note was that lower coverage by coarse coke generated less micro NRI. NRI analyzed 0.029 to $0.016 \%$ S, while slag analyzed essentially no iron. The ratio, (S)/[S], ranged 45 to 82 .

Foregoing observations indicated that a high $\mathrm{CO}$ atmosphere is a necessary condition in producing fused NRI from feed mixtures containing sub-stoichiometric coal. It is also necessary to slow the turbulence of the furnace gas to produce NRI analyzing less than $0.05 \% \mathrm{~S}$.

The reason why the mounds, heated at $1399^{\circ} \mathrm{C}\left(2550^{\circ} \mathrm{F}\right)$, did not fully fuse, while the briquettes fused, may be attributed to the difference in their degree of compaction, as explained in 4.3.2.

2-7.1.3.3 Sulfur distribution: NRI sulfur came from: (1) reductant coal added to feed mixtures, (2) anthracite char used as hearth layers and (3) coarse coke cover materials, when used. Distribution of sulfur in feed mixtures into NRI and slag were estimated from the amounts and sulfur analyses of the reductant coal, and the amounts and sulfur analyses of the products (NRI, micro NRI and slag). Bituminous coal $(F)(0.47 \% S)$ was used as the reductant. Sulfur analyses of micro NRI were generally somewhat higher than NRI in the same product, but were assumed to be the same as NRI since the amounts of micro NRI were small and they were not routinely analyzed. The results are summarized in Table 2-7-1.

In the fifth column in the table, labeled "\%wt products," little over a half of the weights of the feed mixtures were recovered as products (NRI, micro NRI and slag). The weight losses can be accounted for by the sum of the reduction of magnetite concentrate, the loss of coal and the formation of slag-forming components, consisting of gangue, coal ash as well as the additives of hydrated lime and fluorspar. 
Table 2-7-1. The distribution of sulfur in feed into NRI and slag, as affected by the amount of coal addition and coarse coke cover.

\begin{tabular}{|c|c|c|c|c|c|c|c|c|c|c|c|c|}
\hline \multirow{2}{*}{$\begin{array}{l}\text { Test } \\
\text { No. }\end{array}$} & \multirow{2}{*}{$\begin{array}{c}\text { Added } \\
\text { coal } \\
\% \text { stoich. }\end{array}$} & \multirow{2}{*}{$\begin{array}{l}\text { Coke } \\
\text { cover } \\
{\mathrm{lb} / \mathrm{ft}^{2}}^{2}\end{array}$} & \multirow{2}{*}{$\begin{array}{c}\text { Bitu. coal } \\
\text { (F) } \\
\text { Added,\% }\end{array}$} & \multirow{2}{*}{$\begin{array}{c}\% \text { wt } \\
\text { products }\end{array}$} & \multicolumn{2}{|c|}{$\%$ wt of feed ${ }^{1)}$} & \multicolumn{2}{|c|}{$\% \mathrm{~S}$} & \multicolumn{2}{|c|}{ Dist'n S,\% } & \multicolumn{2}{|c|}{$\% S$ to } \\
\hline & & & & & $\mathrm{N}+\mathrm{MN}^{2)}$ & Slag & $\mathrm{NRI}^{3)}$ & Slag & NRI & Slag & products & NRI \\
\hline $21(2)$ & 110 & None & 21.4 & 58.6 & 44.1 & 14.5 & 0.139 & 0.47 & 47.4 & 52.6 & 151 & 71.6 \\
\hline $22(1 a)$ & 85 & 1.0 & 17.3 & 47.7 & 35.5 & 12.2 & 0.027 & 1.03 & 7.1 & 92.9 & 195 & 13.8 \\
\hline$(2 a)$ & 90 & 1.0 & 18.2 & 51.4 & 41.8 & 9.6 & 0.022 & 0.88 & 9.8 & 90.2 & 128 & 12.6 \\
\hline$(3 a)$ & 95 & 1.0 & 19.0 & 53.3 & 43.2 & 10.1 & 0.020 & 1.07 & 7.4 & 92.6 & 152 & 11.4 \\
\hline$(1 b)$ & 85 & 0.5 & 17.3 & 52.4 & 39.6 & 12.8 & 0.040 & 0.97 & 11.3 & 88.7 & 202 & 22.9 \\
\hline$(2 b)$ & 90 & 0.5 & 18.2 & 52.6 & 40.9 & 11.7 & 0.041 & 0.98 & 12.8 & 87.2 & 180 & 23.1 \\
\hline (3b) & 95 & 0.5 & 19.0 & 61.1 & 45.6 & 15.5 & 0.066 & 0.97 & 16.7 & 83.3 & 237 & 39.6 \\
\hline
\end{tabular}

1) Based on feed mixture of $100 \%$; +20 mesh mag. excluded.

2) NRI and micro NRI combined.

3) $\% \mathrm{~S}$ in micro NRI assumed to be the same as in NRI. 
Numbers in the left side of the last column, "\%S to products," were estimated from the amounts of sulfur in the products divided by the amounts of sulfur in the feed mixtures. In all cases, sulfur went to the products from feed mixtures was over $100 \%$, and in some samples over $200 \%$. The extra sulfur could have come from anthracite char used as hearth layer $(0.57 \% \mathrm{~S})$ and coarse coke used as a cover material $(0.65 \% \mathrm{~S})$. Also, some sulfur might have been lost to the furnace gas.

The numbers in the right side of the last column "\%S to NRI" indicate the amount of sulfur in NRI divided by the amount of sulfur in feed mixture. Without cover layer coke, about $70 \%$ of sulfur went to NRI, whereas only about $10 \%$ of sulfur went to NRI when cover layer coke was $4.88 \mathrm{~kg} / \mathrm{m}^{2}\left(1.0 \mathrm{lb} / \mathrm{ft}^{2}\right)$, and about $20 \%$ of sulfur when the cover layer coke was $2.44 \mathrm{~kg} / \mathrm{m}^{2}\left(0.5 \mathrm{lb} / \mathrm{ft}^{2}\right)$. The marked difference between tests without and with cover layer coke illustrated that the coarse coke cover prevented the direct contact with high $\mathrm{CO}_{2}$ and turbulent combustion gas. The difference in the coverage of 2.44 and $4.88 \mathrm{~kg} / \mathrm{m}^{2}\left(0.5\right.$ and $\left.1.0 \mathrm{lb} / \mathrm{ft}^{2}\right)(50 \%$ and $100 \%$ coverage) had a minor influence on the sulfur analyses of NRI of 0.04 and $0.02 \% \mathrm{~S}$, respectively, showing the effectiveness of cover layer by coarse coke.

\section{2-7.1.4 Preliminary tests without hood in Zone 2}

To isolate the effect of coarse coke cover over mounds and briquettes, the hood in Zone 2 was removed, and the damper in Zone 3 was closed while in Zones 1 and 2 were kept open. The pressure in the furnace was thereby kept slightly positive, so that the oxygen concentration at the start of the tests was $0.00 \%$ in all three zones.

Temperature in Zone 3 was lowered to $1399^{\circ} \mathrm{C}\left(2550^{\circ} \mathrm{F}\right)$. By lowering the temperature in Zone 3 by $28^{\circ} \mathrm{C}\left(50^{\circ} \mathrm{F}\right)$, temperatures in Zones 2 and 3 of the LHF were notably stabilized. When a tray moved into Zone 2, the burner in Zone 2 operated at 30 to $40 \%$ of capacity. After the tray moved through Zone 2 in 5 minutes, the burners cut back to $0 \%$. The temperature in Zone 2 did not change and stayed at $1299^{\circ} \mathrm{C}\left(2370^{\circ} \mathrm{F}\right)$ throughout. As the tray moved into Zone 3, the burners increased to 50 to $60 \%$ for a few minutes, then decreased to about $40 \%$. The temperature stayed at $1399^{\circ} \mathrm{C}$ $\left(2550^{\circ} \mathrm{F}\right)$ and was not affected by the introduction of a tray.

\section{2-7.1.4.1 Conclusions:}

1) Removal of the hood had no significant effect on the formation of NRI or the sulfur analyses of NRI.

2) Coarse coke covers produced low sulfur NRI. Sulfur analyses were in the range of 0.02 to $0.03 \% \mathrm{~S}$, and micro NRI generation was $1 \%$ or less.

3) Size and amount of cover layer coke governed the fusion time. Coke covers of $12.7 \mathrm{~mm}+9.525 \mathrm{~mm}\left(1 / 2 "+3 / 8^{\prime \prime}\right)$ at $4.88 \mathrm{~kg} / \mathrm{m}^{2}$ and $3.66 \mathrm{~kg} / \mathrm{m}^{2}\left(1.0\right.$ and $\left.0.75 \mathrm{lb} / \mathrm{ft}^{2}\right)$ and $4 / 6$ mesh at $3.66 \mathrm{~kg} / \mathrm{m}^{2}\left(0.75 \mathrm{lb} / \mathrm{ft}^{2}\right)$ produced satisfactory NRI. When finer coke was used, the coverage needed to be decreased. Coke cover of 4/6 mesh at $4.88 \mathrm{~kg} / \mathrm{m}^{2}\left(1.0 \mathrm{lb} / \mathrm{ft}^{2}\right)$ did not produce fully fused NRI.

4) NRI under cover layer coke analyzed low sulfur (less than $0.05 \% \mathrm{~S}$ ), and readily separated from low iron slag. NRI exposed to furnace atmosphere analyzed high 
sulfur (often over $0.1 \% \mathrm{~S}$ ). The associated high iron slag attached strongly to $\mathrm{NRI}$, and had to be broken apart for separation.

5) Wet briquettes under a coke cover of $-12.7 \mathrm{~mm}(-1 / 2))+4$ mesh, both at 3.66 and $4.88 \mathrm{~kg} / \mathrm{m}^{2}\left(0.75\right.$ and $\left.1.0 \mathrm{lb} / \mathrm{ft}^{2}\right)$, did not show any sign of decrepitation. Dry and wet briquettes showed little difference in their behaviors of forming NRI.

6) Lowering of fluorspar to $1 \%$ had a significant effect on the fusion behaviors of NRI.

2-7.1.4.2 Test procedure: The amount of coal addition in the feed mixtures was kept at $80 \%$ stoichiometric coal. In one test, the amount of fluorspar was decreased to $1 \%$. In the same test, wet and dry briquettes were covered with coke to explore if the decrepitation of wet briquettes by internal pressure of moisture might be alleviated. The amount and size of coke cover were varied to see its effect on fusion behavior. Also the fusion behaviors of mounds and briquettes were compared.

2-7.1.4.3 Mounds: Feed mixture in mounds with $80 \%$ stoichiometric coal in a tray, covered with $-12.7 \mathrm{~mm}(-1 / 2)+4$ mesh coke at $6.1,4.88$, and $3.66 \mathrm{~kg} / \mathrm{m}^{2}(1.25,1.0$ and $\left.0.75 \mathrm{lb} / \mathrm{ft}^{2}\right)$ were extended by $38.1 \mathrm{~mm}(1.5$ ") beyond the edges of the feed, so that the feed would remain covered by the coke without rolling off the edges. In this test, the hood was removed and the time at $1399^{\circ} \mathrm{C}\left(2550^{\circ} \mathrm{F}\right)$ was increased to 30 minutes. Satisfactory NRI formed under all conditions. The amounts of micro NRI were about $1 \%$. The sulfur analyses were in the range of 0.02 to $0.03 \% \mathrm{~S}$, but there was an increasing trend of sulfur with decreasing coke coverage.

A similar test was carried out to investigate the effect of the size and the amount of cover layer coke. Mounds with $80 \%$ stoichiometric coal were placed in four separate islands in a tray: Row (a) was covered with 4/6 mesh coke; Row (b) with -12.7 $\mathrm{mm}+9.525 \mathrm{~mm}\left(-1 / 2 "+3 / 8\right.$ ") coke; Column (1) with coke cover at $2.44 \mathrm{~kg} / \mathrm{m}^{2}\left(0.5 \mathrm{lb} / \mathrm{ft}^{2}\right)$; and Column (2) at $3.66 \mathrm{~kg} / \mathrm{m}^{2}\left(0.75 \mathrm{lb} / \mathrm{ft}^{2}\right)$. In this manner, two different sized coke and two different coverage amounts could be investigated.

The tray was sent through the LHF in a similar manner as before, and the tray was kept in Zone 3 at $1399^{\circ} \mathrm{C}\left(2550^{\circ} \mathrm{F}\right)$ for 25 minutes. All samples fused with the generation of micro NRI of about $1 \%$. The sulfur analyses of the NRI ranged 0.026 to $0.039 \% \mathrm{~S}$.

2-7.1.4.4 Briquettes: To investigate the effect of covering with coke of different sizes of $-12.7 \mathrm{~mm}+9.525 \mathrm{~mm}(-1 / 2 "+3 / 8 ")$ and $4 / 6$ mesh, briquettes of $25 \times 25 \times 19 \mathrm{~mm}(1 \times 1 \times 0.75 ")$ in size with $80 \%$ stoichiometric coal were placed close-packed on a 6/100 mesh anthracite char in four separate islands. In the tray, Row (a) was covered with 4/6 mesh coke; Row (b) with $-12.7 \mathrm{~mm}+9.525 \mathrm{~mm}\left(-1 / 2 "+3 / 8\right.$ ") coke; Column (1) at $3.66 \mathrm{~kg} / \mathrm{m}^{2}$ $\left(0.75 \mathrm{lb} / \mathrm{ft}^{2}\right)$; and Column (2) at $4.88 \mathrm{~kg} / \mathrm{m}^{2}\left(1.0 \mathrm{lb} / \mathrm{ft}^{2}\right)$.

The tray was sent through the LHF in a similar manner as before, and kept in Zone 3 at $1399^{\circ} \mathrm{C}\left(2550^{\circ} \mathrm{F}\right)$ for 20 minutes. Satisfactory NRI were formed with $-12.7 \mathrm{~mm}+9.525$ $\mathrm{mm}\left(-1 / 2 "+3 / 8\right.$ ") coke at the coverage of $4.88 \mathrm{~kg} / \mathrm{m}^{2}$ and $3.66 \mathrm{~kg} / \mathrm{m}^{2}\left(1.0\right.$ and $\left.0.75 \mathrm{lb} / \mathrm{ft}^{2}\right)$ and $4 / 6$ mesh at $3.66 \mathrm{~kg} / \mathrm{m}^{2}\left(0.75 \mathrm{lb} / \mathrm{ft}^{2}\right)$. However, when the coke cover was $4 / 6 \mathrm{mesh}$ and $4.88 \mathrm{~kg} / \mathrm{m}^{2}\left(1.0 \mathrm{lb} / \mathrm{ft}^{2}\right)$, about $37 \%$ by weight of the product did not fuse. Therefore, when finer coke was used, the coverage needed to be decreased. 
Effect of exposure to furnace atmosphere: At the coverage of $3.66 \mathrm{~kg} / \mathrm{m}^{2}\left(0.75 \mathrm{lb} / \mathrm{ft}^{2}\right)$, the cover layer coke over the outermost rows of the products rolled off after the tests, and some of the NRI and slag were exposed to the furnace atmosphere. The slag from the exposed areas appeared black and attached strongly to the NRI, while the slag under well-covered areas appeared essentially white and separated readily from the NRI. The products from the exposed areas and most of the products from the covered areas were separately analyzed to see the effect of getting exposed to the furnace atmosphere. The results are given in Table 2-7-2.

In the table, "High Fe slag" refers to the products from the exposed areas and "Low Fe slag" to the covered areas. NRI associated with the low Fe slag analyzed low, $0.035 \%$ and $0.026 \% \mathrm{~S}$, while those associated with the high Fe slag analyzed $0.158 \%$ and $0.088 \%$ S. Slag associated with the exposed areas had higher iron than those associated with the covered areas. These results clearly indicated that the products need to stay covered with coke through the furnace to produce low sulfur NRI, which could be readily separated from the slag. Also the results show that the longer the time at $1400^{\circ} \mathrm{C}$, the lower the sulfur in NRI.

Table 2-7-2. Analytical results of NRI and slag produced from Lab Komarek briquettes, showing the effect of furnace atmosphere. Cover layer coke $-12.7 \mathrm{~mm}$ $\left(-1 / 2^{\prime \prime}\right)+3$ mesh and $3.66 \mathrm{~kg} / \mathrm{m}^{2}\left(0.75 \mathrm{lb} / \mathrm{ft}^{2}\right)$.

\begin{tabular}{|c|c|c|c|c|}
\hline \multirow{3}{*}{ 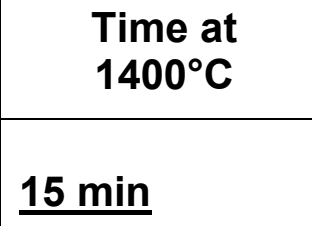 } & \multicolumn{2}{|c|}{ NRI } & \multicolumn{2}{|c|}{ Slag } \\
\hline & $\% \mathrm{C}$ & $\% \mathrm{~S}$ & $\% \mathrm{Fe}$ & $\% \mathrm{~S}$ \\
\hline & & & & \\
\hline Low Fe slag & 3.16 & 0.035 & 0.18 & 0.78 \\
\hline High Fe slag & 4.28 & 0.158 & 0.79 & 0.39 \\
\hline $20 \mathrm{~min}$ & & & & \\
\hline Low Fe slag & 1.58 & 0.026 & 0.55 & 0.89 \\
\hline High Fe slag & 3.01 & 0.088 & 0.59 & 0.51 \\
\hline
\end{tabular}


Effect of moisture in briquettes: In an earlier test, when wet briquettes with $8.5 \%$ moisture without cover layer coke were sent through the LHF, the briquettes decrepitated into small pieces due to build-up of excessive pressure by the vaporization of moisture. A test was performed to investigate if a coarse coke cover over wet briquettes might alleviate the decrepitation of wet briquettes. A tray with two columns of briquettes consisted of dry briquettes in Column (1) and wet briquettes with $8.7 \%$ moisture in Column (2). The wet briquettes were prepared immediately before the test and placed on the tray to prevent the loss of moisture by evaporation. In this test, the amount of fluorspar was lowered to $1 \%$ in both wet and dry briquettes, or slag composition, $\mathrm{L}_{1.5} \mathrm{FS}_{1}$. The briquettes were placed close-packed in four islands as before: Row (a) was covered with $-12.7 \mathrm{~mm}(-1 / 2 ")+4$ mesh coke at $4.88 \mathrm{~kg} / \mathrm{m}^{2}\left(1.0 \mathrm{lb} / \mathrm{ft}^{2}\right)$, and Row (b) with the same-sized coke at $3.66 \mathrm{~kg} / \mathrm{m}^{2}\left(0.75 \mathrm{lb} / \mathrm{ft}^{2}\right)$.

The tray was sent through the LHF in a similar manner as before, and the tray was kept in Zone 3 at $1399^{\circ} \mathrm{C}\left(2550^{\circ} \mathrm{F}\right)$ for 20 minutes. Wet briquettes under a coke cover of $-12.7 \mathrm{~mm}(-1 / 2 ")+4 \mathrm{mesh}$, both at 3.66 and $4.88 \mathrm{~kg} / \mathrm{m}^{2}\left(0.75\right.$ and $\left.1.0 \mathrm{lb} / \mathrm{ft}^{2}\right)$, did not appear to show any sign of decrepitation. Dry and wet briquettes showed little difference in their behaviors of forming NRI. When the briquettes were covered with $4.88 \mathrm{~kg} / \mathrm{m}^{2}$ $\left(1.0 \mathrm{lb} / \mathrm{ft}^{2}\right)$ coke, $57 \%$ and $38 \%$ of the products from the dry and wet briquettes, respectively, did not fuse. When the coverage was lowered to $3.66 \mathrm{~kg} / \mathrm{m}^{2}\left(0.75 \mathrm{lb} / \mathrm{ft}^{2}\right)$ (Row (b)), $9 \%$ and $16 \%$ of the products from the dry and wet briquettes, respectively, did not fuse. Apparently, lowering of fluorspar to $1 \%$ had a significant effect on the fusion behavior of the products. Also coke coverage had a significant effect on the fusion behavior.

The reason why the mounds required somewhat longer time for fusion at $1399^{\circ} \mathrm{C}$ $\left(2550^{\circ} \mathrm{F}\right)$ was examined by plotting the time required for fusion against the weights of two types of briquettes and a 6-segment dome. These agglomerates were heated at $1399^{\circ} \mathrm{C}\left(2550^{\circ} \mathrm{F}\right.$ ) (in a $\mathrm{N}_{2}-\mathrm{CO}$ atmosphere in the box furnace). The two types of briquettes were $53 \times 50 \times 32 \mathrm{~mm}(2.1 \times 2.0 \times 1.25$ ") in size with an average weight of 93 grams, and $25 \times 25 \times 19 \mathrm{~mm}(1 \times 1 \times 0.75$ ) in size with an average weight of 18 grams. A mound made from 6 -segment mold of $43 \times 43 \times 18 \mathrm{~mm}(1.7 \times 1.7 \times 0.7 ")$ had an average weight of 34 grams. The time to form fully fused NRI was determined to be 25 and 10 minutes for the two types of briquettes, respectively, and 15 minutes (probably somewhat less with fine tuning) for the mounds.

The time required for full fusion was shown to be directly related to their individual weights, irrespective of mounds or briquettes. However, when the weights were expressed in terms of loading density, there was no correlation with fusion time. The loading densities of the two briquettes were 35.1 and $28.8 \mathrm{~kg} / \mathrm{m}^{2}\left(7.2\right.$ and $\left.5.9 \mathrm{lb} / \mathrm{ft}^{2}\right)$, respectively, whereas that of the mounds was $15.1 \mathrm{~kg} / \mathrm{m}^{2}\left(3.1 \mathrm{lb} / \mathrm{ft}^{2}\right)$. Also fusion time did not show any correlation with their heights. Apparently, fusion time was complexly dependent on their weights, heights and the degree of packing (apparent density). 


\section{2-7.1.5 Effects of reductant coal, hearth layer and cover layer coke}

From box furnace tests and the preliminary LHF tests, major factors that control the rate of NRI formation in the LHF were identified to be the amount of reductant coal, briquette height and loading, hearth layer thickness and coverage by cover layer coke. In this section, the effects of reductant coal, and of hearth layer and cover layer coke were investigated more in detail.

\section{2-7.1.5.1 Conclusions:}

1) In box furnace tests, an increase in reductant coal from 80 to $95 \%$ of the stoichiometric amount nearly halved the fusion time, and NRI sulfur decreased from $0.1 \%$ to $0.02 \% \mathrm{~S}$ at fusion time, while micro NRI increased from 0 to $7 \%$. Holding the products for 20 minutes at $1400^{\circ} \mathrm{C}$ markedly decreased NRI sulfur. The optimum level of reductant coal was $85 \%$ of the stoichiometric amount.

2) With a single layer of briquettes in the LHF, distributing the total periods of time to $1 / 3$ and $2 / 3$ in Zones 2 and 3 , respectively, and in equal lengths did not affect the fusion time. Distributing the time to $2 / 3$ and $1 / 3$, respectively, required somewhat longer time for fusion.

3) Hearth layer thickness was a primary factor governing the fusion time, suggesting that the thinnest possible hearth layer without allowing the penetration of slag to hearth refractory was desirable. Evidence suggested that the size of hearth layer coke had little effect on fusion time.

4) Increasing reductant coal addition had a significant effect on decreasing fusion time, but not as much as the box furnace tests indicated. In view of increased generation of micro NRI, the optimum level was judged to be $85 \%$ of the stoichiometric amount, in good agreement with the box furnace tests.

5) With multiple layers of briquettes, productivity, defined as the ratio of the loading of briquettes and fusion time, increased from single to double to triple layers. This observation should be regarded with caution. Productivity remained essentially unchanged with multiple layers of briquettes with the continuous moving car system (See 7.2).

6) Fusion time was linearly dependent on loading, or the degree of packing and the number of layers of briquettes.

7) At the same loading, double layers of briquettes fused faster than mounds of an approximate the same height, suggesting that surface exposed per unit weight of feed played a role. The use of multiple layers of balled feed in place of briquettes becomes of interest, as the surface exposed per unit weight is maximized.

2-7.1.5.2 Feed materials: A series of briquettes were prepared from feed mixtures, consisting of taconite concentrate (K), bituminous coal (F) at $80 \%$ to $95 \%$ of the stoichiometric amount, and slag composition, $\mathrm{L}_{1.5} \mathrm{FS}_{2}$. The chemical composition of the feed and the composition of the feed mixtures are given in Tables 2-7-3 and 2-7-4. The feed mixtures were briquetted in a Lab. Komarek briquetting machine. The briquette size averaged $35.1 \mathrm{~mm}$ x $22.4 \mathrm{~mm}$ x $12.2 \mathrm{~mm}$ (1.38"x 0.88"x0.48") and weighed $12.2 \mathrm{~g}$ on average. 
Table 2-7-3. Chemical analyses of LHF test raw materials

(a) Proximate analyses of bituminous coal (J)

\begin{tabular}{|l|c|}
\hline & $\begin{array}{c}\text { Bituminous } \\
\text { coal (F) }\end{array}$ \\
\hline Moisture & 0.55 \\
Volatile & 20.89 \\
Fixed carbon & 70.22 \\
Ash & 8.34 \\
Sulfur & 0.64 \\
Btu/lb & 14,263 \\
kJ/kg & 33,104 \\
\hline
\end{tabular}

(b) Iron ore, additives and coal ash

\begin{tabular}{|l|c|c|c|c|}
\hline & $\begin{array}{c}\text { Taconite } \\
\text { conc (K) }\end{array}$ & $\begin{array}{c}\text { Bituminous } \\
\text { coal (J) }\end{array}$ & $\begin{array}{c}\text { Hydrated } \\
\text { lime }\end{array}$ & $\begin{array}{c}\text { Fluorspar } \\
\text { acid grade }\end{array}$ \\
\hline T.Fe & 67.83 & 5.44 & 0.74 & 0.68 \\
$\mathbf{F e O}$ & & 51.08 & 0.48 & 0.76 \\
$\mathbf{S i O}_{2}$ & 3.37 & 29.61 & 0.00 & 0.04 \\
$\mathbf{A l}_{2} \mathbf{O}_{3}$ & 0.06 & 2.62 & 75.2 & $(1.16)^{*}$ \\
$\mathbf{C a O}$ & 0.69 & 1.16 & 0.39 & 0.04 \\
$\mathbf{M g O}$ & 0.29 & 0.85 & 0.37 & 0.371 \\
$\mathbf{S}$ & & 0.18 & 0.010 & 0.018 \\
$\mathbf{P}$ & & & 18.26 & 1.26 \\
$\mathbf{L O I}_{\mathbf{C a F}}$ & & & & 83.49 \\
$\mathbf{C a C O}_{3}$ & & & 9.85 & 3.50 \\
$\mathbf{C O}_{2}$ & & & \\
\hline
\end{tabular}

${ }^{*}$ Assumed to have formed by calcination of $\mathrm{CaCO}_{3}$. 
Table 2-7-4. Composition of feed mixtures consisting of taconite concentrate (K), bituminous coal $(\mathrm{J})(8.34 \%$ ash, $90 \%-100$ mesh) at different addition levels in terms of the stoichiometric amount and slag composition $\mathrm{L}_{1.5} \mathrm{FS}_{2}$.

\begin{tabular}{|l|c|c|c|c|}
\hline $\begin{array}{l}\text { Coal addn } \\
\text { \% stoich. }\end{array}$ & $\begin{array}{c}\text { Taconite } \\
\text { conc (K) }\end{array}$ & $\begin{array}{c}\text { Bituminous } \\
\text { coal (J) }\end{array}$ & Lime hydrate & Fluorspar \\
\hline $\mathbf{8 0 \%}$ & 75.4 & 16.7 & 5.9 & 2.0 \\
$\mathbf{8 5 \%}$ & 74.55 & 17.45 & 5.9 & 2.0 \\
$\mathbf{9 0 \%}$ & 73.75 & 18.35 & 5.9 & 2.0 \\
$\mathbf{9 5 \%}$ & 72.9 & 19.2 & 5.9 & 2.0 \\
\hline
\end{tabular}

Table 2-7-5. Box furnace test results of Lab Komarek briquettes, consisting of taconite concentrate $(\mathrm{K})$, bituminous coal $(\mathrm{J})(8,34 \%$ ash, $90 \%-100 \mathrm{mesh})$ at different addition levels in terms of the stoichiometric amount and slag composition $L_{1.5} \mathrm{FS}_{2}$. placed on $6 / 100$ mesh coke, and heated at $1400^{\circ} \mathrm{C}\left(2552^{\circ} \mathrm{F}\right)$.

\begin{tabular}{|c|c|c|c|c|c|c|c|}
\hline \multirow{2}{*}{$\begin{array}{l}\text { Coal addn } \\
\% \text { stoich. }\end{array}$} & \multirow{2}{*}{$\begin{array}{l}\text { Time at } \\
1400^{\circ} \mathrm{C}\end{array}$} & \multirow{2}{*}{ NRI } & \multirow{2}{*}{$\begin{array}{c}\text { Micro } \\
\text { NRI }\end{array}$} & \multirow{2}{*}{$\begin{array}{c}-20 \text { mesh } \\
\text { mag. }\end{array}$} & \multirow{2}{*}{ Slag } & \multicolumn{2}{|c|}{ NRI } \\
\hline & & & & & & $\% \mathrm{C}$ & $\% \mathrm{~S}$ \\
\hline \multirow[t]{2}{*}{$80 \%$} & $6 \mathrm{~min}^{*}$ & 82.5 & 0.0 & 0.0 & 17.5 & 2.89 & 0.097 \\
\hline & $20 \mathrm{~min}$ & 82.5 & 0.0 & 0.0 & 17.5 & 3.91 & 0.026 \\
\hline \multirow[t]{2}{*}{$85 \%$} & $5 \mathrm{~min}^{*}$ & 82.6 & 0.1 & 0.1 & 17.2 & 3.26 & 0.032 \\
\hline & $20 \mathrm{~min}$ & 82.4 & 0.0 & 0.1 & 17.5 & 4.51 & 0.010 \\
\hline \multirow[t]{2}{*}{$90 \%$} & $4 \mathrm{~min}^{*}$ & 80.9 & 1.5 & 0.3 & 17.3 & 2.89 & 0.097 \\
\hline & $20 \mathrm{~min}$ & 79.1 & 3.1 & 0.3 & 17.5 & 4.25 & 0.012 \\
\hline \multirow[t]{2}{*}{$95 \%$} & $4 \min ^{* *}$ & 75.9 & 7.0 & 1.9 & 15.2 & 3.09 & 0.023 \\
\hline & $20 \mathrm{~min}$ & 76.8 & 5.3 & 1.0 & 16.9 & 4.54 & 0.006 \\
\hline
\end{tabular}

- Minimum time to fusion.

** Fusion time closer to 3 minutes. 
2-7.1.5.3 Box furnace tests: Six briquettes were placed on 6/100 mesh coke in a graphite tray and heated at $1400^{\circ} \mathrm{C}\left(2552^{\circ} \mathrm{F}\right)$ for different periods of time in the standardized manner to determine fusion time. The results are summarized in Table 27-5.

The fusion time decreased to nearly a half by increasing the coal addition from $80 \%$ to $95 \%$ of the stoichiometric amount. Even though the fusion time of briquettes with $95 \%$ stoichiometric coal is reported as 4 minutes, the briquettes nearly fused in 3 minutes at $1400^{\circ} \mathrm{C}\left(2552^{\circ} \mathrm{F}\right)$, while those with $90 \%$ stoichiometric coal did not. This amounted to an increase of about one minute for an increase of the coal every $5 \%$ of the stoichiometric amount. The amount of micro NRI increased above $90 \%$ stoichiometric coal, while NRI sulfur (particularly at 20 minutes) decreased as coal addition increased. Also evident in the table is the effect of time at temperature. NRI carbon increased, while NRI sulfur decreased with increasing time at temperature.

\section{2-7.1.5.4 LHF tests:}

2-7.1.5.4.1 Single layer of briquettes

Effects of the addition levels of coal and of thickness of hearth layer coke on fusion time were determined. In a $508 \mathrm{~mm}$ x $508 \mathrm{~mm}$ x $50.8 \mathrm{~mm}$ (20"x20"x2") graphite tray, lined with $25.4 \mathrm{~mm}$ (1") fiber board on sidewalls and on bottom, a weighed amount of 3/100 mesh coke, the thickness estimated to be $12.7 \mathrm{~mm}(0.5$ "), $25.4 \mathrm{~mm}$ (1.0") and $38.1 \mathrm{~mm}$ (1.5") from the bulk density, was spread at the bottom, 96 briquettes were arranged close-packed in a $8 \times 12$ pattern in a single layer, and covered with $4.88 \mathrm{~kg} / \mathrm{m}^{2}\left(1.0 \mathrm{lb} / \mathrm{ft}^{2}\right)$ of $-9.525 \mathrm{~mm}(-3 / 8$ ")+3 mesh coke. In the LHF, the tray was preceded by two trays with hearth layer coke and followed also by two trays of hearth layer coke to simulate the furnace gas atmosphere above the sample tray in a continuous operation.

The residence time in Zone 1 was fixed at 3 minutes, and the remaining periods of time in Zones 2 and 3 were distributed $1 / 3$ and 2/3, respectively. Distributing the total periods of time in Zones 2 and 3 in equal lengths did not appear to affect the fusion time, but distributing the time to $2 / 3$ and $1 / 3$, respectively, required somewhat longer time for fusion.

Effects of the addition levels of coal and of thickness of the hearth layer coke on fusion time of the briquettes are summarized in Table 2-7-6. The hearth layer thickness was the primary factor governing the fusion time. The fusion time increased as the hearth layer thickness was doubled and tripled. This would mean that the thinnest possible hearth layer without allowing the penetration of slag to the hearth refractory was desirable. Decrease in fusion time with increasing coal addition was also significant, but in view of increased micro NRI generation, the optimum level was judged to be about $85 \%$ stoichiometric. 
Table 2-7-6. Effects of the addition levels of a low ash coal $(8.34 \%$ ash) and of thickness of the hearth layer coke on fusion time of briquettes, $35.6 \mathrm{~mm} \times 22.9$ $\mathrm{mm} \times 11.4 \mathrm{~mm}$ (1.4"x0.9" $\times 0.45 ")$ in size.

\begin{tabular}{|l|cccc|}
\hline Hearth layer & \multicolumn{4}{|c|}{ Fusion time, min } \\
thickness & $\mathbf{8 0 \%}$ & $\mathbf{8 5 \%}$ & $\mathbf{9 0 \%}$ & $\mathbf{9 5 \%}$ \\
\hline $\mathbf{1 2 . 7} \mathbf{~ m m ~ ( 1 / 2 " ) ~}$ & 26 & 25 & 23 & 22 \\
$\mathbf{2 5 . 4} \mathbf{~ m m ~ ( 1 " ) ~}$ & 30 & 30 & 29 & 27 \\
$\mathbf{3 8 . 1} \mathbf{~ m m ~ ( 1 . 5 ' ) ~}$ & 39 & 39 & 36 & 36 \\
\hline
\end{tabular}

\section{2-7.1.5.4.2 Multi-layers of briquettes}

Briquettes in single, double and triple layers were used to establish the fusion time with two different sizes of coke for the hearth layer and coke (M) for the cover layer. The briquettes were of the standardized composition with $85 \%$ stoichiometric coal. The size distributions of the coke are given in Table 2-7-7. Residence time in Zone 1 was fixed at 3 minutes, and the total periods of time in Zones 2 and 3 were distributed $1 / 3$ and $2 / 3$, respectively.

The fusion time using 'as received' coke $(\mathrm{H})$ for the hearth layer are summarized in Table 2-7-8. When the hearth layer was $12.7 \mathrm{~mm}(1 / 2 ")$, slag reached the hearth refractory due presumably to insufficient fines. Fusion time using 6/100 mesh coke (M) for hearth layers were also investigated to determine the effect of the size of hearth layer coke. The results are included in Table 2-7-8 and compared with those using coke $(\mathrm{H})$ for hearth layers.

Hearth layers of two different sizes of coke gave essentially the same fusion time. Therefore, the size of hearth layer coke had little influence on fusion time. However, even with 6/100 mesh coke, slag penetrated through the coke layer of $12.7 \mathrm{~mm}(1 / 2 ")$ and reacted with TempCHEKs placed at the interface of refractory fiber board and hearth layer.

When the amount of cover layer coke was decreased to $2.44 \mathrm{~kg} / \mathrm{m}^{2}\left(0.5 \mathrm{lb} / \mathrm{ft}^{2}\right)$, a number of briquettes became exposed to the furnace atmosphere and did not fuse. Therefore, the minimum amount of cover layer coke that insured adequate coverage was judged to be approximately $3.66 \mathrm{~kg} / \mathrm{m}^{2}\left(0.75 \mathrm{lb} / \mathrm{ft}^{2}\right)$.

NRI from double layers of the briquettes were 2-3 times larger in size and those from triple layers were even larger yet in size than those obtained from single layers of the briquettes. 
By defining productivity as the ratio of the number of briquettes in a tray and fusion time, productivity as functions of hearth layer and cover layer thicknesses and of the number of layers of briquettes are given in Table 2-7-9. The productivity increased by $40-50 \%$ when briquettes increased from single to double layers, and by $50-60 \%$ when briquettes increased from single to triple layers. These observations suggested that multi layers of briquettes in combination with cover layer coke would be preferable to a single layer. This observation should be regarded with caution. It was observed later that productivity did not change much with multiple layers of briquettes when the continuously moving car system was used (See 7.2).

\section{2-7.1.5.4.3 Effect of briquette loading}

Productivity would be affected by the loading of briquettes. The effect of loosely-packed briquettes in a tray on fusion time was compared with the results of closely-packed briquettes. Briquettes were either closely or loosely packed on $25.4 \mathrm{~mm}$ (1") deep hearth layer of 6/100 mesh coke (M) in single, double and triple layers, then covered with $3.66 \mathrm{~kg} / \mathrm{m}^{2}\left(0.75 \mathrm{lb} / \mathrm{ft}^{2}\right)$ of 'as received' coke $(\mathrm{M})$, and their lengths of fusion time were determined. The results are given in Table 2-7-10, and fusion time was plotted as a function of loading of briquettes in Figure 2-7-2.

As evident in the figure, fusion time was strongly dependent on the degree of packing and the number of layers of briquettes. In other words, fusion time was linearly dependent on the loading of briquettes. As NRI weigh about $50 \%$ of feed briquettes, the production rates of NRI would be about a half of the briquette processing rates

The NRI sulfur tended to increase with increasing number of layers due presumably to longer distance for diffusion, requiring longer time for desulfurization of NRI sulfur to slag. 
Table 2-7-7. Coke samples used

(a) Size distribution

\begin{tabular}{|c|c|c|}
\hline $\begin{array}{l}\text { Size } \\
\text { mesh }\end{array}$ & $\begin{array}{l}\text { Hearth layer coke } \\
\begin{array}{ll}\text { (H) } & \text { (M) }\end{array}\end{array}$ & $\begin{array}{l}\text { Cover } \\
\text { layer coke } \\
\text { (M) }\end{array}$ \\
\hline $\begin{array}{c}9.53 \mathrm{~mm}(3 / 8 ”) \\
6.35 \mathrm{~mm}(1 / 4 ") \\
4 \\
6 \\
8 \\
10 \\
14 \\
20 \\
28 \\
35 \\
48 \\
65 \\
100 \\
-100\end{array}$ & $\begin{array}{r}0.29 \\
24.42 \\
28.09 \\
26.33 \\
16.08 \\
0.97 \\
2.14 \\
0.23 \\
0.08 \\
0.08 \\
0.21 \\
0.17 \\
0.23 \\
0.67\end{array}$ & $\begin{array}{c}2.14 \\
50.91 \\
27.75 \\
11.75 \\
6.86 \\
0.09 \\
0.50^{\star}\end{array}$ \\
\hline
\end{tabular}

(b) Proximate analysis

\begin{tabular}{|l|c|c|}
\hline & $\begin{array}{c}\text { Hearth layer } \\
\text { coke (H) }\end{array}$ & $\begin{array}{c}\text { Cover layer } \\
\text { coke (M) }\end{array}$ \\
\hline Moisture & 0.62 & 0.23 \\
Volatile & 1.02 & 0.83 \\
Fixed carbon & 88.66 & 89.99 \\
Ash & 9.70 & 8.95 \\
Sulfur & 0.69 & 0.61 \\
Btu/lb & 12,622 & 12601 \\
kJ/kg & 29,265 & 29,246 \\
\hline
\end{tabular}


Table 2-7-8. Comparison of fusion time when coke $(\mathrm{H})(-3 / 8$ ") or $6 / 100$ mesh coke (M) was used as the hearth layer

\begin{tabular}{|c|c|c|c|c|}
\hline $\begin{array}{l}\text { Cover layer } \\
\text { coke, } \mathrm{kg} / \mathrm{m}^{2 *}\end{array}$ & \multicolumn{2}{|c|}{$\begin{array}{c}9.53 \mathrm{~mm}(-3 / 8 ") \\
\text { Coke hearth layer (H) } \\
25.4 \mathrm{~mm}(1 ") 12.7 \mathrm{~mm}(1 / 2 ")\end{array}$} & \multicolumn{2}{|c|}{$\begin{array}{c}6 / 100 \text { mesh } \\
\text { Coke hearth layer (M) } \\
25.4 \mathrm{~mm}(1 ") 12.7 \mathrm{~mm}(1 / 2 ")\end{array}$} \\
\hline \multicolumn{5}{|c|}{ Single layer of briquettes } \\
\hline 4.9 & $33 \mathrm{~min}$ & $28 \mathrm{~min}$ & $33 \mathrm{~min}$ & $28 \mathrm{~min}$ \\
\hline 3.7 & $28 \mathrm{~min}$ & $24 \mathrm{~min}$ & $28 \mathrm{~min}$ & $28 \mathrm{~min}$ \\
\hline \multicolumn{5}{|c|}{ Double layers of briquettes } \\
\hline 4.9 & $42 \mathrm{~min}$ & $36 \mathrm{~min}$ & $42 \mathrm{~min}$ & $36 \mathrm{~min}$ \\
\hline 3.7 & $38 \mathrm{~min}$ & $31 \mathrm{~min}$ & $38 \mathrm{~min}$ & $31 \mathrm{~min}$ \\
\hline \multicolumn{5}{|c|}{$\underline{\text { Triple layers of briquettes }}$} \\
\hline 4.9 & $57 \mathrm{~min}$ & $51 \mathrm{~min}$ & $57 \mathrm{~min}$ & $51 \mathrm{~min}$ \\
\hline 3.7 & $51 \mathrm{~min}$ & $45 \mathrm{~min}$ & $51 \mathrm{~min}$ & $45 \mathrm{~min}$ \\
\hline
\end{tabular}

$* 4.9 \mathrm{~kg} / \mathrm{m}^{2}=1.0 \mathrm{lb} / \mathrm{ft}^{2}$ and $3.7 \mathrm{~kg} / \mathrm{m}^{2}=0.75 \mathrm{lb} / \mathrm{ft}^{2}$

Table 2-7-9. Productivity, expressed as the ratio of the number of briquettes in a tray and fusion time in minutes, are as follows:

\begin{tabular}{|c|c|ccc|}
\hline $\begin{array}{c}\text { Hearth } \\
\text { layer }\end{array}$ & $\begin{array}{c}\text { Cover } \\
\text { Layer } \\
\left(\mathbf{k g} / \mathbf{m}^{2}\right)^{*}\end{array}$ & \multicolumn{3}{|l}{ Productivity (No. of NRI/minute) } \\
\hline Single & $\begin{array}{l}\text { Double } \\
\text { layer }\end{array}$ & $\begin{array}{c}\text { Triple } \\
\text { layers }\end{array}$ \\
\hline $\mathbf{2 5 . 4} \mathbf{~ m m ~ ( 1 " ) ~}$ & $\mathbf{4 . 9}$ & 2.9 & 4.4 & 4.6 \\
$\mathbf{2 5 . 4} \mathbf{~ m m ~ ( 1 " ) ~}$ & $\mathbf{3 . 7}$ & 3.4 & 4.8 & 5.2 \\
$\mathbf{1 2 . 7} \mathbf{~ m m ~ ( 1 / 2 " ) ~}$ & $\mathbf{4 . 9}$ & 3.4 & 5.1 & 5.2 \\
$\mathbf{1 2 . 7} \mathbf{~ m m ~ ( 1 / 2 " ) ~}$ & $\mathbf{3 . 7}$ & 4.0 & 5.9 & 5.9 \\
\hline
\end{tabular}

* $4.9 \mathrm{~kg} / \mathrm{m}^{2}=1.0 \mathrm{lb} / \mathrm{ft}^{2}$ and $3.7 \mathrm{~kg} / \mathrm{m}^{2}=0.75 \mathrm{lb} / \mathrm{ft}^{2}$ 
2-7.1.5.5 Mounds: A mound press mold, $279.4 \mathrm{~mm} \times 279.4 \mathrm{~mm}$ (11" $\times 11$ ") in size with $7 \times 7$ pockets of $38.1 \mathrm{~mm} \times 38.1 \mathrm{~mm} \times 25.4 \mathrm{~mm}$ (1.5"x1.5"x1") each, making an array of 49 mounds, was fabricated. Using the standardized feed mixture with $85 \%$ stoichiometric coal (M), mounds, both dry and moist, were prepared with the mold, placed on 6/100 mesh coke for hearth layer and 'as received' coke (M) for cover layer, and heated in the LHF.

Dry feed mixture: The mounds were soft and any impact with a drop of coarse cover layer coke damaged the integrity of the mounds. The grooves and the surrounding areas were carefully filled with $6 / 100$ mesh coke to near the top of the mounds. The mounds were covered with $3.66 \mathrm{~kg} / \mathrm{m}^{2}\left(0.75 \mathrm{lb} / \mathrm{ft}^{2}\right)$ of cover layer coke, and heated in Zones 2 and 3 for 12 and 24 minutes, respectively. The products were far from fusion.

Another tray with dry mounds was heated in Zones 2 and 3 for 16 and 32 minutes, respectively, but again, the products showed little sign of fusion. In view of the fragile nature of the mounds, the tests were discontinued, and turned to using moist feed mixtures, as the presence of water hardened the mounds upon drying by the hydration of lime.

Moist feed mixture: Firm enough mounds were obtained when $12 \%$ by weight of water was mixed with a feed mixture. The mounds were placed on a cardboard, dried in an oven, held at $100^{\circ} \mathrm{C}\left(212^{\circ} \mathrm{F}\right)$. The dried mounds became hard by the hydration of lime. The grooves and surrounding areas were filled with the cover layer coke, then covered with the 'as received' cover layer coke. The tray was heated in Zones 2 and 3 for 13 and 26 minutes, respectively. The products were again far from fusion. By heating in Zones 2 and 3 for 20 and 40 minutes, respectively, fully fused products were obtained. After a few additional tests, the fusion time was estimated to be in the range of 57-63 minutes.

Loading of mounds $\left(18.1 \mathrm{~kg} / \mathrm{m}^{2}\left(3.7 \mathrm{lb} / \mathrm{ft}^{2}\right)\right)$ was similar to the double layers of briquettes $\left(19.03 \mathrm{~kg} / \mathrm{m}^{2}\left(3.9 \mathrm{lb} / \mathrm{ft}^{2}\right)\right)$, but their fusion time was in the range of $57-63$ minutes against about 47 minutes, respectively, with $25.4 \mathrm{~mm}\left(1\right.$ ") hearth layer and $3.66 \mathrm{~kg} / \mathrm{m}^{2}(0.75$ $\mathrm{lb} / \mathrm{ft}^{2}$ ) cover layer. Longer fusion time with a $25.4 \mathrm{~mm}(1$ ") high single layer of mounds than the double layers of briquettes of $12.7 \mathrm{~mm}(1 / 2 ")$ high suggested the role played by the surface areas of agglomerates. As the only way to increase the loading of mounds would be to increase their heights, the processing rates would not be increased as effectively as briquettes. In the box furnace tests, the height of feed mixtures was shown to be the primary variable governing the fusion time. The use of multiple layers of balled feed with cover layer coke in place of briquettes becomes of interest, as the surface exposed per unit weight is maximized. 
Table 2-7-10. Comparison of fusion time with loosely-packed and closely-packed briquettes on fusion time.

\begin{tabular}{|c|c|c|c|}
\hline & $\begin{array}{l}\text { Single } \\
\text { layer }\end{array}$ & $\begin{array}{l}\text { Double } \\
\text { layer }\end{array}$ & $\begin{array}{c}\text { Triple } \\
\text { layer }\end{array}$ \\
\hline \multicolumn{4}{|l|}{ Loosely packed } \\
\hline Loading, $\mathbf{k g} / \mathrm{m}^{2}$ & 9.8 & 19.0 & 27.3 \\
\hline Fusion time, $\min$ & 33 & 38 & 51 \\
\hline \multicolumn{4}{|l|}{ Closely packed } \\
\hline Loading, $\mathrm{kg} / \mathrm{m}^{2}$ & 15.1 & 29.8 & 42.9 \\
\hline Fusion time, $\min$ & 36 & 57 & 63 \\
\hline \multicolumn{4}{|l|}{ Mounds } \\
\hline Loading, $\mathbf{k g} / \mathrm{m}^{2}$ & 18.1 & --- & --- \\
\hline Fusion time, $\min$ & 57 & --- & --- \\
\hline
\end{tabular}




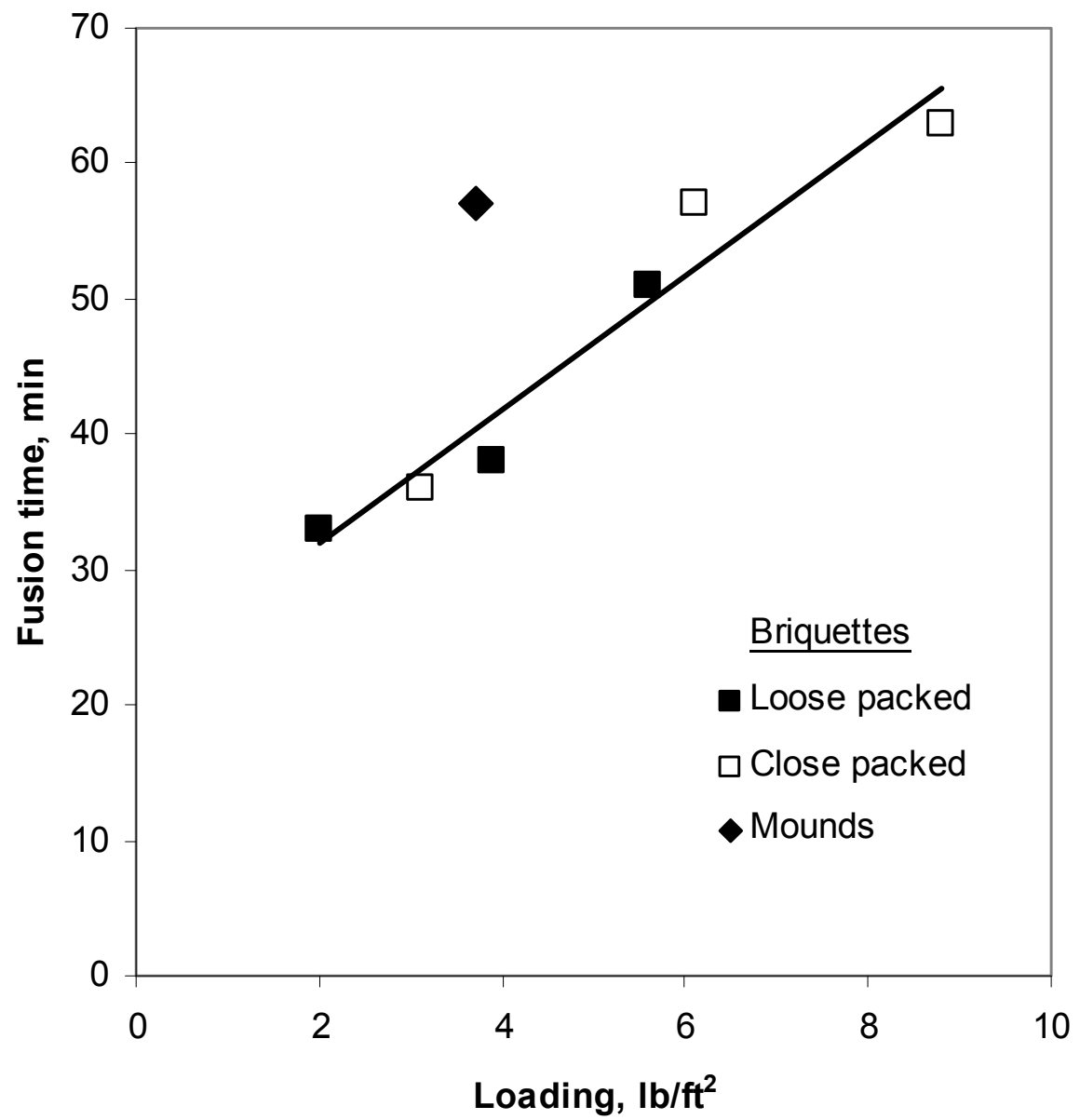

Figure 2-7-2. Fusion time as affected by the loading of loose-packed and closepacked briquettes in single, double and triple layers. Note $1.0 \mathrm{lb} / \mathrm{ft}^{2}=4.88 \mathrm{~kg} / \mathrm{m}^{2}$

\section{2-7.2 Continuous moving pallet car system}

Linear hearth furnace (LHF) with air-fuel burners was characterized by high $\mathrm{CO}_{2}$ and, low $\mathrm{CO}$ concentrations and high turbulence of the burner combustion products. The use of oxy-fuel burners reduces the volume of flue gas, thereby alleviating the turbulence within the furnace and conserving the energy associated with heating chemically inert nitrogen. Reduction of NOX emission is another advantage. Hence, the investigation was extended to replace the air-fuel burners by oxy-fuel burners and to investigate its effect on the operating behaviors of the furnace.

Initial phase of the investigation was directed towards comparing the effect of oxy-fuel and air-fuel burners. The effect of briquette size and the re-installation of a wall between Zones 2 and 3 were investigated. 


\section{2-7.2.1 Conclusions}

1) Car speed to fusion was directly proportional to the coverage by coke layer. Therefore, by lowering the coverage by a half, fusion time was lowered by about a half.

2) Fusion time was shorter by 10 to $30 \%$ when oxy-fuel burners were used than air-fuel burners. This difference may be related to the high turbulence of the furnace gas with air-fuel burners and its effect on the endothermic carbon solution reaction.

3) Contrary to the findings reported earlier, the fusion time with double layers of briquettes required about twice as long as single layers. In other words, there was no advantage in productivity by using double layers.

4) Larger briquettes with greater height $(19.05 \mathrm{~mm}(0.75 "))$ and loading density of $26.35 \mathrm{~kg} / \mathrm{m}^{2}\left(5.4 \mathrm{lb} / \mathrm{ft}^{2}\right)$ required more than $50 \%$ longer time to fuse than small briquettes of lesser height $(12.7 \mathrm{~mm}(0.5))$ ) and loading density of $15.1 \mathrm{~kg} / \mathrm{m}^{2}$ $\left(3.1 \mathrm{lb} / \mathrm{ft}^{2}\right)$. Productivity, expressed in terms of NRI produced, were, respectively, 19.5 and $29.3 \mathrm{~kg} / \mathrm{m}^{2} / \mathrm{h}$ (4 and $6 \mathrm{lb} \mathrm{NRI} / \mathrm{ft}^{2} / \mathrm{h}$ ). It is more efficient to process 12.7 $\mathrm{mm}(1 / 2$ ")-high briquettes than $19.05 \mathrm{~mm}$ (3/4")-high briquettes.

5) Double layers of small briquettes with loading density of $30.3 \mathrm{~kg} / \mathrm{m}^{2}\left(6.2 \mathrm{lb} / \mathrm{ft}^{2}\right)$ took shorter time to fuse than a single layer of larger briquettes $19.05 \mathrm{~mm}(0.75$ ") with loading density of $26.4 \mathrm{~kg} / \mathrm{m}^{2}\left(5.4 \mathrm{lb} / \mathrm{ft}^{2}\right)$, indicating the role played by the exposed surface.

6) $\mathrm{NRI}$ at fusion time analyzed about $0.04-0.05 \% \mathrm{~S}$ under all the conditions tested.

\section{2-7.2.2 Test procedure}

Feed mixtures consisted of taconite concentrate $(\mathrm{K}), 85 \%$ stoichiometric bituminous coal $(\mathrm{J}), 2 \%$ fluorspar and slag composition $\mathrm{C} / \mathrm{S}=1.5$. Feed mixtures (weighing $136.4 \mathrm{~kg}$ (300 lb) were thoroughly mixed dry in a Llittleford mixer for 5 minutes, fed to a Simpson Mixer-Muller together with sufficient water so that the final moisture would be about $8 \%$, and mulled for 3 minutes. The mulled mixture was briquetted in a Lab Komarek machine. Briquettes thus prepared were $35.05 \mathrm{~mm} \times 21.8 \mathrm{~mm} \times 13.2 \mathrm{~mm}$ (1.38"x0.86" $0.52 ")$ in size and weighed $13.0 \mathrm{~g}$ per briquette on the average.

A comparison was made of two different sized briquettes in an attempt to expedite the production of briquettes for LHF tests. The pilot plant briquetting machine was used. The briquettes, made from taconite concentrate $(\mathrm{K})$ and bituminous coal $(\mathrm{J})$ with $4 \%$ molasses as a binder, measured $30.2 \mathrm{~mm}$ x $35.8 \mathrm{~mm}$ x $19.8 \mathrm{~mm}$ (1.19"x1.41"x0.78") in size and weighed $21.1 \mathrm{~g} / \mathrm{briquette}$.

In a ceramic fiber tray with inner dimensions of $457.2 \mathrm{~mm} \times 508 \mathrm{~mm} \times 37.8 \mathrm{~mm}$ (18"x20"x1.5"), briquettes were placed in a close-packed array of $10 \times 18$, either in a single layer or double layers, over a hearth layer of $12.7 \mathrm{~mm}(0.5$ ") deep 6/100 mesh coke. The loading of a single layer of briquettes was $15.1 \mathrm{~kg} / \mathrm{m}^{2}\left(3.1 \mathrm{lb} / \mathrm{ft}^{2}\right)$. The cover

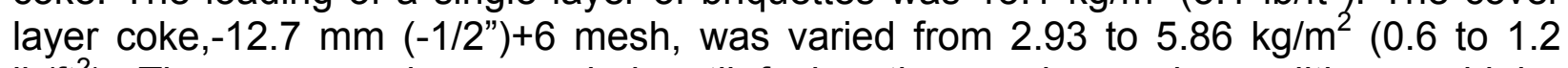
$\left.\mathrm{lb} / \mathrm{ft}^{2}\right)$. The car speed was varied until fusion time under each condition could be determined to within $12.7 \mathrm{~mm}(0.5) / \mathrm{min}$. 


\section{2-7.2.3 Test results}

2-7.2.3.1 Comparison of oxy-fuel and air-fuel burners: Fusion time was determined as a function of the coverage density of cover layer coke and briquettes in a single layer as well as double layers for comparing the effects of oxy-fuel and air-fuel burners. The results are summarized in Table 2-7-11 and depicted in Figure 2-7-3.

Car speed to fusion time was directly proportional to the coverage by coke layer. Therefore, by lowering the coverage by a half, fusion time would be lowered by about a half. Time in the hot zone, reciprocal of the car speed to fusion, was shorter by 10 to $30 \%$ when oxy-fuel burners were used than when air-fuel burners were used. This difference may be related to the high turbulence of the furnace gas with air-fuel burners and its effect on the endothermic carbon solution reaction.

$\mathrm{NRI}$ analyzed about $0.05 \% \mathrm{~S}$ in all cases except when the coke layer coverage was 2.93 $\mathrm{kg} / \mathrm{m}^{2}\left(0.6 \mathrm{lb} / \mathrm{ft}^{2}\right)$. NRI sulfur tended to be somewhat higher than when higher coverage was used, due presumably to oxidation of NRI by insufficient coverage of some NRI. Contrary to the findings reported earlier, the fusion time with double layers of briquettes required about twice as long as single layers. In other words, there appeared to be no advantage in productivity by using double layers. NRI at fusion time analyzed about $0.04-0.05 \%$ S under all the conditions tested.

2-7.2.3.2 Effect of briquette size: The briquettes were arranged close packed on 12.7 $\mathrm{mm}\left(0.5^{\prime \prime}\right)$ deep 6/100 mesh hearth layer coke, and covered with $2.93 \mathrm{~kg} / \mathrm{m}^{2}\left(0.6 \mathrm{lb} / \mathrm{ft}^{2}\right)$ $-12.7 \mathrm{~mm}(-1 / 2 ")+6$ mesh coke. The bulk densities of the hearth layer and cover layer coke were 41 and $30 \mathrm{lb} / \mathrm{ft}^{3}$, respectively. Earlier, box furnace tests indicated that fusion time increased in direct proportion to briquette height (Figure 2-4-3). The fusion behaviors of these briquettes with different heights were determined in the LHF under otherwise identical conditions. 
Table 2-7-11. LHF test summary on taconite concentrate (K), $85 \%$ stoichiometric bituminous coal (J), $2 \%$ fluorspar at slag composition $\mathrm{C} / \mathrm{A}=1.5$. (Note: $4.9 \mathrm{~kg} / \mathrm{m}^{2}=1.0 \mathrm{lb} / \mathrm{ft}^{2}$ )

\begin{tabular}{|c|c|c|c|c|c|c|c|c|}
\hline \multirow{3}{*}{$\begin{array}{c}\text { Cover } \\
\text { layer } \\
\text { coke } \\
\mathrm{kg} / \mathrm{m}^{2}\end{array}$} & \multicolumn{4}{|c|}{ Oxy-fuel burners } & \multicolumn{4}{|c|}{ Air-fuel burners } \\
\hline & \multirow{2}{*}{$\begin{array}{l}\text { Car speed } \\
\mathrm{mm} / \mathrm{min}\end{array}$} & \multirow{2}{*}{$\begin{array}{l}\text { Time in hot } \\
\text { zone, min }\end{array}$} & \multicolumn{2}{|c|}{ NRI } & \multirow{2}{*}{$\begin{array}{l}\text { Car speed } \\
\mathrm{mm} / \mathrm{min}\end{array}$} & \multirow{2}{*}{$\begin{array}{l}\text { Time in hot } \\
\text { zone, min }\end{array}$} & \multicolumn{2}{|c|}{ NRI } \\
\hline & & & $\% \mathrm{C}$ & $\% S$ & & & $\% \mathrm{C}$ & $\% S$ \\
\hline \multicolumn{9}{|c|}{ Single layer briquettes } \\
\hline 2.9 & 9.5 & 29.5 & 3.03 & 0.060 & 8.5 & 33 & 3.38 & 0.042 \\
\hline 3.9 & 8 & 35 & 3.38 & 0.043 & 7 & 40 & 3.16 & 0.042 \\
\hline 4.9 & 6.5 & 43 & 3.29 & 0.053 & 5.5 & 51 & 3.59 & 0.057 \\
\hline 5.9 & 5 & 56 & 3.73 & 0.043 & & & & \\
\hline \multicolumn{9}{|c|}{ Double layer briquettes } \\
\hline 2.9 & 5 & 56 & 2.85 & 0.080 & 4 & 70 & 3.61 & 0.041 \\
\hline 3.9 & 4 & 70 & 3.35 & 0.091 & 3 & 93 & 3.69 & 0.045 \\
\hline 4.9 & 3 & 93 & 3.79 & 0.040 & & & & \\
\hline
\end{tabular}



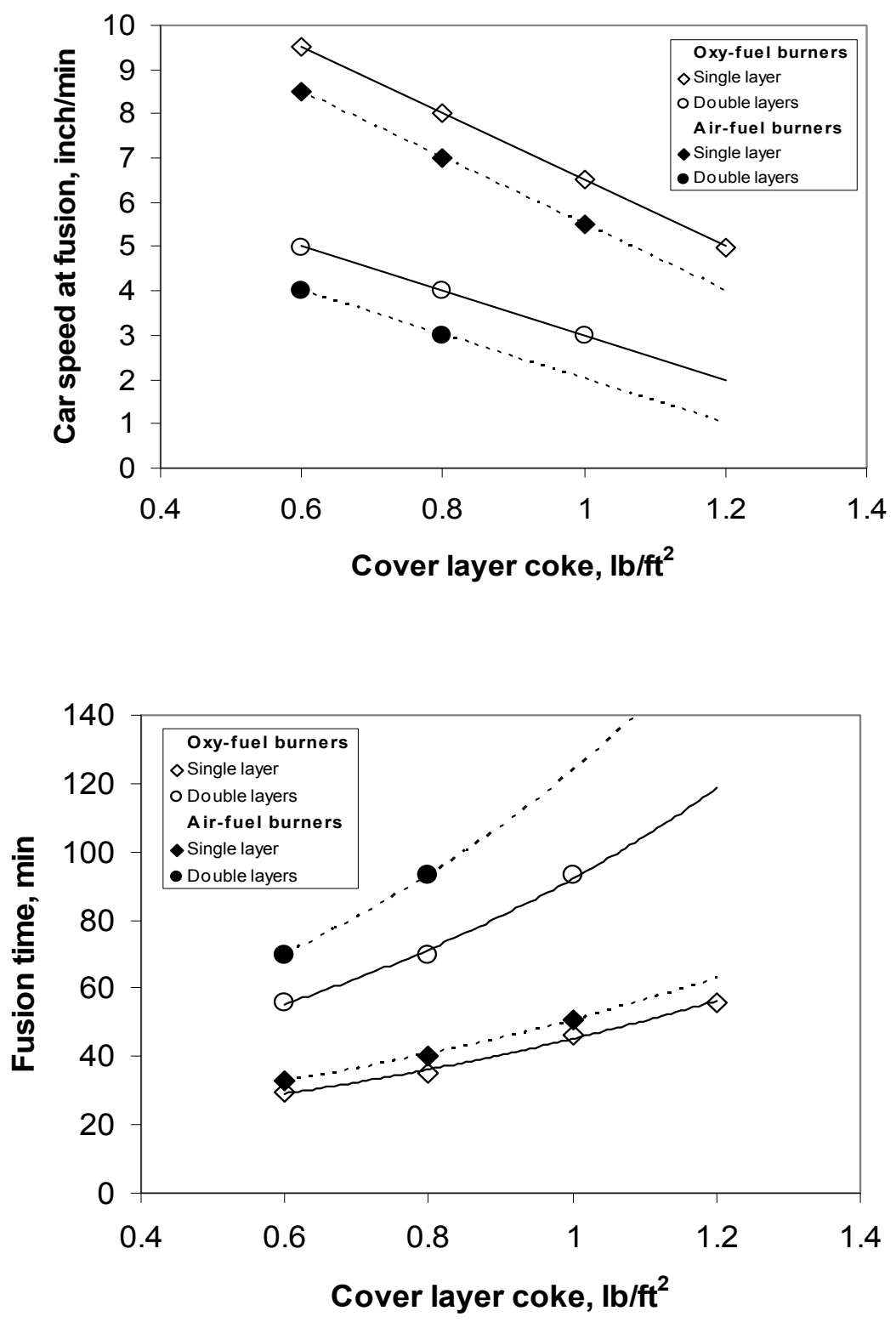

Figure 2-7-3. Comparison of LHF operations using oxy-fuel and air-fuel burners showing the effect of the coverage of cover layer coke on productivity, expressed as (a) car speed at fusion and (b) time to fusion in the high temperature zone. (Note: $4.88 \mathrm{~kg} / \mathrm{m}^{2}=1.0 \mathrm{lb} / \mathrm{ft}^{2}$ ) 
The test results of briquette loading, tray speed at fusion time, and fusion time in the hot zone (7,112 mm (280 inches)), are summarized in Table 2-7-12.

Table 2-7-12. Fusion behaviors of lab and pilot plant briquettes

\begin{tabular}{|c|c|c|c|c|c|c|}
\hline & $\begin{array}{c}\text { Briq. } \\
\text { Loading } \\
\mathrm{kg} / \mathrm{m}^{2} \\
\left(\mathrm{lb} / \mathrm{ft}^{2}\right)\end{array}$ & $\begin{array}{c}\text { Car speed } \\
\mathrm{mm} / \mathrm{min} \\
\text { (inches/min) }\end{array}$ & $\begin{array}{l}\text { Fusion } \\
\text { time } \\
\text { min }\end{array}$ & $\begin{array}{l}\text { Productivity } \\
\mathrm{kg} / \mathrm{m}^{2} / \mathrm{h} \\
\left(\mathrm{lb} \mathrm{NRI//t^{2 } / h )}\right.\end{array}$ & $\% c^{\prime}$ & ${ }^{R}{ }_{\% S}$ \\
\hline \multicolumn{7}{|c|}{ Lab briquettes ( 0.52 " high, $13.0 \mathrm{~g} /$ briquette) } \\
\hline $\begin{array}{l}\text { Single layer } \\
\text { Double layer }\end{array}$ & $\begin{array}{l}15.1(3.1) \\
30.2(6.2)\end{array}$ & $\begin{array}{c}229-241(\sim 9 ") \\
127\left(5^{\prime \prime}\right)\end{array}$ & $\begin{array}{l}31-29.5 \\
56\end{array}$ & $\begin{array}{c}29.3-30.7(6.0-6.3) \\
32.2(6.6)\end{array}$ & $\begin{array}{l}3.03 \\
2.85\end{array}$ & $\begin{array}{l}0.060 \\
0.080\end{array}$ \\
\hline \multicolumn{7}{|c|}{ Pilot plant briquettes (0.78" high, 21.1 g/briquette) } \\
\hline Single layer & $26.3(5.4)$ & 89 (3.5”) & 80 & $20.0(4.1)$ & 3.39 & 0.061 \\
\hline
\end{tabular}

The pilot plant briquettes in a single layer required more than $50 \%$ longer time than that expected from lab briquettes, although box furnace tests indicated that the pilot plant briquettes of $19.05 \mathrm{~mm}(0.75$ ") high required $50 \%$ longer time than the lab briquettes of $12.7 \mathrm{~mm}(0.5$ ") high. With lab briquettes, double layers with the loading density of 30.2 $\mathrm{kg} / \mathrm{m}^{2}\left(6.2 \mathrm{lb} / \mathrm{ft}^{2}\right)$ took shorter time to fuse than pilot plant briquettes with the loading of $26.35 \mathrm{~kg} / \mathrm{m}^{2}\left(5.4 \mathrm{lb} / \mathrm{ft}^{2}\right)$. The difference between lab and pilot plant briquettes, both in single layers, could be reconciled if fusion time was assumed to depend not only on briquette height, but also on briquette loading.

In an attempt to make more direct comparison of the results, productivity was expressed in terms of NRI produced in a square unit of hearth area in an hour $\left(\mathrm{kg} \mathrm{NRI} / \mathrm{m}^{2} / \mathrm{h}\right)$. The productivity with $12.7 \mathrm{~mm}(1 / 2 \mathrm{2})$-high briquettes ranged $29.3-30.7 \mathrm{~kg} / \mathrm{m}^{2} / \mathrm{h}\left(6-6.5 \mathrm{lb} / \mathrm{ft}^{2} / \mathrm{h}\right)$ for both single and double layers, whereas with $19.05 \mathrm{~mm}$ (3/4")-high briquettes in a single layer was $20.0 \mathrm{~kg} / \mathrm{m}^{2} / \mathrm{h}\left(4.1 \mathrm{lb} / \mathrm{ft}^{2} / \mathrm{h}\right)$. These numbers agree with the box furnace tests that showed that fusion time increased in direct proportion to briquette height (Figure 2-4-3).

Based on these results, it was concluded that further tests would be conducted using briquettes made by lab briquetting machine with $12.7 \mathrm{~mm}(0.5 ")$ height.

\section{2-7.2.4 Use of PRB coal}

A comparison with bituminous coal indicated that PRB coal may be used satisfactorily as a reductant in the box furnace tests, but a major drawback was the inability of forming strong enough agglomerates (balls and briquettes) that could withstand handling. A few preliminary briquetting tests indicated that asphalt emulsion, SS-1 h, 
showed promise as a binder. The use of asphalt binders has additional merits of replacing fuel because of their high calorific values. PRB coal, however, posed a problem as cover layer material because heating to the processing temperature of $1400^{\circ} \mathrm{C}\left(2552^{\circ} \mathrm{F}\right)$ lost more than a half of its weight and visibly shrank in size.

LHF tests were initiated to examine how PRB coal behaved as a reductant as well as cover and hearth layer materials. The effect of coke as cover and hearth layer materials were also tested briefly for comparison.

\section{2-7.2.4.1 Conclusions:}

1) Three major issues of concern with the use of $P R B$ coal as a reductant as well as cover and hearth layers in the LHF were

i) Upon heating at the process temperature, $-15.9 \mathrm{~mm}(-5 / 8$ ")+3 mesh PRB coal lost over a half of its weight and shrank in size by about $25 \%$ to $-12.7 \mathrm{~mm}$ $\left(-1 / 2\right.$ "). The final size and weight of $9.8 \mathrm{~kg} / \mathrm{m}^{2}\left(2.0 \mathrm{lb} / \mathrm{ft}^{2}\right)$ of PRB coal cover layer became essentially similar to $-12.7 \mathrm{~mm}(-1 / 2$ ") +6 mesh coke at 4.9 $\mathrm{kg} / \mathrm{m}^{2}\left(1.0 \mathrm{lb} / \mathrm{ft}^{2}\right)$. Covering briquettes fully with PRB coal throughout the process required careful evaluation in order to prevent exposing the briquettes to furnace atmosphere.

ii) Fusion time could not be closely estimated due presumably to the difficulty of covering the briquettes evenly. Nevertheless, NRI sulfur with $9.8 \mathrm{~kg} / \mathrm{m}^{2}(2.0$ $\mathrm{lb} / \mathrm{ft}^{2}$ ) of PRB coal cover layer was notably high, 0.122-0.146\%S.

iii) Copious amounts of black smoke (soot) were generated, particularly in Zone 1. The soot needs to be prevented from depositing in ducts and ending up as stack emissions. Because of the copious generation of black smoke, large weight loss and shrinkage in the process, the use of PRB coal needs to be approached with caution.

2) For comparison, coke cover and hearth layers were briefly tested. With -12.7 $\mathrm{mm}(-1 / 2 ")+6$ mesh coke cover layer, the PRB coal-added briquettes did not fuse regardless of coverage and tray speed. It was speculated that such a behavior might be related to the effect of volatile matter released by PRB coal cover and hearth layers.

3) Volatile matter from the hearth and cover layers played a critical role in the formation of NRI. Apparently, with PRB coal-added briquettes, the lack of volatile matter in coke was unable to protect against oxidizing furnace gases.

2-7.2.4.2 PRB coal properties: Approximately $300 \mathrm{~g}$ of $-15.9 \mathrm{~mm}(-5 / 8$ ") +3 mesh PRB coal to be used for cover layer was placed in a graphite tray and heated in the box furnace at $1400^{\circ} \mathrm{C}\left(2552^{\circ} \mathrm{F}\right)$ for 20 minutes in a $\mathrm{N}_{2}-\mathrm{CO}$ atmosphere. The weight loss was $56 \%$. The changes in size distributions before and after heating were determined and the results are shown in Figure 2-7-4 together with the size distribution of $-12.7 \mathrm{~mm}$ $(-1 / 2$ ") +6 mesh coke. The size shrank by about $25 \%$, or $-15.9 \mathrm{~mm}(-5 / 8$ ") +3 mesh

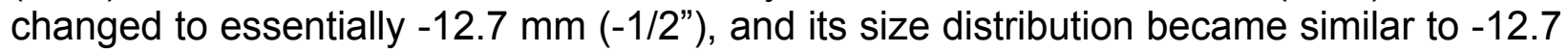
$\mathrm{mm}(-1 / 2 ")+6$ mesh. 
2-7.2.4.3 Test procedure: Lab Komarek briquetting machine was used to briquette $68.2 \mathrm{~kg}(150 \mathrm{lbs})$ of a feed mixture, consisting of taconite concentrate (K), 85\% stoichiometric PRB coal, $2 \%$ fluorspar and slag composition $C / S=1.5$ with $10 \%$ SS- $1 \mathrm{~h}$ asphalt emulsion binder. The average size was $35.1 \mathrm{~mm} \times 21.8 \mathrm{~mm} \times 13.2 \mathrm{~mm}$ (1.38"x0.86" $\times 0.52 ")$, and the average weight was $9.9 \mathrm{~g} /$ briquette. Drop numbers were $34.4 \pm 13.5$ wet and $6.4 \pm 2.4$ dry. The briquettes were dried in an oven at $105^{\circ} \mathrm{C}\left(221^{\circ} \mathrm{F}\right)$ overnight.

2-7.2.4.4 Test results: Initially, the amount of $-15.9 \mathrm{~mm}(-5 / 8$ ") +3 mesh PRB coal, just enough to cover the briquettes, was determined to be $6.8 \mathrm{~kg} / \mathrm{m}^{2}\left(1.4 \mathrm{lb} / \mathrm{ft}^{2}\right)$. The tray after the test, but before removing the cover layer is shown in Figure 2-7-5(a). With this amount of PRB coal, over a half of briquettes were exposed to the furnace atmosphere and did not fuse. Weight loss and shrinkage caused the coverage to become sparse and exposed the briquettes. Increasing the cover layer to $8.8 \mathrm{~kg} / \mathrm{m}^{2}\left(1.8 \mathrm{lb} / \mathrm{ft}^{2}\right)$ still exposed $40-45 \%$ of the briquettes, as shown in Figure 2-7-5(b). It was necessary to use $9.8 \mathrm{~kg} / \mathrm{m}^{2}\left(2.0 \mathrm{lb} / \mathrm{ft}^{2}\right)$ PRB coal to have the briquettes covered throughout the process, as shown in Figure 2-7-5(c).

Minimum car speed to fusion was determined to be $165.1 \mathrm{~mm} / \mathrm{min}(6.5 \mathrm{inch} / \mathrm{min})$, or 43 minutes in the hot zone (7.1 $\mathrm{m}$ (280 inches)). The results are given in Table 2-7-13 along with the results of fusion time when taconite concentrate (K)-85\% stoichiometric bituminous coal $(\mathrm{J})$ briquettes. It is interesting to note that the fusion time of 43 minutes was identical to the fusion time when $-12.7 \mathrm{~mm}(-1 / 2$ ") +6 mesh cover layer coke of 4.9 $\mathrm{kg} / \mathrm{m} 2\left(1.0 \mathrm{lb} / \mathrm{ft}^{2}\right)$ was used on briquettes with bituminous coal reductant. As $9.8 \mathrm{~kg} / \mathrm{m}^{2}$ $\left(2.0 \mathrm{lb} / \mathrm{ft}^{2}\right)$ of $-15.9 \mathrm{~mm}(-5 / 8 ")+3$ mesh PRB coal became essentially $4.9 \mathrm{~kg} \cdot \mathrm{m}^{2}(1.0$ $\left.\mathrm{lb} / \mathrm{ft}^{2}\right)$ of $-12.7 \mathrm{~mm}(-1 / 2 ")+6$ mesh char, the fusion behaviors of the two types of briquettes, covered with essentially the same size and coverage of coke and char, were similar.

Another notable difference between bituminous coal $(\mathrm{J})$ and PRB coal was the sulfur analysis of NRI at fusion time. As included in Table 2-7-13, NRI sulfur, when bituminous coal $(\mathrm{J})$ was used, was $0.045 \% \mathrm{~S}$, while it was $0.122-0.146 \% \mathrm{~S}$ when PRB coal was used. The high NRI sulfur was due presumably to the difficulty of having briquettes fully covered by large weight loss and shrinkage in size, as shown in Figure 2-7-5.

With $10 \%$ asphalt emulsion as a binder, $15-20 \%$ of the NRI product consisted of micro $\mathrm{NRI}$. Apparently, asphalt binders contributed significantly as a reductant carbon to the briquettes. The use of asphalt emulsion as a binder would allow a decrease in the amount of PRB coal in briquettes. The addition of $10 \%$ asphalt emulsion as a binder was estimated to add $35-40 \%$ stoichiometric carbon to the briquettes. Relative effectiveness of carbon in asphalt as a reductant needs to be compared with fixed carbon in coal in order to find out how much coal could be saved by using adequate amount of asphalt emulsion. 


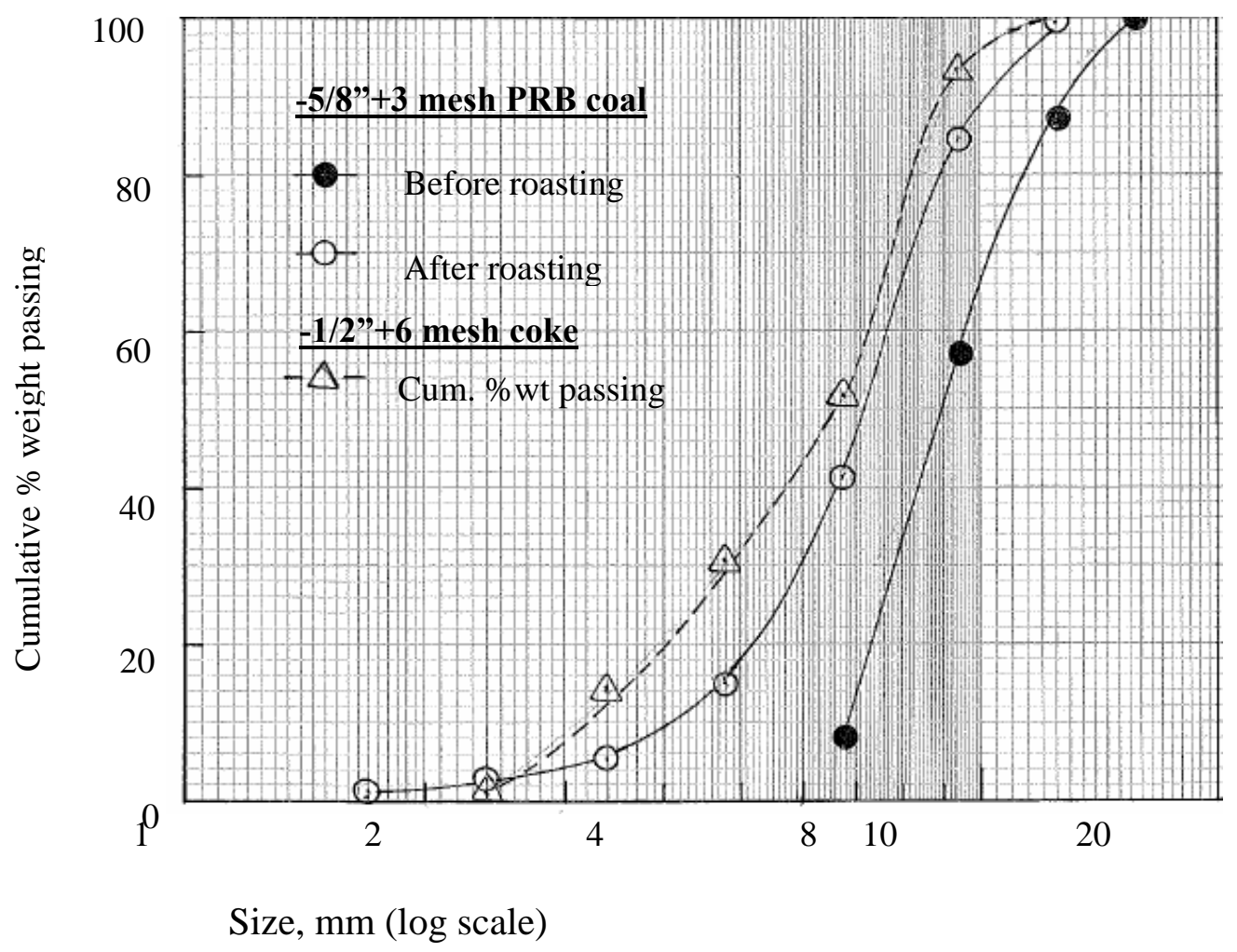

Figure 2-7-4. Size distributions of $-5 / 8$ " +3 mesh PRB coal before and after roasting in the box furnace at $1400^{\circ} \mathrm{C}\left(2552^{\circ} \mathrm{F}\right)$ for 20 minutes in a $\mathrm{N}_{2}-\mathrm{CO}$ atmosphere. Size distribution of $-12.7 \mathrm{~mm}\left(-1 / 2^{\prime \prime}\right)+6$ mesh coke is included for comparison. 


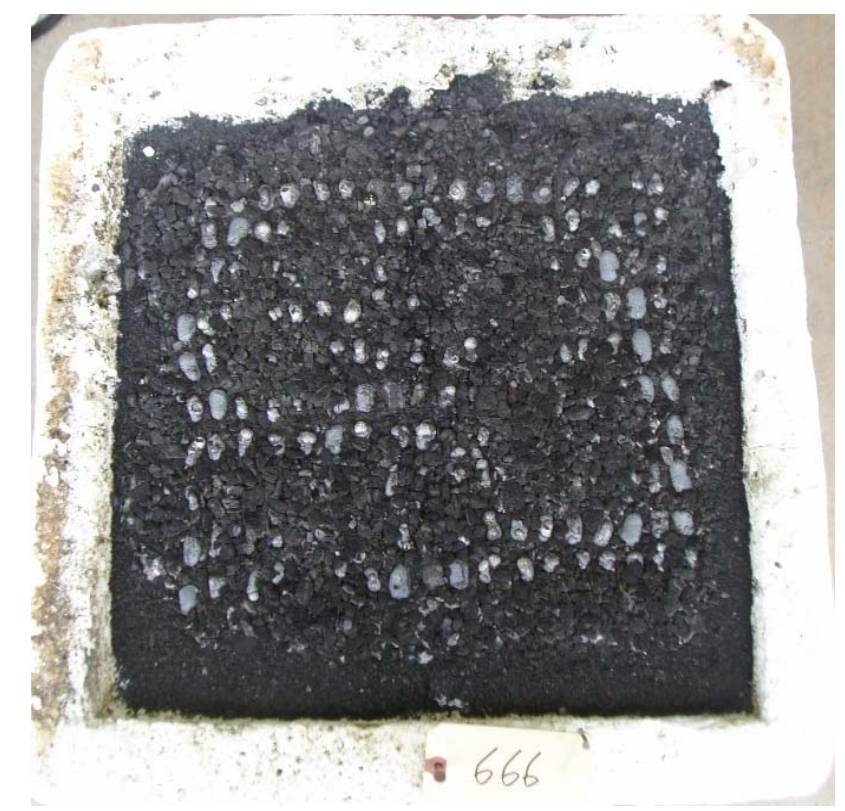

(a) PRB cover layer of $6.8 \mathrm{~kg} / \mathrm{m}^{2}\left(1.4 \mathrm{lb} / \mathrm{ft}^{2}\right)$ ( $>50 \%$ of briquettes exposed to furnace atmosphere)

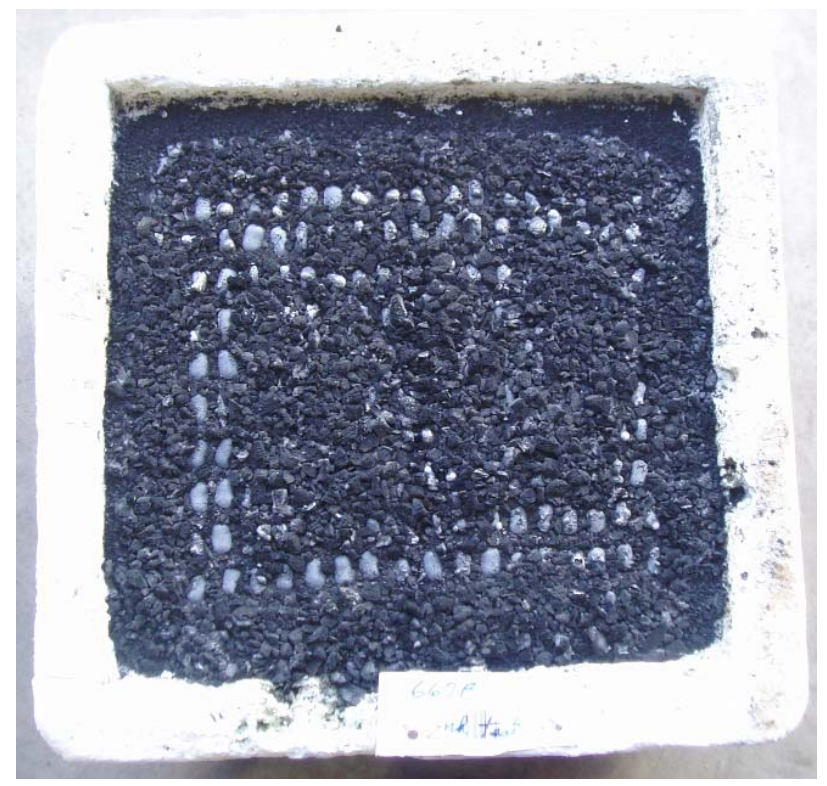

(b) PRB cover layer of $8.8 \mathrm{~kg} / \mathrm{m}^{2}\left(1.8 \mathrm{lb} / \mathrm{ft}^{2}\right)$ (40-45\% exposed to furnace atmosphere)

Figure 2-7-5. Products of lab briquettes in single layer (10\% SS-1h), placed on a $3 / 100$ mesh PRB coal hearth layer of $12.7 \mathrm{~mm}(1 / 2$ ") deep, covered with different amounts of $-15.9 \mathrm{~mm}\left(-5 / 8^{\prime \prime}\right)+3$ mesh PRB coal, heated in the LHF and before PRB char cover removed. 


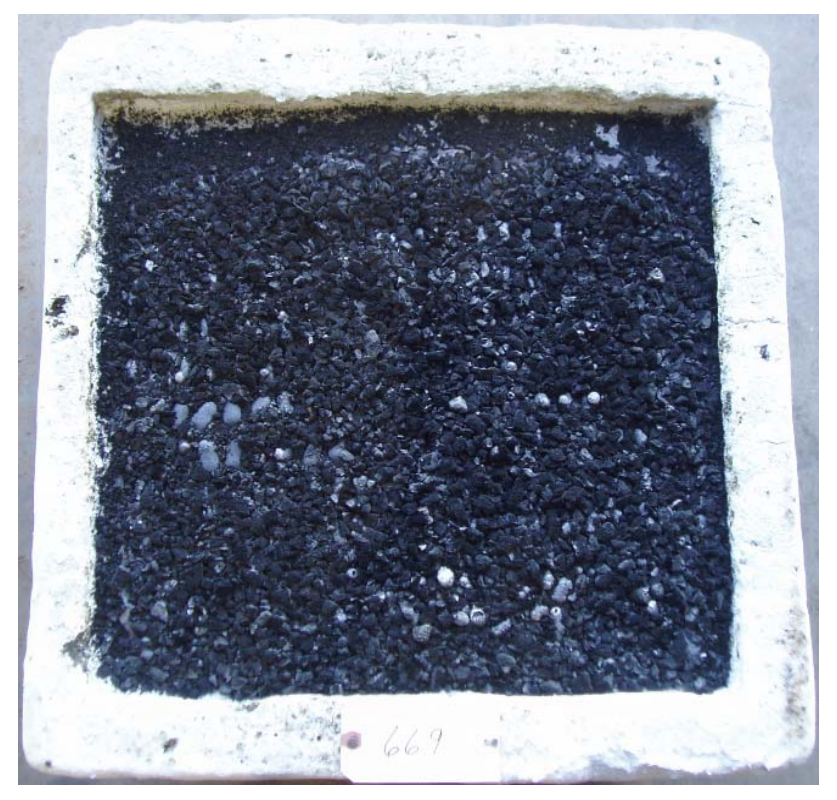

(c) PRB cover layer of $9.8 \mathrm{~kg} / \mathrm{m}^{2}\left(2.0 \mathrm{lb} / \mathrm{ft}^{2}\right)$ (Essentially fully covered)

Figure 2-7-5. Products of lab briquettes in single layer (10\% SS-1h), placed on a $3 / 100$ mesh PRB coal hearth layer of $12.7 \mathrm{~mm}(1 / 2 ")$ deep, covered with different amounts of $-15.9 \mathrm{~mm}\left(-5 / 8^{\prime \prime}\right)+3$ mesh PRB coal, heated in the LHF and before PRB char cover removed. 
Table 2-7-13. LHF test summary on taconite concentrate (K), $85 \%$ stoichiometric bituminous $(\mathrm{J})$ or PRB coal, $2 \%$ fluorspar at slag composition $\mathrm{C} / \mathrm{A}=\mathbf{1 . 5}$.

\begin{tabular}{|c|c|c|c|c|c|c|}
\hline \multirow[b]{2}{*}{$\begin{array}{c}\text { Cover layer } \\
\mathrm{kg} / \mathrm{m}^{2} \\
\left(\mathbf{l b} / \mathrm{ft}^{2}\right)\end{array}$} & \multicolumn{2}{|c|}{$\frac{-12.7 \mathrm{~mm}\left(-1 / 2^{\prime \prime}\right)+6 \mathrm{mesh}}{\text { cover layer }}$} & \multicolumn{4}{|c|}{$-15.9 \mathrm{~mm}\left(-5 / 8^{\prime \prime}\right)+3$ mesh cover layer } \\
\hline & $\begin{array}{l}\text { Car speed } \\
\mathrm{mm} / \mathrm{min} \\
\text { (inch/min) }\end{array}$ & $\begin{array}{l}\text { layer } \\
\text { Time in hot } \\
\text { zone, min }\end{array}$ & $\begin{array}{c}\text { Car speed } \\
\mathrm{mm} / \mathrm{min} \\
\text { (inch/min) }\end{array}$ & $\begin{array}{l}\text { Time in hot } \\
\text { zone, min }\end{array}$ & $\% \mathrm{C}$ & $\begin{array}{l}\text { RI } \\
\% S\end{array}$ \\
\hline \multicolumn{7}{|c|}{ Bituminous coal $(\mathrm{J})$ reductant, coke cover and hearth layer } \\
\hline $2.9(0.6)$ & $229(9)$ & 31 & & & & \\
\hline $3.9(0.8)$ & $203(8)$ & 35 & & & & \\
\hline $4.9(1.0)$ & $165(6.5)$ & 43 & $254(10)$ & 28 & 3.38 & 0.045 \\
\hline $5.9(1.2)$ & $127(5)$ & 56 & & & & \\
\hline \multicolumn{7}{|c|}{$\frac{\text { PRB coal reductant }}{\text { PRB coal cover and hearth layers }}$} \\
\hline $6.8(1.4)$ & & & \multicolumn{2}{|c|}{$>50 \%$ exposed } & & \\
\hline $8.8(1.8)$ & & & \multicolumn{2}{|c|}{$40-45 \%$ exposed } & & \\
\hline $9.8(2.0)$ & & & $\begin{array}{l}152(6) \\
165(6.5)\end{array}$ & $\begin{array}{l}46.5 \\
43\end{array}$ & $\begin{array}{l}1.84 \\
1.90\end{array}$ & $\begin{array}{l}0.146 \\
0.122\end{array}$ \\
\hline \multicolumn{3}{|c|}{ Coke cover and hearth layers } & & & & \\
\hline $2.9(0.6)$ & Not fuse & & & & & \\
\hline $4.9(1.0)$ & Not fuse & & & & & \\
\hline
\end{tabular}


It should be remembered that the use of PRB coal cover and hearth layers generated copious amount of black smoke (soot), particularly when a tray was in Zone 1. In an attempt to control the oxygen level within the furnace, the exhaust ducts were closed and the furnace gas was allowed to escape from the entrance and discharge ends of the furnace. Flame shooting out from the entrance end is shown in Figure 2-7-6(a), and from the discharge end in Figure 2-7-6(b). Obviously, the soot needs to be prevented from depositing in ducts and from emitting from the stack. Because of the copious generation of black smoke, large weight loss and shrinkage in the process, PRB coal for cover and hearth layer application needs to be approached with caution.

In an attempt to bring out the effect of the size of the cover layer material, two series of tests were carried out. In one series, taconite concentrate (K)-bituminous coal (J) briquettes were covered with $-15.9 \mathrm{~mm}(-5 / 8 ")+3$ mesh coke, and in another series, taconite concentrate (K)-PRB coal briquettes were covered with $-12.7 \mathrm{~mm}(-1 / 2$ ") +6 mesh coke.

With $-15.9(-5 / 8 ")+3$ mesh coke cover layer, tray speed could be markedly accelerated to $254 \mathrm{~mm} / \mathrm{min}$ (10 inch/min), or 28 minutes in the hot zone, at the coverage of 4.9 $\mathrm{kg} / \mathrm{m}^{2}\left(1.0 \mathrm{lb} / \mathrm{ft}^{2}\right)$, which was the minimum amount of this coke for full coverage of briquettes. The size of cover layer coke notably affected the fusion behavior. This tray speed was a little faster than that for the minimum coverage of $2.9 \mathrm{~kg} / \mathrm{m}^{2}\left(0.6 \mathrm{lb} / \mathrm{ft}^{2}\right)$ with $-12.7 \mathrm{~mm}(-1 / 2$ ") +6 mesh coke of $229 \mathrm{~mm} / \mathrm{min}$ (9 inch/min), or 31 minutes in the hot zone, showing the advantage of using the cover layer of coarser coke.

With $-12.7 \mathrm{~mm}(-1 / 2 ")+6$ mesh coke cover layer, the PRB coal-added briquettes did not fuse regardless of coverage and tray speed. It was speculated that such a behavior might be related to the role played by volatile matter released by PRB coal cover and hearth layers, perhaps protecting PRB char in briquettes from the carbon solution reaction. 


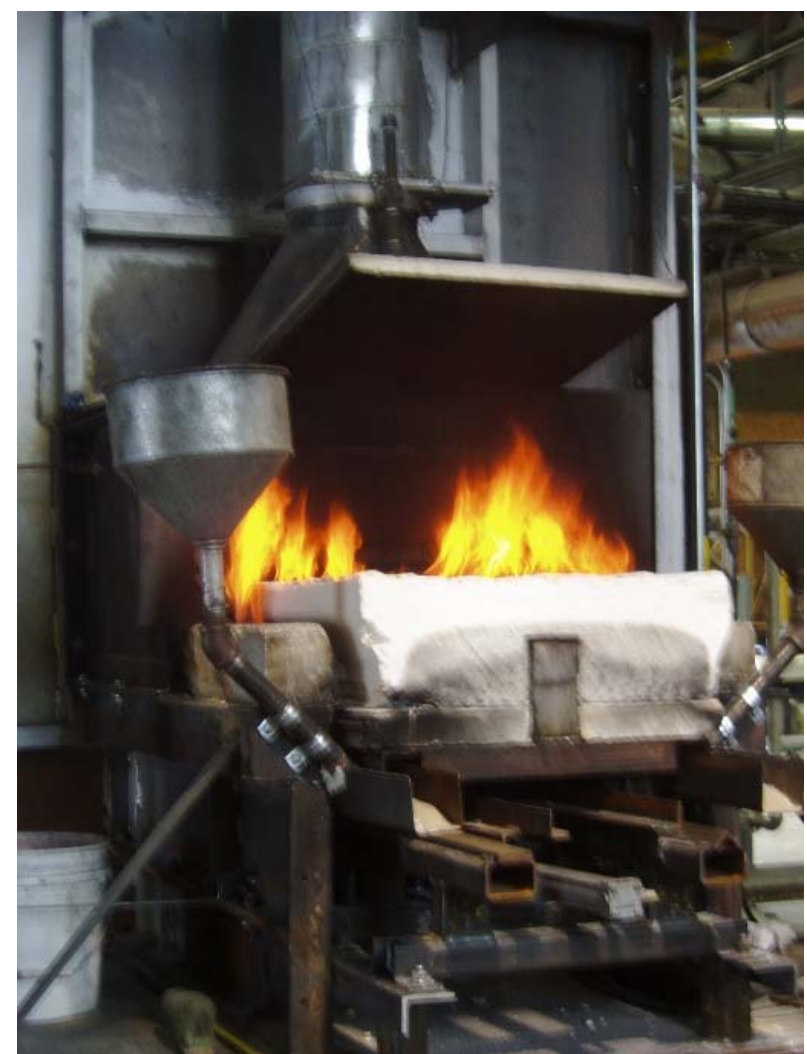

Figure 2-7-6(a). Flame shooting out from the entrance end of LHF when a sample tray was in Zone 1.

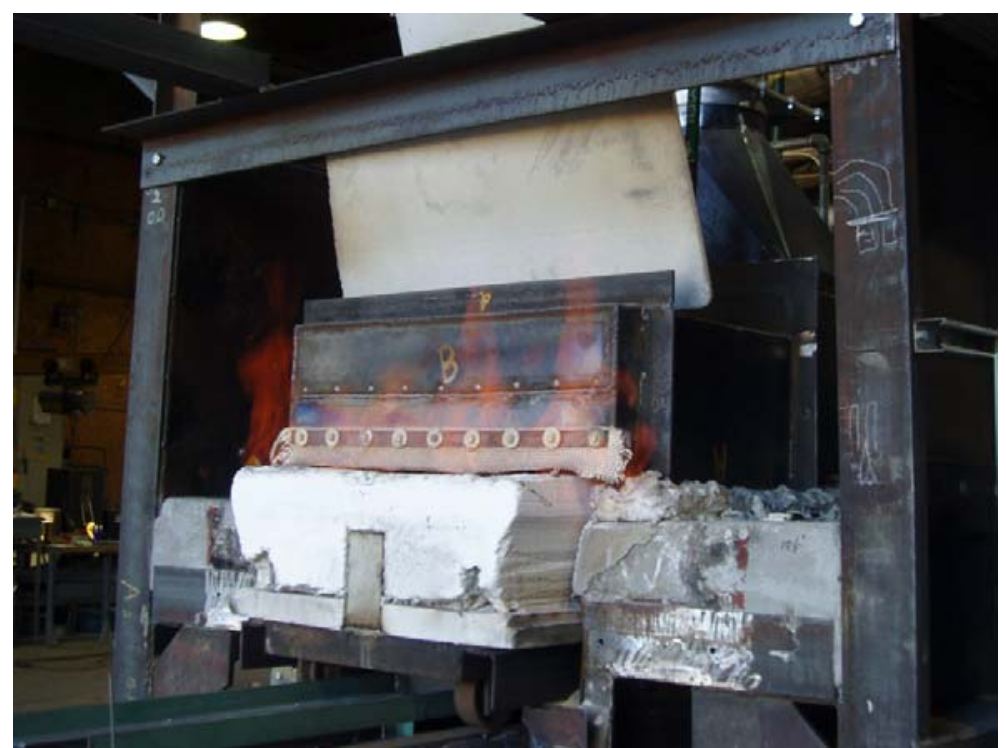

Figure 2-7-6(b). Flame shooting out from the discharge end of LHF when a sample tray was in Zone 3. 


\section{2-7.3 Effect of wall between Zones 2 and 3}

All of the tests up to this point were determined with the wall between Zones 2 and 3 removed. The wall, which was present in the original design, was re-installed and its effect on the fusion behavior was investigated.

\section{2-7.3.1 Conclusion}

Installation of a wall between Zones 2 and 3 required about 1/3 longer time for producing fully fused NRI due perhaps to the change in the temperature profiles by the presence of the wall. NRI sulfur was not affected by the presence of the wall.

\section{2-7.3.2 Test procedure}

Lab Komarek briquettes, consisting of taconite concentrate $(\mathrm{K}), 85 \%$ stoichiometric bituminous coal $(\mathrm{J}), 2 \%$ fluorspar and slag composition C/S of 1.5 , were arranged $10 \times 18$ (180 in total), close packed in a single layer on a hearth layer of $12.7 \mathrm{~mm}(0.5 ")$ deep $\left(8.8 \mathrm{~kg} / \mathrm{m}^{2}\left[1.8 \mathrm{lb} / \mathrm{ft}^{2}\right]\right) 6 / 100$ mesh in a tray, and covered with $3.9 \mathrm{~kg} / \mathrm{m}^{2}\left(0.8 \mathrm{lb} / \mathrm{ft}^{2}\right)$ of $-12.7 \mathrm{~mm}(-1 / 2 ")+6$ mesh coke.

The tray was passed through the LHF according to the standardized schedule. "Time in hot zone" refers to the time of a tray entering Zone 1 to exiting Zone 3 (7.1 m (280 inches)).

\section{2-7.3.3 Test results}

Trays were sent through the LHF at constant car speed and the minimum car speed to produce fully fused NRI were determined. NRI analyses were made on products at or near fusion time. Car speed at the fusion time, time in hot zone and NRI sulfur are summarized in Table 2-7-14.

Table 2-7-14. Effect of wall between Zones 2 and 3 on fusion time and NRI sulfur

\begin{tabular}{|l|cc|c|}
\hline & \multicolumn{2}{|c|}{ Fusion time } & \multirow{2}{*}{$\begin{array}{c}\text { NRI } \\
\text { \%S }\end{array}$} \\
\cline { 2 - 3 } & $\begin{array}{c}\text { Car speed } \\
\text { mm/min } \\
\text { (inch/min) }\end{array}$ & $\begin{array}{c}\text { In hot zone } \\
\text { min }\end{array}$ & \\
\hline Without wall & $203(8)$ & 35 & 0.043 \\
With wall & $152(6)$ & 46.5 & $0.043^{*}$ \\
& $140(5.5)$ & 51 & 0.040 \\
\hline
\end{tabular}

* One briquette not fused. 
Fusion time after the installation of the wall was $152.4 \mathrm{~mm} / \mathrm{min}(6 " / \mathrm{min})(46.5 \mathrm{~min})$, whereas before the installation was $203.2 \mathrm{~mm} / \mathrm{min}(8 " / \mathrm{min})(35 \mathrm{~min})$ or about one-third longer time was required. Temperature readings of the furnace in Zones 1,2 and 3 were $1235^{\circ} \mathrm{C}, 1337^{\circ} \mathrm{C}$, and $1413^{\circ} \mathrm{C}\left(2255^{\circ}, 2440^{\circ}\right.$ and $\left.2575^{\circ} \mathrm{F}\right)$ in the absence of wall, respectively, and $1185^{\circ} \mathrm{C}, 1413^{\circ} \mathrm{C}$, and $1410^{\circ} \mathrm{C}\left(2165^{\circ}, 2440^{\circ}\right.$ and $\left.2570^{\circ} \mathrm{F}\right)$ in the presence of wall, respectively. Therefore, the temperatures in Zones 2 and 3 were essentially identical in both cases. Apparently, the change in the temperature profiles in Zones 2 and 3 was responsible for the difference in the fusion time.

NRI sulfur analyses at the fusion time were in good agreement before and after the installation of the wall. Lower NRI sulfur of $0.040 \% \mathrm{~S}$ at the car speed of $140 \mathrm{~mm} / \mathrm{min}$ (5.5 "/min) (51 minutes in the hot zone) was also in agreement with the experience that longer time in the furnace lowered NRI sulfur.

\section{2-7.4 Effect of agglomerate shape on fusion time}

As the exposed surface areas of feed mixtures appeared to play a role on fusion behavior, a comparison was made of the agglomerate shapes on fusion behaviors with briquettes and balls, prepared from taconite concentrate $(K)$ and bituminous coal $(J)$. Using the agglomerates in single and double layers, fusion time was determined by varying residence time in the LHF.

\section{2-7.4.1 Conclusions}

1) Productivity, expressed as $\mathrm{kg} \mathrm{NRI} / \mathrm{m}^{2} / \mathrm{h}$, remained essentially constant in the range of 20.5 to $21.0\left(4.2\right.$ to $\left.4.3 \mathrm{lb} / \mathrm{ft}^{2} / \mathrm{h}\right)$, regardless of the agglomerate shapes and loading densities at their fusion time.

2) NRI sulfur remained below or near $0.05 \% \mathrm{~S}$.

3) Difference in the fusion time of briquettes and balls, both about $12.7 \mathrm{~mm}(1 / 2 ")$ in height, was within the experimental variation. The choice between briquettes and balls of the sizes used would then depend on the capital and operating costs of producing the two types of agglomerates.

\section{2-7.4.2 Test procedure}

A feed mixture used in the investigation consisted of taconite concentrate $(K), 85 \%$ stoichiometric bituminous coal (J), $2 \%$ fluorspar and slag composition $\mathrm{C} / \mathrm{S}$ of 1.5 . In one series of tests, balls were prepared with a $0.91 \mathrm{~m}$ (3-ft) diameter balling disc using $1.5 \%$ cooked starch as a binder and a size fraction of $-12.7 \mathrm{~mm}+19.5 \mathrm{~mm}(-1 / 2$ " $+5 / 8$ ") was screened out for use. The balls weighed $3.2 \pm 0.5 \mathrm{~g} / \mathrm{ball}$. In another series of tests, briquettes were prepared with Lab Komarek briquetting machine using $4 \%$ molasses as a binder. The briquettes measured $35 \mathrm{~mm}$ x $21.8 \mathrm{~mm}$ x $13.2 \mathrm{~mm}$ (1.38"x0.86"x0.52") and weighed $13.1 \pm 1.0 \mathrm{~g} / \mathrm{briquette}$.

Both agglomerates were arranged close packed, either in a single layer or double layers, over $12.7 \mathrm{~mm}(1 / 2 ")$ deep 6/100 mesh hearth layer coke, and covered with 4.9 $\mathrm{kg} / \mathrm{m}^{2}\left(1.0 \mathrm{lb} / \mathrm{ft}^{2}\right)-12.7 \mathrm{~mm}(-1 / 2 ")+6$ mesh coke. The areas covered by the 
agglomerates were measured and converted to loading density, expressed as $\mathrm{kg} / \mathrm{m}^{2}$ $\left(\mathrm{lb} / \mathrm{ft}^{2}\right)$.

\section{2-7.4.3 Test results}

The test results of loading density, tray speed at minimum time to fusion, fusion time in the hot zone $(7.1 \mathrm{~m}(280 "))$ and the analytical results of NRI, are summarized in Table 2-7-15.

As the loading density varied between balls and briquettes as well as single and double layers, a comparison was made by converting the data to productivity, expressed as $\mathrm{kg}$ $\mathrm{NRI} / \mathrm{m}^{2} / \mathrm{h}$. All the four data remained essentially the same in the range of 20.5 to 21 (4.2 to $4.3 \mathrm{lb} \mathrm{NRI} / \mathrm{ft}^{2} / \mathrm{h}$ ), suggesting that the difference between the agglomerate shapes were within the experimental variation. Nevertheless, NRI sulfur remained below or near $0.05 \%$ S.

Table 2-7-15. Comparison of fusion time of briquettes and balls

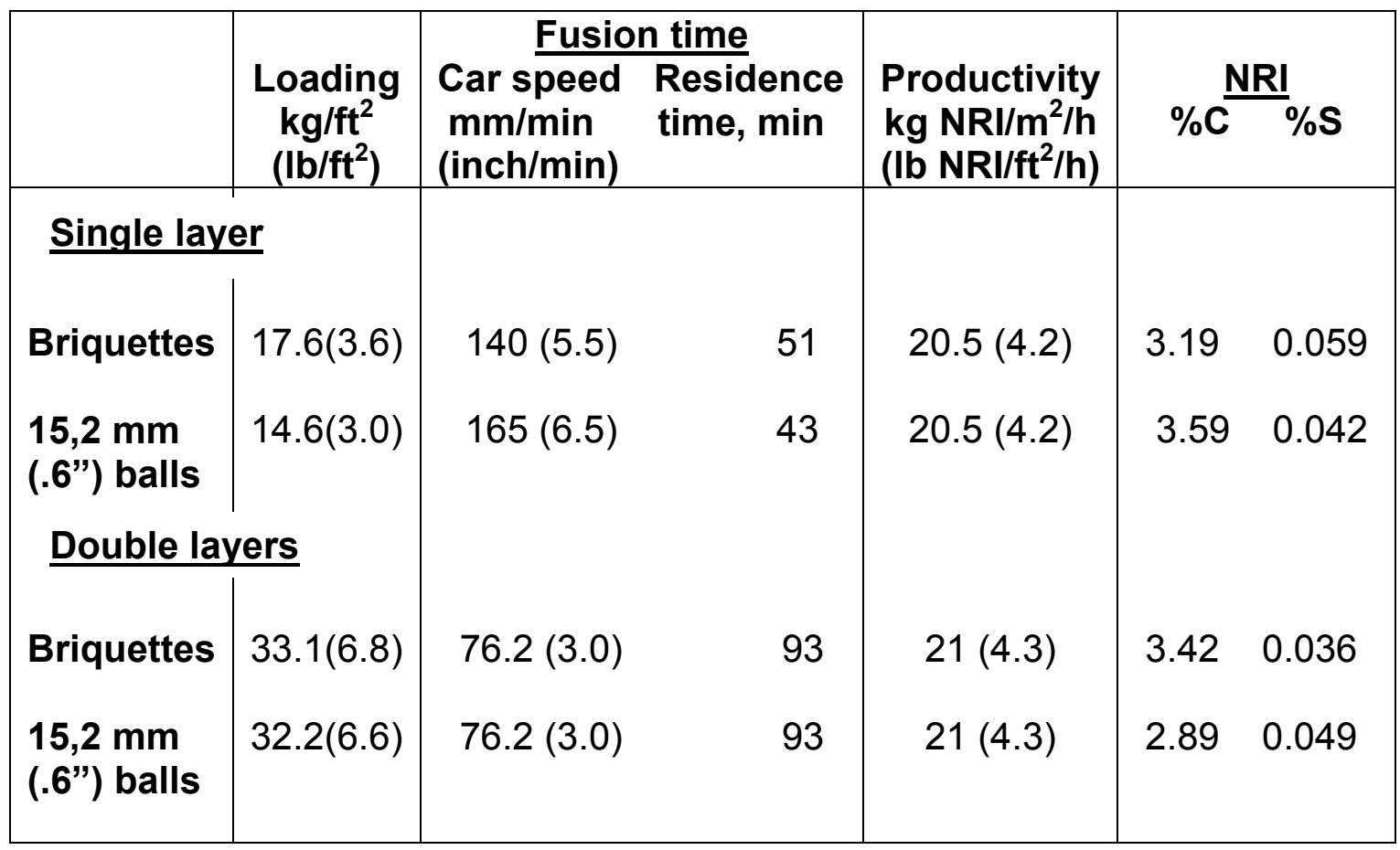




\section{2-8 REFERENCES}

1. "A new process to produce iron directly from fine ore and coal," I. Kobayashi, Y. Tanigaki and A. Uragami, Iron \& Steelmaker, Vol. 27 (2001), No. 9, 19-22.

2. "KSC Develops New Ironmaking Process," Iron \& Steelmaker, Vol. 28 (2001), No. $10,8$.

3. "ITmk3 - Application of a new ironmaking technology for the iron ore mining industry," G. Hoffman and O. Tsuge, Mining Engineering, Vol. 56 (2004), No. 10, 3539.

4. "Steel Success Story. Ironmaking: Quality and Supply Critical to Steel Industry," U.S. Department of Energy, Energy Efficiency and Renewable Energy, Industrial Technologies Program, http://www.eere.energy.gov/industry/steel/ (September 21, 2004).

5. "Mesabi Nugget - The new age of iron," J.A. Hansen, Iron \& Steel Technology, Vol. 2 (2005), No. 3, 149-153.

6. "Mesabi Nugget to start operations in December," Duluth News Tribune, November 26, 2009.

7. "Mesabi Nugget: a steady presence for the Range," Skillings Mining Review, Vol. 98, No. 12, December, 2009.

8. "Mesabi Nugget rolls out first batch," Duluth News Tribune, January 10, 2010.

9. "New coal-based process, Hi-QIP, to produce high quality DRI for the EAF," Y. Sawa, T. Yamamoto, K. Takeda and H. Itoya, 2000 Electric Furnace Conference Proceedings, Vol. 58 (2000), Orlando, Florida, 507-517.

10. "Pilot plant test for production of iron pebble (Development of new reduction and smelting process on coal bed -1)," N. Ishiwata, Y. Sawa and K. Takeda, CAMPISIJ, Vol. 17 (2004), 150.

11. "Hi-QIP, a new Ironmaking Process," Iron \& Steel Technology, Vol. 5 (2008), 87-94.

12. "Metallic Iron Nodule Research," D.R. Fosnacht, I. Iwasaki and R.L. Bleifuss, Final Report to the Economic Development Administration, Project \#06-69-04501, March 25, 2004, 15p. (Patent pending).

13. "Oxygen-enriched combustion can reduce emissions and fuel use in energy intensive industries," DOE/CH 10093-198, DE93000063, September 1993, http://es.epa.gov/techinfo/facts/o2-nrich.html.

14. "Praxair's dilute oxygen combustion technology for pyrometallurgical applications," M.F. Riley, H. Kobayashi, and A.C. Deneys, JOM, Vol. 53 (2001), No. 5, pp.21-24. 


\title{
PART 3:
}

\section{A Computational Fluid Dynamics Process Furnace Model}

\author{
by \\ David J. Englund \\ Program Director Process Fluid Flow and Heat Transfer \\ Coleraine Minerals Research Laboratory \\ 218-245-4216 \\ denglund@d.umn.edu \\ Natural Resources Research Institute \\ Coleraine Minerals Research Laboratory \\ P.O. Box 188 \\ Coleraine, Minnesota 55722
}




\section{TABLE OF CONTENTS:}

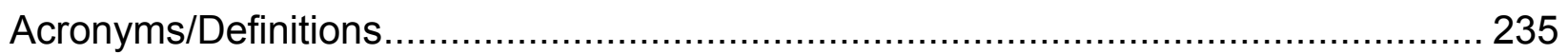

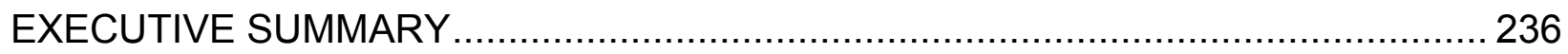

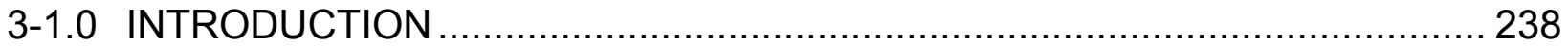

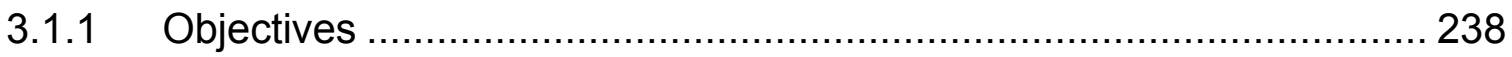

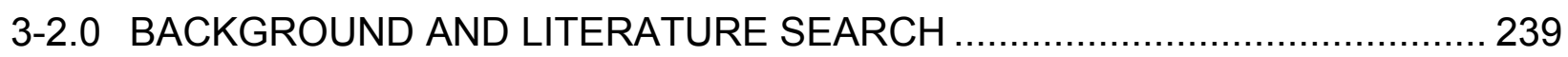

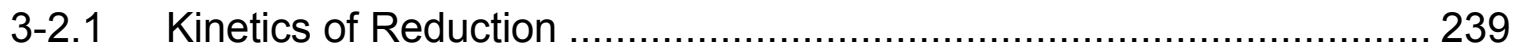

3-2.2 Char/Carbon Gasification by Oxygen and Carbon Dioxide ................ 239

3-2.3 General Concepts Outlined in Rotary Hearth References.................. 239

3-2.4 Flame Chemistry/Oxy-Fuel Combustion ....................................... 240

3-2.5 Fluorspar and Fluorine Emission from Slag .................................... 240

3-2.6 Thermal Conductivity of Chars, Iron and Slags ................................ 241

3-3.0 GLOBAL MASS BALANCE TO ESTABLISH MODEL INPUT BOUNDARY

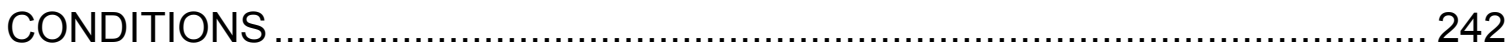

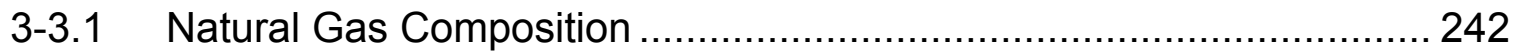

3-3.2 Coal and Gas Volatiles Composition............................................. 242

3-3.3 Remaining Feed Components (Concentrate, Fluorspar, Hydrated Lime, and Molasses ............................................................. 242

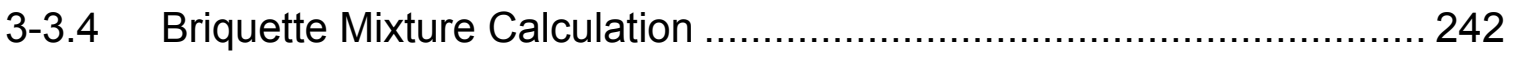

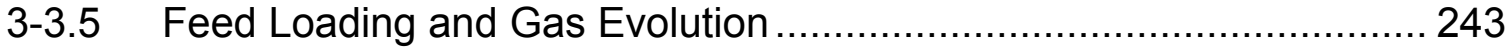

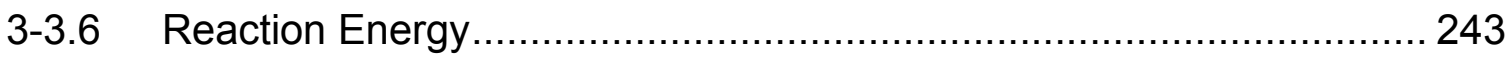

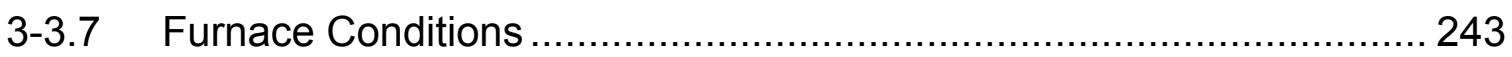

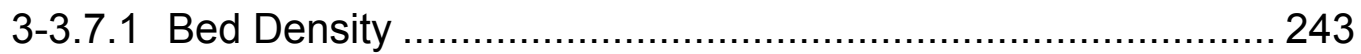

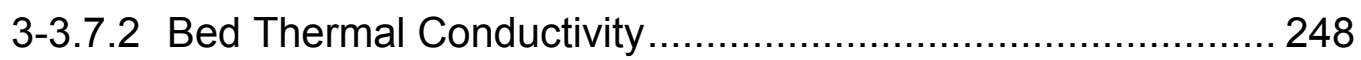

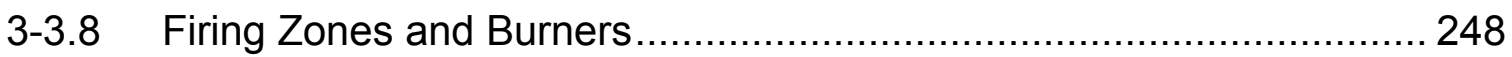

3-3.9 Secondary Oxygen Flows …….............................................. 248

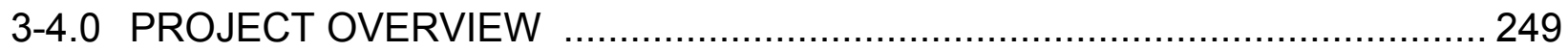

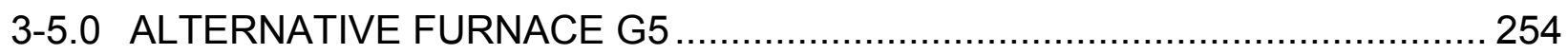

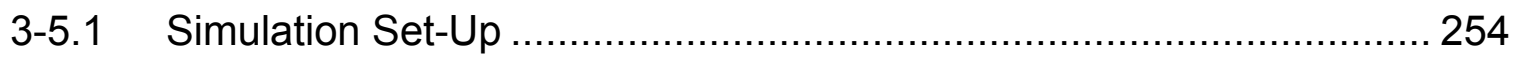

3-5.2 Secondary Oxygen Injection ................................................. 254

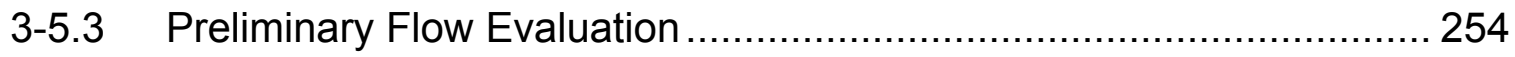

3-5.4 Partial Factorial Simulation Design .............................................. 255

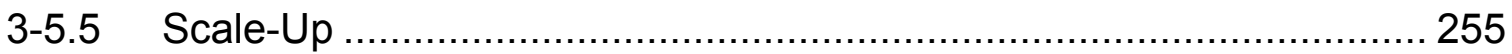

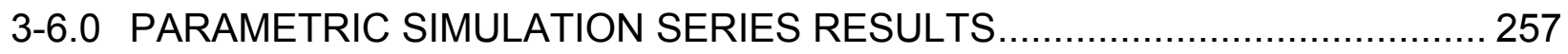

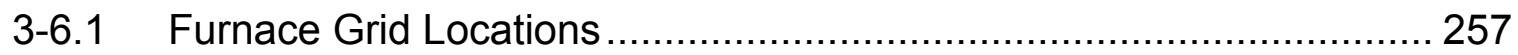

3-6.1.1 Location Specific Results............................................. 257

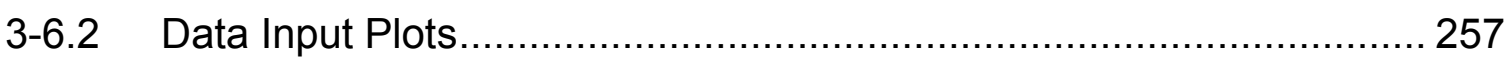

3-6.2.1 Burner Zone GJ/hr vs. Mass Flow kg/s (to burner) ............... 258 
3-6.2.2 Secondary Oxidant Injection Velocity $(\mathrm{m} / \mathrm{s})$ vs. Mass Flow $(\mathrm{m} / \mathrm{s})$

3-6.2.3 Calculated Iron Mass Flow vs. Template Productivity mt $\mathrm{HM} / \mathrm{hr}$

3-6.2.4 Total Gaseous Energy per Total mt of Furnace Feed vs. Template Value

3-6.2.5 Percent Difference in Simulation Flue Gas Mass Flow Spreadsheet Calculated Value

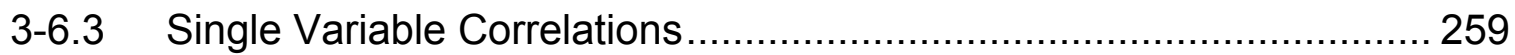

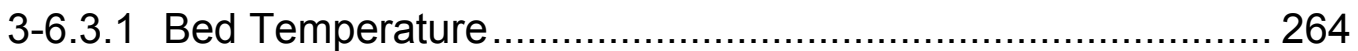

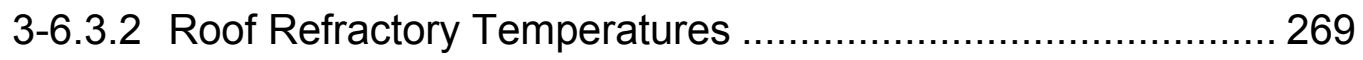

3-6.3.3 Flue Gas Composition .................................................. 269

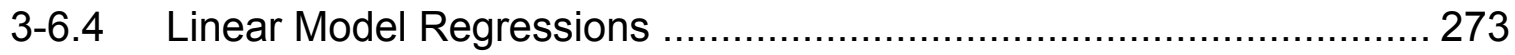

3-6.4.1 Hot Metal Production ......................................................... 273

3-6.4.2 Average Oxidation Degree (OD) ...................................... 273

3-6.4.2.1 Reduction Zone Oxidation Degree ....................... 275

3-6.4.2.2 Melting Zone Oxidation Degree Model .................. 275

3-6.5 Bed Volumetric Maximum Temperature Model ................................ 275

3-6.5.1 Bed Volumetric Maximum Temperature ............................. 277

3-6.5.2 Substitution of Averaged Melting Zone Bed Center

Temperature for Bed Volumetric Maximum Temperature in the Model of Section 6.5.1 ............................................ 277

3-6.6 Productivity ( $\mathrm{mt} \mathrm{HM} / \mathrm{hr}$ ) from Residence Time and Iron Loading......... 278

3-6.7 Flue Gas Carbon Dioxide and Energy Content Model Contours ......... 289

3-6.8 Coal Type Comparison at Constant Operating Conditions.................. 294

3-6.9 Medium Volatile Coal with Varied Natural Gas Comparison ............... 297

3-6.10 Process Oxygen Concentration (Burners and Secondary Injection) ............................................................................ 300

3-6.11 Mass Ratio Oxygen to mt Hot Metal and Total Energy (Natural Gas + Coal $) / \mathrm{mt}$ Hot Metal...................................................... 300

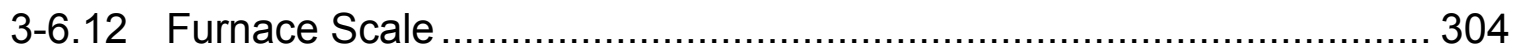

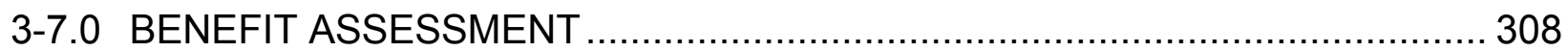

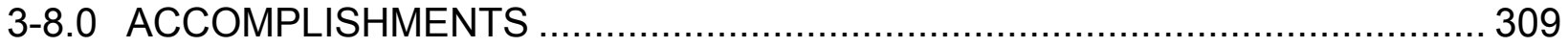

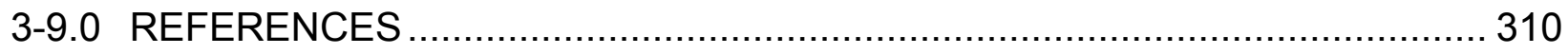




\section{LIST OF FIGURES}

Figure 3-1. Comparison of CFD Output with Measured Flame Temperature......... 250

Figure 3-2. Comparison of Peak Flame Temperatures in Methane - Oxygen

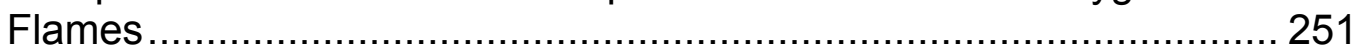

Figure 3-3. Intermediate Furnace Length Comparison - Bed Center

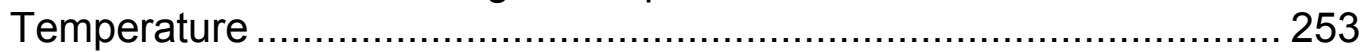

Figure 3-4. Calculated Firing Zone Energy vs. Burner Zone Mass Flow .............. 260

Figure 3-5. Secondary Injection Pipe Set Average Velocity vs. Mass Flow ............ 261

Figure 3-6. Calculated Iron Mass Flow vs. Template Productivity …...................... 262

Figure 3-7. Total Gaseous Energy vs. Total Furnace Mass Flow vs. Template

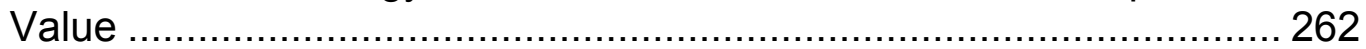

Figure 3-8. Percent Difference Between Simulation Flue Gas Flow and

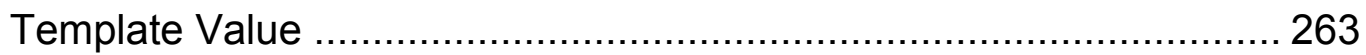

Figure 3-9. $\quad$ CFD Flue Gas Mass Flow vs. Template Value .................................. 263

Figure 3-10. Maximum Bed Temperature vs. Average Bed Center Temperature in Devolatization zone............................................................... 265

Figure 3-11 Maximum Bed Temperature vs. Average Bed Center Temperature in Reduction zone ...................................................................... 266

Figure 3-12. Maximum Bed Temperature vs. Average Bed Center Temperature in Melting zone

Figure 3-13. Average Bed Center Temperature in Melting Zone vs. Reduction

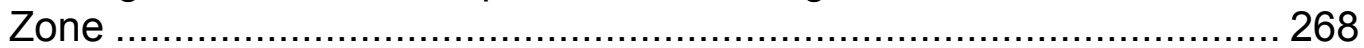

Figure 3-14. Maximum Furnace Roof Temperature vs. Average Roof Temperature ....................................................................... 270

Figure 3-15. Maximum Furnace Roof Temperature vs. Average Bed Center Temperature in Melting zone ...................................................... 271

Figure 3-16. Flue Gas CO and CO2 Content vs. Flue Gas O2 Content................... 272

Figure 3-17. Hot Metal Production Model ..................................................... 274

Figure 3-18. Reduction Zone Oxidation Degree Model ....................................... 276

Figure 3-19. Melting Zone Oxidation Degree Model …....................................... 279

Figure 3-20. Bed Volumetric Maximum Temperature Model................................. 280

Figure 3-21. Bed Volumetric Maximum Temperature Model $\mathrm{O}_{2}$ and Residence

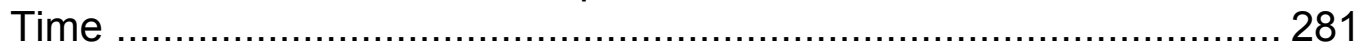

Figure 3-22. Bed Volumetric Maximum Temperature Model $\mathrm{O}_{2}$ and Natural Gas

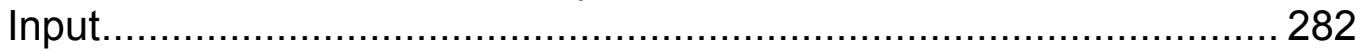

Figure 3-23. Bed Volumetric Maximum Temperature Model $\mathrm{O}_{2}$ and Briquette

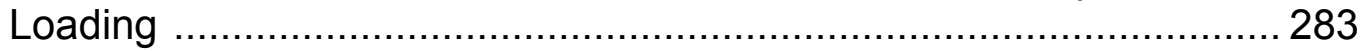

Figure 3-24. Bed Volumetric Maximum Temperature Model $\mathrm{O}_{2}$ and Coal Volatile Content 284

Figure 3-25. Substitution of Averaged Melting Zone Bed Center Temperature for Bed Volumetric Maximum Temperature 285 
Figure 3-26. Comparison Bed Max Ave. Melting Zone Bed Center Temp $\mathrm{O}_{2}$ and Residence Time

Figure 3-27. Comparison Bed Max Ave. Melting Zone Bed Center Temp $\mathrm{O}_{2}$ and Natural Gas Input

Figure 3-28. Comparison Bed Max Ave. Melting Zone Bed Center Temp $\mathrm{O}_{2}$ Briquette Loading

Figure 3-29. Comparison Bed Max Ave. Melting Zone Bed Center Temp $\mathrm{O}_{2}$ Coal Volatile Content.....

Figure 3-30. Productivity Model from Residence Time and Iron Loading Model ...... 288

Figure 3-31. Flue Gas Carbon Dioxide and Energy Content Model ....................... 290

Figure 3-32. Flue Gas Carbon Dioxide and Energy Content Prediction Profiler ...... 291

Figure 3-33. Flue Gas Carbon Dioxide and Energy Content Contours ................... 292

Figure 3-34. Desirability Optimization on Average Bed Center Temperature Melting Zone 293

Figure 3-35. Coal Type Comparison Effect on Bed Center Temperature ................ 295

Figure 3-36. Coal Type Comparison Effect on Gas Velocity .................................. 296

Figure 3-37. Natural Gas Comparison Effect on Bed Center Temperature............... 298

Figure 3-38. Natural Gas Comparison Effect on Gas Velocity .............................. 299

Figure 3-39. Oxygen Concentration Comparison Effect Bed Center

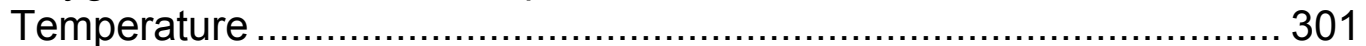

Figure 3-40. Oxygen Concentration Comparison Effect Gas Velocity...................... 302

Figure 3-41. Oxygen:Hot Metal Mass Ratio vs. Energy Input .............................. 303

Figure 3-42. Average Melting Zone Temperature vs. Energy Input ....................... 303

Figure 3-43. Bed Surface Temperature Comparison with Furnace Size .................. 306

Figure 3-44. Gas Velocity Comparison with Furnace Size .................................... 307 


\section{LIST OF TABLES}

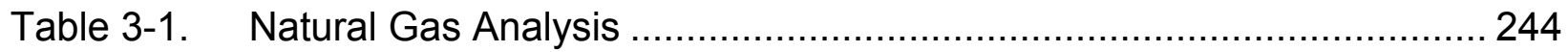

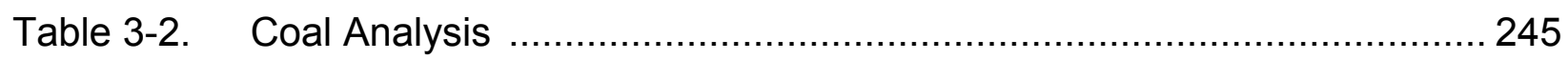

Table 3-3. Briquette Component Mineral Balances Dry Basis .............................. 246

Table 3-4. Briquette Component Mineral Balances Wet Basis .............................. 247

Table 3-5. Component Thermal Conductivities ................................................ 248

Table 3-6. Co-Current vs. Counter Current Mass Flow in Melting Zone ................. 252

Table 3-7. Coal Type and Volatile Energy Content ............................................ 252

Table 3-8. Parametric Factorial Independent Variables ...................................... 256

Table 3-9. Natural Gas Series DOE 11,11a-d..................................................... 297

Table 3-10. Simulation Scale-Up Comparison .................................................... 305 


\section{Acronyms/Definitions}

MMBTU/mt HM British Thermal Units expressed as millions of BTU per metric ton of Hot Metal

Basicity Ratio $\quad \mathrm{B} 2=\mathrm{CaO} / \mathrm{SiO}_{2}, \mathrm{~B} 4=(\mathrm{CaO}+\mathrm{MgO}) /\left(\mathrm{SiO}_{2}+\mathrm{Al}_{2} \mathrm{O}_{3}\right) \%$ wt basis

NRI

CMRL Nodular Reduced Iron

VOC's

Coleraine Minerals Research Laboratory

MFL

Volatile Organic Carbons

CFD

Maximum Flame Temperature Limit

$\mathrm{CHT}$

Computational Fluid Dynamics

OD

Conjugate Heat Transfer

Primary Oxygen

Oxidation Degree $=$ molar fractions $\left(\mathrm{P}_{\mathrm{CO} 2} /\left(\mathrm{P}_{\mathrm{CO}}+\mathrm{P}_{\mathrm{CO} 2}\right)\right.$

Secondary Oxygen Oxygen injected directly into furnace to combust gaseous species resulting from coal devolatization and iron oxide reduction.

Note: Primary oxygen can be supplied as pure oxygen, oxygen enriched air or air, oxygen concentration is used to distinguish source.

LHF

Linear hearth furnace

RHF

Rotary hearth furnace

$\mathrm{DRI}$

Direct reduced iron 85 to $95 \%$ metalized and containing slag constituents.

NRI Nodular reduced iron resulting from melting of reduced iron with separation of slag components

CSL Carbon solution loss, gasification of solid carbon from furnace feed or hearth and cover carbons by water vapor and carbon dioxide combustion products.

PRB Powder River Basin Coal 


\section{EXECUTIVE SUMMARY:}

A spreadsheet template was developed to facilitate boundary condition specification for Computational Fluid Dynamic (CFD) furnace simulations. The template included provision for feed agglomerate blends, furnace size, hearth speed, feed loading, burner firing rate and burner oxygen to fuel ratio. Oxy-fuel CFD burner models were evaluated prior to incorporation in the furnace model. These burner models were partially validated by comparing flame temperature prediction with published data.

A number of furnace grids were developed during the course of the project, early furnace designs produced poor convergence with oxy-fuel based combustion systems. Significant effort was expended developing an understanding of boundary conditions and furnace design leading to steady state converged solutions. The resulting final furnace design was designated G5. It produced converged solutions for a wide range of operating conditions (coal type, feed loading, combustion system etc.).

A parametric series of simulations was generated for three coal types, three natural gas firing rates, three feed loadings, three hearth speeds and three oxidant oxygen concentrations. The G5 furnace grids were dimensionally modified to yield similar velocities based on oxidant oxygen concentration. A total of forty-one simulations were performed.

Statistical analysis indicated that choice of oxidant oxygen concentration and coal type produced significant effect on the furnace operating temperature. The relationship was dependent on flue gas volume and coal volatile energy. High oxygen concentration in the oxidant resulted in decreased flue gas volume. Reductant coal volatile energy increased as fixed carbon content decreased. Coal addition was determined by specified ratio of fixed carbon to iron oxides (stoichiometric ratio).

At constant stoichiometric ratio, low fixed carbon coal supplied proportionately greater volatile energy than high fixed carbon coal. High volatile energy input coupled with low flue gas volume (low fixed carbon coal and high oxidant oxygen concentration) produced very high furnace temperatures $\left(>3000^{\circ} \mathrm{F}\left(>1649^{\circ} \mathrm{C}\right)\right)$ when secondary combustion was carried to completion inside the furnace (zero VOC discharge in flue gas).

Natural gas consumption was minimized (0.75 MMBTU/mt Hot Metal, $(0.79 \mathrm{GJ} / \mathrm{mt} \mathrm{HM})$ ) by balancing oxidant oxygen concentration with coal volatile energy. Carbon dioxide emission increased with increased natural gas consumption, coal volatile content, and feed loading. Increased oxygen concentration resulted in decreased carbon dioxide emission. Carbon dioxide emission ranged between 1140 and $1400 \mathrm{~kg} / \mathrm{mt}$ Hot Metal. To minimize emission it is necessary to optimize furnace temperature, natural gas firing, coal type and briquette loading. This is a multi-variable optimization. The simulations in this report identify variable interactions, but do not provide sufficient data for complete optimization.

The parametric design incorporating both mass flow (hearth speed and feed loading) and natural gas firing rate did not permit a true productivity assessment because 
throughput and energy input were both independent. Bed temperature was a dependent variable, and simulations deviating from acceptable operating bed temperatures resulted in unrealistic productivity rates. The acceptable temperature range was defined as maximum temperature between 2600 and $2800^{\circ} \mathrm{F}\left(1427-1538^{\circ} \mathrm{C}\right)$. Total energy consumption for simulations with acceptable bed temperatures ranged as low as 13 MMBTU/mt Hot Metal $(13.7 \mathrm{GJ} / \mathrm{mt})$. It would be of interest to explore the lower energy conditions with an additional series of tests in which productivity is dependent on bed temperature.

These simulations identified process variable interactions that can be used to evaluate furnace performance and raw material selection. Furthermore the furnace can be designed around raw material and oxidant selection, leading to an efficient process with minimal fuel consumption and carbon dioxide emission. 


\section{3-1.0 INTRODUCTION}

\section{3-1.1 Objectives}

a) Develop Computational Fluid Dynamics (CFD) model of a linear hearth reduction/smelting furnace; and

b) Perform simulations and identify process performance characteristics including mass and energy balances.

Mass and energy balances were developed to assess furnace efficiency using varied operating conditions and agglomerate mixes. CFD simulations permitted comparison of operating modes and feed mixes. The simulations complete a mass and energy balance for each set of conditions.

The simulations described in this report were used for screening purposes, to identify primary variable interactions and define operating windows. A partial-factorial screening experiment design defined simulation operating conditions. Additional simulations are required to explore areas of interest.

ANSY CFX $12.1^{1}$ CFD software was used for the simulations. FactSage ${ }^{2}$ software was used to generate equilibriums and provide thermodynamic data. Two Dell T-7500 Workstations, each with dual Xeon-quad core processors performed the computations. A total of 16 parallel processes were utilized for each simulation. The experimental design was generated using SAS Institute $\mathrm{JMP}^{3}$ Statistical software.

The Linear Hearth Furnace (LHF) used at the Coleraine Minerals Research Laboratory (CMRL) operated in batch mode (transient operation), producing results incompatible with CFD. An alternative furnace design, adaptable to both oxygen and air combustion systems was developed for the CFD simulations.

Variables in the simulations included hearth speed, feed loading, natural gas combustion systems (oxygen or air) and reductant coal volatile content. Hearth speed and feed loading per unit area of hearth were combined to yield productivity rates. Three reductant coal types were evaluated, identified as low volatile anthracite ( $5 \%$ volatiles), medium volatile bituminous ( $21 \%$ volatiles), and high volatile bituminous ( $36 \%$ volatiles). Furnace operation required two sources of oxygen, designated as primary oxygen, fed through natural gas burners, and secondary oxygen injected directly for post combustion of volatiles produced in the process. Both oxygen sources were injected through multiple locations in the furnace. Furnace performance was evaluated by coal type and oxygen concentration. Operating conditions producing minimized carbon dioxide emissions were identified.

The parametric design was carried out using a $2 \mathrm{ft}$ wide by $100 \mathrm{ft}(0.61 \mathrm{~m} \times 30.48 \mathrm{~m})$ long furnace. Symmetry was employed in the CFD solutions to simulate a $4 \mathrm{ft}$ by $100 \mathrm{ft}$ $(1.22 \mathrm{~m} \times 30.5 \mathrm{~m})$ unit. Subsequently the furnace was scaled to $12 \mathrm{ft}$ by $200 \mathrm{ft}(3.66 \mathrm{~m}$ $\times 60.96 \mathrm{~m})$ and $20 \mathrm{ft} \times 325 \mathrm{ft}(6.09 \times 99.06 \mathrm{~m})$ incorporating air based combustion and injection systems. Furnace height varied depending on oxygen source concentration and resultant flue gas volume. Oxygen based systems were limited to $1,000 \mathrm{ft}^{3}(28.3$ $\mathrm{m}^{3}$ ) furnace volume (hot zone) while air based systems simulated furnace volumes approaching $60,000 \mathrm{ft}^{3}\left(1699 \mathrm{~m}^{3}\right)$. A cooling zone was not included in these simulations. 


\section{3-2.0 BACKGROUND/LITERATURE SEARCH}

The search produced papers on iron ore reduction, rotary hearth furnaces (RHF) producing direct reduced iron (DRI) and melted iron nodules (Nodular Reduced Iron); a number of patents were also identified. NRI is essentially DRI that has undergone melting and slag phase separation to produce a pig-iron-like product. Additionally, references on char properties under high temperature conditions, oxy-fuel combustion systems including flue gas recirculation, and oxy-fuel flame temperature measurements were collected.

\section{3-2.1 Kinetics of Reduction}

A three part series of papers related to iron oxide-carbon composites by Freuhan and Halder investigated reduction kinetics and physical changes to iron oxide and carbon composites. ${ }^{4,5,6}$ The work simulated RHF production of DRI fed to a smelting reactor. In an earlier publication, Fortini and Fruehan also suggested pairing an RHF to a Bath Smelter. ${ }^{7}$ The term Oxidation Degree (OD) was taken from this publication and was used to define the oxidized state of gases near the bed. Oxidation Degree is defined as:

$$
\mathrm{OD}=\mathrm{P}_{\mathrm{CO} 2} /\left(\mathrm{P}_{\mathrm{CO} 2}+\mathrm{P}_{\mathrm{CO}}\right)
$$

where $\mathrm{P}_{\mathrm{CO} 2}$ and $\mathrm{P}_{\mathrm{CO}}$ are partial pressures of carbon dioxide and carbon monoxide in the gas leaving the pellets. In this project OD was defined by molar fractions in the gas stream, measured one inch $(25.4 \mathrm{~mm})$ above bed.

\section{3-2.2 Char/Carbon Gasification by Oxygen and Carbon Dioxide}

Several papers were reviewed on char gasification at high temperature. ${ }^{8,9}$ They provided background information. It was desired to predict carbon solution losses in the system for the following reactions:

$$
\begin{aligned}
& \mathrm{C}+\mathrm{CO}_{2}=2 \mathrm{CO} \\
& \mathrm{C}+\mathrm{H}_{2} \mathrm{O}=\mathrm{CO}+\mathrm{H}_{2}
\end{aligned}
$$

Collectively these reactions gasify hearth carbon by reaction with burner combustion products, referred to as Carbon Solution Loss (CSL). Two papers pertained to coal ash melting behavior and vaporization of refractory oxide constituents at high temperature. ${ }^{10,11}$ This information may be helpful in furnace refractory selection to avoid corrosion or fluxing problems associated with coal ash at high temperature.

\section{3-2.3 General Concepts Outlined in Rotary Hearth References ${ }^{12-25}$}

Most of these references described RHF systems for production of DRI or NRI, one reference by Lu and Huang described a paired straight hearth concept for production of DRI in 2004. ${ }^{20}$ Rotary hearth furnace systems recovered flue gas energy using heat exchange to preheat primary and secondary combustion air streams. Some mentioned 
use of hydrocarbon injection on metallic iron to initiate product cooling, prevent iron reoxidation, and yield a preheated secondary fuel source in the furnace. These publications emphasized secondary combustion of volatiles to minimize natural gas consumption.

Furnace separation into oxidizing and reducing zones was common throughout these references. Coal volatiles were burned in a co-flow oxidizing zone. One reference referred to directing oxidant at the feed surface to burn volatiles and maximize heat transfer. Oxygen control was essential to prevent premature carbon burnout. On-line gas analysis was used for oxygen control.

As feed progressed from oxidizing to reducing conditions, oxygen addition gradually decreased to prevent re-oxidation of metallic iron, while burning carbon monoxide produced from iron reduction in the bed. Several stated secondary combustion should take place between burners and bed to maximize heat transfer. In the reduction zone, gas flow was counter-current to hearth direction. The furnace exhaust flue was typically located between the oxidizing and reducing zones pulling gases from both directions.

\section{3-2.4 Flame Chemistry/Oxy-Fuel Combustion}

The proposed LHF combustion system included oxy-fuel combustion. These references involved conversion of existing air fired coal and natural gas combustion systems to oxygen systems in the power generation industry. ${ }^{26-33}$ The objective was increased flue gas carbon dioxide concentration for carbon dioxide sequestration. These methods also evaluated mixtures of flue gas and oxygen as the burner oxidant source. In some cases, the flue gas was preheated. If flue gas recirculation is considered as part of the LHF process, gas cleaning becomes essential to prevent build-up of gases such as, $\mathrm{H}_{2} \mathrm{~S}, \mathrm{SO}_{2}, \mathrm{HF}, \mathrm{HCl}, \mathrm{SiF}_{4}$ and others. Fluorine gas species result from flue gas slag interaction if fluorspar is present in the feed mix.

Three publications discussed combustion flame chemistry associated with oxygen combustion and two included flame temperature data, which was used to partially validate CFD burner models in the furnace. ${ }^{34-39}$ Discussion with ANSYS Technical support provided additional support for simulating oxy-fuel combustion. ${ }^{37}$ Detailed CFD burner models of the oxy-fuel burners were initially developed and partially validated with published results. ${ }^{34-36}$

\section{3-2.5 Fluorspar and fluorine emission from slag:}

The briquetted feed contained approximately $2 \mathrm{wt} \%$ fluorspar $\left(\mathrm{CaF}_{2}\right)$. Fluorspar was added to decrease slag melting temperature and viscosity, promoting slag/metal separation, as well as enhancing sulfur capture. However, at process temperatures, fluorspar reacts with water vapor and metal oxides generating fluorine gas species. In one study it was reported that a fluorite content greater than $12 \%$ in the flux forming species actually increased melting temperature. ${ }^{38-40}$ The reactions are dependent on temperature and slag composition and vary with operating conditions. They are identified as follows: 
$\mathrm{CaF}_{2}(\mathrm{~s}, \mathrm{l})+\mathrm{H}_{2} \mathrm{O}(\mathrm{g})=\mathrm{CaO}+\mathrm{HF}(\mathrm{g})$

$3 \mathrm{CaO} \cdot 2 \mathrm{SiO}_{2} \cdot \mathrm{CaF}_{2}(\mathrm{~s}, \mathrm{I})+\mathrm{H}_{2} \mathrm{O}(\mathrm{g})=2\left(2 \mathrm{CaO} \cdot \mathrm{SiO}_{2}\right)(\mathrm{s}, \mathrm{I})+2 \mathrm{HF}(\mathrm{g})$

$\mathrm{Na}_{2} \mathrm{O}(\mathrm{I})+\mathrm{CaF}_{2}(\mathrm{l})=2 \mathrm{NaF}(\mathrm{g})+\mathrm{CaO}(\mathrm{I})$

$\mathrm{K}_{2} \mathrm{O}(\mathrm{l})+\mathrm{CaF}_{2}(\mathrm{I})=2 \mathrm{KF}(\mathrm{g})+\mathrm{CaO}(\mathrm{I})$

$\mathrm{Al}_{2} \mathrm{O}_{3}(\mathrm{l})+\mathrm{CaF}_{2}(\mathrm{l})=3 \mathrm{CaO}(\mathrm{l})+2 \mathrm{AlF}_{3}(\mathrm{~g})$

where $(s, I, g)$ specifies solid, liquid or gas phase.

\section{3-2.6 Thermal Conductivity of Chars, Iron and Slags}

Thermal conductivities were required for the bed components. Slag thermal conductivity measurements were reported in two publications. ${ }^{41,42}$ The publication by Fortini and Fruehan provided reference to thermal conductivities for magnetite, wustite and iron. ${ }^{7}$ 


\section{3-3.0 GLOBAL MASS BALANCE TO ESTABLISH MODEL INPUT BOUNDARY CONDITIONS}

A spreadsheet mass balance was developed prior to performing CFD simulations. This template generated input boundary conditions, and provided a summary of simulation conditions. A general description follows.

\section{3-3.1 Natural Gas Composition}

Natural gas was used as burner fuel in all simulations. A mass flow format was chosen for inlet conditions in the CFD model. The natural gas composition was chosen from the North American Combustion Handbook Table2.12b for Natural Gas, Birmingham, Al. ${ }^{43}$ Gas composition consisted of methane $\left(\mathrm{CH}_{4}\right)$, ethane $\left(\mathrm{C}_{2} \mathrm{H}_{6}\right)$, and nitrogen $\left(\mathrm{N}_{2}\right)$. The composition is shown in Table 3-1.

\section{3-3.2 Coal and Coal Volatiles Composition}

Three reductant coals were chosen representing a range of fixed carbon, volatile, moisture, and ash content. Briquetted coal addition was specified as percent of stoichiometric requirement using Fixed carbon content and carbon monoxide as the reduction product from the briquettes.

$$
\mathrm{Fe}_{x} \mathrm{O}_{y}+\mathrm{yC}=x \mathrm{Fe}+\mathrm{yCO}
$$

This step determined dry coal mass required per mass of dry iron oxides. Coal volatile composition and mass estimates were required to balance secondary oxygen requirement for volatile combustion.

In cases where ash components did not total $100 \%$, component values were normalized. Table 3-2 shows coal analyses for the three coals.

\section{3-3.3 Remaining Feed Components (Concentrate, Fluorspar, Hydrated Lime, and Molasses)}

Tables 3-3 and 3-4 provide compositions for remaining components. Analytical values were converted to mineral percentages by compound i.e. conversion of $\mathrm{CaO}$ to $\mathrm{CaCO}_{3}$ etc, first on a dry basis and then on wet basis. Mix blends were prepared on an "As Received" moisture basis. Magnetite concentrate containing $3.7 \%$ silica was used as the iron source. This concentrate was produced in a previous study. ${ }^{44}$ Molasses was used as binder.

\section{3-3.4 Briquette Mixture Calculation}

Briquette mixture was determined by basicity, the target basicity was $\mathrm{B} 2=2.0$ $\left(\% \mathrm{CaO} / \% \mathrm{SiO}_{2}\right)$, using hydrated lime to adjust the lime/silica ratio. Molasses and fluorspar additions were held constant. 


\section{3-3.5 Feed Loading and Gas Evolution}

Once the mix was determined, coal volatile and reduction gas species were converted to mass ratio with iron oxides. Gases were related to mass of iron oxides entering the furnace in $\mathrm{lbs} / \mathrm{ft}^{2}$ so that changes in furnace loading, width and hearth speed were translated directly to mass flow.

\section{3-3.6 Reaction Energy}

It was not computationally possible to explicitly simulate reactions and phase transformations in the bed and hearth. A composite bed representing hearth carbon layer, briquette layer, and carbon cover layer was created. A heat sink was provided for reactions and phase transformations in the bed.

\section{3-3.7 Furnace Conditions}

Hearth width and length determined bed area and volume. Width and hearth speed determined total mass rate feeding the furnace. Load was "total mass" including, cover carbon, briquettes, and hearth carbon per hearth unit area.

Since kinetic rates were not incorporated for bed chemical reactions, furnace zones were defined where phase transformations and chemical reactions occurred. The furnace was divided into three zones. Drying and coal devolatization took place in zone 1 , iron reduction in zone 2 and melting in zone 3 . This relationship held for all simulations in the study. Empirical data would help refine zone divisions. Bed depth was specified as 1-5/8 inches $(41.3 \mathrm{~mm})$ corresponding to briquette and hearth carbon loads between $3-5 \mathrm{lbs} / \mathrm{ft}^{2}\left(14.65-24.41 \mathrm{~kg} / \mathrm{m}^{2}\right)$. No cover layer was included in these simulations.

\section{3-3.7.1 Bed Density}

The bed was treated as a solid mono-layer and given properties based on weighted averaged properties of the bed components. Bed bulk density was determined from briquette and hearth carbon loading. Briquette loading was variable at 3,4 or $5 \mathrm{lbs} / \mathrm{ft}^{2}$ $\left(14.65,19.53\right.$ or $\left.24.41 \mathrm{~kg} / \mathrm{m}^{2}\right)$ and hearth loading was fixed at $4.3 \mathrm{lbs} / \mathrm{ft}^{2}\left(21 \mathrm{~kg} / \mathrm{m}^{2}\right)$. The loading range represented variation in agglomerate bulk density and packing density for a feed mono-layer. The furnace discharge loading decreased proportional to mass loss from gas evolution during the conversion process. 
Table 3-1. Natural Gas Composition in Simulations.

Natural Gas Composition - Birmingham, Al. North Amer. Comb Handbook Tables 1.8 and 2.12b

\begin{tabular}{|c|c|c|c|c|c|c|}
\hline & & & Energy $p$ & s Species & wt Ave & wt Ave \\
\hline & Vol \% & Mass Fraction & $\mathrm{MJ} / \mathrm{kg}$ & BTU/lb & $\mathrm{MJ} / \mathrm{kg}$ & BTU/lb \\
\hline $\mathrm{N}_{2}$ & 5.0 & 0.0808 & & & & \\
\hline $\mathrm{CH}_{4}$ & 90.0 & 0.8325 & 11.42 & 23,875 & 9.51 & 19,877 \\
\hline $\mathrm{C}_{2} \mathrm{H}_{6}$ & 5.0 & 0.0867 & 10.68 & 22,323 & 0.93 & 1,936 \\
\hline Totals & 100.0 & 1.0000 & & & 10.44 & 21,812 \\
\hline & & & & Calculated & $\mathrm{MJ} / \mathrm{m}^{3}$ & $\mathrm{BTU} / \mathrm{ft}^{3}$ \\
\hline & & & & $32 \mathrm{~F}$ & 39.29 & 1054 \\
\hline & & & & $60 \mathrm{~F}$ & 37.17 & 998 \\
\hline & & & & Table 2.12b & 37.33 & 1002 \\
\hline
\end{tabular}


Table 3-2. Coal Analysis Used in CFD Simulations.

\section{Coal Analysis Used in CFD Simulations}

Proximate Dry Basis, \%wt

Fix Carbon

Volatiles

Ash

Totals

Sulfur

Proximate Wet Basis, \% wt Moisture

Fix Carbon

Volatiles

Ash

totals

Sulfur

BTU/lb

Ultimate Analysis, \%wt

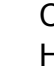

$\mathrm{H}$

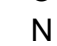

Ash

$S$

Ash (Dry Basis)

$\mathrm{Fe} 2 \mathrm{O} 3$

$\mathrm{SiO} 2$

$\mathrm{Al} 2 \mathrm{O} 3$

$\mathrm{CaO}$

$\mathrm{MgO}$

$\mathrm{Na} 2 \mathrm{O}$

$\mathrm{K} 2 \mathrm{O}$

$\mathrm{TiO} 2$

$\mathrm{SO} 3$

$\mathrm{P} 2 \mathrm{O} 5$

Totals

$\mathrm{S}$ (as SO3) in Ash

$S$ in Ash Prox Basis Dry

$S$ in Ash Prox Basis wet

\% Total Sulfur to Volatiles Dry
Anthracite

78.2

4.85

16.95

0.8

1.9

76.7

4.8

$\begin{array}{r}16.6 \\ \hline \hline 100.0\end{array}$

0.79

12,361

79.2

1.76

0.23

1.05

16.95

0.8

4.92

55.90

32.06

0.63

0.72

0.46

2.96

1.84

0.13

$\begin{array}{r}0.38 \\ \hline 100.00\end{array}$

0.052

0.0088

0.0086

98.90

0.66

21.0

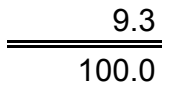

0.65

14,028

81.57

4.58

2.14

1.68

9.37

0.66

11.45

48.30

28.07

4.08

1.14

0.82

1.73

1.20

2.53

0.68

100.00

1.012

0.0948

0.0943

85.63
Bituminous
Medium Volatile

$\begin{array}{r}69.51 \\ 21.12 \\ 9.37 \\ \hline \hline 100\end{array}$

0.87

Bituminous

High Volatile

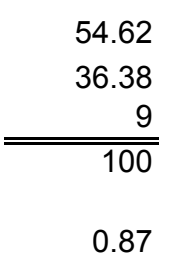

10.0

49.2

32.7

0.86

12,600

77.63

5.19

7.42

1.55

9

0.87
8.28

49.06

28.25

2.97

1.19

0.61

4.01

1.25

4.15

100.00

1.66

0.1494

0.1345

82.83
0.23 
Table 3-3. Briquette Component Mineral Balances Dry Basis.

Dry Assay Data

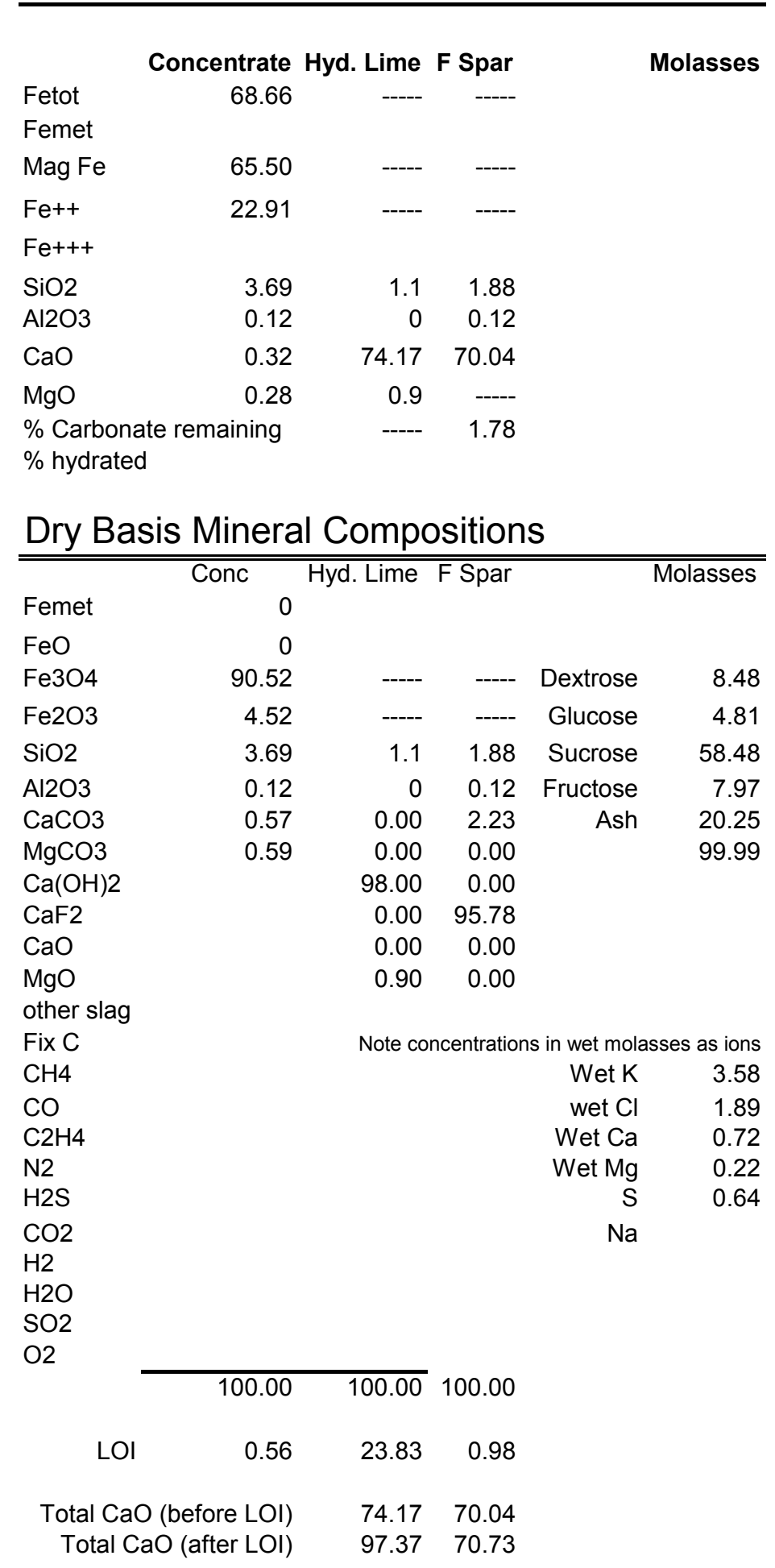




\section{Table 3-4. Briquette Component Mineral Balances Wet Basis.}

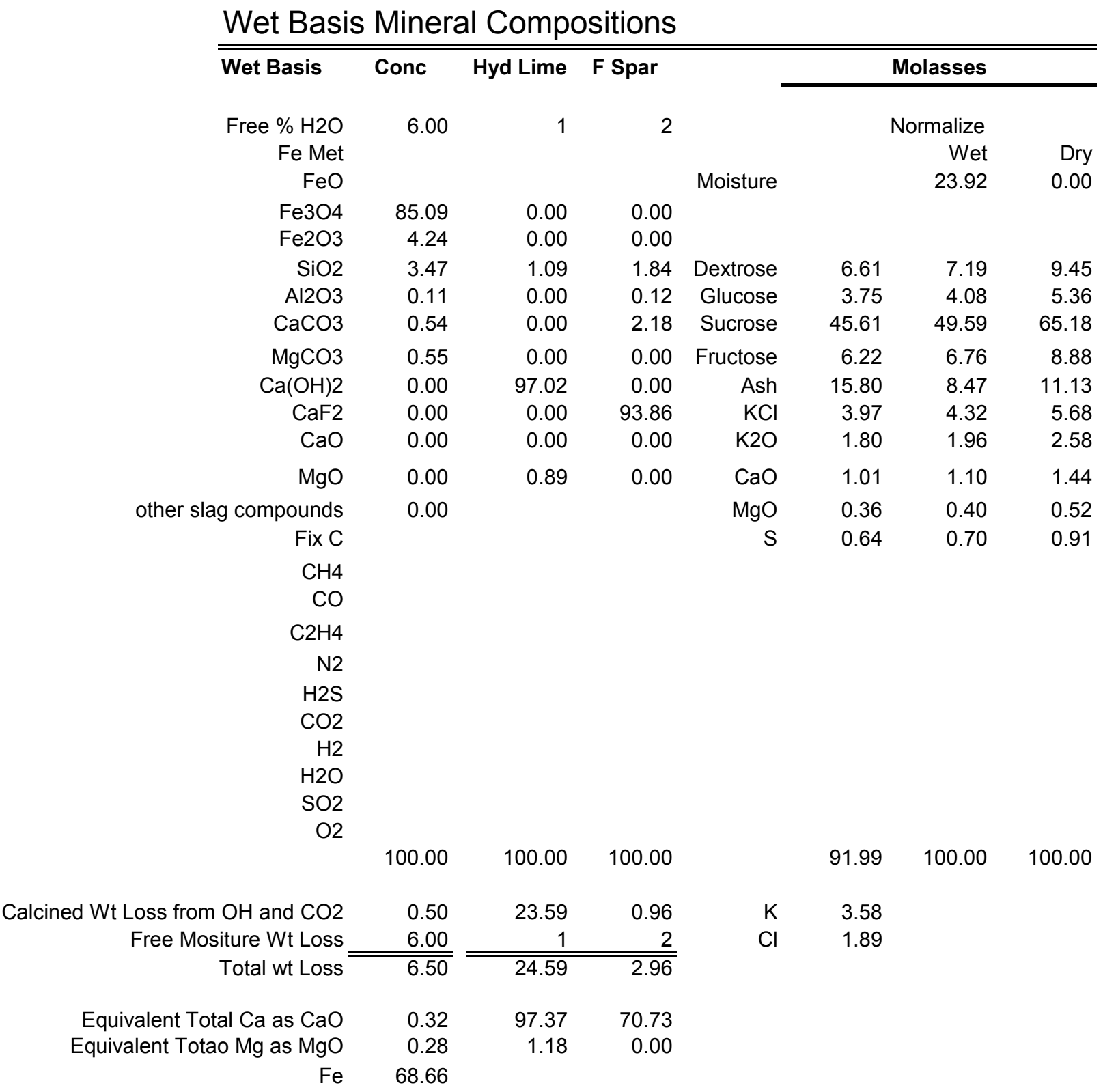




\section{3-3.7.2 Bed Thermal Conductivity}

Bed thermal conductivity varied with phase transformations. Several references reported thermal conductivities for carbon, slag, magnetite, wustite, and iron. Thermal conductivity was treated as a function of location and phase reactions, similar to density. Table 3- 5 provides reference values found in literature. ${ }^{7,41,42}$

\section{3-3.8 Firing Zones and Burners}

Twelve burners were placed on one side of the furnace, with symmetry simulating twenty-four. The burners were grouped into three firing zones. These zones were independent of bed reaction zones. The zones were numbered 1-3, starting from solids entry (Firing zone 1) and ending with the melting zone (Firing zone 3). Burner primary oxygen to fuel ratio was varied with burner location, ranging between 1.1 and 0.75 on stoichiometric basis (1.0 = stoichiometric requirement).

\section{3-3.9 Secondary Oxygen flows}

Secondary oxygen mass flow was determined as required to complete combustion of gaseous fuels in the furnace. The value was found from summation of combustible gas species and the difference between total oxygen required and primary oxygen supplied (burners). Temperatures were set for burner flow and secondary air flow. Burner inlet flow temperature was held constant at $160^{\circ} \mathrm{F}\left(71^{\circ} \mathrm{C}\right)$ while secondary oxygen flow varied as $150^{\circ} \mathrm{F}\left(66^{\circ} \mathrm{C}\right)$ at $95 \% \mathrm{v}, 400^{\circ} \mathrm{F}\left(204^{\circ} \mathrm{C}\right)$ at $56 \% \mathrm{v}$ and $1250^{\circ} \mathrm{F}\left(677^{\circ} \mathrm{C}\right)$ at $21 \% \mathrm{v}$ (air).

Table 3-5. Thermal Conductivity.

Reference

Fortini \& Fruehan

Fortini \& Fruehan

Fortini \& Fruehan

Fortini \& Fruehan

ANSYS

Kang \& Morita
Carbon

Hematite

Magnetite

Wustite

Iron

Slag
Temperature Range ${ }^{\circ} \mathrm{K}$

constant

$373-1273$

$373-1273$

$1000-1533$

constant

373-1673
Thermal Con ductivity

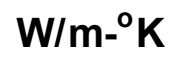

$\mathrm{W} / \mathrm{m}-^{\circ} \mathrm{K}$

0.84

$14.6-4.4$

$15.8-4.8$

$8.2-3.6$

80.2

$0.5-1.0$

Fortini and Fruehan see Reference 7

Kang and Morita see Reference 41 


\section{3-4.0 PROJECT OVERVIEW}

CFD models were developed in parallel with the mass balances integrating bed properties, gas evolution, and a gray-gas radiation model. Initially, burners were simulated using combustion products at elevated temperature. These results are shown in Figure 3-1 and compared with reported measurements. ${ }^{34}$ Burners were later revised to include combustion reactions and predicted results were again compared with published data (Figure 3-2). ${ }^{35,36}$ However each oxy-burner grid required tens of thousands of nodes to resolve combustion. A $100 \mathrm{ft}(30.48 \mathrm{~m})$ long furnace with many burners would exceed computational capability, leading to the conclusion that oxy-fuel combustion could not be simulated on large scale. Emphasis shifted to evaluating alternative furnace designs.

A second furnace grid was developed. This furnace was $3 \mathrm{ft}$ wide $\times 3 \mathrm{ft}$ high $\times 66 \mathrm{ft}(0.91$ $\times 0.91 \times 20.12 \mathrm{~m}$ ) long, with 30 burners and baffle wall. It was used to evaluate air and oxygen enriched air combustion. Length was subsequently increased to $100 \mathrm{ft}$ for comparison. Figure 3-3 plots furnace centerline temperature profiles at bed center for the $66 \mathrm{ft}(20.12 \mathrm{~m})$ and $100 \mathrm{ft}(30.48 \mathrm{~m})$ units.

Co-current vs. Counter current flow scenarios were evaluated. The simulations demonstrated advantages using counter current operation. Comparison of flue gas exit locations revealed differences in oxidized gas species concentration and volume flowing through the melting zone. Increased oxidized gas volume in the melting zone (cocurrent flow) implied increased carbon gasification, and potential metallic iron oxidation. Atmosphere control with co-current flow in the melting zone was more difficult as flue gas volume flow increased. Counter-current flow minimized oxidized gases in the melting zone, yielding improved atmosphere control (reducing potential) and heat exchange with the bed. Table 3-6 shows differences in oxidized species flow rates between co-current and counter-current conditions.

Nine preliminary simulations were completed, evaluating anthracite as a reductant coal at $120 \%$ stoichiometric addition and high volatile bituminous coal at $85 \%$ stoichiometric addition. A baffle wall separated melting from devolatization and reduction zones. Volatile content in the reductant coal was characterized by energy content as shown in Table 3-7.

With the ability to simulate air and oxy-fuel systems and predict convergence based on furnace design, focus shifted to creating an alternative design capable of simulating a wide range of operating conditions. This furnace was designated G5, it contained many elements from previous models. The G5 furnace size was compatible with pure oxygen and air combustion systems and was proven to converge under a wide range of operating conditions. 
Figure 3-1. Comparison of CFD Output with Measured Flame Temperature, Narayan et al. ${ }^{34}$

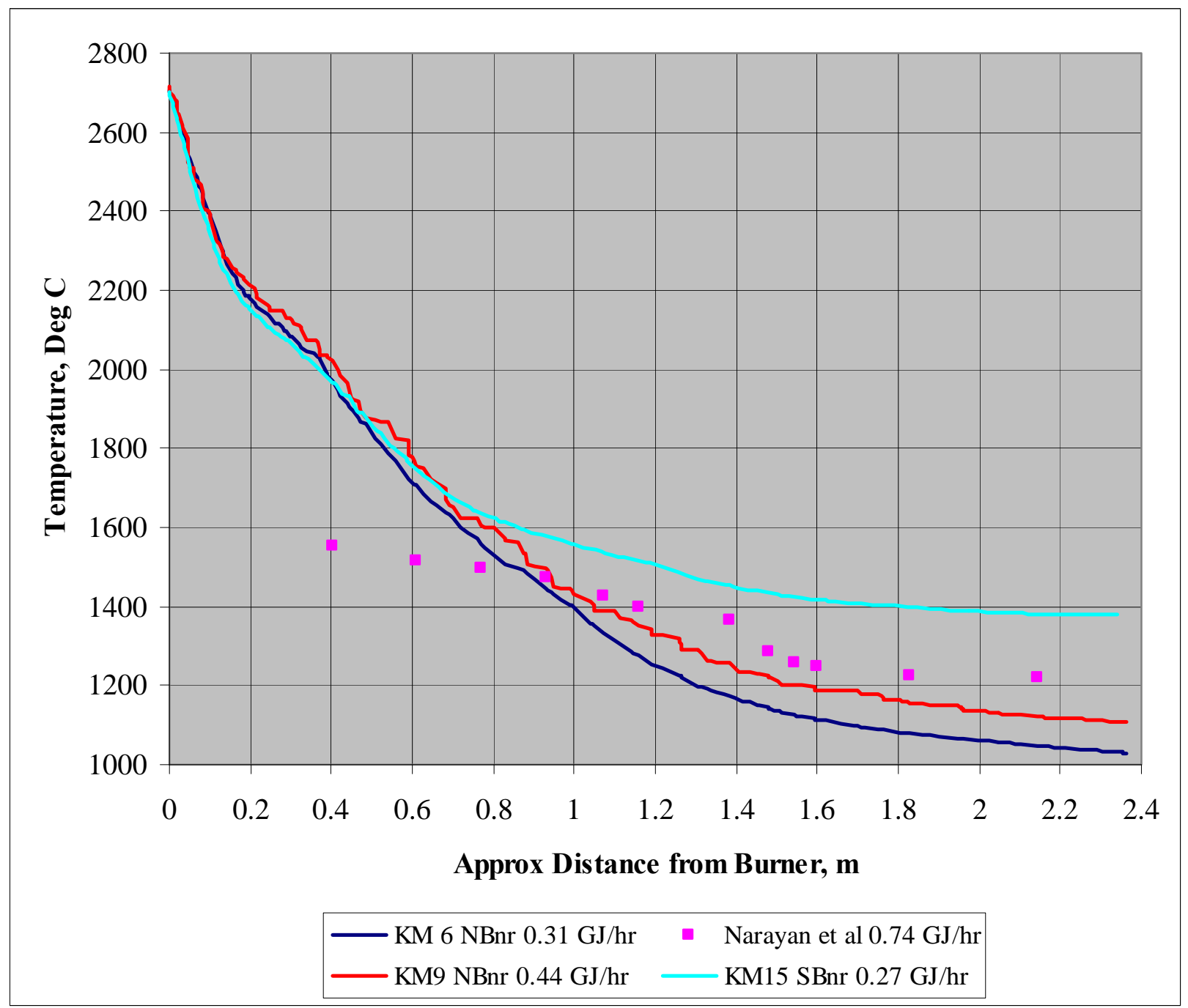


Figure 3-2. Comparison of Peak Flame Temperatures in Methane - Oxygen Flames, Pitz et al..$^{35,35}$

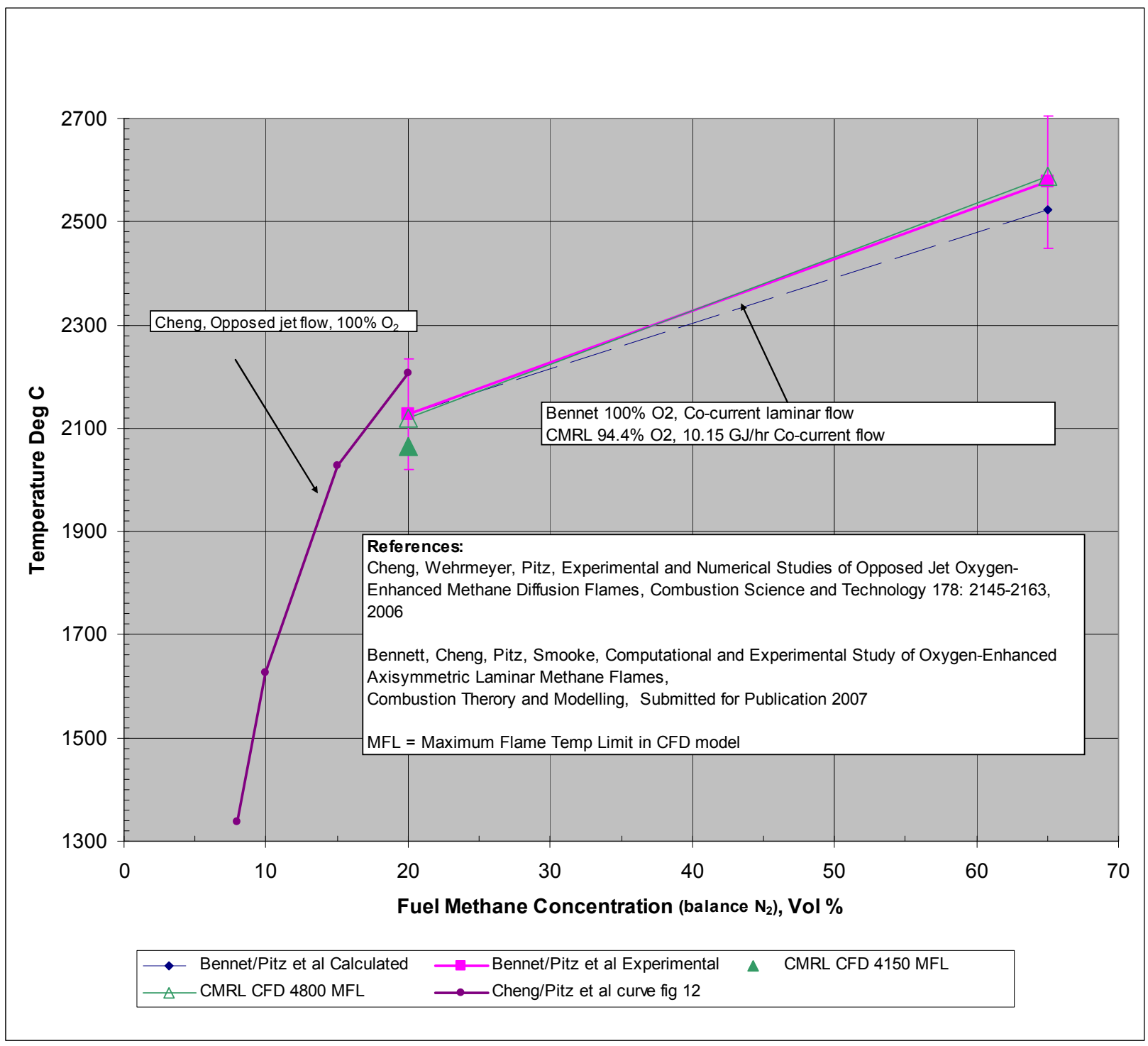


Table 3-6. Co-Current vs. Counter Current Mass Flow in Melting Zone (66 ft (20.12 m) Furnace.

\begin{tabular}{|c|c|c|c|c|c|c|c|c|c|c|c|c|}
\hline & \multicolumn{6}{|c|}{ Co-Current Flow } & \multicolumn{6}{|c|}{ Counter-Current Flow } \\
\hline & \multirow{2}{*}{\multicolumn{2}{|c|}{$\begin{array}{c}\text { Temp } \\
\text { at } 42 \mathrm{ft} \text {, } \\
{ }^{\circ} \mathrm{F} \quad{ }^{\circ} \mathrm{C}\end{array}$}} & \multicolumn{2}{|c|}{$\begin{array}{l}\mathrm{CO}_{2} \text { into } \\
\text { Melting, }\end{array}$} & \multicolumn{2}{|c|}{$\begin{array}{l}\mathrm{H}_{2} \mathrm{O} \text { into } \\
\text { Melting, }\end{array}$} & \multicolumn{2}{|c|}{$\begin{array}{l}\text { Temp } \\
\text { at } 42 \mathrm{ft} \text {, }\end{array}$} & \multicolumn{2}{|c|}{$\begin{array}{l}\mathrm{CO}_{2} \text { into } \\
\text { Melting, }\end{array}$} & \multicolumn{2}{|c|}{$\begin{array}{c}\mathrm{H}_{2} \mathrm{O} \text { into } \\
\text { Melting }\end{array}$} \\
\hline & & & $\mathrm{lbs} / \mathrm{hr}$ & $\mathrm{kg} / \mathrm{hr}$ & $\mathrm{lbs} / \mathrm{h}$ & $\mathrm{kg} / \mathrm{hr}$ & & ${ }^{\circ} \mathrm{C}$ & $\mathrm{lbs} / \mathrm{h}$ & $\mathrm{kg} / \mathrm{hr}$ & $\mathrm{lbs} / \mathrm{hl}$ & $\mathrm{kg} / \mathrm{hr}$ \\
\hline Simulation 1 & & & & & & & 3019 & 1659 & 495 & 224 & 334 & 151 \\
\hline Simulation 2 & 1678 & 914 & 1805 & 818 & 531 & 241 & & & & & & \\
\hline
\end{tabular}

Table 3-7. Coal Type and Volatile Energy Content.

\begin{tabular}{|c|c|c|c|}
\hline Coal Type, & Addition, \% Stoichiometric & \multicolumn{2}{|c|}{ Volatile Energy, } \\
\% Volatiles and \% Moisture & MMTU/mt Fe & 1.12 \\
\hline $\begin{array}{c}\text { Anthracite } \\
(4.5 \% \text { Volatiles - 2\% Moist) }\end{array}$ & 85 & 1.06 & 6.29 \\
\hline $\begin{array}{c}\text { Anthracite } \\
(4.5 \% \text { Volatiles - 2\% Moist) }\end{array}$ & 120 & 5.96 & 7.41 \\
\hline $\begin{array}{c}\text { High volatile bituminous } \\
(32.5 \% \text { Volatiles - 10\% Moist) }\end{array}$ & 100 & 7.02 & 5.22 \\
\hline $\begin{array}{c}\text { PRB } \\
(34.7 \% \text { Volatiles - 21\% Moist) }\end{array}$ & 85 & 4.95 & \\
\hline
\end{tabular}


Figure 3-3. Intermediate Furnace Comparison at $66 \mathrm{ft}$ and $100 \mathrm{Ft}$ (20.12 and $30.48 \mathrm{~m})$ Lengths - Bed Center Temperature.

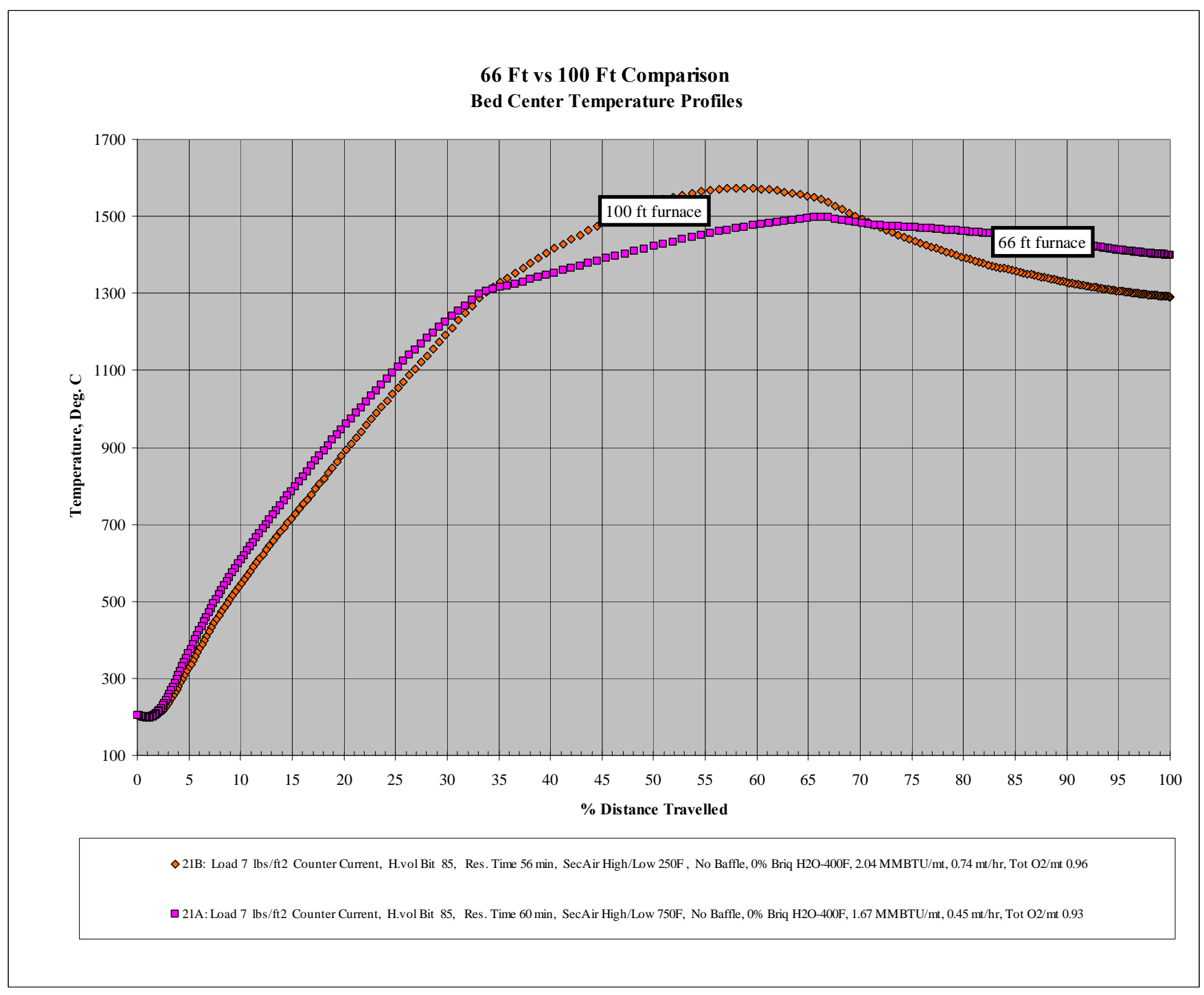




\section{3-5. 0 NEXT GENERATION G5}

The G5 design was adaptable to a range of coal types and combustion systems. However specific dimensions were dependent on coal and oxidant oxygen concentration choices.

\section{3-5.1 Simulation Set-Up}

A spreadsheet template was set up to determine a mass balance including gases evolved from the bed. The spreadsheet also contained provision for oxygen concentration in the burner and secondary combustion streams. Carbon solution loss was specified (lbs/hr) and applied uniformly to the reduction and melting zones. The furnace was divided into three reaction zones:

Zone 1 Moisture evaporation, lime dehydration, coal devolatization.

Zone 2 Iron oxide reduction and carbon solution losses.

Zone 3 Melting and carbon solution losses.

Buoyancy, radiation, moving bed with conjugate heat transfer, combustion reactions for ethane, methane, carbon monoxide, hydrogen, and water gas shift were incorporated into the model. The moving bed was treated as a solid mass, from which coal volatiles, free water, water of hydration, reduction product gases, and carbon solution loss were determined as sources flowing into the weir space above bed

Oxygen concentration in burners and secondary combustion injection ports could have different concentrations, but were kept identical in the parametric design. Roof clearances were dependent on flue gas volume and temperature.

Twelve burners were located on the outside furnace wall in the parametric furnace grid. Burners were grouped into three firing zones, beginning with zone 1 (burners 1-3) on the devolatization end, and zone 2 (burners 4-6) were located in the furnace mid section. Firing zone 3 contained the remaining 6 burners ending in the melting region.

\section{3-5.2 Secondary Oxygen Injection}

Secondary combustion oxygen injection produced highest temperature gradients when injected close to the bed. Secondary oxygen injection was maximized in the first two furnace zones. Injection port diameters were designed to produce similar velocities. The secondary injection port diameter changed with location in the furnace, because oxygen flow was not uniformly distributed. Injection ports were designated as pipe-set 1-4, beginning with pipe-set 1 in the devolatization zone and ending with pipe-set 4 in the melting zone.

\section{3-5.3 Preliminary Flow Evaluation}

Co-current and counter-current flow were evaluated; counter-current yielded lowest natural gas consumption rates and shortest retention times. A combination of co- 
current and counter-current flow showed promise; however, future simulations focused on counter-current flow scenarios.

\section{3-5.4 Partial Factorial Simulation Design}

A screening partial-factorial design, defining forty-one operating conditions was generated. Independent variables and their ranges are given in Table 3-8. Three coal types (volatile content), three firing rates (natural gas), three feed loadings (single layer), three car speeds, and three oxygen levels comprised the independent variables in the design. Some variable combinations generated excessive temperatures, while others generated low temperatures. In some of these situations, additional gas firing rates were included to explore effect on process temperature.

Note, as test conditions deviate from the targeted maximum bed temperature (2600$2800{ }^{\circ} \mathrm{F}\left(1427-1538{ }^{\circ} \mathrm{C}\right)$ ), reactions and phase transformations become less meaningful. They were assumed to proceed independent of bed temperature, and for temperature extremes will not be consistent with actual rates. For example, if conditions produced a cold bed, $\left(<2000^{\circ} \mathrm{F},\left(<1093^{\circ} \mathrm{C}\right)\right)$ only devolatization and dehydration might take place. Similarly at extremely high temperatures, reactions proceed rapidly and occupy a smaller furnace fraction. Future refinement would use a combination of kinetics and empirical data to establish reaction zones. Three furnaces grids were utilized, determined by oxidant oxygen concentration. Furnace width and length remained constant. Burner and secondary injection port diameters were changed to maintain similar injection velocities.

\section{3-5.5 Scale-Up}

The $\mathrm{G} 5$ grid permitted simulating oxidant streams ranging from air $\left(21 \% \mathrm{wt} . \mathrm{O}_{2}\right)$ to $95 \%$ wt. pure oxygen with good convergence. Two simulations were performed at series end, scaling length and width to $12 \mathrm{ft}$ wide $\times 200 \mathrm{ft}(3.66 \times 60.96 \mathrm{~m})$ long and $20 \mathrm{ft}$ wide x $325 \mathrm{ft}(6.09 \times 99.06 \mathrm{~m})$ long. The larger units operated with air, because node requirement for an oxygen system at this scale precluded solution with CMRL's computer installation. 
Table 3-8. Parametric Factorial - Independent Variables.

\begin{tabular}{|lr|r|}
\hline \multicolumn{2}{|c|}{ Independent Variables } & \multicolumn{1}{c|}{ Range } \\
& & Minimum - Maximum \\
\hline Natural Gas Firing Rate, & MMBTU/mt Hot Metal \\
& $\mathrm{GJ} / \mathrm{mt}$ Hot Metal & $3.0-6.0$ \\
& $3.17-6.33$ \\
\hline Coal Volatile Content, & $\mathrm{wt} \%$ & $5-36$ \\
\hline Oxidant Oxygen Concentration, & $\mathrm{wt} \%$ & $23.3-95.6$ \\
\hline Feed Loading, & $\mathrm{lbs} / \mathrm{ft}^{2}$ & $3.0-5.0$ \\
& $\mathrm{~kg} / \mathrm{m}^{2}$ & $14.65-24.41$ \\
\hline Hearth Speed, & $\mathrm{ft} / \mathrm{min}^{2}$ & $2.38-5.56$ \\
& $\mathrm{~m} / \mathrm{min}$ & $0.73-1.69$ \\
\hline
\end{tabular}




\section{3-6.0 PARAMETRIC DESIGN - SIMULATION RESULTS}

Forty-one simulations were completed in the final project phase. The simulations spanned a broad operating range. Predictive error in the simulations increases as temperature conditions deviate from the targeted range, (melting zone $2600-2800^{\circ} \mathrm{F}$ $\left(1427-1538^{\circ} \mathrm{C}\right)$ ). Natural gas firing rate, oxidant oxygen concentration, feed loading, hearth speed (residence time) and reductant coal addition were independent variables, whereas flue gas and solids temperature were dependent variables. The analysis was screening in nature-it identifies variable interactions, but it is limited for prediction and optimization of energy consumption and productivity.

\section{3-6.1 Furnace Grid Locations}

Locations in the furnace grid were defined to extract data useful in quantifying a simulation, providing a basis for comparison. Three reaction zones were defined as Devolatization, Reduction, and Melting. There were six horizontal planes corresponding to these reaction zones: two planes per zone, one plane one-inch $(25.4 \mathrm{~mm})$ above the bed, and one plane in the bed center. There were three line segments running down the furnace centerline; these segments were located one inch $(25.4 \mathrm{~mm})$ above the bed, on the bed top, in the bed center and on the bed bottom.

\section{3-6.1.1 Location Specific Results}

Mass-weighted and area-weighted averaging routines were used to provide averaged variable values from regional sampling planes. Similarly, variable point values were extracted from line segments and plotted on furnace length, by solids distance traveled. Results extracted from the simulations are shown below:

\section{3-6.2 Data Input Plots}

Note for all plots $95 \%$ oxygen appears in blue, $59 \%$ oxygen appears in green, and air simulations are in red. An English engineering unit system was used in the simulations, conversions have been made to the metric system in all following figures.

Mass flow weighted averaging to determine regional averages for:

Burner Gas Velocity (by firing zone) ft/s $(\mathrm{m} / \mathrm{s})$

Secondary Injection Oxygen Velocity (by pipe-set), $\mathrm{ft} / \mathrm{s}(\mathrm{m} / \mathrm{s})$

Flue Gas Exit Temperature, ${ }^{\circ} \mathrm{F}\left({ }^{\circ} \mathrm{C}\right)$

Area weighted averaging to determine regional averages for:

Roof Temperature, ${ }^{\circ} \mathrm{F}\left({ }^{\circ} \mathrm{C}\right)$

Reduction Zone Oxidation Degree, $\mathrm{P}_{\mathrm{CO} 2} /\left(\mathrm{P}_{\mathrm{CO}}+\mathrm{P}_{\mathrm{CO} 2}\right)$

Melting Zone Oxidation Degree, $\mathrm{P}_{\mathrm{CO} 2} /\left(\mathrm{P}_{\mathrm{CO}}+\mathrm{P}_{\mathrm{CO} 2}\right)$

Area Integration for:

Flue gas energy content, BTU/s (GJ/s) 
Volume Search Maximum:

Bed Volume, Maximum Temperature, ${ }^{\circ} \mathrm{F}\left({ }^{\circ} \mathrm{C}\right)$

Linear Plots were created along centerline for:

Oxidation Degree, $\mathrm{P}_{\mathrm{CO} 2} /\left(\mathrm{P}_{\mathrm{CO}}+\mathrm{P}_{\mathrm{CO} 2}\right)$, by zone and for entire furnace

Weir Space Velocity $(6$ inches $(0.15 \mathrm{~m}))$ above bed $), \mathrm{ft} / \mathrm{s}(\mathrm{m} / \mathrm{s})$

Gas Composition for $\mathrm{CO}, \mathrm{CO}_{2}, \mathrm{O}_{2}, \mathrm{H}_{2} \mathrm{O}(6$ inches $(0.15 \mathrm{~m})$ above bed $)$

Bed Temperature on bed surface, by cumulative residence time, minutes

Bed Temperature, top, center, bottom, by distance traveled

Maximum Values on planes and lines for:

Bed Top Temperature on centerline, ${ }^{\circ} \mathrm{F}\left({ }^{\circ} \mathrm{C}\right)$

Maximum Roof Temperature on plane, ${ }^{\circ} \mathrm{F}\left({ }^{\circ} \mathrm{C}\right)$

Maximum Oxygen Content on interface between gas and bed, entire furnace, $\%$ wt

Maximum Oxidation Degree in Reduction and Melting zones, $\mathrm{P}_{\mathrm{CO} 2} /\left(\mathrm{P}_{\mathrm{CO}}+\mathrm{P}_{\mathrm{CO}}\right)$

Total Mass flow for:

Burners, by firing zone, lbs/s $(\mathrm{kg} / \mathrm{s})$

Secondary Injection Ports, lbs/s ( kg/s)

Flue Gas Exit, lbs/s (kg/s)

Gas Composition on Flue Gas Exit Plane:

$\mathrm{C}_{2} \mathrm{H}_{6}, \mathrm{CH}_{4}, \mathrm{O}_{2}, \mathrm{CO}, \mathrm{CO}_{2}, \mathrm{H}_{2}, \mathrm{H}_{2} \mathrm{O}, \mathrm{N}_{2}, \%$ wt

Variables Created from input Data:

Firing Zone BTU/hr, (as check against input value) (GJ/hr)

Total Natural Gas BTU/hr, (as check against input value) (GJ/hr)

Total Natural Gas BTU/mt HM (as check against input value) (GJ/mt HM)

lbs Fe/hr (as check against input value based on loading and mix) $(\mathrm{kg} / \mathrm{hr}$ )

Flue Gas Energy per product mass, MMBTU/mt HM (GJ/mt HM)

Mass Flow in flue gas for, $\mathrm{CO}, \mathrm{CO}_{2}, \mathrm{H}_{2} \mathrm{O}, \mathrm{lbs} / \mathrm{hr}(\mathrm{kg} / \mathrm{hr})$

Mass $\mathrm{CO}_{2}$ per unit mass product, $\mathrm{kg} \mathrm{CO}_{2} / \mathrm{mt} \mathrm{HM}$

Residence time, minutes

Production, $\mathrm{mt} \mathrm{HM} / \mathrm{m}^{2}-24 \mathrm{hr}$

\section{3-6.2.1 Burner Zone GJ/hr vs. Mass Flow kg/s (to burner)}

Figure 3-4 shows calculated firing rate for each burner (firing) zone with premixed fuel and oxidant mass flow. The plots relate total firing zone mass flow and energy input. Burners in the factorial design were distributed as:

Burner (firing) Zone $1=3$ burners

Burner (firing) Zone $2=3$ burners

Burner (firing) Zone $3=6$ burners 


\section{3-6.2.2 Secondary Oxidant Injection Velocity $(\mathrm{m} / \mathrm{s})$ vs. Mass Flow $(\mathrm{m} / \mathrm{s})$}

Similar to the firing zone plots, Figure 3-5 relates mass-flow-averaged velocity with total mass flow to each set of injection ports (Pipe-Set 1- 4). Pipe diameter changed with oxygen concentration. There was some variation in these plots because gas temperature near the inlet varied with furnace firing conditions.

\section{3-6.2.3 Calculated Iron Mass Flow vs. Template Productivity mt HM/hr}

These values should be closely correlated - note that Hot Metal $(\mathrm{HM})$ includes about $2.5 \%$ carbon, whereas iron mass flow is based on iron loading and briquette mix and does not include carbon in solution, shown in Figure 3-6.

\section{3-6.2.4 Total Gaseous Energy per Total mt of Furnace Feed vs. Template Value}

This variable is the sum of energy from natural gas, reduction product $\mathrm{CO}$, and reductant coal volatiles divided by total mass flow,( briquettes plus hearth carbon char). The hearth carbon in these simulations entered the furnace cold $\left(150^{\circ} \mathrm{F}\left(66^{\circ} \mathrm{C}\right)\right.$ ). Dividing total energy by total mass improved the correlation for predicting desired temperature conditions, rather than using only energy per mass of product iron. This plot compares the spreadsheet template value with the value calculated in the statistical data file, the goal being to identify errors in data input or file input. The plot demonstrates there were no errors in data specification or data transfer. This plot is shown in Figure 3-7.

\section{3-6.2.5 Percent Difference in Simulation Flue Gas Mass Flow - Spreadsheet Calculated Value}

As an additional check on the spreadsheet mass balance, simulation flue gas mass flow should match that calculated in the spreadsheet template file. Figure 3-8 shows percent difference as a function of total flow in the system. It ranges from about $6 \%$ to $0.5 \%$. Figure 3-9 correlated the flows with each other (CFD simulation vs. spreadsheet estimate).

\section{3-6.3 Single Variable Correlations}

In this section, X-Y plots are presented showing selected correlations among measured responses. It was difficult to find one or several parameters capable of completely quantifying conditions in each simulation. The correlations in this section show basic interactions, which will be developed further in section 6.4. 
Figure 3-4. Calculated Firing Zone Energy vs. Burner Zone Mass Flow.

Bivariate Fit of BNR Zone 1, GJ/hr By BNR Zone 1, kg/s

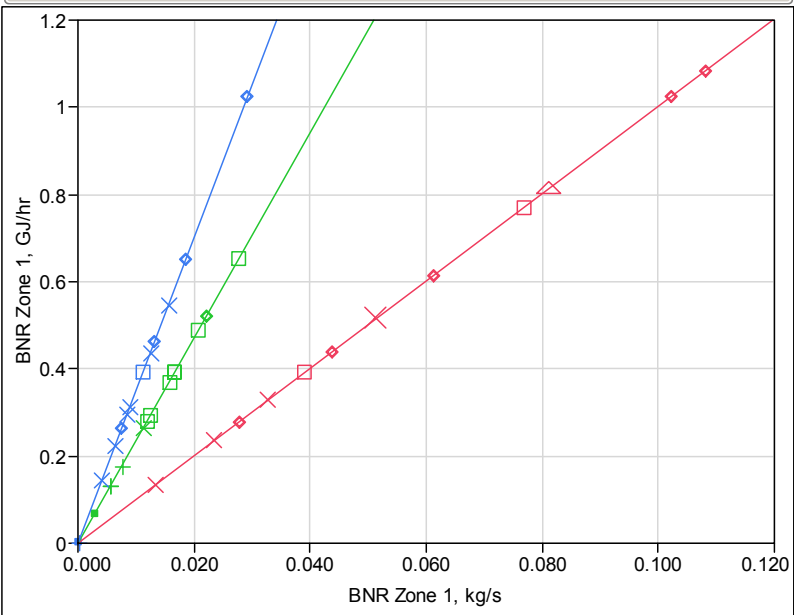

Linear Fit $\mathrm{O} 2 \% \mathrm{wt}==23.3$

Linear Fit O2 \%wt==59.15

Linear Fit $\mathrm{O} 2 \% \mathrm{wt}==95$

Bivariate Fit of BNR Zone 2, GJ/hr By BNR Zone 2, kg/s

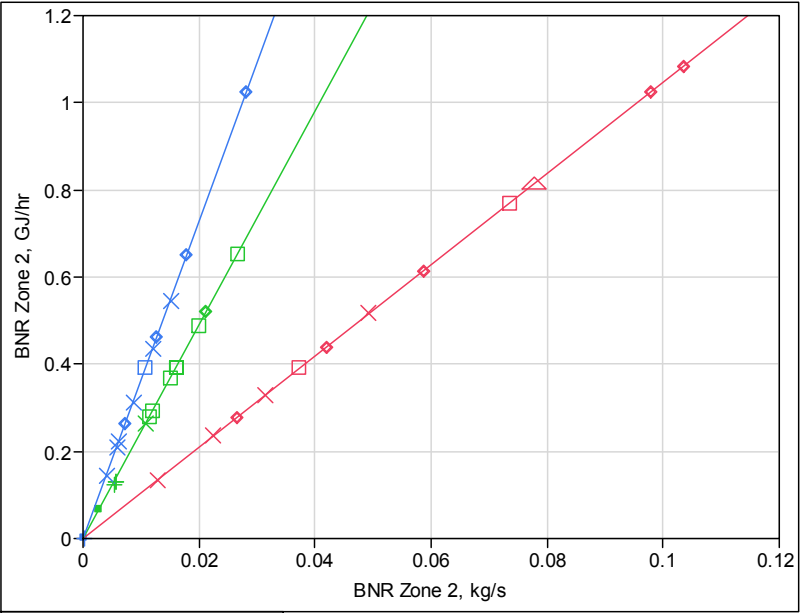

Linear Fit O2 \%wt $==23.3$

Linear Fit O2 \%wt==59.15

Linear Fit O2 \%wt==95

Bivariate Fit of BNR Zone 3, GJ/hr By BNR Zone 3, kg/s

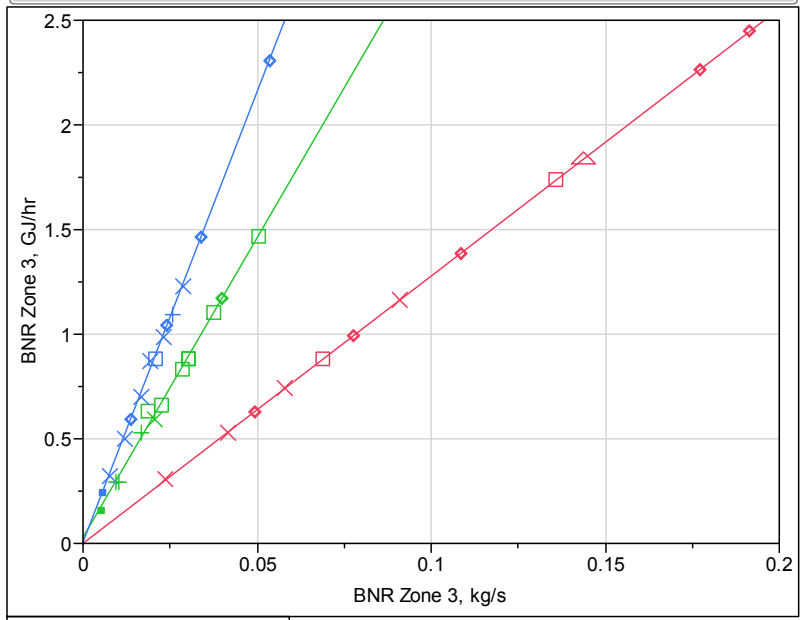

- Linear Fit O2 \%wt==23.3

- Linear Fit $\mathrm{O} 2 \% \mathrm{wt}==59.15$

Linear Fit O2 \%wt==95 
Figure 3-5. Secondary Injection Pipe Set Average Velocity vs. Mass Flow.

Bivariate Fit of O2 Pipe 1 MFA Vel, m/s By O2 Pipe 1, kg/s

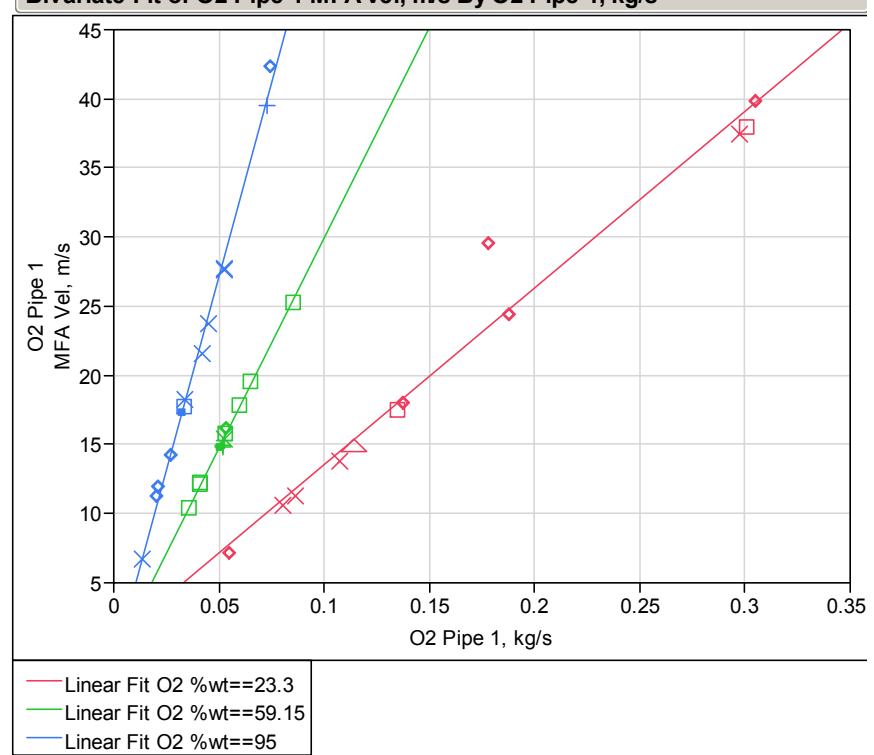

Bivariate Fit of O2 Pipe 3 MFA Vel, m/s By O2 Pipe 3, kg/s

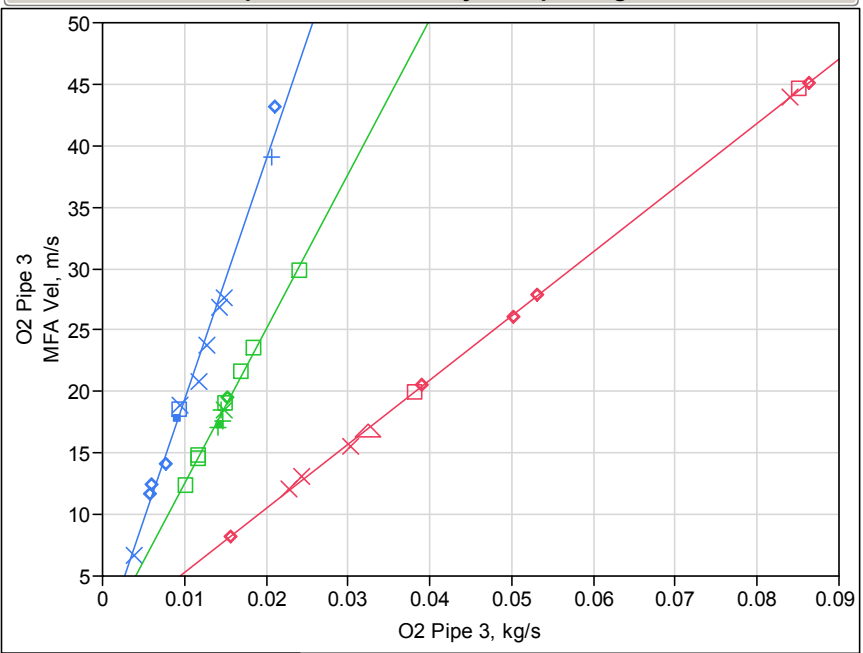

- Linear Fit $\mathrm{O} 2 \% \mathrm{wt}==23.3$

Linear Fit O2 \% wt $==59.15$

- Linear Fit O2 \%wt $==95$

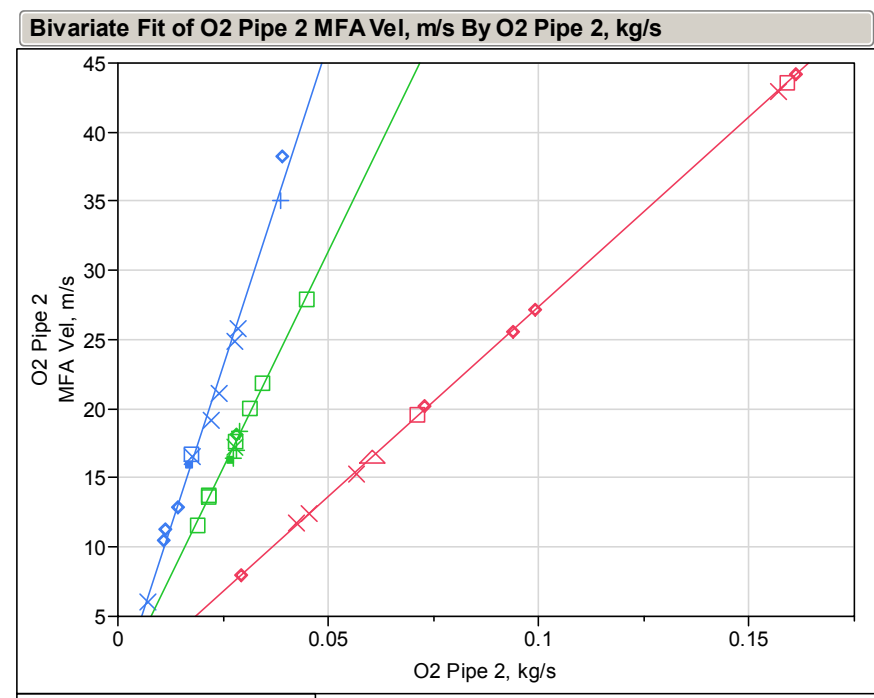

Linear Fit $\mathrm{O} 2 \% \mathrm{wt}==23.3$

Linear Fit O2 \% wt $=59.15$

Bivariate Fit of O2 Pipe 4 MFA Vel, m/s By O2 Pipe 4, kg/s

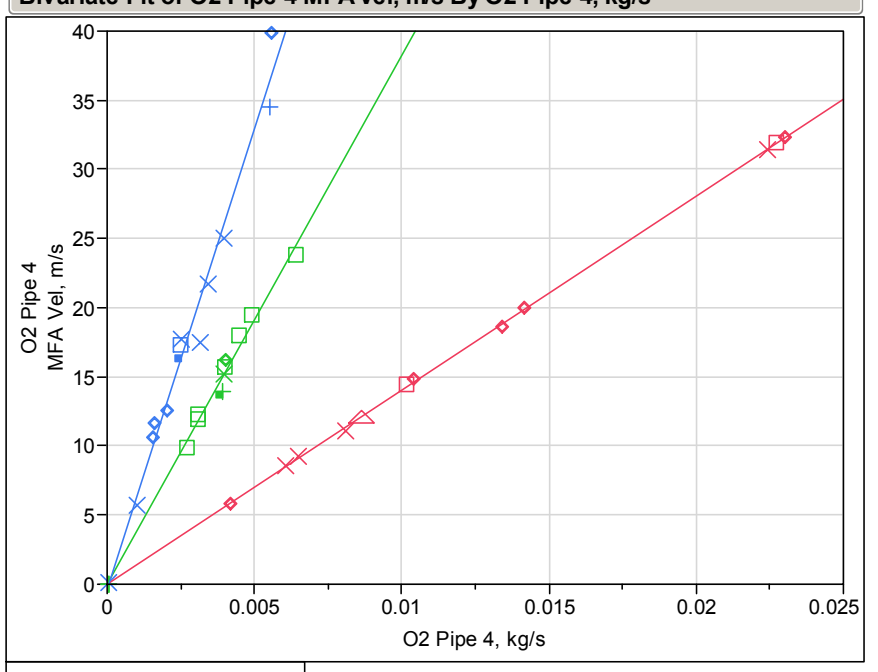

Linear Fit $\mathrm{O} 2 \% \mathrm{wt}==23.3$

Linear Fit $\mathrm{O} 2 \% \mathrm{wt}==59.15$

Linear Fit O2 \% wt $==95$ 
Figure 3-6. Calculated Iron Mass Flow vs. Template Productivity.

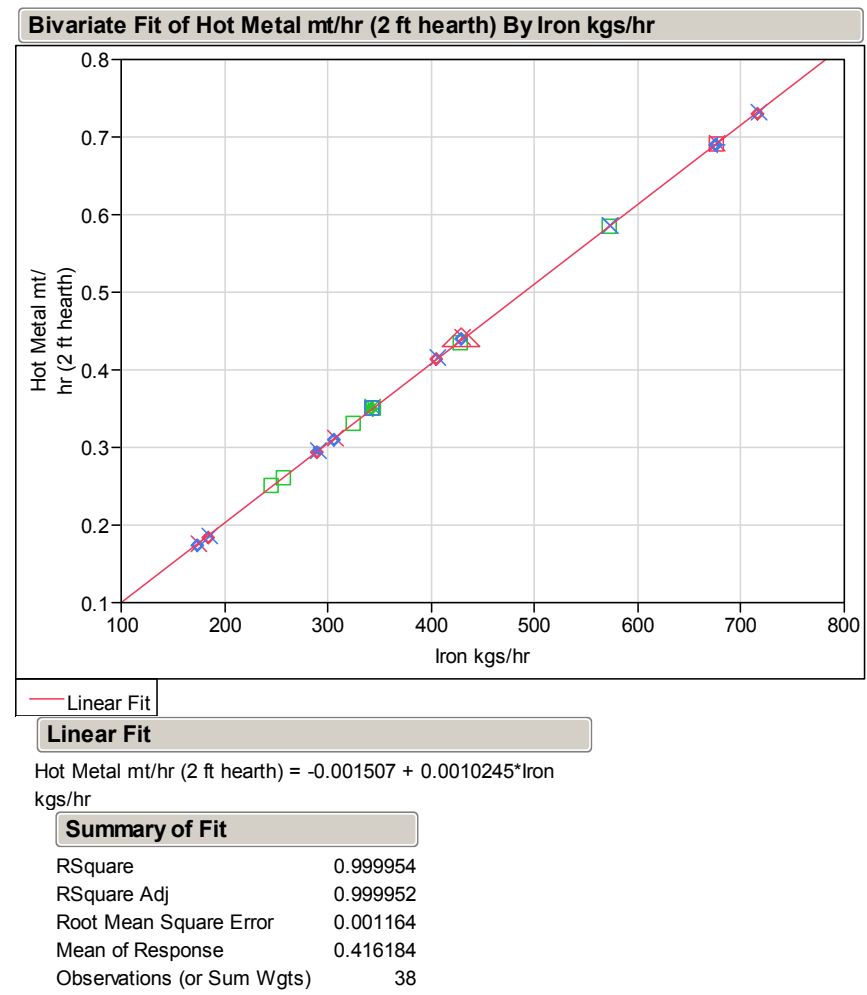

Figure 3-7. Total Gaseous Energy per Total mt of Furnace Feed vs. Template Value.

Bivariate Fit of Calc. Total Gaseous GJ/Total mt (HM+Hearth Char) By Template Total GJ/Total mt(HM+ Hearth Char)

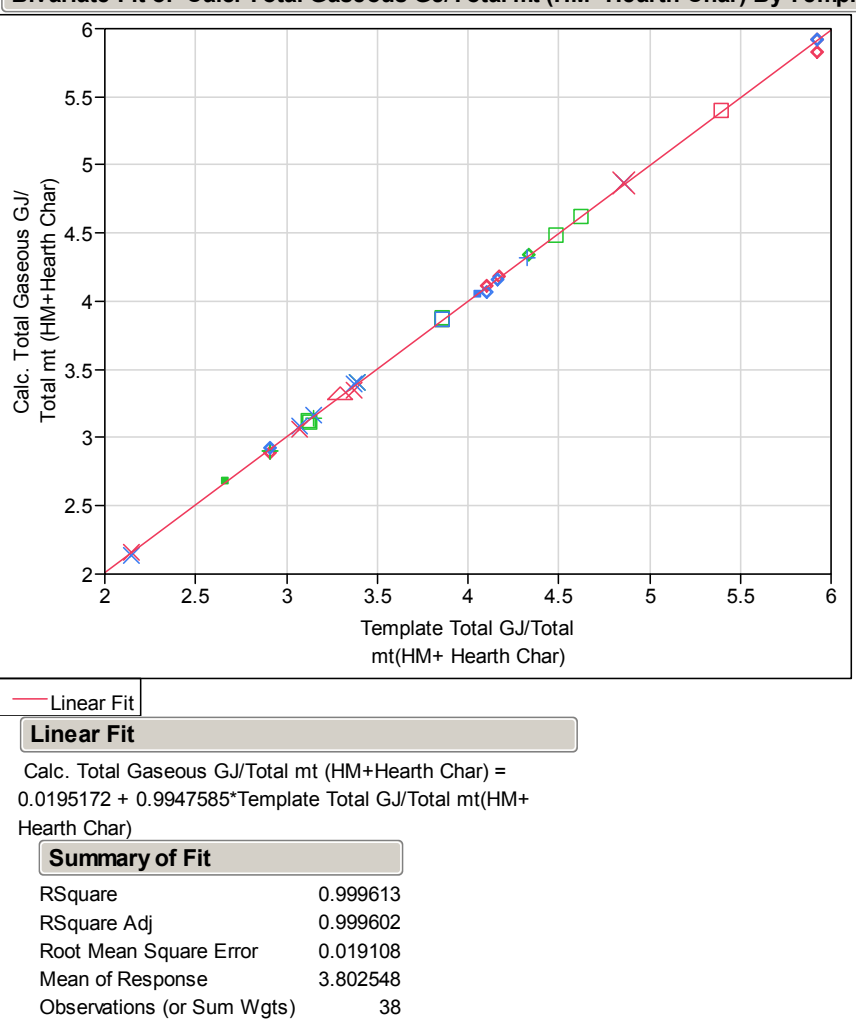


Figure 3-8. Percent Difference Between Simulation Flue Gas Flow and Template Value.

Bivariate Fit of \% Diff (CFD Flue Gas -Excel Flue Gas) By CFD Flue Gas, kg/s

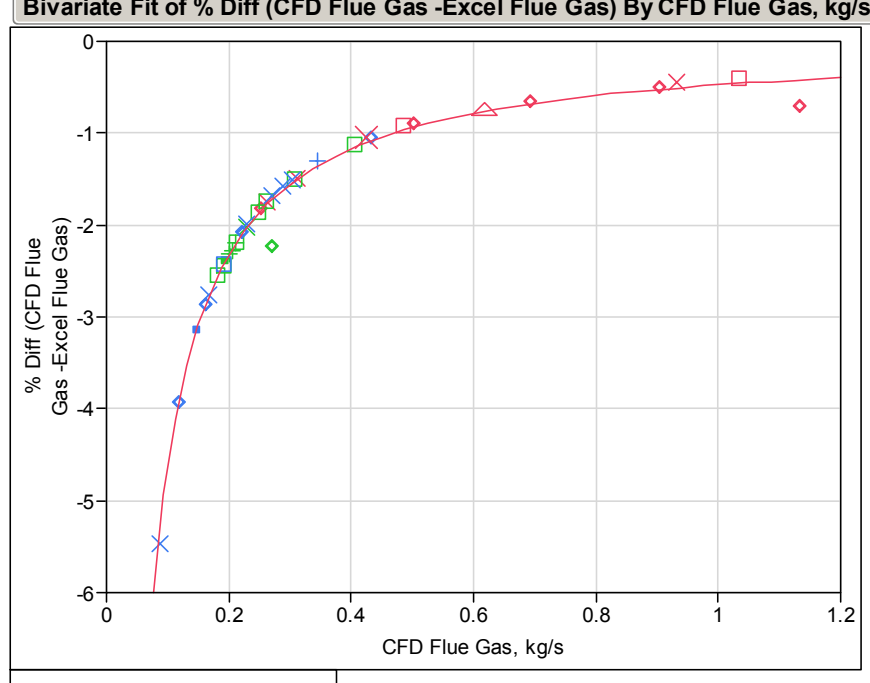

Transformed Fit to Reciprocal

Transformed Fit to Reciprocal

$\%$ Diff (CFD Flue Gas -Excel Flue Gas) $=-0.014659$ -

$0.4615926^{\star}$ Recip(CFD Flue Gas, kg/s)

Summary of Fit

RSquare 0.990735

RSquare Adj 0.990478

Root Mean Square Error $\quad 0.098179$

Mean of Response $\quad-1.84842$

Observations (or Sum Wgts) $\quad 38$

Figure 3-9. CFD Flue Gas Mass Flow vs. Template Value.

Bivariate Fit of CFD Flue Gas, kg/s By Template Mass Bal. Flue Gas, kg/s

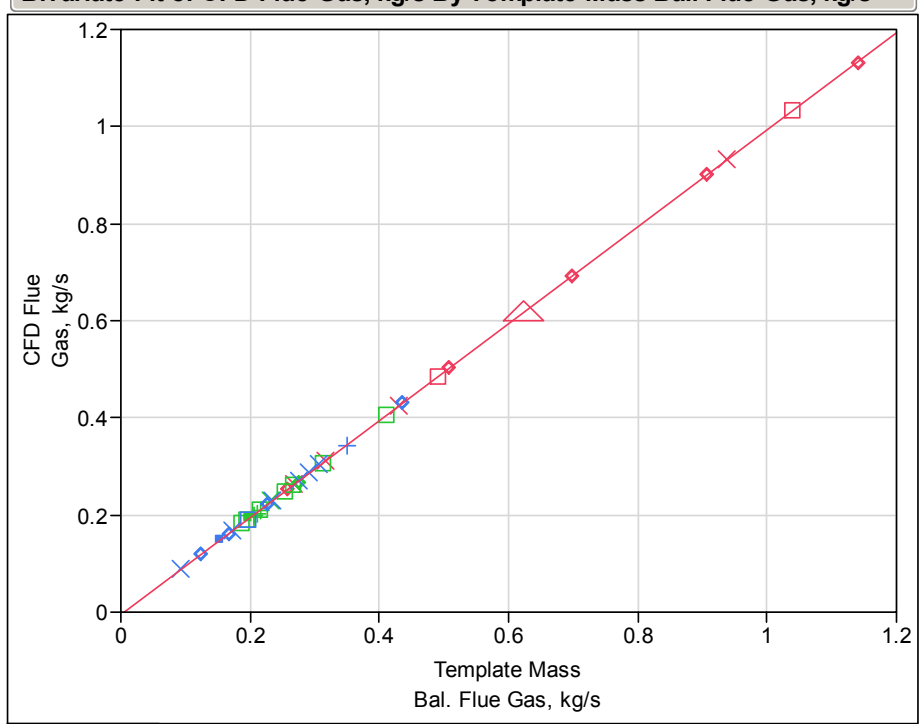

Linear Fit

Linear Fit

CFD Flue Gas, $\mathrm{kg} / \mathrm{s}=-0.004414+0.9992172^{*}$ Template Mass

Bal. Flue Gas, kg/s

Summary of Fit

RSquare

0.999996

RSquare Adj

0.999995

Root Mean Square Error $\quad 0.000554$

Mean of Response $\quad 0.357583$ 


\section{3-6.3.1 Bed Temperature}

Bed temperature is an important characteristic in defining performance and operating conditions. However bed temperature is variable with location, firing conditions and residence time. Two methods were used to characterize bed temperature:

1. Maximum temperature in the bed volume.

2. Area-averaged bed temperatures at bed center for each reaction zone.

Bed thickness was 1-5/8 inches (41.3 mm), comprised of briquette and hearth carbon layers. Bed center averages were used, because they were somewhat buffered from localized gas phase conditions. Maximum bed temperatures exceeding $3000^{\circ} \mathrm{F}$ $\left(1649^{\circ} \mathrm{C}\right)$ indicated severe operating conditions and potential refractory problems. Figures 10-12 show maximum bed temperature vs. the averaged bed center temperature in each reaction zone.

Figure 3-10 shows maximum temperature vs. averaged temperature in the devolatization zone. Reference lines are shown at 2600 and $2800^{\circ} \mathrm{F}\left(1427-1538^{\circ} \mathrm{C}\right)$ identifying the desired target temperature range. Conditions producing extreme temperatures represent unrealistic operating parameters; they are the result of independent variable combinations in the parametric factorial.

Figure 3-11 plots maximum temperature with average center temperature in the reduction zone. The circled points represent simulations that achieved target temperatures. In Figure 3-11, the area-averaged reduction zone bed center temperature corresponding target bed maximum range, falls between 1900 and $2550^{\circ} \mathrm{F}$ (1038$\left.1399^{\circ} \mathrm{C}\right)$.

Figure 3-12 plots maximum temperature with area-averaged melting zone temperature. The desired maximum target range intersects the average melting zone temperature between 2200 and $2700^{\circ} \mathrm{F}\left(1204-1482^{\circ} \mathrm{C}\right)$. Data falling on the extremes represent inoperable conditions, either failing to melt or producing excessively high temperatures. Figure 3-13 shows a linear relationship between the averaged melting zone and averaged reduction zone temperatures in the simulations. 
Figure 3-10. Maximum Bed Temperature vs. Average Bed Center Temperature in Devolatization Zone.

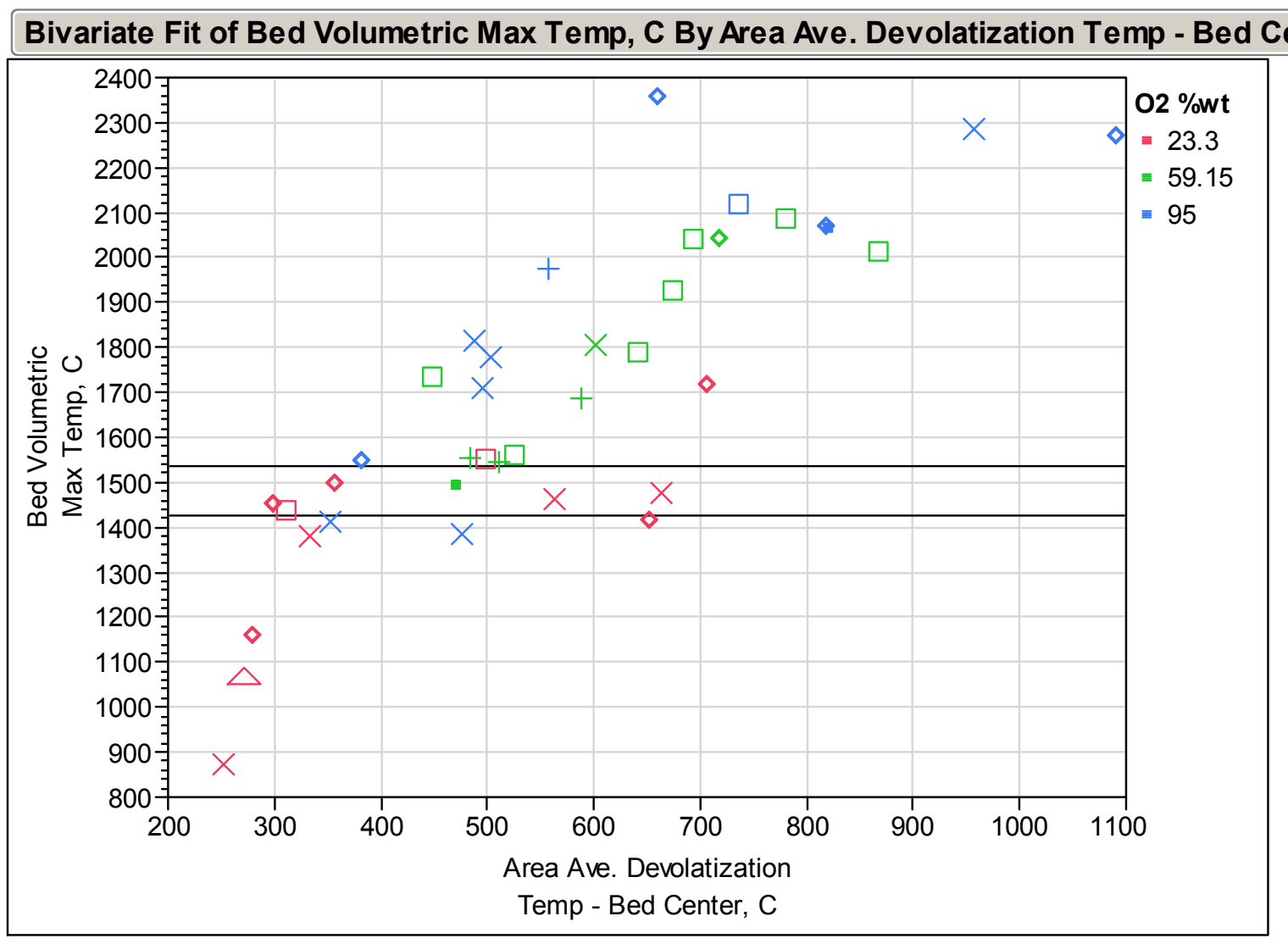

Horizontal reference lines at 2600 and $2800^{\circ} \mathrm{F}\left(1427\right.$ and $\left.1538^{\circ} \mathrm{C}\right)$. 
Figure 3-11. Maximum Bed Temperature vs. Average Bed Center Temperature in Reduction zone.

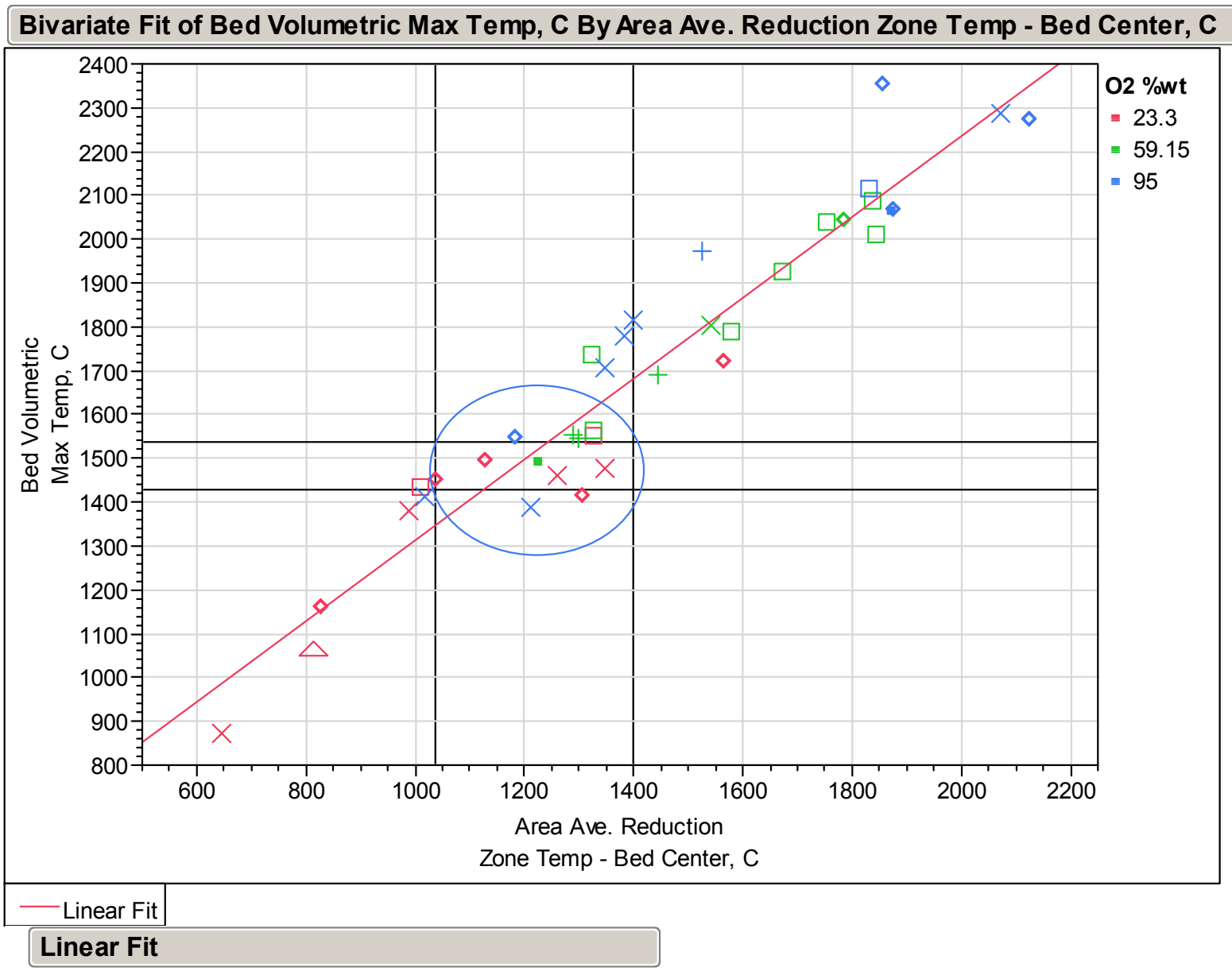

Bed Volumetric Max Temp, C = 390.3809 + 0.9229167*Area

Ave. Reduction Zone Temp - Bed Center, C

\section{Summary of Fit}

RSquare

RSquare Adj

Root Mean Square Error

Mean of Response

0.92186

0.919689

97.45626

1697.266

Observations (or Sum Wgts) 38

Horizontal reference lines at 2600 and $2800^{\circ} \mathrm{F}\left(1427\right.$ and $\left.1538^{\circ} \mathrm{C}\right)$.

Vertical reference lines at 1900 and $2550^{\circ} \mathrm{F}\left(1038\right.$ and $\left.1399^{\circ} \mathrm{C}\right)$. 
Figure 3-12. Maximum Bed Temperature vs. Average Bed Center Temperature in Melting zone.

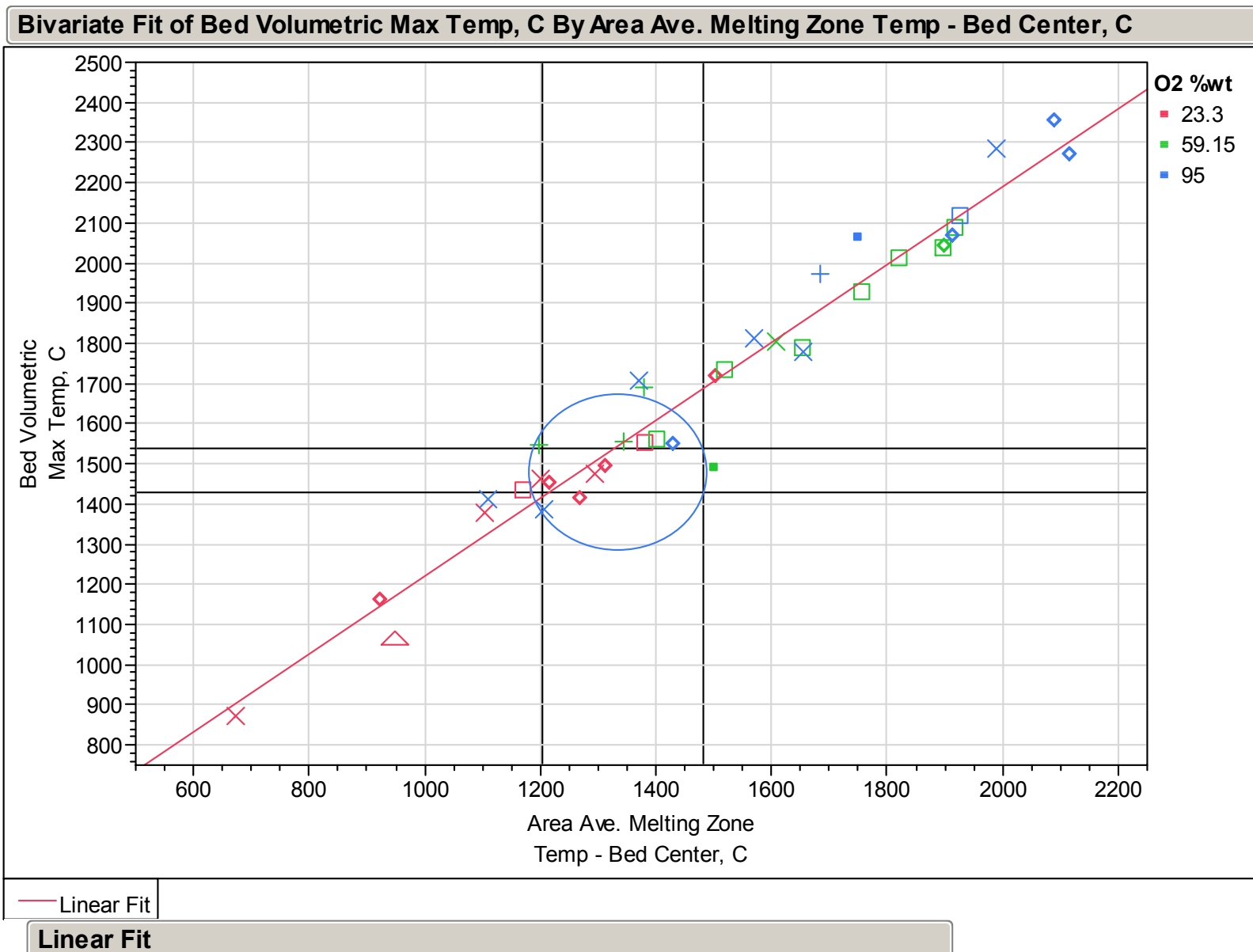

Bed Volumetric Max Temp, C = 251.79382 + 0.9699919*Area

Ave. Melting Zone Temp - Bed Center, C

\begin{tabular}{|lrrrrr|}
\hline Summary of Fit & & & & \\
RSquare & 0.954728 & & & \\
RSquare Adj & 0.953471 & & & \\
Root Mean Square Error & 74.17973 & & & & \\
Mean of Response & 1697.266 & & & & \\
Observations (or Sum Wgts) & 38 & & & & \\
\hline Parameter Estimates & & & & & \\
\hline Term & & Estimate & Std Error & t Ratio & Prob $>|t|$ \\
Intercept & 251.79382 & 53.8229 & 4.68 & $<.0001^{*}$ \\
Area Ave. Melting Zone Temp - Bed Center, C & 0.9699919 & 0.035204 & 27.55 & $<.0001^{*}$
\end{tabular}

Horizontal reference lines at 2600 and $2800^{\circ} \mathrm{F}\left(1427\right.$ and $\left.1538^{\circ} \mathrm{C}\right)$. Vertical reference lines at 2200 and $2700^{\circ} \mathrm{F}\left(1204\right.$ and $\left.1482^{\circ} \mathrm{C}\right)$. 
Figure 3-13. Average Bed Center Temperature in Melting Zone vs. Reduction Zone.

Bivariate Fit of Area Ave. Melting Zone Temp - Bed Center, C By Area Ave. Reduction Zone Temp - Bed Center, C

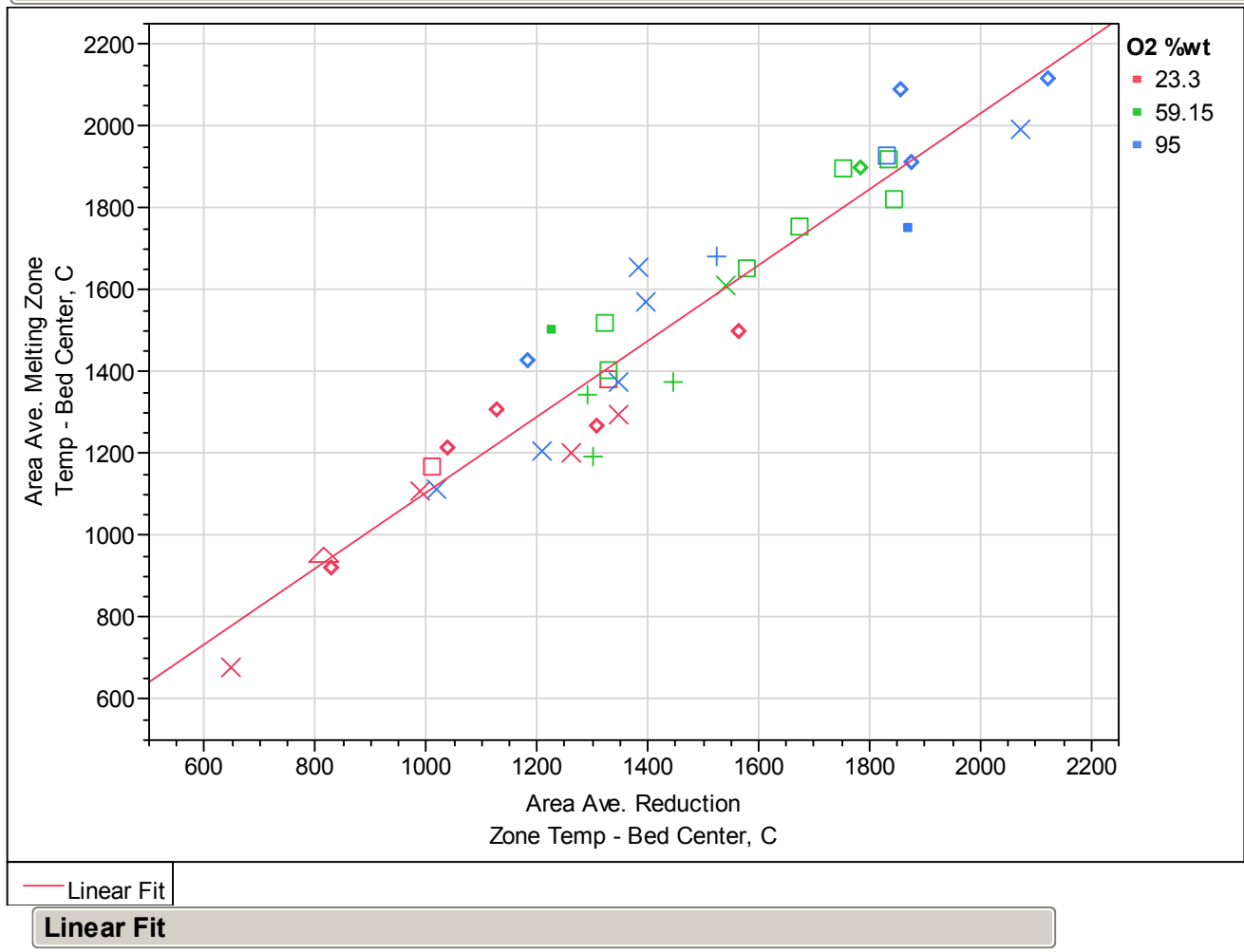

Linear Fit

Area Ave. Melting Zone Temp - Bed Center, C $=180.91487+$

$0.9246045^{*}$ Area Ave. Reduction Zone Temp - Bed Center, C

Summary of Fit

RSquare

0.911818

RSquare Adj

0.909369

Root Mean Square Error $\quad 104.2878$

Mean of Response $\quad 1490.19$

Observations (or Sum Wgts)

38

\begin{tabular}{|lrrrr|}
\hline Parameter Estimates & & & & \\
\hline Term & Estimate & Std Error & t Ratio & Prob $>|\mathbf{t}|$ \\
Intercept & 180.91487 & 69.93728 & 2.59 & $0.0139^{*}$ \\
Area Ave. Reduction Zone Temp - Bed Center, C & 0.9246045 & 0.047923 & 19.29 & $<.0001^{*}$
\end{tabular}




\section{3-6.3.2 Roof Refractory Temperatures}

Roof refractory temperatures were used to identify potential hot spots and location in the furnace. Wall temperatures were not considered in this screening design. Maximum temperatures were identified and maximum roof temperature contour plots generated. An area-averaged temperature was also determined for the roof. Figure 3-14 plots maximum roof temperature with area-averaged roof temperature. Figure 3-15 shows maximum roof temperature plotted against average melting zone temperature (bed center). The circled region becomes the area of interest by limiting maximum roof temperature within an acceptable averaged melting temperature range.

\section{3-6.3.3 Flue Gas Composition}

The objective for secondary oxygen injection was $100 \%$ volatile organic carbon (VOC) combustion inside the furnace, discharging only thermal energy in the flue gas. Turbulence and mixing in the furnace influenced the required excess secondary oxygen. Figure 3-16 plots flue gas $\mathrm{CO}$ and $\mathrm{CO}_{2}$ content against flue gas oxygen content. The flue gas exiting the furnace was not well-mixed; it was possible to have both concentration and thermal gradients across the outlet face. The plot for $\mathrm{CO}$ vs. $\mathrm{O}_{2}$ shows flat lines for oxygen and oxygen-enriched simulations, while air system simulations indicate about $4 \%$ oxygen concentration (mass basis) was required in the off-gas to ensure complete combustion. Methane, ethane and hydrogen were nearly zero in all simulations. In the plot for $\mathrm{CO}_{2}$ vs. $\mathrm{O}_{2}$ the three systems generate unique correlations based on nitrogen concentrations introduced with the oxidant. 
Figure 3-14. Maximum Furnace Roof Temperature Vs Average Roof Temperature.

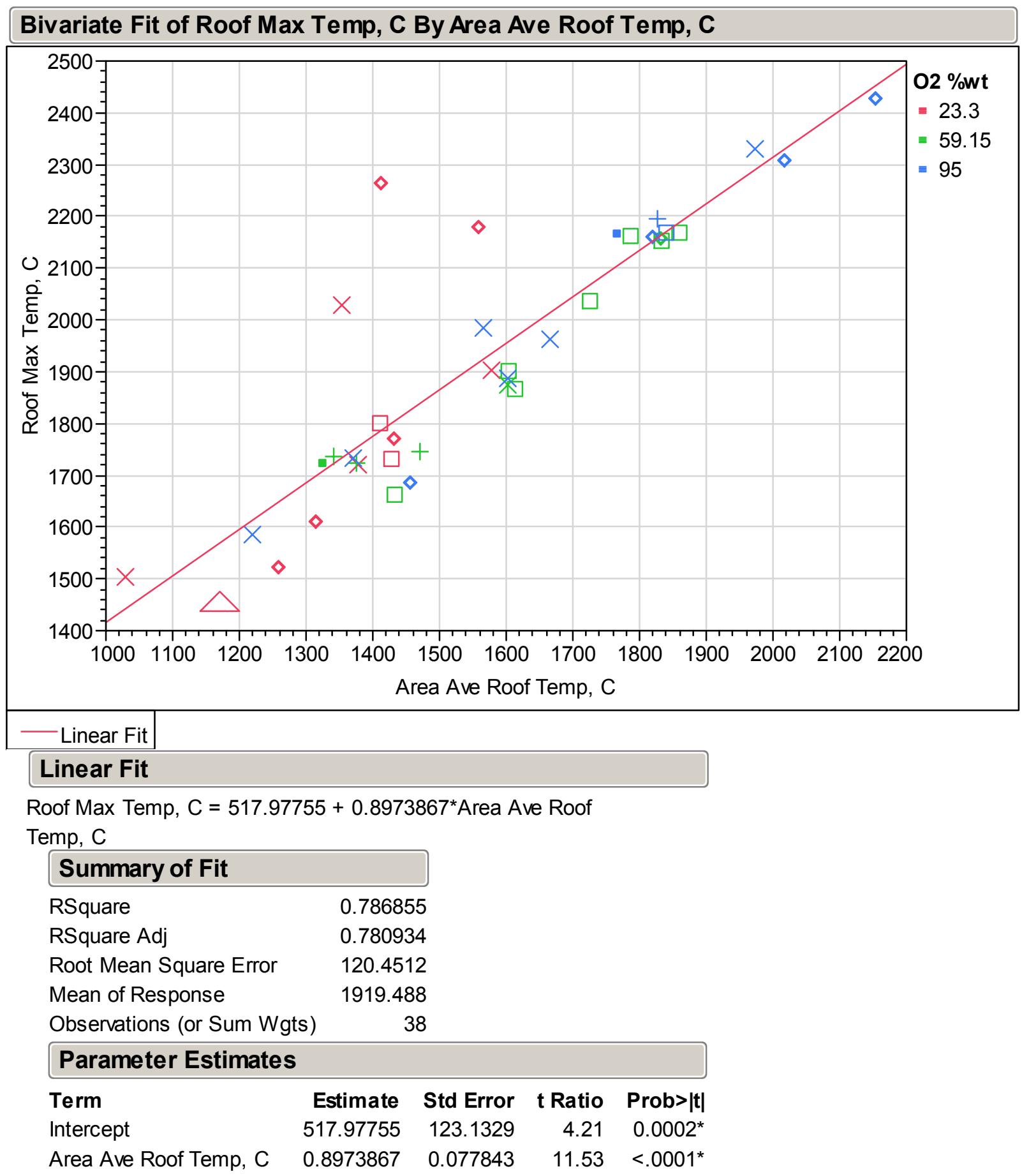


Figure 3-15. Maximum Furnace Roof Temperature Vs Average Bed Center Temperature in Melting zone.

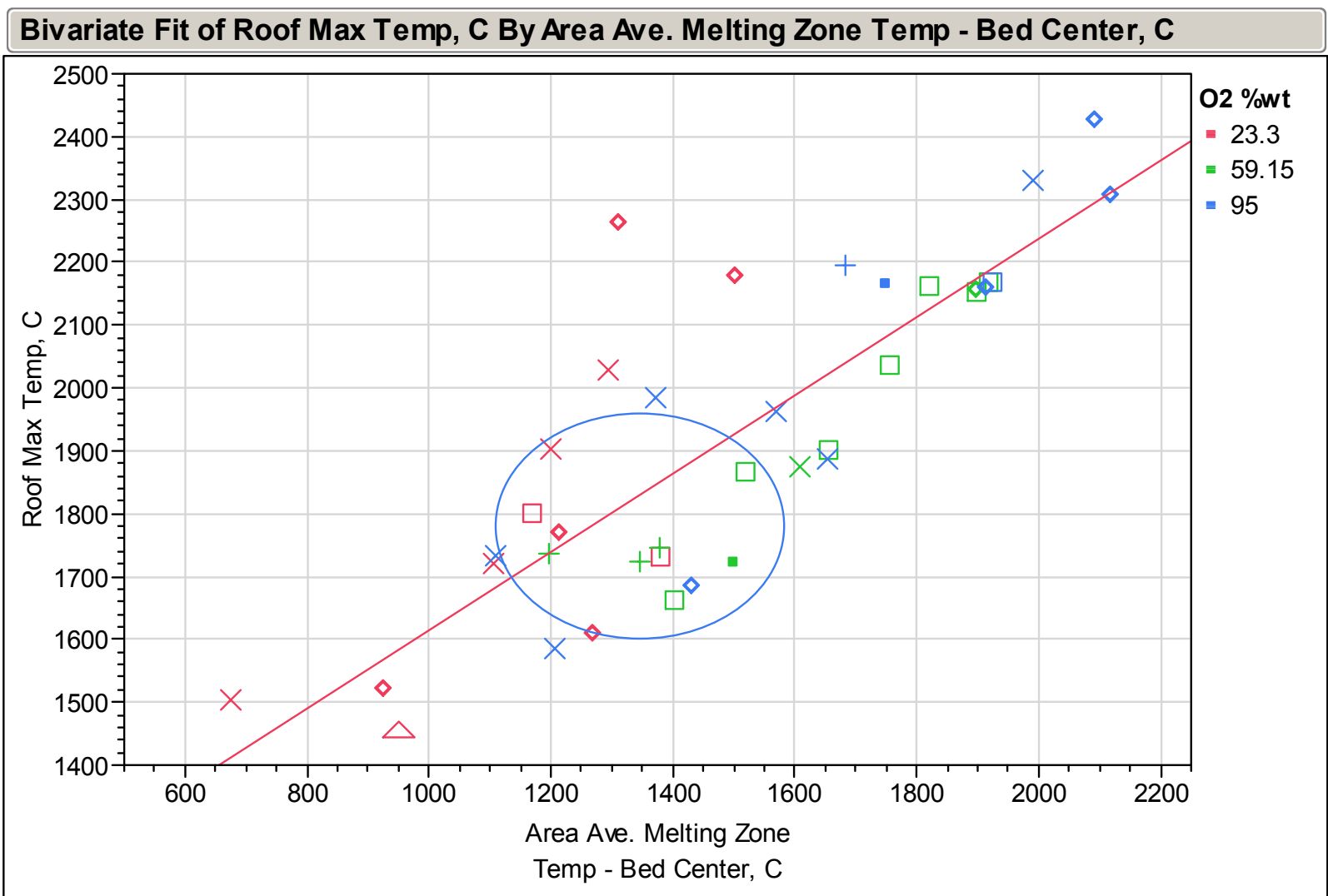

Linear Fit

\section{Linear Fit}

Roof Max Temp, C = 992.93269 + 0.6217701*Area Ave.

Melting Zone Temp - Bed Center, C

\begin{tabular}{lr}
\hline Summary of Fit & \\
\hline RSquare & 0.700489 \\
RSquare Adj & 0.692169 \\
Root Mean Square Error & 142.7841 \\
Mean of Response & 1919.488 \\
Observations (or Sum Wgts) & 38
\end{tabular}

\section{Parameter Estimates}

Term

Intercept

Area Ave. Melting Zone Temp - Bed Center, C
Estimate

992.93269

0.6217701
Std Error

103.6004

0.067762 t Ratio Prob $>|\mathbf{t}|$

$9.58<.0001^{*}$

$9.18<.0001^{*}$ 
Figure 3-16. Flue Gas $\mathrm{CO}$ and $\mathrm{CO}_{2}$ Content vs. Flue Gas $\mathrm{O}_{2}$ Content.

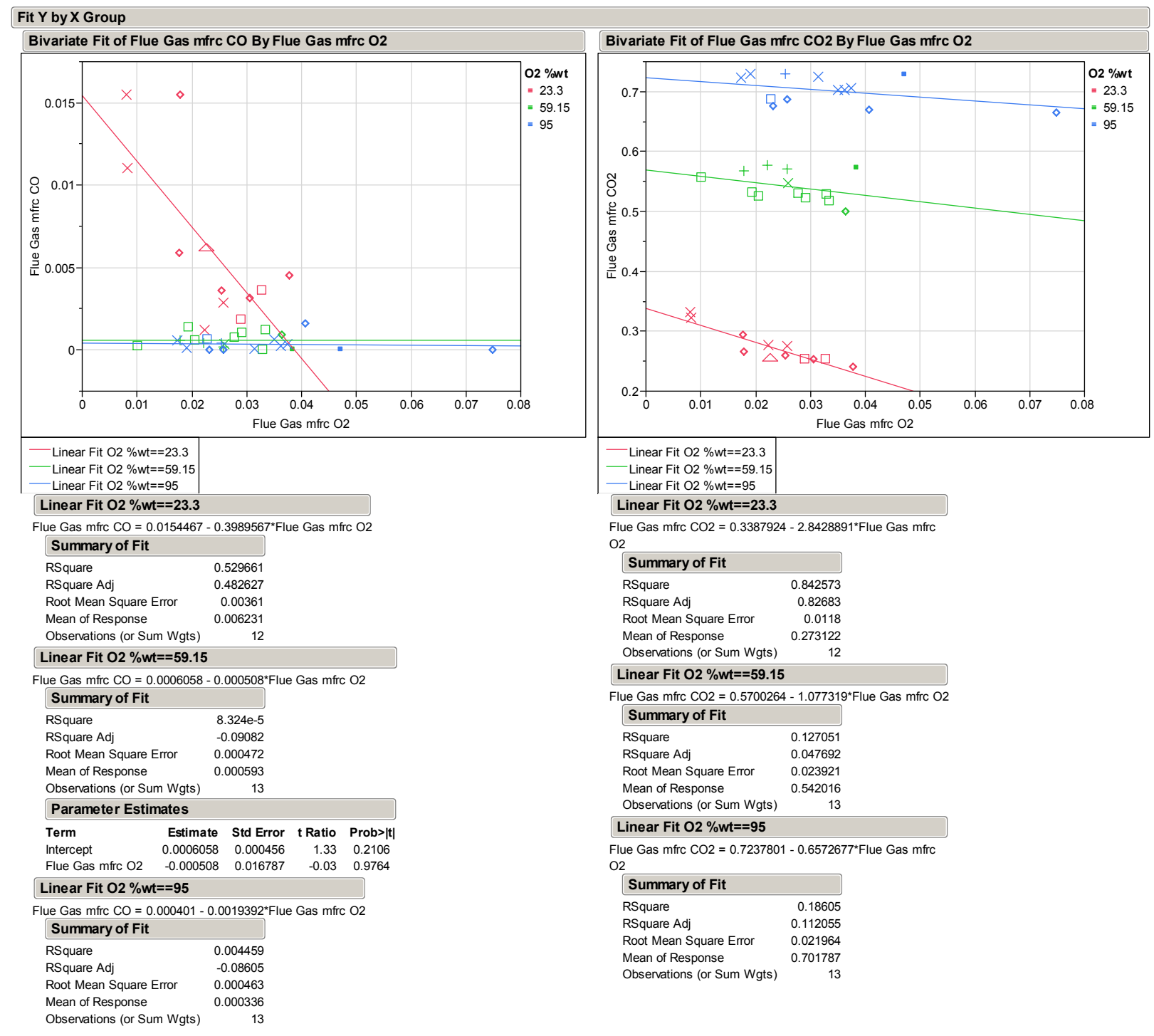




\section{3-6.4 Linear Model Regressions}

Several models were constructed to illustrate relationships in the results. These models were limited to linear relationships.

\section{3-6.4.1 Hot Metal Production}

Productivity was solely a function of briquette loading and hearth speed. It was based on iron flow through the furnace, irrespective of temperatures achieved. In cases where temperature did not reach melting point, production rate was of limited value. Coal type had a small impact on productivity through coal percentage in the mix, determined by coal type (\% Fix C), and ash content affecting flux addition and slag volume. Loading and speed produced a good fit with predicted productivity as shown in the Figure 3-17.

The figures that follow show plots of predicted vs. actual, followed by parameter estimates which contain the prediction equation. A prediction profiler is then presented, which graphically displays independent variables and their impact on the dependent variable, slope is the means to compare relative effects; steep slopes indicate greater impact. The Prob[t] value is statistically significant if the value is $<0.0001$. The sorted parameter section ranks variables in significance from most to least significant.

\section{3-6.4.2 Average Oxidation Degree (OD)}

Oxidation degree was averaged on a plane located one inch $(25.4 \mathrm{~mm})$ above bed in the reduction and melting zones. It was a measure of oxidation (see Fruehan and Fortini $^{7}$ ) in the gas stream determined by:

$$
\mathrm{P}_{\mathrm{CO} 2} /\left(\mathrm{P}_{\mathrm{CO}}+\mathrm{P}_{\mathrm{CO} 2}\right)
$$

where gas species are molar fractions measured in the simulations. 
Figure 3-17. Hot Metal Production Model.

Response Hot Metal mt/hr (2 ft hearth)

Actual by Predicted Plot

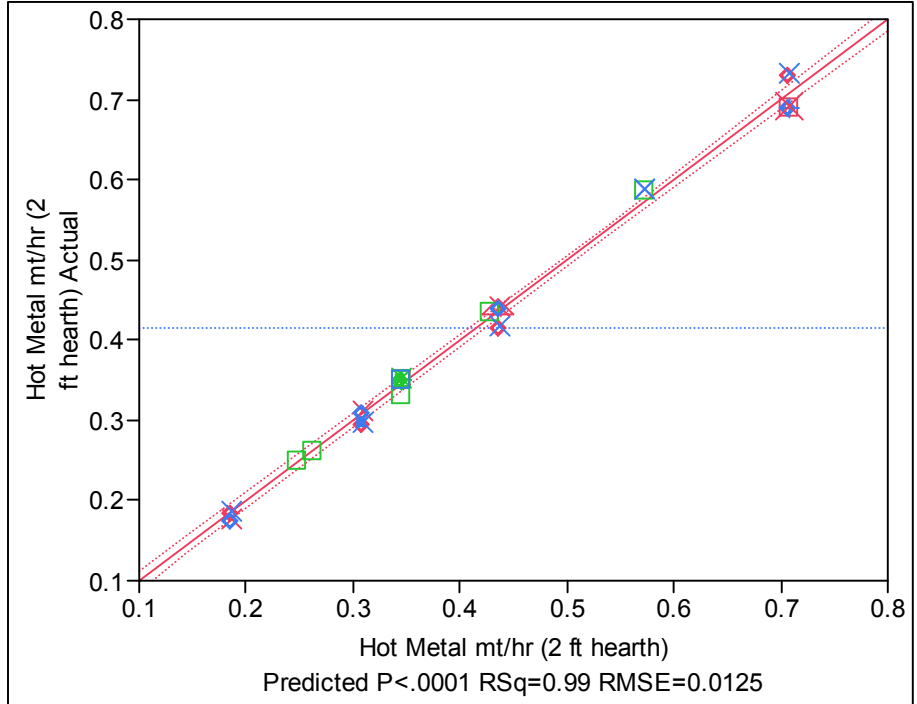

\section{Summary of Fit}

RSquare

RSquare Adj

Predicted $\mathrm{P}<.0001 \mathrm{RSq}=0.99 \mathrm{RMSE}=0.0125$

Root Mean Square Error

Mean of Response

0.994926

0.994478

0.012533

0.416184

Observations (or Sum Wgts)

38

\section{Parameter Estimates}

\section{Term}

Intercept

Briquette Loading, $\mathrm{kg} / \mathrm{m} 2$

Hearth Speed $\mathrm{m} / \mathrm{min}$

(Briquette Loading, kg/m2-19.9137)*(Hearth Speed m/min-1.20703)

\section{Sorted Parameter Estimates}

Term

Hearth Speed $\mathrm{m} / \mathrm{min}$

Briquette Loading, $\mathrm{kg} / \mathrm{m} 2$

(Briquette Loading, kg/m2-19.9137)*(Hearth Speed m/min-1.20703)

Prediction Profiler

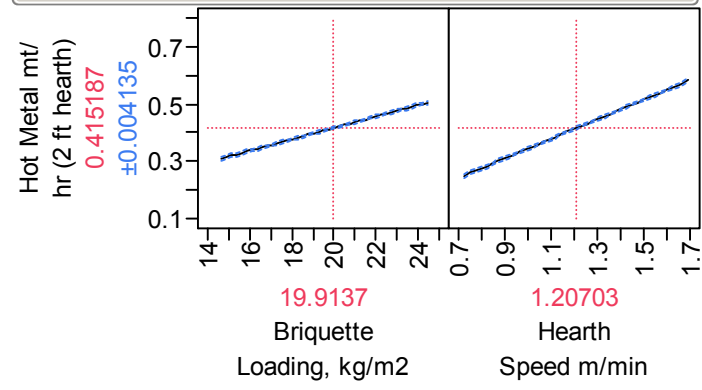

$\begin{array}{rrrr}\text { Estimate } & \text { Std Error } & \text { t Ratio } & \text { Prob }>|t| \\ -0.394985 & 0.012299 & -32.12 & <.0001^{*} \\ 0.0199945 & 0.000541 & 36.95 & <.0001^{*} \\ 0.3413397 & 0.004974 & 68.62 & <.0001^{*} \\ 0.0157361 & 0.001162 & 13.54 & <.0001^{*}\end{array}$

\begin{tabular}{|c|c|c|c|}
\hline Estimate & Std Error & t Ratio & Prob $>|t|$ \\
\hline 0.3413397 & 0.004974 & 68.62 & $<.0001^{*}$ \\
\hline 0.0199945 & 0.000541 & 36.95 & $<.0001^{*}$ \\
\hline 0.0157361 & 0.001162 & 13.54 & $<.0001^{*}$ \\
\hline
\end{tabular}


3-6.4.2.1 Reduction Zone Oxidation Degree: This model incorporated all five independent design variables; however, only oxygen concentration, residence time, and coal volatile content appear significant, as seen in the Sorted Parameter Estimate section in Figure 3-18. Achieving a low OD was relatively easy since gas evolution during reduction prevents oxidized gases from contacting the bed. However, regions developed where gases were heavily oxidized due to localized turbulence and possibly secondary injection velocity. The most significant effect comes from oxygen concentration and residence time. Residence time was substituted for hearth speed to facilitate comparisons. Reductant coal produced a smaller effect, related to increasing volatile content and increased oxidant requirement.

3-6.4.2.2 Melting Zone Oxidation Degree Model: Figure 3-19 summarizes a model for melting zone OD. Burners firing in the melting zone were set to 0.85 of stoichiometric oxygen requirement to decrease generation of oxidized gas species. Despite reduced oxygen input at the burners, gases near the bed remained heavily oxidized. Since there was minimal gas evolution (from the bed) in the melting zone, care must be taken to ensure oxidizing gases do not re-oxidize metallic iron. The OD should be less than 0.35 to prevent re-oxidation.

\section{3-6.5 Bed Volumetric Maximum Temperature Model}

This model predicted maximum bed temperature; the maximum was not necessarily located in the melting zone. In many simulations, bed temperature decreased in the melting zone. The decrease resulted from sub-stoichiometric firing supplying insufficient energy relative to the bed heat sink. This model is shown in Figure 3-20. 
Figure 3-18. Reduction Zone Oxidation Degree Model.

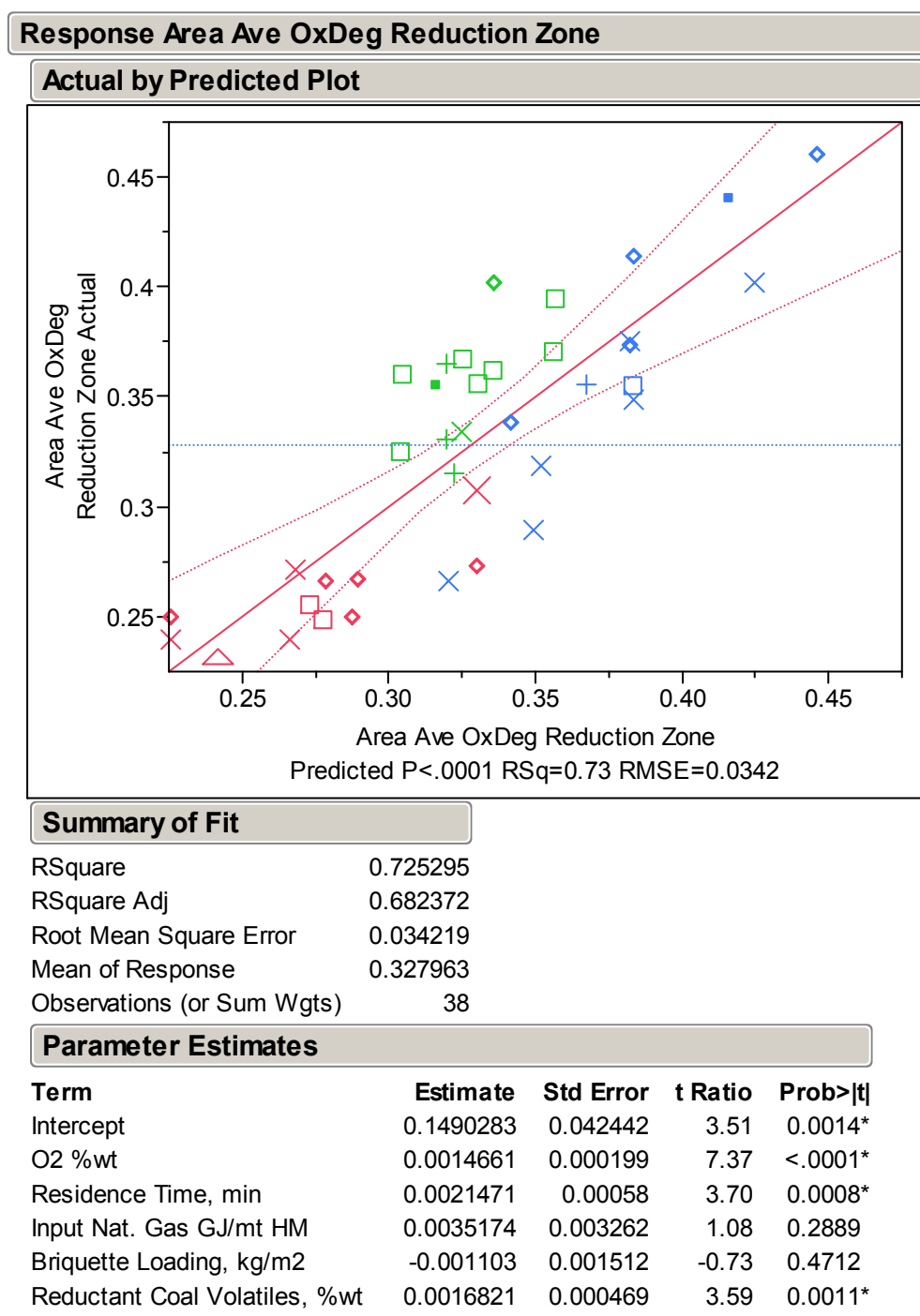




\section{3-6.5.1 Bed Volumetric Maximum Temperature}

A Contour Profiler created two dimensional plots, fixing remaining independent variables (three in this case) constant. Regions of little interest or unrealistic conditions were blocked out. In Figures 21-24, the bed volumetric temperature model is plotted with different independent variable combinations. Oxygen content remains on the vertical axis, while the remaining four independent variables are plotted on the horizontal axis. In the actual process, control loops alter process dynamics avoiding undesirable outcomes. These models cannot account for dynamic change. They provide steady state conclusions for boundary conditions specified. The constant variable values used are as follow:

Residence Time, minutes $=28.4$

Natural Gas MMBTU/mt HM $=3.0(3.17 \mathrm{GJ} / \mathrm{mt} \mathrm{HM})$

Briquette Loading $\mathrm{lbs} / \mathrm{ft}^{2}=4.0\left(19.53 \mathrm{~kg} / \mathrm{m}^{2}\right)$

Coal Volatile Content $\% \mathrm{wt}=21.0$

The plots provide a visual comparison of independent variable interaction in the simulation. Maximum bed temperature contours are shown in red; the acceptable range is between 2600 and $2800^{\circ} \mathrm{F}\left(1427-1538^{\circ} \mathrm{C}\right)$. In Figure $3-21$ oxygen concentration should increase to minimize residence time, assuming constant natural gas input, coal volatile content, and briquette loading. Figure 3-22 shows the same model plotted using oxygen concentration and natural gas input. It is readily apparent that natural gas consumption can be minimized by increasing oxygen concentration. Maximum oxygen concentration did not exceed $70 \mathrm{wt} \%$ under these conditions.

In Figure 3-23 briquette loading is varied. As loading increases oxygen concentration should decrease to maintain an acceptable temperature. Increased loading releases more gaseous fuel and the flue gas must absorb more energy to maintain process temperature equilibrium. Alternatively secondary combustion could be decreased to maintain temperature, in which case VOC content in the flue gas would increase. Figure 3-24 completes the series comparison, plotting oxygen concentration and coal volatile content. The relationship confirmed that changing coal type produced a significant effect on process temperature. Coal volatile input should be maximized to minimize natural gas and residence time, from an energy perspective. However increased coal volatile content drives the required oxidant oxygen concentration down, unless natural gas consumption can be reduced simultaneously.

Lower cost coals such as Powder River Basin (PRB) and high volatile bituminous types are advantageous in displacing natural gas. But they carry high energy content in the volatile fraction that requires a minimum flue gas volume to absorb proportionately more combustion energy, if process temperature is held constant.

\section{3-6.5.2 Substitution of Averaged Melting Zone Bed Center Temperature for Bed Volumetric Maximum Temperature in the Model of Section 6.5.1}

Bed maximum temperature may not be representative of overall bed temperature because it can be influenced by localized conditions. Another means of comparison 
was performed using melting zone area-averaged bed center temperature. Figure 312 plotted the correlation between these two variables. This plot targeted a maximum solids temperature between 2600 and $2800^{\circ} \mathrm{F}\left(1427-1538^{\circ} \mathrm{C}\right)$, which corresponded to an average bed melting temperature between 2200 and $2700^{\circ} \mathrm{F}\left(1204-1482^{\circ} \mathrm{C}\right)$. A revised linear model based on averaged melting zone temperature is shown in Figure 325.

The contour profiler using averaged bed center temperature (blue) is shown side by side with the volumetric maximum temperature results (red), in Figures 26-29. The acceptable bed center temperature range results in a slightly expanded window for oxygen concentration vs. residence time. The same is true for the remaining plots with natural gas consumption, briquette loading and coal volatiles. In these correlations it appears possible to approach conditions with $90 \%$ purity oxygen.

\section{3-6.6 Productivity (mt HM/hr) from Residence Time and Iron Loading}

This model converted residence time and iron loading into productivity units. Productivity was simply $\mathrm{mt} / \mathrm{hr}$ iron or Hot Metal (containing carbon). Productivity was determined by throughput alone and not dependent on bed temperature. It is of limited significance if melting range temperatures are not reached. Figure 3-30 illustrates this model. 
Figure 3-19. Melting Zone Oxidation Degree Model.
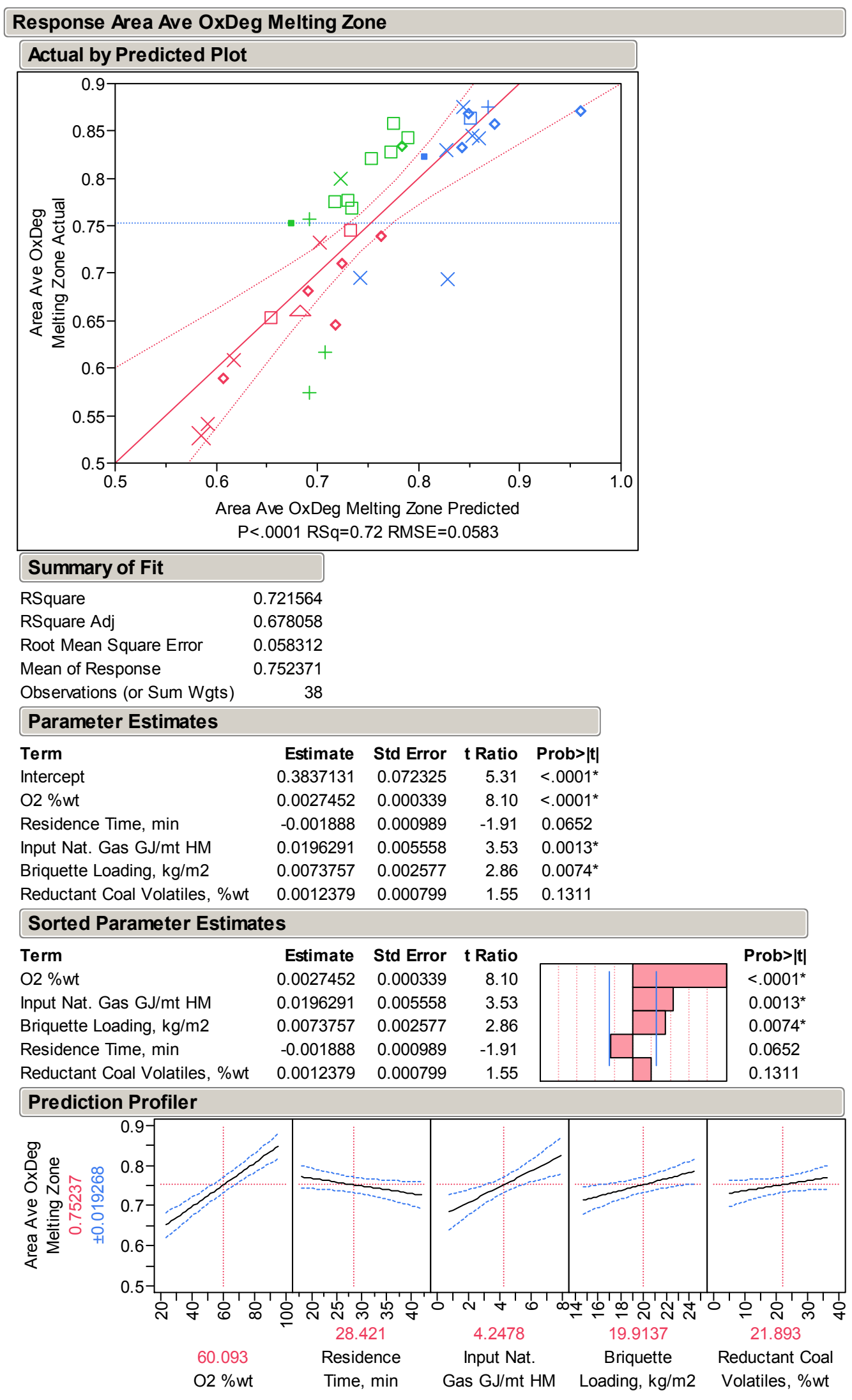
Figure 3-20. Bed Volumetric Maximum Temperature Model.

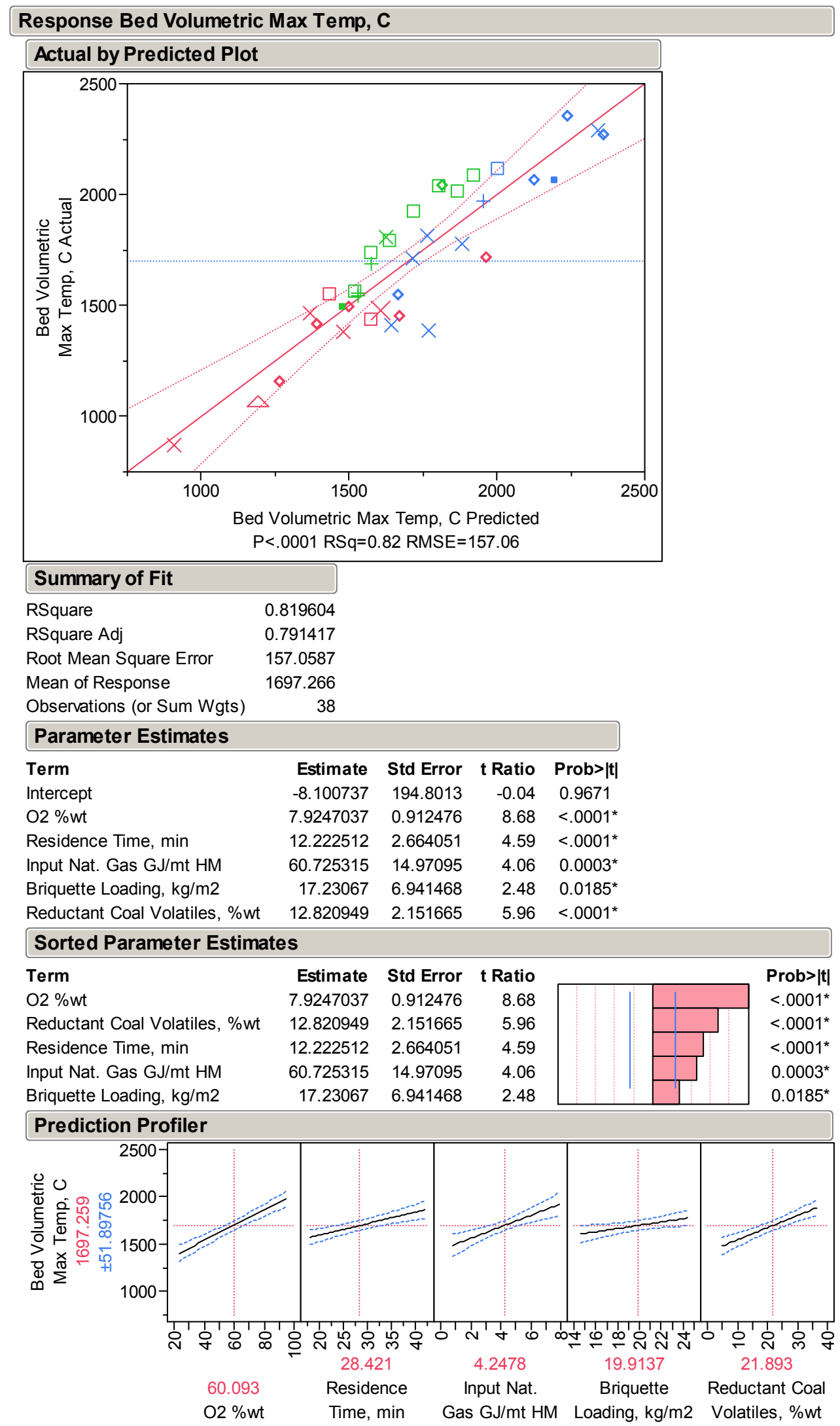


Figure 3-21. Bed Volumetric Maximum Temperature Model $\mathrm{O}_{2}$ and Residence Time.

$1539{ }^{\circ} \mathrm{C}$ Contour is $2800^{\circ} \mathrm{F}$ $1427^{\circ} \mathrm{C}$ Contour is $2600^{\circ} \mathrm{F}$

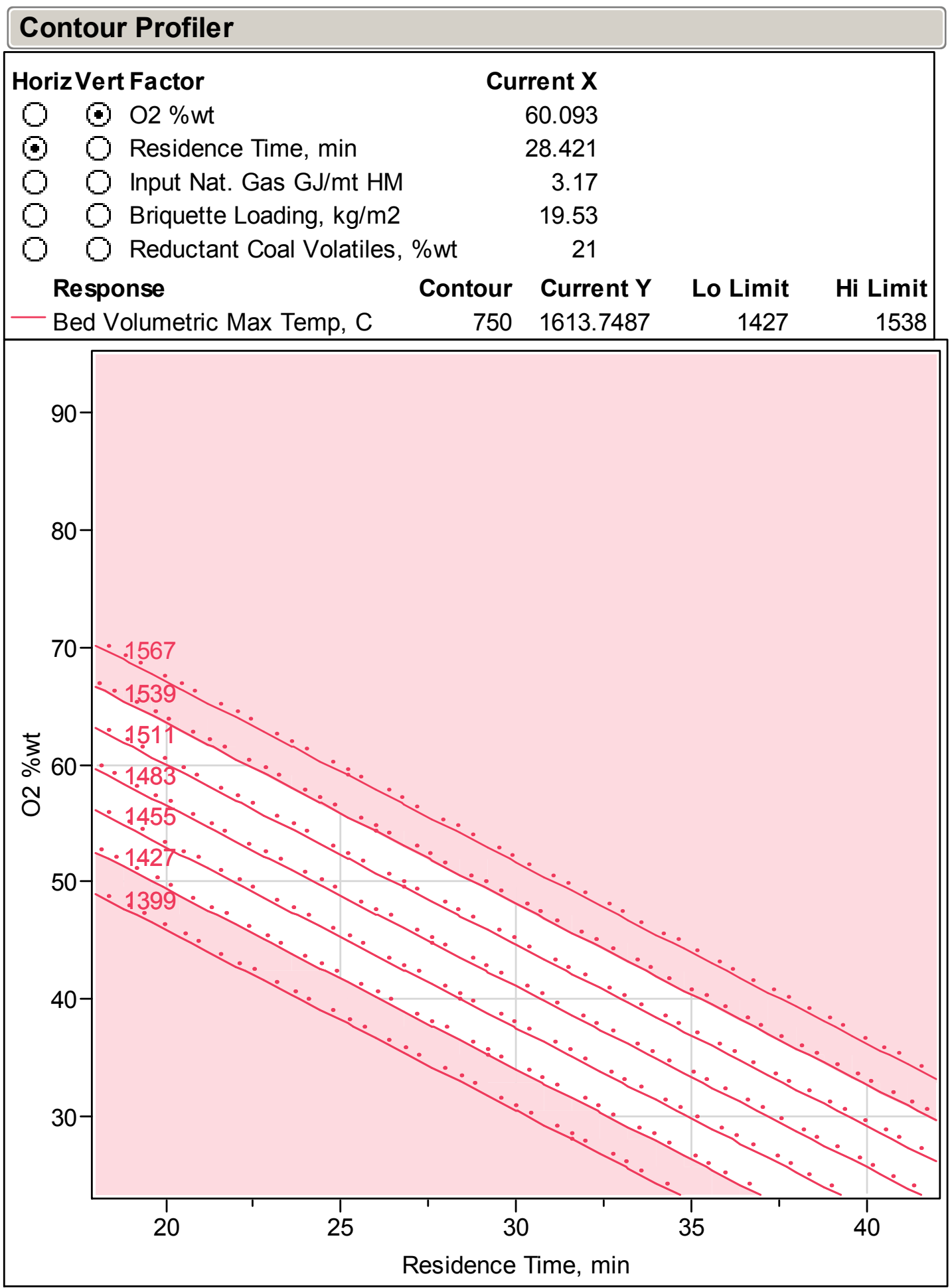


Figure 3-22. Bed Volumetric Maximum Temperature Model $\mathrm{O}_{2}$ and Natural Gas Input.

$1539^{\circ} \mathrm{C}$ Contour is $2800^{\circ} \mathrm{F}$ $1427^{\circ} \mathrm{C}$ Contour is $2600^{\circ} \mathrm{F}$

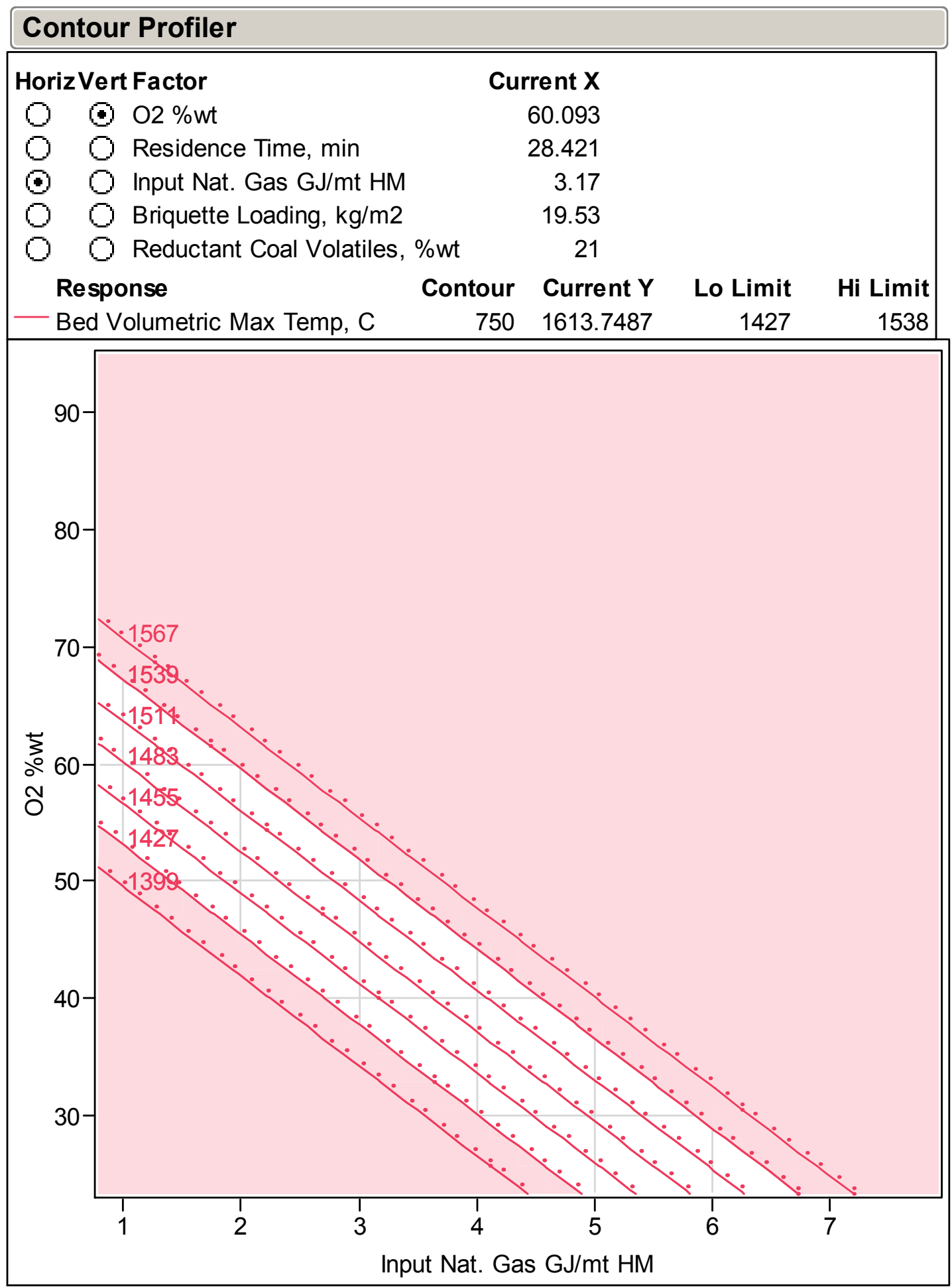


Figure 3-23. Bed Volumetric Maximum Temperature Model $\mathrm{O}_{2}$ and Briquette Loading.

$1539{ }^{\circ} \mathrm{C}$ Contour is $2800{ }^{\circ} \mathrm{F}$ $1427^{\circ} \mathrm{C}$ Contour is $2600^{\circ} \mathrm{F}$

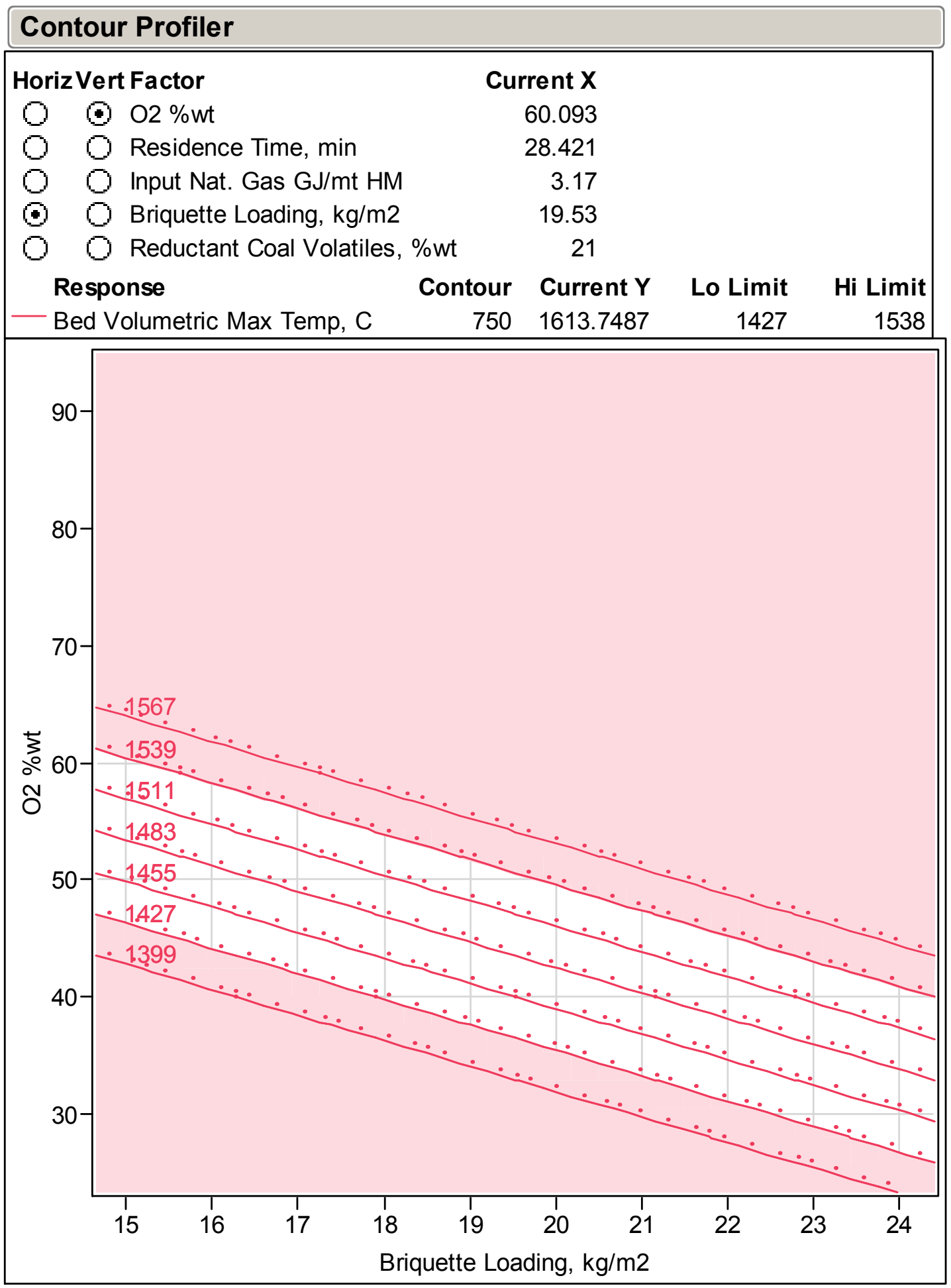


Figure 3-24. Bed Volumetric Maximum Temperature Model $\mathrm{O}_{2}$ and Coal Volatile Content.

$1539^{\circ} \mathrm{C}$ Contour is $2800{ }^{\circ} \mathrm{F}$ $1427^{\circ} \mathrm{C}$ Contour is $2600^{\circ} \mathrm{F}$

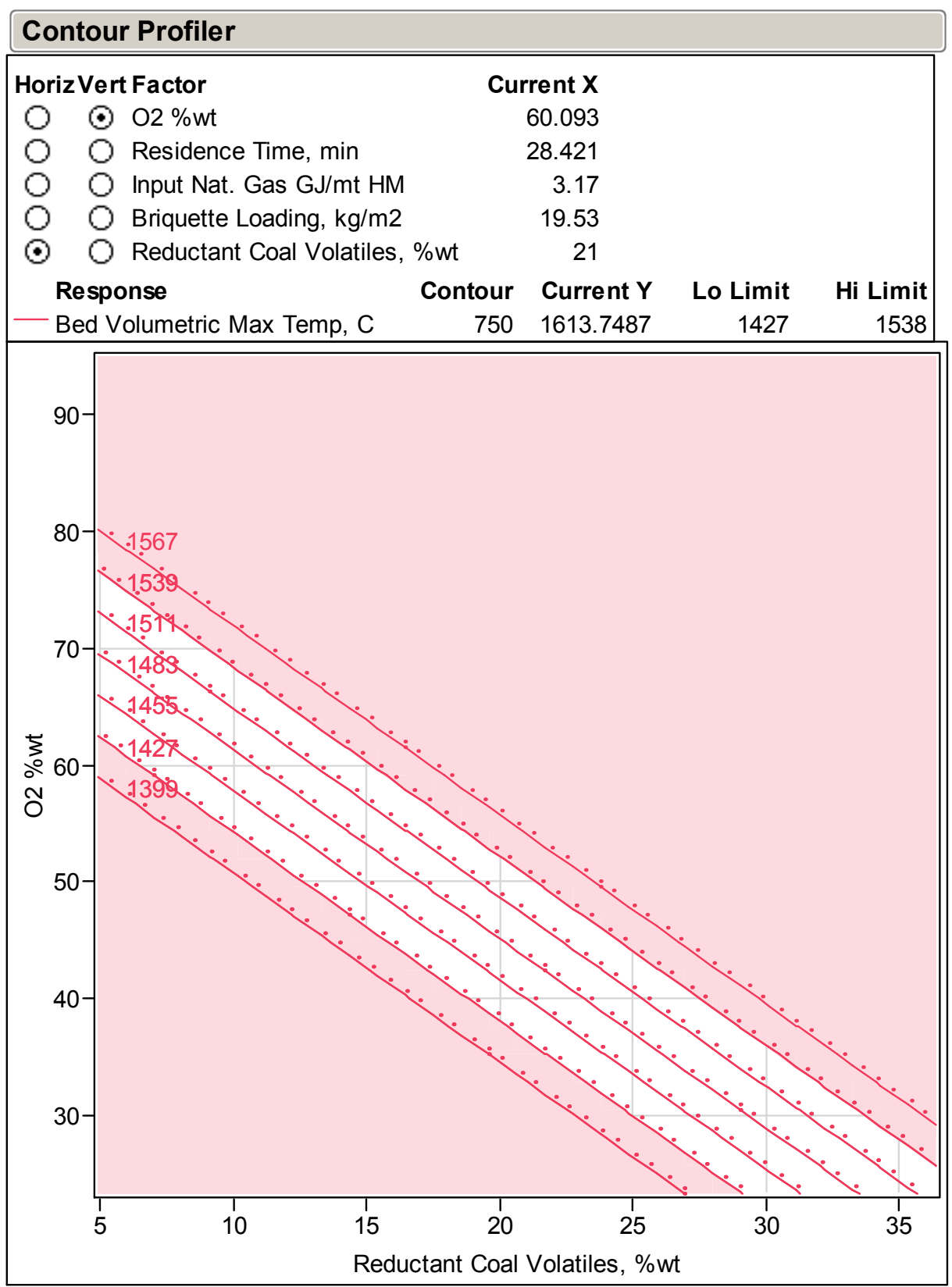


Figure 3-25. Substitution of Averaged Melting Zone Bed Center Temperature for Bed Volumetric Maximum Temperature.
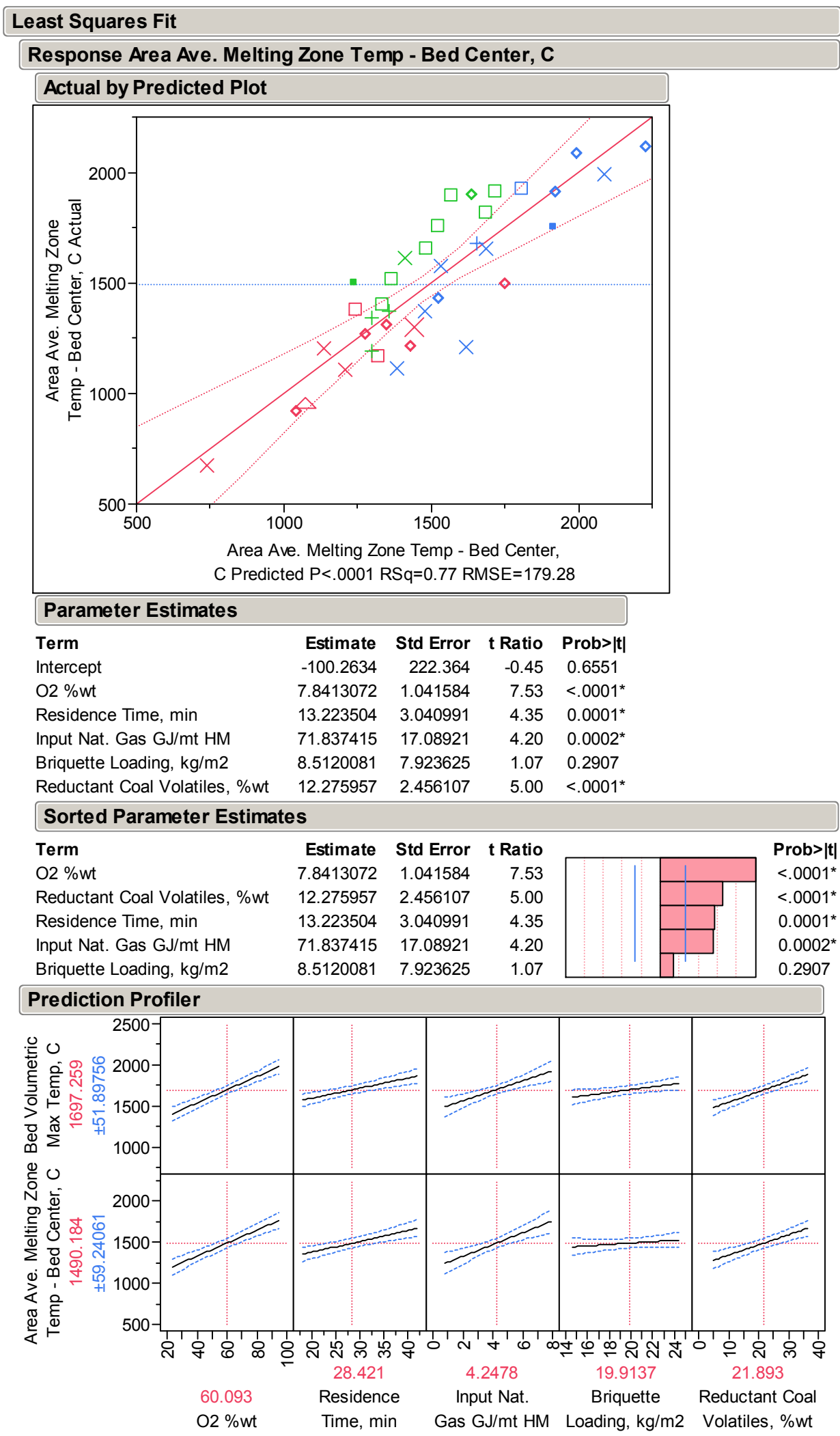
Figure 3-26. Comparison Bed Max and Ave. Melting Zone Bed Center Temp with Residence Time.
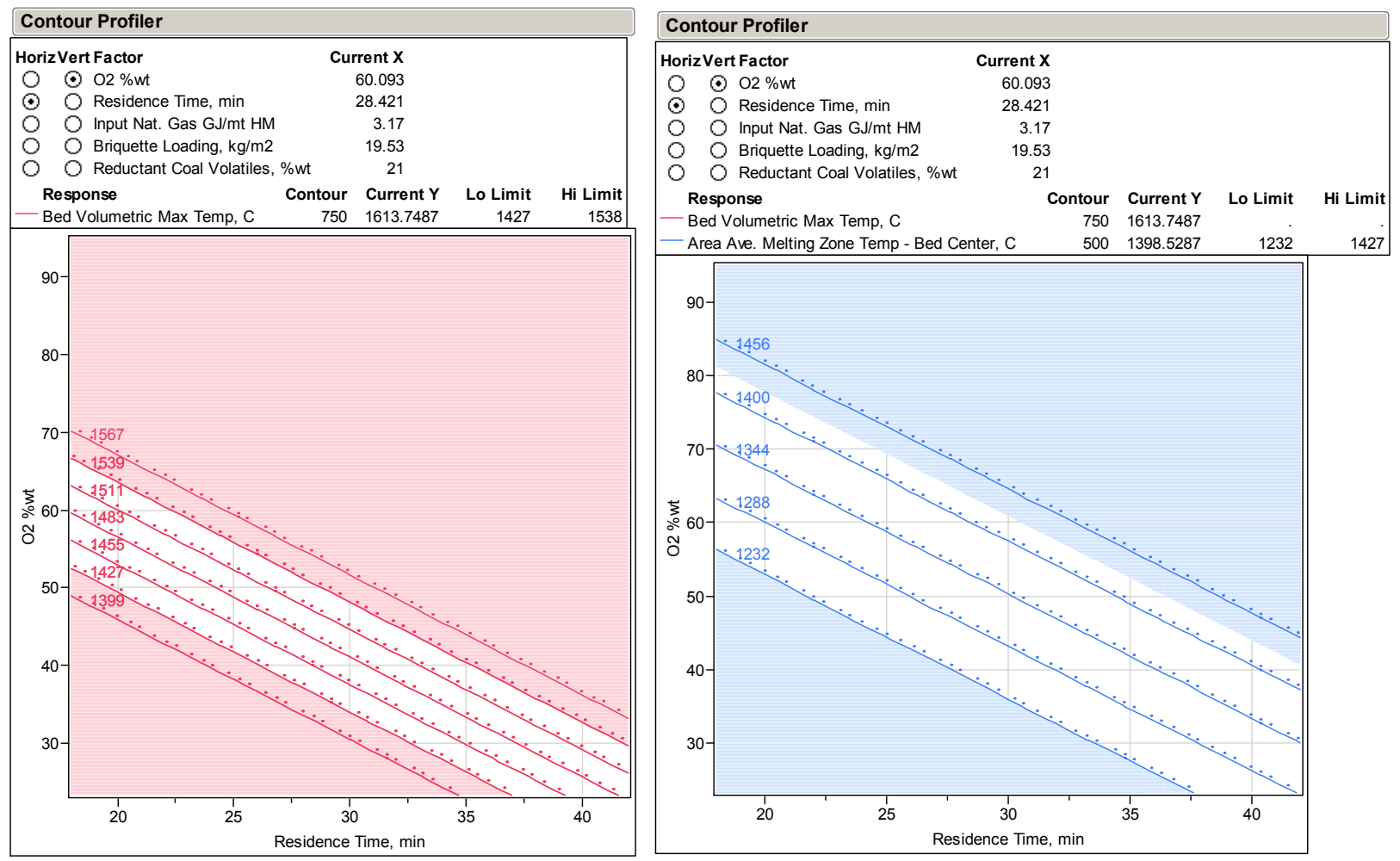

Figure 3-27. Comparison Bed Max and Ave. Melting Zone Bed Center Temp with Natural Gas.
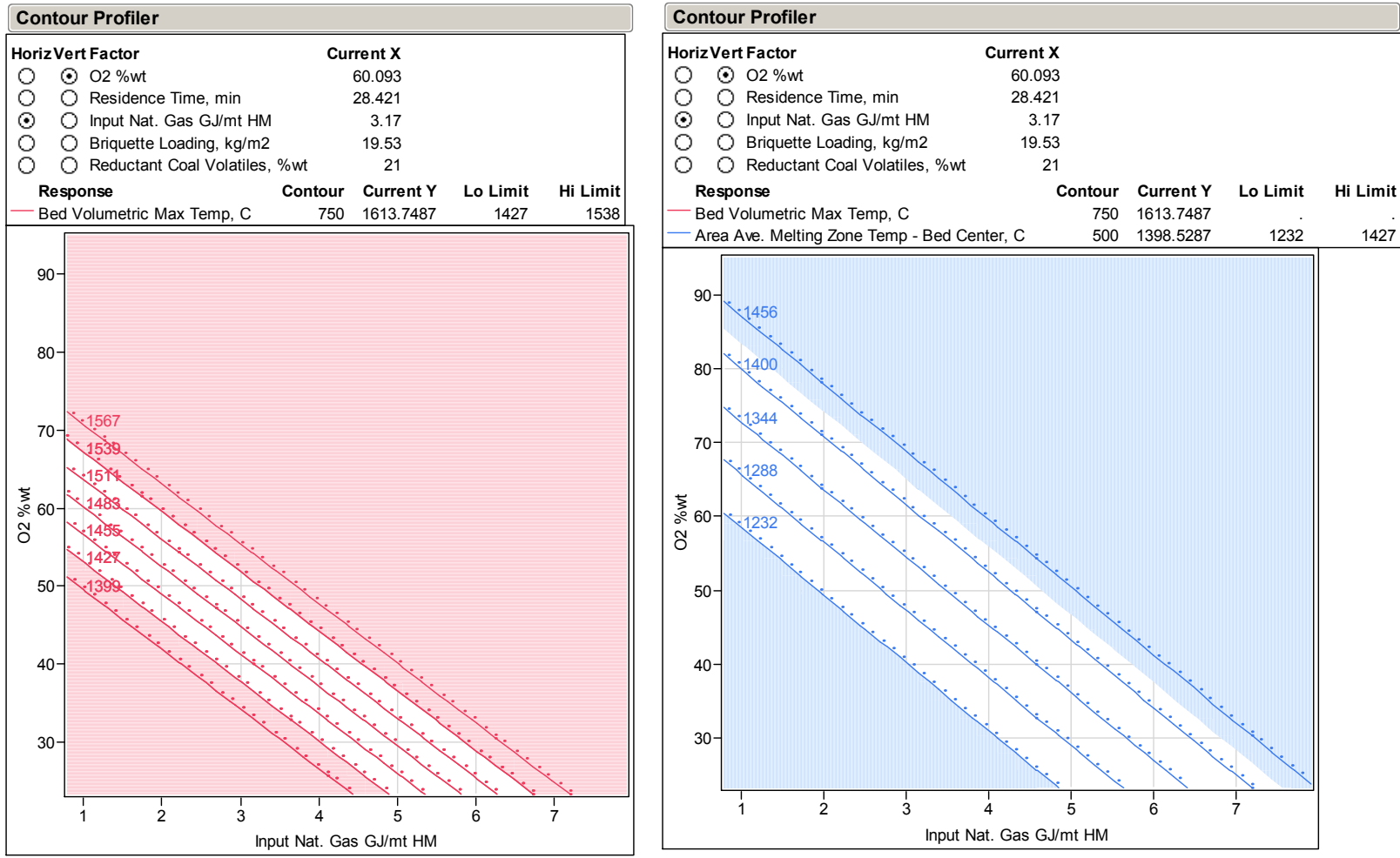
Figure 3-28. Comparison Bed Max and Ave. Melting Zone Bed Center Temp with Briquette Loading.
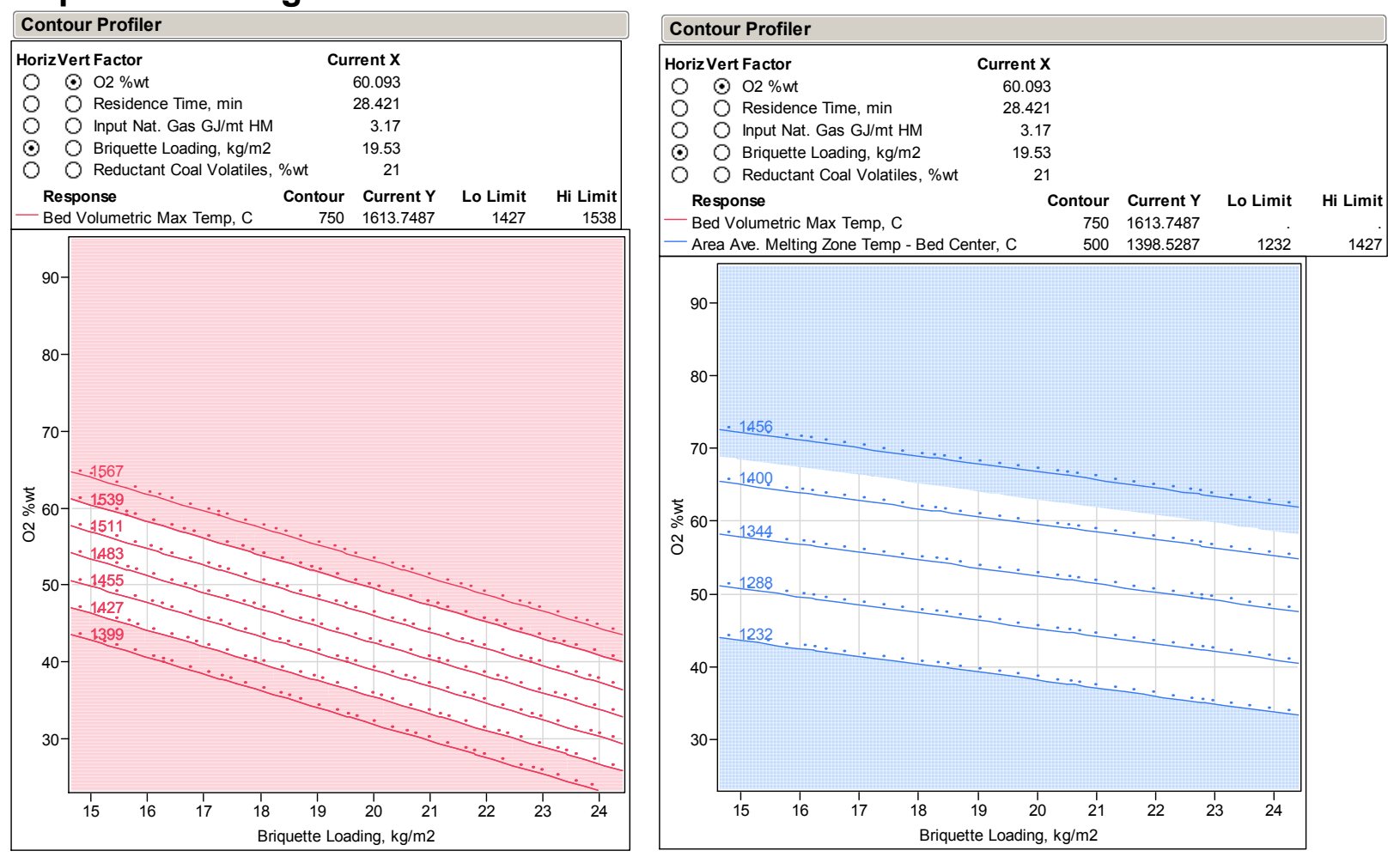

Figure 3-29. Comparison Bed Max and Ave. Melting Zone Bed Center Temp with Coal Volatile Content.
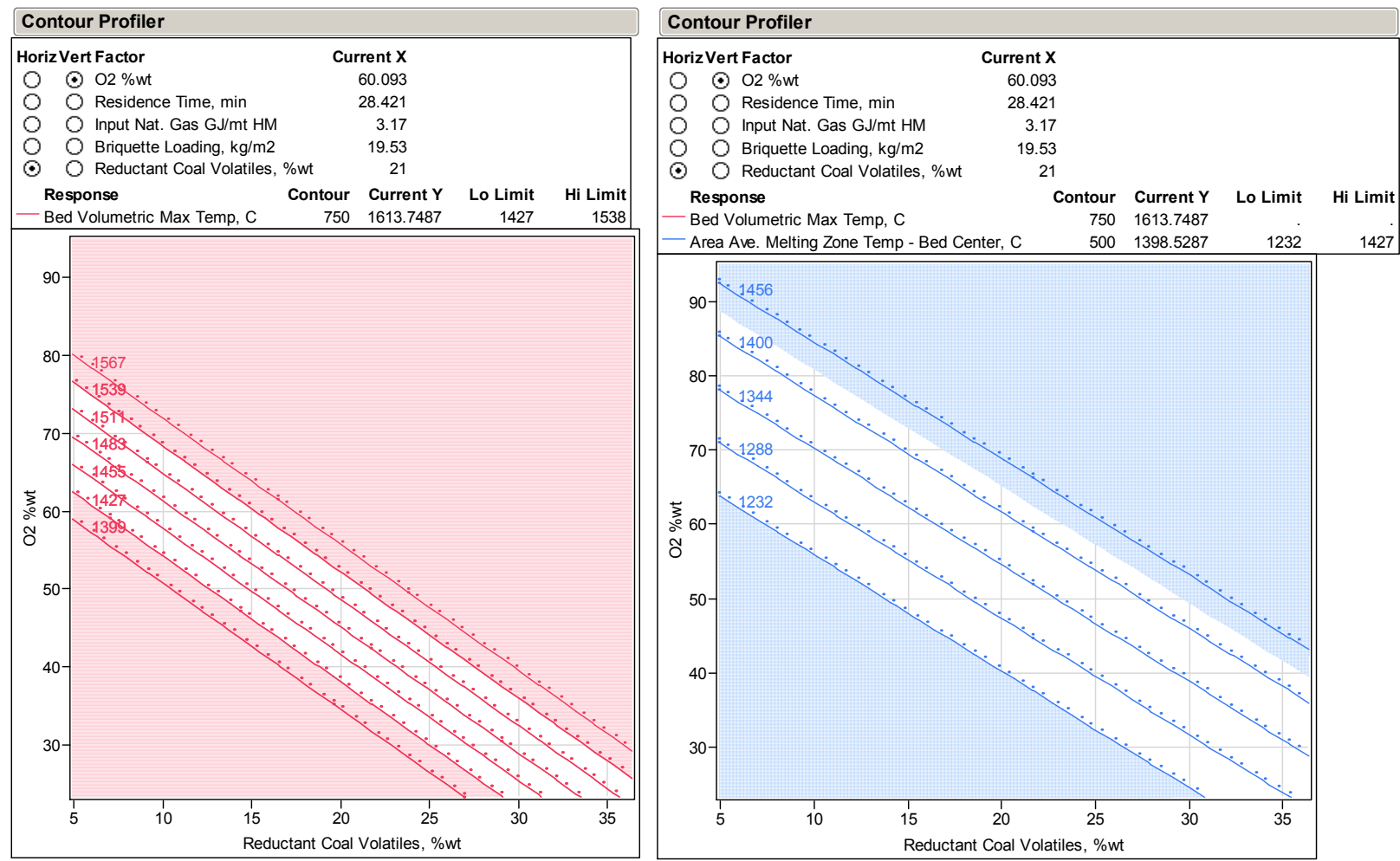
Figure 3-30. Productivity from Residence Time and Iron Loading Model.

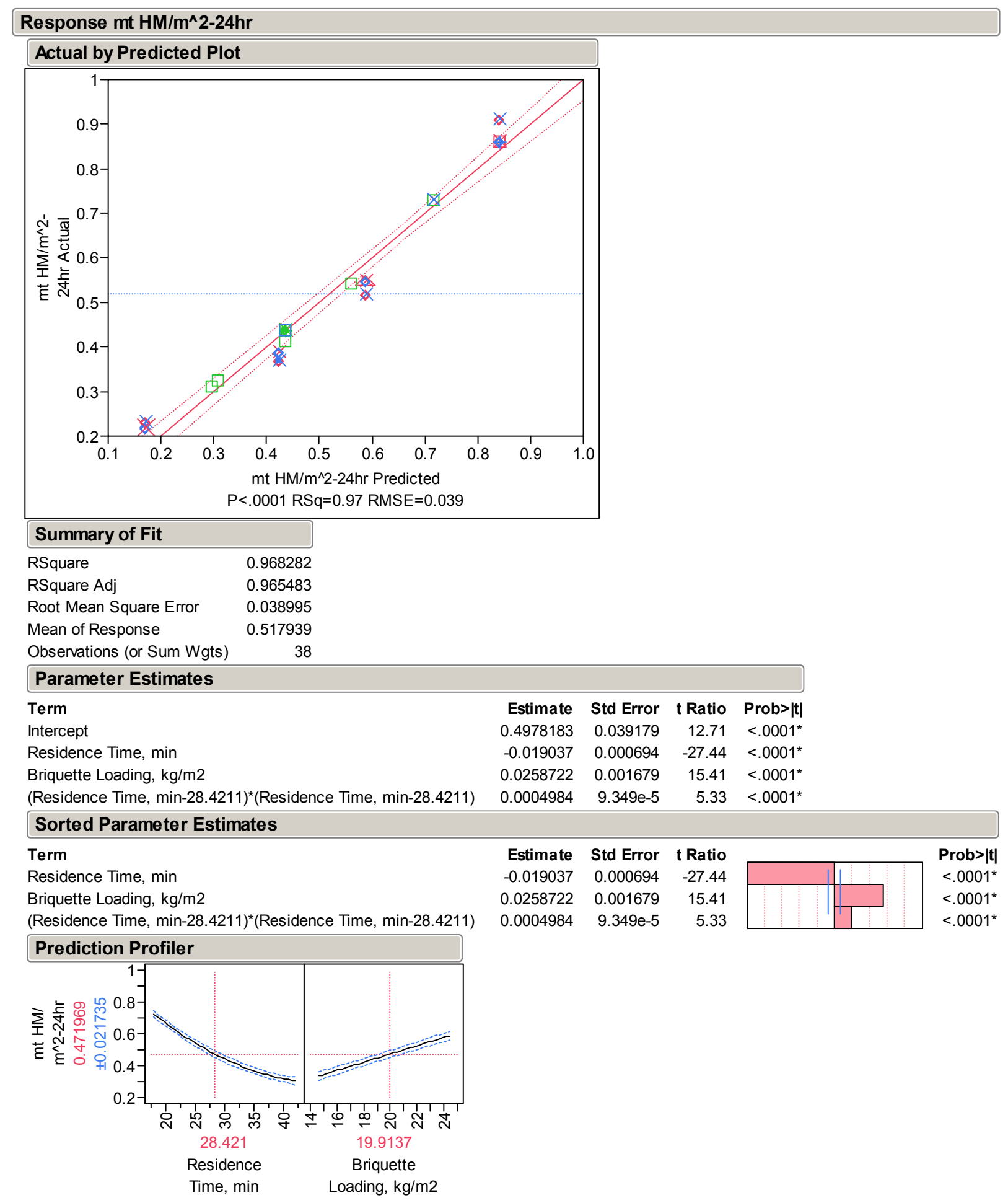




\section{3-6.7 Flue Gas Carbon Dioxide and Energy Content Model Contours}

Two parameters of interest were carbon dioxide emission and flue gas energy content. Using the same five-variable model, carbon dioxide and energy content were predicted in units of $\mathrm{kgs} / \mathrm{mt} \mathrm{HM}$ and $\mathrm{GJ} / \mathrm{mt} \mathrm{HM}$ respectively. The model statistics are shown in Figures 31 and 32.

Profiler plots are shown in Figure 3-33 with contour lines for $\mathrm{kg} \mathrm{CO}_{2} / \mathrm{mt} \mathrm{HM}$ (green) and $\mathrm{GJ} / \mathrm{mt} \mathrm{HM}$ (blue) overlaid. Acceptable operating temperature was based on areaaveraged melting zone temperature. Carbon dioxide emission decreased with decreasing residence time, decreasing natural gas consumption, and decreasing coal volatile content. The emissions increased slightly with increased loading. Energy content contained in the flue gas exhibited minor fluctuations through the windows; the values were more significantly affected by oxygen concentration, increasing with increasing oxygen concentration.

An optimization routine (Desirability) to maximize, match target, or minimize dependent variables shown on the vertical axis was used to minimize carbon dioxide and thermal energy losses in the flue gas. Figure 3-34 demonstrated this option; however, the variation in the data was relatively high, leaving a large degree of uncertainty. Figure 334 was based on matching the average melting zone temperature to $2450^{\circ} \mathrm{F}\left(1343^{\circ} \mathrm{C}\right)$, and minimizing carbon dioxide and thermal energy losses on a per ton product basis. The $95 \%$ confidence limit for target temperature was $\pm 183^{\circ} \mathrm{C}$, and on $\mathrm{CO}_{2}$ was \pm 31.29 $\mathrm{kg} / \mathrm{mt}$, and on energy was $\pm 0.82 \mathrm{GJ} / \mathrm{mt} \mathrm{HM}$. Independent variable values that achieved the target constraints were $82 \%$ oxygen, 35 minutes residence time, $0.79 \mathrm{GJ} / \mathrm{mt} \mathrm{HM}$ natural gas, $24.4 \mathrm{~kg} / \mathrm{m}^{2}$ briquettes, and $4.9 \%$ coal volatiles 
Figure 3-31. Flue Gas Carbon Dioxide and Energy Content Model.

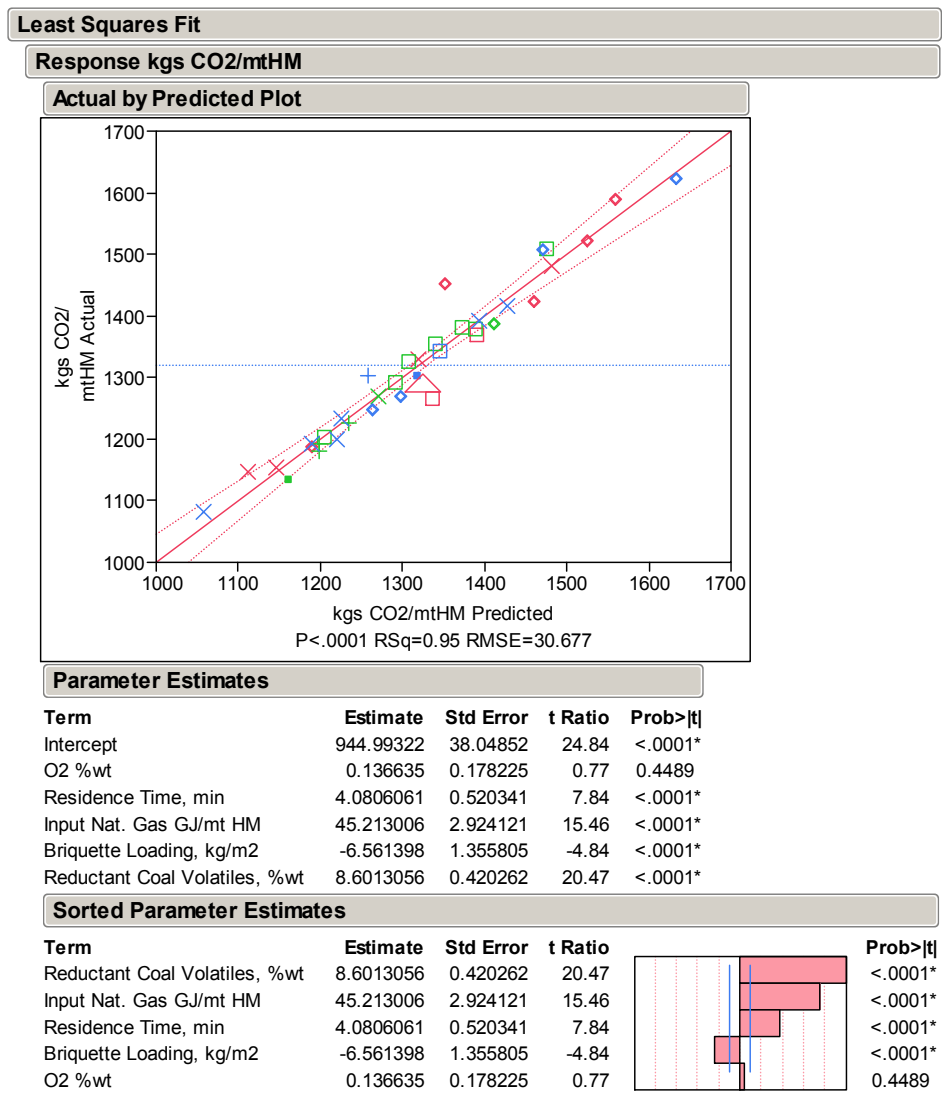

Response Flue Gas Thermal Energy, GJ/mt HM Actual by Predicted Plot

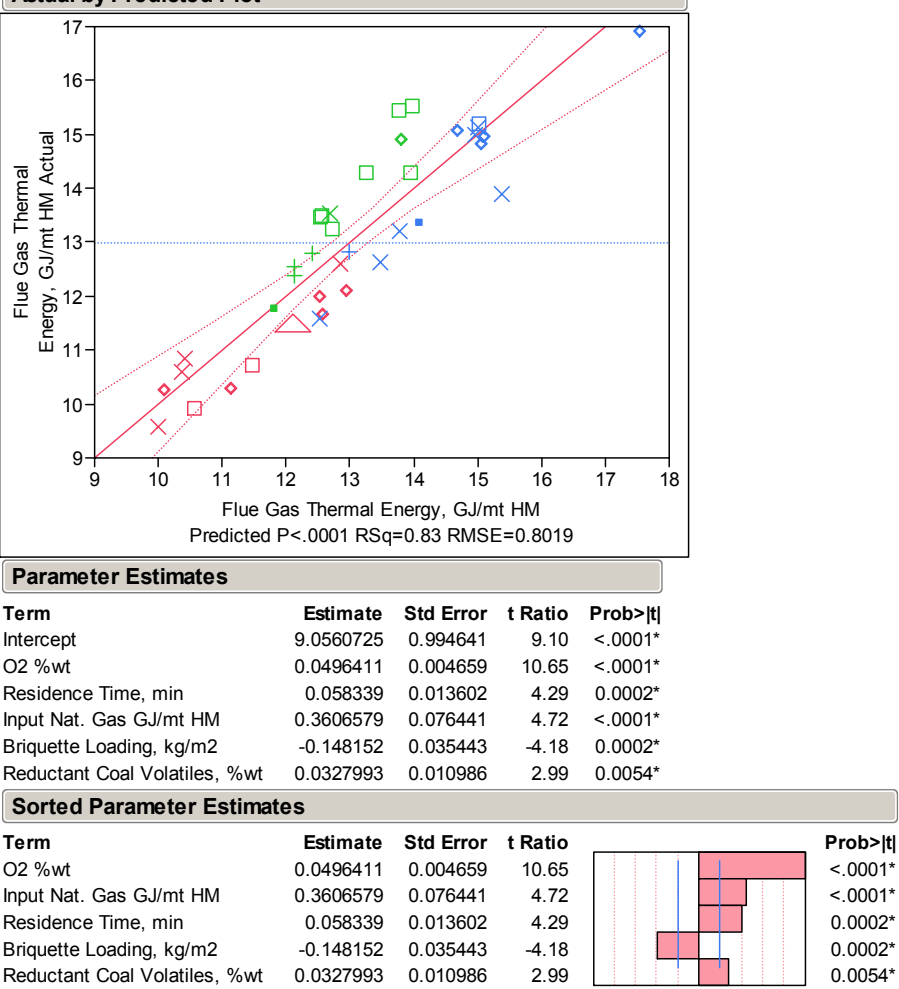


Figure 3-32. Flue Gas Carbon Dioxide and Energy Content Prediction Profiler.

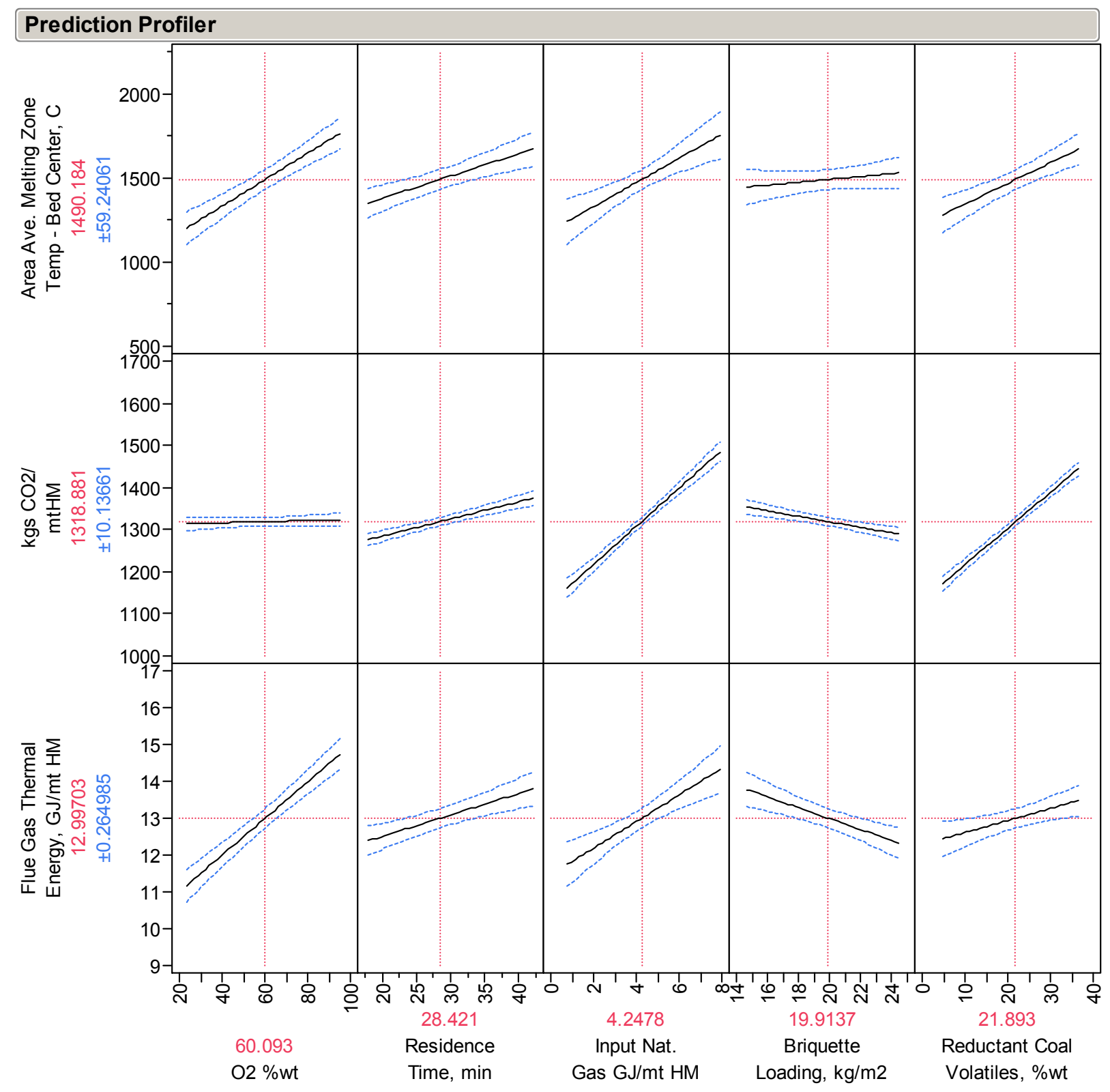


Figure 3-33. Flue Gas Carbon Dioxide and Energy Content Contours.
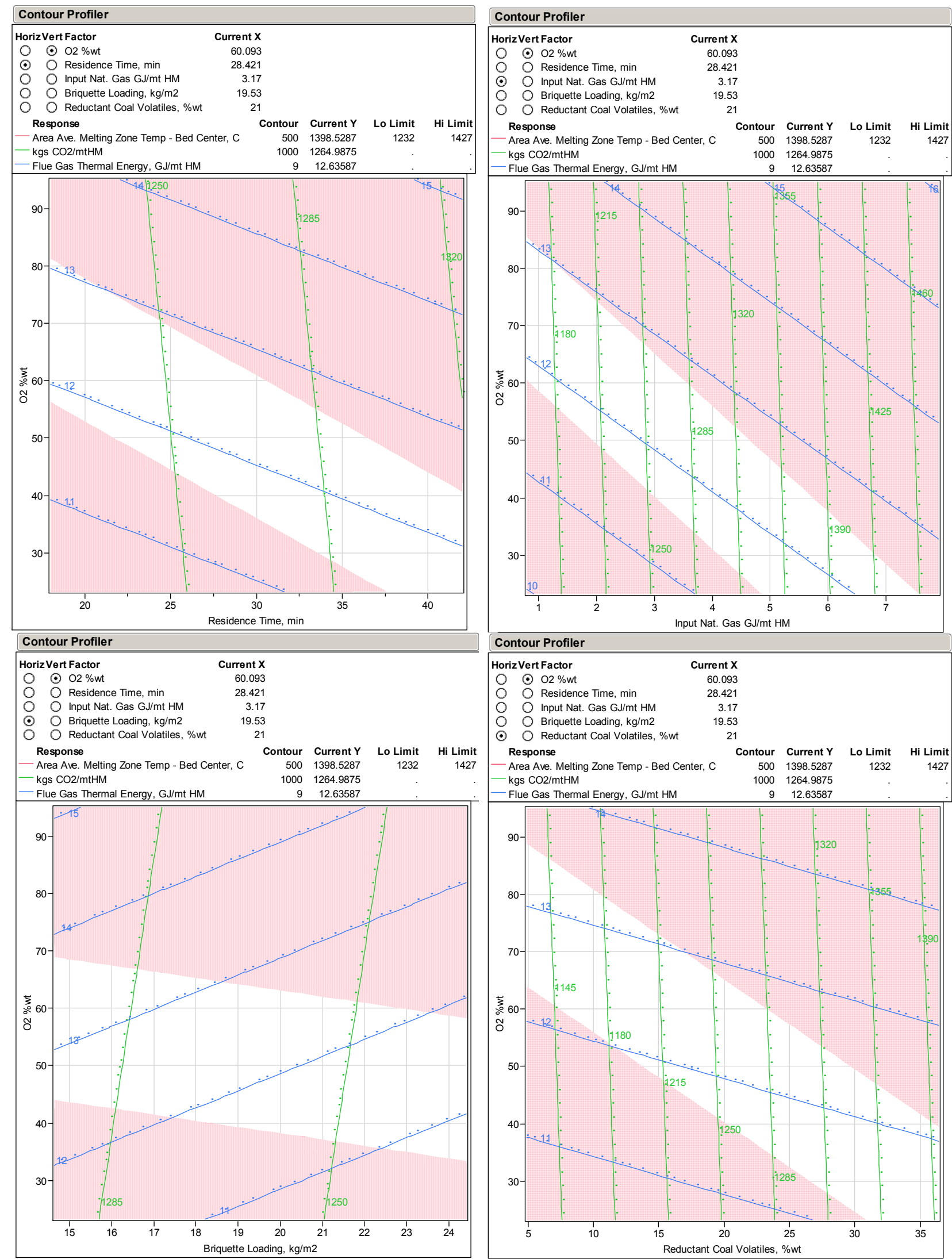
Figure 3-34. Desirability Optimization on Average Bed Center Temperature Melting Zone.

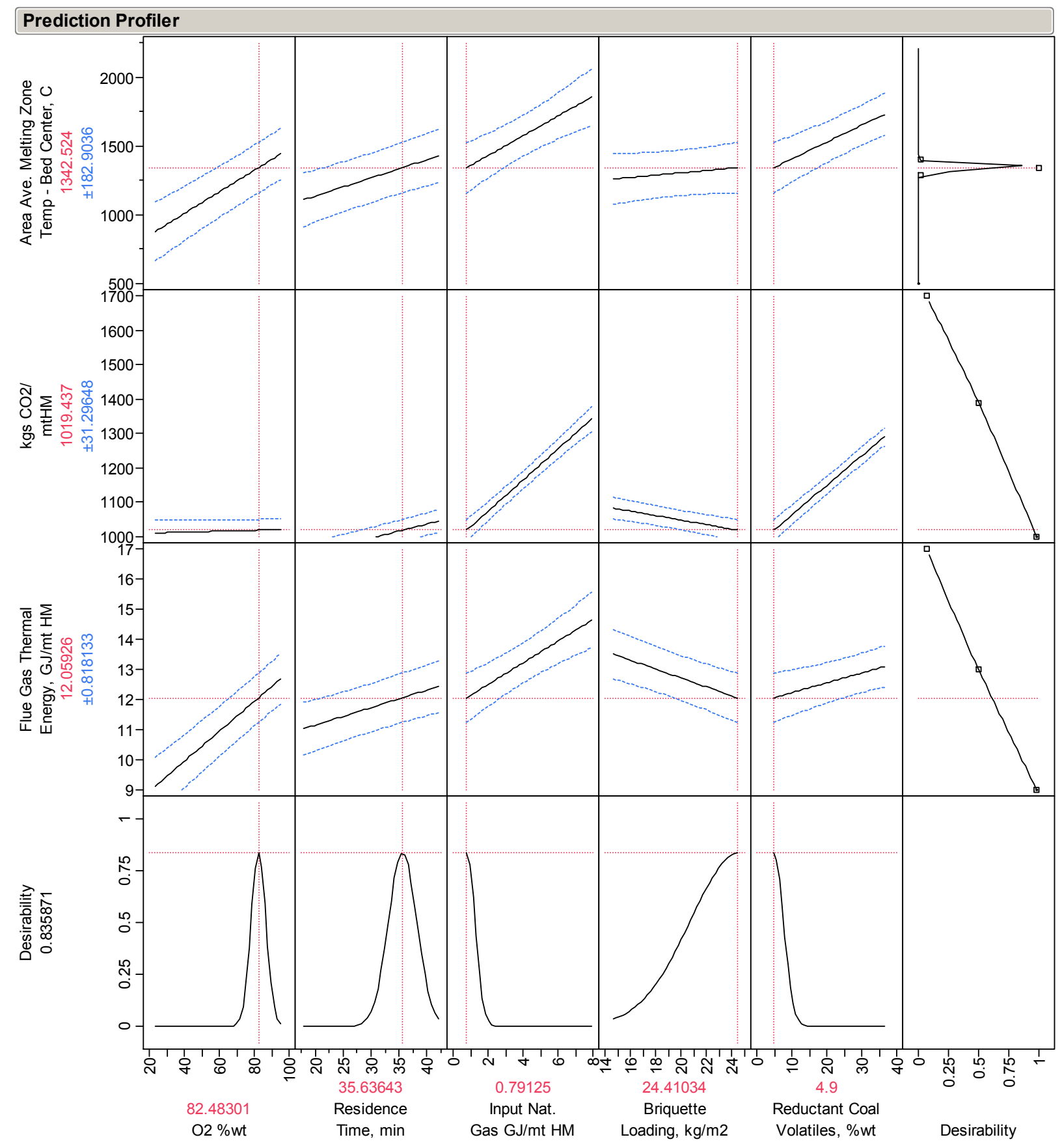




\section{3-6.8 Coal Type Comparison at Constant Operating Conditions}

Simulations DOE 13, DOE 14, and DOE 15 comprised a coal type series. Natural Gas remained constant at 4.5 MMBTU/mt HM $(4.75 \mathrm{GJ} / \mathrm{mt} \mathrm{HM})$, loading at $4.0 \mathrm{lbs} / \mathrm{ft}^{2}(19.53$ $\left.\mathrm{kg} / \mathrm{m}^{2}\right)$, oxygen concentration at $59 \%$, and hearth speed at $3.33 \mathrm{ft} / \mathrm{min}(1.01 \mathrm{~m} / \mathrm{min}-30$ minute residence time). Figures 35 and 36 provide comparison plots for temperature at bed center and velocity at six inches $(0.15 \mathrm{~m})$ above bed along the furnace centerline. It was evident that increasing volatile content increased temperature inside the furnace.

$$
\begin{array}{ll}
\text { DOE } 13=\text { Low Volatile Coal } & =5 \% \text { wt Volatile } \\
\text { DOE } 14=\text { Medium Volatile Coal } & =21 \% \text { wt Volatile } \\
\text { DOE } 15=\text { High Volatile Coal } & =36 \% \text { wt Volatile }
\end{array}
$$

Alternatively natural gas consumption could be decreased to lower temperature. Figure 3-37 provides a bed center temperature comparison showing the trend. Figure 3-38 shows velocity along furnace centerline six inches above bed. Velocity and mass flow increased with increasing coal volatiles and secondary oxygen injection flow. However secondary oxygen distribution at injection points (\% of total flow) remained constant in the series. OD increased with increased coal volatile content, due to fixed injection distribution along the furnace. 
Figure 3-35. Coal Type Comparison effect on Bed Center Temperature.

$\begin{array}{ll}\text { DOE } 13=\text { Low Volatile Coal }= & 5 \% \text { wt Volatile } \\ \text { DOE } 14=\text { Medium Volatile Coal } & =21 \% \text { wt Volatile } \\ \text { DOE } 15=\text { High Volatile Coal } & =36 \% \text { wt Volatile }\end{array}$

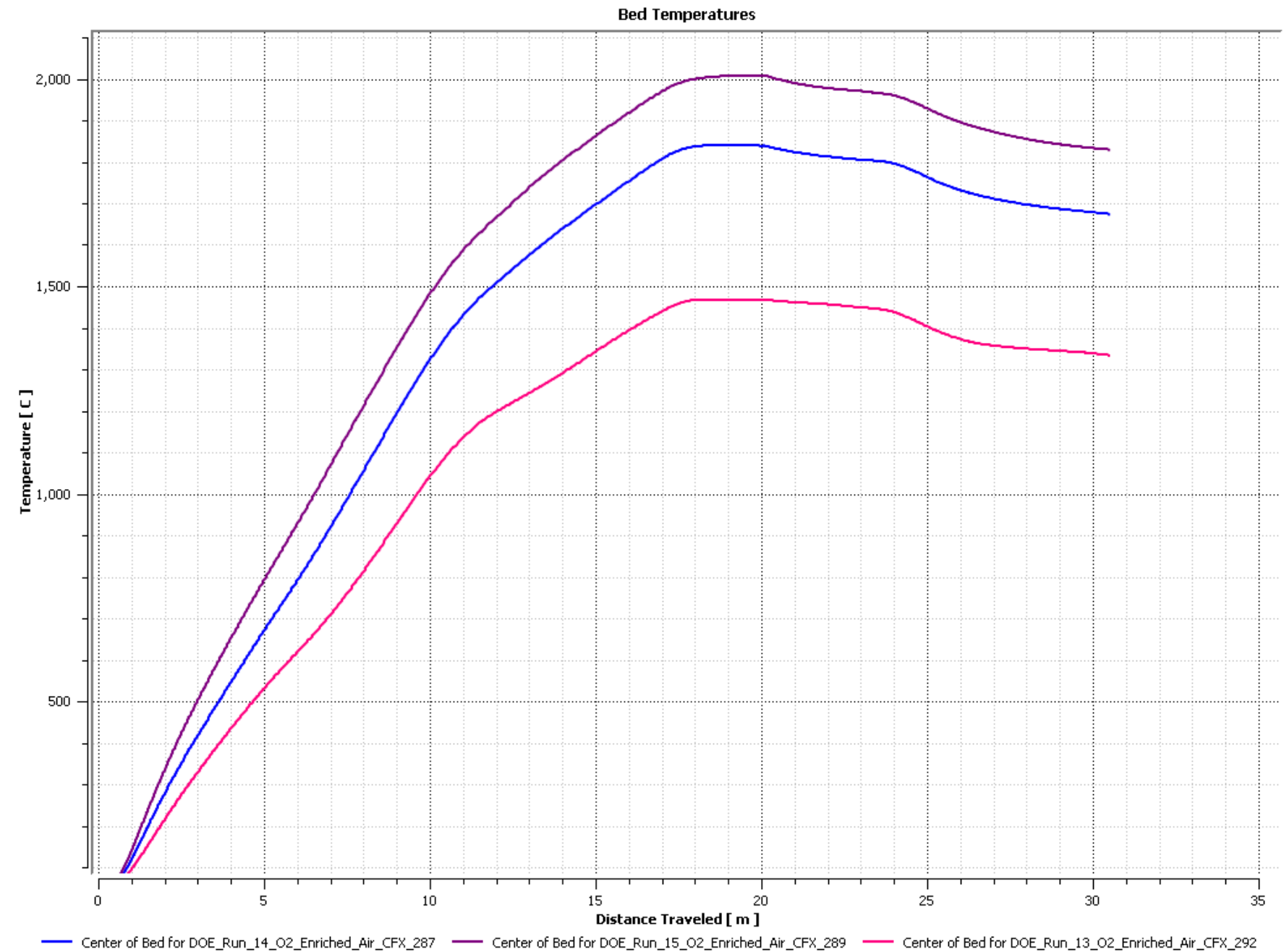




\section{Figure 3-36. Coal Type Comparison effect on Gas Velocity}

$$
\begin{array}{ll}
\text { DOE } 13=\text { Low Volatile Coal }= & 5 \% \text { wt Volatile } \\
\text { DOE } 14=\text { Medium Volatile Coal } & =21 \% \text { wt Volatile } \\
\text { DOE } 15=\text { High Volatile Coal } & =36 \% \text { wt Volatile }
\end{array}
$$

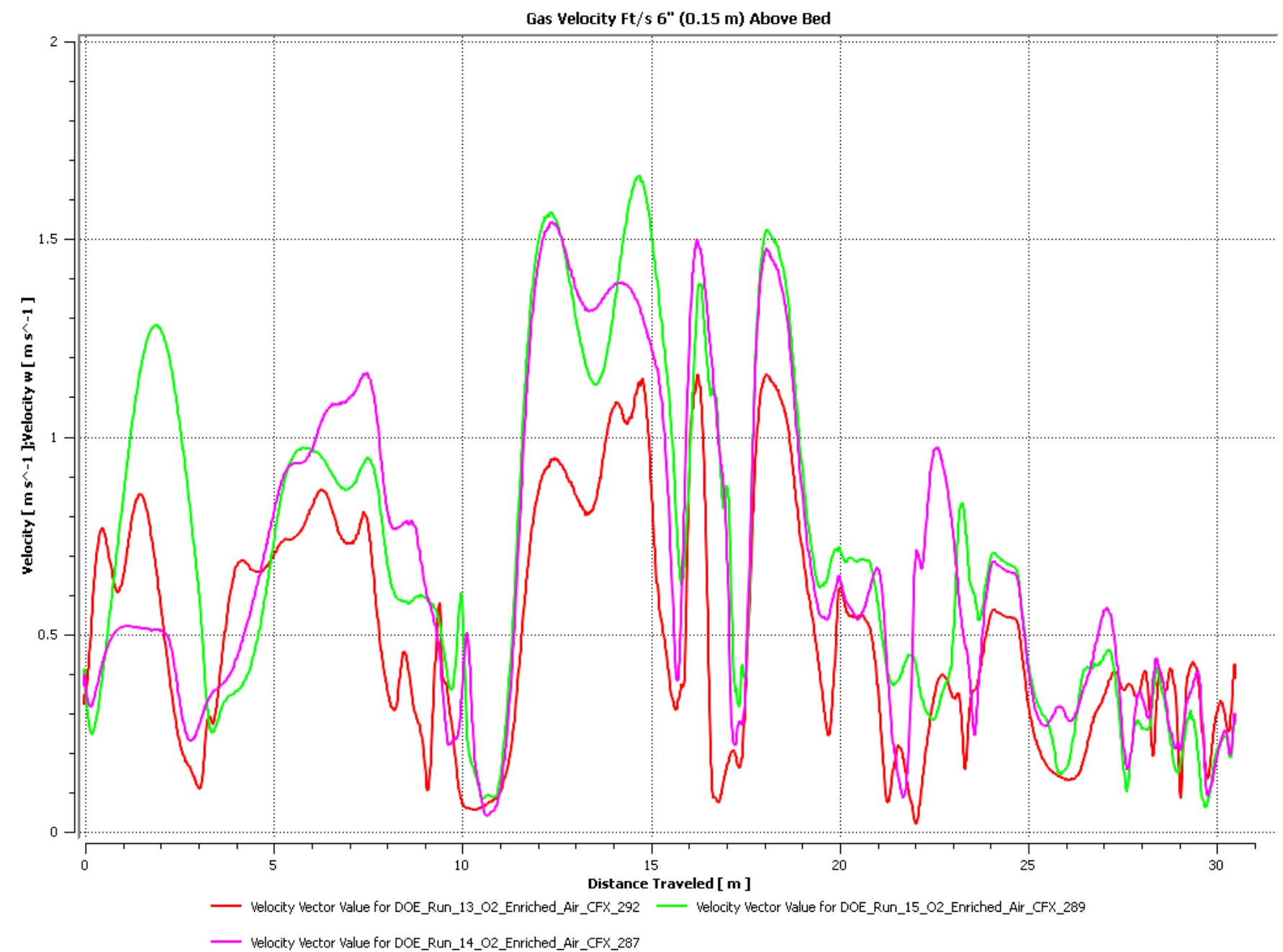




\section{3-6.9 Medium Volatile Coal with Varied Natural Gas Comparison}

DOE Simulations $11,11 \mathrm{a}, 11 \mathrm{~b}$ and $11 \mathrm{~d}$ comprised a natural gas series within the $59 \%$ oxygen group. In these simulations, loading remained constant at $4 \mathrm{lbs} / \mathrm{ft}^{2}\left(19.53 \mathrm{~kg} / \mathrm{m}^{2}\right)$, hearth speed at $3.33 \mathrm{ft} / \mathrm{min}(1.01 \mathrm{~m} / \mathrm{min}$ - 30 minute residence time) and oxygen concentration at $59 \%$. Natural gas was varied as follows:

Table 3-9. Natural Gas Series DOE 11, 11a,b,d.

\begin{tabular}{|c|c|c|c|}
\hline \multirow{2}{*}{$\begin{array}{c}\text { Simulation } \\
\text { ID }\end{array}$} & \multicolumn{2}{|c|}{ Natural Gas Rate } & Burner $\mathrm{O}_{2}$ Stoichiometry \\
& MMBTU/mt HM & GJ/mt HM & By Zone 1/ 2/ 3 \\
\hline DOE 11 & 3.0 & 3.17 & $1.1 / 1.05 / 0.85$ \\
\hline DOE 11b & 1.5 & 1.58 & $1.1 / 1.05 / 0.85$ \\
\hline DOE 11a & 0.75 & 0.79 & $1.1 / 1.05 / 0.85$ \\
\hline DOE 11d & 2.25 & 2.37 & $1.1 / 1.05 / 0.75$ \\
\hline
\end{tabular}

Decreased fuel rate lowered solids temperature in the furnace mid-section. Simulation 11 produced temperatures in excess of $3000^{\circ} \mathrm{F}\left(1649^{\circ} \mathrm{C}\right)$, while simulations $11 \mathrm{a}, \mathrm{b}$, produced temperatures in the target range; however, the fuel distribution at lower firing rates caused temperatures in the melting region to fall below $2500^{\circ} \mathrm{F}\left(1371^{\circ} \mathrm{C}\right)$. Decreased melting zone temperatures may have been acceptable if melting occurred up stream of the zone, shown by peak temperatures around $60 \mathrm{ft}(18.29 \mathrm{~m})$ in Figure 337. Simulation $11 \mathrm{~d}$ departed from burner fuel distribution, burner stoichiometry in firing zone three and secondary oxygen distribution. (Simulation 11c was an intermediate run, not included in the analysis.) These changes produced slightly higher temperatures in the last one-third of the furnace. These simulations demonstrated decreased natural gas consumption was possible; however, more simulations were required to optimize fuel distribution, burner stoichiometry and oxygen injection distribution. Figure 3-38 shows velocity $0.15 \mathrm{~m}$ above bed. Simulations $1 \mathrm{l}$, $\mathrm{a}$, and $\mathrm{b}$ produced very similar values and Ild showed a sharp spike caused by secondary oxygen injection. 
Figure 3-37. Natural Gas Comparison effect on Bed Center Temperature.

DOE $11=3.17 \mathrm{GJ} / \mathrm{mt} \mathrm{HM}$

DOE 11a $=0.79 \mathrm{GJ} / \mathrm{mt} \mathrm{HM}$

DOE 11b $=1.58 \mathrm{GJ} / \mathrm{mt} \mathrm{HM}$

DOE $11 \mathrm{~d}=2.37 \mathrm{GJ} / \mathrm{mt} \mathrm{HM}$

Bed Temperatures

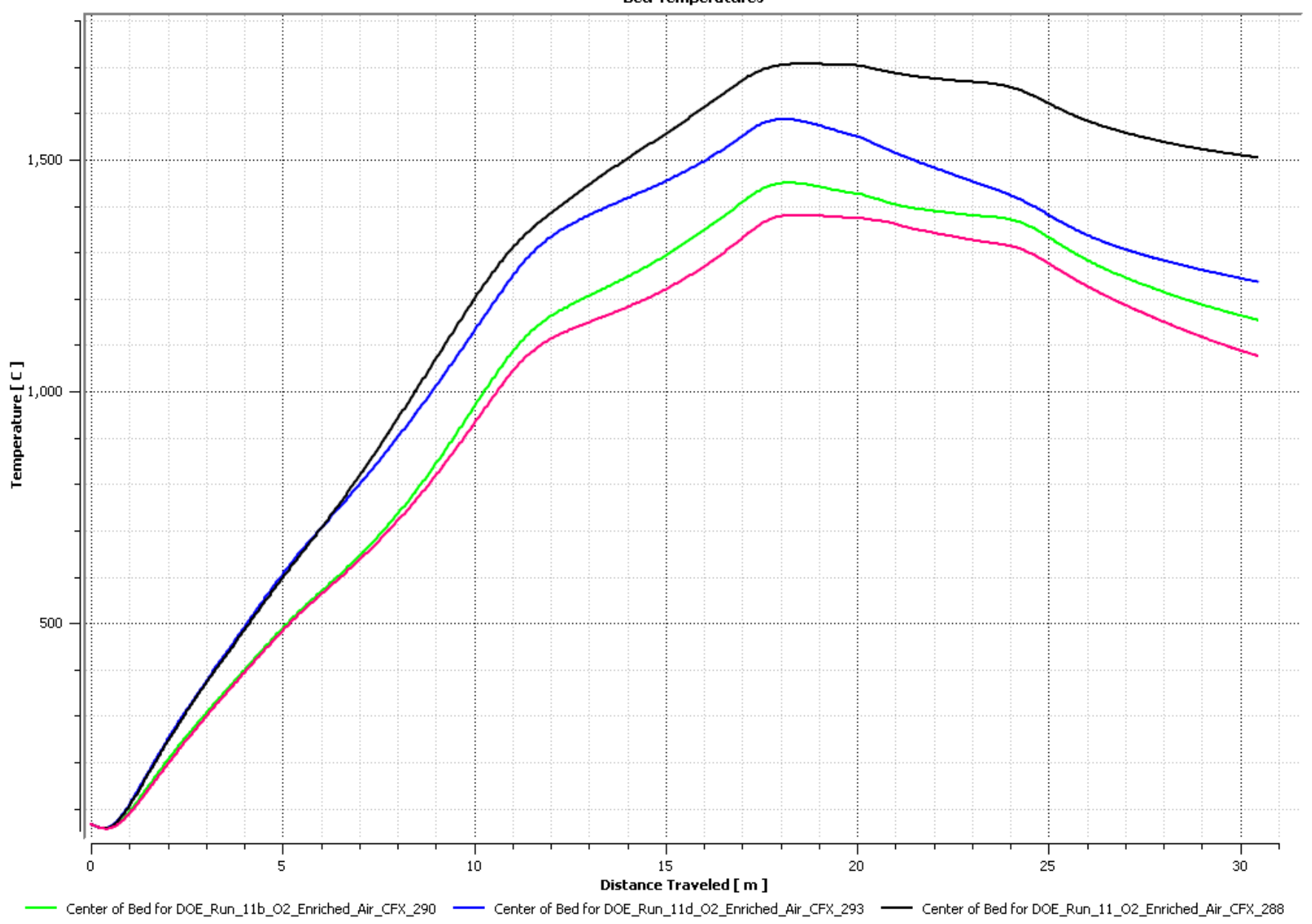

— Center of Bed for DOE_Run_11a_O2_Enriched_Air_CFX_289 
Figure 3-38. Natural Gas Comparison effect on Gas Velocity.

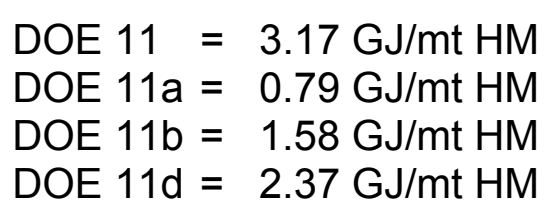

Gas Velocity 6" $(0.15 \mathrm{~m})$ Above Bed

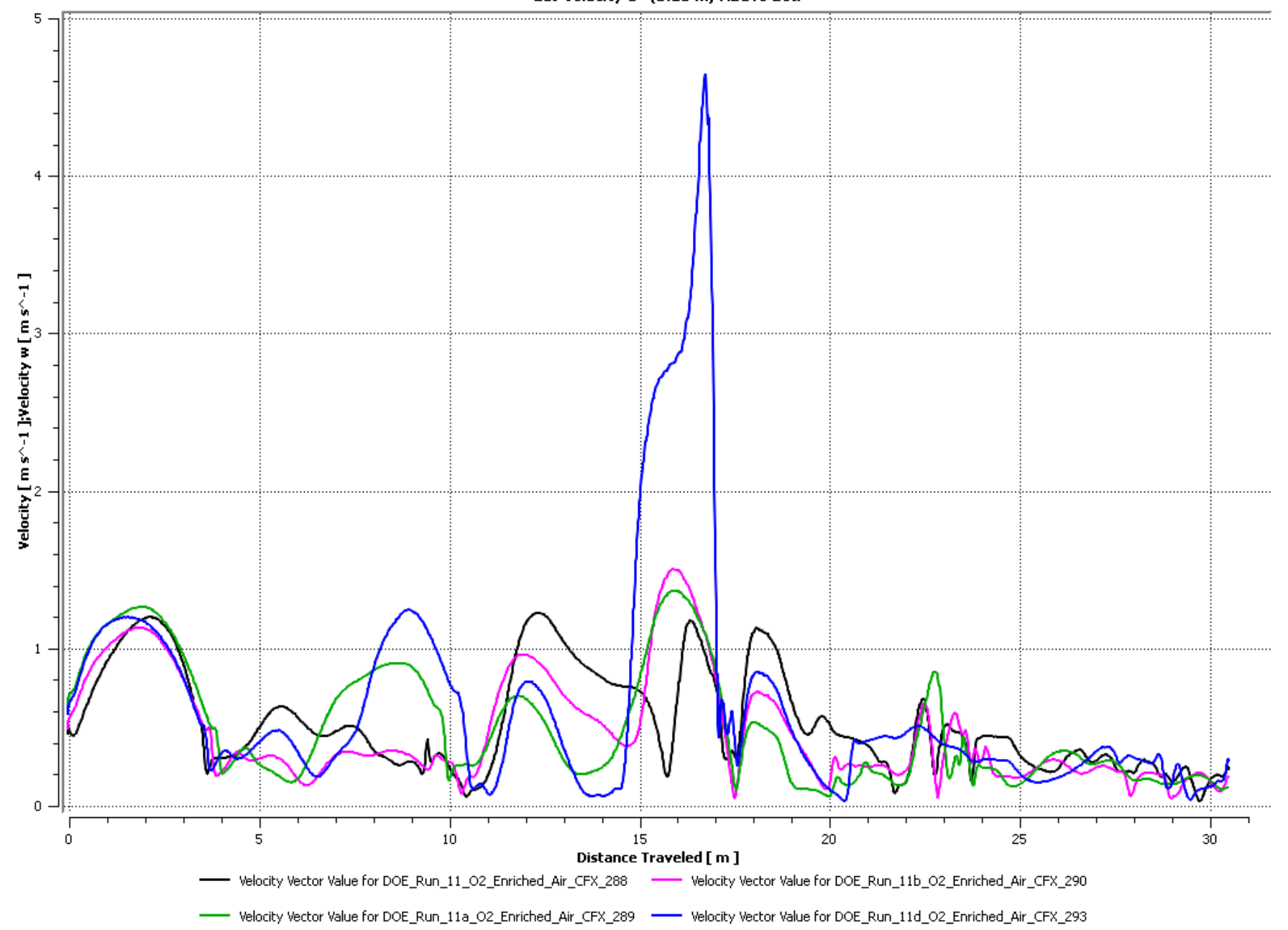




\section{3-6.10 Process Oxygen Concentration (Burners and Secondary Injection)}

Simulations DOE $23\left(95 \% \mathrm{O}_{2}\right)$, DOE $14\left(59 \% \mathrm{O}_{2}\right)$ and DOE $5\left(23 \% \mathrm{O}_{2}\right)$, comprised an oxygen concentration series at 4.5 MMBTU/mt HM natural gas (4.75 GJ/mt HM), 4 $\mathrm{lbs} / \mathrm{ft}^{2}\left(19.53 \mathrm{~kg} / \mathrm{m}^{2}\right)$ loading and $3.33 \mathrm{ft} / \mathrm{min}(1.10 \mathrm{~m} / \mathrm{min})$ hearth speed using a medium volatile coal. In Figure 3-39 the oxygen concentration effects are evident. Bed temperatures exceed $3500^{\circ} \mathrm{F}\left(1927^{\circ} \mathrm{C}\right)$ for most of the furnace when using $95 \%$ oxygen. Temperatures dropped about $200^{\circ} \mathrm{F}$ when the oxygen source concentration decreased to $59 \%$, but were still in excess of $3000^{\circ} \mathrm{F}\left(1649^{\circ} \mathrm{C}\right)$ through most of the furnace. Substituting air resulted in temperatures achieving the target range $\left(1427-1538^{\circ} \mathrm{C}\right)$. Velocity profiles shown in Figure 3-40 were nearly identical, indicating slight increases as coal volatile content increased. In this series the air system produced the lowest melting zone values.

\section{3-6.11 Mass Ratio Oxygen to mt Hot Metal and Total Energy (Natural Gas + Coal)/mt Hot Metal}

Optimizing oxygen consumption and total energy on a production basis was not possible because productivity was determined by mass throughput, and not influenced by temperature. Additional simulations are required where productivity is dependent on the solids temperature. This requires the ability to vary fuel, secondary combustion efficiency, oxygen concentration and loading, which greatly increases the number of simulations. Figures 41 and 42 may be useful for defining an oxygen to Hot Metal mass ratio as a function of total energy based on natural gas and coal inputs, but oxygen consumption cannot be optimized with this data set. Similarly it was not possible to optimize total fuel on a per ton basis because both natural gas and coal were independent variables in the parametric design. 
Figure 3-39. Oxygen Concentration Comparison effect Bed Center Temperature.

$$
\begin{aligned}
& \text { DOE 23 }=95 \% \mathrm{O}_{2} \\
& \text { DOE 14 }=59 \% \mathrm{O}_{2} \\
& \text { DOE 5 }=23 \% \mathrm{O}_{2}
\end{aligned}
$$

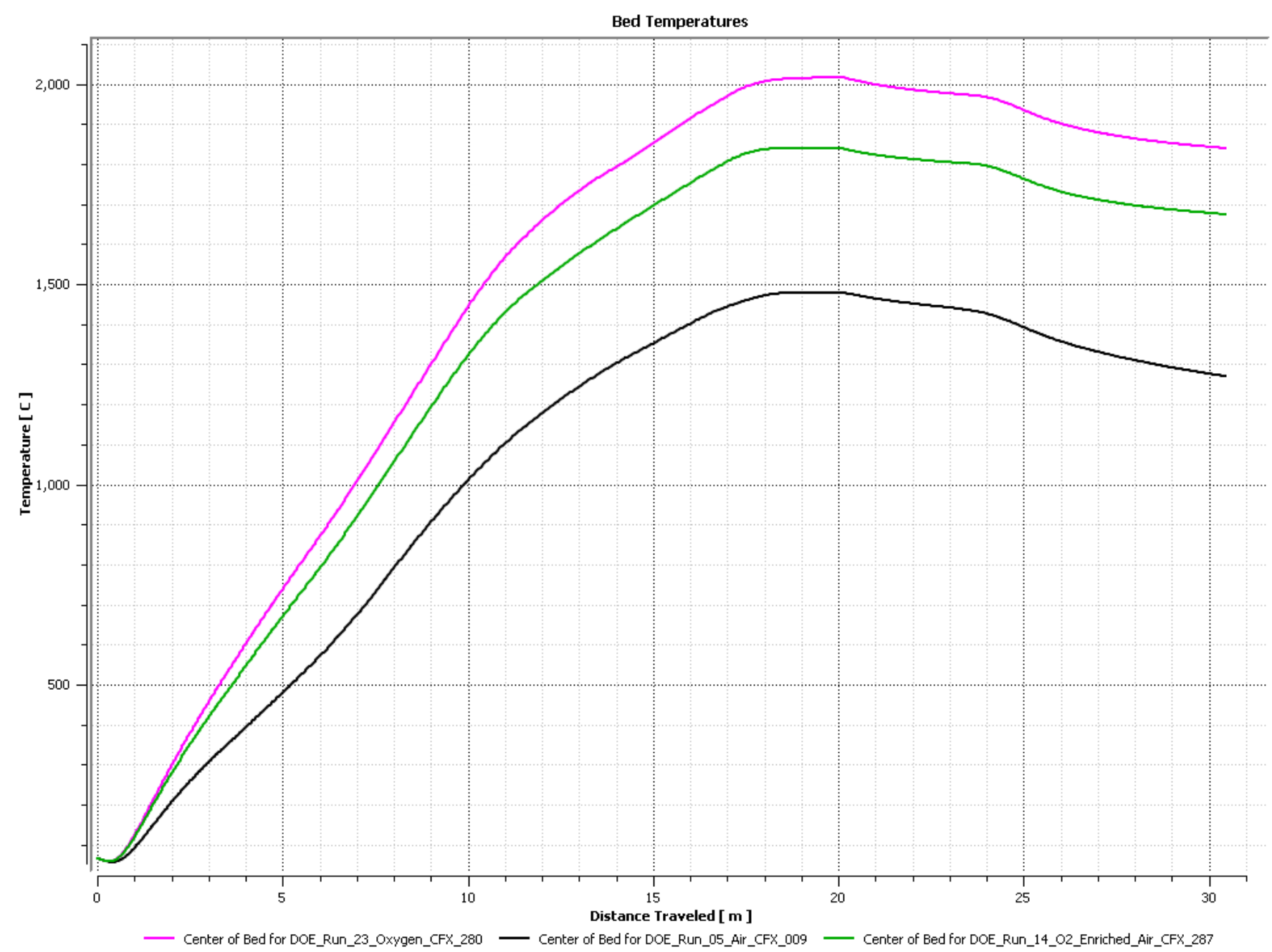


Figure 3-40. Oxygen Concentration Comparison effect Gas Velocity.

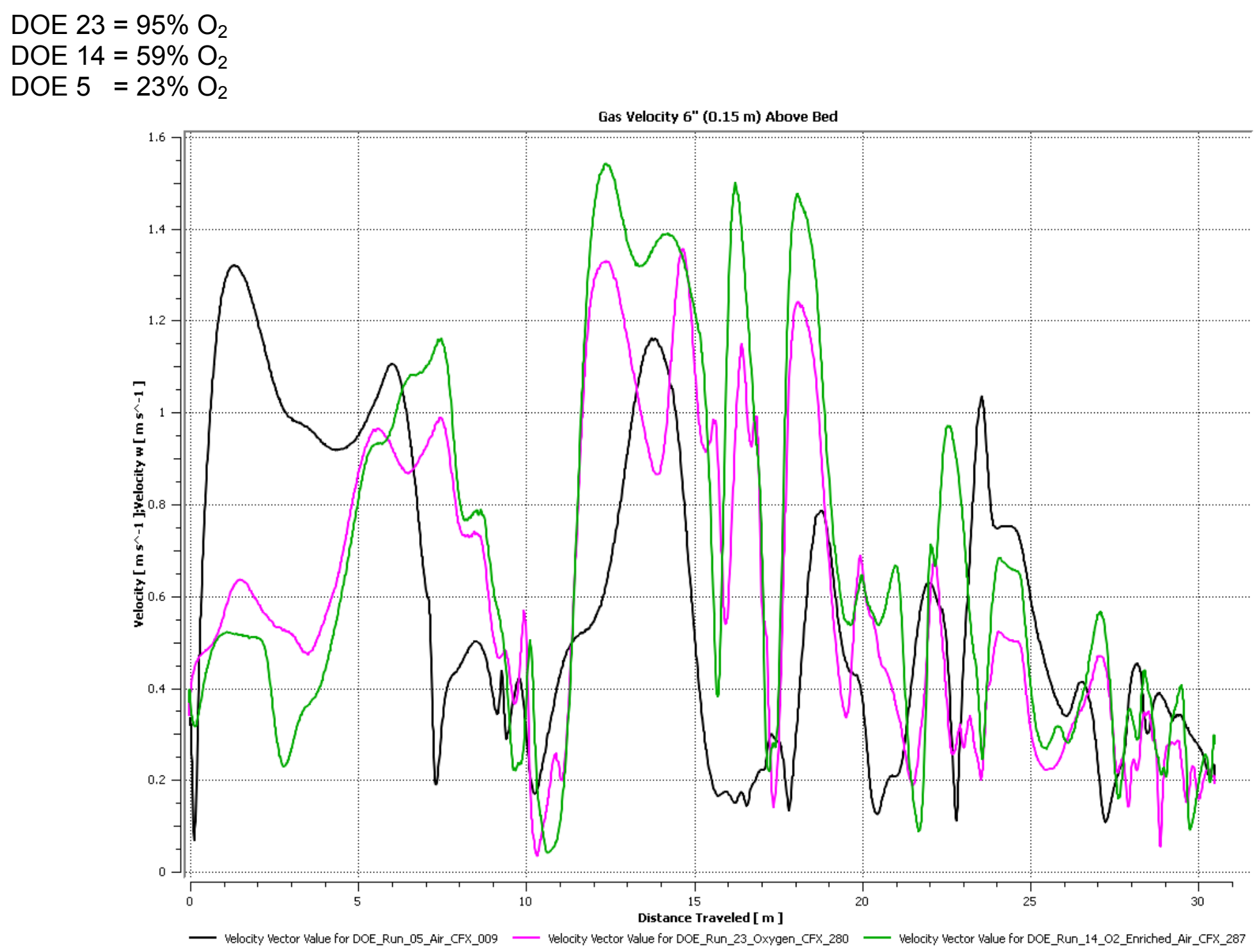


Figure 3-41. Oxygen:Hot Metal Mass Ratio vs. Energy Input.

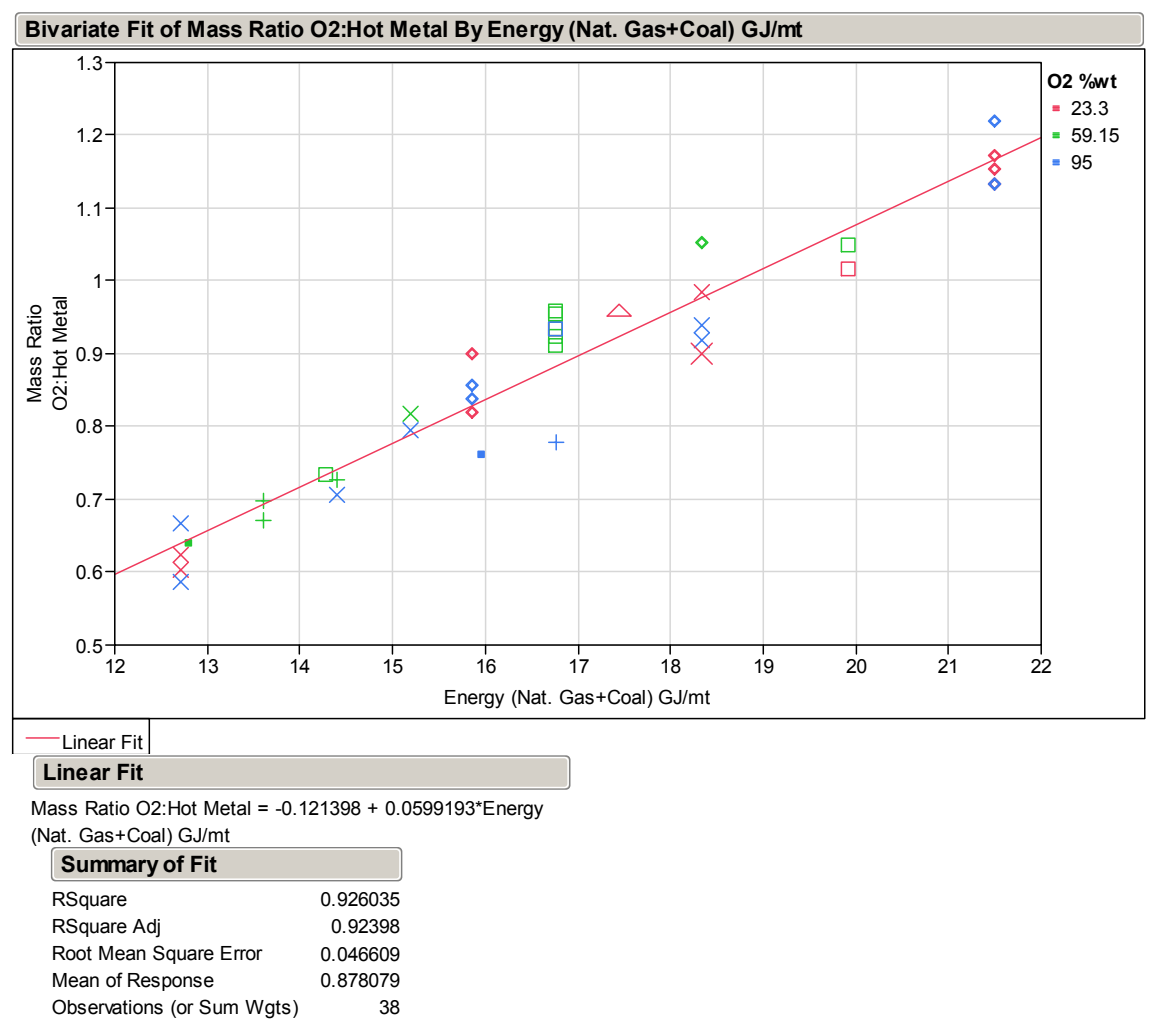

Figure 3-42. Average Melting Zone Temperature vs. Energy Input.

Bivariate Fit of Area Ave. Melting Zone Temp - Bed Center, C By Energy (Nat. Gas+Coal) GJ/mt

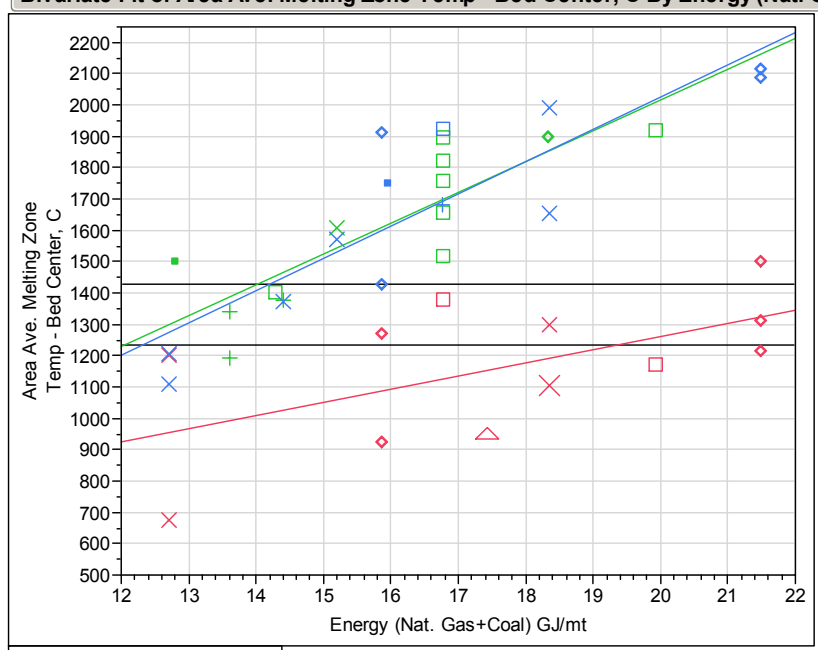

Linear Fit O2 \%wt==23.3
Linear Fit O2 \%wt==59.15
Linear Fit O2 \%wt==95

Linear Fit $02 \% w t==23.3$

Area Ave. Melting Zone Temp - Bed Center, C $=422.22685+$

41.970177Energy (Nat. Gas+Coal) GJ/mt

Linear Fit $02 \% \mathrm{wt}=\mathbf{=} 59.15$

Area Ave. Melting Zone Temp - Bed Center, C $=48.035273+$

98.351448*Energy (Nat. Gas+Coal) GJ/mt

Linear Fit $02 \%$ wt $==95$

Area Ave. Melting Zone Temp - Bed Center, C $=-35.16883+$

103.096^Energy (Nat. Gas+Coal) GJ/mt 


\section{3-6.12 Furnace Scale}

The simulated furnace was $4 \mathrm{ft}$ wide $\times 100 \mathrm{ft}(1.22 \times 30.47 \mathrm{~m})$ long unit (symmetry). At this scale there was concern about effect of furnace size on fluid dynamics and operating conditions. It was desired to make several simulations in larger furnaces to evaluate scale-up. Two simulations evaluated larger furnaces, one at $12 \mathrm{ft}$ wide $\times 200 \mathrm{ft}$ long $(3.66 \times 60.96 \mathrm{~m})$, increasing productivity by a factor of 9.6 from the base unit, and the second at $20 \mathrm{ft} \times 325 \mathrm{ft}(6.09 \times 99.06 \mathrm{~m})$ which increased productivity by a factor of 26 from the base unit. DOE 05 was used for the baseline from the parametric series for comparison. Residence time in the baseline unit was 30 minutes, while in the larger units residence time decreased to 18 minutes. The change in residence time was in part due to maintaining a similar bed temperature profile in the larger units. Table 3-10 summarizes main differences in boundary conditions and also provides several parameters for comparison of units: Oxygen Consumption mass ratio O2/Hot Metal, Flue Gas Emission mass ratio $\mathrm{CO}_{2} / \mathrm{Hot}$ Metal, and Flue Gas Energy ratio $\mathrm{GJ} / \mathrm{mt}$ Hot Metal.

Fuel distribution and firing rate changed as burner number and furnace length increased. A fourth firing zone was added to permit more flexibility in defining the distribution. The baseline (with symmetry) contained 24 burners (12 per side). The larger units which were full scale (no symmetry) had 54 and 63 burners respectively. The simulations were performed using an air system and the medium volatile reductant coal.

Figure 3-43 compares temperature along furnace centerlines. Percent distance traveled is based on solids movement; gas moves counter-current to the solids flow. In the 200 $\mathrm{ft}$ unit bed surface temperatures were marginal, despite a $1.0 \mathrm{MMBTU} / \mathrm{mt} \mathrm{HM}(1.06$ $\mathrm{GJ} / \mathrm{mt})$ increase in natural gas, relative to the baseline $(4 \mathrm{ft} \times 100 \mathrm{ft}(1.22 \times 30.47 \mathrm{~m}))$ unit. This discrepancy was corrected in the $325 \mathrm{ft}$ unit by increasing natural gas by 1.5 MMBTU/mt HM $(1.58 \mathrm{GJ} / \mathrm{mt})$ relative to the baseline. Temperature decreased steadily through melting zone. Additional simulations were required to optimize the fuel distribution and input. Similarly, burner placement was not optimized.

Figure 3-44 compares velocity profiles. It is apparent that velocity tends to increase with furnace length. Flue gas is moving from right to left in these plots, as percent distance traveled is based on solids movement. Furnace clearances were increased with each scale-up but not optimized. Increasing furnace length while maintaining constant velocity profiles requires roof clearances to increase. Furnace width can be used to simultaneously increase productivity and cross sectional area without increasing roof height. Time did not permit simulating width beyond $20 \mathrm{ft}(6.1 \mathrm{~m})$. 
Table 3-10. Simulation Scale-Up Comparison.

Simulation Scale-Up Comparison

\begin{tabular}{|c|c|c|c|c|c|c|c|c|c|}
\hline \multirow{2}{*}{$\begin{array}{l}\text { Simulation ID } \\
\text { Furnace }\end{array}$} & \multicolumn{3}{|c|}{ DOE_05 } & \multicolumn{3}{|c|}{ DOE_04b x 200} & \multicolumn{3}{|c|}{ DOE_04b x 325} \\
\hline & & $\mathrm{ft}$ & $\mathbf{m}$ & & ft & $\mathbf{m}$ & & ft & m \\
\hline Width & & 4 & 1.2 & & 12 & 3.7 & & 20 & 6.1 \\
\hline Length & & 100 & 30.5 & & 200 & 61.0 & & 325 & 99.1 \\
\hline \multirow{3}{*}{ Hearth Area } & & $\mathrm{ft}^{2}$ & $\mathrm{~m}^{2}$ & & $\mathrm{ft}^{2}$ & $\mathbf{m}^{2}$ & & $\mathrm{ft}^{2}$ & $\mathrm{~m}^{2}$ \\
\hline & & 400 & 37.2 & & 2400 & 222.9 & & 6500 & 603.8 \\
\hline & & ${ }^{0} \mathbf{F}$ & ${ }^{\circ} \mathrm{C}$ & & ${ }^{0} \mathbf{F}$ & ${ }^{\circ} \mathrm{C}$ & & ${ }^{0} \mathrm{~F}$ & ${ }^{\circ} \mathrm{C}$ \\
\hline Oxidant and Temp & Air & 1250 & 677 & Air & 1250 & 677 & Air & 1250 & 677 \\
\hline Natural Gas & & 4.5 & 4.75 & & 5.5 & 5.8025 & & 6 & 6.33 \\
\hline \multirow[t]{2}{*}{ Coal Type } & \multicolumn{3}{|c|}{ Med. Vol. Bit. } & \multicolumn{3}{|c|}{ Med. Vol. Bit. } & \multicolumn{3}{|c|}{ Med. Vol. Bit. } \\
\hline & & $\mathbf{l b} / \mathbf{f t}^{2}$ & $\mathbf{k g} / \mathbf{m}^{2}$ & & $\mathbf{l b} / \mathbf{f t}^{2}$ & $\mathrm{~kg} / \mathrm{m}^{2}$ & & $\mathbf{l b} / \mathbf{f t} \mathbf{t}^{2}$ & $\mathrm{~kg} / \mathrm{m}^{2}$ \\
\hline \multirow[t]{2}{*}{ Briquette Load } & & 4.0 & 19.5 & & 4.0 & 19.5 & & 4.0 & 19.5 \\
\hline & & $\mathrm{ft} / \mathrm{min}$ & $\mathbf{m} / \mathbf{m i n}$ & & $\mathrm{ft} / \mathrm{min}$ & $\mathbf{m} / \mathbf{m i n}$ & & $\mathrm{ft} / \mathrm{min}$ & $\mathrm{m} / \mathrm{min}$ \\
\hline Hearth Speed & & 3.33 & 1.02 & & 11.10 & 3.38 & & 18.00 & 5.49 \\
\hline sidence Time, min & & \multicolumn{2}{|c|}{30} & \multicolumn{3}{|c|}{18} & \multicolumn{3}{|c|}{18.1} \\
\hline Firing Zone & Stoich. 02 & MMBT U/hr & GJ/hr & Stoich. 02 & MMBTU/hr & GJ/hr & Stoich. 02 & MMBTU/hr & GJ/hr \\
\hline 1 & 1.10 & 0.74 & 0.78 & 1.10 & 8.5 & 8.97 & 1.10 & 32.7 & 34.50 \\
\hline 2 & 1.05 & 0.74 & 0.78 & 1.05 & 20.3 & 21.42 & 1.05 & 50.1 & 52.86 \\
\hline 3 & 0.85 & 1.67 & 1.76 & 0.875 & 3.7 & 3.90 & 0.875 & 13.1 & 13.82 \\
\hline 4 & & & & 0.825 & 4.4 & 4.64 & 0.825 & 13.1 & 13.82 \\
\hline \multirow[t]{2}{*}{ Metal Mass Ratio } & & \multicolumn{2}{|c|}{0.93} & \multicolumn{3}{|c|}{0.89} & & \multicolumn{2}{|c|}{0.87} \\
\hline & & \multicolumn{2}{|c|}{$\mathrm{kg} / \mathrm{mt} \mathrm{HM}$} & \multicolumn{3}{|c|}{$\mathrm{kg} / \mathrm{mt} \mathbf{H M}$} & & \multicolumn{2}{|c|}{$\mathrm{kg} / \mathrm{mt} \mathrm{HM}$} \\
\hline \multirow[t]{2}{*}{ Flue Gas $\mathrm{CO}_{2}$} & & \multicolumn{2}{|c|}{1,264} & \multicolumn{3}{|c|}{1,370} & & \multicolumn{2}{|c|}{1,361} \\
\hline & & \multicolumn{2}{|c|}{ MMBTU/mt HM GJ/mt HM } & \multicolumn{3}{|c|}{ MMBTU/mt HM GJ/mt HM } & & \multicolumn{2}{|c|}{ MMBTU/mt HM GJ/mt HM } \\
\hline \multirow[t]{2}{*}{ Flue Gas Energy } & & 10.1 & 10.7 & & 10.4 & 11.0 & & 10.2 & 10.8 \\
\hline & & ${ }^{0} \mathbf{F}$ & ${ }^{\circ} \mathrm{C}$ & & ${ }^{0} \mathbf{F}$ & ${ }^{\circ} \mathrm{C}$ & & ${ }^{0} \mathbf{F}$ & ${ }^{\circ} \mathrm{C}$ \\
\hline \multirow[t]{2}{*}{ Gas Exit Temp, F } & & 2,151 & 1177 & & 2,441 & 1338 & & 2,426 & 1330 \\
\hline & & mt Hot $N$ & $\mathbf{1} / \mathbf{y r}$ & & mt Hot 1 & 1/yr & & mt Hot $\mathrm{N}$ & 1/yr \\
\hline $\begin{array}{l}\text { imated Production } \\
\text { ield @7884 hrs/yr) }\end{array}$ & & 5,5 & & & $52, \mathrm{c}$ & & & 143 & \\
\hline$\%$ of Hearth Char & & 4. & & & 2. & & & 1. & \\
\hline
\end{tabular}


Figure 3-43. Bed Surface Temperature Comparison with Furnace Size.

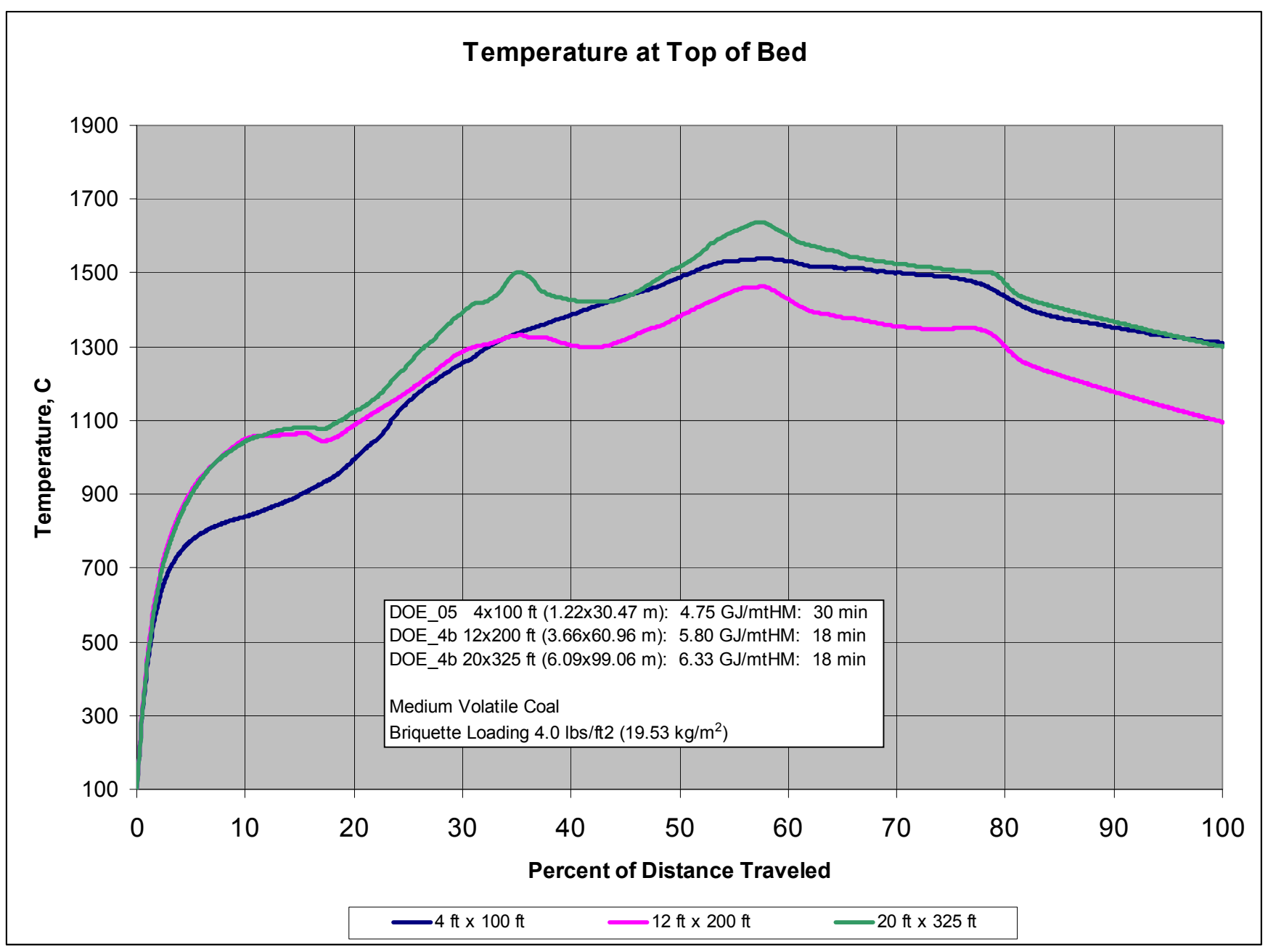


Figure 3-44. Gas Velocity Comparison with Furnace Size.

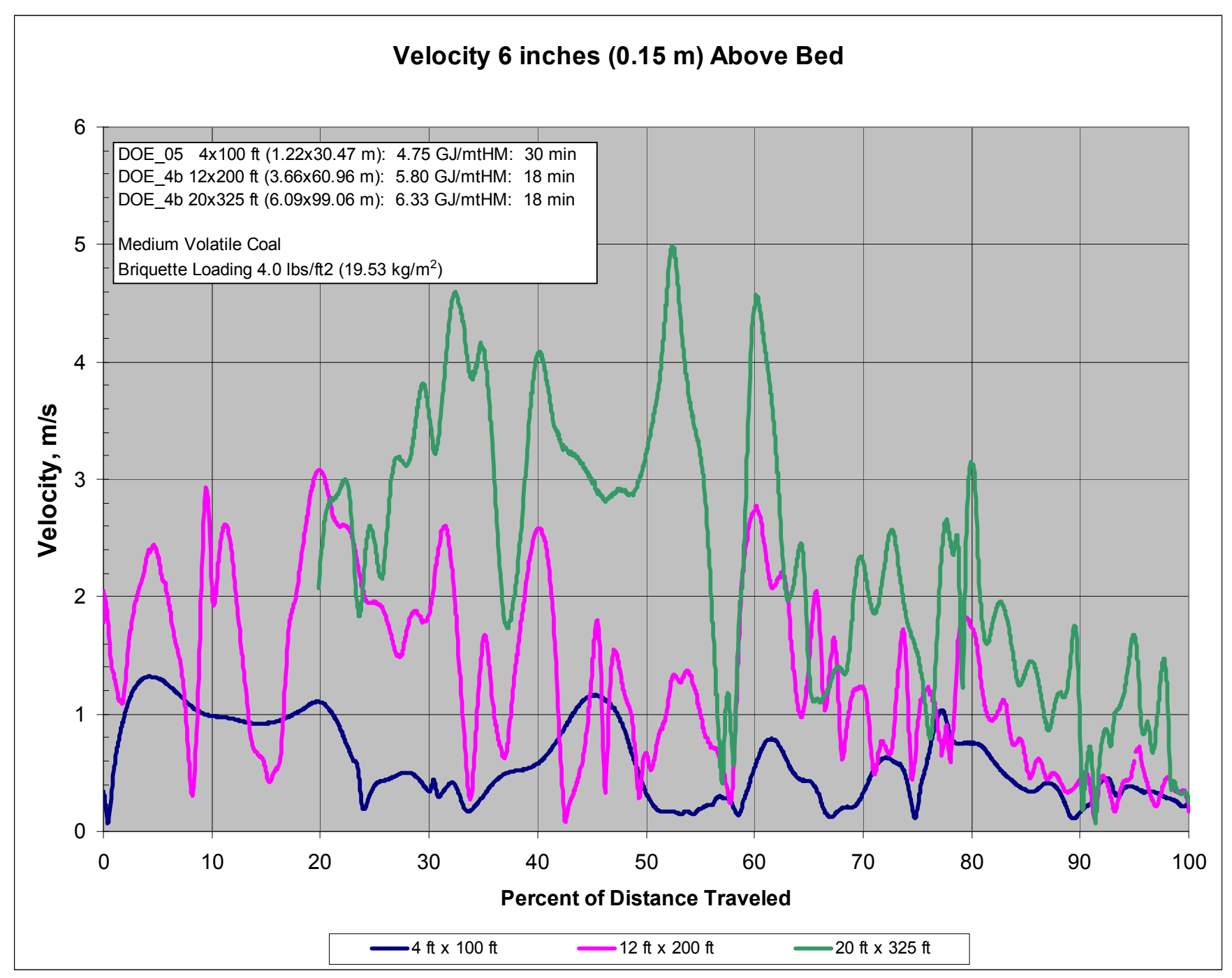




\section{3-7.0 BENEFIT ASSESSMENT}

Natural gas consumption can be minimized by selection of coal type and oxygen concentration in the oxidant streams. Gas consumption rates as low as $0.75 \mathrm{MMBTU} / \mathrm{mt}$ $\mathrm{HM}(0.79 \mathrm{GJ} / \mathrm{mt} \mathrm{HM})$ were achieved when using medium and high volatile bituminous coals. Since coal costs are generally less than natural gas reductant coal energy should be maximized. However reductant coal addition is also constrained by agglomerate mix chemistry, stoichiometric addition rate, and volatile content.

The simulations indicated total energy consumption based on natural gas and reductant coal could be as low as $13 \mathrm{MMBTU} / \mathrm{mt} \mathrm{HM}(13.7 \mathrm{GJ} / \mathrm{mt} \mathrm{HM})$. Hot hearth return (in RHF systems) was not simulated in this series. It is expected that hot hearth return would decrease both energy consumption and residence time. In a linear furnace system hot hearth return implies paired furnaces or an enclosed heated return. These alternatives were not evaluated in this study.

Oxygen consumption on a per ton basis is directly related to productivity and fuel input. It was not possible to optimize oxygen consumption because of the experimental design criteria. Oxygen consumption did not appear affected by oxidant oxygen concentration. Based on these simulations the oxygen to product mass ratio ranged between 0.8 and 1.1.

The simulations demonstrated an alternative for blending coals and/or hearth char to tailor a reductant volatile content for optimum energy input and furnace temperature. This area was not fully explored.

Increased feed loading will help to minimize natural gas consumption, but increased loads are presumed to remain as a monolayer of agglomerated feed, multiple layers in effect increase residence time and decrease productivity.

The benefits associated with pure oxygen were difficult to discern. It may be that an intermediate oxygen concentration or that independent oxidant oxygen concentrations (primary/secondary) streams could minimize energy consumption. This is subject for future study. 


\section{3-8.0 ACCOMPLISHMENTS}

1. Combined spreadsheet mass balances with CFD simulations resulted in a simulation method that can be used to evaluate linear hearth furnaces. It is expected that the same technique could be applied to rotary hearth units.

2. Forty-one simulations were performed in a partial factorial screening design (which permitted the analysis of process variable interaction).

a) Total Energy and Total mass flow (including hearth carbon) to the process must be evaluated, especially if hearth carbon is a significant fraction of the total flow. In these simulations hearth carbon was about $50 \%$ of total flow.

b) The process is temperature sensitive to certain coal types and oxidant sources. Nitrogen introduced with the oxidant functions to absorb energy. As nitrogen content decreases, the system becomes more sensitive to temperature excursions, particularly if coal volatile content is increased.

c) Carbon dioxide emission varied incrementally between 1100 and $1400 \mathrm{kgs} / \mathrm{mt}$ Hot Metal $(2,420$ and $3,080 \mathrm{lb} / \mathrm{mt} \mathrm{HM})$. The rate was mainly affected by natural gas consumption, coal volatile content and marginally by briquette loading. Minimized emissions occurred at $82 \%$ oxygen, 35 minutes residence time, 0.79 $\mathrm{GJ} / \mathrm{mt} \mathrm{HM}$ natural gas $(0.75 \mathrm{MMBTU} / \mathrm{mt} \mathrm{HM}), 24.4 \mathrm{~kg} / \mathrm{m}^{2}\left(5 \mathrm{lbs} / \mathrm{ft}^{2}\right)$ briquettes, and $4.9 \%$ coal volatiles. However given the limitations of the experimental design this minimum may or may not be the global value.

d) Beginning with a $2 \mathrm{ft} \times 100 \mathrm{ft}(0.61 \times 30.48 \mathrm{~m})$ unit, furnace size was successfully increased to $12 \mathrm{ft} \times 200 \mathrm{ft}(3.66 \times 60.96 \mathrm{~m})$ and $20 \mathrm{ft} \times 325 \mathrm{ft}(6.09 \times 99.06 \mathrm{~m})$.

3. It is possible to graphically quantify basic process parameters, such as residence time, feed loading, natural gas consumption, oxidant oxygen concentration and coal type. These graphs can be used to enhance understanding of the process and identify operating conditions of interest.

4. Preliminary evaluation determined a minimum preheat temperature for air, based on yielding similar natural gas consumption rates when using an oxygen system. This temperature occurs around $1250^{\circ} \mathrm{F}\left(677^{\circ} \mathrm{C}\right)$. 


\section{3-9.0 REFERENCES}

1. ANSYS CFX 12 Computational Fluid Dynamics Software, ANSYS, Inc. Southpointe 275 Technology Drive Canonsburg, PA 15317.

2. FactSage Thermochemical Software, Center for Research in Computational Thermochemistry, Dept. Chemical Engineering, University of Montreal, Montreal, Canada H3C 3A7.

3. JMP Statistical Software, SAS Institute Inc.100 SAS Campus Drive Cary, NC 27513-2414.

4. S. Halder and R.J. Fruehan, Reduction of Iron Oxide Carbon Composites: Part 1. Estimation of Rate Constants, Metallurgical and Material Transactions B, Vol. 38B, December 2008, pp. 784-795.

5. S. Halder and R.J. Fruehan, Reduction of Iron Oxide Carbon Composites: Part II. Rates of Reduction of Composite Pellets in a Rotary Hearth Furnace Simulator, Metallurgical and Material Transactions B, 38B, December 2008, pp. 796-808.

6. S. Halder and R.J. Fruehan, Reduction of Iron Oxide Carbon Composites: Part III. Shrinkage of Composite Pellets during Reduction, Metallurgical and Material Transactions B, Vol. 38B, December 2008, pp. 796-817.

7. Otavio Fortini and Richard Fruehan, Evaluation of a New Process for Ironmaking: A Productivity Model for the Rotary Hearth Furnace, Steel Research Int. 75 (2004) No. 10 pp. 625-631.

8. Hao Liu, Chunhua Luo, Shigeru Kato, Shigeyuki Uemiya, Masahiro Kaneko, Toshinori Kojima, Kinetics of CO2/Char Gasification at Elevated Temperatures, Part I: Experimental Results, Fuel Processing Technology 87 (2006) pp.775-781.

9. Hao Liu, Chunhua Luo, Masaomi Toyota, Shigeyuki Uemiya, Toshinori Kojima, Kinetics of $\mathrm{CO} 2$ Char Gasification at Elevated Temperatures: Part II, Clarification of Mechanism through Modeling and Char Characterization, Fuel Processing Technology 87 (2006), pp. 769-774.

10. R.J. Quann and A.F. Sarofim, Vaporization of Refractory Oxides During Pulverized Coal Combustion, 19th Symposium on combustion/The Combustion Institute, 1982, pp. 1429-1440.

11. G. P. Huffman, F. E. Huggins and G. R. Dunmyre, Investigation of the HighTemperature Behavior of Coal Ash in Reducing and Oxidizing Atmospheres, Fuel 1981 Vol. 60, pp. 585-597.

12. D. M. Kundrat, Method of Reducing Metal Oxide in a Rotary Hearth Furnace Heated by an Oxidizing Flame, US Patent 5,567,224, Oct, 221996.

13. D. C. Meissner, T. H. Boyd, J. A. Lepinski, and J. D. Sloop, Method for Rapid Reduction of Iron Oxide in a Rotary Hearth Furnace, US Patent 5,730,775, Mar. 24, 1998.

14. B. Sarma and M. Ding, Production of Direct Reduced Iron with Reduced Fuel Consumption and Emission of Carbon Monoxide, US Patent 5,951,740, Sep. 14, 1999.

15. M. Nishimura and T. Suzuki, Direct Reduction Method and Rotary Hearth Furnace, M. Nishimura and T. Suzuki, US Patent 5,989,019, Nov. 23, 1999.

16. K. Fuji, H. Tanaka, T. Harada, T. Suglyama, Y. Takenaka, K. Miyagawa, S. Shirouchi, H. Iwakiri, M. Nishimura, T. Umeki, S. Hashimoto and T. Uehara, Method of Producing Reduced Iron Agglomerates, US Patent 6,129,777. 
17. Y. Kamei, T. Kawaguchi, H. Yamaoka, Y. Nakumura, Method and Facility for Producing Reduced Iron, US Patent 6,284,017 B1, Sep. 4, 2001

18. M. Tateishi, M. Tetsumoto, Apparatus and Method for Producing Reduced Metal, US Patent 6,368,379 B1, Apr. 9, 2002.

19a. T. Harada, H. Tanaka, H. Sugitatsu, Method for Manufacturing Reduced Metal, Patent Application Publication US 2004/0163493 A1, Aug 26, 2004.

19b. T. Harada, H. Tanaka, H. Sugitatsu, Method for Manufacturing Reduced Metal, US Patent 7,572,316, B2, Aug. 11, 2009.

20. W-K. Lu and D. F. Huang, The Evolution of Ironmaking Process Based on CoalContaining Iron Ore Agglomerates, ISIJ International Vol. 41 (2001) No. 8, pp. 807-812.

21. R. Degel, P. Fontana, G. DeMarchi, H-J. Lehmkuhler, A New Generation of Rotary Hearth furnace Technology for Coal based DRI Production, Stahl und Eisen 120, 2000 Nr.2, pp. 33-40.

22. D. Gilbert, Coal Based DRI: Know the Questions/Get the Answers, Iron Ore for Alternative Iron Units October 25-27, 1999, Charlotte, NC.

23. Direct from Midrex: From the Hearth - RHF Technologies, Special Report Winter 2007/2008.

24. A. Murao, Y. Sawa, H. Hiroha, T. Matsui, N. Ishiwata, T. Higuchi and K. Takeda, Hi-QIP, A New Ironmaking Process, Iron and Steel Technology, March 2008, pp. 87-94.

25. J. Hansen, Mesabi Nugget - The New Age of Iron, Iron and Steel Technology, March 2005, pp. 149-153.

26. T. Kiga, S. Takano, N. Kimura, K. Omata, M. Okawa, T Mori, M. Kato, Characteristics of Pulverized-Coal Combustion the System of Oxygen/Recycled Flue Gas Combustion, Energy Conversion Management Vol. 38, Suppl., pp. S129-S134, 1997.

27. S. Nakayama, Y. Noguchi, T Kiga, S. Miyamae, U. Maeda, , M. Kawai, T. Tanaka, K. Koyata, and H. Makino, Pulverized Coal Combustion in O2/CO2 Mixtures on a Power Plant for CO2 Recovery Energy Conversion Management Vol. 33, No. 5-8, pp. 379-386, 1992.

28 C. S. Wang, G. F. Berry, K. C. Chang, And A. M. Wolsky Combustion of Pulverized Coal Using Waste Carbon Dioxide and Oxygen Combustion and Flame 72: (1988), pp. 301-310.

29. F. Normann, K. Andersson, B. Leckner, F. Johnsson, High-Temperature Reduction of Nitrogen Oxides in Oxy-Fuel Combustion, J. Fuel 2008.06.013.

30. E. Chui, A. Majeski, M. Douglas, Y. Tan, K. Thambimuthu, Numerical Investigation of Oxy-Coal Combustion to Evaluate Burner and Combustor Design Concepts, Energy 29 (2004), pp. 1285-1296.

31. T. Nozaki, S. Takano, T. Kiga, K. Omata, N. Kimura, Analysis of the Flame Formed During Oxidation of Pulverized Coal by an O2/CO2 Mixture, Energy Vol. 22, No. 2/3,1997, pp. 199-205.

32. Y. Tan, J. Douglas, K. Thambimuthu, $\mathrm{CO} 2$ Capture Using Oxygen Enhanced Combustion Strategies for Natural Gas Power Plants, Fuel 81 (2002), pp. 10071016.

33. K. Andersson, F. Johnsson, Flame and Radiation Characteristics of Gas-Fired O2/CO2 Combustion, Fuel 86 (2007) pp. 656-668. 
34. W. Blasiak, W. Yang, K. Narayanan and J. Scheele, Flameless Oxy-Fuel Combustion for Fuel Consumption and Nitrogen Oxides Emissions Reductions and Productivity Increase, Journal of the Energy Institute, Vol. 80 (1) 2007, pp. 311.

35. Z. Cheng, J. Wehrmeyr, R. Pitz, Experimental and Numerical Studies of Opposed Jet Oxygen-Enhanced Methane Diffusion Flames, Combustion Science and Technology 178: 2006, pp. 2145-2163.

36. B. Bennet, Z. Cheng, R. Pitz, and M. Smooke, Computational and Experimental Study of Oxygen-Enhanced Axisymmetric Laminar Methane Flames, Combustion Theory and Modeling Vol. 12, No. 3, 2008, pp. 497-527.

37. J. Cooper, ANSYS Senior Technical Services Specialist, ANSYS Canada Ltd., Waterloo, Canada.

38. K. Shimizu, T. Suzuki, I. Jimbo, and A. Cramb, An Investigation on the Vaporization of Fluorides from Slag Melts, Ironmaking Conference Proceedings, 1996, pp. 727-733.

39. T. Watanabe, H. Fukuyama, and K. Nagata, Stability of Cuspidine (3CaO-SiO.CaF2) and Phase Relations in the CaO-SiO2-CaF2 System, ISIJ International Vol. 42 2002, No.5, pp. 489-497.

40. A. Cruz, F. Chavez, A. Romero, E. Palacios, and V. Arredondo, Mineralogical Phases Formed by Flux Glasses in Continuous Casting Mould, Journal of Materials Processing Technology 182, 2007, pp. 358 -362.

41. Y. Kang and K. Morita, Thermal Conductivity of the CaO-Al2O3-SiO2 System, ISIJ International, Vol. 46, 2006, No. 3, pp. 420-426.

42. H. Ohta, H. Shibata, T. Kasamoto, Estimation of Heat Transfer of Front-Heating Front-Detection Laser Flash Method Measuring Thermal Conductivity for Silicate Melts at High Temperatures, ISIJ International Vol. 46, 2006, pp. 434-440.

43. North American Combustion Handbook, 2nd ed.1978, p. 37.

44. B. Benner and R. Bleifuss, Investigation Into Production of Iron Ore Concentrates with Less Than 3 Percent Silica from Minnesota Taconites - Report 1, NRRI/TR91/09, June 1991. 


\title{
PART 4:
}

\section{Demonstration of the Nodular Reduced Iron Process on the Pilot Linear Hearth Furnace at the Coleraine Minerals Research Laboratory}

by

\author{
Richard F. Kiesel \\ Deputy Director \\ Coleraine Minerals Research Laboratory \\ 218-245-4207 \\ rkiesel@nrri.umn.edu \\ Natural Resources Research Institute \\ Coleraine Minerals Research Laboratory \\ P.O. Box 188 \\ One Gayley Avenue \\ Coleraine, MN 55722
}




\section{TABLE OF CONTENTS}

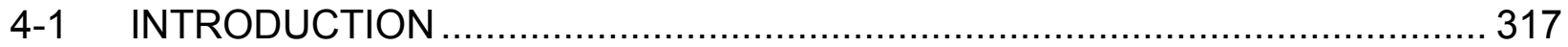

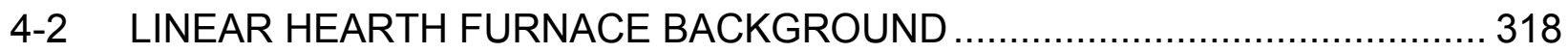

4-2.1 Linear Hearth Furnace Description ................................................... 318

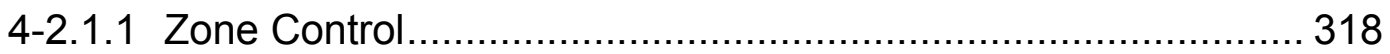

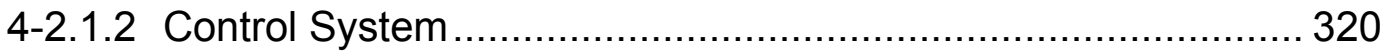

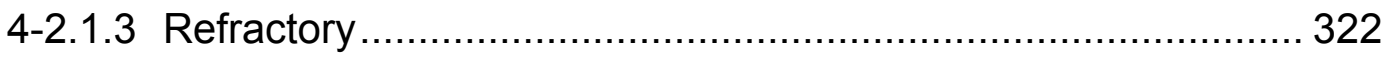

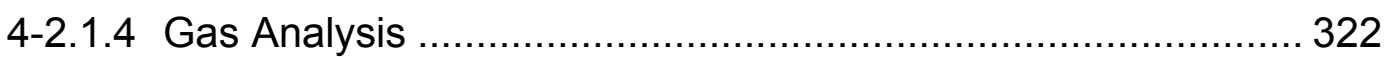

4-2.2 The Linear Hearth Furnace - Original Design .................................... 323

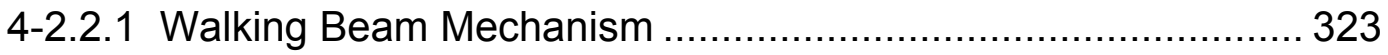

4-2.2.2 Sample trays and tray materials .......................................... 323

4-2.2.3 Feed/Material Handling/Discharge ......................................... 324

4-2.3 The Linear Hearth Furnace - Modified Design ...................................... 325

4-2.3.1 Natural Gas - Air Fuel Combustion System ........................... 325

4-2.3.2 Oxygen - Natural Gas Combustion System .......................... 326

4-2.3.3 Continuous Moving Car System ............................................. 328

4-2.3.4 Dilute Phase Pulverized Coal - Oxygen Combustion

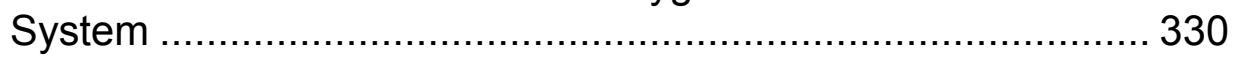

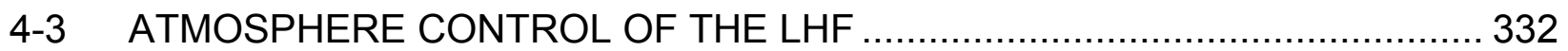

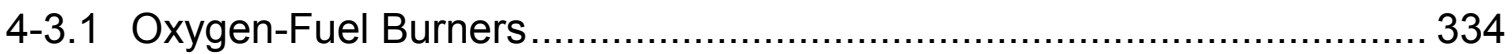

4-3.2 Isolation Layer / Gas Injection......................................................... 334

4-3.3 Atmosphere Control with Oxy-Coal Operation .................................... 335

4-4 STEADY STATE OPERATION AND DEMONSTRATION OF THE LHF

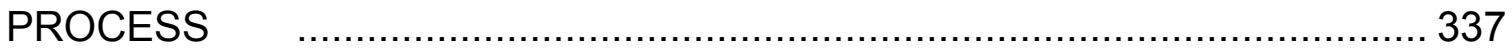

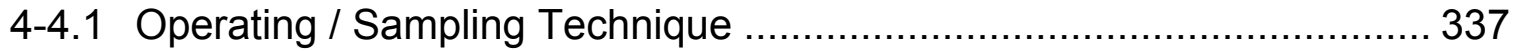

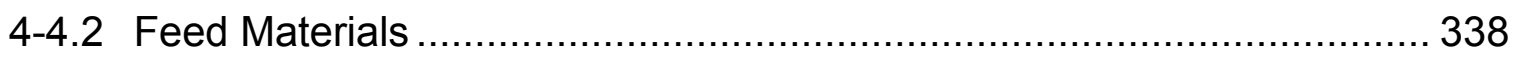

4-4.3 Linear Hearth Furnace Operating Variables ...................................... 339

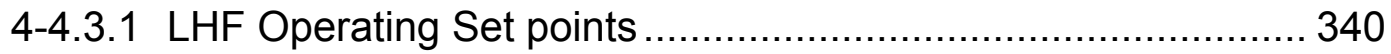

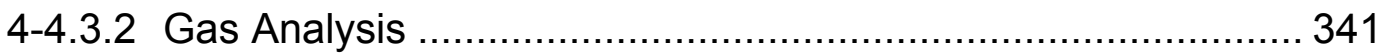

4-4.4 NRI Product Removal and Separation Technique ............................ 344

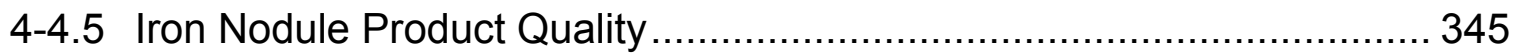

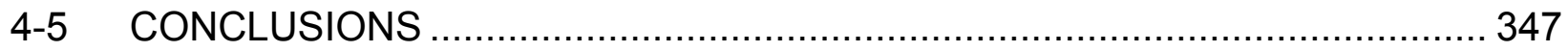

4-5.1 Oxygen-Natural Gas Combustion ................................................. 347

4-5.2 Control of Local Atmosphere Above Feed Mixture ................................. 348

4-5.3 Oxygen-Coal Combustion ........................................................... 348

4-5.4 Continuous Steady-State Demonstration of Operation ........................ 349

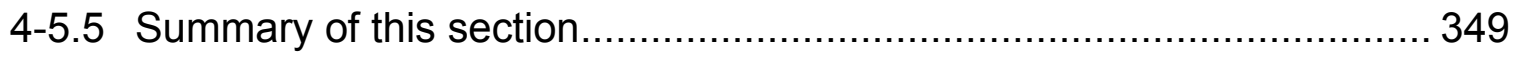

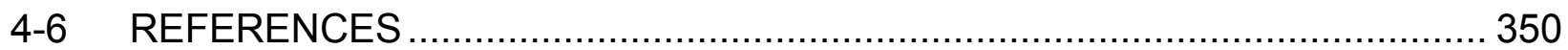




\section{LIST OF FIGURES}

Figure 4-1. Pilot-Scale Linear Hearth Furnace Simulator ...................................... 318

Figure 4-2. Linear Hearth Furnace 3-Zone Configuration........................................ 319

Figure 4-3. Linear Hearth Furnace Exhaust Ductwork ….................................... 320

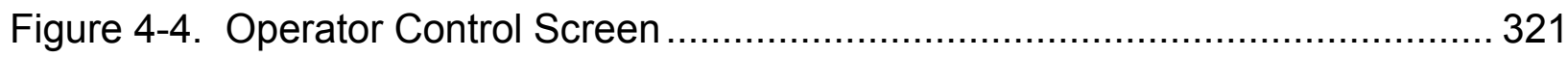

Figure 4-5. Linear Hearth Furnace Setpoint Control Screen ................................... 321

Figure 4-6. Linear Hearth Furnace Zone Control Screen ...................................... 321

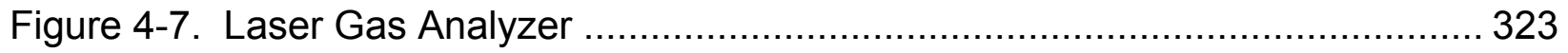

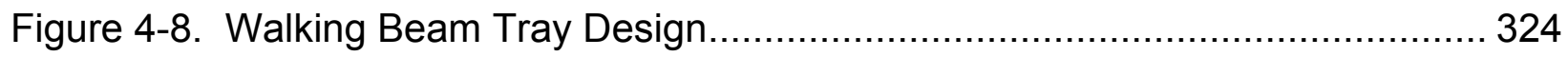

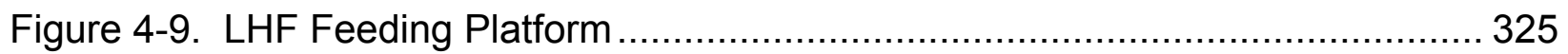

Figure 4-10. Natural Gas - Air combustion burner ............................................ 326

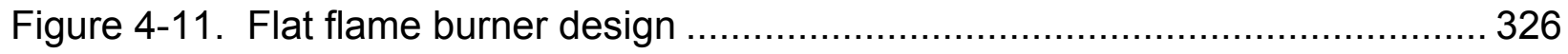

Figure 4-12. Dual - Combustion System Burner Arrangement ................................. 327

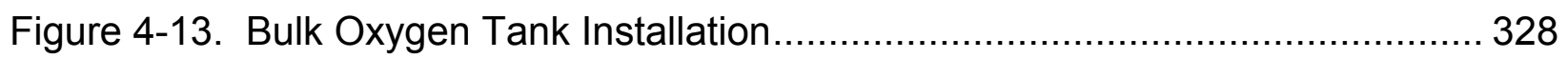

Figure 4-14. Oxygen - Fuel Combustion System valve train ............................... 328

Figure 4-15. Furnace Moving Car System - Feed ................................................ 329

Figure 4-16. Furnace Moving Car System - Discharge .......................................... 329

Figure 4-17. Oxy-coal Burner, Orifice Plate and Eductor System ............................ 330

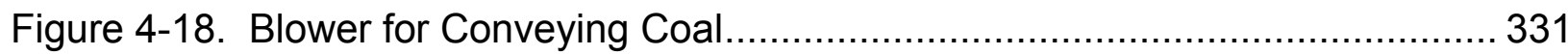

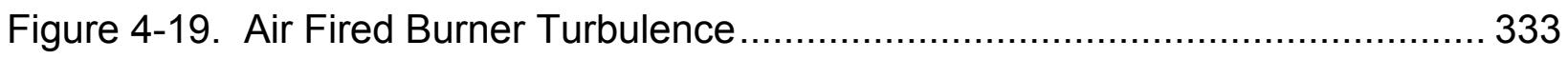

Figure 4-20. Oxygen Fired Burner Turbulence …................................................ 333

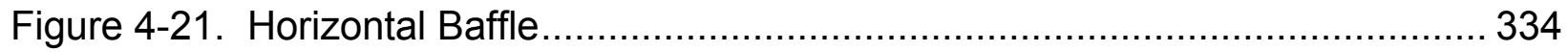

Figure 4-22. Oxy-Coal Combustion - Temperature Profile and Gas Usage................ 336

Figure 4-23. Continuous Operation - Raw Material Feeding …............................. 338

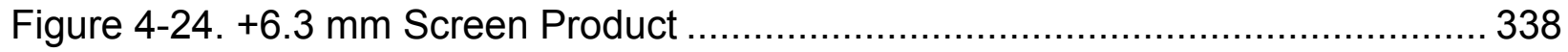

Figure 4-25. Zone Temperature Control Trends...................................................... 340

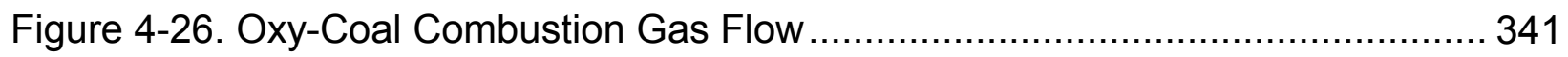

Figure 4-27. Zone One - Gas Analysis Comparison ............................................. 342

Figure 4-28. Zone Two - Gas Analysis Comparison ................................................... 343

Figure 4-29. Zone Two-three - Gas Analysis Comparison....................................... 343

Figure 4-30. Zone Three - Gas Analysis Comparison ........................................... 344

Figure 4-31. Product Separation Material Flow Diagram........................................ 345 


\section{LIST OF TABLES}

Table 4-1. Hearth Layer / Cover Layer Screen Product ............................................. 339

Table 4-2. Average LHF Atmosphere Gas Analysis ............................................. 342

Table 4-3. NRI Product Size Distribution and Chemistry........................................... 346

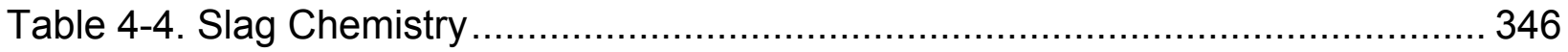




\section{4-1 INTRODUCTION}

The research program was focused on developing the best technology and processing conditions for converting iron oxide resources to high quality metallized iron nodules. The resulting product was targeted to: 1) contain less gangue, 2) contain less sulfur, 3) be resistant to reoxidation, 4) cost less to produce, and 5) use the existing transportation infrastructure and material handling systems. One distinct advantage of this processing technology is that it utilizes solid fuel (coal) rather than natural gas where cost and the effect of the combustion products on the furnace gas atmosphere are problematical. It also uses fine concentrates rather than fired pellets as required in the most prevalent gas-based, shaft DRI (direct reduced iron) systems in use today. The slag phase separated in the process may find application in slag wool preparation, cement raw materials, soil remediation, and water pollution control, thereby offsetting the overall cost and leaving no waste for disposal. The metallic iron nodules will be universally acceptable feedstock across the steel industry, electric arc furnace (EAF), submerged arc furnace (SAF), basic oxygen furnace (BOF), iron foundries, or as supplementary iron units to the blast furnace $(\mathrm{BF})$.

For this application, oxygen-fuel burners offer many advantages over air-fuel burners. They are inherently more stable throughout a wide range of operating conditions and oxygen ratios. They provide good turndown performance. They can be designed and operated to produce either compact, high velocity, low luminosity flames, or, long, highly luminous, low velocity flames. Oxygen-fuel burners can produce a wide range of oxidizing or reducing products of combustion streams. For the LHF, an oxygen-fuel burner capable of producing an optimum atmosphere in the furnace, along with low emissions and a low momentum, highly radiant flame, was the desired goal. 


\section{4-2 LINEAR HEARTH FURNACE BACKGROUND}

\section{4-2.1 Linear Hearth Furnace Description}

The Linear Hearth Furnace (LHF) can be best described as a moving hearth iron reduction furnace simulator. The furnace is a forty-foot long $(12.2 \mathrm{~m})$ iron reduction furnace, consisting of three individual heating zones and a final cooling section (Figure $4-1)$.

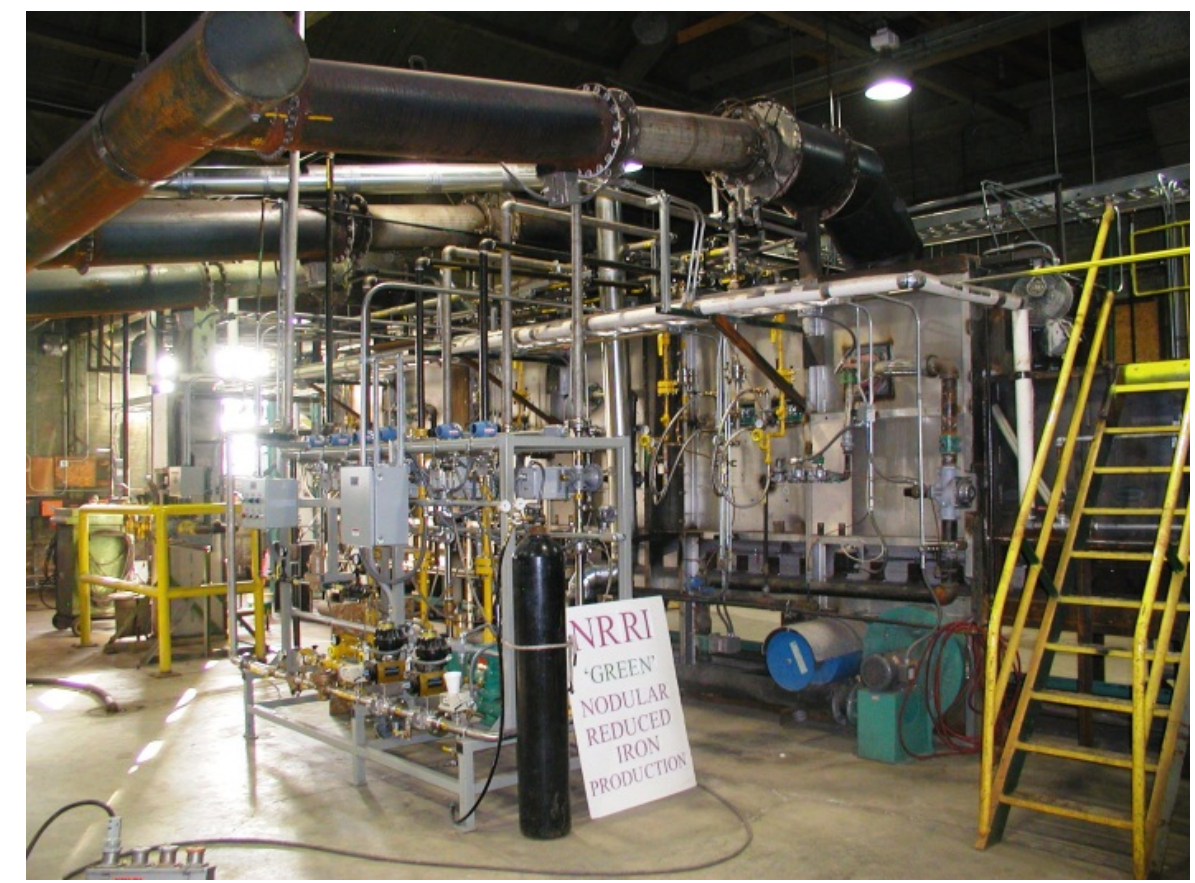

Figure 4-1. Pilot-Scale Linear Hearth Furnace Simulator

The LHF has undergone several stages of development, transitioning from a walking beam, natural gas-air fired furnace to one with a continuous moving car system and three distinct combustion systems that can be used individually or in combination. It has routinely been used to test a variety of the variables shown to be important from the box furnace and tube furnace tests. The primary goal of the program was to develop sufficient understanding of the controlling variables associated with taconite iron ore reduction and smelting using coal based reductant materials. The research has allowed sufficient knowledge to be developed so that nodular reduced iron nuggets can be routinely produced with low levels of tramp impurities using various carbonaceous reduction materials. The laboratory furnaces allow very precise manipulation of key variables under very controlled experimental conditions. The LHF facility allows these basic studies to be expanded to a significantly larger scale and to create bulk samples of product for further testing. The conditions studied in the course of this project have shown that nodules of iron can be produced with various additives and operating conditions by manipulating the correct variables.

\section{4-2.1.1 Zone Control}

It was previously stated the LHF consists of three heating zones and a fourth cooling section. Zones are controlled individually according to temperature, pressure and feed 
rate, making this furnace capable of simulating several reduced iron processes and operating conditions (Figure 4-2).

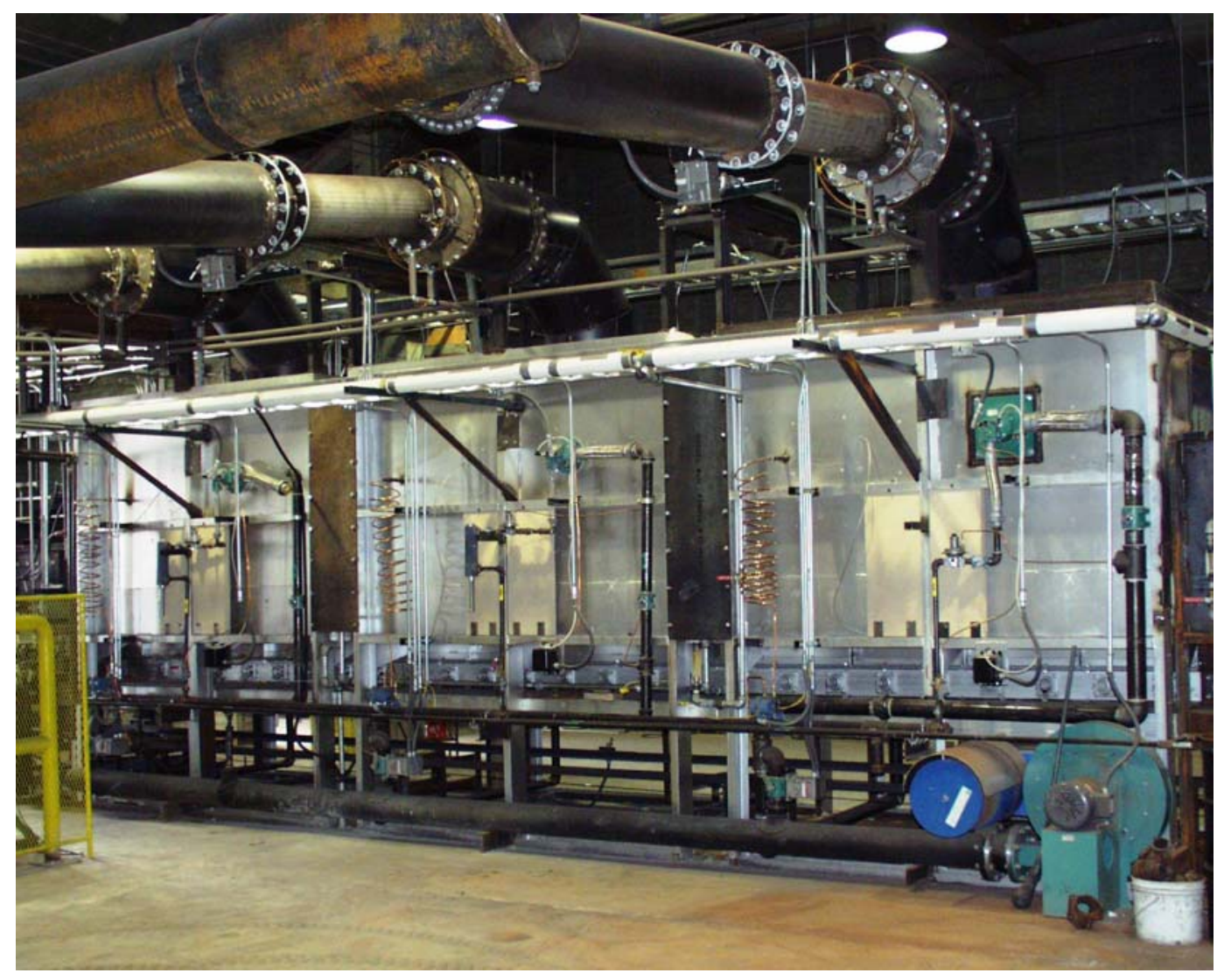

Figure 4-2. Linear Hearth Furnace 3-Zone Configuration

- Zone 1 is described as an initial heating devolatization and reduction zone. Its purpose is to bring samples to sufficient temperature for drying, de-volatilizing hydrocarbons and initiating the reduction stages. The burners are operated substoichiometrically to minimize oxygen levels.

- Zone 2 is described as the reduction zone. The function of this zone is to complete the reduction of iron oxide ores to wustite $(\mathrm{FeO})$ and metallic iron.

- Zone 3 is described as the melting or fusion zone. The function of this zone is to complete the reduction of wustite to metallic iron, fusing the iron into metallic iron nodules also called Nodular Reduced Iron (NRI). This furnace may also be used to make direct reduced iron or sponge iron, the temperatures in this zone would be reduced where complete reduction would be promoted without melting or fusion.

- The final section, or cooling zone, is a water jacketed section of the furnace approximately six $(6)$ feet $(1.83 \mathrm{~m})$ long. The purpose of this zone is to cool the samples so that they can be safely handled and solidify the metallic iron nodules for removal from the furnace.

Each of the three zones have individual temperature and pressure control settings with heating capacity of up to $1426^{\circ} \mathrm{C}\left(2600^{\circ} \mathrm{F}\right)$. Each zone has an individual exhaust duct and control damper to manipulate the flow of process gasses (Figure 4-3). 


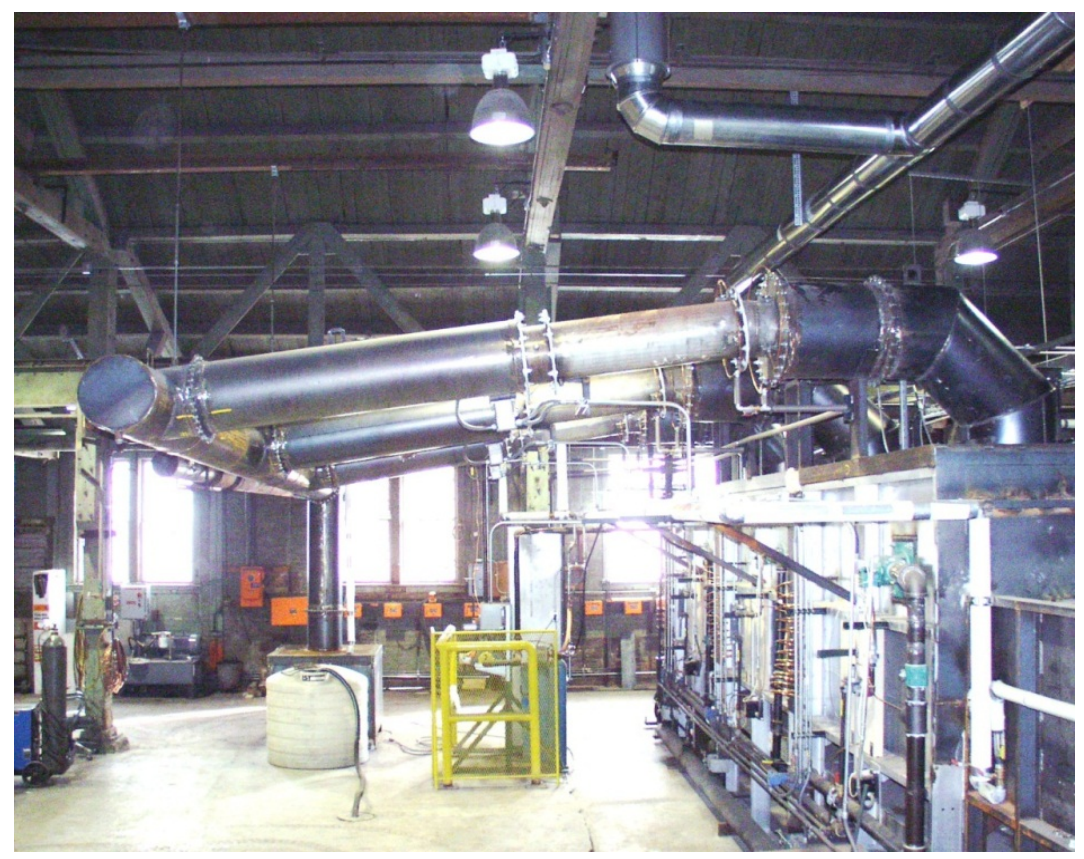

Figure 4-3. Linear Hearth Furnace Exhaust Ductwork

A manually controlled common exhaust damper is also installed to reduce the capacity of the exhaust fan, and allow the individual duct control dampers to manipulate pressures to desired set-points. Distinct pressure control between zones is difficult due to the close proximity of each in relation to the other; however, overall furnace pressure can be regulated and controlled. Residence time in each of the zones is controlled automatically to simulate any size furnace. The furnace is typically operated in a batch mode because it does not have capability for continuous feed or product removal; however, on several occasions we have simulated continuous operation by manually feeding each tray or cart and removing the product on the exit end.

\section{4-2.1.2 Control System}

The control system consists of an ALLEN BRADLEY PLC micro logic controller with RSView HMI (Human Machine Interface). The development of the control system has taken place over the several years to be user friendly and capable of process simulation. Figure 4-4 below shows the operator interface with Figures 4-5 and 4-6 showing the furnace capabilities for temperature setpoints and zone controls located on subsequent screen selection options. 


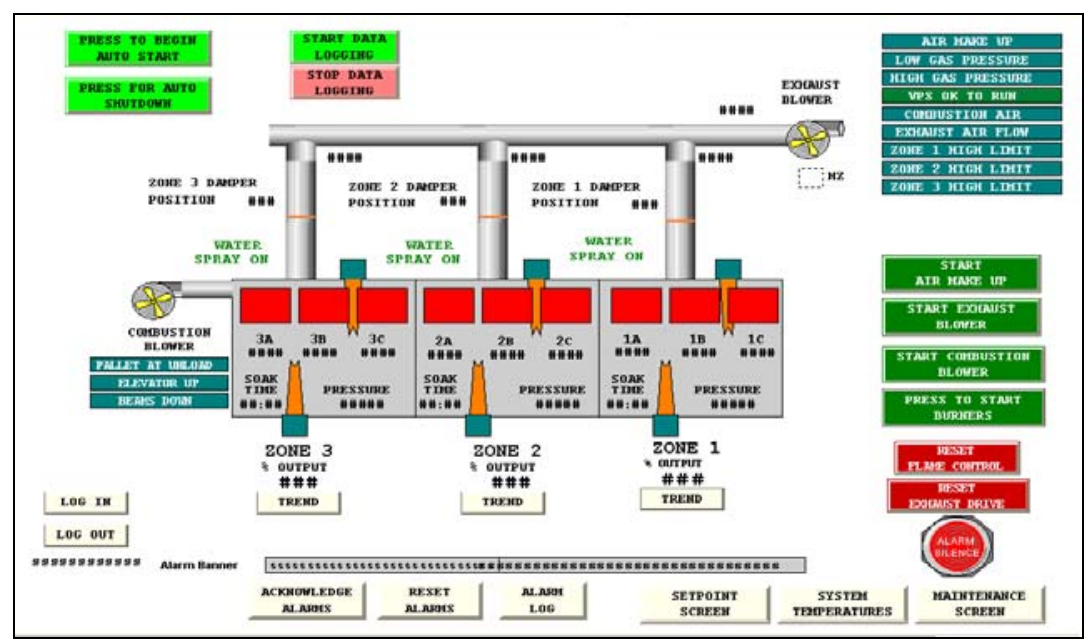

Figure 4-4. Operator Control Screen

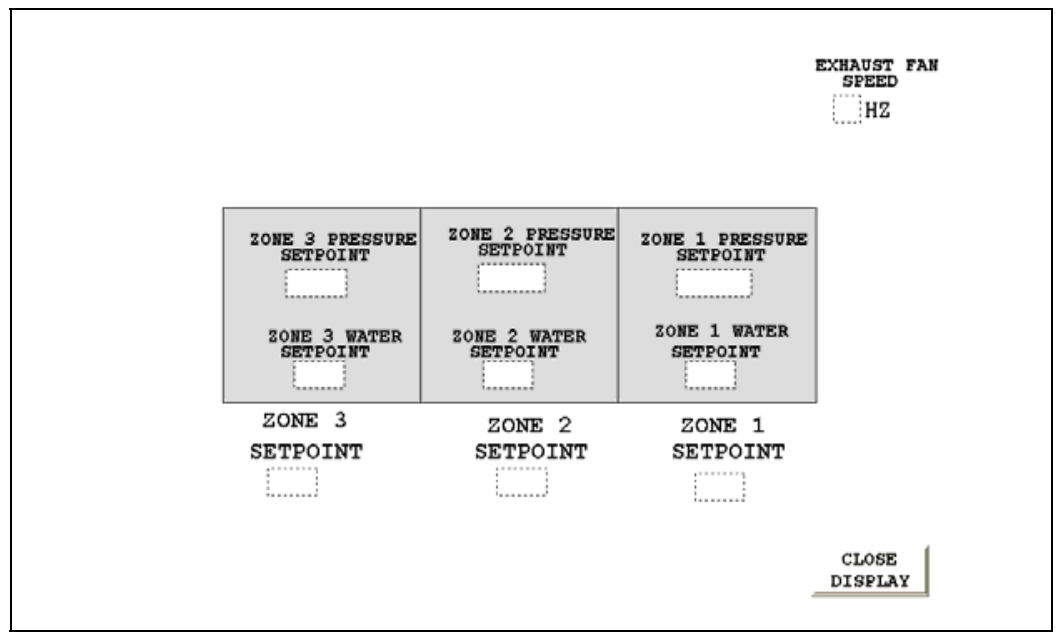

Figure 4-5. Linear Hearth Furnace Setpoint Control Screen

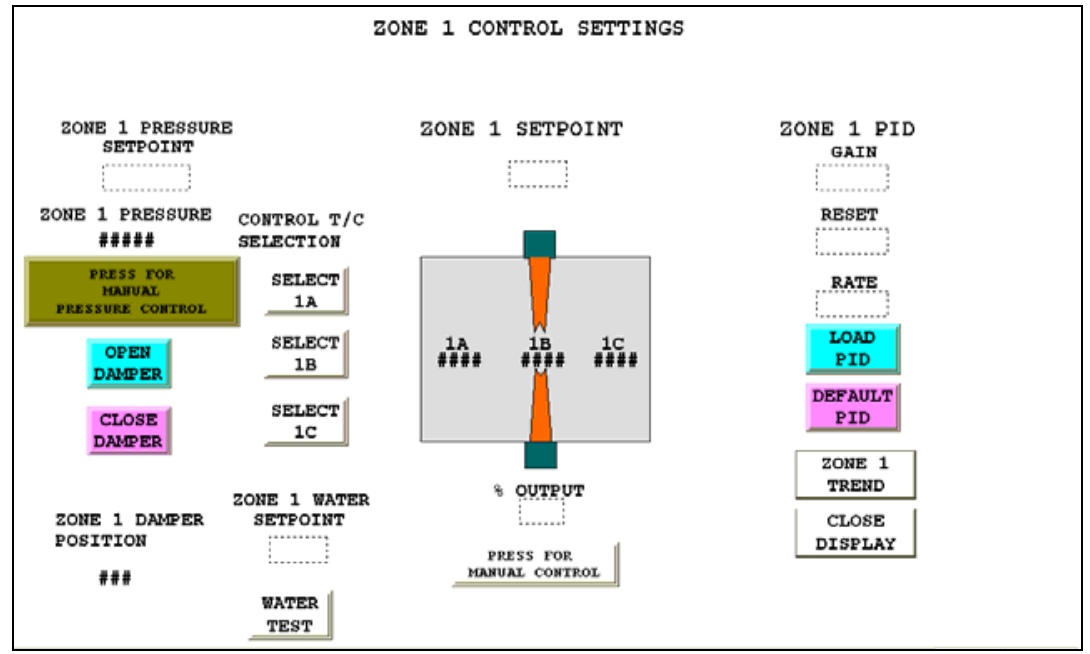

Figure 4-6. Linear Hearth Furnace Zone Control Screen 
The control system has been designed with a safety emphasis by adding skin temperature monitoring, duct temperature monitoring, gas and combustion air monitoring, and exhaust temperature monitoring. As a secondary safety precaution, a barometric leg into a level controlled water tank has been installed between the common header and exhaust fan to absorb any sudden pressure changes. If any of these features are tripped, the furnace will take the necessary steps to ensure safety including an aggressive shut down procedure that is automatically engaged.

\section{4-2.1.3 Refractory}

The LHF furnace is lined with Pyro-Bloc ZR grade ceramic fiber modules designed to a $1426^{\circ} \mathrm{C}\left(2600^{\circ} \mathrm{F}\right)$ maximum temperature. The ceramic fiber facilitates the aggressive heating and cooling schedule required on a pilot furnace. The hearth is a Criterion $80 \mathrm{XL}$ castable refractory designed for an operating temperature up to $1538^{\circ} \mathrm{C}\left(2800^{\circ} \mathrm{F}\right)$ and maximum temperature rating of $1760^{\circ} \mathrm{C}\left(3200^{\circ} \mathrm{F}\right)$. To create thermal storage and minimize temperature drop, a firebrick refractory has been installed on the inner lining of zones two and three. Compressed ceramic fiber has been installed around each of the dust transitions from each of the zones in the furnace. The ductwork is designed with a castable spool piece at the furnace discharge transitioning into a high alloy stainless steel that is quenched with a mist of cooling water which allows us to run carbon steel in the remaining ducts.

\section{4-2.1.4 Gas Analysis}

The LHF is equipped with a Laser Gas Analysis (LGA) system. The LGA is a unique gas sampling and analysis system that measures concentrations of eight gases simultaneously. It includes a completely integrated computer controller and sampling system that rapidly monitors industrial gas process operations. The analyzer has multizone sequencing that measures $\mathrm{O}_{2}, \mathrm{CO}, \mathrm{CO}_{2}, \mathrm{~N}_{2}, \mathrm{H}_{2}, \mathrm{NH}_{3}$ and $\mathrm{CxHy}$. Water vapor is estimated by a calculation using the dew point temperature. The Laser Gas Analyzer uses Raman Spectroscopy that exploits the phenomenon that gas molecules struck by laser light absorb it and re-emit light at frequencies different from the laser. The differences are so discrete and precise that the intensity of light observed at various shifted frequencies is directly proportional to the concentrations of constituent molecules in the atmosphere ${ }^{(12)}$. For this analysis, and since the dew point temperature at $1412^{\circ} \mathrm{C}$ $\left(2575^{\circ} \mathrm{F}\right)$ is impractical to measure the dew point was estimated at $63^{\circ} \mathrm{C}\left(145^{\circ} \mathrm{F}\right)$ and left constant for relative comparison. The analyzer and its screen display are shown in Figure 4-7 below. 

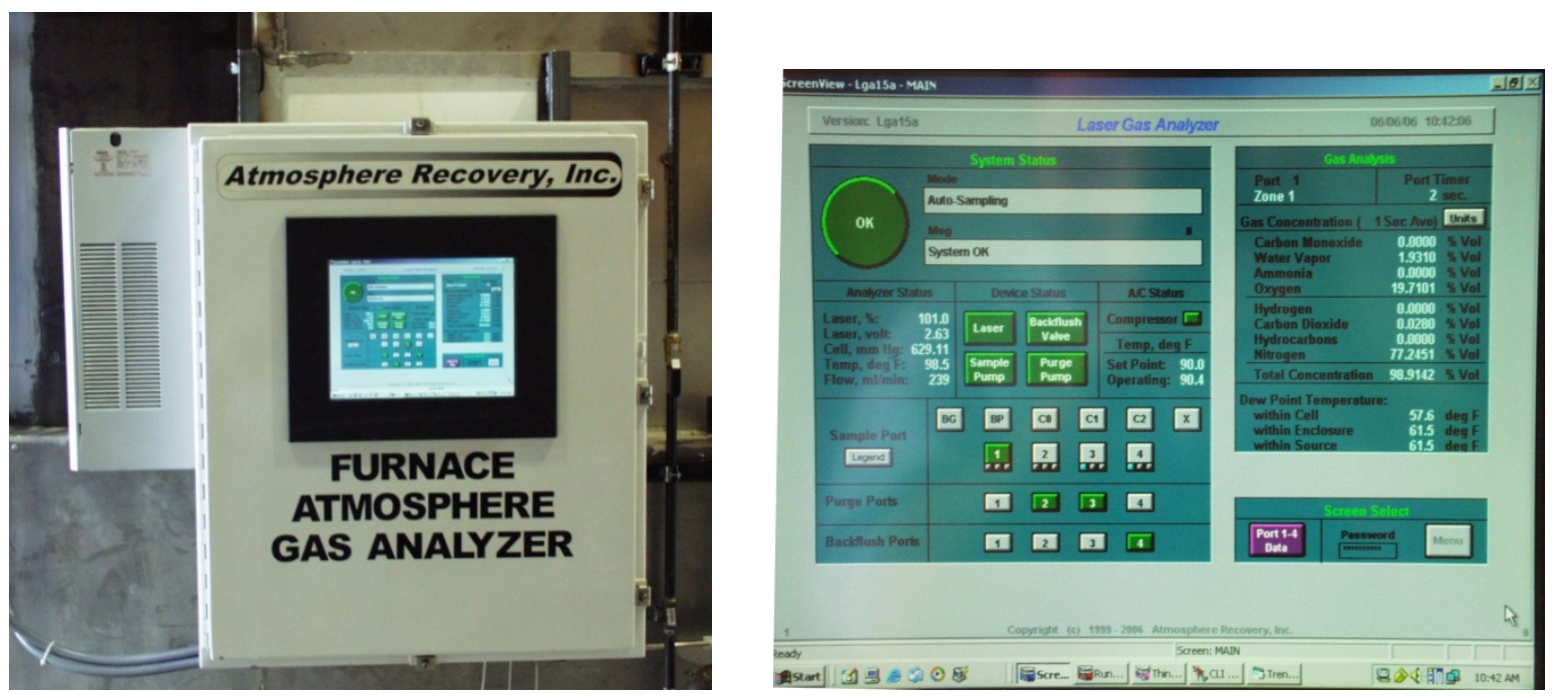

Figure 4-7. Laser Gas Analyzer

Sample plumbing and a valve manifold system connect the detector to the center of furnace zones 1, 2 and 3 (identified as port 1,2, and 4) with an intermediate sampling point between zones 2 and 3 (port 3). The valve manifold assures that the gas samples drawn from each location and presented uncontaminated to the sampling chamber.

\section{4-2.2 The Linear Hearth Furnace - Original Design}

\section{4-2.2.1 Walking Beam Mechanism}

The original LHF design used a walking beam mechanism as a means of conveying samples through the furnace. Feed rate was controlled by a PLC controlled hydraulic walking beam mechanism that advances the trays through the furnace. Monitoring time in each zone and advancing trays accordingly with the walking beam mechanism regulated feed rate. Furnace feed rate and position of the trays was displayed on the operating screen through communication with the PLC. A pair of side-by-side, castable refractory walking beams extends the length of the furnace, driven forward and back with hydraulic cylinders operated through the PLC. The beams are raised and lowered through a second pair of hydraulic cylinders that push the beam assemblies up and down a series of inclines (wedges) on rollers.

\section{4-2.2.2 Sample trays and tray materials}

Several designs of sample trays or pallets have been tested. Originally the trays framework was made from a stainless steel alloy or carbon steel. They were lined with high temperature refractory brick or fiberboard with sidewalls to contain samples. The extreme operating temperatures resulted in rapidly decompose trays made from the carbon steel or stainless alloy. Subsequent tray designs included (HT) fiber board refractories, castable refractories, ceramic tray designs and finally trays made from graphite. Although the reducing environment was deteriorating to the carbon trays, they seemed to hold up better than the steel frames or HT board. Initially it was determined that a significant amount of heat was transmitted from the bottom up, so they were then 
lined with a HT fiber board refractory. The photos in Figure 4-8 show a transition of some of the tray materials used for the walking beam furnace design.

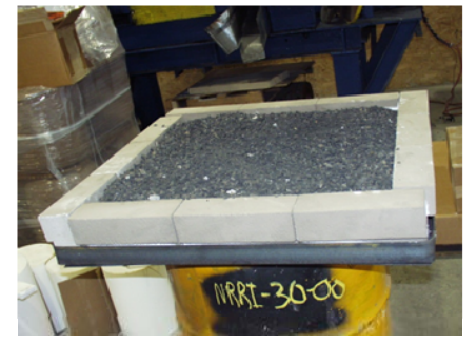

Hard Andalucite brick

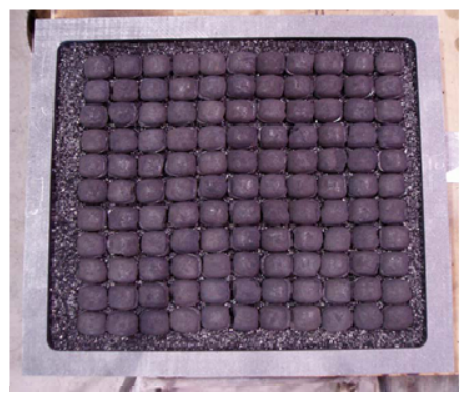

Graphite

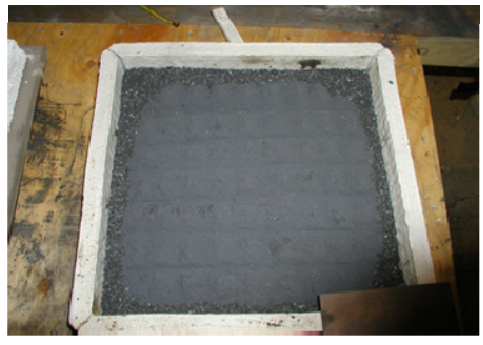

HT Ceramic Fiber Board

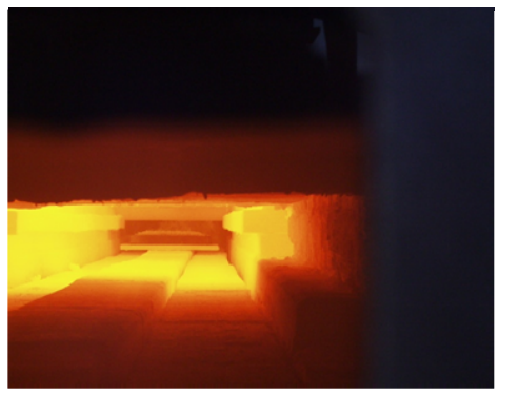

Combination of graphite and $\mathrm{HT}$ Ceramic fiber board

Figure 4-8. Walking Beam Tray Design

\section{4-2.2.3 Feed/Material Handling/Discharge}

Sample trays were manually prepared prior to starting a test. Additional trays were also used, covered with coke or a carbonaceous reductant to regulate the furnace atmosphere. A roll plate platform elevator, raised and lowered with a pneumatic cylinder, was designed to raise and lower sample trays at the feed and discharge end for insertion and removal. The feeding platform is shown in Figure 4-9. Below: 


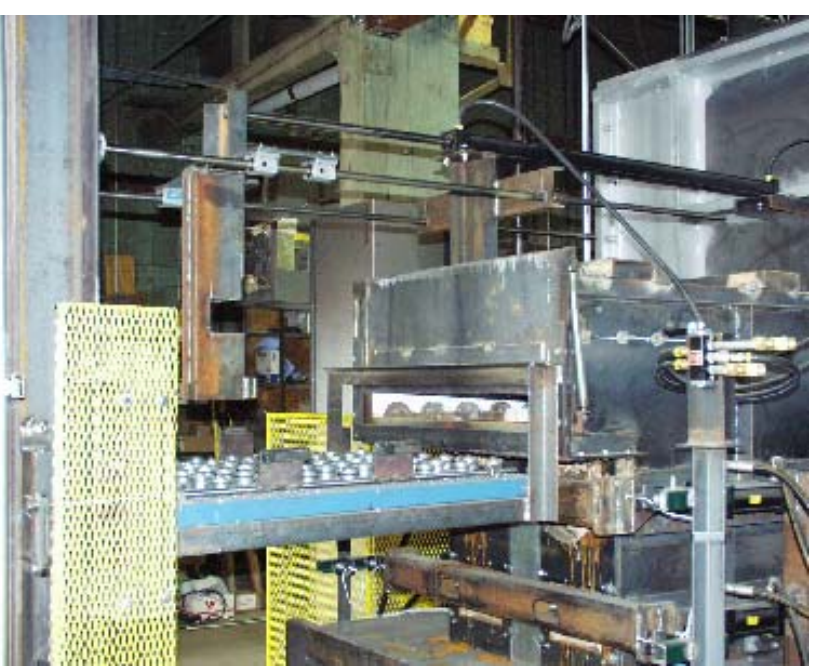

Figure 4-9. LHF Feeding Platform

\section{4-2.3 The Lineaer Hearth Furnace - Modified Design}

A significant issue to be addressed in this project was identified in the proposal to control the furnace atmosphere over sample trays. For this application, oxygen-fuel burners offer many advantages over air-fuel burners. They are inherently more stable throughout a wide range of operating conditions and excess oxygen ratios. They provide good turndown performance. They can be designed and operated to produce either compact, high velocity, low luminosity flames, or, long, highly luminous, low velocity flames. Oxygen-fuel burners can produce a wide range of oxidizing or reducing products of combustion streams. As a result, the LHF furnace has been equipped with three distinct combustion systems that can be operated separately or in combination:

- Eclipse natural gas - combustion air blower system

- Eclipse natural gas - oxygen combustion system

- Maxon pulverized dilute phase coal - oxygen combustion system

\section{4-2.3.1 Natural Gas - Air Fuel Combustion System}

The LHF natural gas- air fuel combustion system consists two Eclipse Thermjet TJ0400, $474,383 \mathrm{~kJ} / \mathrm{hr}(450,000 \mathrm{BTU} / \mathrm{hr})$ natural gas fired burners in each of zones one and two. Zone one is rated for a continuous operating temperature of up to $1316^{\circ} \mathrm{C}\left(2400^{\circ} \mathrm{F}\right)$, while zone two can be continuously operated up to $1427^{\circ} \mathrm{C}\left(2600^{\circ} \mathrm{F}\right)$. Zone three is fired by a pair of $1.05 \mathrm{E}^{6} \mathrm{~kJ} / \mathrm{hr}(1,000,000 \mathrm{BTU} / \mathrm{hr})$, Eclipse Thermjet TJ1000 burners required to achieve the operating temperatures of $1427^{\circ} \mathrm{C}\left(2600^{\circ} \mathrm{F}\right)$ in reasonable time to complete testing. A photograph of the Eclipse Thermjet TJ0400 burner is shown in Figure 4-10. 


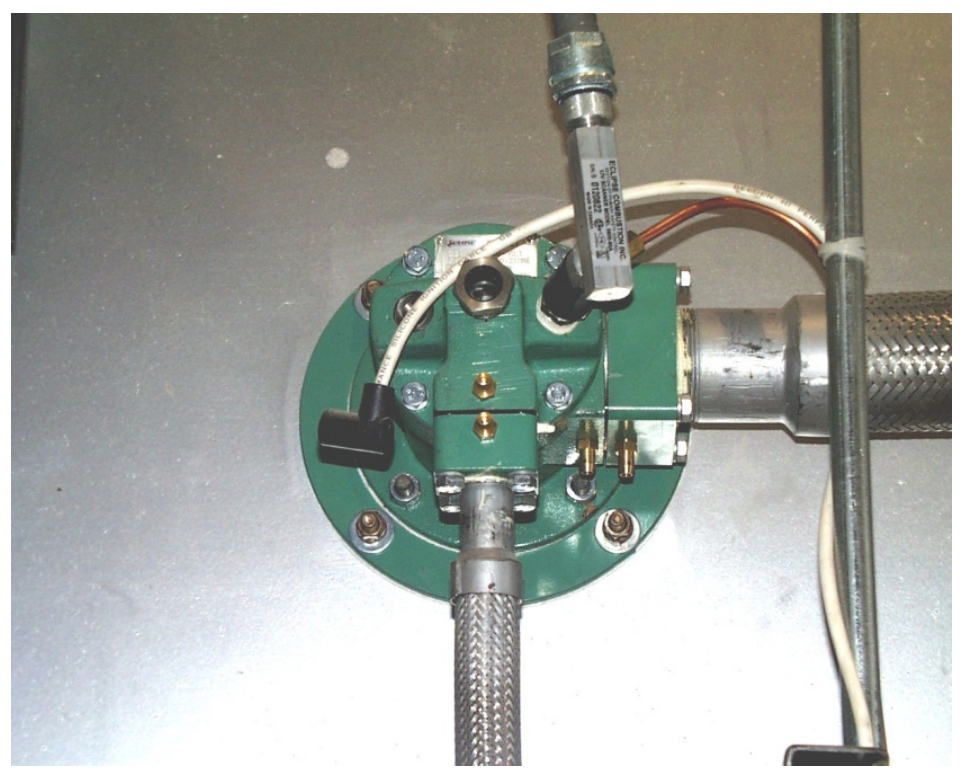

Figure 4-10. Natural Gas - Air combustion burner

\section{4-2.3.2 Oxygen - Natural Gas Combustion System}

Based on the results from the initial studies in Phase I, the appropriate design modifications to the LHF were conducted for installation of oxy-fuel combustion. Several burner designs were considered. The burner was demonstrated at the Eclipse, Inc. development facility in Rockford, IL in Feb. 2008 and the design approved for construction. The burner design chosen is an Eclipse Primefire 300 flat flame burner, located in close proximity to the bed to take advantage of the highly luminescent flame and the radiant energy associated with the oxygen-fuel combustion. The burner was designed to provide a lazy flame profile that can achieve the temperatures without providing oxidants or scrubbing away the atmosphere "boundary layer" established above the samples. Figure 4-11 below shows photos of the burner flame shape, composed of an inner gas flow with an annular oxygen flow.
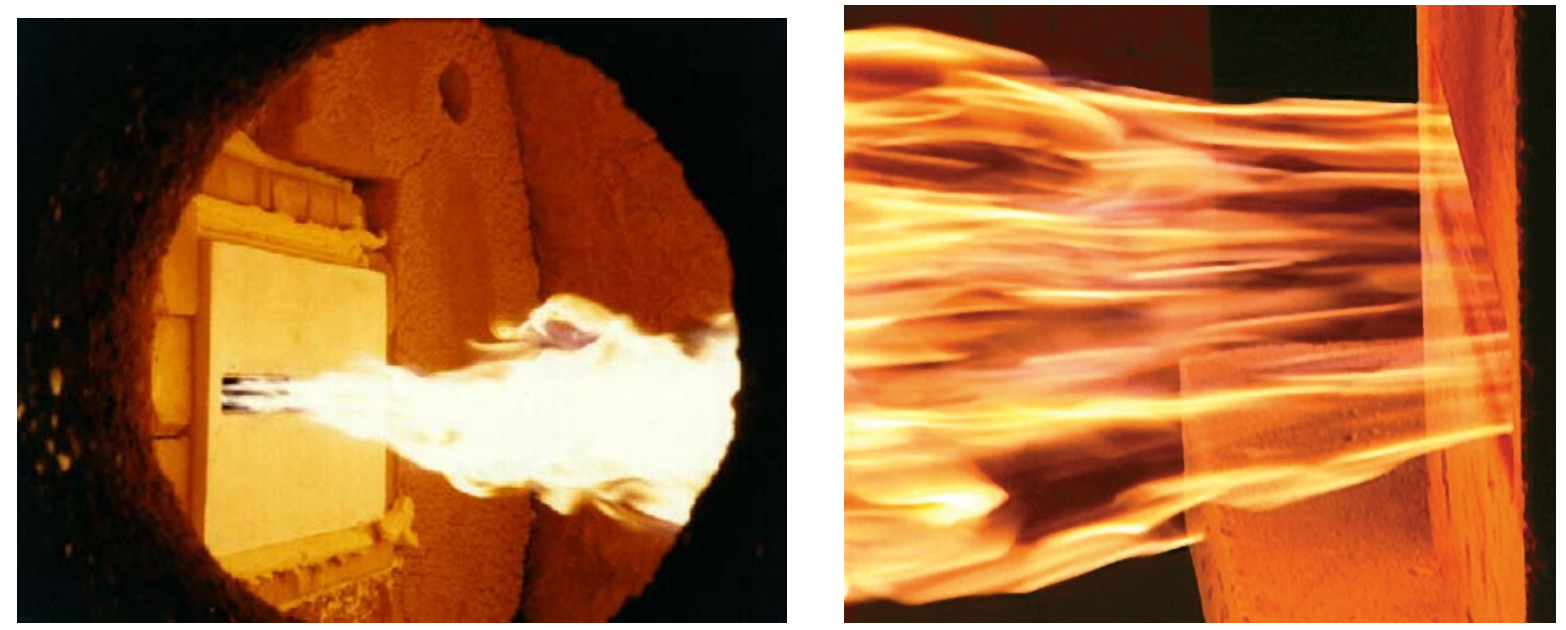

Figure 4-11. Flat flame burner design 
The burners, control system, and oxygen/gas train were sized for application to the LHF. A total of eight (8) $263,546 \mathrm{~kJ} / \mathrm{hr}$ (250,000 Btu/hr) oxy-fuel burners were recommended to achieve the desired temperatures. The burners were located as follows: two (2) in each of zones one and two and a total of four (4) in zone three. Offsetting them from the existing air-fuel burners allowed us to retain both combustion systems for comparison studies (Figure 4-12).

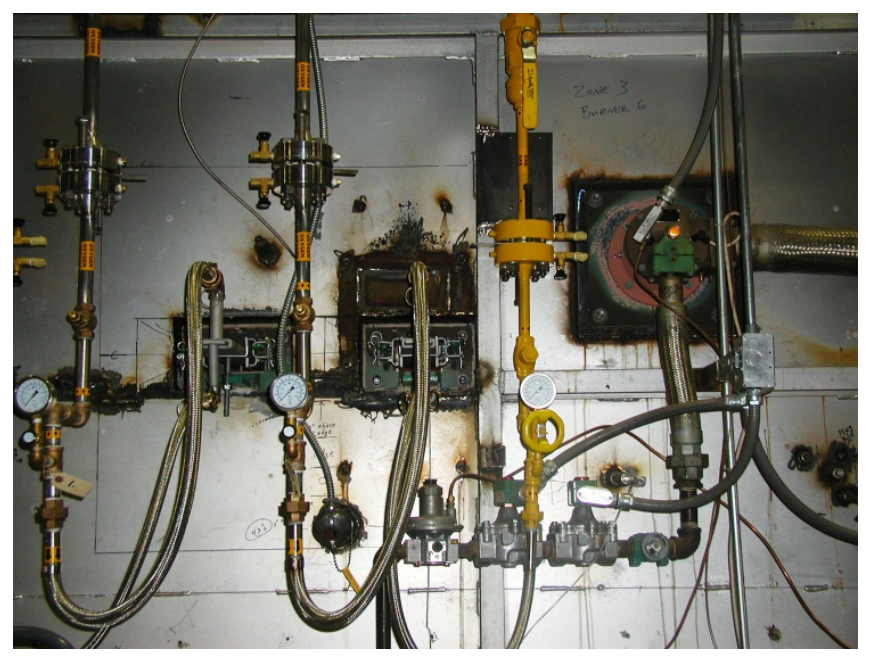

Figure 4-12. Dual - Combustion System Burner Arrangement

The PLC control system was modified to control both systems. The oxygen supply system is composed of a $24 \mathrm{~m}^{3}$ (6400 gallon) oxygen tank installed on a cement pad just outside the location of the furnace to comply with NFPA and University code. Figures 4-13 and 4-14 show the installation of the oxygen tank and the oxygen valve train equipped with mass flow controller for oxygen and natural gas for accurate metering and measurement of flow. 

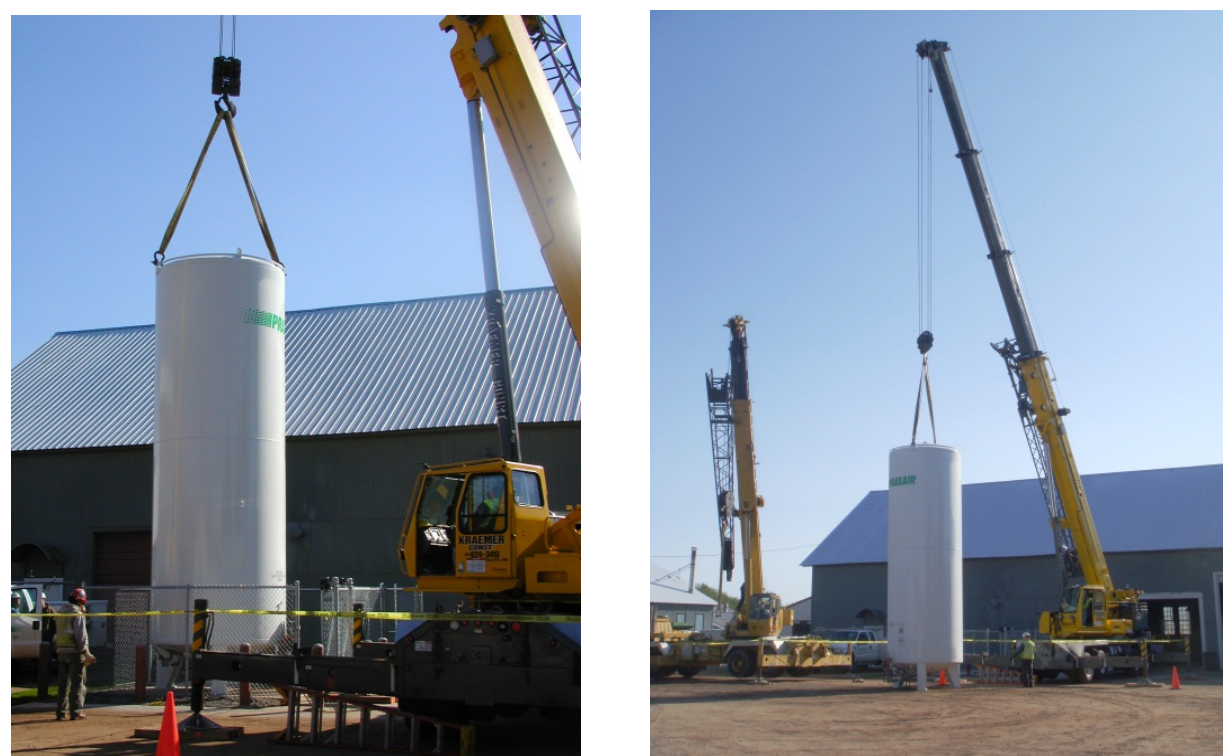

Figure 4-13. Bulk Oxygen Tank Installation

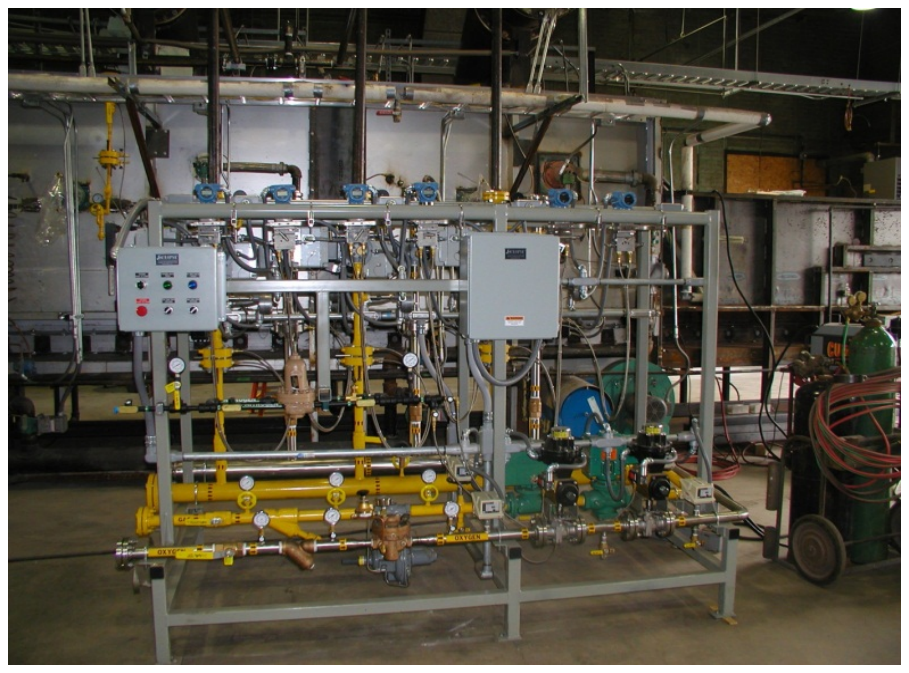

Figure 4-14. Oxygen - Fuel Combustion System valve train

\section{4-2.3.3 Continuous Moving Car System}

In addition to the oxy-fuel modification, the walking beam - tray movement was simultaneously replaced with a PLC controlled, hydraulically driven continuous moving cars to better simulate production. The significant drawback to the walking beam system was the associated bottom-up heating and the relevance to a continuous furnace. The car system is designed with a hydraulic pusher cylinder, cycled from one end to push cars one against the other to move them through the furnace. An indexer on the feed end of the furnace was developed to control the length and number of cycles required by each cylinder to control the car speed. The cars are recycled underneath the furnace back to the feed end, raised and lowered into position using hydraulically driven elevators. The cars are made from carbon steel frames and lined with ceramic fiber refractories to accommodate the aggressive heating and cooling cycles. A sand seal 
along the length of the furnace with a radiation seal by car design is used to prevent furnace atmosphere and temperature from contacting the undercar rails and wheels with graphite bearings. An auxiliary exhaust duct/damper with a pressure sensor was also installed in the undercar region to control the pressure slightly negative to the furnace proper to prevent ingress leakage. Figures 4-15 and 4-16 (furnace inlet and outlet, respectively) show the moving car system.

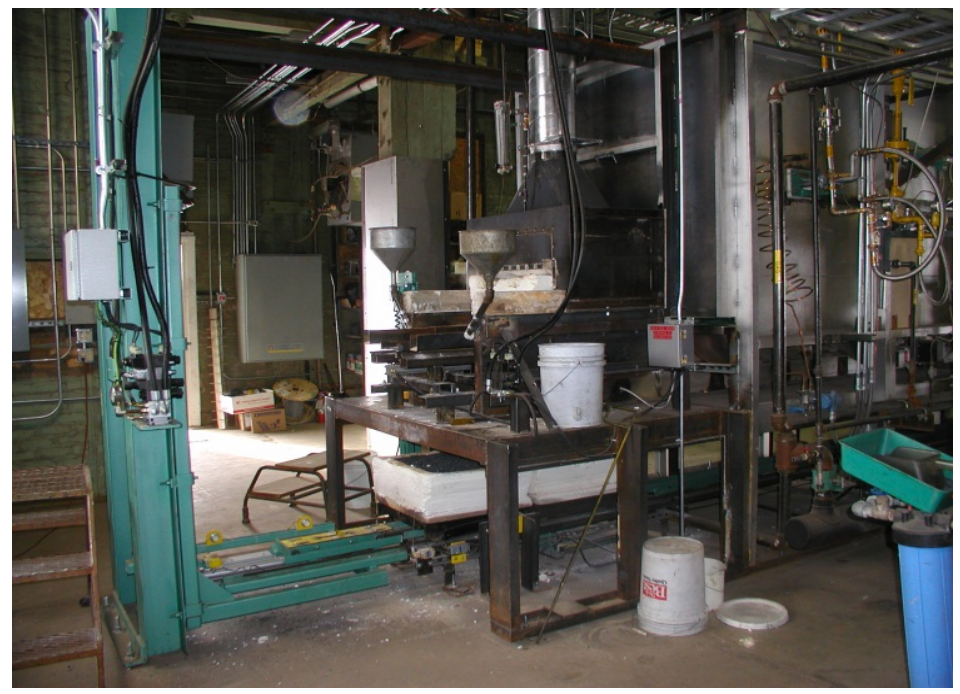

Figure 4-15. Furnace Moving Car System - Feed

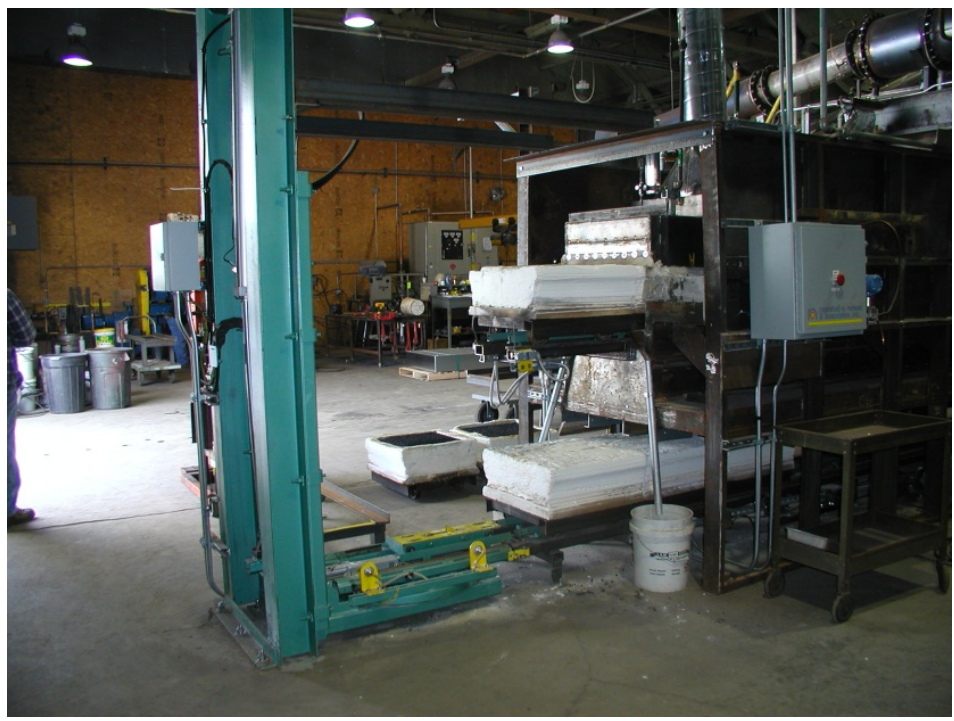

Figure 4-16. Furnace Moving Car System - Discharge

The continuous moving car design allows the furnace flexibility to simulate several processes. Cars can be recycled to mimic hot hearth systems or inserted into the moving train and simulate cold hearth processes. Several refractories surfaces, treatments and types were evaluated to resist slag and molten iron attack and extend furnace availability. 


\section{4-2.3.4 Dilute Phase Pulverized Coal - Oxygen Combustion System}

The third combustion modification to the LHF was the installation of a dilute phase coaloxygen burner. A 590,343 kJ/hr (560,000 Btu/hr) oxy-coal burner was positioned to fire horizontally from the end of the furnace, down the length of the LHF. The coal is fed through a variable feed screw hopper. The pulverized coal, approximately $80 \%$ passing $0.149 \mathrm{~mm}$ (100 Mesh) is conveyed by an air blower through an eductor system (dilute phase coal injection) to give it sufficient velocity through the burner. The airflow rate is regulated by a manual gate valve and controlled/measured with an orifice place installed inline prior to the eductor. A time-weight calibration on the coal feeder is used to determine the flow rate of pulverized solids and is controlled by the PLC. Oxygen is also monitored through the PLC control system to match coal addition and adjust stoichiometry. The feed rate of the coal is operated as a baseline energy load in the LHF while the temperature control is provided through the natural gas-oxygen combustion system. Two different coals were pulverized and tested for comparison: 1) sub-bituminous western coal and 2) bituminous eastern coal. Several feed rates were examined using various amounts of conveying airflow to prevent pulsing and adjust the flame length and shape. The oxy-coal combustion arrangement is shown in Figures 417 and 4-18 below:

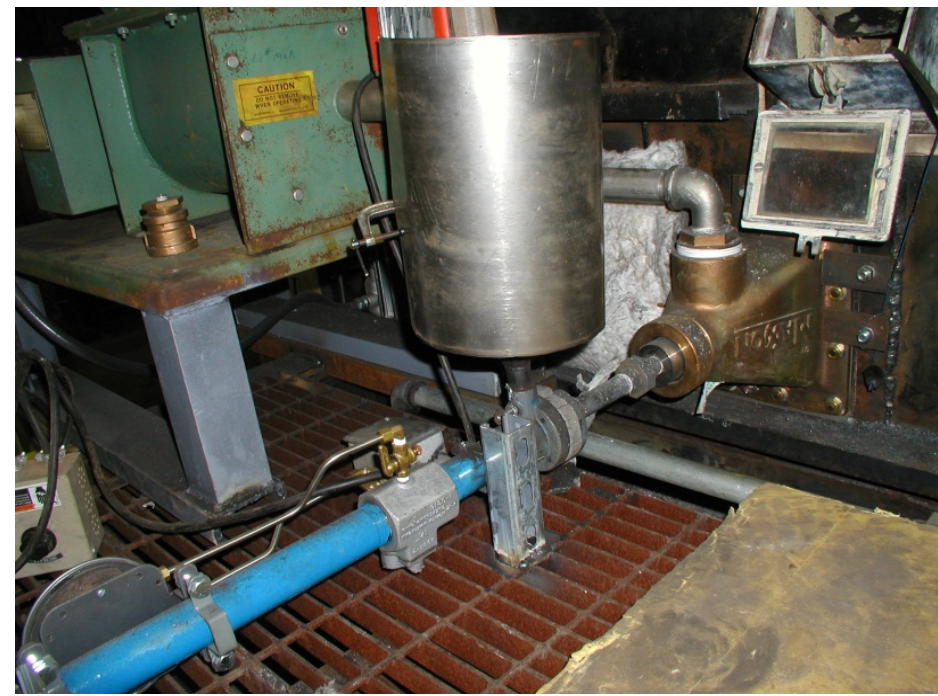

Figure 4-17. Oxy-coal Burner, Orifice Plate and Eductor System 


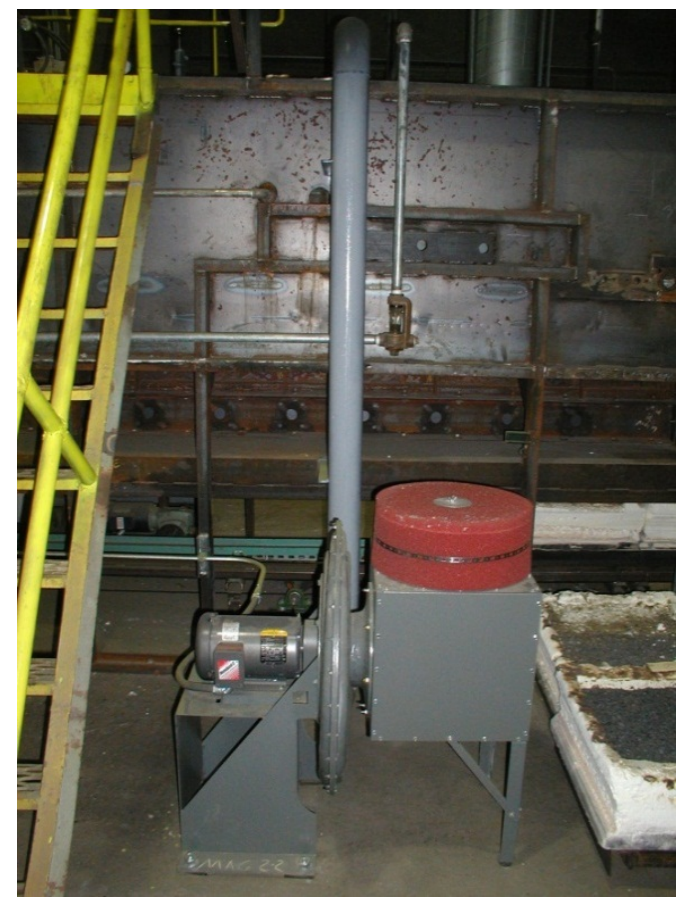

Figure 4-18. Blower for Conveying Coal 


\section{4-3 ATMOSPHERE CONTROL OF THE LHF}

A major difference between laboratory electric furnaces and the LHF is the high turbulence associated with the natural gas - air burner combustion products. In the natural gas-fired LHF, operating under sub-stoichiometric gas and air mixtures provides the required reducing conditions for reduction and smelting. The resulting furnace gas atmosphere contains a relatively low ratio of $\mathrm{CO}: \mathrm{CO}_{2}$ (approximately 1:5). Partially metallized iron ore from the reduction zone directly contacts the high $\mathrm{CO}_{2}$, low $\mathrm{CO}$, further enhanced by the highly turbulent furnace gas at high temperature as they enter the melting zone. Exposure of the partially metallized feed mixtures to this atmosphere causes rapid loss of added reductant carbon and formation of high $\mathrm{FeO}$ slag. The $\mathrm{FeO}$ content in the slag controls the oxidation state, and consequently, makes sulfur removal to the slag less favorable. The furnace atmosphere and the high $\mathrm{FeO}$ content of the slag coupled with the operating temperature typically $1450-1550^{\circ} \mathrm{C}\left(2642-2822^{\circ} \mathrm{F}\right)$ as claimed in previous patents, appears to lead to some difficulty in lowering sulfur in iron nodules to below $0.1 \% \mathrm{~S}$. In our laboratory tests, fully fused iron nodules could be formed at as low as $1325^{\circ} \mathrm{C}\left(2417^{\circ} \mathrm{F}\right)$ under a $\mathrm{N}_{2}-\mathrm{CO}$ atmosphere, and sulfur in iron nodules could be lowered to as low as $0.01 \%$ or less. A need to compensate for reductant lost by the carbon solution reaction required careful adjustment in the type and amount of additives in order to facilitate nodular reduced iron production while minimizing the generation of micro nuggets. To counteract the oxidizing effect of $\mathrm{CO}_{2}$ and high turbulence of combustion gas in the gas-fired LHF, several localized atmosphere control methods were considered.

A simple Computational Fluid Dynamic (CFD) model of the furnace was built and used to demonstrate the impact of nitrogen introduced via burners firing with air, on turbulence in the furnace. Output from the CFD model using air fired burners shows the velocity scale ranges from 0 to $2.5 \mathrm{~m} / \mathrm{s}$. With the same level of energy input, using oxygen at $90 \%$ purity the velocity range is decreased to 0 to $0.8 \mathrm{~m} / \mathrm{s}$. This reduction of turbulence reduces the interaction of high $\mathrm{CO}_{2}$ containing furnace gases and aids the metallization process efficiency. Figure 4-19 illustrates output from the CFD model using air fired burners; here the velocity scale ranges from 0 to 2.5 meters/sec. In Figure 4-20 with the same level of energy input, using oxygen at $90 \%$ purity the velocity range is decreased to 0 to 0.8 meters/sec. This reduction of turbulence reduces the interaction of high $\mathrm{CO}_{2}$ containing furnace gases and aids the metallization process. 


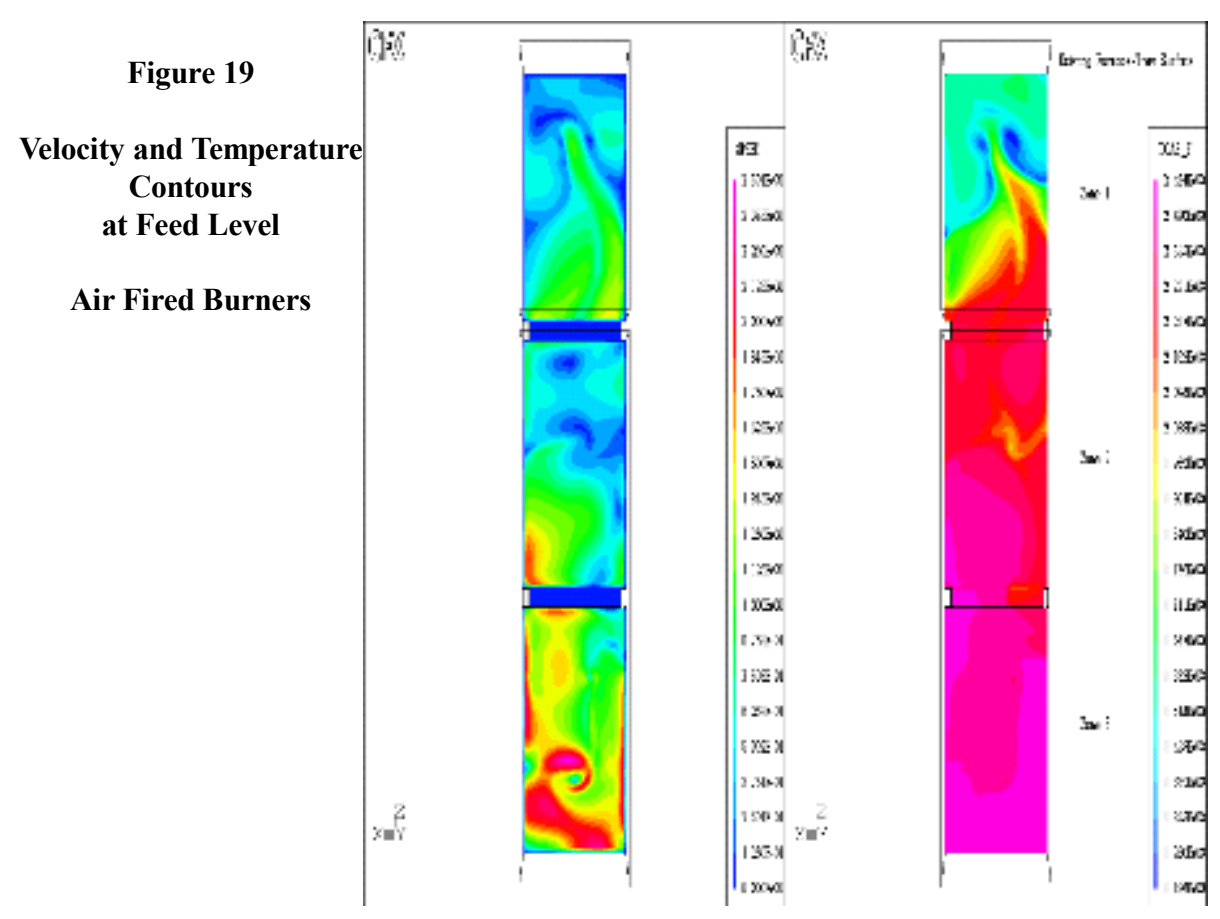

Figure 4-19. Air Fired Burner Turbulence

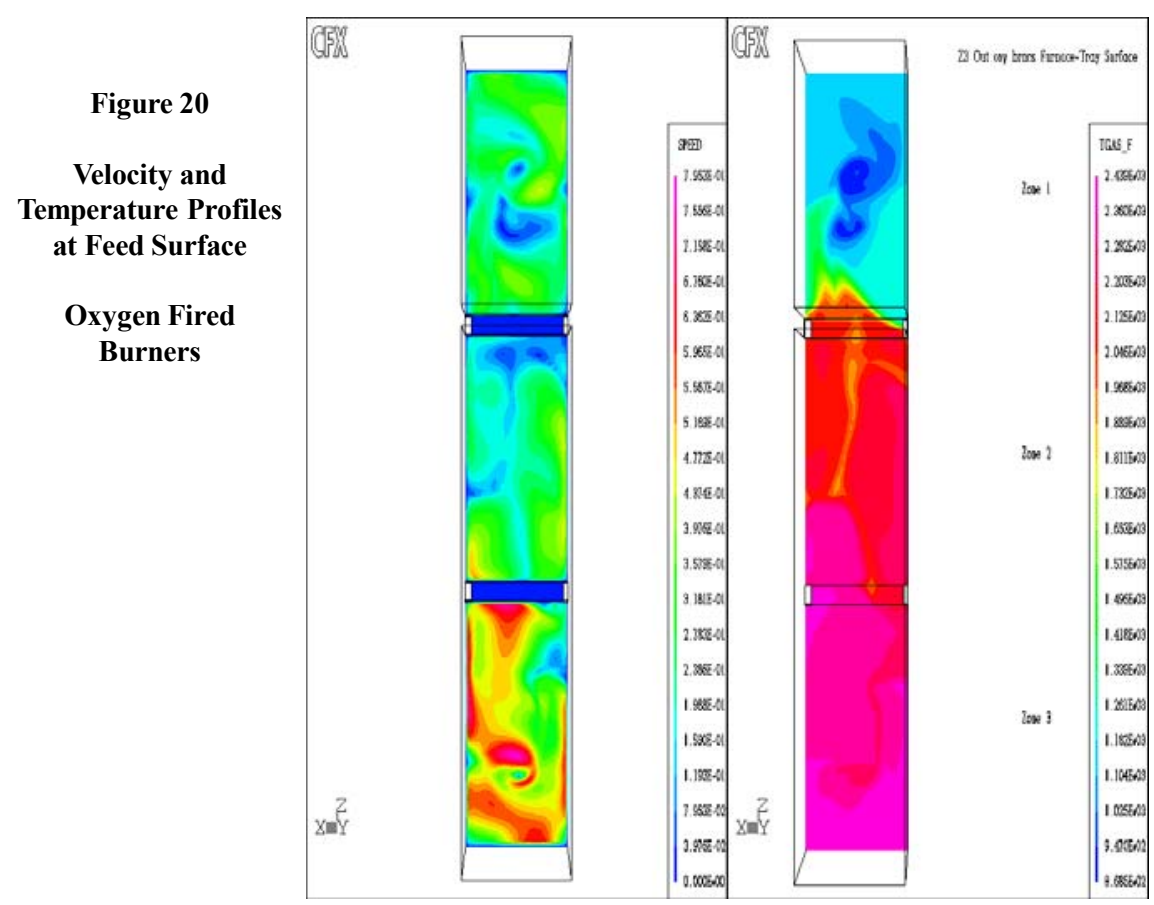

Figure 4-20. Oxygen Fired Burner Turbulence

Thus, from both a product quality standpoint and from an operating standpoint, furnace atmosphere control is a key control variable and must be a key parameter in design of the overall furnace operating conditions. The use of oxygen-fuel burners reduces the volume of flue gas, thereby alleviating the turbulence within the furnace and conserving 
the energy associated with heating chemically inert nitrogen ${ }^{(8)}$. Turbulence may be further reduced through flame shape characteristics.

\section{4-3.1 Oxygen-Fuel Burners}

Natural gas-air fired linear hearth furnace (LHF) tests generated high $\mathrm{CO}_{2}\left(10 \% \mathrm{CO}_{2}\right.$, 2$4 \% \mathrm{CO}$ ) and highly turbulent furnace gas as compared to the electrically-heated box furnace. This difference made it difficult in the LHF to produce satisfactory iron nodules consistently and the nodules produced often had sulfur contents that were undesirably high $(0.1-0.3 \% \mathrm{~S})$. Processing of high sulfur nodules in the EAF would lead to higher steelmaking costs and extra energy use as more slag forming compounds would be needed to purify the steel. LHF remodeled with oxy-fuel combustion system was tested initially by comparing the effect of oxy-fuel and air fuel burners on fusion time using bituminous coal-added briquettes. Fusion time was shorter by 10 to $30 \%$ when oxyfuel burners were used than air-fuel burners. This difference was related to the high turbulence of the furnace gas with air-fuel burners and their effect on the endothermic carbon solution reaction. NRI at fusion time analyzed 3.0 to $3.6 \% \mathrm{C}$ and 0.04 to $0.05 \% S$ under the conditions tested.

\section{4-3.2 Isolation Layer / Gas Injection}

To counteract the oxidizing effect of $\mathrm{CO}_{2}$ and water vapor as a result of natural gas combustion products, an isolation layer of heat and atmosphere resistant material (horizontal baffle)shown in Figure 4-21 was placed above the feed trays to segregate them from the highly turbulent furnace atmosphere.

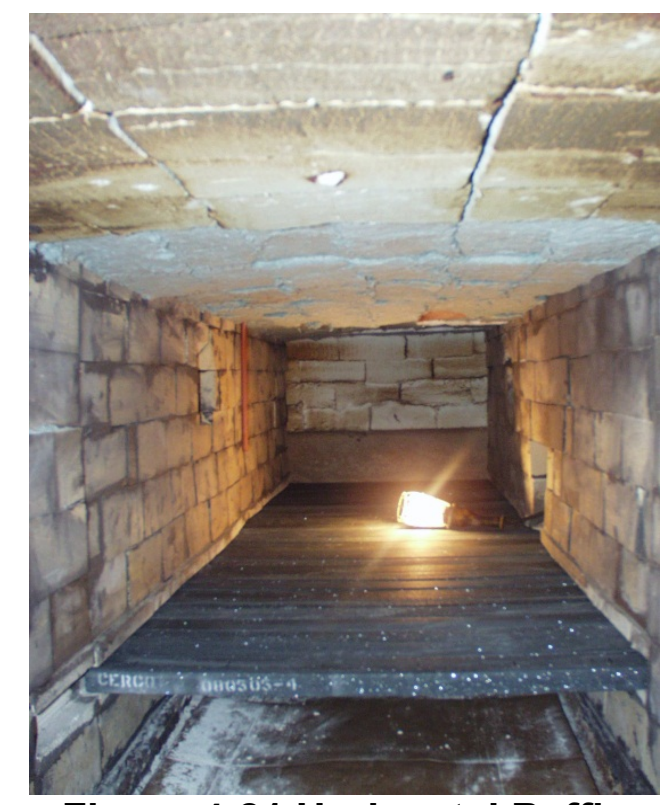

Figure 4-21.Horizontal Baffle 
To generate a reducing atmosphere under this hood, $\mathrm{N} 2, \mathrm{CO}$ and $\mathrm{CH}_{4}$ gas were injected above the reaction mixture, and below the hood arrangement. The tests indicated some promise, by producing a full tray of iron nodules with the $\mathrm{CH}_{4}$ injection and partial fusion with the other two gases. Iron nodules were successfully produced at $1371^{\circ} \mathrm{C}\left(2500^{\circ} \mathrm{F}\right)$ under hood temperature; however, slags were very metallic looking, indicating high iron content that subsequently produced iron nodules that were relatively high in sulfur. Analyses ranged from 0.03 to 0.14 percent, carbon ranged from 2.82 to 3.00 percent. These values demonstrated that the system is viable but will require further development to optimize the system and obtain better sulfur and carbon control.

A vertical baffle wall between Zones II and III was installed to make it possible to independently control the temperature in Zone II and control the degree of metallization before the sample would reach the horizontal hood. The hood was installed on the first $1 / 3$ of Zone III. The baffle wall installed between Zones II and III prevented the temperature from reaching above $1274^{\circ} \mathrm{C}\left(2325^{\circ} \mathrm{F}\right)$ so that preheating and reduction had to be completed under the hood. The result was significant back oxidation occurring after reduction and nodule formation. In addition, the pressure differential between the gas supply and the $\mathrm{N}_{2}$ supply prevented simultaneous injection of both gases so pure NG was injected. The result was some troublesome plugging of the injection ports presumably by $\mathrm{C}$ deposition. The injection ports had to be blown out, or burned out, between runs. These tests showed that further modifications of the LHF would be required to enable closer control of the temperature and to further protect the metalized product from back oxidation.

\section{4-3.3 Atmosphere Control with Oxy-Coal Operation}

A $590,343 \mathrm{~kJ} / \mathrm{hr}(560,000 \mathrm{Btu} / \mathrm{hr})$ oxy-coal burner was positioned to fire horizontally from the end of the furnace, down the length of the LHF. Atmosphere control was investigated while simultaneously controlling temperature by minimizing airflow, operating the burner sub-stoichiometric and controlling furnace zone pressure to prevent heat transfer into adjacent zones. The furnace is identified by three phases of operation, pre-heating/devolatization, reduction and fusion. Previous testing required the installation of a baffle wall between zones II and III of the LHF. The baffle wall and the techniques employed in this installation were determined to be beneficial with regard to heat transfer and atmosphere manipulation; however this resulted in effectively reducing the volume of the fusion zone, and subsequently, an oversized oxy-coal combustion system for the reduced volume. Modifications were required to the furnace that included removing the baffle wall. The extended zone was necessary to accommodate the energy load from the coal burner with the volume of conveying airflow required to prevent plugging and still maintain a reducing atmosphere. These modifications resulted in the LHF operating successfully on the coal-oxygen burner system, controlling both atmosphere and temperature. This was accomplished by reducing the ratio of conveying air to coal with increased fuel flow rates and using sub-stoichiometric oxy-gas burners to control oxygen content. The coal-oxygen burner system was capable of controlling the set point temperature of $1413^{\circ} \mathrm{C}\left(2575^{\circ} \mathrm{F}\right)$ in zone III while maintaining good atmosphere control for production of NRI. The coal type used was a bituminous coal. A maximum loading of 
$0.27 \mathrm{~kg} / \mathrm{min}(0.59 \mathrm{lb} / \mathrm{min})$ of coal or an equivalent of $507,063 \mathrm{~kJ} / \mathrm{hr}(481,000 \mathrm{Btu} / \mathrm{hr})$ was used as a base energy load while the gas - oxy system was used to trim and control the temperature. While the coal system was in operation, the natural gas system was operating at less than $10 \%$ of full fire, and commonly less than1\% on a single burner. Baseline tests were conducted on briquettes prepared with iron ore concentrate and their appropriate additives using the coal-oxy system. Results show that residence slightly increased by $15 \%$ as a result of the loss of radiant energy from the idled oxy-gas burners and difficulty in controlling atmosphere due to the generation of $\mathrm{CO}_{2}$ and water vapor from the conveying airflow. Figure 4-22 below shows the LHF temperature profile with corresponding gas and oxygen use.

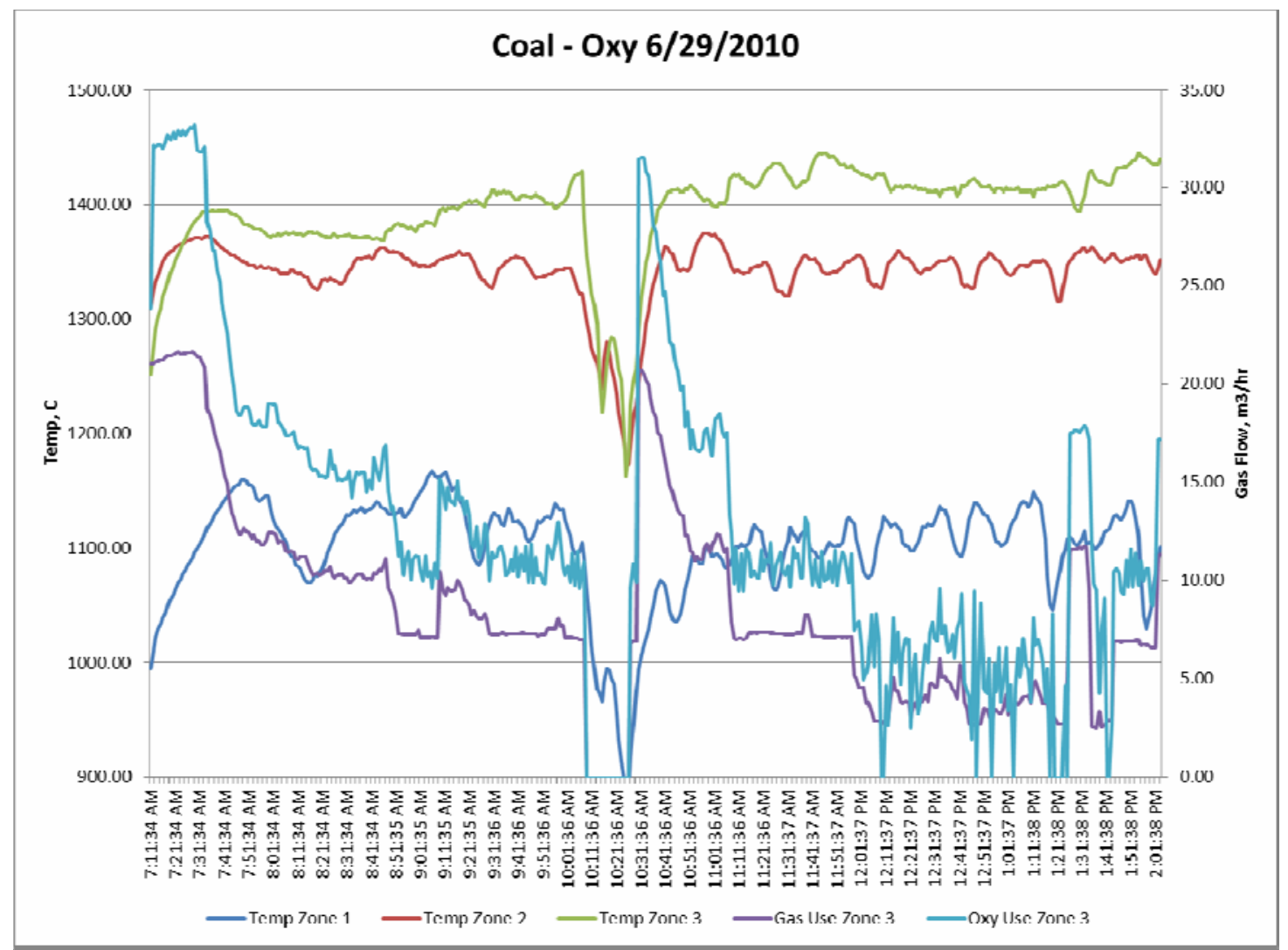

Figure 4-22. Oxy-Coal Combustion - Temperature Profile and Gas Usage

In this figure, the coal system was initiated at approximately 7:30 am at a rate of 0.1 $\mathrm{kg} / \mathrm{min}(0.22 \mathrm{lb} . / \mathrm{min})$. The coal addition rate was increased to $0.19 \mathrm{~kg} / \mathrm{min}(0.41 \mathrm{lb} / \mathrm{min})$ at 9:40 am and again to $0.27 \mathrm{~kg} / \mathrm{min}(0.59 \mathrm{lb} / \mathrm{min})$ at $11: 50 \mathrm{am}$. In each case, it can be seen that the incremental increase in coal addition is accompanied with a corresponding decrease in natural gas and oxygen rate. The high moisture content of the PRB ( 38\%) initially resulted in plugging the eductor system. It was subsequently determined that the moisture content of the PRB must be below $20 \%$ to convey the coal smoothly and control temperature and below 5\% to allow for atmosphere control similarly to the bituminous coal. The lower BTU value of the PRB coal requires a higher coal feed rate to achieve similar results, and therefore, higher conveying airflow. Therefore, the moisture content and the energy content of each coal type were found to have significant influence on the operating parameters of the LHF. 


\section{4-4 STEADY STATE OPERATION AND DEMONSTRATION OF THE LHF PROCESS}

The results from Phases I and II were utilized to operate the Linear Hearth Furnace under simulated steady-state conditions to demonstrate continuous production of Nodular Reduced Iron. High quality NRI can be routinely produced provided the right choice temperature profile, atmosphere control and additives are employed. The baseline operating conditions on both the oxy-gas and coal-oxygen based systems have been established. These were used to demonstrate both combustion systems in routine production of NRI under those conditions. Routine production can be described as continuous operation, producing product of a consistent quality under steady-state operation. In the case of the oxy-coal operation, the furnace was run continuously for a 4 hour period with minimal upsets. Product sampling was conducted on selected furnace cars; however, this test was more focused on the operation of the furnace. In the oxy-gas operation, the LHF was operated continuously for 6 hours and bulk samples of NRI product were collected simultaneously with furnace operating data. The specific conditions identified should allow commercial production of nodules. Considering heat and energy losses, process inefficiencies, excess weir space, secondary combustion and production rates, quantification of the expected energy consumption and overall process economics was not realistic from this demonstration on the LHF. Complete process mass and energy balances for commercial scale development were derived from the CFD modeling using the practical furnace designs described in that section of this report.

\section{4-4.1 Operating / Sampling Technique}

The LHF process was simulated for a continuous operation using manual loading and feeding techniques for an extended period of time to demonstrate steady-state operation. Feeding of briquettes and removal of nodular reduced iron product were both conducted at the feed end of the furnace. The furnace variables were manipulated to operate under positive pressure, and reducing atmosphere using the stoichiometry of the combustion to minimize oxygen content in the furnace atmosphere. The minimum residence time was determined by increasing the cart speed until we visually observed un-fused material in the products exiting the furnace, then decreased it slightly. Each car was hand loaded using pre-weighed charges of hearth layer, briquettes and cover layer. The briquettes were evenly distributed within a $36.8 \mathrm{~cm} \times 38.1 \mathrm{~cm}(14.5$ " $\times 15$ ") metal frame to produce a mono-layer and uniform 13.25 $\mathrm{kg} / \mathrm{m}^{2}\left(2.7 \mathrm{lb} / \mathrm{ft}^{2}\right)$ loading while maintaining a reasonable distance $(5 \mathrm{~cm})$ from the edge of the sample car to prevent sidewall effects. The same technique was used to distribute a $4.88 \mathrm{~kg} / \mathrm{m} 2(1 \mathrm{lb} / \mathrm{ft} 2)$ coarse cover layer of $-6.3 \mathrm{~mm}+3.4 \mathrm{~mm}(-1.4 "+6 \mathrm{Mesh})$ over the briquettes shown below (Figure 4-23). 

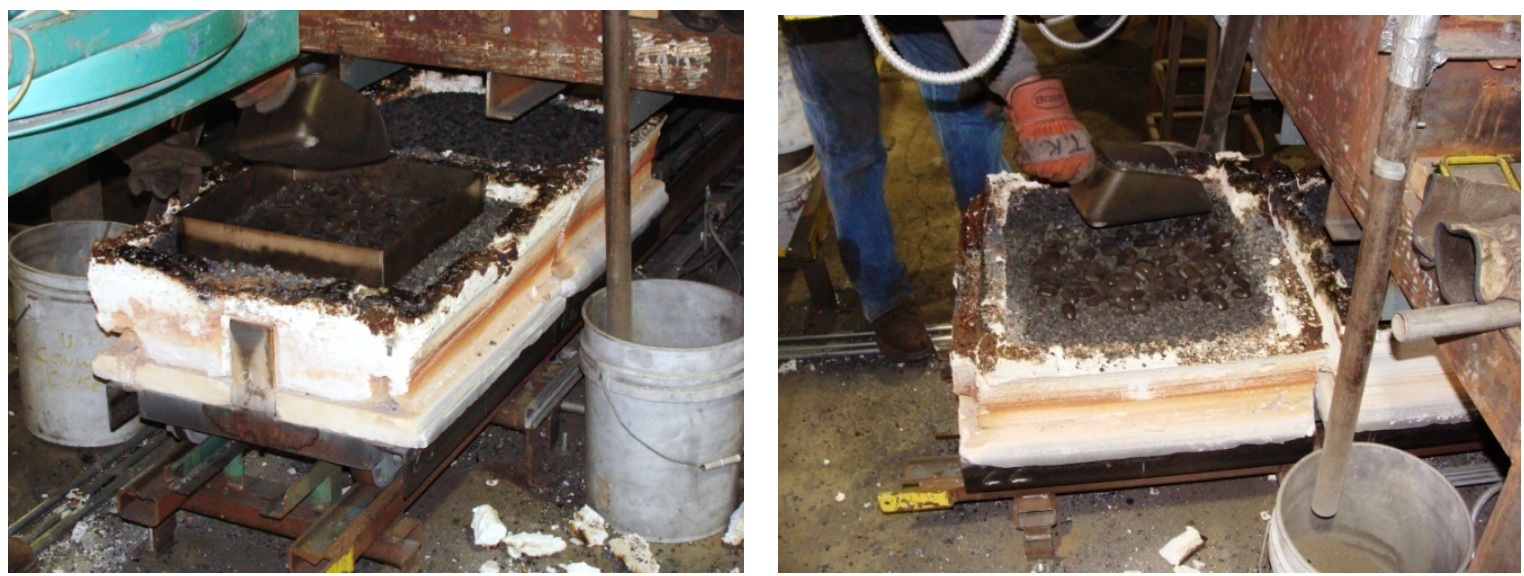

Figure 4-23. Continuous Operation - Raw Material Feeding

The full product car was removed from each car while still hot, screened on $6.3 \mathrm{~mm}$ (1/4") screen to separate product, and the undersize fraction was returned (also still hot) to the surface of the car as recycle hearth layer. Separation techniques were not used to segregate $-6.3 \mathrm{~mm}(1 / 4$ ") slag from recycled carbon for this demonstration; however, this would be necessary step commercially. Any additional $500 \mathrm{~g}$ of hearth layer was also added to each car with the recycled material to simulate any carbon loss. The $+6.3 \mathrm{~mm}(+1 / 4$ ") "product" was allowed to cool in a barrel and then later processed by magnetic separation and screening to separate metallics from non-magnetics, further described in section 4.4. The $+6.3 \mathrm{~mm}(+1 / 4 ")$ screen product is shown in Figure 4-24.
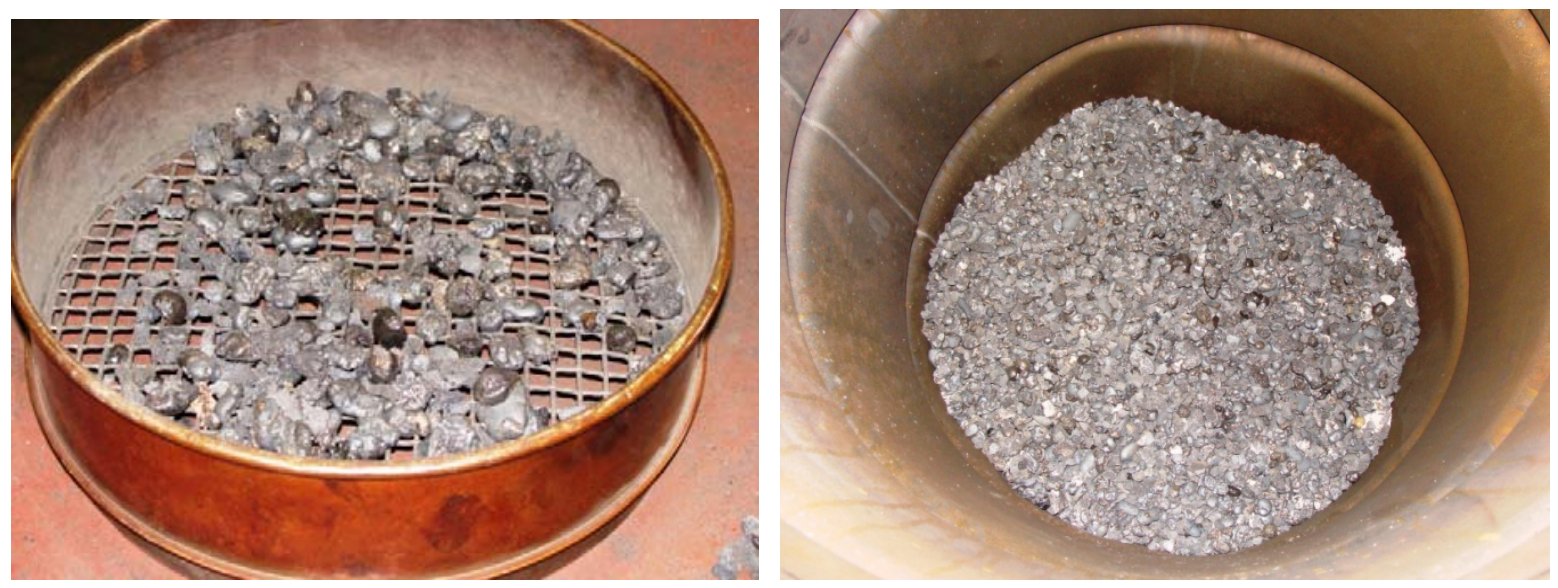

Figure 4-24. $+6.3 \mathrm{~mm}$ Screen Product

\section{4-4.2 Feed Materials}

The raw materials that were used for steady-state operation and demonstration were determined from tube and box furnace tests using the standard and available raw materials. The composition of the hearth layer, cover layer and briquettes fed during this continuous operation are shown below: 
- $\quad-6.7 \mathrm{~mm}(3 \mathrm{Mesh})+0.8 \mathrm{~mm}$ (20 Mesh) coke hearth layer, at $0.125 \mathrm{~cm}(1 / 2 ")$

- $\quad+6.7 \mathrm{~mm}$ (3 Mesh) Coarse coke cover layer

- Baseline almond shaped briquettes (Mix P-269) consisting of:

$\checkmark 70.7 \%$ Magnetite iron ore concentrate from Minnesota

$\checkmark 17.3 \%$ Bituminous, low volatile coal

$\checkmark 6.3 \%$ Hydrated lime

$\checkmark 1.9 \%$ Fluorspar

$\checkmark \quad 3.8 \%$ Molasses Binder

Briquettes were prepared in $2000 \mathrm{~g}$ batches. Ingredients were individually blended in an intensive "V" mixer, then briquetted using the lab scale briquetter. The briquettes were dried and placed into 5-gallon pails for storage until they were used. Hearth layer and cover layer coke were screened using a vibrating screen panel, and then stored in 55gallon drums prior to use. The structure for the screened product is shown in Table 4-1:

Table 4-1. Hearth Layer / Cover Layer Screen Product

\begin{tabular}{|c|c|c|}
\hline \multirow[b]{2}{*}{$\underline{\mathrm{mm}}$} & \multicolumn{2}{|c|}{ Size Distribution, $\%$} \\
\hline & Hearth Layer & Cover Layer \\
\hline+9.5 & 0.0 & 0.0 \\
\hline+6.73 & 0.0 & 42.0 \\
\hline+4.76 & 14.4 & 38.4 \\
\hline+3.36 & 33.1 & 16.5 \\
\hline+2.38 & 24.4 & 1.9 \\
\hline+1.68 & 6.8 & 0.1 \\
\hline+1.19 & 11.2 & 0.2 \\
\hline+0.841 & 6.6 & 0.2 \\
\hline+0.595 & 2.2 & 0.1 \\
\hline-0.595 & 1.4 & 0.6 \\
\hline
\end{tabular}

\section{4-4.3 Linear Hearth Furnace Operating Variables}

The operating variables used for the continuous operation demonstration with baseline briquette loading using hearth and cover layer was determined from previous LHF runs and box furnace tests. Minimum time to fusion was determined on the basis of a fused tray of NRI, using a visual assessment, with the furnace operation held within tight temperature and atmosphere constraints. Temperature control must be constant and holding near set point during the cycling of fully loaded cars to prevent temperature loss. Combustion burners are operated sub-stoichiometrically at a ratio of 1.5:1 (oxygen: gas). This was found through testing to be the minimum ratio we can operate and still achieve set point temperatures. Additional constraints include, no oxygen present in the furnace atmosphere with CO levels as high as possible while still maintaining temperature. This is accomplished by maintaining a positive pressure with the furnace proper while preventing the furnace combustion gasses from exhausting out the feed and product ends. Each end of the furnace has been equipped with an exhaust duct with a pressure and temperature monitor to aid in controlling this pressure. When the furnace is operating properly, a small flame can be seen at each end of the furnace, 
where these ducts capture any harmful gasses. In addition, the under car space has also been equipped with a pressure sensor and damper controlled exhaust to maintain this pressure slightly negative to the furnace and prevent ingress oxygen (air) leakage.

\section{4-4.3.1 LHF Operating Set points}

The operating set points determined from previous operating experience with direction from tube and box furnace tests are shown below. The residence time is measured as the time required to completely travel through the hot zones (zones I through III).

- Car speed $17.8 \mathrm{~cm} / \mathrm{min}(7.0$ “/min)

- Residence Time $=38.01 \mathrm{~min}$

- Furnace Pressure set point $=+12.4 \mathrm{~N} / \mathrm{m}^{2}(+0.05$ "H2O)

- Temperature Set points:

$\checkmark$ Zone $1982^{\circ} \mathrm{C}\left(1800^{\circ} \mathrm{F}\right)$

$\checkmark$ Zone $21343^{\circ} \mathrm{C}\left(2450^{\circ} \mathrm{F}\right)$

$\checkmark$ Zone $31399^{\circ} \mathrm{C}\left(2550^{\circ} \mathrm{F}\right)$

The zone I temperature is typically higher than set point due to the close proximity of the higher temperature zone II which operates under positive pressure and transfers heat under the baffle wall separating the two zones. Figure 4-25 shows that the furnace was operating successfully within temperature set points. Figure 4-26 is a visual depiction of the natural gas and oxygen flow operating at the ratio of 1.5:1.

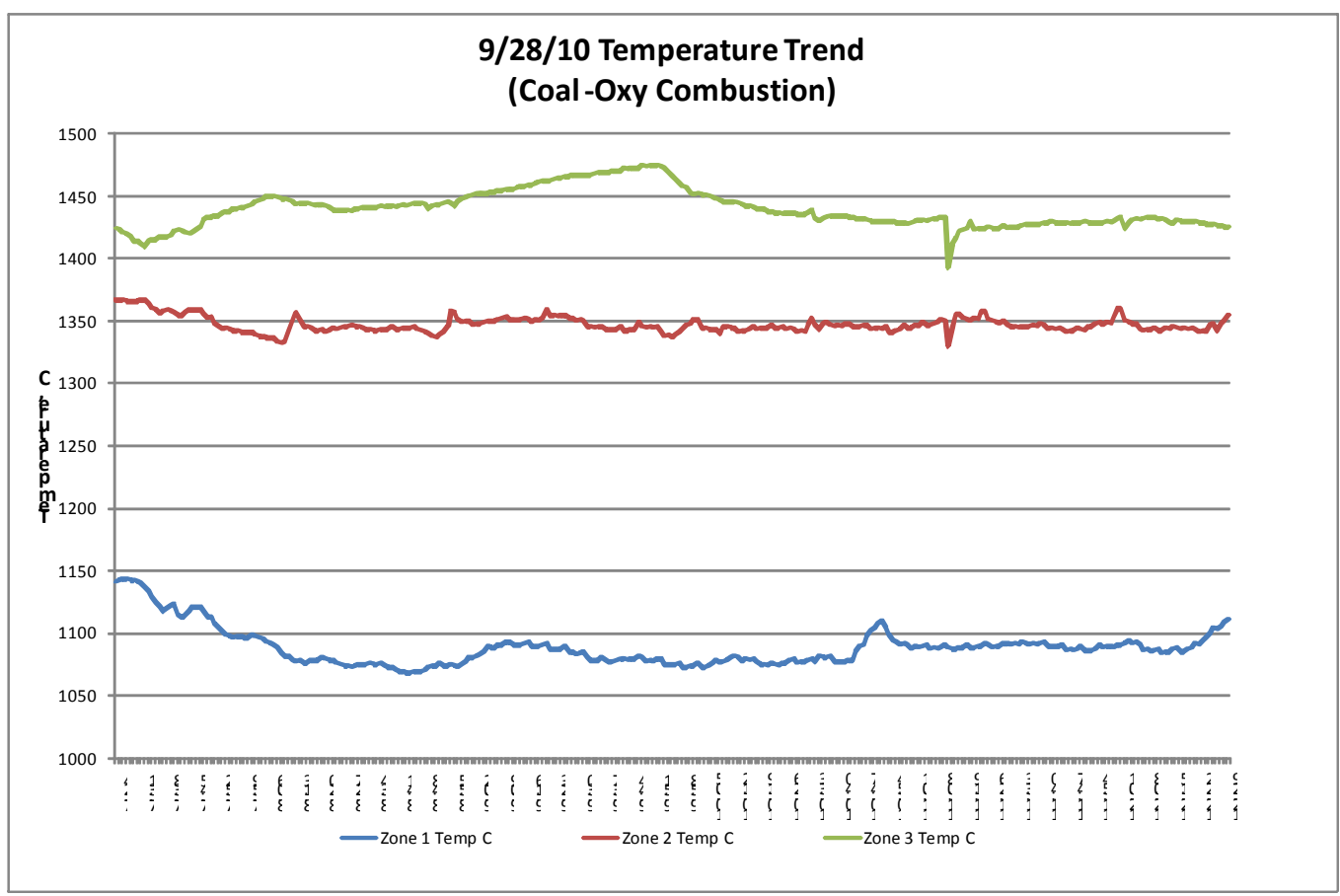

Figure 4-25. Zone Temperature Control Trends 
Figure 4-26 is a illustration of the natural gas and oxygen flow. The data shows the ratio of oxygen to gas is operating at the ratio of 1.5:1, less than 2.1:1 required for perfect combustion creating the reducing environment described by the gas analysis in the next section.

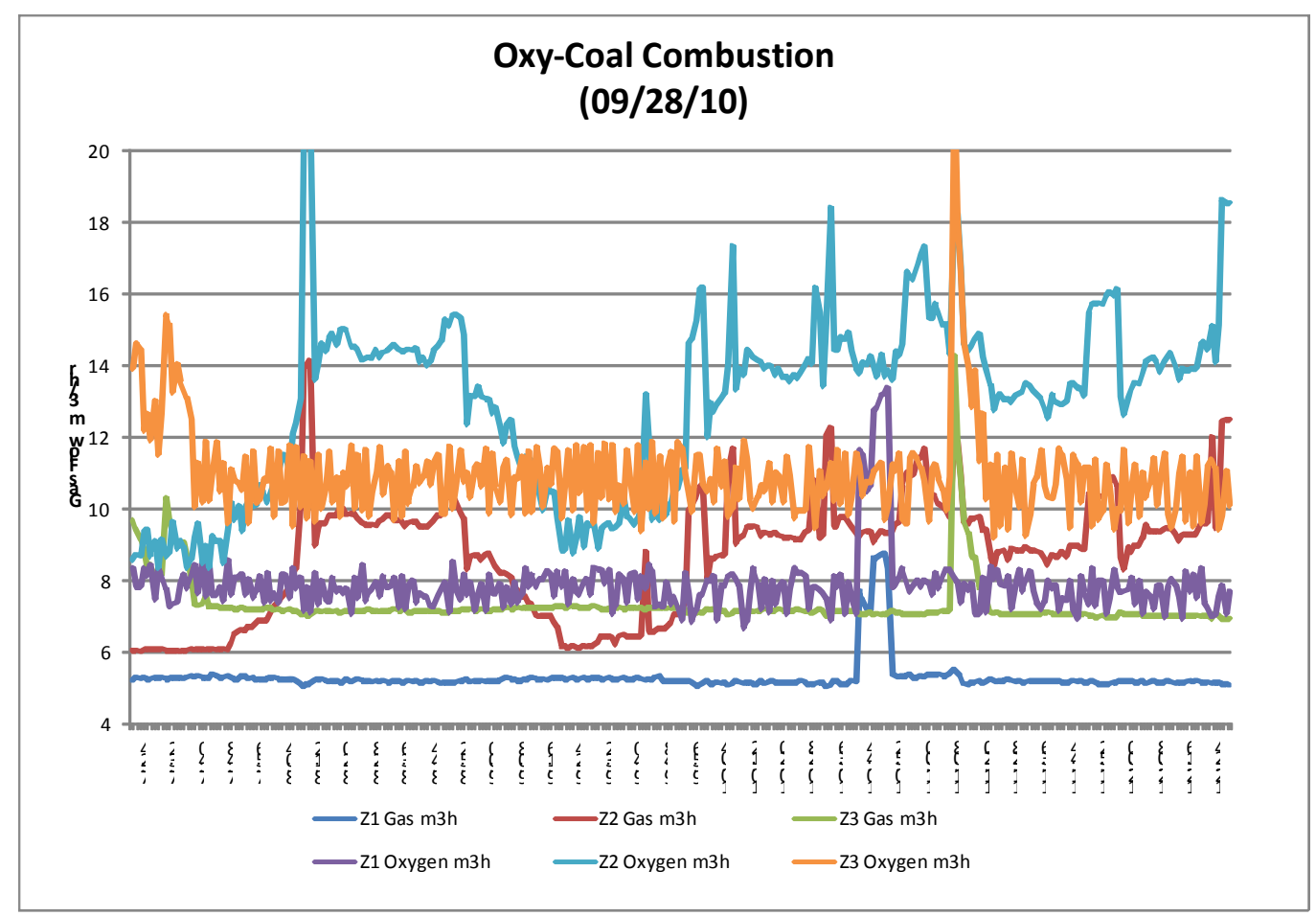

Figure 4-26. Oxy-Coal Combustion Gas Flow

\section{4-4.3.2 Gas Analysis}

Gas atmosphere control uses the combinations of the combustion system operating under low velocity and sub-stoichiometric conditions, the evolution of volatile gases and the reduction of carbonaceous additives to provide the reducing environment required for NRI production. Sample ports are located approximately $15 \mathrm{~cm}$ above the bed and located in the centers of zones I, II, and III. A fourth port is also located at a slightly higher elevation $(\sim 30 \mathrm{~cm})$ in the transition area between zones II and III. The content of the weir space in the furnace consists primarily of $\mathrm{CO}, \mathrm{H}_{2}, \mathrm{CO}_{2}$ and water vapor when operating with the oxy-fuel combustion systems. During each of the steady state operations, an average gas analysis is shown in Table 4-2: 
Table 4-2. Average LHF Atmosphere Gas Analysis

\begin{tabular}{|l|c|c|c|c|c|}
\hline & \multicolumn{5}{|c|}{ Gas Composition } \\
\hline Oxy-Coal & \% CO & \% O2 & \% H2 & \% CO2 & \% CxHy \\
\hline Zone 1 & 17.9 & 1.1 & 12.2 & 22.0 & 0.2 \\
\hline Zone 2 & 7.3 & 0.0 & 5.1 & 19.0 & 0.0 \\
\hline Zone 2-3 & 5.7 & 0.0 & 3.6 & 17.2 & 0.0 \\
\hline Zone 3 & 5.8 & 0.0 & 3.3 & 22.6 & 0.0 \\
\hline Oxy-Gas & & & & & 0.4 \\
\hline Zone 1 & 13.1 & 0.0 & 10.8 & 22.7 & 0.0 \\
\hline Zone 2 & 9.4 & 0.0 & 7.7 & 18.2 & 0.0 \\
\hline Zone 2-3 & 9.7 & 0.0 & 7.9 & 15.4 & 0.0 \\
\hline Zone 3 & 8.0 & 0.0 & 6.6 & 19.5 & \\
\hline
\end{tabular}

Note the slight increase concentration of hydrocarbons measured in zone I in both scenarios due to the devolatilization of the coal and fresh hearth and cover layers. The 0.0 level observed in the remaining zones indicate that devolatilization is completed in this section of the furnace. A three hour snapshot was taken of the atmosphere conditions above the bed from the steady-state operations for both oxy-coal and oxygas is shown in Figures 4-27 to 4-30.

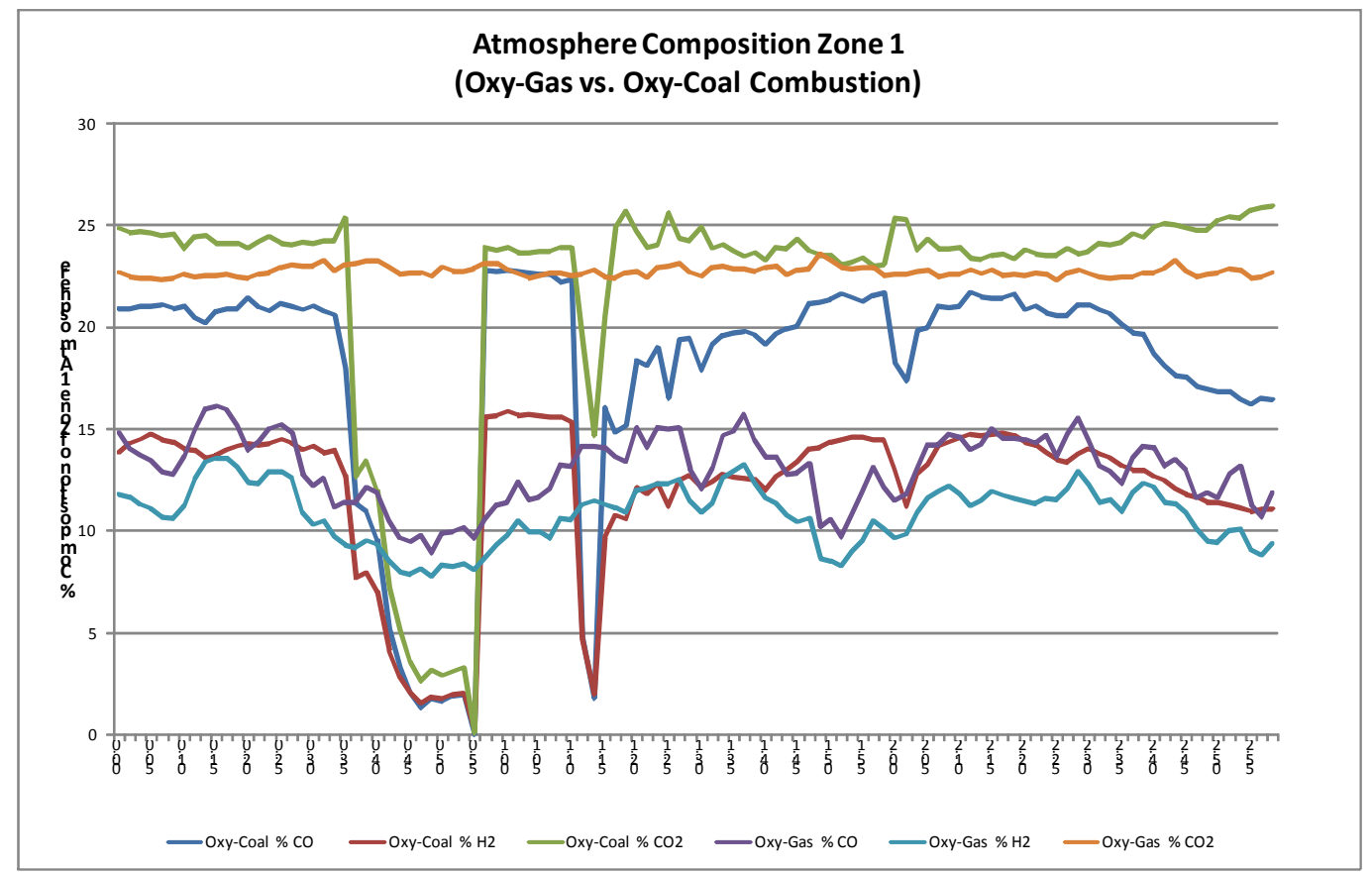

Figure 4-27. Zone One - Gas Analysis Comparison 


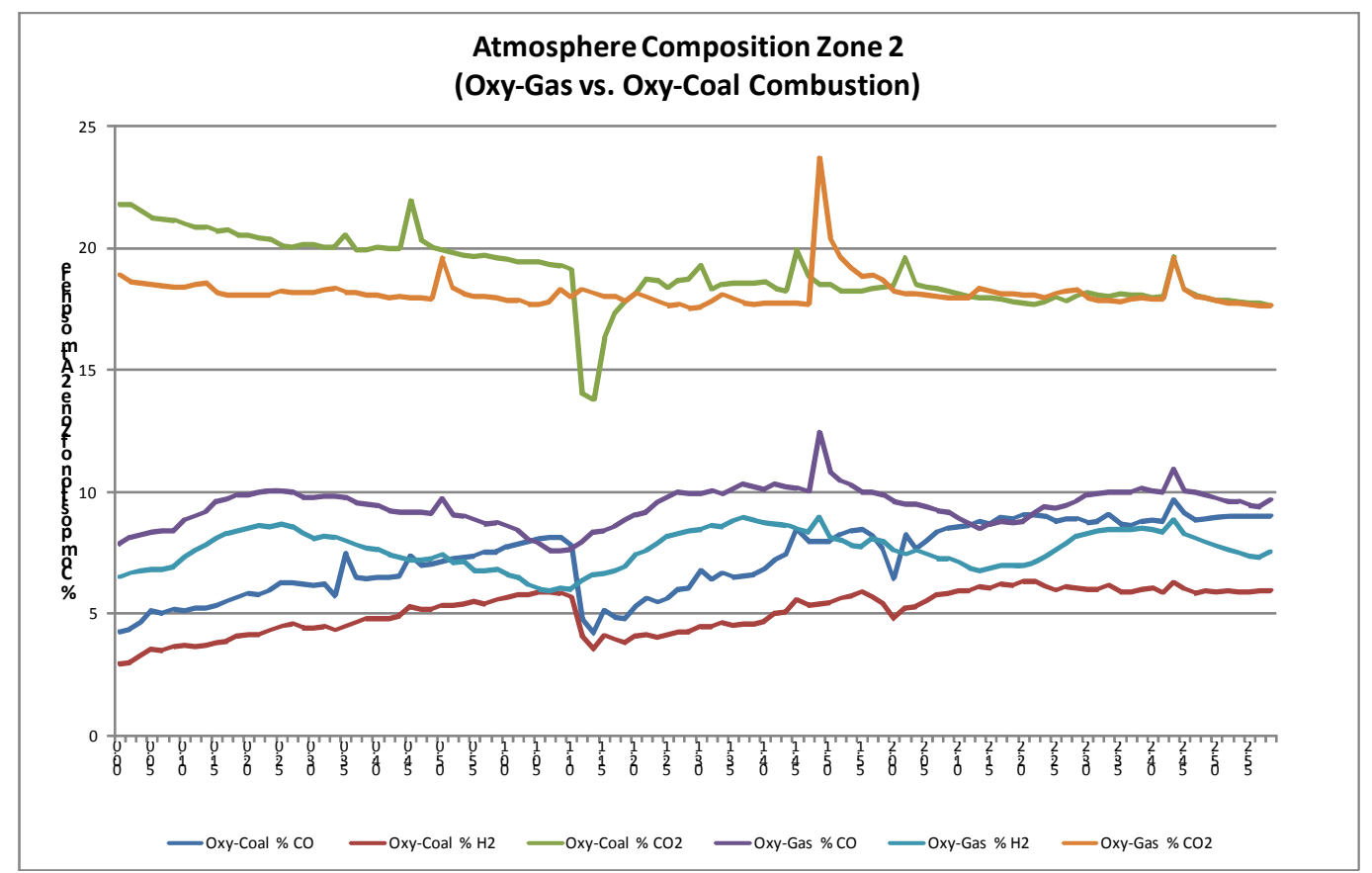

Figure 4-28. Zone Two - Gas Analysis Comparison

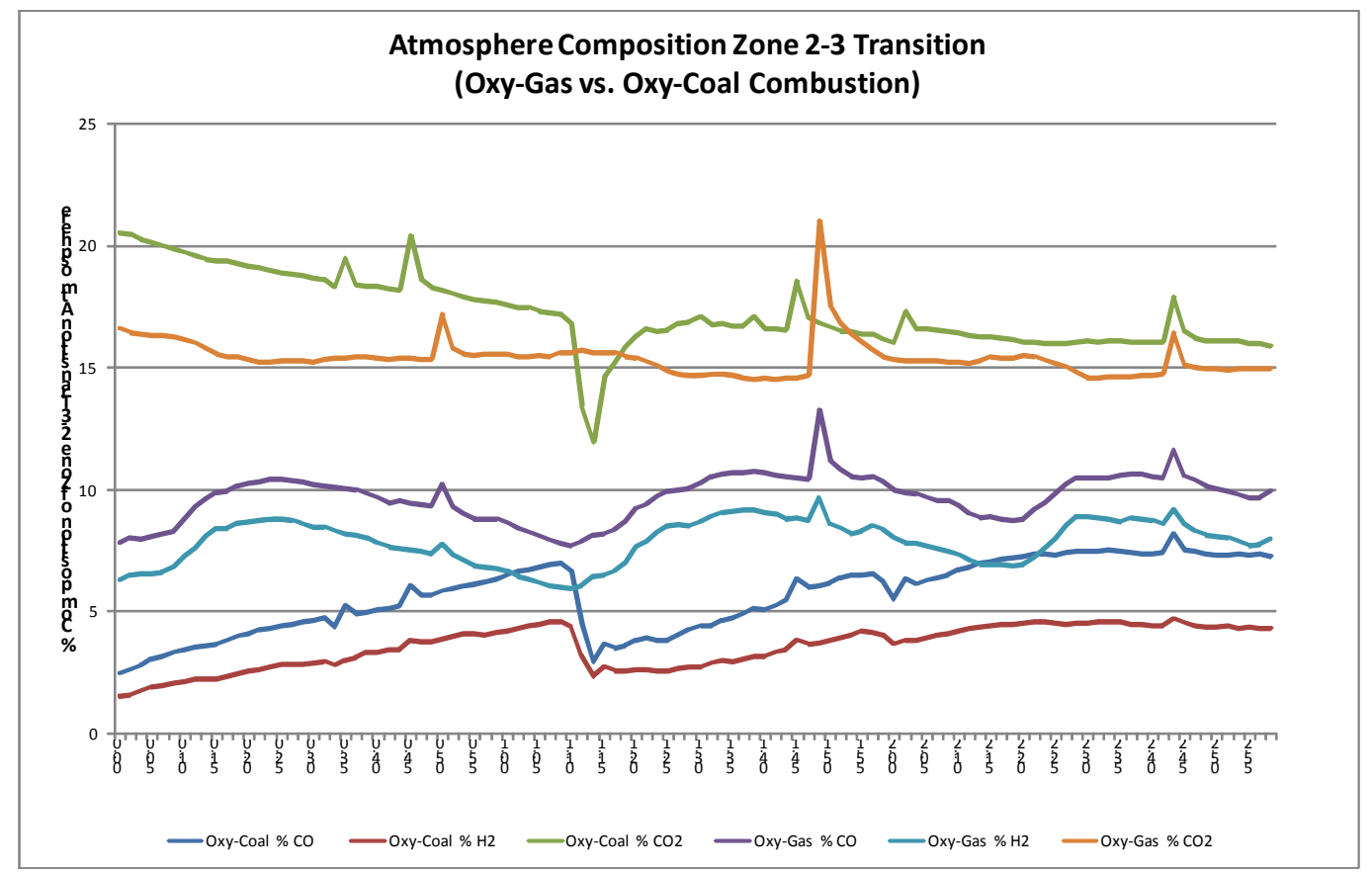

Figure 4-29. Zone Two-three - Gas Analysis Comparison 


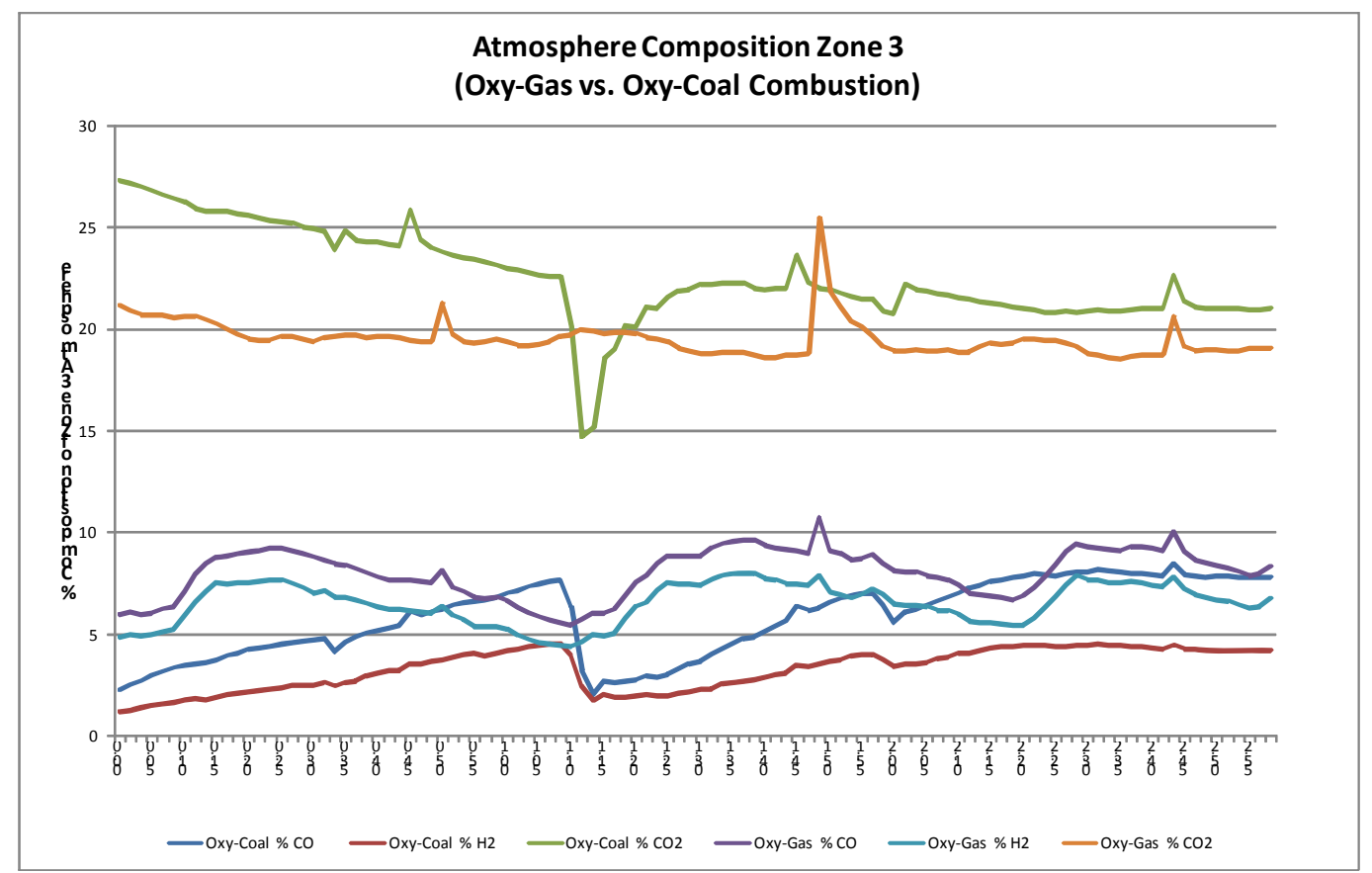

Figure 4-30. Zone Three - Gas Analysis Comparison

Table 4-2 and the figures above shows slightly lower $\mathrm{CO}$ and $\mathrm{H}_{2}$ levels and a slightly higher $\mathrm{CO}_{2}$ content when using the oxy-coal burner system in the reduction and fusion zones. It is logical to assume the oxygen associated with the conveying air is consumed in the initial exposure to the zone II-III atmosphere. It was previously stated that the use of the oxy-coal combustion results in an increase in residence time estimated at approximately $15 \%$ when compared to the oxy-gas system. The atmosphere as a result of the dilution air required to convey the coal in through the burner results in oxidizing the zone III atmosphere. This relationship between $\mathrm{CO}$ and the residence time supports the data previously reported that shows the positive influence of the CO atmosphere on residence time.

\section{4-4.4 NRI Product Removal and Separation Technique}

The entire $+6.3 \mathrm{~mm}$ product from the continuous run was collected during a 4 hour period of steady-state operation. Following the end of the run, the entire sample remaining on the car surfaces was removed and included in the bulk magnetic separation to retain any undersized metallics. The flow diagram shown in Figure 4-31 shows the process for product separation and ultimately analyses. 


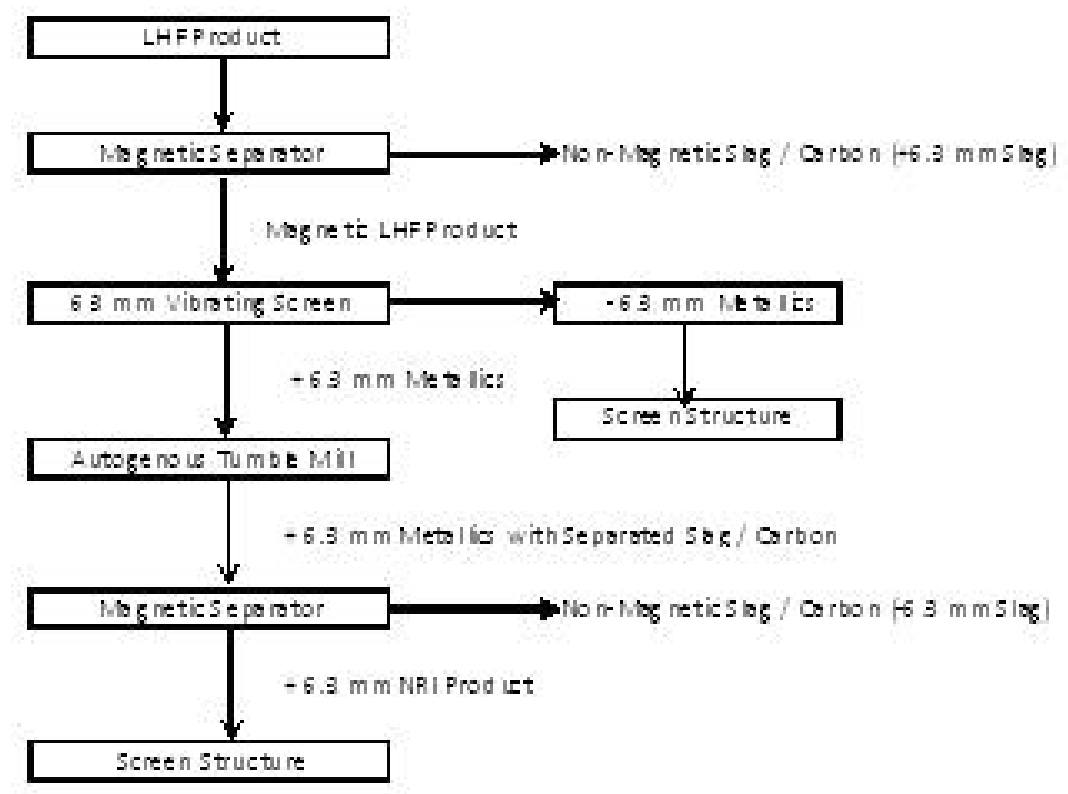

Figure 4-31. Product Separation Material Flow Diagram

\section{4-4.5 Iron Nodule Product Quality}

The LHF was operated continuously for a period of 6 hours. To allow samples entering and exiting the furnace at steady-state condition, a bulk sample was collected over 3 hours and $59 \mathrm{~min}$. The net result of this bulk sample resulted in production of $79.5 \mathrm{~kg}$ of $+6.3 \mathrm{~mm}$ fused NRI or $19.9 \mathrm{~kg} / \mathrm{hr}$. The percentage of "not fully fused" nodules was determined to be $8.1 \%$ of the bulk or $7.2 \mathrm{~kg}$ over the entire sampling period. This fraction was visually separated from the NRI product by hand sorting. The chemistry sample was split out and removed prior to this hand separation; therefore, the metallic iron content of this is lower than expected, and can be explained due the presence of what is assumed to be wustite $(\mathrm{FeO})$ in the product sample. Micro-nodules resulted in a total of $2.1 \%$ of the bulk and metallic fines were less than $1 \%$, (assumed to be residual carbon from the hearth and cover layer). The carbon content resulted in $2.99 \%$ and sulfur content was $0.058 \%$ indicative of high quality nodular reduced iron. The resulting mass screen fraction and the associated chemistry of each fraction are detailed in Table 4-3: 
Table 4-3. NRI Product Size Distribution and Chemistry

\begin{tabular}{|l|c|c|c|c|c|c|c|}
\hline Description & \multicolumn{2}{|c|}{ Product Mass } & \multicolumn{5}{|c|}{ Product Chemistry, \% } \\
\hline & $\underline{\mathrm{kg}}$ & $\underline{\mathrm{F}}$ & $\underline{\mathrm{Met.Fe}}$ & $\underline{\mathrm{Fe}_{\underline{T}}}$ & $\underline{\underline{\mathrm{Fe}}}$ & $\underline{\mathrm{C}}$ & $\underline{\mathrm{S}}$ \\
\hline + 6.3 mm NRI Product & 79.5 & 89.3 & 94.1 & 96.8 & & 2.99 & 0.058 \\
\hline+6.3 mm NRI Product (not fully fused) & 7.2 & 8.1 & & & & & \\
\hline+3.36 mm NRI “micro-nodules” & 0.8 & 0.9 & & 75.7 & 70.9 & 3.20 & 0.327 \\
\hline + 0.84 mm NRI “micro-nodules” & 1.0 & 1.2 & & 96.7 & 93.7 & 1.84 & .099 \\
\hline - 0.84 mm NRI Metallic fines & 0.6 & 0.6 & & 32.18 & 24.7 & 21.8 & 0.677 \\
\hline Total Metallics & 89.1 & & & & & & \\
\hline
\end{tabular}

The slag chemistry was derived from the result of two samples collected during the bulk sampling of the continuous run. The first sample, identified as $+6.3 \mathrm{~mm}$ slag, was representatively split out from the initial separation of the non-magnetic portion from the magnetic belt separator. Any visual carbon found in this sample was removed prior to the preparation for chemical analyses. The second slag sample, identified as $-6.3 \mathrm{~mm}$ slag, was collected from the screen undersize from the autogenous tumble mill product. The NRI product stream was placed into the mill and autogenously tumbled to remove any slag or residual carbon attached to the iron nodules. Slag contamination of the hearth carbon prevented obtaining a sufficient balance for mass fraction determination. The resulting chemistry for the salg samples collected is shown in Table 4-4.

Table 4-4. Slag Chemistry

\begin{tabular}{|c|c|c|c|c|c|c|c|c|}
\hline Description & \multicolumn{8}{|c|}{ Product Chemistry, \% } \\
\hline & $\underline{\mathrm{Fe}_{\mathrm{T}}}$ & $\mathrm{Fe}^{++}$ & $\underline{\underline{C}}$ & $\underline{S}$ & $\underline{\mathrm{CaO}}$ & $\underline{\mathrm{MgO}}$ & $\underline{\mathrm{Al}}_{2} \underline{\mathrm{O}}_{3}$ & $\underline{\mathrm{SiO}_{2}}$ \\
\hline + $6.3 \mathrm{~mm}$ Slag & 10.03 & 9.05 & 1.13 & 0.882 & 56.80 & 2.41 & 4.67 & 29.29 \\
\hline - 6.3 mm Slag & 1.47 & 0.59 & 2.05 & 1.05 & 62.03 & 2.33 & 4.57 & 59.32 \\
\hline
\end{tabular}




\section{4-5 CONCLUSIONS}

The research program was focused on developing the best technology and processing conditions for converting iron oxide resources to high quality metallized iron nodules. The resulting product was targeted to: 1) contain less gangue, 2) contain less sulfur, 3) be resistant to reoxidation, 4) cost less to produce, and 5) use the existing transportation infrastructure and material handling systems. A key to successful operation of the pilot scale Linear Hearth Furnace (LHF) operation is control of the furnace atmosphere through either modification of the combustion system or through auxiliary atmosphere control devices that will enhance the $\mathrm{CO}$ levels near the reacting iron- and carbon-bearing materials. In Phase II of this project, various approaches were evaluated to modify this key condition within the existing pilot LHF. Through the course of this project the LHF has undergone several stages of development, transitioning from a walking beam, natural gas-air fired furnace to one with a continuous moving car system and three distinct combustion systems that can be used individually or in combination. It has routinely been used to test a variety of the variables shown to be important from the box furnace and tube furnace tests. The primary goal of the program was to develop sufficient understanding of the controlling variables associated with taconite iron ore reduction and smelting using coal based reductant materials. The pilot test results clearly demonstrate that high quality nodular reduced iron can be produced from iron ore using the carbothermic reduction process under development in this program. A benefit of testing at the pilot scale has been the ability of the furnace to more closely simulate what might be expected at the next demonstration level. It is very clear that close control of mixture chemistry, coupled with effective atmosphere control and achievement of adequate time and temperature in the metallurgical reactor will allow high quality NRI to be produced using the techniques developed during this program. The next step is to test the concepts at an even more significant scale.

\section{4-5.1 Oxygen-Natural Gas Combustion}

Based on CFD models, for this application, oxygen-fuel burners were determined to offer many advantages over conventional systems. For the Linear Hearth Furnace, an oxygen-fuel burner capable of producing an optimum atmosphere in the furnace, along with low emissions and a low momentum, highly radiant flame, was the desired goal. Several dssigns were considered, and a flat flame oxy-natural gas combustion system was installed. Combustion burners are operated sub-stoichiometrically at a ratio of 1.5:1 (oxygen:gas) to control furnace atmosphere and promote the production of a reducing atmosphere. The results show:

- Fusion time was shorter by 10 to $30 \%$ when oxy-fuel burners were used than air-fuel burners.

- $\mathrm{NRI}$ at fusion time analyzed 3.0 to $3.6 \% \mathrm{C}$ and 0.04 to $0.05 \% \mathrm{~S}$ under the conditions tested. 


\section{4-5.2 Control of Local Atmosphere Above Feed Mixture}

An alternative atmosphere control technique employed an installed horizontal baffle, just above the sample trays so that they are not directly exposed to the ambient furnace atmosphere. Reducing gases were injected through a series of tubes under the hood directly over the sample trays:

- The tests indicated some promise, by producing a fully fused iron nodules with the $\mathrm{CH}_{4}$ injection and partial fusion with the injection of $\mathrm{CO}$ and $\mathrm{N}_{2}$

- It was demonstrated that the system is viable but will require further development to optimize the system and obtain better sulfur and carbon control.

- These tests showed that further modifications of the LHF would be required to enable closer control of the temperature and to further protect the metalized product from back oxidation.

\section{4-5.3 Oxygen-Coal Combustion}

The third combustion modification to the LHF was the installation of a dilute phase coaloxygen burner. The burner was positioned to fire horizontally from the end of the furnace, down the length of the LHF. The pulverized coal is conveyed by an air blower through an eductor system (dilute phase coal injection) to give it sufficient velocity through the burner. Oxygen is also monitored through the PLC control system to match coal addition and adjust stoichiometry. The feed rate of the coal is operated as a baseline energy load in the LHF while the temperature control is provided through the natural gas-oxygen combustion system. The testing shows:

- The coal-oxygen burner system was capable of controlling the set point temperature of $1413^{\circ} \mathrm{C}\left(2575^{\circ} \mathrm{F}\right)$ in zone III while maintaining good atmosphere control for production of NRI.

- While the coal system was in operation, the natural gas system was operating at less than $10 \%$ of full fire, and commonly less than $1 \%$ on a single burner.

- It was determined that the moisture content of the Powder River Basin coal must be below $20 \%$ to convey the coal smoothly and control temperature and below $5 \%$ to allow for atmosphere control similarly to the bituminous coal.

- The moisture content and the energy content of each coal type were found to have significant influence on the operating parameters of the LHF.

- The furnace atmosphere results in slightly lower $\mathrm{CO}$ and $\mathrm{H}_{2}$ levels and a slightly higher $\mathrm{CO}_{2}$ content when compared to the oxy-gas burner system in the reduction and fusion zones.

- The oxy-coal combustion results in an increase in residence time estimated at approximately $15 \%$ when compared to the oxy-gas system.

- This relationship between $\mathrm{CO}$ and the residence time supports the data previously reported that shows the positive influence of the $\mathrm{CO}$ atmosphere on residence time. 


\section{4-5.4 Continuous Steady-State Demonstration of Operation}

The Linear Hearth Furnace was operated continuously for a period under simulated steady-state conditions to demonstrate continuous production of Nodular Reduced Iron. A bulk sample was collected over 3 hours and $59 \mathrm{~min}$. The net result of this bulk sample resulted in:

- Production of $79.5 \mathrm{~kg}$ of $+6.3 \mathrm{~mm}$ fused NRI or $19.9 \mathrm{~kg} / \mathrm{hr}$.

- The percentage of "not fully fused" nodules was determined to $8.1 \%$ of the bulk or $7.2 \mathrm{~kg}$ over the entire sampling period.

- Micro-nodules resulted in a total of $2.1 \%$ of the bulk and metallic fines were less than $1 \%$, (assumed to be residual carbon from the hearth and cover layer).

- The carbon content resulted in $2.99 \%$ and sulfur content was $0.058 \%$ indicative of high quality nodular reduced iron.

\section{4-5.5 Summary of this section}

- High quality NRI can be routinely produced provided the right choice of temperature profile, atmosphere control and additives are employed.

- The baseline operating conditions on both the oxy-gas and coal-oxygen based systems have been established. The furnace variables were manipulated to operate under positive pressure, and reducing atmosphere using the stoichiometry of the combustion to minimize oxygen content in the furnace atmosphere. These techniques were used to demonstrate both combustion systems in routine production of NRI under those conditions.

- The specific conditions identified should allow commercial production of nodules. Considering heat and energy losses, process inefficiencies, excess weir space, secondary combustion and production rates, quantification of the expected energy consumption and overall process economics was not realistic from this demonstration on the LHF.

- Complete process mass and energy balances for commercial scale development were derived from the CFD modeling using the practical furnace designs described in that section of this report. 


\section{4-6 REFERENCES}

1. "Oxygen-enriched combustion can reduce emissions and fuel use in energyintensive industries," DOE/CH10093-198, DE93000063, September 1993, http://es.epa.gov/techinfo/facts/o2-nrich.html.

2. Atmosphere Recovery website, http://www.atmrcv.com/technology.html, R. Rich. 


\section{PART 5:}

\section{Commercialization Potential of the Technology}

by

Donald R. Fosnacht

Director

Center for Applied Research and Technology Development

218-720-4282

dfosnach@nrri.umn.edu

Richard F. Kiesel

Deputy Director

Coleraine Minerals Research Laboratory

218-245-4207

rkiesel@nrri.umn.edu

Natural Resources Research Institute

5013 Miller Trunk Hwy

Duluth, MN 55811 


\section{TABLE OF CONTENTS}

5-1 COMMERCIALIZATION AND MARKET ACCEPTANCE ............................ 353

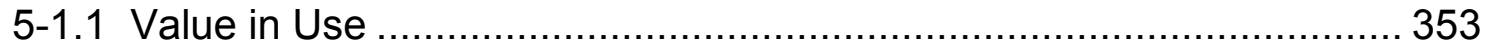

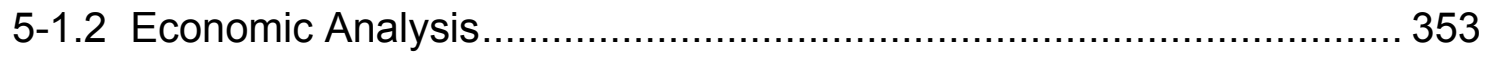

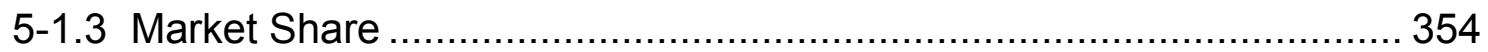

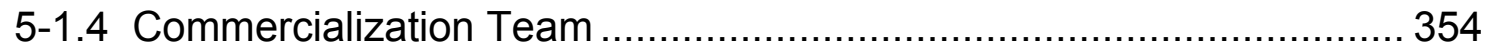

5-1.5 Next Steps to Commercialization.................................................... 354

5.2 THE NEXT GENERATION LINEAR HEARTH FURNACE.............................. 356

5.2.1 Utilization of Developed Process Models ........................................... 357

5.3 FURTHER USE OF THE PILOT FURNACE FACILITY AND

LABORATORY REACTORS …....................................................... 358 


\section{5-1 COMMERCIALIZATION AND MARKET ACCEPTANCE}

\section{5-1.1 Value in Use}

The products from this process development are targeted to provide high quality, low impurity iron units to electric arc furnace (EAF) steel manufacturers, but can also be used to enhance blast furnace productivity, basic oxygen furnace coolant and scrap requirements, and can be used in various iron foundry applications. The material consists of approximately $96.5 \%$ to $97 \%$ metallic iron, 2.5 to $3 \%$ carbon and minimal tramp impurities. The material can be handled using conventional material handling techniques and is very dense and can easily penetrate steel slag. It is anticipated that the material will be used at rates up to $30 \%$ of the metallic charge into a high powered electric furnace and can be added to the furnace on either an intermittent basis or using continuous charging practices. The contained carbon provides valuable chemical energy to displace electrical power requirements during steel processing when oxygen blowing practices are employed in the EAF operation.

\section{5-1.2 Economic Analysis}

Depending on the cost of the incoming iron oxide materials, a preliminary economic analysis of the cost of iron nodule production by the development team indicates that iron nodule production costs can range from $\$ 190$ to $\$ 250$ per tonne using the data generated from the pilot scale testing and the results of our process modeling. The biggest cost items are the cost of iron ore and coal required for the process. These items have escalated in price rapidly due to the world-wide expansion in steel production.

Scrap costs for steel producers at the time of this submission have escalated to well over $\mathbf{\$ 3 5 0}$ per metric tonne. In addition, pig iron costs continue to rise to phenomenal

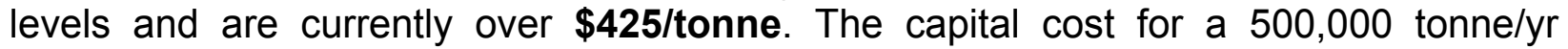
module is estimated to be approximately $\$ 200$ million per standalone module. This is similar to the costs reported for an ITmk3 module of similar size. The actual amount of modules purchased using the technology under development by the current investigators will be dictated by the confirmed process advantage that may arise relative to the Kobe or JFE based technologies that produce similar products. Our analysis indicates that the use of oxyfuel burners (either with natural gas or with coal) can lead to enhanced productivity for the process relative to the other nodular iron processes. In addition, the use of this type of burner technology should allow more effective capture of carbon dioxide in the off-gas stream since it will not be diluted by nitrogen in the air used for combustion. As part of our commercial development effort, we have partnered with a large steelmaker to form a joint technology development company. The company has conducted more detailed economic analyses and is evaluating the results of this project in relation to other proprietary studies done by the company on an independent basis. The results of the work within the newly formed company and from this project indicate that the next logical step to pursue the technology would be a detailed engineering study to determine the capital and projected operating costs for implementing the technology at larger scale. In addition, the results from the investigation indicate that the technology can be potentially employed in combination with existing direct reduced iron (DRI) technologies to convert commercial DRI products 
into NRI if the right chemistry and processing are employed in the hybrid process to lower the cost of use of conventional DRI in the steel production process. More development work beyond the current project needs to be done to confirm these innovative concepts for use on the existing gas based DRI technologies.

\section{5-1.3 Market Share}

The amount of steel produced by electric arc furnaces on a world-wide basis is enormous. Over 393,000,000 tonnes of crude steel was produced in 2007 from steel manufacturers using this type of steel melting facilities worldwide. In the United States, over $\mathbf{5 6 \%}$ of all crude steel was made using this steel processing method. Europe, the Middle East, North America, India, and Africa also utilize this steel production method extensively. The volume of electric arc steel manufactured in Asia is also very high even though the blast furnace/basic oxygen converter process is the predominant steel manufacturing technology employed. The key iron raw materials used in electric furnace steelmaking are scrap, direct reduced iron and purchased pig iron. Based on discussions with our steel partner, a reasonable target for iron nodule use in the metallic charge to an electric arc furnace is estimated to be approximately $30 \%$ of the total metallics. If this technology were widely adopted on a world-wide basis, approximately 118 million metric tonnes of iron nodule product could be utilized based on 2007 production levels and a $30 \%$ market penetration using the proposed technology. This would amount to 236 iron nodule production modules.

\section{5-1.4 Commercialization Team}

The product quality from pilot plant operations at the Coleraine Minerals Research Laboratory was evaluated by a leading electric furnace based steel company in the USA. This steel manufacturer produces over 23 million tonnes of raw steel per year and produces both flat, structural and bar products. The metallurgical evaluation of the product by this organization was extremely favorable. They indicated that the material would be equivalent or better to the purchased pig iron that is routinely purchased and used in their various plants today. As a consequence of their evaluation of the product and their due diligence of the process development, they have formed a joint venture development company with the University of Minnesota to support continued development and they have been our industrial partner on this DOE funded project for Development of Advanced Iron Metallization Concepts. The joint development company is Nulron Technologies, LLC. The development company is governed by a joint management board made up of key personnel from the parent company and the University. The formation of Nulron Technologies, LLC is a key indication of the willingness of the University and its steel partner to bring the technology to commercial scale.

\section{5-1.5 Next Steps to Commercialization}

A key need for the process demonstration is to refine the economic analysis of the process using a facility design that is much closer to commercial size compared to the pilot furnace at the Coleraine Minerals Research Laboratory. The chief barriers to commercialization are: 
(1) Confirmation of the technical feasibility of the pilot scale test results on a demonstration level. This includes establishment of a cost-effective operating regime that will simultaneously achieve the desired yield of metallurgically acceptable high grades of iron nodules and the product size characteristics desired for electric arc furnace consumers.

(2) The desired level of engineering detail must be developed as well so that commercialization issues can be minimized when full scale modules are constructed.

(3) The reliability of the various sub-processes including material preparation, exhaust gas handling, and product removal also need to be established so that working ratios for system availability are well understood.

(4) The costs of the raw materials for the process are within control levels of the original assumptions so that the attractiveness of the new pig iron process remains favorable compared to alternative technology options for pig iron including conventional blast furnace iron production, charcoal mini-blast furnace iron production, or direct reduced iron or iron smelting processes. 


\subsection{THE NEXT GENERATION LINEAR HEARTH FURNACE}

The parametric study conducted in section 3 of this report shows the next generation of the Linear Hearth Furnace (G5) has the potential to meet or exceed the current state of the art technology. Natural gas consumption can be minimized by selection of coal type and oxygen concentration in the oxidant streams. Gas consumption rates as low as $0.75 \mathrm{MMBTU} / \mathrm{mt} \mathrm{HM}(0.79 \mathrm{GJ} / \mathrm{mt} \mathrm{HM})$ were achieved when using medium and high volatile bituminous coals. Since coal costs are generally less than natural gas reductant coal energy should be maximized. However, reductant coal addition is also constrained by agglomerate mix chemistry, stoichiometric addition rate, and volatile content. The study indicated total energy consumption based on natural gas and reductant coal could be as low as $13 \mathrm{MMBTU} / \mathrm{mt} \mathrm{HM}(13.7 \mathrm{GJ} / \mathrm{mt} \mathrm{HM})$. It is expected that hot hearth return would decrease both energy consumption and residence time. In a linear furnace system hot hearth return implies paired furnaces or an enclosed heated return.

Carbon dioxide emission varied incrementally between 1100 and $1400 \mathrm{kgs} / \mathrm{mt}$ Hot Metal $(2,420$ and $3,080 \mathrm{lb} / \mathrm{mt} \mathrm{HM})$. The rate was mainly affected by natural gas consumption, coal volatile content and marginally by briquette loading. Minimized emissions occurred at $82 \%$ oxygen, 35 minutes residence time, $0.79 \mathrm{GJ} / \mathrm{mt} \mathrm{HM}$ natural gas $(0.75$ MMBTU $/ \mathrm{mt} \mathrm{HM}), 24.4 \mathrm{~kg} / \mathrm{m}^{2}$ (5 lbs/ $\left./ \mathrm{ft}^{2}\right)$ briquettes, and $4.9 \%$ coal volatiles.

Oxygen consumption on a per ton basis is directly related to productivity and fuel input. Based on these simulations, the oxygen to product mass ratio ranged between 0.8 and 1.1. The models demonstrated an alternative for blending coals and/or hearth char to tailor a reductant volatile content for optimum energy input and furnace temperature.

Increased feed loading will help to minimize natural gas consumption, but increased loads are presumed to remain as a monolayer of agglomerated feed; multiple layers in effect increase residence time and decrease productivity. The parametric design incorporating both mass flow (hearth speed and feed loading) and natural gas firing rate, did not permit a true productivity assessment, because throughput and energy input were both independent. Bed temperature was a dependent variable, and simulations deviating from acceptable operating bed temperatures resulted in unrealistic productivity rates. The acceptable temperature range was defined as maximum temperature between 2600 and $2800^{\circ} \mathrm{F}\left(1427-1538^{\circ} \mathrm{C}\right)$. Total energy consumption for simulations with acceptable bed temperatures ranged as low as $13 \mathrm{MMBTU} / \mathrm{mt}$ Hot Metal $(13.7 \mathrm{GJ} / \mathrm{mt})$.

Productivity was solely a function of briquette loading and hearth speed. It was based on iron flow through the furnace, irrespective of temperatures achieved. In cases where temperature did not reach melting point, production rate was of limited value. Coal type had a small impact on productivity through coal percentage in the mix, determined by coal type (\% Fix C), and ash content affecting flux addition and slag volume.

The process modeling work has identified a model furnace design that can be used as a basis for full engineering feasibility. It indicates the directional influence of flue gas discharge on the process, the areas where it is very necessary to protect the reduced iron from reoxidation by furnace flue gases, and the areas where oxy-fuel technology 
can be optimally employed. The project team believes that the current process knowledge about the carbothermic conversion of iron ore to nodular reduced iron is sufficient to allow an effective process to be developed using the mix chemistries identified during the course of this investigation. The effective use of the created process models can facilitate any engineering study that is commissioned in the future.

\subsubsection{Utilization of Developed Process Models}

1. Combined spreadsheet mass balances with CFD simulations resulted in a simulation method that can be used to evaluate linear hearth furnaces. It is expected that the same technique could be applied to rotary hearth units and /or combinations of linear and rotary hearth process designs.

2. Forty-one simulations were performed in a partial factorial screening design during the course of this investigation (which permitted the analysis of process variable interaction).

a) Total Energy and Total mass flow (including hearth carbon) to the process must be evaluated, especially if hearth carbon is a significant fraction of the total flow. In these simulations hearth carbon was about $50 \%$ of total flow.

b) The process is temperature sensitive to certain coal types and oxidant sources. Nitrogen introduced with the oxidant functions to absorb energy. As nitrogen content decreases, the system becomes more sensitive to temperature excursions, particularly if coal volatile content is increased. The models can guide raw material selection.

c) c) Carbon dioxide emission varied incrementally between 1100 and $1400 \mathrm{kgs} / \mathrm{mt}$ Hot Metal $(2,420$ and $3,080 \mathrm{lb} / \mathrm{mt} \mathrm{HM})$. The rate was mainly affected by natural gas consumption, coal volatile content and marginally by briquette loading. Minimized emissions occurred at $82 \%$ oxygen, 35 minutes residence time, 0.79 $\mathrm{GJ} / \mathrm{mt} \mathrm{HM}$ natural gas(0.75 MMBTU/mt HM), $24.4 \mathrm{~kg} / \mathrm{m} 2$ (5 lbs/ft2) briquettes, and $4.9 \%$ coal volatiles. The modeling work can be used to guide emissions related process design.

d) Beginning with a $2 \mathrm{ft} \times 100 \mathrm{ft}(0.61 \times 30.48 \mathrm{~m})$ unit, furnace size was successfully increased to $12 \mathrm{ft} \times 200 \mathrm{ft}(3.66 \times 60.96 \mathrm{~m})$ and $20 \mathrm{ft} \times 325 \mathrm{ft}(6.09 \times 99.06 \mathrm{~m})$. The models can be used to assess conditions at projected commercial scale size.

3. It is possible to graphically quantify basic process parameters, such as residence time, feed loading, natural gas consumption, oxidant oxygen concentration and coal type. These graphs can be used to enhance understanding of the process and identify operating conditions of interest. This information can greatly aid the engineering development work undertaken in the future. 


\subsection{FURTHER USE OF THE PILOT FURNACE FACILITY AND LABORATORY REACTORS}

As a consequence of University, US DOE, and US DOC funding, a unique metallurgical pilot plant with a variety of capabilities has been established at the University of MN Duluth's Natural Resources Research Institute and its Coleraine Minerals Research Laboratory. This facility coupled with the laboratory metallurgical furnaces provides a unique capability for continued development of the nodular iron concept from iron ores of various types and waste materials containing iron oxides. The unique combination of burner and fuel configurations should allow further design optimization of energy use for any commercial process that is considered for the future. In addition, potential reaction mixtures that are contemplated for commercial development can be evaluated before commercial testing to assure that they meet desired metallurgical targets. 


\section{PART 6:}

\section{Intellectual Property}


Nu-Iron Technology, LLC

Published Applications and Issued Patents

December 2010

\begin{tabular}{|c|c|c|c|}
\hline TITLE & COUNTRY & APP. NO. & PATENT NO. \\
\hline \multirow{7}{*}{ LINEAR HEARTH FURNACE } & UNITED STATES & $11 / 095,005$ & $7,413,592$ \\
\hline & AUSTRALIA & 2005330295 & \\
\hline & BRAZIL & P10520011-3 & \\
\hline & CANADA & $2,603,086$ & \\
\hline & WIPO & PCT/US05/34597 & \\
\hline & UNITED STATES & 12/PCT/194,303 & $7,666,249$ \\
\hline & UNITED STATES & $12 / 710,546$ & \\
\hline \multirow{7}{*}{ METHOD AND SYSTEM FOR PRODUCING METALLIC IRON NUGGETS } & AUSTRALIA & 2007279272 & \\
\hline & CANADA & $2,658,897$ & \\
\hline & EUROPE. & 07813408.7 & \\
\hline & INDIA & $487 / \mathrm{CHENP} / 2009$ & \\
\hline & WIPO & PCT/US07/74471 & \\
\hline & UNITED STATES & $12 / 359,729$ & \\
\hline & UNITED STATES & $12 / 569,176$ & \\
\hline \multirow{27}{*}{ METHOD AND SYSTEM FOR PRODUCING METALLIC IRON NUGGETS } & AUSTRALIA & 2005313001 & 2005313001 \\
\hline & AUSTRALIA & 2005312999 & 2005312999 \\
\hline & BRAZIL & PI0515750-1 & \\
\hline & BRAZIL & PI0515812-5 & \\
\hline & CANADA & $2,590,267$ & \\
\hline & CANADA & $2,590,259$ & \\
\hline & CHINA & 200580047838.5 & \\
\hline & CHINA & 200580047866.7 & \\
\hline & EUROPE & 05824314.8 & \\
\hline & EUROPE & 05824307.2 & \\
\hline & INDIA & $3006 / \mathrm{CHENP} / 200$ & \\
\hline & INDIA & $3002 / \mathrm{CHENP} / 200$ & \\
\hline & JAPAN & $2007-545061$ & \\
\hline & JAPAN & $2007-545060$ & \\
\hline & MEXICO & $\mathrm{MX} / \mathrm{a} / 2007 / 00678$ & \\
\hline & MEXICO & $\mathrm{MX} / \mathrm{a} / 2007 / 00678$ & \\
\hline & TAIWAN & 094143138 & \\
\hline & UNITED STATES & $11 / 296,179$ & $7,628,839$ \\
\hline & UNITED STATES & $11 / 296,197$ & $7,632,335$ \\
\hline & UNITED STATES & $11 / 296,198$ & $7,695,544$ \\
\hline & UNITED STATES & $11 / 296,583$ & $7,641,712$ \\
\hline & VENEZUELA & $2005-002488$ & \\
\hline & WIPO & $\mathrm{PCT} / \mathrm{IB} 05 / 054110$ & \\
\hline & WIPO & $\mathrm{PCT} / \mathrm{IB} 05 / 05 \mathrm{PCT} / \mathrm{IB05}$ & \\
\hline & WIPO & $\mathrm{PCT} / \mathrm{IB} 05 / 054107$ & \\
\hline & UNITED STATES & $12 / 639,584$ & \\
\hline & AUSTRALIA & 2010202010 & \\
\hline \multirow{5}{*}{ METHOD AND SYSTEM FOR PRODUCING METALLIC IRON NUGGETS } & AUSTRALIA & 2009215703 & \\
\hline & CANADA & $2,713,442$ & \\
\hline & EUROPE & 09712738.5 & \\
\hline & EUROPE & 10013645.6 & \\
\hline & WIPO & PCT/US09/32519 & \\
\hline \multirow{3}{*}{$\begin{array}{l}\text { MULTIPLE HEARTH FPCT/US09/32519UCING IRON OXIDE } \\
\text { FURNACE }\end{array}$} & CANADA & $2,669,314$ & \\
\hline & WIPO & PCT/US07/84029 & \\
\hline & UNITED STATES & $12 / 513,872$ & \\
\hline PRODUCTION OF IRON FROM METALLURGICAL WASTE & WIPO & PCT/US10/21790 & \\
\hline \multirow{2}{*}{$\begin{array}{l}\text { SYSTEM AND METHOD FOR COOLING AND REMOVING IRON } \\
\text { EROM } \triangle H E A R T H\end{array}$} & CANADA & $2,675,311$ & \\
\hline & WIPO & $\mathrm{PCT} / \mathrm{US08/50855}$ & \\
\hline \multirow{4}{*}{ SYSTEM AND METHOD FOR PRODUCING METALLIC IRON } & AUSTRALIA & 2007303141 & \\
\hline & CANADA & $2,665,562$ & \\
\hline & WIPO & PCT/US07180362 & \\
\hline & UNITED STATES & 12/PCT/US07/80362 & \\
\hline SYSTEM AND METHOD FOR PRODUCING METALLIC IRON & WIPO & PCT/US07/80364 & \\
\hline
\end{tabular}




\section{Published Applications and Issued Patents}

December 2010

\begin{tabular}{|l|l|l|l|}
\hline TITLE & COUNTRY & APP. NO. & \multicolumn{1}{|l|}{ PATENT } \\
\hline \multirow{5}{*}{ SYSTEM AND METHOD FOR PRODUCING METALLIC IRON } & AUSTRALIA & 2008343167 & \\
\cline { 2 - 4 } & BRAZIL & PI0821356-9 & \\
\cline { 2 - 4 } & CANADA & $2,709,487$ & \\
\cline { 2 - 4 } & EUROPE & 08867608.5 & MX/a/2010/00677777 \\
\cline { 2 - 4 } & MEXICO & $12 / 337,998$ & PCT/US08/87353 \\
\cline { 2 - 4 } & UNITED STATES & 2009201322 & $2,661,419$ \\
\cline { 2 - 4 } & WIPO & $12 / 418,037$ & \\
\hline
\end{tabular}




\section{BIBLIOGRAPHY}




\section{BIBLIOGRAPHY}

K. Andersson, F. Johnsson, Flame and Radiation Characteristics of Gas-Fired O2/CO2 Combustion, Fuel 86 (2007) pp. 656-668.

ANSYS CFX 12 Computational Fluid Dynamics Software, ANSYS, Inc. Southpointe 275 Technology Drive Canonsburg, PA 15317.

B. Benner and R. Bleifuss, Investigation Into Production of Iron Ore Concentrates with Less Than 3 Percent Silica from Minnesota Taconites - Report 1, NRRI/TR-91/09, June 1991.

B. Bennet, Z. Cheng, R. Pitz, and M. Smooke, Computational and Experimental Study of Oxygen-Enhanced Axisymmetric Laminar Methane Flames, Combustion Theory and Modeling Vol. 12, No. 3, 2008, pp. 497-527.

W. Blasiak, W. Yang, K. Narayanan and J. Scheele, Flameless Oxy-Fuel Combustion for Fuel Consumption and Nitrogen Oxides Emissions Reductions and Productivity Increase, Journal of the Energy Institute, Vol. 80 (1) 2007, pp. 3-11.

Z. Cheng, J. Wehrmeyr, R. Pitz, Experimental and Numerical Studies of Opposed Jet Oxygen-Enhanced Methane Diffusion Flames, Combustion Science and Technology 178: 2006, pp. 2145-2163.

E. Chui, A. Majeski, M. Douglas, Y. Tan, K. Thambimuthu, Numerical Investigation of Oxy-Coal Combustion to Evaluate Burner and Combustor Design Concepts, Energy 29 (2004), pp. 1285-1296.

J. Cooper, ANSYS Senior Technical Services Specialist, ANSYS Canada Ltd., Waterloo, Canada.

A. Cruz, F. Chavez, A. Romero, E. Palacios, and V. Arredondo, Mineralogical Phases Formed by Flux Glasses in Continuous Casting Mould, Journal of Materials Processing Technology 182, 2007, pp. $358-362$.

R. Degel, P. Fontana, G. DeMarchi, H-J. Lehmkuhler, A New Generation of Rotary Hearth furnace Technology for Coal based DRI Production, Stahl und Eisen 120, 2000 Nr.2, pp. 33-40.

Direct from Midrex: From the Hearth - RHF Technologies, Special Report Winter 2007/2008.

Duluth News Tribune, Mesabi Nugget to start operations in December, Duluth News Tribune, November 26, 2009.

Duluth News Tribune, Mesabi Nugget rolls out first batch, Duluth News Tribune, January 10, 2010. 
FactSage Thermochemical Software, Center for Research in Computational Thermochemistry, Dept. Chemical Engineering, University of Montreal, Montreal, Canada H3C $3 \mathrm{~A} 7$.

O. Fortini and R. Fruehan, Evaluation of a New Process for Ironmaking: A Productivity Model for the Rotary Hearth Furnace, Steel Research Int. 75 (2004) No. 10 pp. 625631.

D.R. Fosnacht, I. Iwasaki and R.L. Bleifuss, Metallic Iron Nodule Research, Final Report to the Economic Development Administration, Project \#06-69-04501, March 25, 2004, 15p. (Patent pending).

K. Fuji, H. Tanaka, T. Harada, T. Suglyama, Y. Takenaka, K. Miyagawa, S. Shirouchi, H. Iwakiri, M. Nishimura, T. Umeki, S. Hashimoto and T. Uehara, Method of Producing Reduced Iron Agglomerates, US Patent 6,129,777.

D. Gilbert, Coal Based DRI: Know the Questions/Get the Answers, Iron Ore for Alternative Iron Units October 25-27, 1999, Charlotte, NC.

S. Halder and R.J. Fruehan, Reduction of Iron Oxide Carbon Composites: Part 1. Estimation of Rate Constants, Metallurgical and Material Transactions B, Vol. 38B, December 2008, pp. 784-795.

S. Halder and R.J. Fruehan, Reduction of Iron Oxide Carbon Composites: Part II. Rates of Reduction of Composite Pellets in a Rotary Hearth Furnace Simulator, Metallurgical and Material Transactions B, 38B, December 2008, pp. 796-808.

S. Halder and R.J. Fruehan, Reduction of Iron Oxide Carbon Composites: Part III. Shrinkage of Composite Pellets during Reduction, Metallurgical and Material Transactions B, Vol. 38B, December 2008, pp. 796-817.

J. Hansen, Mesabi Nugget - The New Age of Iron, Iron and Steel Technology, March 2005, pp. 149-153.

T. Harada, H. Tanaka, H. Sugitatsu, Method for Manufacturing Reduced Metal, Patent Application Publication US 2004/0163493 A1, Aug 26, 2004.

T. Harada, H. Tanaka, H. Sugitatsu, Method for Manufacturing Reduced Metal, US Patent 7,572,316, B2, Aug. 11, 2009.

Hi-QIP, a new Ironmaking Process, Iron \& Steel Technology, Vol. 5 (2008), 87-94.

G. Hoffman and O. Tsuge, ITmk3 - Application of a new ironmaking technology for the iron ore mining industry, Mining Engineering, Vol. 56 (2004), No. 10, 35-39.

G.P. Huffman, F.E. Huggins and G.R. Dunmyre, Investigation of the High-Temperature Behavior of Coal Ash in Reducing and Oxidizing Atmospheres, Fuel 1981 Vol. 60, pp. 585-597. 
N. Ishiwata, Y. Sawa and K. Takeda, Pilot plant test for production of iron pebble (Development of new reduction and smelting process on coal bed -1), CAMP-ISIJ, Vol. 17 (2004), 150.

JMP Statistical Software, SAS Institute Inc.100 SAS Campus Drive Cary, NC 275132414.

Y. Kamei, T. Kawaguchi, H. Yamaoka, Y. Nakumura, Method and Facility for Producing Reduced Iron, US Patent 6,284,017 B1, Sep. 4, 2001.

Y. Kang and K. Morita, Thermal Conductivity of the CaO-Al2O3-SiO2 System, ISIJ International, Vol. 46, 2006, No. 3, pp. 420-426.

T. Kiga, S. Takano, N. Kimura, K. Omata, M. Okawa, T Mori, M. Kato, Characteristics of Pulverized-Coal Combustion the System of Oxygen/Recycled Flue Gas Combustion, Energy Conversion Management Vol. 38, Suppl., pp. S129-S134, 1997.

I. Kobayashi, Y. Tanigaki and A. Uragami, A new process to produce iron directly from fine ore and coal, Iron \& Steelmaker, Vol. 27 (2001), No. 9, 19-22.

KSC Develops New Ironmaking Process, Iron \& Steelmaker, Vol. 28 (2001), No. 10, 8.

D. M. Kundrat, Method of Reducing Metal Oxide in a Rotary Hearth Furnace Heated by an Oxidizing Flame, US Patent 5,567,224, Oct, 221996.

Hao Liu, Chunhua Luo, Shigeru Kato, Shigeyuki Uemiya, Masahiro Kaneko, Toshinori Kojima, Kinetics of CO2/Char Gasification at Elevated Temperatures, Part I: Experimental Results, Fuel Processing Technology 87 (2006) pp.775-781.

Hao Liu, Chunhua Luo, Masaomi Toyota, Shigeyuki Uemiya, Toshinori Kojima, Kinetics of $\mathrm{CO} 2$ Char Gasification at Elevated Temperatures: Part II, Clarification of Mechanism through Modeling and Char Characterization, Fuel Processing Technology 87 (2006), pp. 769-774.

Lockwood Greene, Ironmaking Process Alternatives Screening Study - ITmk3 process to produce shot iron, DOE LG Job No. 010529.01, October 2000.

W-K. Lu and D. F. Huang, The Evolution of Ironmaking Process Based on CoalContaining Iron Ore Agglomerates, ISIJ International Vol. 41 (2001) No. 8, pp. 807-812.

D. C. Meissner, T. H. Boyd, J. A. Lepinski, and J. D. Sloop, Method for Rapid Reduction of Iron Oxide in a Rotary Hearth Furnace, US Patent 5,730,775, Mar. 24, 1998.

A. Murao, Y. Sawa, H. Hiroha, T. Matsui, N. Ishiwata, T. Higuchi and K. Takeda, Hi-QIP, A New Ironmaking Process, Iron and Steel Technology, March 2008, pp. 87-94.

S. Nakayama, Y. Noguchi, T Kiga, S. Miyamae, U. Maeda, , M. Kawai, T. Tanaka, K. Koyata, and H. Makino, Pulverized Coal Combustion in O2/CO2 Mixtures on a Power 
Plant for CO2 Recovery Energy Conversion Management Vol. 33, No. 5-8, pp. 379-386, 1992.

M. Nishimura and T. Suzuki, Direct Reduction Method and Rotary Hearth Furnace, M. Nishimura and T. Suzuki, US Patent 5,989,019, Nov. 23, 1999.

F. Normann, K. Andersson, B. Leckner, F. Johnsson, High-Temperature Reduction of Nitrogen Oxides in Oxy-Fuel Combustion, J. Fuel 2008.06.013.

North American Combustion Handbook, 2nd ed.1978, p. 37.

T. Nozaki, S. Takano, T. Kiga, K. Omata, N. Kimura, Analysis of the Flame Formed During Oxidation of Pulverized Coal by an O2/CO2 Mixture, Energy Vol. 22, No. 2/3,1997, pp. 199-205.

H. Ohta, H. Shibata, T. Kasamoto, Estimation of Heat Transfer of Front-Heating FrontDetection Laser Flash Method Measuring Thermal Conductivity for Silicate Melts at High Temperatures, ISIJ International Vol. 46, 2006, pp. 434-440.

R.J. Quann and A.F. Sarofim, Vaporization of Refractory Oxides During Pulverized Coal Combustion, 19th Symposium on combustion/The Combustion Institute, 1982, pp. 1429-1440.

R. Rich, Atmosphere Recovery website, http://www.atmrcv.com/technology.html.

M.F. Riley, H. Kobayashi, and A.C. Deneys, Praxair's dilute oxygen combustion technology for pyrometallurgical applications, JOM, Vol. 53 (2001), No. 5, pp.21-24.

B. Sarma and M. Ding, Production of Direct Reduced Iron with Reduced Fuel Consumption and Emission of Carbon Monoxide, US Patent 5,951,740, Sep. 14, 1999.

Y. Sawa, T. Yamamoto, K. Takeda and H. Itoya, New coal-based process, Hi-QIP, to produce high quality DRI for the EAF, 2000 Electric Furnace Conference Proceedings, Vol. 58 (2000), Orlando, Florida, 507-517.

K. Shimizu, T. Suzuki, I. Jimbo, and A. Cramb, An Investigation on the Vaporization of Fluorides from Slag Melts, Ironmaking Conference Proceedings, 1996, pp. 727-733.

Skillings Mining Review, Mesabi Nugget: a steady presence for the Range, Skillings Mining Review, Vol. 98, No. 12, December, 2009.

Y. Tan, J. Douglas, K. Thambimuthu,CO2 Capture Using Oxygen Enhanced Combustion Strategies for Natural Gas Power Plants, Fuel 81 (2002), pp. 1007-1016.

M. Tateishi, M. Tetsumoto, Apparatus and Method for Producing Reduced Metal, US Patent 6,368,379 B1, Apr. 9, 2002. 
U.S. Department of Energy, Steel Success Story. Ironmaking: Quality and Supply Critical to Steel Industry, U.S. Department of Energy, Energy Efficiency and Renewable Energy, Industrial Technologies Program, http://www.eere.energy.gov/industry/steel/ (September 21, 2004).

U.S. EPA, Oxygen-enriched combustion can reduce emissions and fuel use in energy intensive industries, DOE/CH 10093-198, DE93000063, September 1993, http://es.epa.gov/techinfo/facts/o2-nrich.html.

C.S. Wang, G.F. Berry, K.C. Chang, and A.M. Wolsky Combustion of Pulverized Coal Using Waste Carbon Dioxide and Oxygen Combustion and Flame 72: (1988), pp. 301310.

T. Watanabe, H. Fukuyama, and K. Nagata, Stability of Cuspidine (3CaO-SiO.CaF2) and Phase Relations in the CaO-SiO2-CaF2 System, ISIJ International Vol. 42, 2002, No.5, pp. 489-497. 